
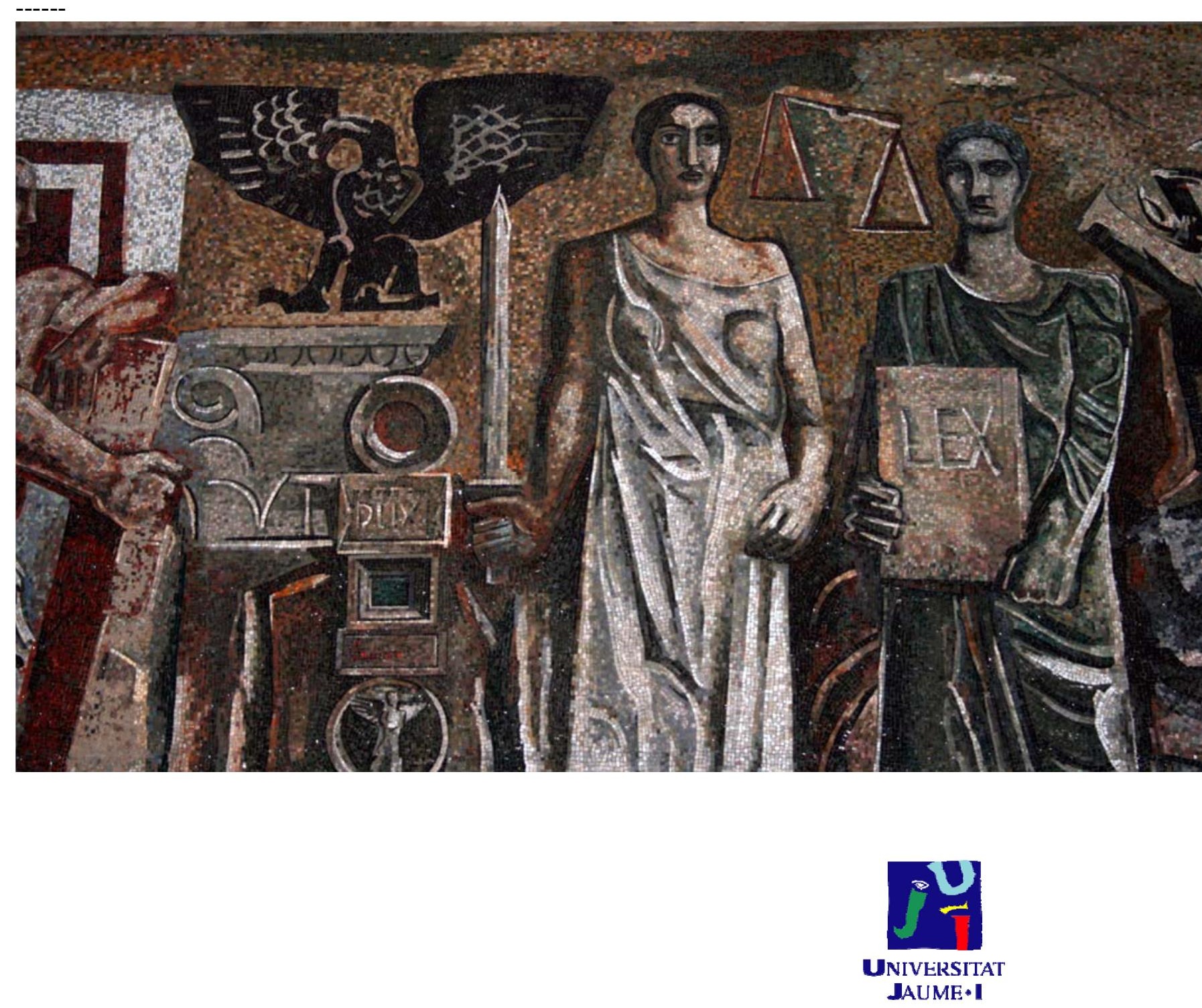

\title{
Diseño de una herramienta de evaluación de la calidad del desempeño del intérprete judicial: INTER-Q
}

Marta Sancho Viamonte

Directoras:

María Jesús Blasco-Mayor

Micaela Moro Ipola

Septiembre de 2018 



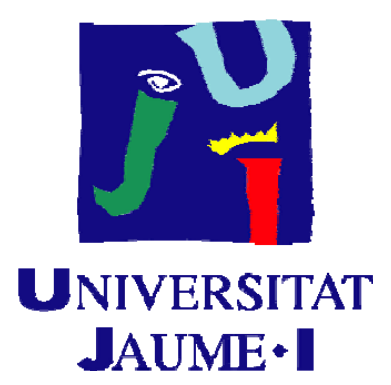

Programa de Doctorat en Lenguas Aplicadas, Literatura y Traducción (RD99/2011)

Escuela de Doctorado de la Universitat Jaume I

\section{Diseño de una herramienta de evaluación de la calidad del desempeño del intérprete judicial: INTER-Q}

Memoria presentada por Marta Sancho Viamonte para optar al grado de doctora por la Universitat Jaume I

Marta Sancho Viamonte

María Jesús Blasco-Mayor

Micaela Moro Ipola

Castellón de la Plana, septiembre de 2018 



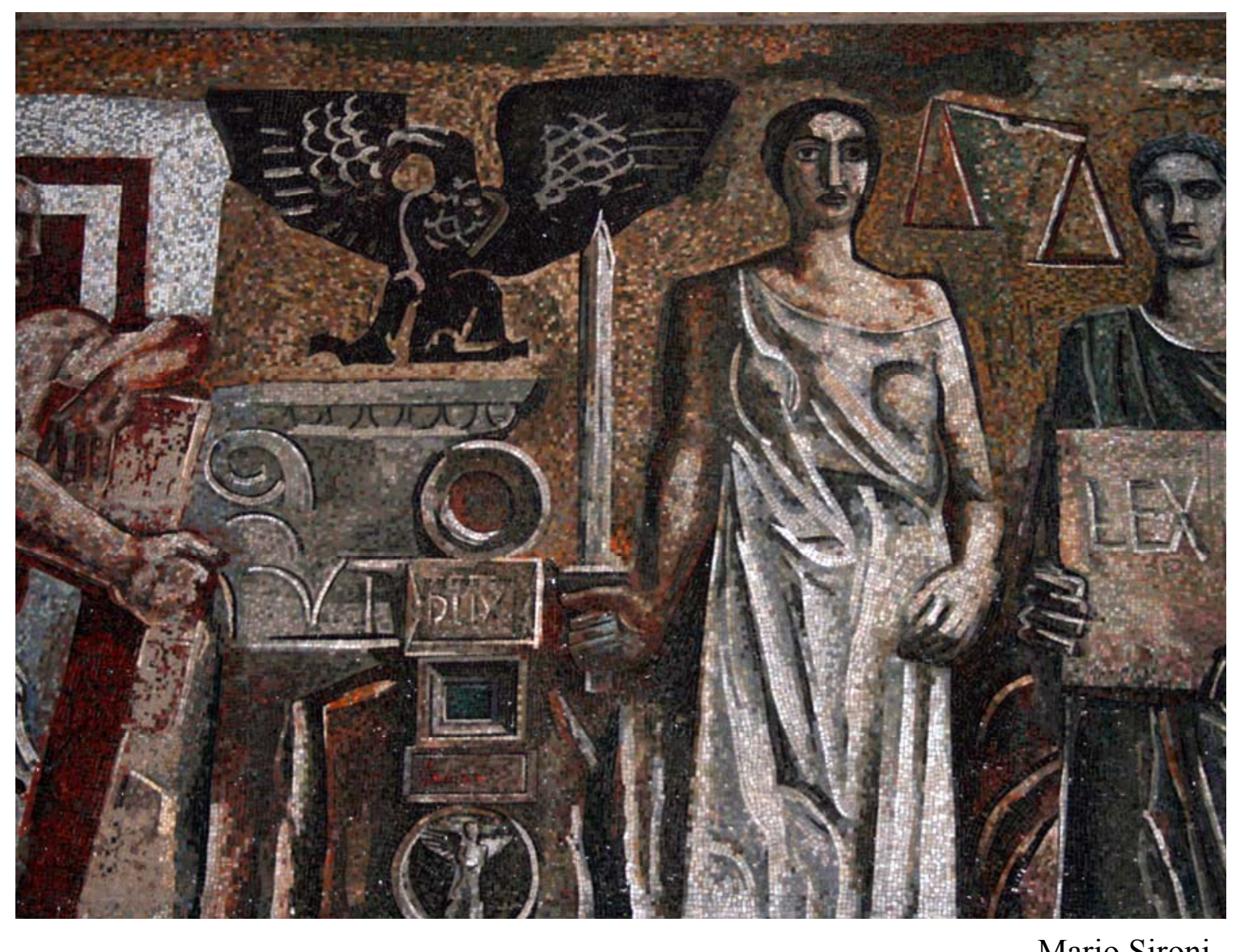

Mario Sironi

La Giustizia armata con la Legge (detalle)

Mosaico (1936)

Sala - Corte d'Assise d'Appello - Tribunal de Milán 

In realtà questo approccio hobbistico diciamo così, non è soltanto tecnicamente povero, mi riferisco all'approccio hobbistico dell'attività d'interpretariato e la traduzione. È un po' pericoloso, perché le ricadute di una funzione tecnicamente povera, svolta male, si scaricano non tanto sul soggetto che la rende, ma sul soggetto che è destinato in qualche modo a subirla. Cioè, l'interprete, in qualche modo, si trova in una posizione in certo modo analoga a quella del giudice, che si opera male, innanzitutto fa pagare ad altri i propri errori, in prima battuta, poi forse, un giorno, qualcuno lo chiamerà a rispondere, della propria povertà o pocchezza professionale, forse, ma intanto qualcuno gli errori li paga subito. E questo il rischio che si corre con una attività d'interpretariato mal resa

Michele Consiglio 

A los pilares de mi vida A Jose Luis, mi padre, descanse en paz A Marco María, mi esposo y compañero 


\section{Índice}

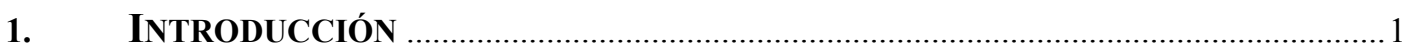

1.1. FUNDAMENTOS DE LA INVESTIGACIÓN ___ 1

1.2. ANTECEDENTES ___ 4

1.3. OBJETIVOS DE LA INVESTIGACIÓN __ 5

1.4. METODOLOGÍA__ 6

1.5. PARTES DEL TRABAJO_ 7

2. LA INTERPRETACIÓN JUDICIAL COMO ESPECIALIDAD INDEPENDIENTE ...... 9

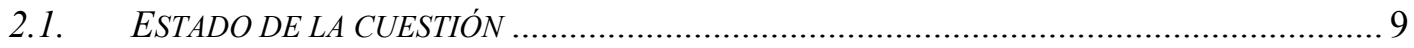

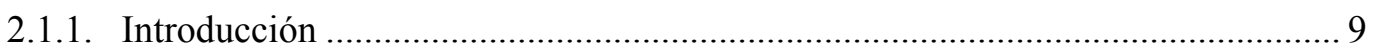

2.1.2. Características de la interpretación judicial.................................................... 11

2.1.3. Modalidades utilizadas en la interpretación judicial ........................................ 12

2.1.4. Interpretación judicial frente a interpretación en los servicios públicos ............. 12

2.1.5. Intérprete judicial frente a intérprete de conferencias ......................................... 15

2.1.6. Entornos de la interpretación en el ámbito de la justicia.................................... 17

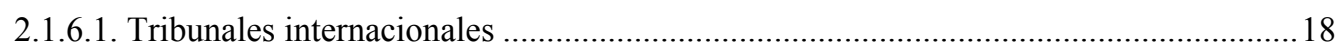

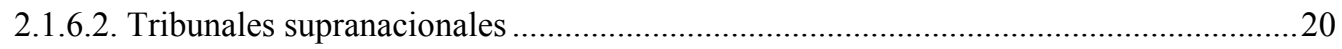

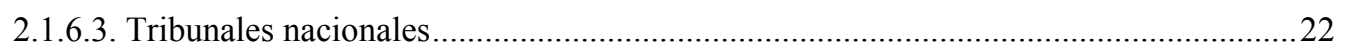

2.2. EL PAPEL DEL INTÉRPRETE JUDICIAL__ 30

2.2.1. El intérprete como mediador interlingüístico oral............................................ 33

2.2.2. El intérprete judicial desde el punto de vista del código deontológico ................ 38

2.2.3. El uso del análisis del discurso para el estudio de la figura del intérprete judicial 40

2.2.4. Otros perfiles profesionales que puede asumir el intérprete .............................. 41

2.3. BREVE PANORAMA DE LA INTERPRETACIÓN JUDICIAL Y POLICIAL EN ESPAÑA___ 46

2.4. BREVE PANORAMA DE LA INTERPRETACIÓN JUDICIAL Y POLICIAL EN ITALIA

2.5. CONCLUSIONES

3. EL DERECHO A LA TRADUCCIÓN Y A LA INTERPRETACIÓN COMO GARANTÍA

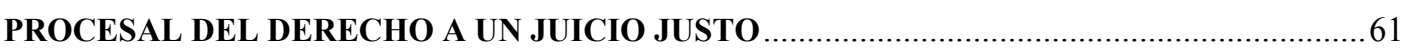

3.1. INTRODUCCIÓN

3.2. ALGUNOS PRECEDENTES NORMATIVOS SOBRE EL RECONOCIMIENTO DEL DERECHO A LA INTERPRETACIÓN EN TRATADOS INTERNACIONALES __ 62

3.3. EL DERECHO A LA INTERPRETACIÓN COMO GARANTÍA PROCESAL EN EL DERECHO COMPARADO _ 64

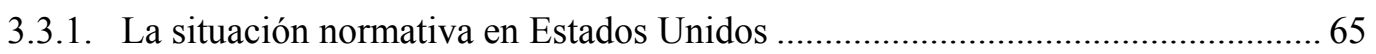

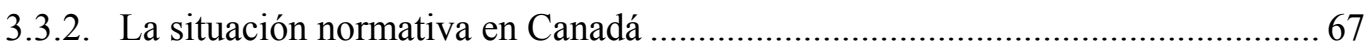




\subsection{EL DERECHO A LA INTERPRETACIÓN EN EUROPA: UN LARGO RECORRIDO NO EXENTO}

DE DIFICULTADES _ 67

3.4.1. En el ámbito del Consejo Europeo ........................................................................ 67

3.4.2. La Unión Europea y la creación de un espacio común de libertad, seguridad y justicia como factor determinante en el reconocimiento del derecho a la interpretación 69 3.4.3. La Directiva 2010/64/UE como un hito en el reconocimiento del derecho a la traducción e interpretación en los procesos penales

3.4.4. La transposición de la Directiva 2010/64/UE por los Estados miembros: retrasos y amplio margen de los Estados para su cumplimiento 84

3.4.5. La tortuosa e incompleta transposición de la Directiva 2010/64/UE al ordenamiento español.

3.4.6. La transposición de la Directiva 2010/64/UE al ordenamiento italiano: una transposición formal y poco efectiva.

3.4.7. Una visión comparada de las trasposiciones de la Directiva 2010/64/UE a los ordenamientos italiano y español

3.4.8. El derecho a la interpretación y traducción en otras directivas europeas......

3.4.8.1. Directiva 2012/13/UE relativa al derecho a la información en los derechos penales. 109

3.4.8.2. Directiva 2012/29/UE relativa a los derechos, apoyo y protección de las víctimas de delito

3.4.8.3. Directiva 2013/48/UE relativa al derecho a la asistencia de letrado en los procesos penales

3.4.8.4. Directiva 2016/800/UE relativa a las garantías procesales de los menores sospechosos o acusados.

3.5. CONCLUSIONES_L 113

4. LA CALIDAD EN INTERPRETACIÓN: ESTADO DE LA CUESTIÓN ……................115

4.1. INTRODUCCIÓN _ 115

4.2. LA CALIDAD COMO CONDICIÓN NECESARIA EN TODOS LOS ÁMBITOS__ 116

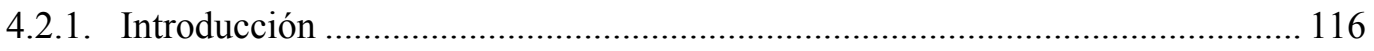

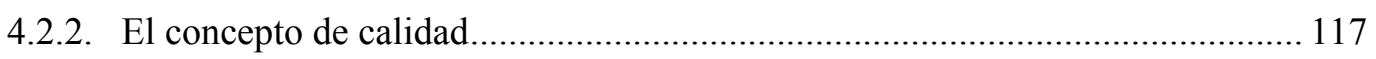

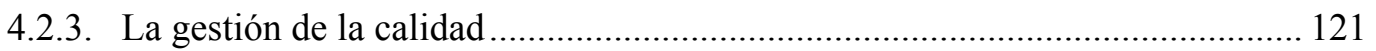

4.2.4. Modelos normativos de gestión de la calidad ................................................ 122

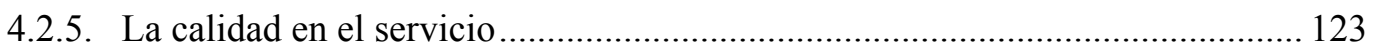

4.3. LA CALIDAD EN LA INTERPRETACIÓN _ـ 125

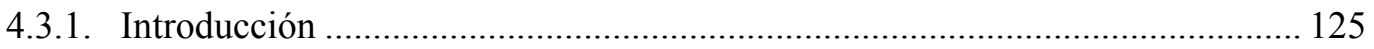

4.3.2. Hacia una definición del complejo concepto de calidad en interpretación ........ 126

4.3.3. El paradigma de la calidad en la interpretación: evolución de los estudios ...... 131

4.3.4. Estudios empíricos sobre la calidad en la interpretación................................... 134 
4.3.4.1. Métodos desarrollados en los estudios de interpretación según Pöchhacker

4.3.4.2. Clasificación de los estudios sobre calidad según Collados Aís ................................ 137

4.3.4.2. Estudios de evaluación de la calidad según Martínez-Gómez ................................... 138

4.3.4.3. Métodos de investigación en calidad en interpretación según Hale y Napier .............139

4.3.4.4. Análisis de los estudios según Grbić..................................................................... 139

4.3.5. Hacia una apertura del estudio de la calidad en la interpretación dialógica y en

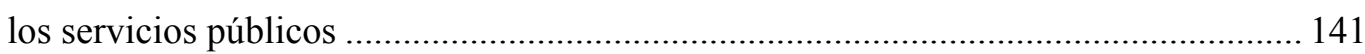

4.4. CONCLUSIONES__ 144

5. LA CALIDAD EN LA INTERPRETACIÓN JUDICIAL ............................................ 147

5.1. INTRODUCCIÓN _ـ 147

5.2. CARACTERÍSTICAS DEL CONTEXTO JUDICIAL Y CALIDAD DE LA INTERPRETACIÓN_ _ 148

5.3. LA CALIDAD EN LA DIRECTIVA EUROPEA 2010/64/UE SOBRE EL DERECHO A

INTERPRETACIÓN Y TRADUCCIÓN EN LOS PROCESOS PENALES Y EN DOCUMENTOS EUROPEOS

VINCULADOS _ 149

5.3.1. La Directiva 2010/64/UE sobre el derecho a interpretación y traducción en los

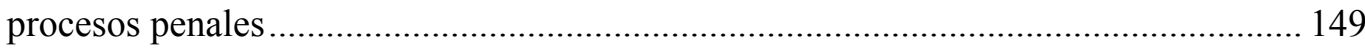

5.3.2. Propuesta de Decisión Marco relativa al derecho a interpretación y a traducción

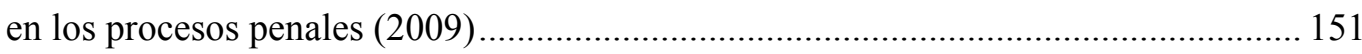

5.3.3. Conclusiones del Foro de Reflexión sobre el Multilingüismo y la Formación del

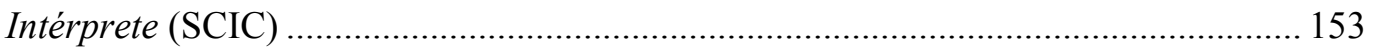

5.4. AVANCES EN LA INVESTIGACIÓN SOBRE LA CALIDAD DE LA INTERPRETACIÓN JUDICIAL_

5.5. COMPONENTES DE LA CALIDAD EN INTERPRETACIÓN JUDICIAL___ 155

5.5.1. Los códigos deontológicos como aseguramiento de la calidad ....................... 155

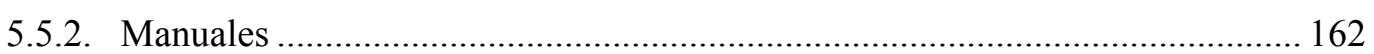

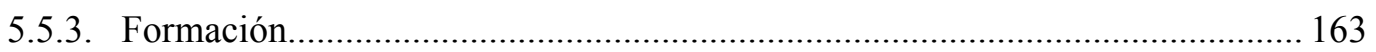

5.5.4. Normas ISO relativas a la interpretación relacionadas con los entornos judiciales 165

5.5.4.1. La ISO/DIS 29228 en favor de una interpretación legal de calidad........................... 165

5.5.4.2. Otras normas ISO en relación con los servicios de interpretación .............................. 169

5.5.5. Sistemas de acreditación y registros profesionales ...................................... 170

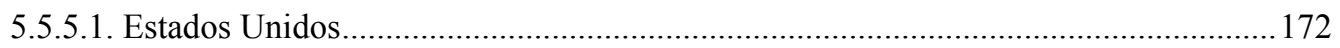

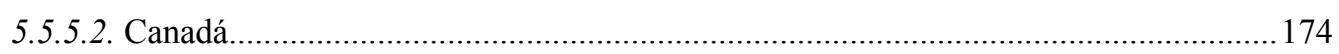

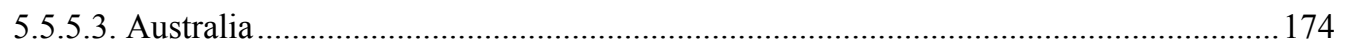

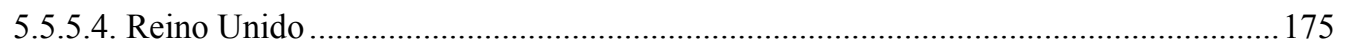

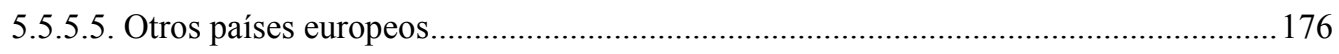

5.5.5.6. Nuevos modelos y propuestas de acreditación ....................................................... 177 
5.5.6. Proyectos de la Dirección General de Justicia (CE) y otras acciones en aras de la calidad en interpretación judicial ............................................................................. 179

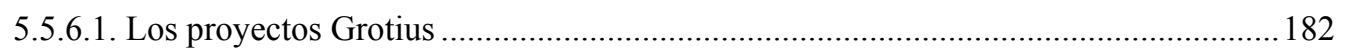

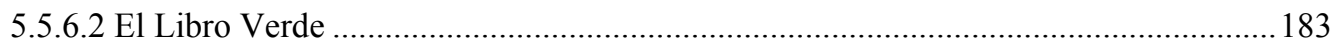

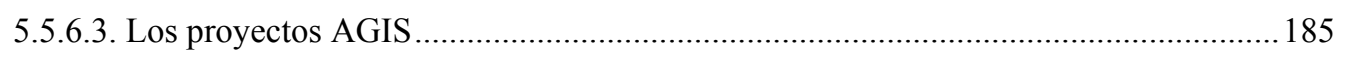

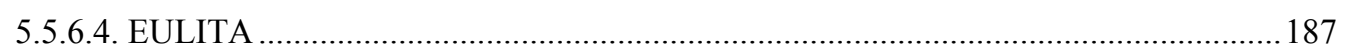

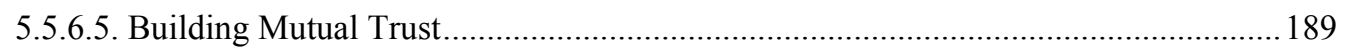

5.5.6.6. Video-Mediated Interpreting (AVIDICUS) …………………………………....... 190

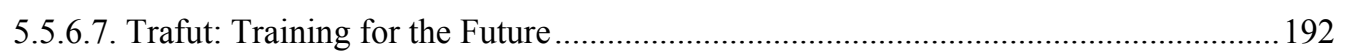

5.5.6.8. ImPLI: Improving Police and Legal Interpreting.................................................. 192

5.5.6.9. Qualitas: Assessing LI Quality through Testing and Certification............................. 193

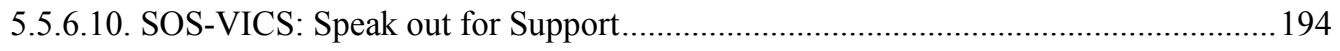

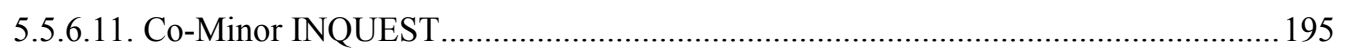

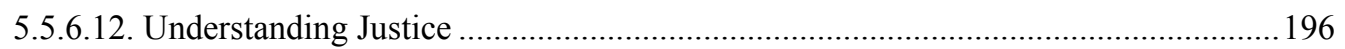

5.5.6.13. TraiLLD: Training in Languages of Lesser Diffusion .............................................. 197

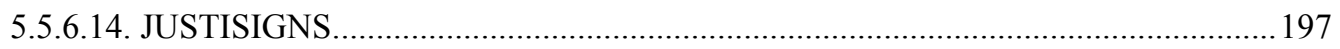

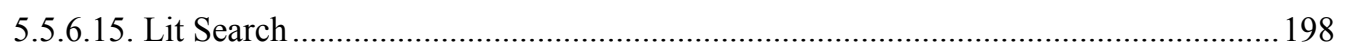

5.6. CONCLUSIONES_ 199

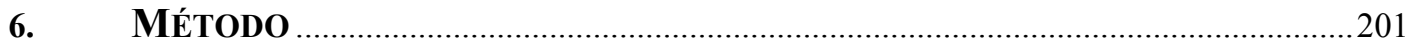

6.1. INTRODUCCIÓN__ 201

6.2. DEFINICIÓN DEL PROPÓSITO DEL CUESTIONARIO__ 204

6.3. DESCRIPCIÓN DE LO QUE SE INTENTA MEDIR___ 205

6.4. REDACCIÓN DEL BORRADOR INICIAL _ 205

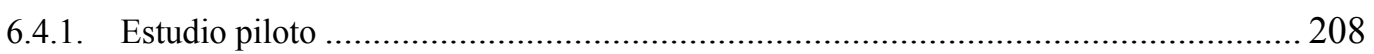

6.5. ESTUDIO EMPÍRICO _ 216

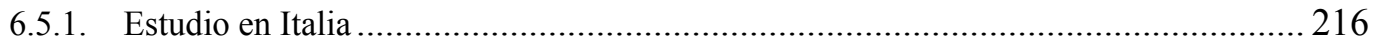

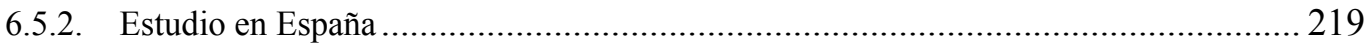

6.6. MÉTODO DEL ESTUDIO CUALITATIVO___ 222

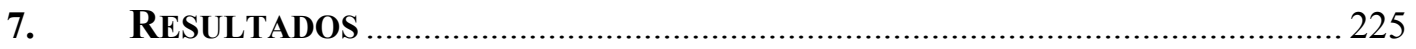

7.1. ESTADÍSTICA DESCRIPTIVA__ 225

7.2. FIABILIDAD 227

7.3. VALIDEZ 2227

7.4. COMPORTAMIENTO DE LOS ÍTEMS __ 233

7.5. RESULTADOS DE LOS DATOS CUALITATIVOS _ 244

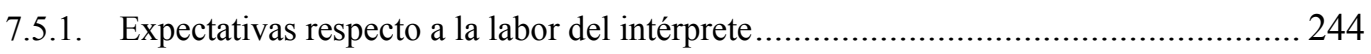

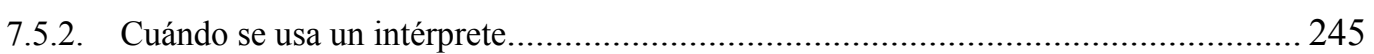




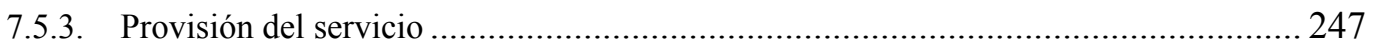

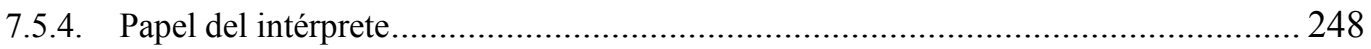

7.5.5. Preparación que debe tener un intérprete ………................................................... 249

7.5.6. La importancia de la comunicación no verbal (CNV) ............................................ 251

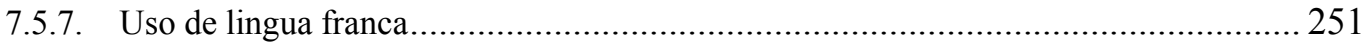

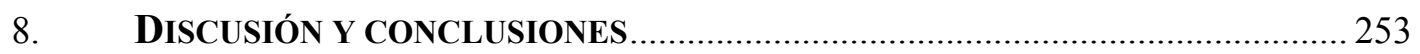

8.1. DISCUSIÓN — 253

8.2. CONCLUSIONES EN CASTELLANO __ 263

8.3. CONCLUSIONI IN ITALIANO__ 264

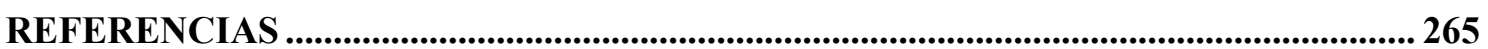

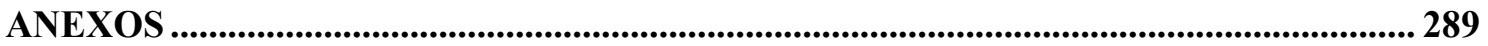

ANEXo 1: CARTA DE ACOMPAÑAMIENTO A FASE DE PILOTAJE........................................... 291

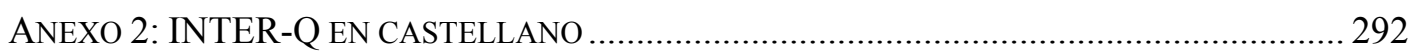

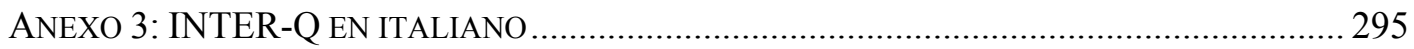

AneXo 4: CARTA Al PRESIDENTE del TRIBUnal De GÉNOVA CON FIRMA DE

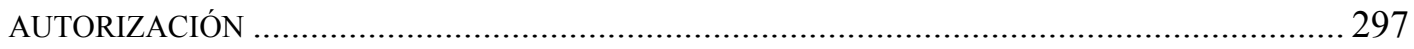

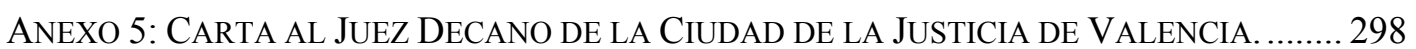
ANEXO 6: AUTORIZACIÓN A REALIZAR LAS PRÁCTICAS EN LA CIUDAD DE LA JUSTICIA DE

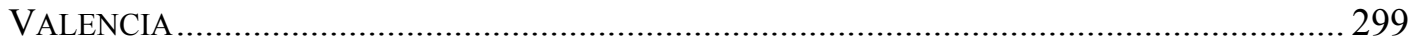

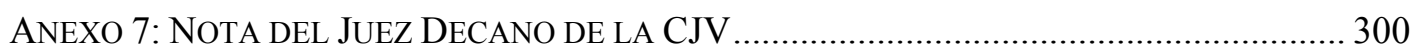

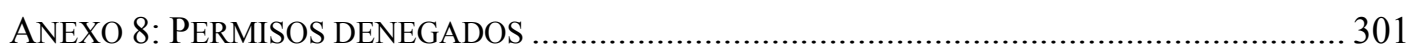

CARABINIERI _ 301

GUARCIA CIVIL _ 302

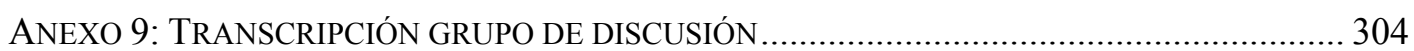

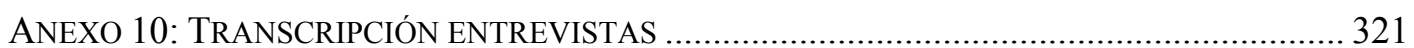

ENTREVISTA 1 _ 321

ENTREVISTA $2 \longrightarrow 329$

ENTREVISTA $3 \longrightarrow 337$ 


\section{Índice de tablas y figuras}

Tabla 1: Posibles papeles del intérprete judicial según Hale (2008, p. 102).....

Tabla 2: Comparación entre las especificaciones de la Directiva y las transposiciones española e italiana 104

Tabla 3: Concepto de calidad según Camisón et al. (2006, p. 147) 118

Tabla 4: Análisis comparativo de las propuestas del PDM y de la Directiva 2010/64/UE en favor de la calidad. 152

Tabla 5: Concepto de fidelidad en los principales códigos deontológicos de interpretación judicial. 158

Tabla 6: Concepto de imparcialidad en los principales códigos deontológicos de interpretación judicial. 160

Tabla 7: Situaciones y contextos de interpretación. 207

Tabla 8: INTER-Q Versión inicial 208

Tabla 9: Análisis de las propiedades métricas de los ítems del borrador inicial 211

Tabla 10: Cuestionario definitivo 215

Tabla 11: Estadísticas de la muestra italiana por profesiones 226

Tabla 12: Estadísticas de la muestra española por profesiones 226

Figura 1: Registro oficial de intérpretes y traductores legales en los Estados miembros de la Unión Europea (FRA, 2016, p. 46).

Figura 2: Modelo de calidad según Pöchhacker (2001, p. 413)

Figura 3: Distinciones y solapamiento relacionado con los eventos mediados con intérpretes para los servicios públicos según la ISO 13611

Figura 4: Resultados de valoración por parte de expertos

Figura 5: Transformación de los ítems del borrador inicial y composición del cuestionario definitivo. 
Figura 6: Participantes en el cuestionario italiano por profesión.

Figura 7: Lenguas de los intérpretes evaluados en el cuestionario en Italia............................. 219

Figura 8: Participantes en el cuestionario español por profesión ............................................. 221

Figura 9: Participantes en el cuestionario italiano por profesión................................................. 221

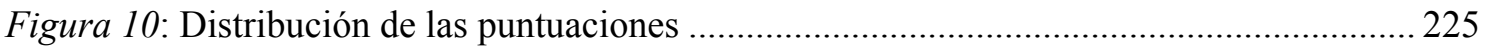

Figura 11: Porcentaje de aciertos, fallos y respuestas en blanco del ítem 1 ............................. 234

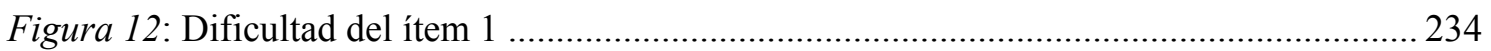

Figura 13: Porcentaje de aciertos, fallos y respuestas en blanco del ítem 2 ............................. 234

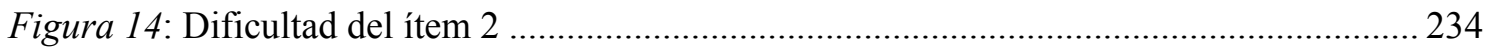

Figura 15: Porcentaje de aciertos, fallos y respuestas en blanco del ítem 3 ............................ 235

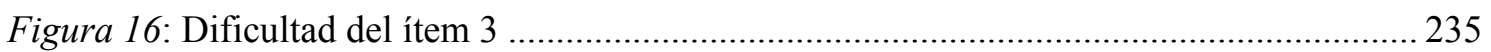

Figura 17: Porcentaje de aciertos, fallos y respuestas en blanco del ítem 4............................ 235

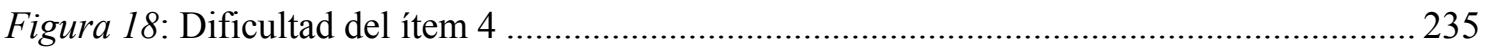

Figura 19: Porcentaje de aciertos, fallos y respuestas en blanco del ítem 5 ...............................236

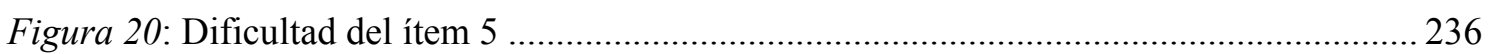

Figura 21: Porcentaje de aciertos, fallos y respuestas en blanco del ítem 6 .............................2. 236

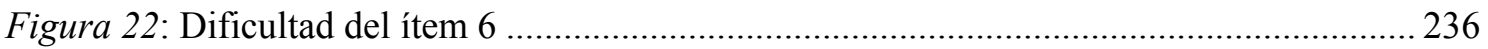

Figura 23: Porcentaje de aciertos, fallos y respuestas en blanco del ítem 7 ..............................2237

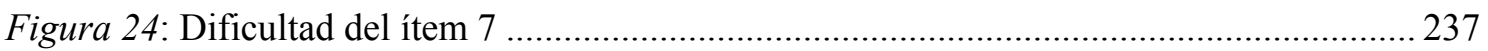

Figura 25: Porcentaje de aciertos, fallos y respuestas en blanco del ítem 8 ............................. 237

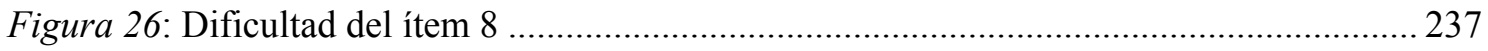

Figura 27: Porcentaje de aciertos, fallos y respuestas en blanco del ítem 9 ..............................2 238

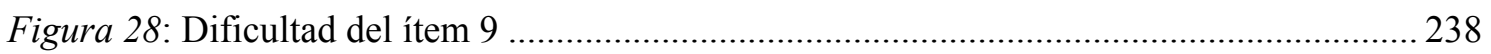

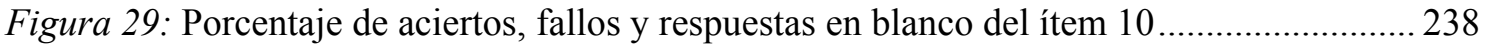


Figura 30: Dificultad del ítem 10

Figura 31: Porcentaje de aciertos, fallos y respuestas en blanco del ítem 11 ........................... 239

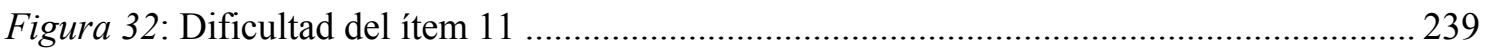

Figura 33: Porcentaje de aciertos, fallos y respuestas en blanco del ítem 12 ...........................239

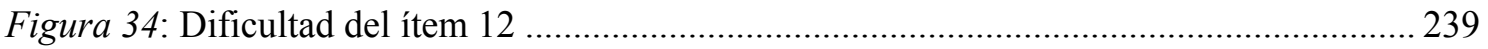

Figura 35: Porcentaje de aciertos, fallos y respuestas en blanco del ítem 13 ...........................240

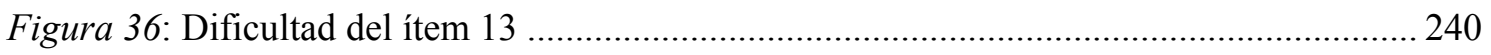

Figura 37: Porcentaje de aciertos, fallos y respuestas en blanco del ítem 14 ........................... 240

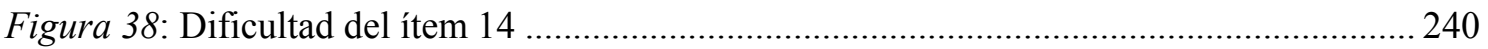

Figura 39: Porcentaje de aciertos, fallos y respuestas en blanco del ítem 15 ............................241

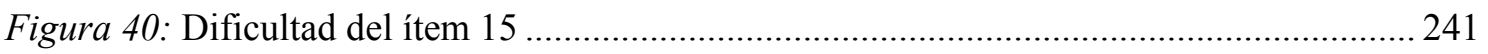

Figura 41: Porcentaje de aciertos, fallos y respuestas en blanco del ítem 16.......................... 241

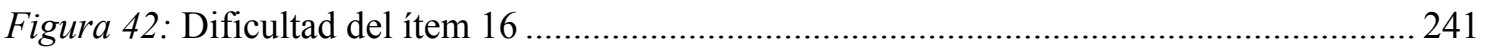

Figura 43: Porcentaje de aciertos, fallos y respuestas en blanco del ítem 17 ..........................242

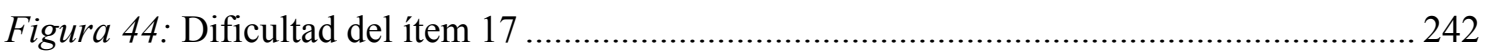

Figura 45: Porcentaje de aciertos, fallos y respuestas en blanco del ítem 18 .......................... 242

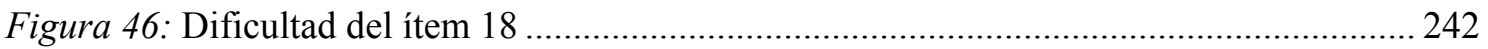

Figura 47: Porcentaje de aciertos, fallos y respuestas en blanco del ítem 19........................... 243

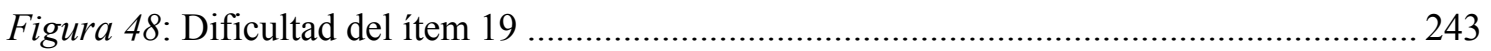

Figura 49: Porcentaje de aciertos, fallos y respuestas en blanco del ítem 20......................... 243

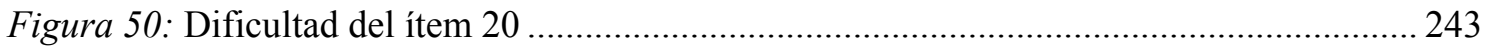

Figura 51: Porcentaje de aciertos, fallos y respuestas en blanco del ítem 21 ........................... 244

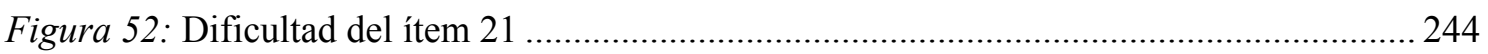




\section{Abreviaturas y acrónimos}

\begin{tabular}{|c|c|}
\hline AIIC & Association International des Interprètes de Conférence \\
\hline AEQUALITAS & $\begin{array}{l}\text { Proyecto europeo Equal Access to Justice across Language and } \\
\text { Culture in the EU }\end{array}$ \\
\hline AEQUITAS & $\begin{array}{l}\text { Proyecto europeo Access to Justice across Language and Culture } \\
\text { in the EU }\end{array}$ \\
\hline AITI & Associazione Italiana Traduttori e Interpreti \\
\hline ANSI & American National Standards Institute \\
\hline APTIJ & $\begin{array}{l}\text { Asociación Profesional de Traductores e Intérpretes Judiciales y } \\
\text { Jurados }\end{array}$ \\
\hline AssITIG & Associazione Italiana Traduttori e Interpreti Giudiziari \\
\hline AUSIT & The Australian Institute of Interpreters and Translators inc. \\
\hline AVIDICUS & Proyecto europeo Video-Mediated Interpreting \\
\hline AVLIC & Association of Visual Language of Canada \\
\hline BMT & Proyecto Europeo Building Mutual Trust \\
\hline BSI & British Standard Institute \\
\hline CCDUTI & $\begin{array}{l}\text { Conferencia de Centros y Departamentos Universitarios de } \\
\text { Traducción e Interpretación de España }\end{array}$ \\
\hline CCL & Credencial Community Language \\
\hline CDFUE & Carta de los Derechos Fundamentales de la Unión Europea \\
\hline CEDH & $\begin{array}{l}\text { Convenio Europeo para la Protección de los Derechos Humanos y } \\
\text { la Libertades Fundamentales }\end{array}$ \\
\hline $\mathrm{CNV}$ & Comunicación no verbal \\
\hline $\mathrm{CPP}$ & Codice di Procedura Penale \\
\hline
\end{tabular}




\begin{tabular}{|c|c|}
\hline СPP & Código de Procedimiento Penal \\
\hline ECBA & European Criminal Bar Association \\
\hline CCBE & The Council of Bars and Law Societies of Europe \\
\hline CGPJ & Consejo General del Poder Judicial \\
\hline CTTIC & Canadian Translators, Terminologists and Interpreters Council \\
\hline $\mathrm{DE}$ & Desempeño Evaluado (Evaluated Performance) \\
\hline DIGOS & Divisione Investigazioni Generali e Operazioni Speciali \\
\hline $\mathrm{DM}$ & Discurso meta \\
\hline DO & Discurso original \\
\hline DOUE & Diario Oficial de la Unión Europea \\
\hline DPSI & Diploma in Public Service Interpreting \\
\hline DUDH & Declaración Universal de los Derechos Humanos \\
\hline ECHR & Tribunal Europeo de Derechos Humanos \\
\hline ENAC & Entidad Nacional de Acreditación \\
\hline EU & Unión Europea \\
\hline EUDH & Convención Europea de Derechos Humanos \\
\hline EULITA & European Association for Legal Interpreters and Translators \\
\hline FIT & Fédération International des Traducteurs \\
\hline FRA & Agencia de los Derechos Fundamentales de la Unión Europea \\
\hline IC & Interpretación consecutiva \\
\hline ICTR o TPIR & Tribunal Penal Internacional para Ruanda \\
\hline ICTY o TPIY & Tribunal Penal Internacional para la Ex Yugoslavia \\
\hline ID & Interpretación dialógica \\
\hline
\end{tabular}


IMPLI Proyecto europeo Improving Police and Legal Interpreting

IS

ISO

ISP

JCCD

LECrim

LEGAII

LEP

LIBE

LIT

LO

LOPJ

MAEC

MIRAS

NAATI

NAJIT

NCHCI National Council on Interpreting in Health Care

NCSC

NHANES

NQ

NRPSI

Interpretación simultánea

International Organization for Standardization

Interpretación en los Servicios Públicos

Judicial Council on Cultural Diversity

Ley de Enjuiciamiento Criminal the Implementation of a National Register

Limited and non English speaking

Legal Interpreter and Translator

Ley Orgánica

Ley Orgánica del Poder Judicial en el Ámbito Social Ltd

National Center for State Courts

Normalized Quality / Calidad Normalizada

National Register for Public Service Interpreters
Proyecto Legal Interpreting in Italy: Training, Accreditation and

Comisión de Libertades Civiles, Justicia y Asuntos de Interior

Ministerio de Asuntos Exteriores y Cooperación

Grupo de investigación Mediación e Interpretación: Investigación

National Accreditation Authority for Translators and Interpreters

National Association of Judiciary Interpreters and Transtators

National Health and Nutrition Examination Survey 


\begin{tabular}{|c|c|}
\hline ONU & Organización de las Naciones Unidas \\
\hline PCTI & Proyecto sobre Cortes y Tribunales Internacionales \\
\hline PDM & Propuesta de Decisión Marco \\
\hline PESC & Política Exterior y de Seguridad Común \\
\hline PIDCP & Pacto Internacional de Derechos Civiles y Políticos \\
\hline QUALETRA & Proyecto europeo Quality in Legal Translation \\
\hline QUALITAS & $\begin{array}{l}\text { Proyecto europeo Assessing Legal Interpreting Quality through } \\
\text { Testing and Certification }\end{array}$ \\
\hline RAE & Real Academia de la Lengua Española \\
\hline RID & Registry of Interpreters for the Deaf \\
\hline RITAP & Red de Intérpretes y Traductores de la Administración Pública \\
\hline SCIC & Dirección General de Interpretación de la Unión Europea \\
\hline SGC & Sistema de Gestión de la Calidad \\
\hline SOS-VICS & Proyecto europeo Speak Out for Support \\
\hline SPSS & Statistical Package for the Social Sciences \\
\hline SSML & Scuola Superiore Mediatori Linguistici \\
\hline STEDH & Sentencia del Tribunal Europeo de Derechos Humanos \\
\hline TEDH & Tribunal Europeo de Derechos Humanos \\
\hline TIPp & Traducción e Interpretación en los procesos penales \\
\hline TRI & Teoría de la Respuesta al Ítem \\
\hline TJUE & Tribunal de Justicia de la Unión Europea \\
\hline TRAFUT & Proyecto europeo Training for the Future \\
\hline TraiLLD & Proyecto europeo Training in Languages of Lesser Diffusion \\
\hline
\end{tabular}


UE

UNI

UPGSP

\section{Unión Europea}

Ente Nazionale Italiano di Normazione

Uffici per l'immigrazione, Polizia di Frontiera

aerea/marittima/terreste 


\section{Agradecimientos}

En la andadura que ha llevado a la realización de esta tesis tengo que dar las gracias a muchas personas por su valiosa ayuda. Quiero dar las gracias a María Jesús BlascoMayor y a Micaela Moro Ipola sin cuya dirección hubiera sido difícil llegar a la meta. Gracias por su dedicación incondicional y por todo el tiempo que me han dedicado con tanta generosidad. Su orientación, buen criterio, guía, acertadas críticas y ánimos han sido fundamentales para poder llevar a cabo este trabajo. He sido muy afortunada. Por sus consejos, incluso en el planteamiento del tema, que han sido fundamentales, además de su visión y conocimientos. Por animarme en los momentos de desánimo, su apoyo durante mi estancia y por cuidarme cuando lo necesité. Gracias por su tiempo.

Gracias a Mara Morelli que me encauzó hace ya siete años hacia la Universidad Jaume I y a Cristina Balleto por dirgirme ambas durante la estancia en la Università degli Studi de Génova. A Elena Errico por su ayuda continua durante estos años.

A Flavia Caciagli por la ayuda a la hora de recuperar material y corregir el borrador del cuestionario italiano. Gracias también a Daniela Amodelo Perillo.

A Lucia Carretti y a Catia Lattanzi, por sus correcciones, su ayuda continua con el italiano y su amistad.

A Rosa «Bombón» Sena por su ayuda durante mi estancia en la Ciudad de la Justicia de Valencia y por su acogida durante la redacción de este estudio. Gracias también a su familia.

A todos los jueces que participaron durante la fase previa, la validación y las entrevistas, tanto españoles como italianos. En particular quiero agradecer a los magistrados Giovanna Ichino, Elisabetta Canevini, Isabel Tomás García, Eusebio Revilla Revilla, Francisco Hazas Viamonte, Marta López Vozmediano, Jose Manuel Ortega Lorente, Jesús Rojo Santaolalla, Javier Hernández García, José Ramón Corral Quintana y Nieves Pérez Martin.

Gracias al Juez Decano de la ciudad de la Justicia de Valencia por haberme brindado su apoyo durante las estancias, al igual que todo el resto del personal.

Gracias a los presidentes de los tribunales de Génova y de Milán por la autorización para realizar el proyecto piloto.

Gracias a Juan Miguel Ortega-Herráez, Maribel del Pozo Triviño, Sandra Hale, Anne Martin, Mar Jimeno Bulnes, Clara Carrón Fernandez por la ayuda prestada y facilitarme material aún no publicado o de difícil acceso. 
Gracias a los miembros de APTIJ que han colaborado, especialmente a María del Mar Quijada y Nuria Hernández Cebrián y a los miembros de AssITIG. por su labor en la asociación y por llevar adelante su trabajo y dar ejemplo como intérpretes.

Gracias a Alberto, Carlos y Jaime París por concederme generosamente a su madre.

A mis hermanos biológicos Manrique e Inmaculada por todo, también por haberme sustituido en algún momento, y políticos Camino, Antonio, Ángela y Mimmo, por estar a mi lado y sostenerme. A mis sobrinos por su cariño. A los demás miembros de mi familia que han dado su apoyo, gracias Chelo. A mi suegra Bice, que ha sabido comprender mis inquietudes. Un gracias especial a Chiara D'Amato Ceriani por sus dibujos, que al final no he podido usar.

A la jovenzuela de la familia, siempre inquieta y animosa. Gracias Carmen, por tus ánimos.

Gracias a mi padre por inculcarme todos los principios de trabajo y justicia y el estar presente para ayudarnos y guiarnos. Por su alegría y su cariño, por su entrega y su fe. Es difícil expresar con palabras la huella profunda que ha dejado con discreción, con su vida y su muerte.

A Fernando Gascón Nasarre, compañero de andadura desde el master, paño de lágrimas en algunas ocasiones y consejero. A Ana Aurora Gonzalo Lecuona por su amistad y buen corazón. A Rafael Revenga por su apoyo discreto pero continuado y también a Amaya Revenga por su ayuda.

Gracias a los intérpretes de la Ciudad de la Justicia de Valencia que accedieron de buena gana a colaborar, en especial a Hira, Claudia, Isabel, Carlos y Samira.

Gracias a Rosa Iglesias por ayudarme a corregir el borrador. A Joaquín García Andrés por sus ánimos, su ejemplo y la ayuda en la maquetación. Gracias a Luis Esteban Delgado del Rincón por el empujón final en un capítulo que me resultó difícil de concluir. Gracias también al servicio de préstamo interbibliotecario de la Universidad IULM de Milán

Quiero dar las gracias también a todas aquellas personas que me ayudaron, sostuvieron y animaron durante los momentos de recogida de datos y de redacción de esta memoria, que coincidieron con el agravamiento de las condiciones de salud de los dos pilares de mi vida. Su apoyo constante, moral e intelectual, hizo que que pudiera concluir este trabajo.

Gracias Marco María por tu apoyo constante, por creer en mí y no escatimarme jamás tu ayuda, por comprender mis ausencias, por quererme. 


\section{Resumen}

\section{Resumen en castellano}

La calidad de la interpretación en el ámbito judicial no es solo una característica deseable de la profesión, sino que se convierte en parte integrante de un derecho, el derecho a entender y ser entendido de la persona acusada alófona, y de la presencia efectiva de la misma en el procedimiento judicial.

La evolución de la profesión del intérprete judicial a lo largo del siglo XX y la falta de calidad del servicio de interpretación en los distintos juzgados y tribunales de algunos países europeos, concretamente España e Italia ha sido estudiada y documentada (Ortega-Herráez, 2011; Garwood, 2012; Orozco Jutorán, 2017). La causa principal de la falta de calidad en el sector se debe principalmente a la irrupción de personas no cualificadas que actúan como intérpretes y a la ausencia de mecanismos de control de la calidad de la interpretación judicial por parte de la administración de justicia. A esto hay que unir el desconocimiento del papel del intérprete por parte de los operadores judiciales, que han tenido que adaptarse en un corto espacio de tiempo a la realización de su trabajo a través de intérpretes sin haber recibido formación específica para ello.

Hasta la fecha no se ha desarrollado ningún instrumento de medida o de evaluación de la calidad de la interpretación judicial durante su desempeño, a pesar de que las leyes que se han promulgado tanto en la Unión Europea (Directiva 2010/64/UE, entre otras) como en España (Ley Orgánica 5/2015) e Italia (D. Legs. 4 marzo 2014 n. ${ }^{\circ}$ 32) establecen un control de la calidad de la interpretación en el ámbito judicial penal. Con el fin de rellenar tal vacío se ha desarrollado un instrumento de medida de la actuación del intérprete en el contexto judicial mediante el diseño de la herramienta de evaluación INTER-Q, cuestionario dirigido a los operadores judiciales. En esta tesis se presenta la metodología de diseño de test (Meyer, 2014) que se ha seguido para la elaboración de dicho instrumento con el fin de que respondiese a los criterios científicos de fiabilidad, validez y utilidad. Se exponen los resultados obtenidos tras la administración de dicho cuestionario en juzgados italianos y españoles para su validación. De igual manera se presentan datos del estudio de campo realizado durante las estancias en los juzgados y las entrevistas a jueces, que sirven para describir el contexto y explicar los resultados cuantitativos obtenidos mediante el testeo del instrumento. Finalmente, se describen los posibles usos que podría darse al cuestionario, con indicaciones para su administración en el contexto judicial.

Palabras clave: calidad, interpretación judicial, Directiva 2010/64/UE, evaluación de la actuación del intérprete, instrumento de medida, cuestionario, INTER-Q). 


\section{Riassunto en italiano}

La qualità nell'interpretazione nell'ambito della giustizia non è solo una caratteristica auspicabile della professione, bensì elemento costitutivo di un diritto, il diritto a capire ed essere capito dall'imputato alloglotto, e alla presenza effettiva dello stesso nel processo penale.

L'evoluzione della professione dell'interprete giudiziario nel ventesimo secolo e l'erogazione di un servizio d'interpretazione di scarsa qualità nei tribunali di alcuni paesi europei, nella specie Italia e Spagna, sono state oggetto d'indagine da parte di diversi studiosi (Ortega-Herráez, 2011; Garwood, 2012; Orozco Jutorán, 2017). La causa principale della mancanza di qualità nel settore è da ricercarsi principalmente nell'accesso all'amministrazione della giustizia di persone non qualificate che operano come interpreti e altresì nell'assenza di strumenti di controllo della qualità dell'interpretazione in ambito giudiziario da parte della macchina della giustizia. A questo stato di cose viene a sommarsi la misconoscenza, se non ignoranza, relativamente al ruolo svolto dell'interprete da parte dei diversi operatori incaricati di amministrare la giustizia, che hanno dovuto adattarsi in maniera piuttosto frettolosa, quando non approssimativa, all'espletamento delle proprie mansioni, per il tramite degli interpreti senza essere stati nel frattempo adeguatamente formati.

Ad oggi, non è stato elaborato alcun metodo di rilevazione o valutazione della qualità nell'interpretazione giudiziaria, malgrado l'emanazione di dispositivi normativi sia a livello comunitario (tra cui la Direttiva 2010/64/UE) sia nazionale, in Spagna (Ley Orgánica 5/2015) e in Italia (D. Legs. 4 marzo 2014 n 32) che sanciscono l'opportunità di un controllo della qualità nell'interpretazione nell'ambito della giustizia penale. Al fine di colmare questo vuoto è stato messo a punto uno strumento di valutazione della performance dell'interprete in setting giudiziari tramite la progettazione dello strumento di valutazione, vale a dire, INTER-Q. Si tratta di un questionario rivolto ai vari operatori della giustizia. In questa tesi viene presentata la metodologia di progettazione di test (Meyer, 2014) adottata ai fini dell'elaborazione dello strumento in grado di soddisfare i criteri scientifici di affidabilità, validità e fruizione. Vengono esposti i risultati ottenuti dopo aver distribuito il questionario nei tribunali italiani e spagnoli al fine di verificarne la validità. Allo stesso modo, vengono presentati i dati raccolti sul campo durante il lavoro svolto nei tribunali e le interviste a giudici e magistrati, che servono per descrivere il contesto e spiegare i risultati quantitativi ottenuti testando lo strumento. Infine, vengono descritti gli eventuali utilizzi del questionario, con cenni sulla modalità di distribuzione nell' ambiente giudiziario.

Parole chiave: qualità, interpretazione giudiziaria, Direttiva 2010/64/UE, valutazione della performance dell'interprete, strumento di valutazione, questionario, INTER-Q. 


\section{Introducción}

En este capítulo se presentan las fases que se han llevado a cabo para realizar este trabajo. En primer lugar, se comienza con una justificación, se continúa con una descripción de los distintos temas abordados en el marco teórico, se presentan los objetivos del trabajo y los métodos utilizados y, por último, se realiza un resumen de los diferentes capítulos de los que consta la tesis.

\subsection{Fundamentos de la investigación}

El origen de cualquier trabajo de investigación tiene un carácter personal y este no es una excepción. Tras una formación inicial humanística, como licenciada en Historia, me interesé por los estudios de interpretación debido al gran atractivo que me suscitan los idiomas. Comencé a trabajar como traductora e intérprete y fui completando la formación requerida para esta profesión.

Esta evolución personal ha ido paralela con otra social y política que ha ido experimentando Europa en las últimas décadas. Los cambios demográficos y las relaciones institucionales han tenido una repercusión importante en el ámbito lingüístico, pues existen en la actualidad veinticuatro lenguas oficiales en la Unión Europea. La movilidad de los ciudadanos entre los distintos Estados miembros y los flujos migratorios procedentes de otras zonas del mundo hacen que los servicios de interpretación sean una necesidad imperiosa en la Europa del tercer milenio, necesidad que abarca todos los ámbitos de la sociedad; es de especial relevancia en aquellos que tienen que ver con la Administración pública y con la justicia, tema de la presente tesis doctoral.

Los datos sobre desplazamientos de ciudadanos tanto intra como extracomunitarios indican que la tendencia en la última década es al alza. En 2014, el porcentaje de personas que residían en un Estado miembro de la Unión Europea con ciudadanía de otro Estado miembro era el 2,8 \% de la población total (12,3 millones de personas). Las personas procedentes de países terceros suponían el 3,9\% de población $(19,6 \text { millones })^{1}$. En enero de 2016, el número de personas residentes en los Estados miembros de la Unión Europea con ciudadanía de otro país miembro era del 3,1 \% de la población (16 millones), mientras que los procedentes de otros países no miembros se

\footnotetext{
1 Véase Estadísticas de migración y población migrante, disponible en http://ec.europa.eu/eurostat/statisticsexplained/index.php/Migration_and_migrant_population_statistics/es.
} 
estimaban en un 4,1\% (20,7 millones). A estas cifras hay que añadir las de los solicitantes de asilo y refugio, cuyos datos solo se basan en aproximaciones, así como las de la inmigración clandestina que, por razones obvias, resulta difícil de estimar.

Podemos afirmar que el incremento de la movilidad de la población ha llevado a que se modifique el orden lingüístico en Europa. De las 250 lenguas indígenas censadas en el continente (Anderson, 2010) hay que añadir las lenguas de los inmigrantes, de las que se han registrado 438 lenguas en Europa (Dirección General de Interpretación. Comisión Europea, 2011, p. 9).

El Acuerdo de Schengen ha permitido una mayor movilidad de los ciudadanos en busca de trabajo, intercambios económicos y de formación. El turismo también ha visto incrementadas sus cifras, así como las redes internacionales de delincuencia. En consecuencia, se están registrando en todo el mundo, y en Europa en particular, un número cada vez mayor de procedimientos penales en los que el acusado, las víctimas o los testigos no hablan el idioma oficial del lugar donde se celebra el procedimiento.

La figura del intérprete judicial es esencial para garantizar una comunicación fidedigna y de calidad durante todas las fases del procedimiento por dos razones fundamentales: el derecho de toda persona a un juicio equitativo y el cumplimiento de la ley. Si las garantías procesales se mantuvieran, toda persona recibiría el mismo tratamiento independientemente de si habla la lengua del proceso o no, ya sea víctima, acusado o testigo, y de esta forma se evitarían injusticias y recursos innecesarios.

Mi llegada a la interpretación judicial puede considerarse en cierto modo fortuita, pues empecé a trabajar como tal en una situación de emergencia. En esos momentos cursaba los estudios de Traducción e Interpretación, y mis conocimientos de la situación $\mathrm{y}$ de los protocolos de actuación y legales eran escasos. Me enfrenté a situaciones difíciles sin haber recibido formación específica y las resolví en parte con sentido común y en parte por la propia experiencia. Así fui intentando suplir de forma autónoma las lagunas formativas, a la vez que llegué al convencimiento de que era necesario formar y emplear intérpretes profesionales para alcanzar una interpretación de calidad en el contexto judicial.

Los estudios de máster me llevaron a plantearme la posibilidad de investigar sobre la interpretación judicial. Antes de centrarme en un tema concreto, empecé a interesarme de manera creciente por casos de buenas y malas prácticas como resultado de mi experiencia personal en interpretación judicial y los conocimientos teóricos que iba adquiriendo. Mi encuentro con una de mis directoras de tesis, María Jesús BlascoMayor, fue fundamental a la hora de elegir y centrar el tema, pues su visión completa y comprometida contribuyó a que dirigiera mis esfuerzos hacia un punto específico: la calidad en interpretación judicial y la posibilidad de evaluar las prestaciones reales de 
los intérpretes en sede judicial y policial. La incorporación de la profesora Micaela Moro Ipola, especialista en la construcción y validación de tests , permitió formar un equipo multidisciplinar necesario para abarcar los desafíos que se presentaban. Sus conocimientos en psicometría, análisis y construcción de instrumentos de evaluación han sido fundamentales en el planteamiento del trabajo que se presenta a continuación.

Durante mis estudios de máster, me centré en la comunicación no verbal en interpretación consecutiva. A partir de entonces, me fui cuestionando ciertos planteamientos relacionados con el estudio de la calidad en interpretación, pues se hacía referencia a la gestión de la calidad pero de manera vaga y centrada fundamentalmente en la interpretación de conferencias, aislándola de los demás conceptos relacionados con la calidad y la gestión de la calidad en otras ramas de conocimiento. Esto llevaba a que la calidad se considerara un concepto resbaladizo, poco definido, en el que podían aplicarse los mismos conceptos que se aplican para el marketing (Kurz, 2001). Por ejemplo, se mencionaba que «Quality must begin with customers' needs and end with customer perception» (Kotler y Amstrong, 2004, p. 568). Gile y Collados Aís (2002) defendían por su parte que la calidad se mide en relación con el éxito comunicativo.

Aunque es cierto que no existe una unanimidad en relación con la noción de calidad en interpretación, no cabe duda de que se trata de un concepto imprescindible en la actualidad cuando se aborda el estudio de la interpretación en los servicios públicos. En el caso de la interpretación en el contexto judicial y policial, la calidad de la interpretación implica la obligación de garantizar derechos como son el de entender y ser entendido durante un proceso judicial.

Se ha considerado la interpretación como la prestación de un servicio que resuelve problemas de comunicación (Jiménez Ivars, 2004, p. 136). La definición de un servicio de calidad incluye la adecuación de dicho servicio y la satisfacción del cliente. Los servicios tienen, de por sí, una naturaleza intangible y perecedera, a diferencia de los productos. Si el resultado de la actividad es deficiente, solo se puede mejorar repitiéndola, lo que supone una merma en la percepción de la calidad y una pérdida de tiempo (p. 138). En la actualidad, la certificación de la calidad del servicio es obligatoria en algunos sectores. De ella dependerán también la adjudicación de contratos y la posibilidad de captar clientes. Por otro lado, la aparición y el uso de las nuevas tecnologías ha terminado con el carácter efímero de muchos servicios (Kalina, 2015 , p. 16), aunque no son suficientes para superar las dificultades principales de producción inmediata y las de recuperar los posibles errores cometidos. Es importante señalar que los errores no dependerán únicamente del intérprete, sino que se verán afectados por las condiciones generales donde se produce el servicio: velocidad del 
habla, acento, problemas acústicos, dificultades terminológicas y de preparación, jornadas de trabajo más o menos largas, entre otros.

Por otro lado, la investigación en la gestión de la calidad resalta la necesidad de establecer indicadores para su evaluación (Collados Aís y García Becerra, 2015b). Para medir la calidad del servicio de interpretación se han utilizado parámetros específicos y diferentes procedimientos como la cumplimentación de cuestionarios tras escuchar una interpretación en situación real y también en situaciones controladas, comparándolos con las expectativas de los usuarios y clientes. Si en otros contextos la evaluación de la calidad es importante, en el caso de la interpretación en contextos judiciales se convierte en primordial, pues afecta a los derechos y la libertad de las personas.

\subsection{Antecedentes}

La investigación en calidad en interpretación se ha desarrollado desde época muy temprana en relación con el reconocimiento de la profesión. Los primeros estudios los llevaron a cabo profesionales con el objetivo de reflexionar sobre la mejora de la profesión.

En un primer momento, los estudios se centraron en la evaluación de la calidad en interpretación de conferencias, para lo que se estudiaron una serie de parámetros. Se observó que el éxito en la comunicación variaba de manera significativa en relación con el contexto. Aunque generalmente centrados en la interpretación simultánea, algunos estudios se ocuparon de manera más específica en la interpretación consecutiva teniendo en cuenta distintos parámetros con una concepción holística que abarcaba al mismo tiempo las expectativas de los usuarios y las evaluaciones en situaciones controladas.

Tras estos estudios, fueron surgiendo otros que se ocupaban más específicamente de la interpretación en los servicios públicos centrados en la calidad según las expectativas de los usuarios. Para el análisis de la situación, se empleaban cuestionarios que evaluaban situaciones reales (Kadric, 2000). Al mismo tiempo, se iniciaron estudios que planteaban las necesidades y las características específicas de la interpretación dialógica (Mason 1999, 2001), que forjaban nuevos retos y corrientes de pensamiento relacionados con la invisibilidad del intérprete y con su propio papel (Angelelli, 2004).

Los resultados de estos estudios llevan al planteamiento de que, de la misma manera que los principios del marketing no sirven para la interpretación de conferencias, tampoco los de esta pueden extrapolarse sin más a la interpretación judicial. En este último caso, existen entornos distintos y situaciones muy variadas y, 
además, hay que tener en cuenta las leyes que garantizan los derechos de la persona acusada, de la víctima o el testigo. De ahí que en este trabajo se plantease el diseño de nuevos procedimientos de evaluación del desempeño del intérprete que no solo tuvieran en cuenta las expectativas, el éxito de la comunicación o la fidelidad del enunciado, sino también aspectos objetivos que se integran en lo que debe ser una interpretación adecuada, de buena calidad.

Aunque el contexto y otros indicadores influyen en la prestación del servicio, la realidad es que la interpretación en los servicios públicos en general (y judicial en particular) tiene unas implicaciones de tal calado que es preciso tener en cuenta las consecuencias de una interpretación de poca calidad. Además, las características tan específicas de este tipo de interpretación han demostrado que no basta con ser un buen intérprete de conferencias para ser un buen intérprete judicial (Navarro-Hall, 2017). Se necesita una preparación específica que incluya las técnicas de interpretación, pero también conocimientos legales, culturales y técnicos. Por otro lado, y como se ha indicado en varios instrumentos legales que parten de la Directiva europea 2010/64/UE, es preciso desarrollar y aplicar mecanismos de control de la calidad de la interpretación que garanticen el derecho de los ciudadanos a un juicio justo.

\subsection{Objetivos de la investigación}

El objetivo de este trabajo es elaborar un instrumento de evaluación basado en criterios objetivos y cuantificables que permita evaluar el desempeño del intérprete judicial en su labor diaria, en cualquier entorno y en cualquier país. Dicho instrumento puede incluirse en una estrategia de control de la calidad de la interpretación que establezca la administración de justicia a nivel regional o nacional.

Para ello, se fijaron varios objetivos:

1. Analizar el contexto de la interpretación judicial en general, observando cómo se lleva a cabo en los distintos países.

2. Analizar el contexto legislativo que regula el desempeño de la interpretación judicial en el mundo, con los ejemplos específicos de Estados Unidos, Australia y Reino Unido, donde la interpretación judicial ha adquirido una cierta consideración social, y en particular en Europa, donde se ha aprobado una ley específica en relación con el derecho a interpretación y traducción en los procesos penales.

3. Analizar los estudios de calidad desde su más amplia concepción hasta cómo se fue desarrollando el interés por la calidad durante el siglo xx y el principio de la gestión de 
la calidad total orientada no solo al producto sino también a los servicios. A continuación, se revisa la literatura sobre la calidad en interpretación, en conferencias y en los servicios públicos; en especial los proyectos europeos centrados en interpretación judicial.

4. Diseño de un cuestionario de evaluación de la calidad de la interpretación judicial a partir de los resultados presentados en los trabajos analizados y realización de un estudio piloto con la participación de operadores judiciales, intérpretes judiciales y docentes expertos. Realizar un estudio empírico del cuestionario para poder corroborar sus propiedades técnicas, como fiabilidad y validez.

Tras la realización de todos estos pasos, se analizarán los resultados del estudio empírico y el posible empleo y aplicación real de dicho instrumento.

\subsection{Metodología}

Como ya se ha señalado, no existen trabajos que analicen la calidad de la interpretación desde un punto de vista objetivo. Hasta el momento, los estudios se han centrado fundamentalmente en las expectativas o en la evaluación teniendo en cuenta ciertos parámetros verbales y no verbales que tienen que ver con el rendimiento, pero en los que tiene gran importancia la cuestión lingüística.

Partiendo de que el receptor de la interpretación no conoce la lengua extranjera, y que se ha considerado que no es y no puede ser un buen evaluador (Gile, 1994), se ha buscado otra manera que permitiera evaluar el rendimiento del intérprete en función de datos objetivos y medibles.

Para ello, se realizó en primer lugar una revisión bibliográfica sobre el concepto de calidad y de calidad en interpretación.

En segundo lugar, se procedió a la elaboración de un borrador del instrumento de medida y a su posterior pilotaje y validación.

Durante la fase de validación, se consideró fundamental recabar datos cualitativos sobre la percepción de la calidad de la interpretación judicial a partir de observaciones en sala y entrevistas con jueces, como elemento que complementa y ayuda a explicar los datos cuantitativos recogidos en dicha fase.

Finalmente, se procesaron los datos cuantitativos, se analizaron y valoraron, y se triangularon con los datos cualitativos, de modo que se pudieron extraer unas conclusiones de la investigación a partir de las cuales se plantearon las distintas posibilidades de explotación del instrumento y posibles vías futuras de investigación. 


\subsection{Partes del trabajo}

Esta tesis doctoral tiene como objetivo principal el diseño y la validación de un instrumento de evaluación que permita medir la calidad del desempeño de los intérpretes en un entorno judicial, de manera que se puedan cumplir los principios defendidos en el considerando 24 de la Directiva 2010/64/UE.

Para ello, en primer lugar (capítulo 2) se ha llevado a cabo una revisión sobre la profesión del intérprete judicial y su reconocimiento como disciplina y profesión independiente con respecto a la interpretación para los servicios públicos. Se expone su concepción en distintos países, sus bases y los problemas que plantea. En la última parte de este capítulo, se propone una pequeña panorámica sobre la situación de la interpretación judicial en los países donde se llevó a cabo la validación del instrumento, que son España e Italia.

En el capítulo 3 se ha ahondado en las bases legales del derecho a interpretación y a la traducción en los procesos penales a nivel internacional. A continuación, se profundiza en la realidad de la Unión Europea con la emanación de la Directiva 2010/64/UE, considerada un momento crucial y de cambio radical en el reconocimiento de los derechos del acusado y de la concepción misma del intérprete, que es visto no solo como asistente de la autoridad, sino como auxiliar de las personas acusadas, víctimas o testigos en los procesos penales, lo que permite cumplir con ciertas garantías procesales.

Una vez establecidos el marco profesional y legal, se pasa a analizar el estudio de la calidad, partiendo de una base general y revisando la bibliografía existente sobre la interpretación de conferencias, después su comparación con la interpretación judicial y, por último, la de los servicios públicos. Este será el contenido del capítulo 4 . No se ha pretendido hacer una revisión bibliográfica exhaustiva de la literatura, pues se considera que este trabajo ya ha sido realizado de manera pormenorizada por otros estudiosos, sino que se han intentado analizar las corrientes y las tendencias en dichos estudios, como el marco teórico necesario para la elaboración del cuestionario y el estudio empírico.

El capítulo 5 se centra en la calidad de la interpretación judicial, las características que debe poseer y de dónde se puede recabar información para su estudio. Se analizan los distintos proyectos que se han llevado a cabo en aras de una mejora de la calidad en la interpretación judicial en el seno de la Unión Europea.

Después de haber sentado de esta manera las bases que constituyen los fundamentos de esta tesis, se pasa a detallar el proceso que ha llevado a la construcción 
del instrumento de evaluación de la calidad de la interpretación judicial. Por ello, el capítulo 6 se ocupa de la metodología seguida para desarrollar el instrumento.

Una vez elaborado el instrumento de evaluación, se procedió a su validación mediante la distribución de cuestionarios en dos entornos judiciales (italiano y español). Los datos cuantitativos obtenidos en esta fase se completaron con el trabajo de campo de la investigadora que siguió todo el proceso. Posteriormente se procedió al tratamiento estadístico de los datos.

El capítulo 7 presenta los resultados obtenidos en el análisis estadístico de los datos, la comparación de las muestras italiana y española y una descripción pormenorizada del funcionamiento y características de cada una de las preguntas del cuestionario. También se incluye una segunda parte con los datos cualitativos recogidos en los cuadernos de campo.

Por último, en el capítulo 8 se expone la discusión de los resultados cuantitativos y cualitativos, considerando los objetivos planteados y las publicaciones relevantes. Este capítulo termina con la exposición de las principales conclusiones de esta investigación.

Se han seguido las normas de redacción de la American Psychological Association (APA), versión 6 (2016), en las referencias, tablas y figuras. Para la compilación de la bibliografía se ha utilizado la aplicación para gestión de referencias Mendeley (www.mendeley.com). 


\section{La interpretación judicial como especialidad independiente}

\subsection{Estado de la cuestión}

\subsubsection{Introducción}

La primera aproximación que es preciso realizar antes de abordar un estudio relacionado con la calidad en la interpretación judicial es glosar en la literatura la figura del intérprete judicial, pues esto proporcionará un marco de referencia a partir del cual se podrá ir avanzando en la elaboración de las distintas hipótesis, teorías y propuestas metodológicas. Estudiar en la literatura la figura del intérprete judicial y su función será, por tanto, el primer paso que habrá de darse.

Definir la interpretación judicial puede resultar en cierto modo sencillo si se tiene en cuenta únicamente el entorno judicial penal, aquel en el que se requiere de interpretación con mayor frecuencia. Siguiendo a Hertog (2015b, p. 230), se trata de la interpretación que se desarrolla en los distintos estadios del procedimiento criminal, que abarcan desde el momento del descubrimiento del delito, pasando por todas las fases de la investigación y de la vista oral, hasta llegar al momento en que se dicta sentencia. De hecho, se puede requerir de interpretación desde el momento en que se emite una orden de detención, durante los interrogatorios de la policía, las entrevistas con el abogado, todas las fases de la vista oral y las entrevistas con el abogado en prisión. Sin embargo, en algunos países como Estados Unidos o Reino Unido se incluyen las entrevistas para determinar la libertad condicional, las vistas orales en las que se establece la acusación y las audiencias para solicitar asilo (González, Vásquez, y Mikkelson, 2012).

En inglés existen una gran variedad de términos para definir este tipo de interpretación, entre los que se incluyen: court interpreting (González et al., 1991, 2012; Mikkelson 2000, 2017); judicial interpreting (Driesen, 1985, en Hertog, 2015b), forensic interpreting (Roberts-Smith, 2009), police interpreting (Pérez, 2015, pp. 310312; Ortiz Soriano, 2015, pp. 207-241; Amato y Mack, 2015, pp. 43-56; Tipton y Furmanek, 2016, pp. 37-51), prison interpreting (Martínez-Gómez, 2015, pp. 320-321) o asylum interpreting (Maryns, 2015, pp. 23-25; Pöllabauer, 2007, pp. 202-216; Tipton y Furmanek, 2016, p. 76-112), dependiendo del entorno en el que se lleva a cabo dicha interpretación. En Estados Unidos se considera un género independiente, mientras que en otros países, como Australia (Hale, 2007) y Reino Unido (Corsellis, 2008), se incluye como subgénero en la interpretación en los servicios públicos. González et al. 
(2012, p. 95) dividen la interpretación judicial en dos ámbitos fundamentales, el que se desarrolla específicamente en las salas de un juzgado (que denominan court interpreting) y el que se lleva a cabo fuera de las salas del juzgado (que consideran quasi-judicial interpreting). Hertog ha optado por la denominación legal interpreting, mucho más amplia, teniendo también en cuenta los diferentes entornos y situaciones más allá del específicamente judicial (Hertog y Van Gucht, 2006; 2015: pp. 230-235).

En español no existe una equivalencia para el legal inglés, que abarca muchas situaciones y contextos dentro del ámbito jurídico, no únicamente el judicial y policial. En su lugar se utiliza el término genérico jurídica, sobre todo para la traducción, pero no hay consenso sobre su utilización al referirse a la interpretación judicial y policial, de modo que algunos autores hablan de interpretación jurídica (Borja Albi, 2012; Osoro Pérez-Puchal, 2012) mientras que otros prefieren referirse a ella como judicial y policial, o utilizan judicial como término genérico que abarca todo el contexto (BlascoMayor y Del Pozo Triviño, 2015). Se puede afirmar, por tanto, que en España apenas se suele utilizar el término interpretación jurídica, sino que se prefiere la denominación judicial o para la justicia (Ortega-Herráez, 2006, 2011) o de tribunales, recurriendo a un denominador más específico al referirse a otros contextos jurídicos: notarial (Del Pozo Triviño, 2008), en contextos de asilo y refugio (Blasco-Mayor, en prensa), policial (Foulquié Rubio, 2002, Olalla Fernández, 2006). Para el propósito de este trabajo, y en términos generales, se utilizará la denominación interpretación judicial para referirse a la que tiene lugar en cualquier momento del proceso judicial, desde la detención o denuncia hasta la sentencia.

Morris (2015, p. 91) considera court interpreting aquella que se desarrolla en un entorno judicial para superar los problemas de comunicación de uno o más participantes que no hablen o comprendan el idioma del procedimiento, o tengan impedimentos de habla o audición. Incluye entre los participantes a acusados, testigos, abogados, jurados $\mathrm{y}$ jueces que necesitan dichos servicios para el buen desarrollo del proceso penal durante todas sus fases. El caso de los abogados, jurados o jueces que no hablan el idioma del procedimiento se produce en los tribunales internacionales.

Tras examinar las diferentes definiciones presentes en la literatura, y teniendo en cuenta que el propósito de este trabajo es la realización de un instrumento de evaluación de la calidad en entornos judiciales tal y como establece el artículo 5 de la Directiva 2010/64/UE, se ha optado por utilizar la denominación interpretación judicial para referirse a toda aquella que se desarrolle en cualquier escenario posible del procedimiento penal, desde el momento en que las autoridades competentes ponen en conocimiento de una persona sospechosa o acusada de haber cometido una infracción penal hasta que finaliza el proceso con la sentencia (Blasco-Mayor, 2015, p. 269). 
Abarca, por tanto, las investigaciones y diligencias policiales y de aduanas, las audiencias previas al juicio, los interrogatorios o las declaraciones con el juez, las reuniones entre abogado y cliente, las denuncias, las vistas orales, los juicios propiamente dichos y los trámites posteriores a ellos, las audiencias de los solicitantes de asilo, los procedimientos de orden de detención europea y las comisiones rogatorias, entre otros.

\subsubsection{Características de la interpretación judicial}

El principal rasgo definitorio de la interpretación judicial, independientemente del entorno concreto en el que esta tenga lugar, es que en muchos países está regulada por ley. El concepto de linguistic presence ${ }^{2}$ (González et al., 2012, p. 160), es decir, el derecho de un acusado a entender las acusaciones que se le imputan y a poder ser entendido, se convierte, pues, en un principio fundamental para la presencia efectiva del acusado en su juicio. De ello se hablará con más detalle en el capítulo 3.

De la misma manera que hay ciertos entornos y actuaciones en los que la figura del intérprete judicial comparte características con la del intérprete de conferencias, como es en los tribunales internacionales, existen otros entornos a nivel nacional en los que se acerca mucho más a la interpretación en los servicios públicos, de la que algunos autores consideran que forma parte (Martin, 2003; Abril Martí, 2006; Hale, 2007, Corsellis, 2008). En el proceso de la interpretación judicial se produce una bidireccionalidad que ocurre normalmente en la versión dialógica por medio de interpretación consecutiva, combinada con la interpretación susurrada y la traducción a la vista (Hale, 2007; Corsellis, 2008; Rudvin y Tomassini, 2011). Otros autores, sin embargo, la consideran un género independiente y diferencian de manera precisa la interpretación que tiene lugar en contexto judicial de la que se produce en un entorno social. Precursoras de esta última corriente fueron las estudiosas estadounidenses que promovieron la regulación de la profesión en Estados Unidos y establecieron la formación y acreditación de intérpretes judiciales (Mikkelson, 2000 y 2017; González et al., 1991; 2012).

Es preciso recordar que la función del intérprete judicial es diferente de la del traductor y, por tanto, requiere destrezas y capacidades distintas (Hale, 2007, p. 8; Caciagli, Balleto y Rivezzi, 2009; Del Pozo Triviño y Baigorri Jalón, 2015; Borja Albi y Del Pozo Triviño, 2015; Arumí Ribas, 2018, p. 45), por lo que cada figura precisa una capacitación y preparación específicas. El traductor trabaja con la lengua escrita,

\footnotetext{
${ }^{2}$ Sentencia de Us. ex. rel. Negrón contra New York en 1970 (González et al., 2012, p.160-163).
} 
mientras que el intérprete se ocupa fundamentalmente de la traducción oral, aunque en ciertas ocasiones deberá traducir oralmente documentos escritos.

Por otro lado, la interpretación judicial exige un dominio profundo de los idiomas de trabajo, de los distintos registros, del lenguaje especializado y de la terminología técnica (Blasco-Mayor y Del Pozo Triviño, 2015, p. 31). Se requiere también un conocimiento del sistema legal y del propio procedimiento judicial, y un dominio de las técnicas de interpretación y de los temas que se abordan en el evento comunicativo, amén de poseer una competencia profesional, de buenas prácticas, y un dominio de los protocolos de actuación (p. 31-32). De igual manera, el intérprete debe ser capaz de hacer frente a situaciones de estrés y de fuerte impacto emocional (Shlesinger, 2015, p. 434; Aguilera Ávila, 2015, pp. 272-293).

\subsubsection{Modalidades utilizadas en la interpretación judicial}

Las modalidades utilizadas en la interpretación judicial son la interpretación consecutiva y la simultánea, con o sin la ayuda de dispositivos electrónicos, de manera presencial o remota (Del Pozo Triviño y Baigorri Jalón, 2015, pp. 37-39). En ciertas ocasiones, la prevalencia de una modalidad de interpretación dependerá del entorno donde se realice dicha labor. La interpretación simultánea se convertirá en susurrada si se realiza sin equipo técnico, susurrando el mensaje a la persona que lo necesite. Se utiliza la interpretación bilateral, que es aquella en la que el intérprete trabaja en dos lenguas para restituir la intervención del interlocutor en el idioma de la otra persona (Abril Martí, Toledano Buendía, Ugarte Ballester y Fernández Pérez, 2015), respetando los turnos de habla y sirviendo de enlace en la comunicación. Teniendo en cuenta la asimetría de poder que se produce en estos contextos, el intérprete deberá poseer destrezas sociales de comunicación, como son la escucha activa, la asertividad y la flexibilidad, entre otros (Abril Martí et al., 2015, p. 58). El intérprete judicial también ejecuta tareas de traducción oral, llamada a la vista (Edwards, 1995; González et al., 2012; Lee, 2015; Del Pozo Triviño y Baigorri Jalón, 2015; Mikkelson, 2017) cuando tiene que traducir oralmente un texto escrito.

\subsubsection{Interpretación judicial frente a interpretación en los servicios públicos}

La interpretación en los servicios públicos (ISP) es la que se produce entre los individuos que no hablan las lenguas oficiales de la sociedad o el país en el que viven y 
las instituciones de dicho país. Abril Martín defiende una definición de la ISP que reza como sigue:

... aquella que facilita la comunicación entre los servicios públicos nacionales, policiales, judiciales, médicos, administrativos, sociales, educativos y religiosos, y aquellos usuarios que no hablan la lengua oficial del país y que habitualmente pertenecen a minorías lingüísticas y culturales: comunidades indígenas que conservan su propia lengua, inmigrantes políticos, sociales o económicos, turistas y personas sordas $(2006$, p. 5$)$.

Esta definición incluye también la interpretación judicial, pero si se reflexiona sobre la categorización de la misma como un género independiente o perteneciente al ámbito de la interpretación en los servicios públicos, cabe concordar con el enunciado de Pöchhacker, que considera la interpretación judicial independiente de la ISP basándose en las limitaciones impuestas en la tarea del intérprete judicial, pues estas contradicen ciertas normas profesionales (2016, p. 161).

Aunque sería justificable incluir la interpretación judicial dentro de la ISP, la naturaleza del sistema legal y los protocolos de actuación rígidos impiden que el intérprete pueda realizar el tipo de intervenciones que podría llevar a cabo en otros entornos de los servicios públicos (González et al., 2012, p. 86).

Hale, por su parte, integra la interpretación judicial en la ISP, señalando las semejanzas de esta con la interpretación sanitaria, aunque reconoce la existencia de diferencias significativas en la manera de actuar del intérprete (2007, p. 66). Considera que la interpretación judicial abarca diversos ámbitos, según el sistema jurídico subyacente en el que se produzca. La autora apunta que los distintos ámbitos dentro de la interpretación judicial se diferencian en cuanto a la relación entre los interlocutores, la finalidad de la interacción, la formalidad del evento, el papel de los participantes, la función del lenguaje y las consecuencias que tendrán para el intérprete (op. cit. p. 65).

Corsellis por su parte contribuye al debate con una visión de la interpretación judicial en la que destaca la existencia de requisitos jurídicos concretos, lo que ha conducido a la elaboración de directrices de buenas prácticas y normas de actuación, pero en general tiene mucho en común con el resto de contextos de los servicios públicos: se produce una disimetría de poder y se utilizan las técnicas de interpretación consecutiva, susurrada y de traducción a la vista (2008, p. 22).

En la misma línea que los autores citados, Mikkelson advierte de la singularidad de la interpretación en el contexto judicial, argumentando que en la interpretación judicial han de trasladarse todos los enunciados del discurso original: «every single element of meaning in the source language message must be accounted for in a target language version» (Mikkelson, 2000, p. 71; 2017, p.100). El intérprete no puede 
permitirse el lujo de ser más conciso, como es la praxis en la interpretación consecutiva, donde el intérprete puede eliminar algunos elementos paralingüísticos que no son indispensables o que carecen de finalidad expresiva a fin de no hacer más pesada la escucha por parte del público (Errico, 2015, p. 43). En el caso de la interpretación judicial, el intérprete ha de trasladar todos los elementos paralingüísticos, correcciones, repeticiones, titubeos y errores, aunque se trate de elementos redundantes «which entail the preservation of the form and content of the linguistic and paralinguistic elements of the discourse, hesitation and emotions as they are conveyed through tone of voice, word choices, and intonation» (González et al., 2012, p. 15). Además, se añade el problema de la brecha existente entre distintos sistemas legales, que puede conllevar dificultades de interpretación de conceptos inexistentes en la lengua de la persona que precisa el intérprete, como puede ser el concepto de propiedad privada para algunas comunidades indígenas centroamericanas en Estados Unidos (Navarro-Hall, 2017). Esta no es, en realidad, una característica específica del entorno judicial, pues la traslación de contenido cultural puede existir y presentar dificultades en cualquier contexto público o privado.

Por otra parte, la interpretación judicial incluye algunos contextos que ciertos autores consideran una «zona gris» (Bancroft, Bendana, Bruggeman y Feuerle, 2013, p. 26), zona que González et al. (2012, pp. 95-96) definen como quasi-judicial interpreting, pues en Estados Unidos algunas actuaciones de la Administración se llevan a cabo fuera de los juzgados (como pueden ser los servicios de inmigración, las denuncias por discriminación, los arbitrajes laborales, las mediaciones para la custodia durante una separación o divorcio, la interpretación para la ejecución de algunas leyes o los programas de libertad condicional). Lo que caracteriza a estos ámbitos es que suelen afectar a los derechos individuales y tienen consecuencias a largo plazo (Tipton y Furmanek, 2016, p. 54).

En los ámbitos judicial y policial, la dinámica que rige la comunicación con intérprete está muy regulada, pues las intervenciones y los turnos de palabra están ya predeterminados en algunos casos con patrones muy rígidos (Angelelli, 2004, p. 152). Por esta razón, se entiende que la posibilidad de que el intérprete participe activamente es más reducida en comparación con otros entornos de la interpretación para los servicios públicos (Abril Martín et al., 2015, p. 84).

La división neta entre interpretación judicial y en los servicios públicos no queda clara tampoco para Ortega-Herráez (2011, pp. 9-10), que ejemplifica la situación en varios países como Reino Unido y Australia, y más específicamente en Estados Unidos, donde la ley federal «le otorga [al intérprete judicial] una posición privilegiada frente a 
otros profesionales que desempeñan sus labores en ausencia de un marco jurídico-legal tan claro como puede ser el caso de los servicios sanitarios» (2011, p. 14).

La International Standard Organization (ISO) establece normas diferentes para las dos actividades (la de interpretación en los servicios públicos y la judicial), lo que hace intuir que existen diferencias marcadas entre ambas. Se trata de la ISO 13811 del 1 de diciembre de 2014, dedicada a la ISP (Intepreting-Guidelines for Community Interpreting), y la ISO 20228, específica para la interpretación judicial (Interpreting Services Legal Interpreting Requirements), que determina la necesidad de normas específicas por lo que atañe a la interpretación judicial en el sentido más amplio (Katschinka, 2017). En el capítulo 5 se profundiza sobre las mismas.

\subsubsection{Intérprete judicial frente a intérprete de conferencias}

Aunque se haya defendido que todas las modalidades de interpretación comparten algunos aspectos y que «interpreting is interpreting» (Mikkelson, 1999), existen modalidades cuyas características repercuten en el desempeño (simultánea, consecutiva monológica, dialógica). El hecho de que se interprete con dispositivos técnicos o sin ellos (en cabina, con dispositivos móviles o simplemente consecutiva), presencial o remotamente (por videoconferencia o teléfono) y los distintos contextos en los que se lleva a cabo (diplomático, militar, conferencias, entre otros) influyen en el resultado final. En general, se hace una diferenciación dependiendo del entorno específico en el que se produce la interpretación, que suele conllevar distinto reconocimiento a nivel profesional. De hecho, los intérpretes de conferencias son los mejor considerados y, en general, los mejor pagados.

La interpretación de conferencias es la que ha obtenido mayor consideración y prestigio a lo largo del siglo Xx, la que impuso una selección estricta de sus miembros y desarrolló inquietudes asociativas. La Asociación Internacional de Intérpretes de Conferencia (AIIC) es la asociación de intérpretes más prestigiosa del mundo, posee un código deontológico y ha conseguido establecer acuerdos en aras de una protección y reconocimiento de sus asociados, como, por ejemplo, el acuerdo establecido entre AIIC y la Unión Europea, formalizado desde $1969^{3}$ para garantizar seguridad y transparencia a las condiciones laborales de los intérpretes que trabajan para las instituciones

\footnotetext{
${ }^{3}$ La Unión Europea estableció un acuerdo con AIIC relativo a las condiciones de trabajo y a la remuneración de los intérpretes (AIIC_EU Convention. Agreement on working conditions and the pecuniary regime for auxiliary conference interpreters recruited by the Institutions of the European Union), que se aplica a los intérpretes de conferencias auxiliares (ACI).
} 
comunitarias, el establecido entre AIIC y Naciones Unidas entre 2014 y 2017 o el estipulado entre AIIC y las Organizaciones Coordinadas entre 2014 y 2018, entre otros ${ }^{4}$.

González et al. (2012, p. 91) definen la interpretación de conferencias como aquella cuyos servicios facilitan la comunicación entre hablantes de distintos idiomas que asisten a reuniones y conferencias. Destacan algunas características distintivas de la interpretación de conferencias, esto es: el trabajo en equipo, el uso de cabinas y dispositivos de escucha y el hecho de que se les proporcione el material por adelantado.

La Asociación Internacional de Intérpretes de Conferencias (AIIC) define la interpretación de conferencias como aquella que se lleva a cabo en el entorno concreto de las conferencias, y especifica las modalidades consecutiva y simultánea: «Conference interpreting can be defined as the rendering of speeches delivered in one language into another at formal and informal conferences and in conference-like settings, in either the simultaneous or the consecutive mode» (AIIC, 1983 en Diriker, 2015: p. 78). En general, se refieren a conferencias internacionales, reuniones multilaterales o talleres, y se extiende asimismo a cenas oficiales, notas de prensa, sesiones parlamentarias, tribunales internacionales e incluso conferencias universitarias (Diriker, 2015). Se incluye también la interpretación en lengua de signos (Turner, 2007).

Los intérpretes de conferencias pueden mejorar de manera deliberada la exposición del orador, condensar la elocución del mensaje original (Gile, 1995; Seleskovitch, 1978). Pueden pulir la sintaxis, realizar predicciones, omitir repeticiones, vacilaciones y monotonía con el propósito de canalizar el mensaje de la mejor manera. Han de ser capaces de proporcionar una interpretación fidedigna del original (Jones, 1998) pero se aceptan ciertas libertades pues el fin último es transmitir el mensaje a un nivel global y no pormenorizado (González et al., 2012: p. 97). Viezzi, haciendo referencia a la precisión con referencia a los cuatro objetivos que debe cumplir una interpretación (equivalencia, precisión, adecuación y utilidad), admite una pérdida de información con tal de que se consigan los demás objetivos (1996, p. 148).

En la interpretación judicial, por el contrario, la equivalencia se convierte en imprescindible para transmitir no solo el significado original, sino también el registro, las repeticiones, los errores y el estilo, y algunos autores llegan a incluir la mímica (González et al., 2012, p. 96).

Otro aspecto que cabe destacar es que la interpretación de conferencias se desarrolla en contextos donde los participantes comparten el poder y el conocimiento, y

4 Los distintos acuerdos firmados entre AIIC y las distintas instituciones se recogen en la página de la asociación, disponible en https://aiic.net/agreements. 
constituyen una comunidad discursiva homogénea (Errico, 2016, p. 166). En ocasiones, utilizan a los intérpretes por cuestiones políticas o de organización. Los participantes comparten ideas y conceptos, por lo que el intérprete puede producir una versión que satisfaga las expectativas de la audiencia en términos de lenguaje y facilidad de comprensión (Llewellyn-Jones y Lee, 2014, p. 46). Al mismo tiempo, dicha comunidad muestra una cierta consideración por la labor del intérprete.

Esta situación se ve totalmente alterada en la interpretación judicial, pues solo en muy pocos contextos los interlocutores comparten el mismo estatus, dándose generalmente un desequilibro de poder (Angelelli, 2004).

Diriker (2015, p. 78) y AIIC consideran la interpretación ante los tribunales internacionales como una interpretación de conferencias a todos los efectos, y por ello han conseguido acuerdos, reconocimientos y una buena remuneración. Los estudios realizados en los órganos internacionales, como el Tribunal de Justicia de la Unión Europea (Amodeo Perillo, 1989) o en el Tribunal de La Haya (Schweda-Nicholson, 2010), concuerdan con que la interpretación en estos contextos posee las características y el reconocimiento de la interpretación de conferencias. Los intérpretes en estos contextos trabajan con los medios utilizados generalmente por los intérpretes de conferencias (Tipton y Furmanek, 2016, p. 53), pero, al igual que los demás intérpretes judiciales, han de mantener la fidelidad en todo momento. La posibilidad de preparación, el uso de dispositivos para llevar a cabo la interpretación simultánea y trabajar en equipo facilitan la labor de estos profesionales, altamente cualificados. Además, la direccionalidad en este entorno suele ser únicamente hacia el idioma nativo del intérprete.

\subsubsection{Entornos de la interpretación en el ámbito de la justicia}

Los entornos donde trabaja el intérprete judicial pueden variar de manera considerable, y con ellos su estatus, que conllevará un mayor o menor reconocimiento profesional, requisitos de acceso a la profesión y una preparación específica. La interpretación judicial puede llevarse a cabo en tribunales internacionales, supranacionales y nacionales. Se iniciará haciendo una pequeña exposición sobre los tribunales internacionales, para examinar a continuación los casos específicos de algunos países, que se han demostrado punteros a la hora de desarrollar programas de interpretación judicial, más elaborados y orientados al cumplimiento de los derechos humanos. 


\subsubsection{Tribunales internacionales}

Si bien la evaluación del desempeño de los intérpretes en los tribunales internacionales y supranacionales no forma parte de este trabajo de investigación, se ha considerado importante hacer un pequeño esbozo de este contexto por considerar que las técnicas y las condiciones de trabajo, el acceso a la profesión, la remuneración, la preparación, los códigos deontológicos y el seguimiento/evaluación de los intérpretes que trabajan en dichos tribunales son un ejemplo de buenas prácticas y una demostración de la factibilidad si existe voluntad para ello. Los intérpretes en los tribunales internacionales trabajan normalmente en cabinas con el soporte técnico necesario y tienen la posibilidad de prepararse, pues se les facilita el expediente antes de la vista. Todos los intérpretes que trabajan para la justicia, ya sea en contextos nacionales o internacionales, deberían reunir estas características y poder gozar del mismo reconocimiento.

Es preciso citar en este subepígrafe dedicado a los tribunales internacionales los juicios que se celebraron para juzgar los crímenes de guerra tras la II Guerra Mundial; los juicios de Núremberg (1945-1946) y el juicio de Tokio (1946-1948) han de considerarse un hito para la consolidación de la profesión del intérprete de conferencias y de la interpretación simultánea (Gaiba, 1999; Baigorri Jalón, 2004; Watanabe, 2009; Takeda, 2010). Estos juicios son representativos desde varios puntos de vista, pues serán un ejemplo para el juzgamiento de otros crímenes posteriores contra la humanidad $y$, en cuanto a la interpretación, se consideran como un hito en el nacimiento de la interpretación simultánea y en la organización del trabajo de los intérpretes (Baigorri Jalón, 2004, pp. 225-265; Gaiba, 1999, pp. 9-22). La presencia de los intérpretes durante los juicios de Núremberg fue fundamental para permitir la coordinación entre los jueces, la comprensión de todo el proceso y la comunicación con los medios de comunicación. En este caso, los intérpretes llevaron a cabo más labores de las que desempeñan hoy en día (Baigorri, 2004), pues se trataba de una profesión nueva. A partir de dichos juicios se generalizó el uso de cabinas para la interpretación simultánea. Respecto al Tribunal Penal Militar Internacional para el Lejano Oriente, conocido como el Juicio de Tokio (1946-1948), Watanabe (2009) y Takeda (2010) proporcionan una descripción pormenorizada del sistema organizativo de los intérpretes, centrándose en el poder, la verdad y el control, dando gran importancia a la estructura jerárquica de los intérpretes y al rígido control de calidad que existió durante el juicio. 
Entre los tribunales internacionales, destacan los que dependen de forma más o menos directa de las Naciones Unidas ${ }^{5}$. El principal órgano internacional de justicia de las Naciones Unidas es la Corte Internacional de Justicia, con sede en La Haya (Países Bajos), establecida en 1946, que fue la evolución de la precedente Corte Internacional de Justicia. Se ocupa de decidir sobre las controversias entre los distintos Estados y también emite opiniones de consulta sobre cuestiones que pueden someterle órganos o instituciones especializadas de la ONU. Los idiomas oficiales usados son el inglés y el francés, por lo que todos los testimonios se traducen a ambas lenguas (Phelan, 2001).

Existe otra serie de tribunales internacionales que se encuentran bajo la tutela de las Naciones Unidas, pero que son independientes. Entre ellos se encuentran la Corte Penal Internacional (que no forma parte de la ONU, pues se considera un órgano judicial independiente) y el Tribunal Internacional del Derecho del Mar' ${ }^{6}$.

En la última década del siglo XX nacieron otros tribunales cuyo propósito era juzgar genocidios y crímenes contra la humanidad siguiendo la tradición de los de Núremberg y Tokio, que fueron denominados Tribunales Penales ad hoc, bajo los auspicios de la ONU: el Tribunal Penal Internacional para Ruanda (ICTR o TPIR), con sede en Arusha (República Unida de Tanzania) ${ }^{7}$, y el Tribunal Penal Internacional para la antigua Yugoslavia (ICTY o TPIY), que tenía su sede en La Haya, cuya labor concluyó en $2017^{8}$. Los intérpretes que trabajaban en dichos tribunales poseían un código deontológico específico 9 .

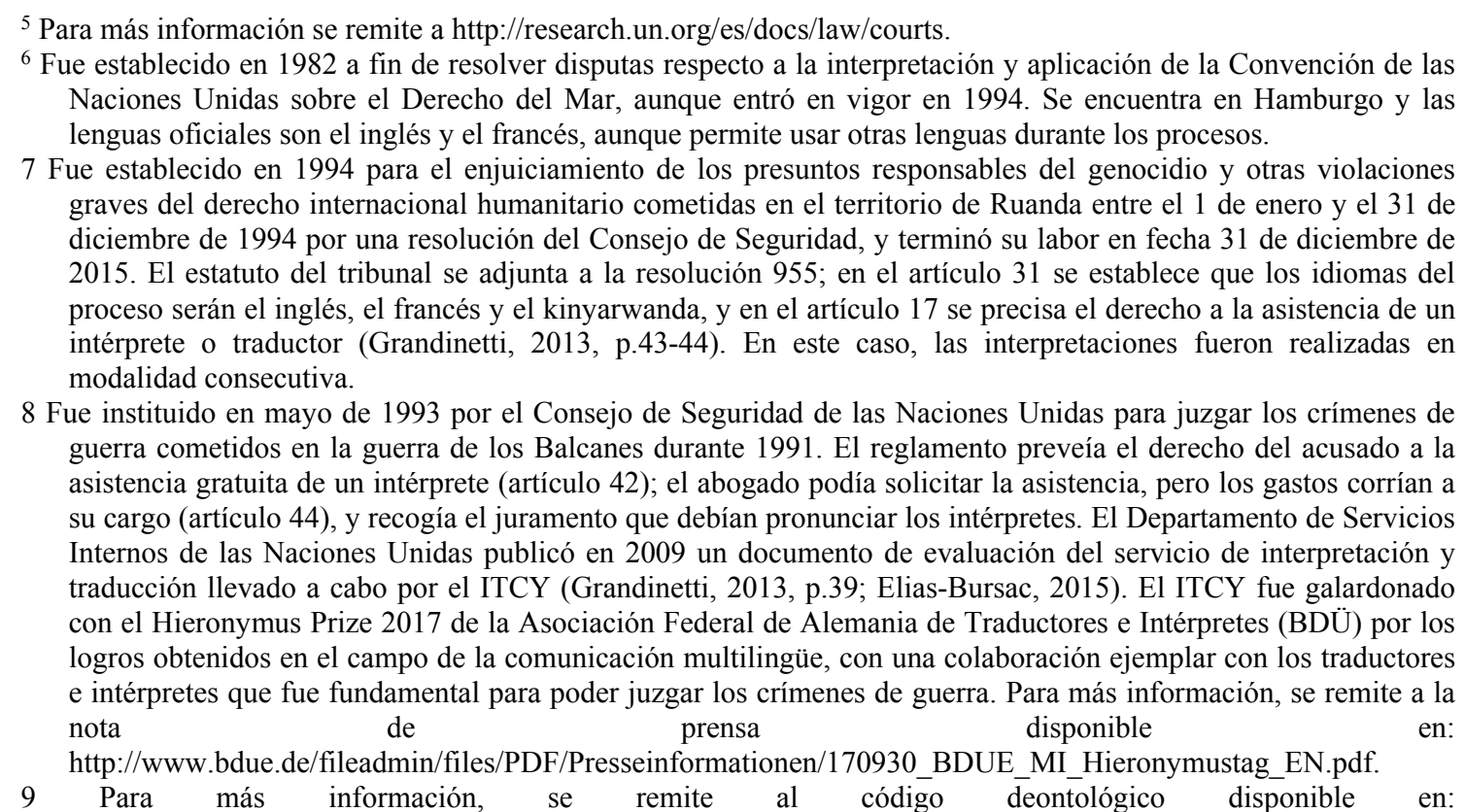
9 Para más información, se remite al código deontológico dispon translators.pdf. 
De acuerdo con el Proyecto sobre Cortes y Tribunales Internacionales (PCTI), existen hoy en día algunos tribunales conocidos como «tribunales híbridos» establecidos en algunos países como Sierra Leona, Camboya, Timor Oriental y Kosovo, que garantizan el derecho a la interpretación gratuita (González et al., 2012, p. 309).

\subsubsection{Tribunales supranacionales}

Los tribunales supranacionales se han instaurado en los distintos continentes con el propósito de aplicar y defender los derechos humanos en las regiones de referencia (González et al., 2012, pp. 309-313). Se mencionarán únicamente los europeos, pues es el ámbito de este trabajo. Cabe, pues, citar al Tribunal de Justicia de la Unión Europea (TJUE) y el Tribunal Europeo de Derechos Humanos (ECHR, por sus siglas en inglés).

El TJUE tiene la función de «garantizar que la legislación de la UE se interprete y aplique de la misma manera en cada uno de los países miembros [...], también resuelve los litigios entre gobiernos nacionales y las instituciones europeas». Además, pueden acudir al Tribunal los particulares, las empresas y las organizaciones que crean vulnerados sus derechos por una institución de la Unión Europea ${ }^{10}$. Fue creado en 1952 y tiene su sede en Estrasburgo.

El Estatuto del Tribunal de Justicia y sus normas de procedimiento establecen un régimen lingüístico estricto basado en el concepto de lengua de procedimiento.

En principio, la lengua de procedimiento es elegida por el demandante entre las 24 lenguas oficiales de la Unión Europea. Para garantizar un acceso equitativo de todos los ciudadanos a la justicia, resulta indispensable que las partes en los procedimientos ante los órganos jurisdiccionales de la Unión puedan expresarse cada una en su propia lengua. Esta es la razón por la que es necesaria una interpretación simultánea en las vistas públicas.

La interpretación durante las vistas celebradas ante el Tribunal de Justicia y el Tribunal General es responsabilidad de la Dirección de Interpretación, que cuenta con unos 70 intérpretes permanentes y recurre, asimismo, en función de las necesidades del servicio, a intérpretes independientes experimentados.

La composición de los equipos de intérpretes se lleva a cabo en función de la lengua de procedimiento elegida, de la lengua de los Estados miembros representados en la vista y de las necesidades de interpretación de los jueces, así como de los eventuales grupos de visitantes. El número de lenguas utilizadas puede variar de una vista a otra. La función del intérprete no es asimilable a la del traductor. En efecto, interpretar no consiste en traducir un texto escrito previamente, sino en trasladar fielmente un mensaje expresado oralmente a otra lengua distinta de la del orador. El intérprete trabaja pues en tiempo real y en estrecho contacto con el orador y el destinatario del informe oral (CURIA) ${ }^{11}$.

\footnotetext{
${ }^{10}$ Se remite a la página institucional de la Unión Europea, disponible en: https://europa.eu/european-union/abouteu/institutions-bodies/court-justice_es.

11 Información disponible en https://curia.europa.eu/jcms/jcms/Jo2_12357/es.
} 
El Tribunal delibera tradicionalmente en francés, y en este caso para la traducción se utilizan solo juristas, pues:

Debido a este importante papel intermediador, el Tribunal de Justicia solo emplea a juristas. Por ello, la Dirección General de Traducción (al servicio de los dos órganos jurisdiccionales) está compuesta por juristas lingüistas, todos ellos licenciados en Derecho. El artículo 42 del Reglamento de Procedimiento del Tribunal de Justicia prevé, por otra parte, que el servicio lingüístico estará «compuesto por expertos que posean una cultura jurídica adecuada» (CURIA) ${ }^{12}$.

En cuanto a la interpretación, se exponen la organización y las características que tiene que poseer el intérprete:

Durante la fase oral del procedimiento, la Dirección de Interpretación es responsable de la comunicación entre las partes y los Jueces. Las vistas ante los órganos jurisdiccionales de la Unión son objeto de interpretación simultánea a tantas lenguas como sea preciso.

La interpretación tiene por objeto la comunicación oral. Para respetar la propia naturaleza del debate oral, no puede tratarse en este caso de una traducción literal. La misión del intérprete consiste en restituir fielmente, en tiempo real, el mensaje del orador en otra lengua.

Los intérpretes del Tribunal de Justicia deben poseer, además de un perfecto conocimiento de sus lenguas de trabajo, buenos conocimientos de la materia que se tratará en la vista. Por lo tanto, se atribuye especial importancia al estudio de los autos del procedimiento. Los intérpretes - sometidos a una estricta obligación de confidencialidad - tienen pleno acceso a los autos de los asuntos, lo que les permite familiarizarse con las cuestiones jurídicas y la terminología pertinentes (CURIA).

El Tribunal Europeo de Derechos Humanos (European Court of Human Rights, ECHR) reviste una importancia fundamental en relación con el presente estudio. Se trata de una jurisdicción internacional de ámbito regional con sede en Estrasburgo. Fue instituido en 1959 a partir del Convenio Europeo para la Protección de los Derechos Humanos y las Libertades Fundamentales, de él forman parte los miembros del Consejo de Europa, que hoy en día son cuarenta y siete. Los jueces actúan a título individual y no representan los intereses de ningún Estado. Las lenguas oficiales son el francés y el inglés, y el uso queda establecido en el artículo 34 del Reglamento del Tribunal (ECHR, 2018, p. 17). El derecho al intérprete para aquellas personas que han de asistir al tribunal y que no entienden o hablan la lengua del proceso queda garantizado como

12 Información disponible en https://curia.europa.eu/jcms/jcms/Jo2_10739/direction-generale-de-la-traductionregime-linguistique. 
establece el artículo 6.3 del CEDH. Pueden recurrir al tribunal tanto los Estados como las personas, físicas o jurídicas, que presenten denuncias de violación de los derechos fundamentales del hombre, ya sean individuales o políticas. Algunos de los casos más importantes que han creado jurisprudencia para el derecho a traducción e interpretación han sido juzgados por este tribunal europeo para la salvaguardia de los derechos humanos y las libertades fundamentales (Grandinetti, 2013, pp. 19-24; Ortega-Herráez, 2011; Jimeno Bulnes, 2007, pp. 159-160; Gialuz, 2018, pp. 33-69) y han abierto el camino a la promulgación de la Directiva 2010/64/UE. En el caso específico de los intérpretes autónomos que trabajan para el tribunal, se les hace un contrato de dos días: el primero para preparar el proceso y el segundo es el de interpretación. Aparece una cláusula de confidencialidad en dicho contrato (Grandinetti, 2013, pp. 27-28; Amodeo Perillo, 2017).

\subsubsection{Tribunales nacionales}

La interpretación judicial a nivel nacional está profundamente vinculada a los flujos migratorios que se han ido produciendo a lo largo de las décadas en los distintos países, lo que ha conllevado un aumento de las interpretaciones en los tribunales y juzgados a nivel local y nacional (Falbo, 2013, p. 16), así como al reconocimiento de los derechos de las personas con una competencia deficiente o nula del idioma que se habla en el país de acogida. Desde mediados del siglo XX, se ha ido desarrollando una mayor concienciación en relación con los derechos de las personas alófonas que ha producido una serie de leyes en favor de dichas personas. Esto ha producido un mayor interés por la formación y la acreditación de intérpretes cualificados, en un primer momento en algunos países anglosajones (Estados Unidos, Australia, Canadá y Reino Unido). Las cosas están cambiando lentamente en el resto del mundo, donde esa transformación a veces está vinculada al paso de un sistema inquisitorial a uno acusatorio (como es el caso de Japón, Argentina y otros países asiáticos) (Mikkelson, 2017: pp. 15-18). Aunque se habla de derechos de las personas alófonas, cada vez están cobrando mayor importancia las políticas lingüísticas y los derechos de hablantes de lenguas minoritarias o nativas, como ocurre en Sudáfrica, América Latina o Canadá.

En este apartado se citarán únicamente algunos de los países en los que la interpretación judicial posee unas características bien definidas y en los que ha tenido una cierta evolución. Por tanto, se enunciarán los casos más emblemáticos, considerados en cierto modo ejemplares para la profesionalización de la interpretación judicial. 


\section{Australia}

Australia es un país multicultural y multilingüe, a pesar de que su única lengua oficial es el inglés. Dos aspectos que caracterizan a la interpretación judicial en Australia han sido el programa de migración y la presencia de la National Accreditation Authority for Translators and Interpreters (NAATI), la autoridad australiana oficial de traductores e intérpretes para los servicios públicos, que es la encargada de fijar estándares y otorgar la acreditación a traductores e intérpretes en ese país. Dicha asociación también tiene en cuenta a las lenguas indígenas y a la lengua de signos (Gentile, 2015, p. 27), que se integran dentro de la denominada Community Interpreting (Ozolins, 1998). En 2013 se añadió también la acreditación de deaf interpreter. La NAATI se convirtió en 1983 en una sociedad anónima de propiedad de los Gobiernos federal, estatal y territorial, y proporciona cinco niveles de acreditación. Esta puede obtenerse de varias maneras, que incluyen la formación universitaria o exámenes; las pruebas se llevan a cabo en casi cien idiomas, entre los que se encuentran una gran cantidad de lenguas indígenas. En enero de 2018 se creó un nuevo sistema de certificación que sustituye al sistema precedente; y en marzo de 2018 se estableció también el Credential Community Language (CCL) ${ }^{13}$.

El sistema de acreditación va acompañado de cursos de capacitación en universidades australianas donde imparten clases algunos de los estudiosos que han dado una aportación importante para el desarrollo de la profesión, la capacitación cubre los principales idiomas; sin embargo, hay algún problema con las lenguas de grupos recién llegados.

Aunque no existen aún disposiciones legales para que los operadores judiciales usen intérpretes acreditados ante NAATI, las políticas gubernamentales sobre el uso de intérpretes sí que establecen como requisito que se posea la acreditación NAATI (Hale, 2011).

El trabajo de difusión que llevan a cabo los estudiosos (Hale, 2015) ha adquirido también gran importancia para dar valor y hacer que se comprenda mejor la labor del intérprete. En 2017, el Judicial Council on Cultural Diversity desarrolló los Australian National Standards for Working with Interpreters in Courts and Tribunals para establecer normas y buenas prácticas en Australia, a los que acompañan Model Rules y Model Practice Note, que permiten llevar a la práctica dichos estándares. El propósito de estas normas de actuación es facilitar el trabajo de los operadores judiciales y los intérpretes que actúan durante el proceso penal. Aunque las normas son

\footnotetext{
${ }^{13}$ Para más información, se remite al sitio electrónico de la NAATI, disponible en: https://www.naati.com.au/otherinformation/ccl-testing/.
} 
recomendaciones y no son prescriptivas, el propósito es implementarlas de manera progresiva, adaptándolas a las necesidades y al contexto legislativo de cada jurisdicción, como ha confirmado la estudiosa Sandra Hale. En estas normas se especifican los protocolos de actuación, la provisión del intérprete, cuestiones presupuestarias, la formación de los operadores judiciales para trabajar con intérpretes y las obligaciones de dichos agentes con respecto a los intérpretes.

Por todas estas razones, Australia se presenta como un ejemplo virtuoso de la interpretación judicial, a pesar de demostrar también las dificultades que intérpretes formados presentan al trabajar en este contexto (Hale, 2004; 2017).

\section{Canadá}

El carácter oficial del inglés y el francés en Canadá ha conducido al uso habitual de los servicios de intérpretes y traductores. El Official Language Act de 1970 establece como lenguas oficiales el francés y el inglés, lo que posibilita a los canadienses usar ambos idiomas ante los tribunales. La sociedad canadiense posee un carácter multirracial y multiétnico en el que se integran los grupos francófonos, anglófonos y una variedad muy amplia de culturas y etnias. Aunque el uso de intérpretes se puede constatar en el sistema judicial canadiense desde su fundación en 1867, el derecho a intérprete no fue recogido en el Canadian Charter of Rights and Freedoms hasta 1982, en la sección 14 (González et al., 2012, p. 317). Durante los años ochenta del pasado siglo hubo un mayor interés por la calidad de las interpretaciones ante los tribunales, por lo que en 1985 se estableció un grupo de trabajo, el Task Group on Court Interpreting in British Columbia, que condujo a la adopción de un examen de certificación en interpretación judicial. Aunque inicialmente se desarrolló en las provincias de Colombia Británica y Ontario, en 1993 fue adoptado en todo el país por el organismo oficial canadiense de traductores e intérpretes, el Canadian Translators, Terminologists and Interpreters Council (CTTIC) ${ }^{14}$. Cabe señalar los esfuerzos del Gobierno canadiense por desarrollar programas de interpretación para las lenguas indígenas. El primer curso de especialización en interpretación judicial fue realizado en el Vancouver Community College en 1979 (Mikkelson, 2017, p. 9), y hay universidades que ofrecen formación en interpretación judicial tanto para las lenguas indígenas como para los principales idiomas (Roberts, 1997; Sammons, 1993).

\footnotetext{
${ }^{14}$ Información obtenida en la Canadian Translators, Terminologists and Interpeters Council (CTTIC) en su web institucional, disponible en: http://www.cttic.org/certification.asp.
} 


\section{Estados Unidos}

Cabe señalar que Estados Unidos es el país que, junto con Australia, más se ha preocupado por el reconocimiento de la figura del intérprete judicial: es donde están mejor remunerados $\mathrm{y}$ donde la profesión ha llegado a cierto estado de madurez, separándose desde hace décadas de la interpretación de conferencias. Existen centros que imparten cursos específicos de formación en interpretación judicial, sobre todo en relación con la lengua española (Mikkelson, 2017, p. 9).

En Estados Unidos y en América en general, el multilingüismo predominó durante la etapa colonial (González et al., 2012, p. 129), estando presentes las lenguas indígenas, el español, los idiomas africanos de los esclavos procedentes de África y las lenguas europeas de los nuevos colonizadores, por lo que antes de la Constitución americana convivían cientos de lenguas africanas y nativas americanas, europeas y árabes (p. 130). La población nativa fue sometida a la «civilización», obligándola a estudiar las lenguas europeas, y los esclavos africanos fueron los primeros que abandonaron sus lenguas nativas. Por otra parte, durante los siglos XIX y XX se fue asistiendo a una imposición del inglés como lengua oficial y predominante de la sociedad estadounidense en aras de una unidad nacional, lo que provocó una fuerte exclusión y marginalidad en un número importante de ciudadanos y residentes.

La presencia del intérprete se considera esencial para garantizar el derecho del acusado a un juicio justo, como se especificará también en el capítulo 3, pues asegura el derecho de este a entender y a ser entendido (lingustic presence) en aquellos casos que no comprende la lengua o presenta una discapacidad auditiva (Mikkelson, 2017, p. 15).

La primera asociación de intérpretes judiciales en Estados Unidos fue la California Court Interpreters Association, surgida en 1971. Ya en esa fecha, los intérpretes se dieron cuenta de la necesidad de profesionalizarse a fin de lograr unas normas y mejores prácticas en el sector. El proceso culminó con la Federal Court Interpreters Act del 1978, ley del Gobierno de Carter que reconoció la labor del intérprete y exigió que, en los tribunales federales, la labor de interpretación hacia otra lengua o hacia la lengua de signos fuese realizada por intérpretes certificados. La ley incorporaba también los emolumentos que debía recibir el intérprete y se reconocía como prioritaria la calidad de la interpretación. En 1988 se promulgó la Court Interpreters Ammendements Act, que se ocupa de la necesidad de certificación de otras lenguas y los criterios sobre los que dicha certificación debía basarse.

El primer examen de certificación para español se realizó en 1979. Resultó ser muy sencillo, por lo que fue superado por muchos intérpretes (Navarro-Hall, 2017). Al constatarse que las personas que habían superado el examen no estaban preparadas para 
trabajar en el entorno judicial, se realizaron varias reformulaciones del examen hasta llegar al formato actual ${ }^{15}$. Al mismo tiempo, el Registry of Interpreters for the Deaf (RID) desarrolló un certificado de aptitudes jurídicas que complementaba el examen de certificación general ya ofrecido desde 1972 (Mikkelson, 2017, p. 7).

En relación con los tribunales estatales, cada Estado tuvo que establecer sus normas y elaborar sus propios exámenes de certificación. No obstante, existía un problema de falta de reconocimiento entre las certificaciones emitidas por distintos Estados, por lo que se promovió un examen de certificación con validez en todo el país. Así, en 1997 se creó el Consortium for Language Access in the Courts, cuyo propósito era desarrollar pruebas de certificación de acuerdo con las normas de los distintos Estados, de manera que los intérpretes que obtuvieran la certificación pudieran trabajar en todos ellos. Hoy en día, se adhieren a la prueba de certificación de dicho consorcio cuarenta y tres Estados, y las pruebas se realizan en más de veintidós idiomas (González et al., 2012, pp. 1182-1183).

Mientras tanto, en 1978 nació la Court Interpreters and Translators Association en Nueva York, que en 1988 se convirtió en la National Association of Judiciary Interpreters and Transtators (NAJIT). NAJIT tuvo hasta 2015 su propia certificación en español. Además de la asociación nacional, existen varias asociaciones estatales. La importancia del asociacionismo en Estados Unidos es fundamental, pues han sido las asociaciones las principales promotoras del establecimiento de códigos deontológicos, reglas de conducta y la obligación de formación continua para ejercer profesionalmente.

A nivel universitario, el Monterey Institute of International Studies ofreció por primera vez el certificado de intérprete judicial en 1983, dentro del Máster de Interpretación de Conferencias. Ese mismo año, la Universidad de Arizona puso en marcha un curso de verano en interpretación judicial. A partir de entonces, varias universidades han ido ofreciendo cursos de interpretación judicial, además de cursos específicos para la obtención de la certificación.

Aunque el caso estadounidense constituye una referencia en la gestión del servicio de interpretación en los tribunales, siguen existiendo aspectos críticos en cuanto a las lenguas de menor difusión y de calidad de interpretación en juicios de instancias inferiores. Cabe señalar el uso de las nuevas tecnologías, como la interpretación remota y la consecutiva con soporte grabado (Sim-Consec ${ }^{\mathrm{TM}}$ ) (Navarro-Hall, 2017). 15 Para un detalle pormenorizado de los exámenes federal y estatal, es posible consultar los capítulos 46 y 47 de
González et al., 2012, p.1159-1207. 


\section{Europa}

El derecho a intérprete para las personas que no entienden el idioma del procedimiento judicial está garantizado teóricamente en Europa por la Convención para la Protección de los Derechos Humanos y las Libertades Fundamentales desde 1950, como se especifica en el capítulo 3. En los contextos nacionales, «legal interpreting is typically set in a particular national context and thus constrained by a specific judicial framework and legal tradition» (Kolb y Pöchhacker, 2008, p. 26), tomando en parte las legislaciones ya existentes (LECrim en España o el CPP en Italia), ya que en teoría todos los países garantizan el derecho a intérprete (Mikkelson, 2017, p. 14), o creando otras nuevas que defiendan el derecho a intérprete del acusado alófono, como es la Directiva 2010/64/UE relativa al derecho a la interpretación y a la traducción en los procesos penales.

Con todo, cabe señalar que cada vez hay una mayor concienciación, y en los últimos tiempos se han establecido una serie de procedimientos y cambios jurídicos que conllevan la presencia de los intérpretes a fin de que se produzca un juicio equitativo. Por lo que atañe a la situación actual de la interpretación judicial en la Unión Europea, se remite a Giambruno (2014, pp. 149-190), que lleva a cabo una panorámica dentro del proyecto Qualitas. La autora considera que falta uniformidad con respecto a las normas de certificación, formación y registro en los Estados miembros.

En general, la modalidad de trabajo en estos entornos incluye la interpretación consecutiva, la consecutiva corta, la interpretación susurrada y la interpretación a la vista. En las últimas décadas se están desarrollando también técnicas de interpretación a distancia en consecutiva y simultánea y técnicas mixtas de interpretación consecutiva con simultánea. El intérprete raramente trabaja en equipo y no suelen utilizarse dispositivos de soporte a la memoria. Solo en algunos casos específicos se ha utilizado la interpretación simultánea en el ámbito nacional, como fue el caso del juicio contra los acusados del atentado terrorista del 11M en Madrid (Martínez-Gómez, 2015; Martin y Ortega-Herráez, 2013).

De los países europeos, se expondrá únicamente el caso del Reino Unido, por ser un caso emblemático, y los casos de Italia y España, que se ilustrarán en un subepígrafe independiente, por ser los países en donde se ha llevado a cabo la investigación. Por lo que atañe al resto de los países de la Unión Europea, la situación presenta diferencias que han sido ya analizadas en el proyecto Qualitas (Giambruno, 2014, pp. 149-190) y en el informe de la European Union Agency for Fundamental Rights (FRA), Rights of suspected and accused persons across the EU: translation, interpretation and 
information (2016), que abordan la cuestión en relación con la implantación de la Directiva 2010/64/UE, de la que se hablará en el capítulo 3.

\section{Reino Unido}

Reino Unido, como los demás países europeos, pero también debido a su carácter imperialista precedente, ha acogido una gran cantidad de inmigrantes durante el siglo $\mathrm{XX}$ procedentes de las antiguas colonias británicas y sobre todo en las últimas décadas por la mayor movilidad de las personas dentro de la Unión Europea. Aunque Reino Unido no tenga una lengua oficial declarada legalmente, la lengua principal es el inglés. De todas formas, existe una gran variedad de lenguas habladas.

En 1998 fue promulgada la Human Rights Act que establecía el derecho del acusado a ser asistido por un intérprete si no hablaba la lengua inglesa (Summers, 2005). En 2002 se estableció The National Agreement on the Arrangements for the use of interpreters and translators in the Criminal Justice System en Inglaterra y Gales, revisado en $2007^{16}$, que supone una guía para la contratación de intérpretes cualificados para trabajar en la justicia penal e incluye también la lengua de signos. La firma de dicho acuerdo tuvo una gran relevancia para la justicia penal del Reino Unido, aunque, al no ser vinculante, dejaba gran libertad a los oficiales de policía y judiciales de eludirlo (Gallai, 2012, p. 145).

Corsellis (2008, pp. 14-23) describe la situación existente a principios de los años ochenta del siglo Xx, cuando se produjeron varios incidentes que promovieron la búsqueda de intérpretes cualificados. En 1983 se inició un proyecto de colaboración entre la Fundación Nuffield y el Chartered Institute of Linguists que culminó en 1994 con el establecimiento del UK National Register for Public Service Interpreters (NRPSI). Mientras tanto, los métodos utilizados para procurarse intérpretes fueron muy variados y en algunos casos discutibles (Colin y Morris, 1996, p. 78). En 2011 el NRPSI se independizó del Chartered Institute of Linguists, convirtiéndose en una organización sin ánimo de lucro que engloba a un número considerable de intérpretes de alrededor de cien idiomas. Se trata de un organismo regulador, que posee su código de conducta. Para poder entrar a formar parte del mismo, es preciso demostrar la competencia obteniendo el Diploma en Interpertación para los Servicios Públicos (DPSI, por sus siglas en inglés) en varias especializaciones, entre las que se encuentra la judicial. Existe un gran interés por la interpretación para la justicia en varias instituciones

\footnotetext{
${ }^{16}$ Para el documento completo, se remite a:

http://webarchive.nationalarchives.gov.uk/20080726221025/http://police.homeoffice.gov.uk/publications/operational -policing/national-agreement-interpret.pdf?view=Binary.
} 
académicas que preparan a la obtención del DPSI. Diversas universidades han participado y liderado proyectos europeos en aras de una mejor calidad en la interpretación ante la justicia, de los que se hablará en el capítulo dedicado a la calidad (por ejemplo, Building Mutual Trust de la Universidad de Middlesex).

Desafortunadamente, la situación en cierto modo ejemplar y virtuosa existente en Reino Unido se desmanteló cuando el Ministerio de Justicia anunció el 9 de agosto de 2010 la intención de abandonar el National Agreement. Se preveía también la abolición del registro NRPSI para desplazarse a un acuerdo de tipo comercial que proporcionase los servicios lingüísticos para los tribunales, lo que provocó la llegada de un solo interlocutor privado que se ocupa de toda la gestión. En 2012, la compañía Applied Language Solutions fue contratada para los servicios de provisión de intérpretes judiciales en Inglaterra y Gales (Fowler, 2013, p. 38). Como analiza de manera pormenorizada Gallai, esto condujo al desplome de la calidad del servicio y al incumplimiento de las disposiciones establecidas por la Directiva 2010/64/UE, pues permite contratar a personal no capacitado y cualificado, además de menoscabar la seguridad, ya que parte del personal de la agencia proveedora del servicio se encuentra fuera de la Unión Europea (2012, p. 148). Como consecuencia de dicha maniobra, los intérpretes profesionales abandonaron en su mayoría el trabajo en los tribunales (Corsellis, 2015, p. 110).

Por otra parte, los intérpretes profesionales se están uniendo para promover y salvaguardar los intereses de los intérpretes en los servicios públicos registrados en el NRPSI y mantener las normas dentro de la profesión (PIA Mission Statement, 2010). De hecho, en los últimos años una serie de comisiones parlamentarias han pedido explicaciones al Gobierno respecto a la falta de calidad en la interpretación en los procesos penales. Tras las distintas críticas recibidas, el Ministerio de Justicia británico publicó algunos documentos relativos a la revisión, las encuestas y la respuesta del Gobierno sobre la calidad de la interpretación ante los tribunales en los que defendía su modo de proceder y respondía a las distintas críticas recibidas ${ }^{17}$.

Se llevó a cabo una revisión, pero las críticas continuaron y, de hecho, en enero de 2017 se formuló una pregunta parlamentaria relativa a la calidad del servicio de traducción e interpretación proporcionado por el nuevo proveedor de servicios The Big

17 Disponible en: https://www.gov.uk/government/publications/moj-language-services-framework-independentreview-and-the-government-response. 
Word, con el que el Gobierno estableció un contrato a partir del 31 de octubre de $2017^{18}$.

Cabe señalar que el sistema británico (aún en construcción, pero en muchos sentidos admirado por modélico) habría podido servir de inspiración al resto de países europeos que carecen de un sistema que garantice la calidad de la interpretación en este contexto; sin embargo, se ha convertido en el ejemplo que debería evitarse a toda costa.

\section{Otros países}

Otros países de la Unión Europea presentan una gran variedad de realidades que han sido objeto de análisis en varios proyectos europeos, como el proyecto Qualitas (Assessing Legal Interpreting Quality through Testing and Certification, 2014) y el informe FRA Rights of suspected and accused persons accross the EU: translation, interpretation and information (2016), relacionado con el desarrollo e implementación de la Directiva 2010/64/UE, de la que se hablará más adelante.

En el resto del mundo, se está produciendo una concienciación cada vez mayor acerca de la importancia de la calidad del servicio de interpretación en el ámbito judicial. Los cambios que se han introducido en los sistemas penales de muchos países (que han pasado del sistema inquisitorial al acusatorio, donde la oralidad adquiere una mayor importancia) han llevado a un mayor uso de los intérpretes en dicho entorno, y en muchos casos ya se han incorporado buenas prácticas inspiradas en la experiencia positiva de otros países, con mejores condiciones técnicas y mayor concienciación sobre la importancia de la calidad (González et al., 2012; Mikkelson, 2017, p. 15-18). De hecho, ha proliferado la publicación de las experiencias en países específicos como el caso de Suecia (Niska, 2007, pp. 297-310), Malasia (Ibrahim, 2007, p. 89-95), Hong Kong (Ng, 2015, p. 243-270) o Corea del Sur (Lee, 2015), entre otros.

\subsection{El papel del intérprete judicial}

En un trabajo de investigación como el que nos ocupa, definir las funciones del intérprete judicial se convierte en una cuestión prioritaria. El contexto judicial posee características particulares, entre las que se encuentran la distribución jerárquica de las funciones, los rituales donde se desarrolla la situación interpretativa, los protocolos de actuación, además de objetivos específicos (Gibbons, 2003; Hertog, 2015a, p. 232).

18 Disponible en http://www.parliament.uk/business/publications/written-questions-answers-statements/writtenquestions-answers $/$ ?page $=1 \& \max =20 \&$ questiontype $=$ AllQuestions \&house $=$ commons $\% 2$ Clords\&usedates $=$ True $\&$ answered-from $=2017-01-01 \&$ answered-to $=2017-01-27 \&$ member $=3829$. 
Todo ello debe tenerse en cuenta a la hora de presentar y analizar el papel que desempeña el intérprete en el contexto judicial.

Esta cuestión se ha estudiado mucho en los últimos tiempos y ha sido uno de los temas más debatidos por los estudiosos que se han ocupado de la interpretación judicial (Hale, 2007, 2008; Corsellis, 2008; Mikkelson, 1999, 2000, 2008, 2017; Ortega-Herráez 2011, pp. 151-191, entre otros). Existe, por tanto, una gran cantidad de publicaciones en las que se ponen de manifiesto las especificidades de este tipo de interpretación en relación con el sistema legal en el que se asienta, del que no se puede separar (Mikkelson, 2008, p. 81). Se encuentran diferencias dependiendo de los países, que se traducirán en un mayor reconocimiento y remuneración.

González et al. (2012) retoman la definición realizada por González en 1986, en la que se requiere que el intérprete traslade todo lo escuchado en la lengua de origen a la lengua de destino sin alterar, resumir, añadir u omitir significado. Debe ser lo más fiel posible al enunciado original y esto permite que el acusado esté física y cognitivamente presente durante todo el procedimiento. El intérprete debe, pues:

... transfer all the meaning he or she hears from the source language into the target language, not editing, summarizing, adding meaning or omitting. The court interpreter is required to transfer the message into the other language exactly, or as close to exactly, as originally spoken [...] the court interpreter is a language mediator who through interpretation allows the defendant to be linguistically and cognitively present in a legal setting $(2012$, p. 411$)$.

A pesar de que Mikkelson haya defendido en alguna ocasión que «interpreting is interpreting» (2009), la autora enumera una serie de tareas y funciones que el intérprete ha de desempeñar en el entorno judicial, a saber: ayudar a los organismos encargados del cumplimiento de la ley a interrogar a testigos y sospechosos; permitir que los abogados se comuniquen con sus clientes, e interpretar en los procedimientos judiciales para los acusados, los litigantes y los testigos. Lo considera, de hecho, como un brazo de la ley, parte del equipo de defensa o de acusación, perito experto u oficial imparcial del juzgado (2017, p. 13).

El Judicial Council on Cultural Diversity de Australia considera que el papel del traductor y del intérprete judicial es eliminar las barreras lingüísticas para que la parte esté presente de manera efectiva en el proceso y tenga así la misma posición que una persona de habla inglesa. Esto le permite participar en el procedimiento en su propio idioma (2017, p. II).

La National Association of Judiciary Interpreters y Translators (NAJIT, 1988) de Estados Unidos define la función del intérprete judicial en su código ético y considera que el intérprete debe ser capaz de eliminar la barrera lingüística del idioma en la 
medida de lo posible para que las personas que no hablan inglés puedan acceder a la justicia y colocarlas en la misma situación de aquellas personas para las que no existe dicha barrera.

Arumí Ribas especifica cómo debe realizar su trabajo el intérprete judicial, recalcando la importancia de la imparcialidad en su actuación y el respeto de un código deontológico:

El intérprete judicial no solo ha de realizar una traducción e interpretación íntegra, veraz y completa, sino que en su actuación permanecerá en todo momento imparcial, no revelará información confidencial, será veraz en cuanto a su formación y se abstendrá de intervenir en un asunto si carece de la competencia adecuada para ello (2018, p. 46).

La misma autora puntualiza las características que debe poseer dicha interpretación para que sea de calidad, cuyo objetivo último es el acceso a la justicia de la persona alófona:

Conseguir la equivalencia jurídica: transmitir el significado de la frase original pero también todas las repeticiones, interrupciones, errores, etc. Y también fidelidad al estilo, tono, registro con el objetivo de facilitar el acceso a la justicia por parte de la persona con conocimiento limitado de la lengua (Arumí Ribas, 2017).

Ortega-Herráez declara que «el objetivo de la interpretación judicial será garantizar la igualdad de condiciones en sus relaciones con la justicia a toda parte que no comparta el idioma del tribunal» (2011, p 43), con el propósito de obtener la equivalencia legal.

Caciagli, Balleto y Rivezzi (2009) estiman que la función del intérprete judicial y del traductor jurídico es eliminar las barreras lingüísticas existentes y permitir así que los acusados, los testigos o las víctimas que no entienden la lengua del proceso estén en las mismas condiciones que un ciudadano de habla italiana. Reflexionan, además, sobre el papel del intérprete judicial, que requiere un estándar profesional alto y homogéneo desde el punto de vista deontológico.

Por su parte, Hertog define al intérprete judicial como:

... un profesional cualificado y formado que proporciona interpretación a aquellos que se ven inmersos, en cualquier forma o calidad, en un ordenamiento jurídico cuya lengua no hablan, y que lleva a cabo su tarea de acuerdo con un código profesional de conducta en interés de la justicia y plenamente dispuesto a colaborar de manera eficaz con los servicios jurídicos y otros profesionales forenses $(2009$, p. $10)$. 
Esta definición implica ya una formación y cualificación profesional, además de un código deontológico. Todas estas definiciones defienden en cierto modo lo que las publicaciones anglosajonas definen como realizar una interpretación verbatim, que en muchos casos se ha considerado erróneamente como realizar una interpretación palabra por palabra, tal y como recogen algunos códigos deontológicos (códigos de la NAATI, la NAJIT, la APTIJ o la AssITIG, entre otros, de los que se hablará más específicamente en el siguiente subepígrafe y en el capítulo 4). En realidad, como la mayoría de los autores que se han ocupado del tema especifican, lo que ha de observarse es una traducción fiel y exacta, desde el punto de vista conceptual, donde se recoja todo el contenido, manteniendo el registro lingüístico, tono, titubeos, etc. (González et al., 2012; Hale, 2007; Mikkelson, 2017). Esto la diferencia de la interpretación de conferencias, donde es fundamental transferir los conceptos manteniendo un registro elevado (Errico, 2016, p. 168). En la interpretación judicial es fundamental la fidelidad, esto es: «Court interpreting is polished translation» (Leeth, 1985, p: 8, en González et al., 2012, p. 27), pues no puede embellecerse o mejorarse.

González et al. defienden que la interpretación ha de realizarse conservando el mismo registro, tono e intención del hablante (2012, p. 411), que no debe añadirse ni elidirse nada. Pero, en realidad, se ha demostrado que la literalidad no es sinónimo de fidelidad e imparcialidad. Como señala Ortega-Herráez, esta definición sería totalmente lógica, pero este tipo de interpretación podría llevar a un fracaso en la comunicación (2011, p. 156).

A continuación, se analiza la figura del intérprete desde varios puntos de vista, siguiendo la clasificación realizada por Ortega-Herráez (2011, pp. 151-191), por considerar que incluye los aspectos principales relacionados con ella.

\subsubsection{El intérprete como mediador interlingüístico oral}

La defendida invisibilidad del intérprete era hasta ahora prácticamente imposible, teniendo en cuenta que se trata de un evento donde está bien visible, evidenciado en primera instancia por el juramento que el intérprete tiene que realizar en sede judicial y que pone de manifiesto su presencia ${ }^{19}$ (Berk-Seligson, 1990/2002, p. 56; Colin y Morris, 1996; Wadensjö, 1995), que incide en la complejidad del papel del intérprete en el ámbito judicial. El hecho de estar físicamente presente condiciona la interacción (Wadensjö, 1998) y debe asumir un doble papel, esto es: ha de coordinar la interacción

19 Esto está cambiando rápidamente con la evolución de las nuevas tecnologías. Algunas jurisdicciones estadounidenses sitúan al intérprete apartado con «bidule» o directamente en una especie de call center. Agradecemos a María Jesús Blasco-Mayor la información ofrecida. 
además de interpretar, adquiriendo, por tanto, un papel negociador para que la conversación fluya. Por ello, asume un papel activo de coordinación de la interacción, siendo al mismo tiempo transmisor (relayer) y coordinador (Wadensjö, 1992, p. 266). De esta manera, la autora ofrece una perspectiva del intérprete en la que debe resolver problemas de traducción y también de entendimiento mutuo. Dicha presencia puede conllevar intervenciones del intérprete que en cierto modo se alejan del texto fuente, con non-renditions y zero renditions (Wadensjö, 1998, p 108), es decir, intervenciones que no son ni interpretación ni omisiones, sin relación con el texto original interpretado. La autora sostiene en un trabajo posterior $(1999$, p. 205) que la interacción monolingüe difiere de la que tiene lugar a través de intérprete y que por esa razón no es posible compararlas, pues constituyen géneros de comunicación distintos, cada uno de ellos gobernado por reglas y parámetros diferentes.

En un estudio dedicado a la interpretación en la lengua de signos, Roy (2000, p. 6) señala que comparte ciertos rasgos con la interpretación en los servicios públicos debido a la dimensión triádica de la comunicación (Ortega-Herráez, 2011, p. 152), la evolución que ha seguido la figura del intérprete en relación con la profesionalidad adquirida, que conlleva además una mayor remuneración. La autora tiene en cuenta el análisis del discurso y la sociolingüística, pues considera que el intérprete es en realidad el único que puede utilizar fácilmente las estrategias discursivas en los dos idiomas, lo que le convierte en un participante activo que puede influir en el resultado del evento comunicativo.

De hecho, las condiciones de trabajo, la forma en que se inicia la conversación y la gestión de los turnos influyen decisivamente en la interpretación. La estudiosa remarca también la importancia de la acción comunicativa en la que se desarrolla la interpretación, pues esta varía mucho dependiendo de si habla un único orador o la comunicación es de tipo conversacional (Ortega-Herráez, 2011, pp. 44-45), lo que claramente influye en el papel que debe asumir el intérprete. En situaciones monológicas, el intérprete puede tener menos implicación, pues simplemente debe traducir el enunciado original.

En un trabajo precedente (1993), Roy establece cuatro modelos de papeles que puede asumir el intérprete de lengua de signos, pero también de aplicación en la interpretación lingüística:

- como cooperador, que en general realizan familiares y amigos;

- como profesional, que se muestra como un canal de comunicación y llega a negar la responsabilidad en cuanto al éxito en la comunicación; 
- como facilitador de la comunicación, donde se sigue considerando fundamental la transmisión del mensaje sin que el intérprete se involucre;

- como especialista bilingüe y bicultural defiende el papel activo que asume el intérprete, pues él es único que puede ajustar la comunicación.

Morris considera que los intérpretes han de exponer los mensajes de manera simultánea sin cambiar la intención del mensaje y que deberían hacerlo con una precisión excepcional, manteniendo al mismo tiempo una postura de imparcialidad y neutralidad (1999, p. 9).

Mason analiza la interpretación desde un punto de vista dialógico y dinámico de la interacción mediada por intérprete. Considera que todos los actores participantes en esta actividad triádica participan activamente, incluido el intérprete, por lo que estima que la invisibilidad del intérprete es, en realidad, un mito (2001, p. ii). La intervención del intérprete provoca una respuesta en las intervenciones de los demás interlocutores y afecta a la relación entre ellos (Mason y Steward, 2001, p. 67-68). En un trabajo posterior (2009) y en un marco sociolingüístico, considera que la noción de papel no es suficiente para definir la figura del intérprete por considerarlo estático y prefiere basarse en el concepto de posicionamiento (2009, p 53), ya que la comunicación cambia continuamente, la posición de los participantes varía y estos se influyen unos a otros. Nartoska matiza la función de coordinación que lleva a cabo el intérprete, pues controla las declaraciones de las personas que no hablan la lengua e incluso pueden influir con su pasividad. «When interpreters show a lack of their own initiative in the courtroom by not taking on the necessary coordination or by refraining from necessary clarifications, communication problems and misunderstandings arise, which results in a change in the interaction» (2017, p. 100). Incluso, pueden influir hasta el punto de cambiar las estrategias de los abogados, por lo que resultan participantes visibles y con poder.

Los mismos intérpretes han reflexionado sobres sus funciones (Angelelli, 2004), en este caso en relación con la interpretación en el ámbito médico-sanitario, donde se cuestiona la invisibilidad del intérprete, ya que este participa activamente en la creación del sentido y el desarrollo de la interacción. Por otra parte, el intérprete asumirá el papel que se le permita en los distintos entornos, pues se le impondrán restricciones, y el intérprete deberá arrogarse ciertas funciones características, dependiendo de las necesidades y las limitaciones (p. 13). Martin y Ortega-Herráez (2009/2014, pp. 141155) analizan la autopercepción de los intérpretes teniendo en cuenta la asunción de su papel propiamente dicho y su relación con los clientes, asumiendo un papel más activo con respecto a lo defendido por la corriente estadounidense y adoptando conscientemente estrategias para facilitar la comunicación, como pueden ser adaptar el 
registro o explicar algunas diferencias culturales o cuestiones legales. Los mismos autores analizan en 2013 el caso específico de los juicios del 11M, donde dos intérpretes tuvieron que actuar también como peritos, y los retos que supuso para el sistema judicial español adaptarse a la interpretación simultánea durante los juicios del 11M en Madrid (Martin y Ortega-Herráez, 2013, p. 101-114), lo que implicó un cambio en el modo de trabajar habitual y una concienciación respecto a la necesidad de trabajar con intérpretes profesionales y capacitados. De hecho, los autores consideran que este juicio supuso un giro radical en la interpretación judicial en España.

Por otro lado, la figura del intérprete judicial se ha analizado desde el punto de vista de las expectativas de los usuarios abogados y jueces (Fowler, 1997; Kadric, 2000; Kelly, 2000; Morris, 2007; Lee, 2009), desde el punto de vista de los usuarios y de los mismos intérpretes (Ortega-Herráez y Foulquié Rubio, 2008, entre otros), o desde el punto de vista de los policías e intérpretes. Dichos estudios demuestran que las expectativas no siempre son realistas y los demás actores desconocen el papel que debe asumir el intérprete, por lo que pretenden que este realice una labor que va más allá de sus competencias, que actúen a su favor, incluso en contra de lo que proclaman los códigos deontológicos. De la misma forma, Corsellis (2011, p. 159) apunta que, si el intérprete no conoce bien el papel que debe asumir porque no está bien preparado, aceptará realizar ciertas funciones que están totalmente fuera de sus competencias.

Hale establece varios papeles posibles que puede desempeñar el intérprete judicial (2008, p. 102) dependiendo de la neutralidad y la precisión con las que lleva a cabo su labor, que implican, además, una mayor o menor invisibilidad (tabla 1). 
Tabla 1: Posibles papeles del intérprete judicial según Hale (2008, p. 102)

\begin{tabular}{|c|c|c|c|}
\hline Description of task & Role identity & $\begin{array}{l}\text { Accuracy } \\
\text { requirements }\end{array}$ & $\begin{array}{l}\text { Impartiality } \\
\text { requiriments }\end{array}$ \\
\hline $\begin{array}{l}\text { 1. To help the minority } \\
\text { language speaker present } \\
\text { his/her case in the best } \\
\text { possible way }\end{array}$ & $\begin{array}{l}\text { Advocate for the powerless } \\
\text { participant }\end{array}$ & Medium & $\begin{array}{l}\text { Nil. Partial to the } \\
\text { minority } \\
\text { speaker }\end{array}$ \\
\hline $\begin{array}{l}\text { 2. To help the service } \\
\text { provider/institution. To } \\
\text { serve as an institutional } \\
\text { asssistant }\end{array}$ & $\begin{array}{l}\text { Advocate for the powerful } \\
\text { participant }\end{array}$ & Medium & $\begin{array}{l}\text { No partiality to either } \\
\text { party - power to the } \\
\text { interpreter }\end{array}$ \\
\hline $\begin{array}{l}\text { 3. To be an active third } \\
\text { participant in the } \\
\text { interaction and decid on } \\
\text { what should and should } \\
\text { not be uttered }\end{array}$ & $\begin{array}{l}\text { Gatekeeper. } \\
\text { The interpreter becomes the } \\
\text { only powerful participant }\end{array}$ & Low & $\begin{array}{l}\text { Impartial. Both parties } \\
\text { «helped» by the } \\
\text { interpreter }\end{array}$ \\
\hline $\begin{array}{l}\text { 4. To ensure effective } \\
\text { communication between } \\
\text { the participants }\end{array}$ & $\begin{array}{l}\text { Filter, embellisher, clarifier, } \\
\text { speech assistant }\end{array}$ & $\begin{array}{l}\text { Medium } \\
\text { to High }\end{array}$ & $\begin{array}{l}\text { Impartial } \\
\text { Responsability for } \\
\text { communication left to } \\
\text { authors of the utterances }\end{array}$ \\
\hline $\begin{array}{l}\text { 5. To remove the } \\
\text { language barrier and } \\
\text { place the minority } \\
\text { language speaker in as } \\
\text { similar a position as } \\
\text { possible as someone who } \\
\text { speaks the mainstream } \\
\text { language }\end{array}$ & $\begin{array}{l}\text { Faithful renderr of the } \\
\text { original utterances }\end{array}$ & Content alone & $\begin{array}{l}\text { Impartial } \\
\text { Responsability for } \\
\text { communication left to } \\
\text { authors of the utterances }\end{array}$ \\
\hline
\end{tabular}

En el primer caso, advocate for the minority language speaker, el interprete asiste a la parte más débil y se convierte en portavoz; por ello añade información, omite y crea coherencia donde no existe. El segundo, advocate for the institutions or the service provider, en el que el intérprete está al servicio de la institución, la institución ofrece la posibilidad de resumir, omitir e intermediar, por lo que el intérprete pierde la capacidad de desempeñar su profesión según su código deontológico y depende del obrar de las demás partes implicadas, y más específicamente de las partes con una posición de poder en la interacción. El tercer papel será el de gatekeeper, en el que el intérprete selecciona el contenido que traduce, minando el poder tanto de la persona alófona como de la institución. En cuarto lugar, puede asumir el papel de facilitator of communication, donde el intérprete proporciona explicaciones de tipo lingüístico y cultural, mejora la 
coherencia y la cohesión del enunciado y omite las repeticiones. En estos cuatro primeros papeles, no existe imparcialidad o neutralidad. Finalmente, cita el papel del «intérprete fiel de los enunciados de los demás», tal y como defienden la mayoría de los códigos deontológicos, pero al mismo tiempo aboga por una mayor comunicación con los proveedores del servicio a fin de evitar malinterpretaciones. La autora menciona también una mayor formación de los intérpretes y de los demás actores presentes en el acto interpretativo (Hale, 2015).

Sigue siendo actual el enunciado de Ortega-Herráez respecto al papel del intérprete en el sentido de que, «independientemente del prisma desde el que se analice, [el papel] está estrechamente ligado a los propios códigos deontológicos que rigen la profesión, en la medida en que son estos los que establecen qué debe hacer el intérprete y cómo debe hacerlo» (2011, p. 154). La comunicación mediada por intérpretes implica una gran complejidad, que en cuestiones legales adquiere una dinámica muy precisa. El papel del intérprete no puede ser el de un simple conducto, sino que este tiene que ser consciente de los propios deberes y de la manera de actuar, sin interferir excesivamente, de manera que sean las personas usuarias del servicio quienes se comuniquen entre sí. El código deontológico será de ayuda en los momentos críticos a la hora de seguir unas pautas y de tomar las decisiones oportunas para una mejor ejecución y mayor calidad en su trabajo (Hale, 2007, p. 104).

\subsubsection{El intérprete judicial desde el punto de vista del código deontológico}

Algunos códigos deontológicos exponen con claridad cuál es la función del intérprete judicial. Como ya se ha citado anteriormente, la National Association of Judiciary Interpreters and Translators (NAJIT) considera que la función del intérprete es eliminar la barrera del idioma para que las personas que no hablen el inglés puedan acceder a la justicia en igualdad de condiciones de quienes sí lo hablan.

El Australian Institute of Interpreters and Translators (AUSIT) subraya el importante papel que desempeñan los intérpretes y traductores en la comunicación entre las partes que no comparten el idioma, siendo su objetivo garantizar la transmisión completa y precisa del mensaje y de la intención, evitando todo tipo de sesgo. Por ello, «they do not soften, strengthen or alter the messages being conveyed» (AUSIT, 2012) ${ }^{20}$.

\footnotetext{
$20 \begin{aligned} & \text { Para la consulta del código deontológico } \\ & \text { https://ausit.org/AUSIT/Documents/Code_Of_Ethics_Full.pdf. }\end{aligned}$
} 
La definición del papel del intérprete judicial está profundamente vinculada a los principios que defienden dichos códigos deontológicos, que a su vez están ligados al concepto mismo de calidad en interpretación. Aunque se abordan en el capítulo 5, dedicado a la calidad en interpretación judicial, cabe mencionar aquí que los rasgos fundamentales que debe poseer un intérprete judicial son: fidelidad, confidencialidad, formación continua e integridad, como reflejan los códigos de AUSIT, NAJIT, EULITA, AssITG o APTIJ, entre otros. No obstante, la concienciación profesional de los intérpretes que trabajan en entornos judiciales con el fin de fomentar el reconocimiento y la profesionalización de una práctica azotada por el intrusismo ha llevado en los últimos años a un trabajo de concienciación de los profesionales desde las distintas asociaciones. Partiendo de la definición de lo que significa una profesión, esto es, un grupo de personas que comparten una experiencia común y profesan un código deontológico y de conducta en favor de sus clientes, colegas y patrimonio de conocimiento que va más allá del interés propio de los profesionales (Corsellis y Fernández Leandro, 2001, p. 77), los autores definen no solo los requisitos, sino también la conducta, pues consideran fundamental la formación, la evaluación y el establecimiento de directrices de buenas prácticas y de procedimientos disciplinarios.

El problema surge no tanto con respecto al código deontológico, sino con el propio papel de intérprete (Firtsh-Rudser, 1988, citado por Ortega-Herráez, 2011, p. 154), teniendo en cuenta que, hoy en día, muchos países carecen de un código específico y vinculante de actuación para los intérpretes judiciales (p. 156). Como apunta también el autor, la «puesta en práctica dependerá en buena medida de la forma en que se desarrolle el procedimiento judicial y del sistema judicial concreto en el que se encuentre el intérprete judicial» (p. 157).

Diversas asociaciones de varios países, en colaboración con instituciones nacionales e internacionales y universidades, han elaborado códigos de conducta o protocolos para el trabajo con intérpretes, como el de la Policía Metropolitana de Londres (2007/2010), las directrices de la National Health and Nutrition Examination Survey en el entorno sanitario (NHANES, 2006), los protocolos de proyectos ejecutados bajo la égida de la Unión Europea como Building Mutual Trust (BMT) o Speak Out for Support (SOS-VICS), de los que se hablará más adelante, o las recomendaciones publicadas para trabajar con intérpretes en juzgados y tribunales en Australia (2017). 


\subsubsection{El uso del análisis del discurso para el estudio de la figura del intérprete judicial}

Una contribución muy importante en relación con la figura del intérprete judicial es la proporcionada por distintos trabajos de investigación realizados bajo el enfoque del análisis del discurso, dentro del campo de la lingüística aplicada. Fairclough (1995) distingue principalmente dos acepciones de discurso: a) discurso como acción social e interacción (que es la acepción dominante en los estudios lingüísticos), y b) discurso como construcción social de la realidad, forma de conocimiento (que es la acepción que se utiliza fundamentalmente en la teoría social postestructuralista de Foucault). En su definición más sencilla, se trata del análisis sistemático del uso del lenguaje, a través de la aplicación de una variedad de métodos, teorías y enfoques (Hale y Napier, 2013, p. 119).

La importancia de la comunicación cara a cara en la interpretación judicial, la asimetría entre los participantes y las diferencias culturales y lingüísticas entre ellos (Ortega-Herráez, 2011, p. 157) hacen que el análisis del discurso resulte de gran interés en los trabajos de investigación. Dicho enfoque se ha aplicado sobre todo a la investigación en interpretación ante los tribunales, pues en este contexto es relativamente más sencillo recuperar información que en los entornos policiales, de solicitud de asilo o en prisiones.

Los trabajos seminales de Bersk-Seligson (1988/2002; 1990; 1999) demuestran que, en realidad, el intérprete no solo realiza funciones de intérprete; en algunas ocasiones precisa aclaraciones o habla directamente con los participantes de la interacción. De hecho, considera que el intérprete judicial está lejos de ser la figura discreta que desearían los jueces y los abogados (Berk-Seligson, 1990, p. 96). El estudio, que parte de una base etnográfica y sociolingüística, analiza por medio de un amplio corpus de declaraciones de testigos en interacciones mediadas por intérpretes aquellas ocasiones en las que el intérprete habla con su propia voz, proporciona explicaciones, comentarios e información adicional. De hecho, su intervención altera en muchas ocasiones el estilo discursivo original de los demás oradores, alejándose de lo que habitualmente se considera una buena interpretación, es decir, no intrusiva.

La distribución asimétrica del poder en los entornos judiciales se considera una de las cuestiones principales en el estudio de la interpretación dialógica (Pérez-González, 2016 , p. 393). Hale analiza en varios estudios (2004; 2007, 2011; 2017) la importancia del uso del lenguaje en los tribunales y cómo influye el cambio pragmático del uso del lenguaje, interrupciones y omisiones, para trasladar información importante, incluso en intérpretes formados. En el estudio realizado, la investigadora demuestra que las 
variaciones pragmáticas del discurso original hacen que el control que deberían ejercer los representantes de la justicia pase al intérprete, que altera la declaración de los participantes, consciente o inconscientemente, con su discurso personal (Hale, 2004, p. 240). De hecho, la autora demuestra que, para que la interpretación mantenga el mismo efecto que en la lengua de partida, es fundamental mantener todos los elementos adicionales, marcadores del discurso, repeticiones y vacilaciones, entre otros, pues son claves para revelar la actitud del hablante, por lo que resulta fundamental mantener las características estilísticas del original (Hale, 2004, p. 105).

Partiendo del análisis de los distintos estudios sobre el análisis del discurso, Ortega-Herráez sostiene la importancia de la fidelidad al original en la interpretación, a pesar de las dificultades, puesto que:

... los postulados básicos del legal equivalent siguen teniendo validez en la medida en que es una forma que preconiza la más absoluta fidelidad al original por parte del intérprete de cara a garantizar que el acceso a la justicia se produzca en igualdad de condiciones independientemente de la presencia del intérprete. No obstante $[\ldots]$ es muy importante que dichos postulados no se confundan con el mito de traducir literalmente palabra por palabra. [...] No obstante, no es menos cierto que empiezan a levantarse voces que abogan por una mayor intervención del intérprete, lo que nos lleva a pensar en aquellas funciones que en ocasiones desempeña el intérprete y que, a priori, superan los límites que establecen las normas que rigen la profesión (2011, p. 173).

\subsubsection{Otros perfiles profesionales que puede asumir el intérprete}

Siguiendo a Ortega-Herráez (2011, pp. 177-191), se reseñarán otros perfiles que puede asumir el intérprete judicial que superan los asignados por los códigos deontológicos, entre los que cabe destacar el de traductor, el de perito y el de mediador.

El intérprete judicial ha de asumir en algunos países la función de traductor, a pesar de que los estudiosos consideren que sería conveniente separar la acreditación de los traductores e intérpretes judiciales (Caciagli, Balletto y Rivezzi, 2009; Caciagli, 2014; Hertog, 2015, p. 95; Blasco-Mayor y Del Pozo Triviño, 2015, pp. 16-17, entre otros). En países como Italia y España, esta función la llevan a cabo a menudo las mismas personas. De hecho, en Italia la función de intérprete es vista en algunos casos como «trampolín» para poder realizar ciertas traducciones. En ambos países, la traducción puede ser directa pero también inversa, y puede incluir una serie de documentos que pueden dividirse en varios tipos (Ortega-Herráez, 2011, pp. 177-178) a) documentos jurídicos propiamente dichos (autos, sentencias, legislación, comisiones rogatorias, entre otros); b) documentos judiciales no jurídicos, y c) documentos técnicos (informes económicos, periciales, médicos-forenses, entre otros). Al mismo tiempo, al 
intérprete se le solicita a menudo que realice transcripciones y traducciones de escuchas telefónicas, tarea complicada que depende de los protocolos de cada país.

Por lo que atañe al intérprete como perito, Ortega-Herráez señala que «existen dudas en torno al estatus legal del que disfruta el intérprete, ya que de su consideración como mediador interlingüístico o como perito pueden derivar numerosas consecuencias» (2011, p. 179). Como señala el autor, si el intérprete se considera como perito, puede ser recusado y «según el acta recoja que el intérprete actúa en calidad de perito (expert) o en calidad de personal al servicio de la justicia (court official), las repercusiones legales y el procedimiento que se debe seguir diferirán» (p. 180). Fernández Carrón considera que no puede atribuirse este papel de perito al intérprete y apunta que, si la actuación del traductor-intérprete fuera considerada como un peritaje, podría estar sometida al interrogatorio de las partes (2017, p. 121). Según la definición de Edwards (1995, p. 137), cuando el intérprete actúa como perito su función queda clara, pues trabaja como experto, ya sea describiendo su propio trabajo o el de algún colega explicando en la vista de manera imparcial los procedimientos y los métodos apropiados de interpretación. En realidad, el intérprete actúa como tal cuando traslada un enunciado de un idioma al propio del tribunal, y actúa como perito cuando realiza un dictamen pericial, y, en este caso, sí puede ser sometido a interrogatorios, pues tendrá que defender su traducción ante un juez, tal y como hace un perito en su informe. En Italia el problema se plantea legalmente, pues el intérprete judicial es denominado directamente perito en el procedimiento penal si es contratado por el juzgado y ausiliario si le contrata la policía judicial, mientras que recibe el nombre de consulente tecnico del giudice en el proceso civil. En relación con las nomenclaturas arriba citadas, se considera al intérprete un auxiliar del juez, pero no puede ser considerado perito cuando realiza sus funciones de interpretación, puesto que no da su opinión experta sobre algo, sino que interpreta; su función, por tanto, está vinculada a la garantía de un derecho procesal. Por otra parte, tanto en Italia como en Estados Unidos, el intérprete no puede actuar como tal si ha realizado la transcripción de las escuchas telefónicas, y en este caso podría ser llamado a actuar como perito para justificar su propia actuación. Esta situación confusa se ha generado a partir de la falta de reconocimiento y delimitación de las funciones del intérprete tanto en Italia como en España. En Italia, por ejemplo, la falta de pertenencia a un colegio conlleva que la labor del intérprete sea remunerada muy por debajo de la que reciben otros peritos colegiados (Caciagli, 2014), situación que en España tiene un claro reflejo.

En cuanto a la función de mediador intercultural, las funciones del intérprete no quedan claras, ni siquiera entre los estudios de la interpretación en los servicios públicos, y en cada país se ha interpretado de distinta manera. La denominación de 
intérprete en los servicios públicos ha conducido en ocasiones a esta confusión (Pöchhacker, 2008), que ratifica Ortega-Herráez (2011, p 183). Los estudiosos de la interpretación tienden a separar claramente ambos perfiles profesionales (González et al., 2012; Mikkelson, 2017; Tipton y Furmanek, 2016), pero en cierto modo esta separación no es tan nítida para los profesionales que colaboran con ellos.

Pöchhacker (2008) relaciona los nuevos estudios de interpretación en los servicios públicos con el cultural turn de los estudios de traductología y el valor semántico de la palabra mediación con sus múltiples significados: mediación lingüística, que está vinculada a la mediación lingüística-cultural, mediación interpersonal y mediación cognitiva, siendo partidario de una separación entre los distintos tipos.

Es preciso aclarar que el intérprete posee funciones diferentes a las del mediador intercultural, aunque ambos se ocupen de «la comunicación intercultural mediada» (Arumí Ribas, 2018, p. 45). El primero realiza una actividad de intermediación cuando se producen dificultades en el proceso de comunicación y así poder conciliar o poner de acuerdo a las personas o las partes. Según la autora, el intérprete tiene que:

...descodificar mensajes procedentes de un emisor que tiene una lengua (y por tanto una cultura) diferente a la de su receptor y actuar de vehículo para la comunicación transfiriendo mensajes orales de una lengua a otra para que los interlocutores puedan comunicarse de manera autónoma e independiente (Arumí Ribas, 2018, p. 45).

En Italia esta situación se complica aún más desde el momento en que los estudios de grado (laurea triennale) en traducción e interpretación reciben desde los años noventa la denominación de Scienze della mediazione lingüística, mientras que el posgrado de dos años (laurea specialistica) pasó a denominarse Interpretariato di conferenze (Pöchhacker, 2008, p. 19-22; Falbo, 2013, pp. 28-45). Gavioli (2009, p. 14) analiza la relación entre lingüístico/interlingüístico y cultural/intercultural en la interacción mediada, colateral a la actividad intercultural de la mediación, remarcando que los estudios de interpretación y traducción han subrayado los aspectos lingüísticos del proceso traductológico y han ignorado los aspectos antropológicos; estos, por su parte, han considerado la actividad traductológica como colateral y accesoria a la actividad intercultural de la mediación. Gavioli y Baraldi, (2011) consideran que, en realidad, los intérpretes son mediadores lingüísticos, pues contribuyen a la interacción siendo participantes activos, la coordinan, reduciendo o ampliando las declaraciones de los demás participantes en sus interpretaciones y produciendo conversaciones adicionales, mejorando así la comprensión mutua (Gavioli y Baraldi, 2012, p. 20). En esta definición, la función del intérprete sobrepasa el papel de facilitador, pues está 
tomando decisiones (añadir o elidir) que no le competen, eliminando la fidelidad en su ejecución, fundamental para la interpretación judicial.

Falbo especifica el valor polisémico de la palabra mediación, que se especifica mediante el adjetivo que lo acompaña. Según su definición, el propósito de la mediación lingüístico-cultural es realizar una práctica atenta a la inclusión de los nuevos ciudadanos y a la cohesión social (Falbo, 2013, pp. 29-30), vinculándola así a políticas de integración de los inmigrantes. Para algunos autores analizados, el mediador desempeña tareas que son del intérprete y del traductor sin que su papel finalice en el cumplimiento de dichas tareas, tal y como recogen también algunas circulares del Ministerio de Educación italiano (Falbo, 2013, p. 32). Sin aceptar que el intérprete se tome ciertas prerrogativas sobre lo que ha de traducirse y lo que no, considera que la actividad de interpretación no difiere de la actividad que desempeña el mediador lingüístico-cultural, figura cuya definición permanece vaga desde una perspectiva profesional, cuando tiene que traducir en ciertos contextos y llevando a cabo una tarea de coordinación en la interacción. Por ello, tiende a favorecer una recomposición de la figura del intérprete y mediador, pudiendo coincidir ambas figuras en algunas ocasiones (Baraldi, 2014), aunque no elimina las diferencias, pues el intérprete es el que está «en medio» (Falbo, 2013, p. 41); y que en unas ocasiones podría utilizarse el mediador, sobre todo en las fases fuera de las salas del juzgado y al intérprete en el juzgado. Spinzi (2013) considera que el mediador ha de saber relacionarse y resolver conflictos de comunicación, pragmáticos y culturales, y Maffei (2013, p. 43) sostiene que la misma persona puede ser intérprete y mediador.

De nuevo, Falbo indica que la diferencia entre el intérprete y el mediador no reside tanto en tener en cuenta la cultura y trasladarla, sino en ser aceptado como miembro de la comunidad lingüística cultural y desempeñar bien su labor, con una competencia psicológica y cultural (Falbo, 2013, p. 44), y con ello afirma que el hecho de que una persona asuma las dos funciones es totalmente aceptable.

Rudvin (2015) y Spinzi (2015) exploran la confusión que se ha creado en Italia entre los términos mediación lingüistica y mediación cultural a través de las características que distinguen a las dos ocupaciones, y defienden una diferenciación entre la figura del mediador lingüístico y el intérprete, mientras que Spinzi tiende hacia una formación más intercultural del intérprete (Spinzi, 2015, p. 151) por medio de una «reflexión metacultural».

Tras el análisis de las contribuciones anteriores, puede afirmarse que esta nomenclatura no hace más que crear confusión entre los actores implicados, que exigen por ello una mayor involucración del intérprete, que suele conllevar un menor reconocimiento de su auténtico papel. Esta es la situación actual en Italia, provocada por 
el desconcierto generado por la atribución inadecuada del papel de mediador a los intérpretes que trabajan en los servicios públicos. Por otra parte, el intérprete se encuentra hoy en día en una sociedad multicultural en la que a veces tiene que proporcionar información de tipo cultural que permita el desarrollo de la comunicación (Ortega-Herráez, 2011, p. 190), pero esto puede resultar complicado si el intérprete se extralimita en sus funciones.

En esta misma línea, Hale señala que «ofrecer información cultural puede ser muy arriesgado. La mayoría de las diferencias interculturales que quedan reflejadas en el lenguaje, como la cortesía, el carácter indirecto u otras consideraciones pragmáticas, deben abordarse en una interpretación pragmática, fiel al original, sin la necesidad de interrumpir la conversación» $(2007, \text { p. } 132)^{21}$. No obstante, el intérprete puede destacar únicamente las convenciones culturales más generales, pues las demás podrán depender de cuestiones personales, como la educación u otros factores. La estudiosa considera que se precisan más estudios al respecto (2007, p. 144). Las diferencias culturales pueden ser muy complejas y específicas, por lo que, si el intérprete no es un antropólogo experto, por muy cercano culturalmente que esté, la información cultural que transmita es solo su punto de vista, que puede estar sesgado o equivocado (González et al., 2012). Esta consideración la comparte también el código deontológico de la National Council on Interpreting in Health Care (NCHCI) estadounidense. Kelly, por su parte, añade la dificultad que puede existir en el caso de que se interprete una lengua que se habla en diferentes países o una lengua franca como el inglés o el árabe (2000, p. 145). El proceso de interpretación es de por sí difícil, requiere un gran esfuerzo cognitivo y gran concentración. Apartar la atención realizando otras tareas puede minar la calidad de la labor principal. De la misma forma que el juez debe centrarse en realizar su trabajo y el abogado el suyo, el intérprete ha de realizar una serie de tareas ya de por sí complejas, además de poseer una cierta formación de tipo pragmático.

${ }^{21}$ Traducción de Cobas Álvarez y Valero Garcés, 2010, p.137. 


\subsection{Breve panorama de la interpretación judicial y policial en España}

El derecho a intérprete quedaba garantizado en España por la Constitución española de 1978, que garantizaba la protección del derecho a un juicio justo (OrtegaHerráez, 2011, pp. 31-33). España traspuso la Directiva 2010/64/UE con retraso y con muchas lagunas respecto a la cualificación y acreditación de los intérpretes capacitados para trabajar en ámbito judicial, lo que ha provocado el descontento en las distintas asociaciones de traductores e intérpretes y de algunos magistrados conocedores del problema y concienciados, al igual que de algunos letrados de oficio.

En España, la falta de delimitación y reconocimiento de la figura y atribuciones del intérprete judicial tiene un origen distinto: la gran confusión que existe sobre las figuras del traductor e intérprete jurado y el traductor e intérprete judicial, lo que provoca aún mayor desconcierto a la hora de reconocer la labor profesional del segundo. Esta confusión ya ha sido recogida por Feria García (1999, pp. 90-93) y Blasco-Mayor (2013), quienes exponen algunas de las iniciativas desarrolladas con el propósito de mejorar la situación y promover la profesionalización de la interpretación judicial en España.

El intérprete jurado (ahora llamado traductor-intérprete jurado) es aquel que «está habilitado para dar fe pública ante cualquier organismo del Estado (también, por supuesto, ante la Administración de la Justicia)» (Feria García, 1999, p. 91). Recibe su nombramiento de la Oficina de Interpretación de Lenguas del Ministerio de Asuntos Exteriores y Cooperación (MAEC), que establece las pruebas de acceso, y de las comunidades autónomas de Cataluña, Galicia y País Vasco, que tienen competencias en esta materia. Este nombramiento le permite ejercer como profesional independiente; aunque pueden trabajar para la justicia, no suelen hacerlo debido a los bajos emolumentos. Las traducciones juradas se requieren hoy en diferentes ámbitos, tanto públicos (documentos del registro civil, académicos, entre otros) como privados (documentos notariales, societarios o que deban presentarse ante la Administración pública). Existen varias vías para acceder, aunque la principal es superar el examen que convoca el citado Ministerio. Como apunta Ortega-Herráez, se trata, en sentido estricto, de la única acreditación profesional existente por el momento, y:

\footnotetext{
... ningún trabajo que verse sobre la figura del intérprete judicial en nuestro país puede pasar por alto la existencia de los intérpretes jurados que, a día de hoy, son los únicos profesionales habilitados como fedatarios públicos entre lenguas distintas, aunque no son los únicos que realizan traducciones oficiales o «fehacientes» (2011, p. 63).
} 
El traductor e intérprete judicial es, según la definición de APTIJ, «aquel que trabaja para los órganos judiciales y los cuerpos y las fuerzas de seguridad del Estado y de las comunidades autónomas» ${ }^{22}$. Existen traductores-intérpretes de plantilla y freelance.

Por lo que respecta a la contratación actual de los intérpretes que trabajan para la justicia, sigue estando vigente el sistema constatado por RITAP (2011, p. 47-71) y por Ortega-Herráez (2011, p. 95). Existen, según este autor, tres sistemas fundamentales de contratación de traductores e intérpretes en el entorno judicial. Hay que señalar también que algunas competencias de la justicia han sido transferidas a las comunidades autónomas, por lo que ciertos servicios permanecen centralizados mientras que otros han sido asignados a las distintas comunidades. Por tanto, los sistemas actuales son:

1) Modelo tradicional: en dicho modelo hay una convivencia de intérpretes de plantilla (que han accedido mediante concurso público de oposición) y de intérpretes freelance (que son utilizados cuando la carga de trabajo es fuerte y para la interpretación de idiomas que no cubre el personal en plantilla).

El personal contratado en plantilla no está englobado en un régimen único y aplicable, sino que cabe distinguir dos grupos fundamentales (RITAP) ${ }^{23}$ : los profesionales que trabajan en comunidades autónomas en las que los medios personales de la Administración de Justicia dependen del Ministerio de Justicia, y quienes ejercen sus funciones en los órganos centrales (Audiencia Nacional y Tribunal Supremo). Se trata, pues, de empleados públicos que han superado una oposición. Dependiendo del órgano de la Administración de Justicia al que pertenezca, varía el tipo de titulación exigida, que puede ser bachillerato, diplomatura, licenciatura o equivalentes. A estos dos grupos hay que añadir también el personal que trabaja como traductor-intérprete policial de plantilla para la policía, que pertenece al Ministerio del Interior.

En segundo lugar, se encuentran los traductores e intérpretes del ámbito judicial/policial freelance. Se trata de profesionales independientes. En el modelo tradicional, está formado por profesionales que trabajan en las comunidades autónomas que han asumido las competencias en materia de medios personales y materiales de la Administración de Justicia.

\footnotetext{
22 Para más información, se remite al sitio institucional de la asociación APTIJ: http://www.aptij.es/index.php?l=es\&s=f.

${ }^{23} \mathrm{P}$ ara más información, véase el sitio de RITAP: http://www.ritap.es/traduccion-institucional/justicia/.
} 
2) Subcontratación de servicios, llamado «modelo de contratas», en el que la Administración pública efectúa una licitación a la que optan empresas privadas. La empresa actúa como intermediaria y gestiona la contratación del personal. Los traductores e intérpretes freelance son profesionales independientes que trabajan para la empresa adjudicataria. La Administración favorece este tipo de contratación, pues de esta manera debe dialogar con un único interlocutor, mantiene asegurado el servicio durante las veinticuatro horas del día, durante todo el año, sin tener en cuenta la lengua necesaria, pues la empresa adjudicataria se encarga de proveer el servicio incluso para las lenguas de menor difusión (Arumí Ribas, 2018, p. 54). Las titulaciones que se exigen dependen del idioma y aparecen reflejadas en los pliegos de condiciones redactados por la Administración para el concurso de licitación (Ortega-Herráez, 2011, pp. 108-135). Entre los intérpretes que trabajan para las empresas o contratas, hay algunos traductores/intérpretes jurados, aunque no es imprescindible este nombramiento para actuar en sede judicial y policial. En resumidas cuentas, la subcontratación conlleva una reducción importante de las tarifas que perciben los traductoresintérpretes, pues la empresa adjudicataria e intermediaria se queda con una parte considerable de los pagos que realiza la Administración, aduciendo, entre otras razones, gastos de gestión y de formación de los intérpretes. El fin que persiguen dichas empresas es el beneficio económico (Gascón Nasarre, 2017, p. 23), y esto provoca una merma de la calidad, tal y como se hizo constar ya en su día en el Libro Blanco de la Traducción y la Interpretación Institucional (RITAP, 2011, p. 52-66). Las condiciones de trabajo son precarias: las tarifas que pagan estas empresas varían dependiendo de cada comunidad autónoma, pero rondan los diez euros por hora, sin incluir los desplazamientos y en algunos casos tampoco el tiempo de espera, y por ello muchos profesionales rechazan las propuestas al considerar dichos honorarios indignos y no rentables. El vacío de profesionales se ha colmado con personal en muchos casos improvisado. Se han producido numerosas quejas y denuncias sobre el hecho de estar utilizando intérpretes no profesionales en ámbito de la justicia (De Luna Jimenez de Parga, 2009, 2010; Red Vértice, 2012; Blasco-Mayor et al., 2013).

3) Gestión integral pública de los servicios de traducción e interpretación judicial: este modelo es por el momento exclusivo de la provincia de Las Palmas, donde un traductor-intérprete en plantilla coordina la contratación y gestión de todos los demás intérpretes. Aunque este modelo presenta algunas desventajas (Ortega-Herráez, 2011, pp. 141-142), también presenta aspectos positivos como es la remuneración más digna de los intérpretes y traductores, con tarifas íntegras, y el control de calidad por parte del intérprete coordinador (Blasco-Mayor y Del Pozo Triviño, 2015, p. 16). 
Hasta la fecha, el modelo que prevalece y que se ha impuesto en la mayor parte del territorio español es el modelo de contratas, que constituye el auténtico «talón de Aquiles de la interpretación judicial en España» y el eslabón débil de la cadena (Gascón Nasarre, 2017, p. 152). El aumento de las causas con encausados, víctimas o testigos extranjeros, y la falta de personal han hecho que la Administración pública trasfiera los servicios de traducción e interpretación de tribunales y policía mediante licitación pública (Ortega-Herráez y Foulquié Rubio, 2008, p. 125; Ortega-Herráez, 2011, p. 7394). Dichas empresas disponen los requisitos de contratación ${ }^{24}$, escogen a los traductores e intérpretes, establecen los horarios, las guardias y demás condiciones de trabajo. Las empresas hacen acopio del curriculum vitae de profesionales con alta capacitación a fin de presentar un perfil creíble a la hora de licitar, pero finalmente contratan a personal en su mayoría no capacitado y no formado ${ }^{25}$, en muchos casos sin estudios superiores, tal y como ha sido señalado frecuentemente por otros estudiosos (Ortega-Herráez, 2011, 2013, 2016; Blasco-Mayor y Del Pozo Triviño, 2015) y por magistrados (De Luna de Parga, 2009, 2010). Los casos de falta de calidad han tenido eco en los medios de comunicación en numerosas ocasiones y los colectivos de profesionales (RITAP, Red Vértice, 2012; APTIJ, 2010, 2013) se han lamentado de ello. Los académicos pugnan por proponer nuevas fórmulas en aras de una mayor calidad en la interpretación y la traducción en entornos judiciales, haciendo por su parte propuestas para racionalizar el gasto, crear un registro de traductores-intérpretes como condición ineludible si se desea obtener un servicio de calidad, promoviendo pruebas de acreditación (Blasco-Mayor et al., 2013; Blasco-Mayor y Del Pozo Triviño, 2015) y desarrollando programas formativos que colmen el vacío institucional, con créditos especiales para la formación de intérpretes judiciales en programas de posgrado y máster (Universidad Autónoma de Barcelona, Universidad de Alicante, Universidad de Alcalá de Henares, Universidad de La Laguna y Universidad Pontificia de Comillas) (Arumí Ribas, 2018, p. 49), un máster específico dedicado a la traducción jurídica e interpretación judicial en la Universidad Autónoma de Barcelona y un curso de capacitación para trabajar como traductor e intérprete en el ámbito de la justicia en la Universidad Jaume I de Castellón (2017).

\footnotetext{
${ }^{24}$ Curiosamente, una de las empresas licitadoras prefería, según el comentario de algunos de los profesionales que trabajan para ellas de forma freelance, a los estudiantes/licenciados en turismo o en derecho, no considerando fundamentales los estudios en traducción e interpretación.

25 Este hecho me ha sido confirmado por dos intérpretes de lenguas de menor difusión, de formación universitaria y buena preparación, que han comentado a voce precisamente este caso. La empresa de subcontratación de servicios ha presentado su curriculum para una comunidad autónoma diferente de aquella donde residen y trabajan las intérpretes en cuestión.
} 
En los últimos años se han dado casos evidentes de mala calidad en la interpretación y traducción que socavan los derechos de los acusados, imputados, testigos o víctimas. Por si esto fuera poco, se han dado casos evidentes de corrupción de intérpretes, algunos de ellos ya condenados, otros detenidos y otros que pertenecían directamente a bandas criminales ${ }^{26}$. Recientemente, el proyecto TIPp ha sacado a la luz las graves deficiencias en la interpretación ante los juzgados de Barcelona (Orozco Jurotán, 2017; Bestué Salinas y Orozco Jurotán, 2017; Arumí Ribas, 2018, Bestué, 2018), escenario que podría aplicarse a todos los demás juzgados españoles. Según el proyecto, en las salas de lo penal que se han estudiado se traduce menos de un $50 \%$ de lo que se dice en sala, y en ese porcentaje inferior al $50 \%$ se han detectado errores graves que minan el derecho fundamental a entender y ser entendido (Orozco Jurotán, 2017; Arumí Ribas, 2018; Bestué, 2018). La prensa se ha hecho eco de los casos más clamorosos, apoyando a las asociaciones de profesionales de la interpretación y del personal de la Administración de la Justicia, al igual que la Asociación Profesional del Traductores e Intérpretes Judiciales y Jurados (APTIJ). Alonso Araguás et al. (2018) exponen algunos de los delitos de falso testimonio, descubrimiento y revelación de secretos, apropiación de documentación confidencial y cohecho en los que han incurrido intérpretes contratados por las empresas adjudicatarias en los últimos años (2018, p. 15$22)^{27}$. Gascón Nasarre (2015), por su parte, recoge comentarios de conductas inadmisibles y delictivas por parte de intérpretes. Más allá de estos casos extremos, en ocasiones se observan conductas de captación de clientes para otros servicios diferentes a los de interpretación, lo cual es éticamente reprobable.

La Asociación Profesional de Traductores e Intérpretes Judiciales y Jurados (APTIJ) interpuso una queja ante el defensor del pueblo el 22 de julio de 2016, con el respaldo del sector profesional y académico, «ante el mal funcionamiento de los servicios de traducción e interpretación judicial y policial». Las motivaciones fueron las siguientes:

Actualmente, estos servicios están, en su mayor parte, externalizados. La ausencia de control por parte de la Administración, unida a la precariedad laboral de los traductores e intérpretes que prestan servicio a estas empresas, ha provocado que

26 El último caso que se ha conocido se ha producido en Burgos. Se trata de una intérprete rumana por revelación de secretos. Para más información, se remite a: https://www.burgosconecta.es/provincia/detenidos-heroinaincautada-20180129121420-nt.html.

27 Además de los datos recogidos por las autoras y denunciados por la APTIJ, se han conocido otros ejemplos similares durante conversaciones con jueces, abogados e intérpretes, además del último caso publicado recientemente sobre una traductora intérprete de búlgaro en Burgos que pertenecía a una banda de narcotraficantes (http://www.lagacetadesalamanca.es/sucesos/2018/01/29/traductora-bulgara-formaba-partebanda-narcotraficantes/228433.html), que ya había sido investigada en 2014 por los mismos hechos en distintas conversaciones con jueces, intérpretes y abogados. 
muchos de ellos no cuenten con la cualificación necesaria para desempeñar sus funciones e incluso ha permitido que personas con antecedentes penales ejerzan estas labores.

Esta falta de cualificación pone en serio riesgo el acceso a la justicia por parte de las víctimas y atenta contra los derechos de defensa y de traducción e interpretación de los encausados, vulnerando así el derecho a un juicio justo.

Dadas las graves consecuencias que estos hechos pueden tener sobre la seguridad nacional, así como sobre los derechos fundamentales de las personas, es necesario que los ministerios encargados de prestar este servicio tomen las medidas oportunas para impedir que estas situaciones sigan produciéndose (APTIJ, 2016) ${ }^{28}$.

La queja ha sido respaldada por catorce asociaciones de traductores e intérpretes, además de veinticinco universidades españolas que imparten estudios de traducción e interpretación, amén de varias federaciones y asociaciones nacionales e internacionales (entre las que se encuentran FIT, EULITA y NAJIT).

A pesar de este clima de unión de todos los colectivos implicados en favor de una mayor calidad en la traducción e interpretación en los procesos penales, se han producido una serie de intervenciones jurisprudenciales que socavan los logros obtenidos. Por lo que respecta a los criterios jurisprudenciales posteriores a la entrada en vigor de la directiva, cabe señalar la Sentencia 18/2016 del Tribunal Supremo en la que se justifican como inevitables los posibles errores de traducción y el hecho de que no se haya interpretado todo el proceso. Para un análisis más pormenorizado de la jurisprudencia, se remite a Gascón Nasarre (2017, p. 27-29) y Blasco-Mayor (2016).

\subsection{Breve panorama de la interpretación judicial y policial en Italia}

Puede decirse que en Italia existe una falta de claridad sobre la figura del traductor e intérprete judicial, a la que se ha hecho ya referencia en el capítulo 2.2.4. No se constata una separación neta entre ambas actuaciones, y se produce una cierta confusión terminológica, pues la mayoría de los operadores hablan simplemente de «traducción». Esta falta de transparencia se puede resumir en tres aspectos fundamentales de su labor: el traductor-intérprete jurado ${ }^{29}$, el traductor-intérprete perito y el traductor-intérprete en relación con la figura del mediador lingüístico-cultural.

28 Para una lectura pormenorizada, se remite a: http://www.aptij.es/index.php?l=es\&s=n\&c=70.

29 En realidad, en Italia, el traductor puede jurar únicamente ante el juez; no existe un reconocimiento oficial como en España, sino que el juramento se realiza siempre ante un oficial de la justicia. Algunos juzgados permiten asseverare únicamente a los intérpretes traductores incluidos en los listados de dicho juzgado o a los pertenecientes a las asociaciones profesionales. 
Al igual que España, también Italia traspuso la Directiva 2010/64/UE con bastante retraso y no pocas críticas en relación con la cualificación, la acreditación y la falta de registro de los intérpretes que habían de trabajar en el entorno judicial. En la actualidad, y como se expone en el capítulo 3, el derecho a la asistencia lingüística se rige por el título específico del código de enjuiciamiento penal italiano que establece normas sobre el nombramiento del intérprete, la incapacidad e incompatibilidad del intérprete, la recusación y abstención, el otorgamiento del encargo, el plazo para las traducciones escritas y la sustitución del intérprete.

La aplicación de la ley está colmada de dificultades, como se puede deducir de las publicaciones que se han ocupado del tema (Di Donato, 2004; Sandrelli, 2011; Mometti, 2013, 2014; Candi, 2014; Falbo, 2013, 2014; Ballardini, 2005, 2014; Gialuz, 2013, 2014, 2018). No existe ninguna ley que prohíba a la autoridad nombrar libremente como intérprete a una persona no cualificada, sin competencia específica, cualificación ni formación. Para ello, es suficiente que se le considere capaz de cumplir «bien y fielmente con su función» (Ballardini, 2014, p. 62). Como expresa Falbo: «La parola interprete sembra svuotarsi del suo vero significato $[. .$.$] per assumere quello più ampio$ e quasi simbolico di colei/colui che conosce la lingua straniera richiesta e funge da interprete» (2013, p. 42). No obstante, es el juez el responsable último de la elección de la persona que deberá interpretar o traducir, y su elección puede ser obligatoria e inapelable para el intérprete (Codice di Procedura Penale, artículo 123).

Igualmente, la Directiva 2010/64/UE y la transposición italiana permiten que la lengua extranjera empleada para la interpretación sea otra diferente a la materna de la persona alófona (Gialuz, 2013, p. 8; 2018, p 141-144; Ballardini, 2014, p. 60; Falbo, 2013, p. 20-21), a diferencia de lo que sucede con las minorías lingüísticas, que tienen el derecho de poder usar su lengua nativa. Es suficiente con que el idioma elegido sea conocido por el acusado, la víctima o el testigo. En caso de idiomas de menor difusión, las autoridades pueden elegir si designar un intérprete de una lengua franca vehicular, después de haber comprobado que dicha persona conozca dicho idioma, o encomendar la labor a un hablante de la lengua de menor difusión que no posea las competencias técnicas necesarias para realizar dicho trabajo. Las dos opciones presentan sus puntos débiles. La primera porque no se sabe hasta qué punto la persona alófona conoce dicha lengua, lo cual provoca una situación de disimetría de poder que le sitúa más por debajo si cabe (Ballardini, 2014, p. 63). En el segundo caso, aumenta el riesgo de desamparo real, pues las malas interpretaciones y la falta de pericia del intérprete conlleva de hecho una indefensión, lo que finalmente podría desembocar en recursos.

Tal y como señalan Amato y Mack (2015, p 47), la denominación del intérprete que actúa en el procedimiento penal varía dependiendo de la fase en la que se encuentre 
dicho procedimiento. En la fase de investigación, cuando trabaja para la policía, se le denomina ausiliario di polizia giudiziaria; cuando trabaja para el ministerio público, recibe el nombre de perito si es en causas penales y consulente tecnico del giudice para las causas civiles, y cuando es nombrado por el juez, consulente tecnico d'ufficio. Aunque en teoría el intérprete que trabaja durante la fase de investigación no debería trabajar durante la vista oral, en la realidad esta norma no siempre se observa, por lo que podrían ser llamados a realizar una pericia sobre su propia labor durante una vista. Esto es lo que sucede, en general, con los intérpretes que trabajan en las escuchas, que no pueden asumir la función de intérprete durante la vista oral y pueden ser citados como peritos a declarar.

En cuanto al modo de provisión de servicio de los intérpretes que colaboran con la justicia, se pueden reunir en tres grandes categorías:

1) Intérpretes de plantilla del Ministerio del Interior: en el Ministerio del Interior hay 350 intérpretes, 250 de ellos en plantilla, que reciben el nombre de funzionari linguistici, y los restantes assistenti (Vecchione, 2014, p. 5); optan a dicho puesto mediante oposición, pruebas que se iniciaron en la década de los ochenta con la llegada de inmigrantes; en los exámenes no se incluyen pruebas de interpretación. Un cuarto del total trabaja en la sede central de Ministerio y el resto lo hacen en las oficinas periféricas (Questure, Divisione Investigacioni Generali e Operazioni Speciali [DIGOS], Ufficio Prevenzione Generale e Soccorso Pubblico [UPGSP], Uffici per l'immigrazione, Polizia di Frontiera aerea/marittima/terreste). Se ocupan tanto de traducciones escritas como de interpretaciones. Las lenguas que cubren los funcionarios son: inglés, francés, alemán, español, portugués, ruso, esloveno, árabe, albanés, chino y turco. El resto de las lenguas no tienen personal de plantilla, y el trabajo está externalizado. Existe una incompatibilidad de los funcionarios a la hora de trabajar en los juzgados (Giambruno, 2014, p. 163).

2) Intérpretes o personas freelance contratados directamente por los juzgados o las autoridades judiciales o policiales: en teoría, los intérpretes autónomos están llamados a traducir documentos escritos e interpretar en procedimientos orales. No hay certificación ni registro nacional único de traductores e intérpretes profesionales, como ya se ha apuntado. Por esa razón, en el entorno judicial confluyen listados en manos de la autoridad judicial, los albi dei consulenti tecnici (para asuntos civiles) y albi dei periti (juzgado de lo penal), y se integran en las disposiciones que la ley del 14 de enero de 2013 establece para las professioni non organizzate, profesiones no reguladas. Los traductores e intérpretes están incluidos en dichas listas junto a profesiones reguladas 
como arquitectos o arqueólogos. Además de estas listas de expertos más o menos formales, existen otras locales y alternativas que las autoridades judiciales usan cuando se necesita un intérprete o traductor (aunque se pueden designar personas que no están en la lista si se proporciona una justificación).

Las personas que desean ser incluidas en los registros (albi) deben residir en el distrito judicial en cuestión y pagar unas tasas. Aparte de esto, los requisitos específicos para la inclusión varían dependiendo de la región y del tribunal. Por ejemplo, para trabajar en los tribunales penales de Roma, los solicitantes deben proporcionar un curriculum y documentación que demuestre la experiencia profesional, poseer un diploma del idioma o traducciones e interpretación, y tener un conocimiento básico del procedimiento penal italiano. El tribunal de Milán requiere para las lenguas de mayor difusión el registro previo en la Cámara de Comercio, a la que se accede también mediante títulos. Otros tribunales establecen criterios inferiores. En muchos casos, los requisitos mínimos no se aplican a los intérpretes de lenguas de menor difusión, y los hablantes nativos de un idioma extranjero no suelen ser evaluados por su conocimiento del italiano. Una comisión específica evalúa las solicitudes; de ella deberían formar parte representantes de las principales asociaciones italianas de traductores e intérpretes, que se han mostrado críticos con este sistema, pues no existe una prueba de acreditación (Caciagli, 2014). En general, las autoridades competentes realizan investigaciones respecto a los antecedentes penales de los solicitantes antes de incluirlos en los registros.

Los honorarios de los peritos expertos nombrados por los tribunales, incluidos los intérpretes, están establecidos por ley y siguen un sistema anticuado y bastante complicado que queda a discreción total del juez que debe firmar la petición de liquidación de honorarios. Se basan en el tiempo que se pasa en el tribunal: el primer período de dos horas se paga actualmente a $14,68 €$ y el pago posterior a las dos horas siguientes a $8,15 €^{30}$. La baja remuneración contribuye a la renuencia de los profesionales a trabajar para los tribunales. Para complicar aún más la situación, dichos honorarios han de ser solicitados mediante factura electrónica y el pago puede llegar a tener retrasos de más de tres años, debiendo anticipar el trabajador autónomo el IVA. La baja remuneración está provocando un «éxodo de los profesionales cualificados» (Caciagli, Balletto y Rivezzi, 2009, p. 8), debido también a la falta de criterios de selección. Muchos de los intérpretes desempeñan este trabajo de manera temporal o complementaria, realizando trabajos a veces afines y otros muy lejanos de la profesión

\footnotetext{
${ }^{30}$ A estas tarifas hay que detraer los impuestos. La facturación ha de realizarse en formato electrónico, lo que encarece la tramitación, y con suerte se cobra tras dos años. Para más información sobre el sistema italiano de los registros en los tribunales (albi) y al sistema de las vacazioni, se remite a Ferro (2012).
} 
(Sandrelli, 2011, p. 3). Aunque el trabajo está mal remunerado, algunos intérpretes aceptan dicha labor por el gran volumen de trabajo que puede suponer la traducción de documentos y su consiguiente remuneración.

La pertenencia al registro de los tribunales, el albo, es, en algunos casos, necesaria para poder realizar traducciones asseverate, que son aquellas que tienen valor legal ante la Administración y son solicitadas en algunas instancias. Los jueces pueden requerir la actuación de una persona como intérprete aunque no posea la titulación oportuna, tal y como estableció la Cassazione ya en 1973, tanto a nivel policial como judicial. De hecho, el juez tiene libertad para elegir al intérprete, sin que nada le impida elegir a aquellos que no posean un título universitario específico o un certificado de capacitación profesional:

Gli interpreti, tanto se chiamati a prestare assistenza alla polizia giudiziaria (art. 223 c.p.p.) quanto se nominati dal giudice (art. 326 stesso codice), possono essere scelti liberamente, a nulla quindi rilevando la circostanza che non siano in possesso di un attestato di abilitazione ufficiale. L'apprezzamento sulla sussistenza della capacità professionale e delle cognizioni inerenti al compito che l'interprete è chiamato a svolgere, spetta al giudice del merito e non è sindacabile in sede di legittimità. (Cass., Sez. II, [ud. 07-12-1971], causa Golisano, Cassazione penale, 1973, $782 \mathrm{~m}$ ).

El nombramiento y la autorización al pago de los honorarios depende del juez, que puede obligar al intérprete a actuar de oficio, reducir o aumentar los honorarios a discreción. Además de crear cierto descontento, esto provoca también alguna actitud de sumisión por parte de los intérpretes, que temen enemistarse con los jueces.

3) Subcontratación del servicio: hay servicios del Ministerio del Interior, del Dipartimento di Libertà Civili e Immigrazioni, la Commissione Nazionale per il Diritto d'Asilo y de comisiones territoriales para el reconocimiento de la protección internacional que se han subcontratado por medio de licitación. La empresa adjudicataria contrata directamente al personal para las lenguas de menor difusión y también a intérpretes inscritos en las listas del tribunal. La remuneración es baja $(12,50 € /$ hora). A diferencia de la contratación directa, pagan las horas de espera y los gastos de viaje, y el pago es a 90 días. La cooperativa posee un código deontológico que hace firmar a los intérpretes freelance antes del primer encargo, y existen también normas de actuación claras y precisas ${ }^{31}$.

\footnotetext{
${ }^{31}$ En conversaciones mantenidas con dichos intérpretes, se ha sabido que estos se niegan a trabajar directamente para los juzgados debido a condiciones de trabajo peores.
} 
A partir de este sistema, los trabajos de investigación que se han realizado en los últimos años (Sandrelli, 2011; Amato y Mack, 2015; Falbo, 2013, 2014; Mometti, 2014; Gialuz, 2013, 2014, 2018; Ballardini, 2014, entre otros) demuestran que el panorama actual de la interpretación judicial en Italia presenta un aspecto desolador. Se cometen errores judiciales graves por mala interpretación, las irregularidades dan pie a recursos y se incumplen los principios que fundamentan la Directiva 2010/64/UE y posteriores.

La pertenencia a un registro de intérpretes de un tribunal no garantiza su capacitación pues no existe un examen o prueba de acceso. Aunque en los últimos años se han vuelto más severos en la aceptación de las solicitudes, no existe, como ya se ha apuntado en los párrafos precedentes, un criterio único de selección de intérpretes a nivel nacional. La situación es aún más complicada para las lenguas de menor difusión, donde resulta difícil hallar personas capacitadas ${ }^{32}$.

Hoy en día no se ha establecido un registro único ni un sistema de acreditación y capacitación de intérpretes para los entornos judiciales. Aunque el Decreto Legislativo n. ${ }^{\circ} 129$, de 23 de junio de 2016, establece Disposizioni integrative e correttive del decreto legislativo 4 marzo 2014, $n .^{\circ} 32$, di attuazione della direttiva 2010/64/UE, y propone la creación de un listado nacional de intérpretes y traductores inscritos en los registros de peritos de cada tribunal, este aún no se ha llevado a cabo. Irónicamente, el documento oficial declara que la previsión que se ha introducido es una solución que equilibra de manera razonable el ejercicio de una profesión no regulada:

La direttiva impone agli Stati membri un meccanismo di verifica della qualità del servizio offerto dall'assistente linguistico e la previsione introdotta rappresenta una soluzione in grado di bilanciare ragionevolmente, da un lato, il diritto al libero esercizio di una professione non regolamentata, quale quella dell'assistente linguistico e, dall'altro, l'esigenza, imposta dall'Unione Europea, di prevedere un sistema efficiente di accesso al servizio di interpretariato ed un meccanismo trasparente di nomina di un ausiliario qualificato, per dare contenuto ed effettività al diritto espressamente sancito (GU Serie Generale ${ }^{\circ} 163$, de 14 de julio de 2016).

No existen actualmente sistemas de control de la calidad de la actuación de los intérpretes (Sandrelli, 2011; Mometti, 2014; Falbo, 2013, 2014; Ballardini, 2014; Amato y Mack, 2015).

\footnotetext{
32 el último caso deplorable que se ha conocido en Italia es que los tribunales están contratando estudiantes de mediación escasamente formados y con un nivel lingüístico y cultural insuficiente.
} 
A nivel universitario, faltan cursos de formación específica. Aunque se hayan dado pasos respecto a la traducción escrita (hay cursos específicos en Trieste, Génova, Milán, Forli), poco se ha hecho aún respecto a la formación específica en interpretación judicial. Cabe señalar el curso de formación permanente Assistenza lingüistica per l'ambito giudiziario organizado por la Universidad de Bolonia, que se encuentra ya en su cuarta edición ${ }^{33}$.

Existe una gran dispersión de esfuerzos por parte de las asociaciones ${ }^{34}$, las universidades e incluso los profesionales que trabajan para la justicia. En algunas ocasiones, se observa una relativa colaboración entre ellas para la realización de algún proyecto, pero en general se puede decir que el panorama italiano adolece de un frente común que reúna a todos los grupos implicados en cuanto a la formación, capacitación y desempeño de la profesión, de manera que se pueda ejercer cierta presión ante las autoridades.

\subsection{Conclusiones}

La interpretación judicial está adquiriendo cada vez más fuerza en una sociedad multiétnica debido a la movilidad de las personas. En los estudios de interpretación, la interpretación judicial ha ido obteniendo mayor interés por parte de los investigadores, desde varios puntos de vista: con un enfoque etnográfico, de análisis del discurso o centrándose específicamente en el papel que debe asumir el intérprete judicial.

La modalidad de interpretación varía considerablemente dependiendo del entorno donde se produce dicha interpretación, pues también las técnicas difieren. La interpretación judicial se acerca a la interpretación de conferencias en los entornos de los tribunales internacionales de Derechos Humanos, contra los crímenes de guerra o europeos. Está profundamente vinculada a la interpretación en los servicios públicos en la interpretación judicial llevada a cabo en cada país, donde las técnicas y el tipo de comunicación triádica influye en el acto comunicativo. En cualquier caso, es preciso reafirmar el carácter unitario de la actividad de interpretación, aun dependiendo del contexto y de los participantes del proceso de comunicación (Falbo, 2013, p. 24; Gentile 1997, p. 118; Pöchhacker, 2007, p. 11-12). Por otro lado, las nuevas técnicas de interpretación implican entornos y situaciones completamente nuevas (Braun y Traylor, 2012; Braun, Davitti y Dicerto, 2016; Navarro-Hall, 2017).

\footnotetext{
${ }^{33}$ Para más información, se remite al sitio del curso: http://www.unibo.it/it/didattica/corsi-di-alta-formazione/20162017/assistenza-linguistica-per-lambito-giudiziario-cod-9157-formazione-permanente.

${ }^{34}$ Divididas a su vez entre sí.
} 
No obstante, el denominador común de la interpretación judicial en cualquier situación dentro del procedimiento penal es la prioridad de una interpretación fiel al original. Es fundamental respetar este principio que en otros contextos puede considerarse secundario (entiéndase la interpretación de conferencias, donde la cohesión lógica y el estilo tienen un valor mayor). Por otra parte, no puede negarse que la interpretación judicial en ámbito nacional comparte muchas características con la interpretación en otros servicios públicos: suelen necesitarlas personas extranjeras que no hablan o hablan deficientemente la lengua del país, donde a menudo se encuentran en una situación desfavorecida con un desequilibrio de poder en cuanto al acceso a los servicios públicos. La modalidad de interpretación suele ser de tipo dialógico y a nivel profesional; salvo excepciones como en Estados Unidos, Reino Unido y Australia, los intérpretes carecen frecuentemente de una formación profesional específica. En otros países, aun existiendo personal cualificado, por cuestiones económicas se tiende a utilizar personal poco formado y no cualificado (Ortega-Herráez, 2013) y se está alejando a los intérpretes profesionales de las salas de los juzgados por falta de reconocimiento profesional (Caciagli, Balletto y Rivezzi, 2009).

Un problema al que tiene que enfrentarse el intérprete es el desconocimiento de sus funciones y de su papel en el entorno judicial; se entiende que el conocimiento de sus funciones por parte de los operadores judiciales redundaría en una mejora considerable de la comunicación en este contexto, a la vez que contribuiría a que se le respete y valore como profesional, y se reconozca, por tanto, la importancia de contratar personal formado y capacitado. Dicho aspecto será decisivo a la hora de obtener una consideración profesional y unos emolumentos adecuados, además de estar vinculado a legislación vigente en cada lugar. Existe, con todo, una gran diferencia entre los postulados teóricos y el desempeño real de la profesión (Ortega-Herráez, 2011, p. 152). En algunas ocasiones, y teniendo en cuenta que la actuación de cada interviniente influye en la manera de comportarse de los demás, si el resto de los actores no entienden o no consideran su papel, esto influirá negativamente en el desempeño mismo del intérprete, pues no le será posible llevar a cabo sus funciones según todos los requisitos y respetando los códigos deontológicos.

El uso de una terminología ambigua para referirse al intérprete en el ámbito de los servicios públicos está creando una gran confusión, no solo entre los mismos profesionales y docentes, sino también entre todos los usuarios. La diferente capacitación que poseen las distintas figuras no hace más que aumentar dicha confusión, y el uso de mediadores lingüísticos y culturales en vez de intérpretes en las fases preprocesales puede provocar, y, de hecho, menoscaba el derecho real del acusado o la 
víctima, como señala Corsellis (2010), a la vez que puede ocasionar más daños de los que realmente soluciona (Erasmus, 2000, p. 199).

Independientemente de la definición, la consideración y el papel del intérprete, la realidad es que la interpretación judicial representa hoy una auténtica emergencia (Falbo, 2013, p 16), pues sin la asistencia de intérpretes formados y capacitados en idiomas de amplia difusión y minoritarios resulta imposible garantizar una asistencia jurídica efectiva y el respeto de los derechos humanos y de las libertades fundamentales, ya sea de víctimas, acusados o imputados que no hablan el idioma del lugar en el que se encuentran. Por ello, la calidad de la interpretación en el ámbito judicial es fundamental y resulta perentorio formar, acreditar y evaluar a los intérpretes que trabajan en estos entornos (Corsellis, 2011; Hale, 2007; Blasco-Mayor y Del Pozo Triviño, 2015), a la par que concienciar y formar a los distintos actores que deben trabajar con ellos (Hale, 2015).

Llama la atención la diferencia de reconocimiento que el intérprete recibe con respecto a los órganos internacionales de justicia. En estos casos, los intérpretes son considerados a todos los efectos intérpretes de conferencias y trabajan normalmente en simultánea, en grupo, interpretando fundamentalmente hacia su lengua nativa. Están bien considerados y remunerados, y reciben todo el material para poder prepararse de manera eficaz para las vistas, interrogatorios y demás (Amodeo Perillo, 2017). Cabe preguntarse entonces si no influye la falta de visibilidad, los intereses políticos y el value for money en la falta de interés por la calidad de la interpretación judicial en los entornos nacionales.

La falta de reconocimiento en muchos países, la carencia de sistemas de acreditación, de formación continua, la inexistencia de registros relativos a los intérpretes judiciales y el intrusismo son lacras para la consecución de la calidad en estos entornos. Los mismos intérpretes no formados se sienten inseguros, lo que les conduce a subestimar su labor y asumir funciones que consideran más importantes que la suya, como son la de trabajador social o abogado (Hale, 2010, p. 174).

En el caso de España, y con el fin de trabajar en la mejora de los problemas que acucian al sector de la interpretación judicial, las asociaciones profesionales (Red Vértice) y las universidades (Conferencia de Centros y Departamentos Universitarios de Traducción (CCDUTI, ahora AUnETI) decidieron formar una comisión mixta en la que representantes de ambos colectivos llevan adelante iniciativas conjuntas ante la Administración pública, el estamento político y los medios de comunicación como representantes de un colectivo unido que presenta una sola voz en defensa de la profesión. 
La situación de la interpretación judicial en los distintos países de la Unión Europea, que presenta una gran variedad, ha sido analizada en varios proyectos europeos, como el proyecto Qualitas (Giambruno, 2014), entre otros, y en el informe FRA Rights of suspected and accused persons accross the EU: translation, interpretation and information (FRA, 2016), que analiza la implementación de la Directiva 2010/64/UE en ellos. En cuanto a España e Italia, cabe señalar que poseen algunos puntos en común: la figura del intérprete estaba ya presente en sus ordenamientos legales desde antes de la transposición de la Directiva; ambos sistemas cuentan con traductores e intérpretes funcionarios en la Administración pública (justicia, interior, exterior), aunque su acceso no requiera un título específico; existe además, en ambos países un gran intrusismo de personas sin formación para realizar las funciones de intérprete dentro de los tribunales y de los demás entornos relacionados con la justicia; están mal remunerados, lo que ahuyenta a buena parte de profesionales preparados, aunque no se puede ignorar a aquellos profesionales que por convencimiento personal realizan una gran labor. La función del intérprete judicial es poco conocida por el resto de los profesionales que trabajan en el ámbito de la justicia, al no existir protocolos de actuación para el trabajo con intérpretes (salvo en el caso del trabajo en contextos de asilo en Italia). Sin embargo, una cosa que diferencia a ambos sistemas es el modo de provisión del servicio en policía y juzgados, que es antitético. Por consiguiente, se puede deducir que la calidad de la interpretación judicial no depende tanto del modo de provisión en sí, ya sea esta directa o subcontratada, sino del reconocimiento profesional del intérprete, de su capacitación, de su remuneración y de la preparación de los demás operadores para trabajar junto a ellos. 


\section{El derecho a la traducción y a la interpretación como garantía procesal del derecho a un juicio justo}

Se trata de una garantía procesal de otro derecho más importante, como es el derecho a la tutela judicial efectiva (en el contexto constitucional español o italiano), el derecho a un juicio justo o equitativo o el derecho al proceso debido (en el contexto jurídico europeo).

\subsection{Introducción}

Ortega-Herráez afirma que «uno de los rasgos que distinguen a la interpretación judicial de otros géneros de interpretación es la existencia de disposiciones legales que establecen las condiciones de nombramiento de intérpretes y el derecho a hacer uso del mismo» (2011, p. 16). No es baladí, pues en torno a estos requisitos se articularán todas las características fundamentales de la interpretación judicial, in primis la calidad. En caso de que esta faltara o fuera deficiente, el derecho a la interpretación judicial se estaría minando y se abriría el camino a los recursos y a los errores.

El derecho a la asistencia lingüística ha llegado a considerarse como un metaderecho, esto es, como una posición jurídica subjetiva que es prioritaria respecto a cualquier otro derecho (Gialuz, 2018, p. XV) que coloca a la persona alófona en situación de igualdad en el acceso a la justicia — desde el punto de vista formal y sustancial- y que, además, es prejudicial en relación con el derecho de defensa y fundamental para la existencia de un juicio equitativo (Gialuz, 2018, p. 28).

La tutela de los derechos fundamentales de las personas ha evolucionado desde el ámbito del derecho nacional, en el que cada Estado se ocupaba de aprobar sus propias normas y establecer sus controles (Fernández Carrón, 2017, p. 19), hasta el ámbito del derecho internacional. En el contexto internacional, el derecho a un intérprete se ha configurado como una garantía procesal de un derecho fundamental, el derecho a un juicio justo (Jimeno Bulnes, 2007, p. 156), y de ahí ha vuelto a integrarse en los niveles nacionales y supranacionales.

En este capítulo se expondrá la evolución del derecho a la traducción e interpretación partiendo de un contexto mundial, en el que se mencionarán los casos más interesantes, para centrarnos después en la Unión Europea y, en particular, en los ordenamientos de Italia y España. Comenzaremos haciendo referencia a determinados antecedentes normativos del derecho a la interpretación judicial (surgidos, sobre todo, a 
partir de la segunda mitad del siglo XX), sin ahondar en la historia precedente, que ha sido estudiada ya por Sarmiento Pérez (2011), Giambruno (2008), Colin y Morris (1996), entre otros. Es en este momento histórico cuando se internacionaliza el reconocimiento de un derecho a la traducción y a la interpretación como garantía del derecho fundamental a un proceso equitativo. El ámbito en el que centraremos el análisis normativo del derecho a la interpretación judicial será el penal, dejando aparte el estudio de la interpretación judicial en el ámbito civil, jurada (Mayoral, 2000; 2003; Vigier Moreno, 2007), notarial (Del Pozo Triviño, 2008; 2009), de arbitraje (Rossi, 2017) y mediadora (Hertog, 2017).

\subsection{Algunos precedentes normativos sobre el reconocimiento del derecho a la interpretación en tratados internacionales}

En la sociedad que se fue desarrollando durante el siglo $\mathrm{xx}$, la diversidad lingüística obtuvo una mayor consideración. La creación de organismos supranacionales que se basan en un multilingüismo y el aumento de la movilidad de las personas ha llevado a que cada vez adquiera mayor importancia el plurilingüismo en la sociedad moderna.

En este contexto se desarrolla el concepto del lenguaje como un derecho fundamental para garantizar la presencia efectiva del acusado (Hertog, 2002, p. 145). La Declaración Universal de los Derechos Humanos (DUDH) de 1948 reconoce en sus artículos 8 y 10 el derecho a un juicio justo y a presentarse ante la justicia en condiciones de plena igualdad, «a ser oído públicamente y con justicia por un tribunal independiente e imparcial».

La Declaración es un documento político y jurídico donde se enumeran los derechos y las libertades que se consideran esenciales (Barrena, 2012, p. 7). Como ya señala Ortega-Herráez, la Declaración «no deja de ser una recomendación, que solo adquiere fuerza vinculante a través de diversos instrumentos en ella inspirados» (2011, p. 18).

Será en el Pacto Internacional de Derechos Civiles y Políticos (PIDCP) del 16 de diciembre de 1966, que entró en vigor el 23 de marzo de 1976, donde se aluda directamente a la figura del intérprete en los procedimientos judiciales. En dicho Pacto, que es un texto jurídico legal de carácter vinculante (Jimeno Bulnes, 2017, p. 157), se considera el idioma como un posible factor discriminador. Así, el artículo 14 dedicado al proceso justo enuncia: 
1. Todas las personas son iguales ante los tribunales y cortes de justicia. Toda persona tendrá derecho a ser oída públicamente y con las debidas garantías por un tribunal competente, independiente e imparcial, establecido por la ley, en la substanciación de cualquier acusación de carácter penal formulada contra ella o para la determinación de sus derechos u obligaciones de carácter civil.

3. Durante el proceso, toda persona acusada de un delito tendrá derecho, en plena igualdad, a las siguientes garantías mínimas:

a) A ser informada sin demora, en un idioma que comprenda y en forma detallada, de la naturaleza y causas de la acusación formulada contra ella;

$[\ldots]$

f) A ser asistida gratuitamente por un intérprete, si no comprende o no habla el idioma empleado en el tribunal...

Como apunta Barrena, el tratado adquiere valor en el momento que se aplica y su interpretación es la que ha enriquecido las distintas cláusulas:

El tratado vive a través de su aplicación. Además de la labor del Comité de Derechos Humanos, tribunales nacionales, regionales e internacionales han desarrollado el contenido del Pacto. Aunque el texto del tratado controla el sentido que debe darse a sus cláusulas, la interpretación judicial ha llenado de detalles y enriquecido el sentido sobre cómo deben leerse los términos allí consignados. En términos generales, la Convención de Viena sobre Derecho de los Tratados contiene las reglas de interpretación aplicables (2012, p. 64).

La Convención Americana de Derechos Humanos, firmada en San José (Costa Rica) en 1969 y adoptada en 1978 en el seno de la Organización de los Estados Americanos, reconoce en el artículo 8 (dedicado a las garantías procesales) el derecho de toda persona a ser oída, y su apartado $2 .^{\circ}$ trata sobre «el derecho del inculpado de ser asistido gratuitamente por el traductor o intérprete, si no comprende o no habla el idioma del juzgado o tribunal».

La Convención sobre los Derechos del Niño de 1989 alude en el artículo 40.2.b a «todo niño de quien se alegue que ha infringido las leyes penales o a quien se acuse o declare culpable de haber infringido esas leyes», y en el punto 4.2.b.vi especifica que «el niño contará con la asistencia gratuita de un intérprete si no comprende o no habla el idioma utilizado» ${ }^{35}$.

La Convención Internacional sobre la Protección de los Derechos de los Trabajadores Migratorios y los Miembros de sus Familias de 1990 establece en el artículo 16.8 que los trabajadores migratorios y sus familiares «recibirán la asistencia, gratuita si fuera necesario, de un intérprete cuando no pudieren entender o hablar el idioma utilizado» si fueran privados de su libertad por detención o prisión y tendrán el

${ }^{35}$ Disponible en: https://www.unicef.org/ecuador/convencion_2.pdf. 
derecho a incoar procedimientos ante un tribunal. En el artículo 18.1 se establece su derecho a ser oídos públicamente y con las debidas garantías por un tribunal competente; y en el apartado 18.2.f, «a ser asistido gratuitamente por un intérprete si no comprende o habla el idioma empleado en el tribunal» durante el proceso, si ha sido acusado de un delito.

En el plano internacional, puede citarse también el Estatuto del Tribunal Penal Internacional firmado en Roma el 17 de julio de 1998, que regula en los artículos 55 y 67 el derecho a intérprete y traducción en las fases de instrucción y juicio oral. En el artículo 55.1.c, se exige que «quien haya de ser interrogado en un idioma que no sea el que comprende y habla perfectamente contará, sin cargo alguno, con los servicios de un intérprete competente y las traducciones que sean necesarias a los efectos de cumplir el requisito de equidad». Como señala Jimeno Bulnes, no «parece admisible la participación de cualquier persona como intérprete ni que esa interpretación tenga lugar a cualquier idioma que meramente sea conocido, aun cuando este tampoco se trate de la lengua materna» (2007, p. 162). En el artículo 67 de dicho Estatuto, se regulan, además, los derechos del acusado, entre los que se encuentran el punto a («... el derecho a ser informado sin demora y en forma detallada, en un idioma que comprenda y hable perfectamente, de la naturaleza, la causa y el contenido de la acusación que se le imputan») y el punto $\mathrm{f}$ ( «... a ser asistido gratuitamente por un intérprete competente y a obtener las traducciones necesarias para satisfacer los requisitos de equidad, si en las actuaciones antes la Corte o en los documentos presentados en la Corte se emplea un idioma que no comprende o no hable»).

También la Convención sobre los Derechos de las Personas con Discapacidad, de 13 de diciembre de 2006, establece en el artículo 13 (dedicado al acceso a la justicia) que las personas con discapacidad han de tener un acceso a la justicia en igualdad de condiciones que los demás.

\subsection{El derecho a la interpretación como garantía procesal en el derecho comparado}

Este apartado comienza con una advertencia. Aunque en determinados países se haya llegado a un cierto reconocimiento de los intérpretes judiciales y exista una organización y un reconocimiento de la interpretación judicial como una profesión González et al., 2012, pp. 307-325; Mikkelson, 2017), no se hará una panorámica de todos los países, sino que la intención es centrarse en aquellos casos en los que existe una legislación específica que reconozca el derecho a interpretación como garantía procesal. El caso más emblemático es el de Australia (Hale, 2007, 2017): aunque 
existen reglas y recomendaciones de los juzgados que se ocupan de las necesidades existentes en caso de acusados, víctimas o testigos que no hablen inglés (González et al., 2012, p. 320; Mikkelson, 2017, p. 17), aún no han sido traspuestas en leyes.

Por tanto, se citarán solo los ejemplos más representativos, aun considerando que se están llevando a cabo iniciativas en todo el mundo en aras de reconocer el derecho a la interpretación y traducción como un derecho fundamental para mantener un juicio equitativo (Mikkelson, 2017, p. 15-18).

\subsubsection{La situación normativa en Estados Unidos}

La Constitución estadounidense de 1787 garantiza el derecho a un proceso justo a través de la cuarta, quinta, sexta, octava y decimocuarta enmiendas (González et al., 2012, pp. 6-7). Dichas enmiendas avalan el derecho a un acceso lingüístico a la justicia. A pesar de ello, el hecho de que el inglés haya sido y siga siendo el idioma dominante en la vida pública y política hace que exista una discriminación lingüística en un país multirracial y multiétnico hacia las personas que no hablan o no dominan dicho idioma (limited and non English speaking, cuyo acrónimo es LEP, en inglés), y por esta razón deban ser protegidas a favor del derecho a entender y ser entendido (linguistic presence, en inglés) del acusado durante el procedimiento penal.

La jurisprudencia americana recoge innumerables casos de violación del proceso justo debido a la falta de comprensión por parte del imputado, pues la presencia del intérprete garantiza la protección de dichos derechos y asegura la «presencia efectiva» ${ }^{36}$ del acusado, ya que le proporciona una interpretación completa de todo lo que se dice en el juicio (González et al., 2012, p. 160-163; Mikkelson, 2017, p. 15). El derecho del acusado a estar presente en todos los estadios del procedimiento fue reconocido por primera vez en el caso Lewis contra United States en 1892 (Mikkelson, 2015, p. 15) y la noción de linguistic presence. Es decir, el hecho de que para garantizar la presencia efectiva del acusado este tiene que entender el idioma del juicio fue establecido por primera en Us. ex. rel. Negrón contra New York en 1970, que representan un hito en la jurisprudencia en lo que atañe a la discreción del tribunal para determinar la necesidad de un intérprete. Asimismo, sentó las bases para la promulgación de la Court Interpreters Act de 1978 (González et al., 2012, p. 161). En dicho caso, la jurisprudencia estableció por primera vez la presencia efectiva del acusado. Otros casos muy importantes fueron Estados Unidos contra Carrion (1973) y Arizona contra

\footnotetext{
${ }^{36}$ No se ha encontrado la traducción del término inglés linguistic presence, por lo que se ha decidido traducir el concepto de dar voz al acusado para que pueda entender y sea entendido como «presencia efectiva».
} 
Natividad (1974), en los que se estableció la necesidad efectiva de un intérprete para poder asegurar la presencia lingüística del acusado, sin el cual no pueden considerarse legalmente presentes en el juicio las personas con un conocimiento deficiente o nulo de inglés (González et al., 2012, p. 162), por lo que no se respetan los principios de un proceso equitativo.

La necesidad imperante y los casos judiciales llevaron a las minorías lingüísticas, abogados y juristas a reclamar el reconocimiento del derecho a un intérprete como parte del derecho fundamental a un juicio justo, que culminó con la promulgación de la Court Interpreters Act en 1978, de carácter federal. Esta ley obliga a usar intérpretes judiciales durante el procedimiento en los tribunales federales. Dicho intérprete ha de estar cualificado a través de un examen de certificación. De esta forma, las personas que no hablen inglés podrán ejercer su derecho a un juicio justo. La aprobación de la ley desembocó en el establecimiento de un examen de certificación en 1979 hacia la lengua española en primer lugar, desarrollado según el ejemplo de exámenes realizados en el Estado de California.

Otro hito importante para el reconocimiento de las garantías procesales en Estados Unidos lo constituye la Executive Order 13166 (2000) que modifica el título VI de la Ley de Derechos Civiles de 1964, en la que se reitera la obligación de proporcionar un acceso efectivo a la justicia a las personas que hablan otro idioma diferente del inglés. No solo subraya la necesidad urgente $\mathrm{y}$ acuciante de intérpretes formados $\mathrm{y}$ competentes, sino que delinea los requisitos para proporcionar un servicio eficiente y de calidad continuo en traducción e interpretación en los tribunales.

González et al. exponen precisamente que, para que las personas que no hablen inglés puedan tener acceso a la justicia, es preciso que se les facilite la ayuda de intérpretes cualificados. De esta manera, se les colocará en las mismas condiciones que tendrían si hablaran el idioma. Para ello, es fundamental la ayuda de intérpretes capacitados:

... to achieve social justice, LEP [limited and non English speaking] individuals must have access to a full range of languages services, including proficient, bilingual personnel; validly tested, certified interpreters, and materials translated into languages the understand. Language access does no offer LEP individuals any advantage over English speakers, but grants them a fair and impartial process that affords LEP persons equal footing and justice under the law. Unquestionably, without access to certified or highly qualified interpreters, LEP persons are systematically excluded from the legal process $(2012$, p. 4).

Para concluir, es preciso hacer referencia al tema de la calidad en la legislación estadounidense, pues esta alude al hecho de que el intérprete garantiza que el acusado 
entienda todo y que todo lo que se dice se traslada. Para que esto se produzca y se asegure la calidad de la interpretación, se recomienda a los jueces que utilicen intérpretes cualificados y certificados que conocen los protocolos de la interpretación judicial, les faciliten la labor por medio de descanso y el acceso al material, hagan un seguimiento del desempeño del intérprete, planteen objeciones en el caso de que tengan dudas acerca de la interpretación y cuenten con ellos como especialistas lingüísticos que pueden aclarar ciertos conflictos idiomáticos (González et al., 2012, p. 570).

\subsubsection{La situación normativa en Canadá}

En Canadá, los intérpretes han sido utilizados en el sistema judicial desde la fundación del país en 1867 (González et al., 2012, p. 317), pero el derecho efectivo llegó con la promulgación de The Canadian Charter of Rights and Freedoms en 1982, especificando en la sección 14 que «a party or witness in any proceeding who does not understand or speak the language in which the proceedings are conducted or who is deaf has the right of the assistance of an interpreter» (Northwest Territories Justice; 1993, p. 1-2).

\subsection{El derecho a la interpretación en Europa: un largo recorrido no exento de dificultades}

\subsubsection{En el ámbito del Consejo Europeo}

En el ámbito del Consejo Europeo, el acceso a un juicio justo se garantiza a través de una serie de instrumentos, en especial el Convenio Europeo de Derechos Humanos de 1950. Algunos autores apuntan, sin embargo, a algunos aspectos críticos en el reconocimiento de los derechos fundamentales, pues no existe un mecanismo específico de protección de dichos derechos ni un texto jurídico vinculante que los enumere (Iglesias Buhígues, 2009, p. 25 y 30; Fernández Carrón, 2017, p. 20).

El Convenio Europeo de Derechos Humanos (CEDH) de 4 de noviembre de 1950, firmado en Roma, tenía como propósito tomar medidas que garantizaran algunos derechos de los enunciados en la Declaración Universal de los Derechos del Hombre de 1948. El convenio consagraba una serie de derechos y libertades civiles y políticas (Fernández Carrón, 2017, p. 23) y establecía un sistema para garantizar el cumplimiento de dichos derechos y libertades con la creación de varias instituciones de control, entre las que cabe destacar el Tribunal Europeo de Derechos Humanos.

El Convenio se convierte en el instrumento cardinal para la salvaguardia de los derechos de los sospechosos o acusados en los procesos penales, pues, en el artículo 5 
(Derecho a la libertad y a la seguridad), apartado 2, establece que toda «persona detenida debe ser informada, en el plazo más breve posible y en una lengua que comprenda, de los motivos de su detención y de cualquier acusación formulada contra ella». En el artículo 6 (Derecho a un proceso equitativo), apartado 3a, que toda persona «tiene derecho a ser informada, en el más breve plazo, y en una lengua que comprenda y de manera detallada, la naturaleza y la causa de la acusación formulada contra él», y en el apartado 3c, «a ser asistido por un intérprete si no comprende o no habla la lengua empleada en la audiencia». Como expone Hertog, el traductor teje un vínculo decisivo a la hora de garantizar los derechos procesales de los ciudadanos:

... the procedural rights of all European citizens should be protected across languages, cultures or impediments. Interpreters and translator therefore constituted a critical link in the communications whenever and where an Eu citizen became involved in the legal system of another Member State (2015, p 76).

La jurisprudencia europea dictada por el TEDH resulta fundamental a la hora de interpretar las normas consagradas en el Convenio, pues en algunos casos juzgados por dicho tribunal se ratifica el derecho a la interpretación tanto en las actuaciones procesales como preprocesales, y condena a algún Estado miembro por haber vulnerado el derecho que poseen los ciudadanos de asistencia gratuita de intérprete en caso de no conocer la lengua del proceso. Se tratarán únicamente los asuntos más emblemáticos ${ }^{37}$.

Entre ellos, cabe destacar el asunto Luedicke, Belkacem y Koç contra Alemania (STEDH n. ${ }^{\circ}$ 6210/73; 6877/75; 7132/75, de 28 de noviembre de 1978, p. 19; Jimeno Bulnes, 2007, p. 159; Vanden Bosch, 2003, p. 15; Fernández Carrón, 2017, p. 63), en el que se estableció que el acusado tiene derecho a interpretación gratuita, aun en el supuesto de que fuera condenado; los asuntos del Tribunal Europeo de Derechos

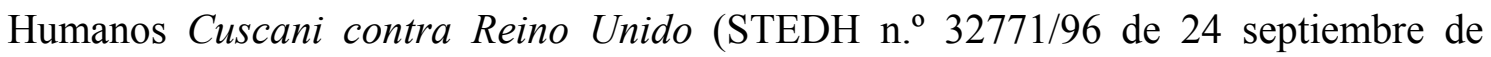
2002; Jimeno Bulnes, 2007, p. 159; Fernández Carrón, 2017, p. 118; Gialuz, 2018, p. 57), en los que se falla que el intérprete ha de ser competente y el juez debe garantizar la imparcialidad del proceso; K contra Francia (STEDH n. ${ }^{\circ}$ 10210/82, de 7 de diciembre de 1983), en relación con las minorías lingüísticas, o Hermi contra Italia (STEDH n. ${ }^{\circ}$ 18114/02, de 18 de octubre de 2006). En relación con el derecho a la interpretación, evaluar la capacidad de desenvolverse en el idioma del juicio y participar de manera

\footnotetext{
${ }^{37}$ Para un estudio pormenorizado de los distintos asuntos relativos a la asistencia lingüística, se remite a la literatura principal que se ha ocupado de ello (Hertog y Vanden Bosch, 2011; Vanden Bosch, 2003; Jimeno Bulnes, 2007; Vidal Fernández, 2007; Brannan, 2010; Arangüena Fanego, 2011; Ortega-Herráez, 2011; Gialuz, 2013, 2014, 2018; FRA, 2016; Fernández Carrón, 2017).
} 
efectiva en el procedimiento, se especifica que son los órganos jurisdiccionales los que tienen que probar que el acusado habla de manera apropiada la lengua del tribunal.

En el asunto Baybasin contra Países Bajos (STEDH n. ${ }^{\circ}$ 13600/02, de 6 de julio de 2006), se establece que los Estados están obligados a nombrar un intérprete, pero su obligación no se limita al nombramiento, sino que ha de extenderse también al control de la calidad de la interpretación, «de manera que el Estado no cumple su obligación con la mera designación de intérprete, sino que debe vigilar el desempeño correcto de dicha función» (Alvarez de Neyra Kappler, 2018, p. 85).

El asunto de Kamasinski contra Austria (STEDH n. ${ }^{\circ}$ 9783, de 19 de diciembre de 1989) marca un precedente sin igual dentro de la Corte europea, pues en él se considera «que la asistencia gratuita del intérprete va mucho más allá de la fase de juicio oral y considera que todo Estado signatario del CEDH debe también garantizar servicios de traducción e interpretación en las fases previas del juicio» (Ortega-Herráez, 2011, p. 20) que garantizan el derecho a un juicio justo del imputado (Gialuz, 2018, pp. 40-41). Otra de las conclusiones fundamentales de este asunto es que las autoridades tienen la obligación de ejercer un control de la calidad de la interpretación, pues su responsabilidad no termina con el nombramiento del intérprete, sino que están obligadas «a ejercer su vigilancia sobre el desempeño de las funciones de interpretación (o traducción) sin que su responsabilidad finalice con la mera designación del intérprete o traductor» (Jimeno Bulnes, 2007, p. 160).

\subsubsection{La Unión Europea y la creación de un espacio común de libertad, seguridad y justicia como factor determinante en el reconocimiento del derecho a la interpretación}

La Unión Europea introdujo los asuntos de justicia y de interior como materias de común interés con el Tratado de Maastricht, firmado en 1992, que entró en vigor en 1993. Con el Tratado de Ámsterdam de 1999 y el de Niza de 2000 se creó un espacio europeo de libertad, seguridad y justicia, y en el que los derechos procesales se convierten en el tercer pilar de la Unión Europea. La articulación de la Unión Europea en tres pilares comunitarios, v. gr. las comunidades europeas, la política exterior y de seguridad común (PESC) y la cooperación en los ámbitos de la justicia y los asuntos de interior (JAI), constituye una de las innovaciones más singulares del Tratado de la Unión Europea (Valbuena González, 2008, p. 175).

El 5 de noviembre de 1992 fue aprobada y firmada la Carta Europea de las Lenguas Regionales o Minoritarias, que defiende la protección y promoción de las lenguas utilizadas por minorías lingüísticas (ratificada en España con la publicación en 
el BOE el 15 de septiembre de 2001). En el artículo 4.a se aplica la traducción o la interpretación eventualmente solicitadas (con referencia a los artículos 1, 2 y 3).

En este entorno se integra la Carta de Derechos Fundamentales de la Unión Europea (CDFUE), firmada el 7 de diciembre de 2000 en Niza y proclamada el 12 de diciembre de 2007 de manera solemne en Estrasburgo. La Carta reúne el compendio de derechos civiles, políticos, económicos y sociales de los ciudadanos europeos. En su capítulo VI, dedicado a la justicia, se establece el derecho a la tutela judicial efectiva y el derecho a un juez imparcial (artículo 47), la garantía del respeto de los derechos de defensa a cualquier persona acusada de un delito, y la presunción de inocencia (artículo 48).

El Consejo Europeo celebró una reunión especial en Tampere, en octubre de 1999, en la que se creó un Espacio Europeo de Libertad, Seguridad y Justicia, aprovechando las posibilidades que otorgaba el Tratado de Ámsterdam. El propósito era proporcionar a los ciudadanos un mejor acceso a la justicia y la aproximación de las legislaciones que llevarían a un reconocimiento mutuo de los distintos Estados a nivel judicial. En las conclusiones del Consejo se especifica que el objetivo primario de la Unión es que «la libertad, en la que se incluye el derecho a circular libremente por toda la Unión, pueda disfrutarse en condiciones de seguridad y justicia accesibles a todos» (Comisión Europea, 1999) ${ }^{38}$.

En dicho Consejo Europeo se erigió el principio de reconocimiento mutuo como «piedra angular de la cooperación judicial, tanto en los asuntos civiles como penales» (Comisión de las Comunidades Europeas, 2003, p. 9), pues existían hasta entonces problemas de reconocimiento, confianza mutua y carencias de armonización verdadera (Arangüena Fanego, 2008, p. 121-123). A partir de entonces, se han llevado a cabo una serie de programas cuyo propósito era promover la cooperación en materia de justicia e interior, y entre ellos se desarrollaron algunos que se centraban específicamente en la traducción e interpretación jurídica, de los que se hablará en el capítulo 4 (Grotius I y Grotius II).

Pueden distinguirse varias fases para conseguir la armonización de las garantías procesales en los Estados miembros de la Unión Europea. Como advierte Valbuena González (2011, p 208), la primera fase de estudio, que se inició en 2002, tenía como propósito analizar el estado de la cuestión de las garantías procesales en los Estados miembros y culminó con la publicación en 2003 del Libro Verde de la Comisión sobre garantias procesales para sospechosos e inculpados en procesos penales en la Unión

\footnotetext{
${ }^{38}$ Conclusiones de la Presidencia. Consejo Europeo de Tampere, 15 y 16 de octubre de 1999. Disponible en: http://www.europarl.europa.eu/summits/tam_es.htm.
} 
Europea. En la segunda etapa se pretendió formalizar las acciones, y su resultado fue la Propuesta de Decisión Marco del Consejo (PDMC) en octubre de 2004, que se vio frustrada y no se llevó a cabo. Por último, tras la entrada en vigor del Tratado del Lisboa, se publicó en 2009 la resolución del Consejo sobre un plan de trabajo para reforzar los derechos procesales de sospechosos o acusados en los procesos penales.

El estudio que culminó con la publicación del Libro Verde constituye el antecedente de la Propuesta de Decisión Marco y se proponía analizar el nivel de garantías procesales en los distintos Estados miembros, a fin de fomentar la confianza y fortalecer un espacio de justicia común (Ortega-Herráez, 2011, p. 23). En la consulta, que se llevó a cabo en los meses de enero y febrero de 2002, participaron abogados, expertos y representantes gubernamentales. Se identificaron así los distintos ámbitos que primaba someter a consideración especial, y estos fueron:

- acceso a la representación por abogado defensor, antes y durante el juicio;

- acceso a la interpretación y a la traducción;

- comunicación a sospechosos e inculpados de sus derechos mediante una «carta de derechos»;

- garantía de una protección adecuada a sospechosos e inculpados vulnerables;

- asistencia consular a detenidos extranjeros.

Se consideró que dichos derechos habían de ser tutelados por medio de una acción conjunta, puesto que, aun gozando de cierto reconocimiento en los distintos Estados miembros, su aplicación divergía en los distintos territorios. Para que los Estados miembros tuvieran confianza en los sistemas judiciales de los otros, deberían adoptarse unas normas mínimas comunes que respetaran las garantías procesales y la imparcialidad de los procesos (Comisión Europea, 2003, p. 3). Se necesitaba, pues, «una cabal propuesta de normas mínimas comunes sobre garantías procesales adoptada de manera concertada» (García Roca, 2007, p. 56), que generara una confianza mutua.

El Libro Verde retoma los derechos previamente citados del CEDH, el PIDCP y el Estatuto de Roma. Hace referencia a los proyectos Grotius I y II, que promovieron el establecimiento de normas equivalentes de interpretación y traducción en los Estados miembros, con recomendaciones para la formación, la evaluación y la acreditación de intérpretes y traductores. La Comisión considera que, «para cumplir con los requisitos del Tribunal Europeo de Derechos Humanos y otros numerosos instrumentos internacionales, todos los Estados miembros deben garantizar que se presta formación, 
acreditación y registro a los traductores e intérpretes jurados» ${ }^{39}$ (Comisión Europea, 2003, p. 32). Para ello, se siguen las propuestas Aequitas, que establecen ciertos requisitos mínimos:

- sistema de acreditación/homologación de traductores e intérpretes;

- sistema de registro no ilimitado en el tiempo (con una validez, por ejemplo, de cinco años);

- institución de un sistema de formación profesional continuo;

- adopción de un código deontológico idéntico para toda la UE;

- compromiso de formación a abogados y jueces para que comprendan el papel de traductores e intérpretes y aprendan a trabajar con ellos;

- adopción de un enfoque interdisciplinar.

El Libro Verde aboga por una diferenciación de acreditación y registro respecto a traductores e intérpretes, tiene en consideración los problemas que pueden plantear algunas lenguas y reclama una retribución digna, pues «una mejor retribución ha de atraer a más gente a la profesión» (Comisión de las Comunidades Europeas, 2003, p. 33). Como señala Jimeno Bulnes (2007, p. 172), la Comisión sigue muy de cerca el planteamiento de la jurisprudencia del TEDH y de la sentencia Kamasinski contra Austria antes citada. En cuanto al análisis, se establece que han de interpretarse todos los procedimientos orales, el acceso lingüístico ha de ser completo y el acusado «debe estar en condiciones de comprender todo lo que se dice». En cuanto al derecho a la traducción, no se especifican claramente los documentos procesales que han de ser traducidos de manera obligatoria. Como se puede observar, los objetivos del Libro Verde eran muy ambiciosos y sus contenidos eran más amplios que la directiva actual, tal y como segnala Hertog (2015b, p. 79).

De esta fase de estudio se pasó a la fase de «formalización de las acciones» (Valbuena González, 2011, p. 209), con la Propuesta de Decisión Marco del Consejo (Comisión de las Comunidades Europeas, 2004) relativa a determinados derechos procesales celebrados en la Unión Europea, que fue presentada a la comisión en abril de 2004 y debía entrar en vigor en enero de $2006^{40}$.

Esta decisión era «un instrumento característico del tercer pilar en el que se incluyen los asuntos penales en el marco general del Derecho Comunitario y se utiliza

\footnotetext{
${ }^{39}$ Comparto la opinión de Ortega-Herráez (2011, p.24) respecto al uso impropio del término traductor e intérprete jurado en la traducción al castellano del Libro Verde.

40 Para los trámites que siguió del Libro Verde a la Propuesta de Decisión Marco, véanse: Ortega-Herráez, 2011, p. 25-26; Gialuz, 2018, 83-84.
} 
para aproximar disposiciones legislativas y reglamentarias de los Estados miembros» (Ortega-Herráez, 2011, p. 26). Interviene en una serie de derechos que estima básicos para el desarrollo de un juicio justo y que, en realidad, ya estaban presentes en los sistemas judiciales penales de los Estados miembros. Estos son: el derecho a la asistencia de un abogado y a comprender «la naturaleza y la causa de la acusación» (Comisión Europea, 2004, p. 4); de esto deriva el derecho al intérprete y la traducción gratuitos, el derecho a la atención específica en aquellos casos de grupos vulnerables; a comunicarse inter alia con las autoridades consulares, y a notificar sus derechos a las personas sospechosas. Como apunta García Roca, es fundamental la asistencia de un intérprete cualificado para que el acusado pueda comprender las causas de la acusación:

El derecho a una interpretación gratuita permite comprender la naturaleza y causa de la acusación, de él se deriva el acceso a la traducción de documentos y el derecho a un intérprete cuando el acusado no comprenda la lengua del procedimiento. Se incorporan previsiones específicas para personas con problemas de habla o audición, también la traducción gratuita de documentos relevantes en el proceso y las obligaciones positivas de los estados de asegurarse de la cualificación profesional de traductores e intérpretes y de grabar el proceso para verificar la exactitud de la interpretación (2011, p. 52).

El documento de trabajo que se presentó en la misma fecha de la Propuesta de Decisión Marco exponía una serie de problemas, más concretamente:

... inadecuada provisión de profesionales competentes en materia de lenguas en el ámbito procesal penal, diferencias salariales de carácter sustancial entre los Estados miembros en lo que respecta a la retribución de estos profesionales, gran diversidad entre los mismos Estados miembros por lo que respecta al sistema de formación de intérpretes y traductores, insuficiencia de número de intérpretes y traductores jurados (especialmente para las lenguas menos habituales) y de ahí el recurso a profesionales freelance [...] también la falta de entrenamiento por parte de los operadores judiciales — jueces, abogados, funcionarios de la Administración de la Justicia- para «interactuar» con intérpretes y traductores por lo que también será necesario prever unas pautas de conducta dirigidas a ellos (Jimeno Bulnes, 2007, p. 174).

Por lo que se refiere a la traducción e interpretación, se recoge en los artículos 6, $7,8,9,14$, que se reproducen íntegros a continuación.

Artículo 6

Derecho a interpretación gratuita

1. Los Estados miembros asegurarán que se ofrece interpretación gratuita a la persona sospechosa que no comprenda la lengua del proceso para salvaguardar la equidad del proceso. 
2. Los Estados miembros asegurarán que, en caso necesario, la persona sospechosa disponga de interpretación gratuita de la asistencia de abogado recibida a lo largo de todo el proceso penal.

3. El derecho a interpretación gratuita se aplica a las personas con problemas de audición o habla.

\section{Artículo 7}

Derecho a traducción gratuita de los documentos pertinentes

1. Los Estados miembros asegurarán que se proporciona a la persona sospechosa que no comprenda la lengua del proceso la traducción gratuita de todos los documentos pertinentes para salvaguardar la equidad del proceso.

2. La decisión sobre qué documentos necesitan traducirse corresponderá a las autoridades competentes. El abogado de la persona sospechosa podrá pedir la traducción de otros documentos.

\section{Artículo 8}

Exactitud de la traducción e interpretación

1. Los Estados miembros asegurarán que los traductores e intérpretes empleados estén suficientemente cualificados para proporcionar una traducción e interpretación fidedignas.

2. Los Estados miembros asegurarán que si se pone de manifiesto que la traducción o interpretación no son fidedignas, exista un mecanismo para reemplazar al intérprete o traductor.

\section{Grabación del proceso}

\section{Artículo 9}

1. Los Estados miembros asegurarán que, cuando el proceso se lleve a cabo a través de un intérprete, se efectúe una grabación de audio o vídeo para garantizar el control de calidad. Se proporcionará una trascripción de la grabación a las partes en caso de conflicto. La trascripción solo podrá utilizarse con el fin de verificar la exactitud de la interpretación.

\section{Derecho a atención específica}

\section{Artículo 10}

1. Los Estados miembros asegurarán que la persona sospechosa que no pueda entender el contenido o significado del proceso debido a su edad o estado mental, físico o emocional reciba atención específica para salvaguardar la equidad del proceso.

2. Los Estados miembros obligarán a las autoridades competentes a considerar y consignar por escrito la necesidad de atención específica en el proceso, desde el momento en que haya indicios de que el apartado 1 del artículo 10 es aplicable.

3. Los Estados miembros asegurarán la consignación por escrito de cualquier medida adoptada como consecuencia de este derecho.

\section{Artículo 11}

Derechos de las personas sospechosas que precisan atención específica

1. Los Estados miembros asegurarán la grabación de audio o vídeo de cualquier interrogatorio que se haga a las personas sospechosas con derecho a atención específica. Se proporcionará una trascripción de la grabación a las partes en caso de conflicto.

2. Los Estados miembros asegurarán la asistencia médica siempre que sea necesario. 
3. En su caso, la atención específica podrá incluir el derecho a la presencia de una tercera persona durante todo interrogatorio policial o judicial.

$$
[\ldots]
$$

Artículo 14

Deber de informar a la persona sospechosa de sus derechos por escrito. Carta de derechos

1. Los Estados miembros asegurarán que a todas las personas sospechosas se les informe por escrito de sus derechos procesales inmediatos. Esta información incluirá, entre otros, los derechos establecidos en esta Decisión marco.

2. Los Estados miembros asegurarán la existencia de una traducción tipo de la notificación escrita en todas las lenguas oficiales de la Comunidad. Las traducciones se elaborarán de manera centralizada y se remitirán a las autoridades competentes a fin de garantizar que todos los Estados miembros utilicen el mismo texto.

3. Los Estados miembros asegurarán que las comisarías de policía disponen del texto de la notificación escrita en todas las lenguas oficiales de la Comunidad a fin de poder ofrecer a la persona arrestada una copia en una lengua que comprenda. 4. Los Estados miembros requerirán que tanto el agente del orden como la persona sospechosa, si lo desea, firmen la Carta de derechos, como prueba de su ofrecimiento, entrega y aceptación. La Carta de derechos deberá presentarse por duplicado: una copia (firmada) para el funcionario de aplicación de la ley y la otra copia (firmada) para la persona sospechosa. Se consignará por escrito en el expediente que la Carta de derechos se ofreció a la persona sospechosa y si esta efectivamente acordó firmarla (Comisión de las Comunidades Europeas, 2004).

La propuesta fue objeto de una larga y complicada negociación que duró tres años, presentándose numerosas enmiendas al articulado y discusiones (Jimeno Bulnes, 2007, pp. 176-179) que alteraron el contenido inicial, se suprimieron los artículos 8 y 9 y se reformuló el artículo 6, que quedó despojado de toda referencia a la exigencia de calidad (Ortega-Herráez, 2011, p. 28; Vidal Fernández, 2007, p. 231; Jimeno Bulnes, 2007, p. 181; Gialuz, 2018, pp. 83-86).

La Propuesta de Decisión Marco del Consejo relativa a determinados derechos procesales fracasó y nunca se llevó a cabo, por lo que se desestimó en junio de 2007. La causa fue la oposición férrea de algunas delegaciones que consideraban ya suficientes los derechos establecidos por los artículos 5 y 6 de la CEDH (Valbuena González, 2011, p. 219) y eran contrarios a la labor de armonización de las instituciones europeas. Además, y como criticaron algunas instituciones implicadas, como Amnistía Internacional, European Criminal Bar Association o la comunidad de intérpretes y traductores (Hertog, 2015, p 81), la propuesta se había ido despojando en las distintas mociones y discusiones de los aspectos recogidos en el Libro Verde que garantizaban la calidad en la actuación de los traductores e intérpretes, quedando en una «propuesta de mínimos» (Ortega-Herráez, Plaza Vázquez, Fiol Wolfrum, y Hernández Cebrián, 2007, p. 253), pues reducía el número de derechos y su alcance. Por otra parte, la propuesta contravenía el principio de subsidiariedad, podría provocar una gran confusión con 
respecto a la legislación nacional y un aumento considerable de los costes (Hertog, 2015, p. 77). Aun así, fue el primer intento armonizador para combatir la desconfianza en el cumplimiento efectivo de las garantías procesales (Valbuena González, 2011, p. 225).

En julio de 2009, la Comisión presentó una propuesta de decisión marco relativa al derecho a la traducción e interpretación en los procesos penales en su empeño de intentar materializar el contenido de la primera PDMC, haciéndolo desde un enfoque progresivo, para ir avanzando. Dicha propuesta formaba parte de un conjunto cuyo propósito era establecer una serie de derechos procesales en los procedimientos penales dentro de la Unión Europea (Ortega-Herráez, 2011, p. 29-30; Gialuz, 2018, p. pp. 9095).

A partir de la aprobación del Tratado de Lisboa (firmado en Lisboa en 2007, pero que no entró en vigor hasta diciembre de 2009), los asuntos que atañen al tercer pilar no pueden llevarse a cabo por medio de decisiones marco, sino que deben realizarse a través de instrumentos normativos como directivas comunitarias, tal y como se establece en el capítulo 4 sobre la cooperación judicial en materia penal, punto 2: «El Parlamento Europeo y el Consejo podrán establecer normas mínimas mediante directivas adoptadas con arreglo al procedimiento legislativo ordinario» (Comisión de las Comunidades Europeas, 2007, pp. 306-364).

Ortega Lorente explica de manera precisa las diferencias entre los reglamentos y las directivas, que tendrán un alcance político, pues deja mayor libertad a los Estados miembros a la hora de su aplicación y transposición:

Conforme a lo previsto en el art. 288 del TFUE, la Directiva obliga al Estado miembro destinatario en cuanto al resultado que deba conseguirse, dejando, sin embargo, a las autoridades nacionales la elección de la forma y de los medios. Optar por la Directiva y no por el Reglamento, como herramienta para la unificación en materia penal, tiene una evidente lectura política como la antes recogida; téngase en cuenta que el Reglamento tiene alcance general, es obligatorio en todos sus elementos y directamente aplicable en cada Estado miembro, mientras que la Directiva marca objetivos, deja un espacio para la iniciativa y la discrecionalidad estatal y solo es directamente aplicable una vez transcurrido el plazo de transposición y solo en aquellas disposiciones que sean incondicionales y suficientemente claras y precisas (sentencia del TJUE del 4 de diciembre de 1974, Van Duyn) (2017).

Entre estas normas se encuentran las relativas a los derechos de las personas durante el procedimiento penal y los derechos de las víctimas de delitos, siempre en función del $\mathrm{CEDH}$. Los aspectos más importantes atañen al derecho a la traducción (artículo 2), a la traducción de los documentos esenciales, esto es, el atestado o 
acusación y todo material documental pertinente, además de «toda medida de seguridad $\mathrm{u}$ orden por la que se prive a la persona de libertad y toda resolución judicial que sea necesaria para que la persona ejercite su derecho de apelación» (artículo 3), y se establece también que deberá traducirse la orden de detención europea. Los Estados miembros deberán hacerse cargo de los costes de traducción en interpretación (artículo 4) y se asientan unos requisitos básicos que garanticen la calidad de la traducción e interpretación (artículo 5).

El auténtico punto de ruptura llegó con la resolución adoptada por el Consejo el 30 de noviembre de 2009 (Hertog, 2015, p. 81), en Estocolmo, en la que se establecía un plan de trabajo para reforzar los derechos procesales de sospechosos o acusados en los procedimientos penales a escala de la Unión Europea. Se establecían así unas garantías mínimas procesales de los sospechosos o acusados (Fernández Carrón, 2017, p. 26), con una serie de medidas:

- traducción e interpretación, que parte de la premisa de que todo sospechoso o acusado tiene el derecho de entender lo que está ocurriendo y de hacerse entender, por lo que precisará de un intérprete si no habla la lengua del proceso y la traducción de los documentos procesales;

- información sobre derechos e información sobre la acusación que se le imputa, que ha de ser verbal y cuando proceda por escrito sobre sus derechos fundamentales;

- asesoramiento jurídico y justicia gratuita;

- comunicación con los familiares, el empleador y las autoridades consulares;

- salvaguardias especiales para acusados o sospechosos que sean vulnerables;

- instauración de un Libro Verde sobre la detención provisional.

El Plan de Trabajo sigue el planteamiento de la frustrada Propuesta de Decisión Marco, pero la Unión Europea puede gozar de un margen de acción mayor a fin de velar por la aplicación y elevar el nivel de garantías (Valbuena González, 2011, p. 219). En este caso, se opta por abordar separadamente las distintas garantías, pues defiende que así se dará el valor que merecen cada una de ellas, debido a su importancia y complejidad, con un acercamiento gradual. El propósito era facilitar el principio de reconocimiento mutuo de resoluciones judiciales por medio de estándares mínimos análogos de protección de derechos fundamentales de las personas sospechosas y acusadas en los procedimientos penales. Esto favorecería la confianza recíproca de los Estados miembros, a la par que acrecentaría la confianza de los ciudadanos de la Unión Europea, y poseía una «proyección facilitadora de la eficacia en la respuesta de un delito partiendo, para ello, de la generalización de patrones de garantía en los derechos 
de sospechosos y acusados» (Ortega Lorente, 2017). Valbuena González señala cómo se aprecia una rebaja del nivel de garantías con respecto a la Propuesta de Decisión Marco, pues limitaba el número de derechos y su alcance «centrándose en normas generales y evitando especificar detalladamente la forma en que se ejercitarían los derechos de cada Estado miembro» (Valbuena González, 2011, p. 218). Por esta razón, se prefirió el establecimiento únicamente de unas normas mínimas.

Hoy en día, este Plan de Trabajo ha dado como resultado seis directivas:

- Directiva 2010/64/UE del Parlamento Europeo y del Consejo, de 20 de octubre de 2010, relativa al derecho a interpretación y a traducción en los procesos penales;

- Directiva 2012/13/UE del Parlamento Europea y del Consejo, de 22 de mayo de 2012, relativa al derecho a la información en los procesos penales;

- Directiva 2013/48/UE del Parlamento Europeo y del Consejo, de 22 de octubre de 2013, sobre el derecho a asistencia de letrado en los procesos penales y en los procedimientos relativos a la orden de detención europea, y sobre el derecho a que se informe a un tercero en el momento de la privación de libertad y a comunicarse con terceros y con autoridades consulares durante la privación de libertad;

- Directiva 2016/343 del Parlamento Europeo y del Consejo, de 9 de marzo de 2016, por la que se refuerzan en el proceso penal determinados aspectos de la presunción de inocencia y el derecho a estar presente en el juicio;

- Directiva 2016/800/UE del Parlamento Europeo y del Consejo, de 11 de mayo de 2016, relativa a las garantías procesales de los menores sospechosos o acusados en los procesos penales y a las personas buscadas en virtud de un procedimiento de orden europea de detención;

- Directiva 2016/1919/UE del Parlamento Europeo y del Consejo, de 26 de octubre de 2016, relativa a la asistencia jurídica gratuita a los sospechosos en los procesos penales y a las personas buscadas en virtud de un procedimiento de orden europea de detención.

A estas hay que añadir las que aparecen en el Libro Verde, aunque no se mencionan en el Plan de Trabajo de 2009:

- Directiva 2011/36/UE del Parlamento Europeo y del Consejo, de 5 de abril de 2011, relativa a la prevención y lucha contra la trata de seres humanos y a la protección de víctimas, y por la que se sustituye la Decisión marco 2002/629/JAI del Consejo;

- Directiva 2012/29/UE del Parlamento Europeo y del Consejo, de 25 de octubre de 2012, por la que se establecen normas mínimas sobre los derechos el apoyo y la 
protección de las víctimas de delitos, y por la que se sustituye la Decisión Marco 2001/220/JAI del Consejo.

En este trabajo se hablará más específicamente de la primera Directiva, que es la que se refiere al derecho a la traducción e interpretación, y se dará únicamente un apunte somero de las demás, vinculadas a la primera, pues, si se incumple dicha Directiva, se incumplen directamente las otras, ya que se niegan los derechos que promueven, pues si no comprende el idioma del procedimiento, los individuos se encuentran en realidad en un estado de indefensión y ausencia, sin tener la capacidad de defenderse.

\subsubsection{La Directiva 2010/64/UE como un hito en el reconocimiento del derecho a la traducción e interpretación en los procesos penales}

La Directiva 2010/64/UE fue la primera promovida del Plan de Trabajo y se refiere a la medida A del plan de trabajo de 2009, en el ámbito del derecho a interpretación y traducción en los procesos penales (DOUE de 26 de octubre de 2010, n. ${ }^{\circ}$ L 280, pp. 17). El valor simbólico es considerable, pues el primer derecho reconocido explícitamente al acusado o sospechoso en la Europa multilingüe que promueve desde sus inicios la libre circulación de bienes, servicios y capitales fue precisamente la asistencia lingüística (Gialuz, 2014, p. 84), que se fundamenta en el principio de no discriminación basada en la lengua reconocido en el artículo 21 de la Carta de Derechos Fundamentales de la Unión. La rapidez con la que fue aprobada arranca en realidad del fracaso de la Propuesta de Decisión Marco de 2004 (Arangüena Fanego, 2011). Se habían realizado trabajos y estudios al respecto (proyectos Grotius y AGIS) cuyo propósito era promover normas de equivalencia en la traducción e interpretación judicial para los distintos Estados.

De acuerdo con lo manifestado por Hertog, se trata de un hito en relación con el derecho a traducción e interpretación en la Unión Europea, pues:

Resulta difícil sobreestimar la importancia de la Directiva 2010/64/UE del Parlamento Europeo y del Consejo, de 20 de octubre de 2010, relativa al derecho a interpretación y a traducción en los procesos penales. Se trata de la primera directiva emanada del Tratado de Lisboa, de la primera directiva en el ámbito de la justicia (hasta entonces se recurría solamente a las decisiones marco), de la primera directiva sobre lenguas desde los tratados fundacionales de la UE; y, por supuesto, de la primera directiva sobre traducción e interpretación (2015b, p. 73). 
Los considerandos (5, 7 y 14) hacen mención explícita al artículo 6 del CEDH y a los artículos 47 y 48 de la Carta de los Derechos Fundamentales de la Unión Europea, donde se consagra el derecho a un juicio equitativo y el respeto del derecho de defensa, pues, si el acusado no comprende la documentación, al letrado o al tribunal, dicho derecho quedaría relegado a un «simulacro de defensa» (Palomo del Arco, 2007, p. 191). Se añade que las disposiciones de la nueva Directiva han de aplicarse e interpretarse de manera coherente con los derechos arriba citados y con arreglo a la jurisprudencia emanada del EUDH y del TJUE (32 y 33). Advierte también que se inspira en la propuesta de la Comisión de una Decisión Marco relativa al derecho a interpretación y traducción en los procesos penales de 8 de julio de 2009 (14). Los derechos establecidos deberán aplicarse asimismo «a la ejecución de una orden de detención europea», y los Estados miembros deberán sufragar los costes (15), sea cual sea el sentido de la resolución final (artículo 4). Se hace referencia explícita a la gratuidad (19) y a la comunicación entre sospechoso y abogado para la preparación de la defensa (20). Debe establecerse un mecanismo que determine si el sospechoso o acusado habla o entiende la lengua del proceso penal (21), por lo que se establece el ámbito subjetivo de aplicación (17), ya que se ofrece a todo sospechoso o acusado, sea o no sea ciudadano de la Unión Europea o de terceros países, pues las garantías procesales emanan de las personas (Arangüena Fanego, 2011). En comparación con la antigua propuesta, presenta menor atención a la cuestión de la calidad, aunque se haga mención de ella (26), pues no detalla de manera tan específica sus mecanismos de control y de creación de registros. Se tiene en cuenta a las personas con impedimentos físicos y vulnerables (27), así como a los nuevos sistemas de comunicación remota (28). En cuanto a la traducción, se especifica que ha de facilitarse al sospechoso o acusado la traducción de los documentos esenciales (30); todo ello, en aras de salvaguardar la equidad del proceso (22 y 30). Los destinatarios de la Directiva son todos los Estados miembros, incluidos Reino Unido e Irlanda (35); Dinamarca decidió permanecer fuera (36), por lo que se fija ahí el ámbito de aplicación territorial.

El artículo 1 se ocupa del objeto y el ámbito de aplicación para establecer las normas relativas al derecho a interpretación y traducción en los procesos penales y también a los procedimientos correspondientes a la ejecución de una orden de detención europea. Este derecho se inicia en el momento que las autoridades competentes de un Estado miembro ponen en conocimiento de una persona el ser sospechosa o acusada de haber cometido una acción hasta el final del proceso, incluida la sentencia y la resolución de cualquier recurso. No se aplicará en las situaciones posteriores al proceso, como son la fase de libertad provisional o prisión (Hertog, 2015, p. 83). Este derecho no 
se aplicará en caso de infracciones menores fuera del tribunal, sino solo en caso de recurso.

El artículo 2 disciplina el derecho a la interpretación, que ha de ser proporcionada sin demora (punto 1). Se incluye específicamente la fase de interrogatorio policial y todas las vistas judiciales, incluidas las intermedias. La interpretación ha de garantizarse para que el acusado o sospechoso se comunique con su abogado (2). Incluye de forma explícita la asistencia a personas con limitaciones auditivas o de expresión oral (3). El hecho de ser extranjero no provoca el derecho a traductor e intérprete; por ello, ha de establecerse un mecanismo para determinar si el acusado habla y entiende la lengua del proceso y si requiere de la asistencia del intérprete (4), atribuyendo así a los Estados la carga de la prueba de la necesidad del intérprete (Arangüena Fanego, 2011). Aunque la directiva no lo señala de manera evidente, la interpretación podrá realizarse en un idioma diferente al nativo del sospechoso o acusado, con tal de que este lo entienda y hable. Por ello, será preciso prestar mucha atención a las lenguas de menor difusión, como indica Hertog (2015b, p. 84): «Great care needs to be taken here (particularly by defense lawyers) that the problems ensuing from languages of lesser diffusion are not offhandedly dealt with». Se hace referencia a la calidad de la interpretación, que ha ser suficiente para salvaguardar la equidad del proceso (8), aunque se hace de forma muy vaga, y se especifica que el sospechoso o acusado podrá presentar una reclamación en caso de calidad insuficiente (5). Podrán utilizarse tecnologías de comunicación como la videoconferencia, el teléfono o Internet, salvo que sea necesaria la presencia física del intérprete (6). Este derecho incluye los procedimientos correspondientes a la ejecución de una orden de detención europea (7).

El derecho a la interpretación posee características especiales, pues es bidireccional, ya que se configura como el derecho del acusado de comprender y hacerse comprender. Por ende, es irrenunciable y no fungible (Gialuz, 2018, p. 137).

El artículo 3 recoge el derecho a la traducción de los documentos esenciales en un plazo razonable (1) para poder ejercer el derecho de defensa y salvaguardar la equidad del proceso. Se identifican algunos de los documentos esenciales, v. gr.: «... cualquier resolución que prive a una persona de libertad, escrito de acusación o sentencia» (2). Las autoridades competentes podrán decidir si resultan esenciales otros documentos y el sospechoso o el abogado podrán presentar una solicitud motivada (3), pudiendo recurrir en caso de que se le deniegue la traducción o que la calidad fuera insuficiente (5). Con todo, no será necesario traducir los documentos completos, sino solo los pertinentes para que el acusado o sospechoso entienda la acusación que se le imputa (4). Esta limitación del derecho concuerda con la doctrina sentada por la jurisprudencia, aunque no especifica quién deberá realizar dicha valoración (Arangüena Fanego, 2011). Como 
caso excepcional (Cass y De Matteis, 2010), podría facilitarse una traducción o resumen oral de los documentos esenciales (7), con tal de que ello no afecte a la equidad del proceso y quede constancia de esta eventualidad mediante un registro, tal y como se especifica luego en el artículo 7. Dicha renuncia debe ser realizada con conocimiento de las consecuencias y ha de ser voluntaria (8). En cuanto a la orden de detención europea, el Estado miembro que la ejecuta deberá velar para que se facilite una traducción escrita de dicho documento a la persona sujeta a dichos procedimientos y que no entienda la lengua $(6)^{41}$. Por último, la calidad habrá de ser suficiente para permitir ejercer el derecho de defensa (8).

El artículo 4 se ocupa de los costes de traducción e interpretación que deberán ser sufragados por los Estados miembros sea cual sea el resultado del proceso. Retoma, por tanto, la sentencia de 1978 del Tribunal Europeo de Derechos Humanos en el asunto Luedicke, Belkacem y Koç contra Alemania, ya citado. A diferencia de otros gastos que anticipa el Estado y que tras su condena el condenado tiene que resarcir, en este caso no es así. Como interpreta Gialuz, la prestación lingüística ha considerarse en un plano diferente del gasto, pues implica la esencia misma de la comunicación:

La prestazione collegata alla tutela linguistica si colloca su un piano diverso da tutte le altre [spese], perché attiene all'essenza stessa della comunicazione, alla capacità dell'individuo sottoposto a processo a comprendere e di esprimersi. È per questo che i costi dell'attuazione del diritto alla presenza linguistica nel processo non possono essergli accollati nemmeno in caso di condanna: non si può infatti imputare al condannato la non conoscenza della lingua del luogo nel quale ha commesso il reato, esattamente come non si può imputare al condannato sordo o muto la propria menomazione (2018, pp. 179-180).

El artículo 5 se ocupa específicamente de la calidad, a fin de que se salvaguarde la equidad del proceso. Esta ya se había apuntado en el apartado 2 y 8 del artículo 2 y en los apartados 5 y 9 del artículo 3. Para garantizar dicha calidad, la Directiva adopta varios mecanismos que permitan lograr este objetivo, uno de los cuales es exigir que los Estados miembros establezcan «registros de traductores e intérpretes independientes debidamente cualificados» (2), y se hace referencia a la confidencialidad del servicio prestado (3). Esto implicaría un código de conducta o ético vinculante, que debería ir acompañado de procedimientos disciplinarios en caso de incumplimiento (Hertog, 2015b, p. 87). A diferencia de lo que establecía el Libro Verde, en este caso no se especifica el modo en que los traductores e intérpretes pueden acceder a dicho registro,

\footnotetext{
${ }^{41}$ Existe un formulario online para evitar largas y costosas traducciones, que entró en funcionamiento en 2017, disponible en: https://www.ejn-crimjust.europa.eu/ejn/EJN_Home.aspx.
} 
lo que ha dado pie a irregularidades en algunos países (Giambruno, 2014, pp. 149-190; FRA, 2016).

El artículo 6 se preocupa de la formación de los distintos operadores judiciales, más allá de las diferencias existentes en los sistemas judiciales de la Unión y de su independencia. De hecho, establece lo siguiente: «Los Estados miembros solicitarán a los responsables de la formación de jueces, fiscales y personal judicial que participen en procesos penales el que presten una atención particular a las particularidades de la comunicación con la ayuda de un intérprete, de manera que se garantice una comunicación efectiva y eficaz».

El artículo 7 exige que se lleven registros de las tareas de interpretación «recurriendo al procedimiento de registro previsto por el derecho nacional del Estado miembro en cuestión», no especificándose, por tanto, el tipo de registro ni la llevanza de dicho registro.

El artículo 8 establece la cláusula de no regresión, pues las nuevas disposiciones no podrán interpretarse como una limitación o excepción a los derechos que ya garantizan la CEDH, la Carta Europea de Derechos Fundamentales u otras disposiciones.

El artículo 9 establece que esta directiva ha de incorporarse al derecho interno de los Estados miembros y, como caso excepcional, establece un plazo de tres años (Gialuz, 2013, p. 2). En el artículo 10, establece que la Comisión presentará al Parlamento Europeo y al Consejo un informe de evaluación de la adopción por parte de los Estados miembros de las medidas necesarias para hacer cumplir la directiva.

Pueden destacarse algunas características específicas de esta Directiva. Su carácter innovador deriva de proclamar dos derechos diferentes: el derecho a la interpretación (artículo 3) y el de traducción (artículo 4). Juntos, se integran en un «macroderecho» unitario, que es el de la asistencia lingüística (Gialuz, 2014, p. 84; 2018, pp. 133-141), cuyo propósito último es garantizar los derechos del sospechoso o acusado y la equidad del proceso. La razón de estos dos «microderechos» es asegurar que el acusado alófono pueda comprender y ser comprendido y, de esta manera, participar activamente en el proceso penal. La importancia de los dos derechos deriva también del sistema procesal mismo, que integra partes escritas y orales. Como ya se ha señalado anteriormente, el derecho a la interpretación es irrenunciable y no fungible en el caso de que no se conozca la lengua del proceso, mientras que el relativo a la traducción sí que lo es, aunque está supeditado a la renuncia de dicho derecho (Arangüena Fanego, 2011²; Gialuz, 2018, p. 137).

\footnotetext{
${ }^{42}$ La versión consultada es la electrónica, por lo que no se puede especificar la página.
} 
La calidad puede considerarse como el punto clave de la Directiva, que se estima una exigencia indispensable. Se insta por ello a que se establezcan registros de intérpretes debidamente cualificados y se exige que se habilite un cauce para que los imputados y acusados puedan reclamar contra la falta de calidad. Se prefiere dejar abierto el modo con que los Estados tomen las medidas para la búsqueda de dicha calidad, siendo mucho más vaga con respecto a la PDM de 2004. Se exige a los Estados que quede constancia de los procedimientos mediante registro, aunque no se especifica cuál. Es importante también la obligación de formar a los operadores jurídicos para el trabajo con intérpretes debido a las peculiaridades que entraña el trabajo con ellos y favorecer la comunicación de manera efectiva y eficaz. De la calidad en la Directiva se hará un calado en el capítulo 5.

La Directiva debería haber estado acompañada de un documento no vinculante que implementara la asistencia lingüística, que podría tomar la forma de «recomendaciones del Consejo»y adoptarse de manera contextual con la directiva (Gialuz, 2018, p. 100). De hecho, la asociación EULITA criticó inmediatamente, en noviembre de 2010, la inercia demostrada por las instituciones europeas y esperaba que se adoptara un instrumento no vinculante que guiara la implementación de la Directiva y retomara el contenido del informe del foro de reflexión sobre el multilingüismo y la formación de intérpretes ${ }^{43}$.

\subsubsection{La transposición de la Directiva 2010/64/UE por los Estados miembros: retrasos y amplio margen de los Estados para su cumplimiento}

La Directiva 2010/64/UE ha supuesto un avance considerable a la hora de reforzar los derechos de sospechosos y acusados en los procedimientos penales, pero ha dejado a los Estados miembros un margen muy amplio de disponibilidad en lo que concierne a la transposición en sus ordenamientos jurídicos de las previsiones de la Directiva, por ser «muchas de ellas excesivamente abiertas» (Fernández Carrón, 2017, p. 40; Arangüena Fanego, 2011, p. 285).

Los Estados miembros debían adoptar las disposiciones legales, reglamentarias y administrativas necesarias antes del 27 octubre de 2013 para dar así cumplimiento a la Directiva. En esa fecha, dieciséis Estados miembros no habían comunicado aún las

\footnotetext{
${ }^{43}$ Véase EULITA'S position concerning the implementation of the EU Directive on the right to interpretation and translation in criminal proceedings, en Documento del Consejo n. ${ }^{\circ}$ 16164/10, de 12 de noviembre de 2010. Disponible en: http://eujusticia.net/images/uploads/pdf/interpretation-translation-2010-11-12-16164-eulitaposition-on-implement.pdf.
} 
medidas de transposición a la Comisión, por lo que esta inició un procedimiento de infracción contra aquellos países que no habían traspuesto la directiva en tiempo y forma, como es el caso de España. En el sitio web de la Unión Europea se encuentran todas las leyes de transposición de los distintos países ${ }^{44}$, y el estado de implementación y aplicación de la Directiva en todos los países se halla también en la Red Judicial Europea $^{45}$.

Por su parte, la Comisión debía emitir un informe al Parlamento Europeo y al Consejo sobre la transposición de la Directiva en todos los Estados miembros antes del 27 de octubre de 2014. En el momento de la redacción de este trabajo, dicho informe aún no ha sido entregado. En 2016, se presentó una denuncia por infracción a la Comisión Europea argumentando que Italia y Francia no habían traspuesto correctamente la Directiva, pues Italia no había establecido un registro de traductores intérpretes y Francia había fijado un número máximo de intérpretes registrados. En enero de 2017, la Comisión archivó la reclamación de infracción que había presentado el demandante contra Italia y Francia porque consideraba que las cuestiones planteadas no violaban la Directiva, y señalaba que dicha Directiva no obligaba a los Estados miembros a establecer registro de traductores e intérpretes cualificados ni establecía normas para el registro y la contratación. Afirmaba también que estaba preparando el informe relativo a la transposición. El demandante recurrió al defensor del pueblo europeo cuando en junio de 2017 la Comisión aún no había presentado el informe. Al responder a la investigación de este en septiembre de 2017, la Comisión afirmó que todos los Estados miembros habían comunicado las medidas nacionales de transposición de la Directiva y que la Comisión estaba en condiciones de preparar el informe en el que evaluaba la medida adoptada por los Estados miembros para cumplir con la Directiva. La Comisión declaró que estaba preparando el informe, que se publicaría tan pronto como finalizara la evaluación del cumplimiento de las medidas nacionales, a más tardar a principios de 2018. Tres meses después, el 23 de marzo de 2018, no había presentado aún el informe y el defensor del pueblo «confiaba» en que la Comisión lo entregara sin más demora, cerrando de todas formas la investigación ${ }^{46}$.

El informe final TRAINAC alude al gran valor del derecho a la interpretación y expone la falta de aplicación en algunos países:

44 Disponible en http://eur-lex.europa.eu/legal-content/EN/NIM/?uri=uriserv:OJ.L .2010.280.01.0001.01.ENG 45 Disponible en https://www.ejn-crimjust.europa.eu/ejn/EJN_Library_StatusOfImpByCat.aspx?CategoryId=96

${ }^{46}$ Para el informe completo del defensor del pueblo europeo, se remite a Decision in case 969/2017/LM on the European Commission's failure to prepare a report, within the statutory deadline, on Member States' compliance with Directive 2010/64/EU on the right to interpretation and translation in criminal proceedings, disponible en: https://www.ombudsman.europa.eu/fr/cases/decision.faces/en/91729/html. 
... apart from Greece (where the directive is not properly applied), the legal mechanism for the right to interpretation is valuable for suspect and defendants. Belgium and Luxembourg have not yet implemented the directive, but the respondents report the law and practice in those Member States already cover most of the directive's requirements (Goldsmith, 2016, p. 19).

No obstante, es posible observar una gama muy amplia de estrategias y políticas de transposición, que varían de forma significativa de un país a otro. Todas las trasposiciones deberían atenerse al espíritu de la Directiva y ser aprobadas por la Comisión (Hertog, 2015b, p. 89). El mismo autor señala que el final de 2014 marca un giro en el desarrollo de la política relativa a la justicia en la Unión Europea, pues concluye el plan de acción iniciado en Estocolmo.

En algunos países, la transposición de los estándares mínimos que establece la Directiva puede mejorarse; en otros casos, será la aplicación de las disposiciones legales la que podrá implementarse (FRA 2016, p. 9) ${ }^{47}$. Diecisiete países han adoptado un registro de traductores e intérpretes judiciales a nivel nacional: Austria, Bulgaria, Chipre, Croacia, Eslovaquia, Eslovenia, Estonia, Finlandia, Francia, Alemania, Grecia, Luxemburgo, Países Bajos, Polonia, República Checa y Suecia (FRA, 2016, p. 45). En la mayoría de los casos, el Ministerio de Justicia se ocupa directamente de dicho registro; en otros, como Estonia, Holanda o Suecia, lo administran otras agencias. Austria, por ejemplo, posee un sistema híbrido, pues existe un banco de datos de los intérpretes que administra directamente el Ministerio de Justicia y un listado específico para los procedimientos penales que administra el Ministerio de Interior.

Con relación a los requisitos para inscribirse en los registros nacionales, en la mayoría de los Estados miembros se prevén exámenes específicos, aunque en otros casos es suficiente con presentar documentación que demuestre la experiencia profesional o la especialización. Solo ocho de los diecisiete países que poseen un registro obligan de manera explícita a que las autoridades los utilicen.

47 Para un análisis pormenorizado de la transposición en cada uno de los países, se remite a dicho informe y al informe INFOCRIM REPORT: Rights of suspected and accused persons across the EU: translation, interpetation and information. FRA: European Union Agency for Fundamentals Rights, 2016. 


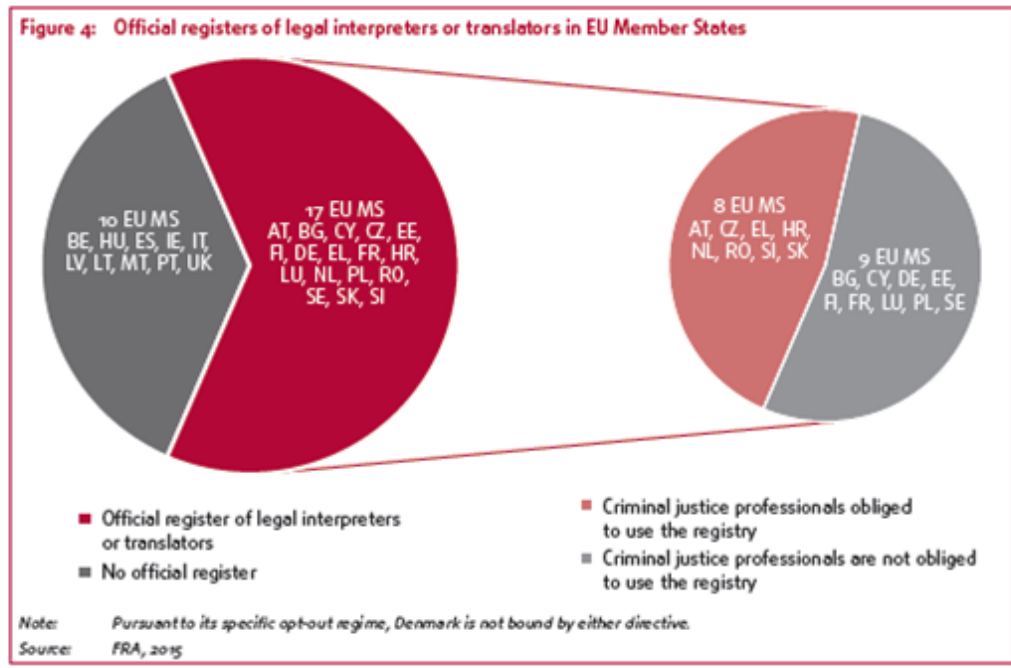

Figura 1: Registro oficial de intérpretes y traductores legales en los Estados miembros de la Unión Europea (FRA, 2016, p. 46).

Los aspectos que pueden destacarse con relación a la transposición, a los que hace referencia el informe FRA 2016, son los siguientes:

- evaluación de la necesidad de interpretación y traducción y plazos de provisión del servicio;

- traducción efectiva de los documentos esenciales;

- traducción oral/renuncia a la traducción escrita: en algunos países existe la posibilidad, pero está condicionada a la presencia del letrado defensor;

- creación o existencia de registros de intérpretes;

- exámenes de acreditación para poder actuar como traductor o intérprete en ámbito judicial;

- sistemas de grabación de las interpretaciones;

- gratuidad de los servicios;

- garantías de calidad;

- instrumentos de evaluación de la calidad;

- remedios en caso de falta de calidad.

Según dicho informe, muchos Estados miembros carecen de mecanismos o procedimientos para poder determinar la necesidad de un intérprete, aunque algunos poseen criterios claros o directrices en aras de garantizar dicho derecho al acusado o sospechoso, que puede considerarse como una práctica prometedora.

La mayoría de los países establecen en sus códigos de enjuiciamiento criminal qué estamento es responsable de determinar la necesidad de interpretación durante la fase 
preprocesal (en general, suelen ser oficiales de policía, fiscales o jueces), salvo República Checa, Hungría, Malta, Rumanía y España, que no lo especifican. Tampoco existen reglas que establezcan la necesidad de traducción o interpretación. La práctica actual es preguntar para determinar la capacidad de entender la lengua del proceso o prever la presencia del intérprete allí donde el declarante tenga nombre y apellidos extranjeros, sin preguntar o averiguar si necesita intérprete. Tampoco está claro cuál es el nivel mínimo de entendimiento de un idioma por debajo del cual es preciso proveer al acusado o sospechoso del servicio de interpretación. Aunque un buen número de ordenamientos judiciales de los Estados miembros incluyen el derecho de reclamar en caso de mala calidad del servicio de traducción e interpretación, sería importante establecer medidas que aseguren la calidad y se eviten traducciones e interpretaciones de baja calidad.

El informe FRA 2016 apunta asimismo una serie de prácticas que se han puesto en marcha en algunos países y que sería deseable establecer de manera generalizada con el fin de mejorar el servicio de traducción e interpretación ante los tribunales, a saber:

- formación de traductores e intérpretes para trabajar ante la justicia (por ejemplo, Bélgica $)^{48}$. Existen muchos países con formación, aunque a veces no se emplee en los tribunales al personal formado, como sucede en España.

- directrices para los traductores e intérpretes judiciales que trabajan en los tribunales (Letonia);

- sistemas de seguimiento del trabajo de los intérpretes (Irlanda del Norte);

- estándares de calidad común para todos los profesionales que se ocupan de la traducción e interpretación judicial;

- normas de conducta para el uso del servicio de interpretación (Suecia);

- directrices para comunicarse de manera efectiva con los intérpretes y traductores judiciales;

- directrices sobre cómo proceder en el caso de que sea negada la traducción o interpretación;

- procedimientos que se ocupen de las quejas en caso de traducción o interpretación de baja calidad (Holanda);

- exigencia a los representantes legales de que alerten en caso de calidad insuficiente de la interpretación.

\footnotetext{
${ }^{48}$ Existen muchos países con formación de traductores e intérpretes para trabajar ante la justicia. Otra cosa es que se exija o no.
} 
Por su parte, el Consejo Europeo emite informes sobre la eficiencia de la justicia; en 2014 presentó el quinto informe en el que se hacía referencia explícita a la Directiva y en él se declara que el derecho de interpretación de «alta calidad» es una prioridad para los Estados miembros:

\begin{abstract}
Another positive trend, which has been noted is that the principle of public funding of an interpreter for someone who has been arrested or prosecuted, according to articles 5.2 y 6.3.e of the European Convention for the Protection of Human Rights and Fundamental Freedoms, has now been incorporated into all domestic legal systems. Directive 2010/64/EU on the right to interpretation and translation in criminal proceedings has strengthened these requirements for all EU countries. The right to an independent and high-quality interpreting is a priority within the main rights of the defense, and 24 member states of the Council of Europe claim to have established high standards with regard to the conditions governing the certification of interpreters and the services they provide in judicial matters (Jean, 2015, p. 3).
\end{abstract}

El informe hace referencia a los veinticuatro países del Consejo Europeo, la mayoría de ellos integrantes de la Unión Europea, pero también algunos no pertenecientes. La trascendencia de una interpretación de calidad es tal que, según el informe, veinticuatro Estados manifiestan haber establecido unos niveles altos de exigencia en relación con las condiciones del proceso de certificación de intérpretes y de los servicios que se proveen en el contexto judicial. En realidad, no queda tan claro que sea así, a pesar de lo que declaran los países. El apartado 10 del informe se ocupa específicamente de los intérpretes judiciales, con una serie de preguntas con respuesta «sí» o «no» (NA/NAP) ${ }^{49}$. El informe que se publicará en 2018 es el séptimo, que aún no ha sido presentado, con datos relativos a 2016. Las preguntas del apartado 10 son las siguientes:

197. Is the title of the court interpreters protected?

198. Is the function of court interpreters regulated by legal norms?

199. Number of accredited or registered court interpreters.

200. Are there binding provisions regarding the quality of court interpretation within judicial proceedings? If yes please specify (eg. having passed a specific exam).

201. Are the courts responsible for selecting court interpreters?

Yes for recruitment and/or appointment for a specific term of office

for recruitment and/or appointment on an ad hoc basis, according to the specific needs of given proceedings

No If not, please specify which authority selects court interpreters (CEPEJ, 2017).

\footnotetext{
${ }^{49}$ NA: no disponible; NAP: no aplicable.
} 
A partir de la fundación de la European Legal Interpreters and Translators Association (EULITA) en 2009, se han desarrollado grupos de trabajo cuyo propósito es hacer un seguimiento de la situación, difundir los resultados y establecer propuestas que fomenten las buenas prácticas y promuevan la calidad. En algunos talleres organizados por la asociación, se han debatido las posibles soluciones y aplicaciones sobre la calidad, la renuncia a la traducción de documentos y la creación de un registro ${ }^{50}$. En el mismo año, se organizó un foro de reflexión sobre el multilingüismo y la formación del intérprete en los servicios públicos, en el que se insistía también en la formación de los operadores para trabajar con los profesionales y se auguraba el fomento y la protección de dicha profesión. Teniendo en cuenta que estos aspectos atañen principalmente a la calidad, se remite al próximo capítulo.

El carácter gravoso del derecho a la traducción y a la interpretación ha sido y sigue siendo quizá un obstáculo a la implementación de la Directiva, ya desde los momentos de la preparación de la Propuesta de Decisión Marco de 2009 (Gialuz, 2018, p. 182). Por otro lado, tampoco se puede eludir el tema de que, para garantizar una asistencia lingüística de calidad, la acreditación, la formación y la existencia de un registro no son suficientes, sino que deben existir tarifas congruentes con la profesión que hagan de la interpretación y la traducción judicial una profesión atractiva para el talento potencial, tal y como se apuntaba en el informe TRAFUT (Hertog, 2012, p. 16).

Una crítica que se ha hecho a la Directiva es que no cubre las actividades posteriores al dictado de la sentencia, salvo los recursos. Como señala Ortega Lorente: «En fase de ejecución se dictan resoluciones relevantes que afectan tanto al modo de cumplimiento de la pena impuesta como a veces a la extensión o intensidad de la sanción penal. De igual modo, se dictan resoluciones relativas a la responsabilidad civil» (2017). Se trata, pues, de una crítica sustancial, porque afecta también al derecho a un juicio justo, aunque sea en la fase de ejecución de la sentencia.

\subsubsection{La tortuosa e incompleta transposición de la Directiva 2010/64/UE al ordenamiento español}

La figura del intérprete estaba ya prevista en la legislación española, de acuerdo con lo previsto en la Constitución española de 1978, que en los artículos 17 y 24 preconiza el derecho a un juicio justo (Ortega-Herráez, 2011, pp. 31-42).

\footnotetext{
${ }^{50}$ Véanse los talleres de TRAFUT en la página electrónica de EULITA, disponible en http://eulita.eu/wp/trainingfuture
} 
De hecho, ya existían sentencias del Tribunal Constitucional en las que se recordaba la necesidad del reconocimiento legal del derecho a intérprete (STC 71/1988, de 19 de abril).

El derecho a un intérprete surge como necesario y coherente corolario del derecho a la asistencia letrada a fin de evitar que los reclamados no hablen o no comprenda la lengua del Estado donde han sido detenidos se les pueda producir indefensión por razón de dicha desventaja. No obstante, para que se produzca una indefensión no es suficiente que se invoque en la causa una mera acción formal, sino que es preciso que se llegue a causar realmente una efectiva indefensión material que impida al interesado realizar alegaciones y defenderse o ejercitar su derecho de contradicción en el proceso (Álvarez de Neyra Kappler, 2018, p. 83).

A la espera de la transposición, se habían ido desarrollando iniciativas en aras de una mejora del servicio por parte de los distintos organismos, como fue la publicación del Libro Blanco de la Traducción y la Interpretación Institucional (RITAP, 2011), en el que se analizaba la situación en ese momento, además de la propuesta planteada en el informe elaborado por la Conferencia de Centros y Departamentos Universitarios de Traducción e Interpretación de España (CCDUTI) para el Ministerio de Justicia español sobre la transposición de la Directiva 2010/64/UE (Blasco-Mayor et al., 2013), cuyo propósito era la creación de un registro con exigencia de formación y examen en su acceso. La Comisión Europea envió un dictamen al Gobierno en mayo de 2014 por no haber tomado las medidas necesarias para la transposición, y el 5 de septiembre de 2014 se publicó el proyecto de ley ${ }^{51}$. Como señala Ortega-Herráez (2016), la tramitación del proyecto de ley fue anormal e inusual, pues el propio Gobierno impidió el debate de las enmiendas presentadas por las asociaciones, las universidades y los grupos políticos en la Comisión de Justicia del Parlamento español, e intentó por todos los medios que su aprobación pasase por el Congreso sin pena ni gloria (Ortega-Herráez, 2016; BlascoMayor, comentario personal).

España traspuso la Directiva con harto retraso y no poco malcontento por parte de los profesionales (Ortega-Herráez, 2013), los académicos (Blasco-Mayor et al., 2013) y los mismos magistrados (De Luna Jiménez de Parga, 2010). La Ley Orgánica 5/2015, de 27 de abril, por la que se modifican la Ley de Enjuiciamiento Criminal y la Ley Orgánica 6/1985, de 1 de julio, del Poder Judicial, se aprobó por fin el 5 de enero de 2015. Con dicha ley se trasponían la Directiva 2010/64/UE, de 20 de octubre de 2010, relativa al derecho a interpretación y a traducción en los procesos penales, y la Directiva

\footnotetext{
${ }^{51}$ En 2016, Ortega-Herráez expuso de manera detallada todo el procedimiento seguido para la transposición de la Directiva.
} 
2012/13/UE, de 22 de mayo de 2012, relativa a la información en los procesos penales (BOE 2015, pp. 36559-36568). El mismo día 27 de abril se traspuso también la Directiva 2012/29/UE por medio de la Ley 4/2015.

La Ley de Enjuiciamiento Criminal (LECrim) fue reformada y se añadió un nuevo capítulo al título $\mathrm{V}$ del libro $\mathrm{I}$, denominado «Del derecho a la traducción e interpretación». En él se incorpora de manera explícita el derecho a ser asistido por intérprete en cinco artículos, del 123 al 127 del Código de Enjuiciamiento Criminal. La transposición cambió de ubicación, integrándose en el derecho de defensa y asistencia gratuita, por lo que cambió también de perspectiva (Ortega-Herráez, 2016). La ley española ha entremezclado los dos derechos (el de traducción e interpretación), lo que supone un inconveniente, pues ambos son distintos e independientes pese a presentar aspectos comunes (Fernández Carrón, 2017, p. 76), ya que exigen competencias diferentes. La transposición ha resultado «engañosa, porque la incorporación de la Directiva a nuestro ordenamiento nacional ha resultado incompleta e incluso vacía de contenido en uno de sus aspectos cardinales» (Gascón Nasarre, 2017, p. 25).

El artículo 123 de la LECrim regula el derecho a la interpretación y reconoce en el apartado 1 el derecho a ser asistido por un intérprete de los sospechosos o acusados que no hablen o entiendan la lengua del proceso que se utiliza durante las actuaciones procesales en las que sea necesaria su presencia, incluyéndose expresamente en el precepto la referencia al interrogatorio policial por el ministerio fiscal y a todas las vistas judiciales (artículo 121.1a). No todas las diligencias se incluyen explícitamente, aunque sí lo están todas las actuaciones, incluso las de entrada y registro (Fernández Carrón, 2017, p. 80). Quedan excluidos los delitos leves, al igual que en la Directiva.

El derecho a intérprete durante todas las actuaciones del juicio oral, que se recoge en el apartado 1c del artículo 121, es el que ratifica el derecho del acusado a la presencia efectiva durante el juicio. En el apartado $1 \mathrm{~b}$ se reconoce «el derecho del imputado o acusado a servirse de intérprete en las conversaciones que mantenga con el abogado y que tenga relación directa con su posterior interrogatorio o toma de declaración o que resulten necesarias para la presentación de un recurso o para otras solicitudes procesales». Este derecho se reconoce cuando dichas conversaciones tengan que ver con el proceso, no para alargar el proceso (Fernández Carrón, p. 84).

El apartado 2 del artículo 123 hace referencia a la interpretación simultánea, aunque lo haga de una manera artificiosa, de manera negativa: «En el caso de que no pueda disponerse del servicio de interpretación simultánea, la interpretación de las actuaciones del juicio oral [...] se realizará mediante una interpretación consecutiva». Lo que podría haber sido un punto positivo en relación con la Directiva, en la que no se especifica el tipo de interpretación que ha de realizarse, se convierte en una manera de 
superar el escollo. La falta de dotación de los tribunales de cabinas de interpretación y la misma disposición primera adicional que señala que no habrá ulteriores dotaciones para el establecimiento de la ley hacen que la norma se convierta en la excepción y se siga usando como norma la interpretación consecutiva en las vistas orales y la susurrada para traducir al sospechoso o acusado, en el caso de que se haga (Ortega-Herráez, 2011; Fernández Carrón 2017, pp. 84-85; Orozco-Jurotán, 2017). Como señala Fernández Carrón: «No se pueden reconocer derechos alegremente en un artículo si después este no va acompañado de las medidas necesarias que permitan que tales derechos puedan ser efectivos y que no queden en agua de borraja» $(2017$, p. 26).

En el apartado 5 del artículo 123 de la LECrim, se apunta que la asistencia del intérprete «se podrá prestar por medio de videoconferencia o cualquier medio de telecomunicación, salvo que el tribunal o juez o el fiscal, de oficio a instancia del interesado o de su defensa, acuerde la presencia física del intérprete para salvaguardar los derechos del imputado o acusado». Las opiniones al respecto son muy diferentes, pues, mientras algunos autores se muestran totalmente en contra (Fernández Carrón, 2017, pp. 184-198), otros ven en este sistema una posibilidad en aquellos casos donde existe un riesgo para la incolumidad de los intérpretes, para la seguridad del acusado o imputado, o en casos de lenguas de menor difusión para las que no se encuentre intérprete disponible. La opinión mayoritaria es que en casos de no disponibilidad de intérprete acreditado se podría recurrir al uso de tecnologías de la comunicación, ya que siempre ofrecerá mayor garantía de calidad que recurrir a intérpretes no cualificados.

El punto 6 del artículo 123 es controvertido, pues resulta incoherente en relación con la llevanza de registro propugnada en el artículo 7 de la Directiva y da pie a que no se graben las entrevistas con jueces o interrogatorios y se acepten como válidas las actas escritas, por lo que se recoge en su totalidad:

Las interpretaciones orales o en lengua de signos, con excepción de las previstas en la letra b) del apartado 1, podrán ser documentadas mediante la grabación audiovisual de la manifestación original y de la interpretación. En los casos de traducción oral o en lengua de signos del contenido de un documento, se unirá el acta copia del documento traducido y la grabación audiovisual de la traducción. Si no se dispusiera de equipos de grabación, o no se estimare conveniente ni necesario, la traducción o interpretación y, en su caso, la declaración original, se documentará por escrito (CPP: artículo 123.6).

De la dicción de este precepto puede deducirse que, en este caso, no se ha respetado el espíritu del artículo 7 de la Directiva. En primer lugar, porque se ha excluido una obligatoriedad de la grabación; en segundo lugar, porque la decisión dependerá de cada tribunal, lo que puede dar lugar a actuaciones arbitrarias (Guerrero 
Palomares, 2016, pp. 15-16). El problema de la documentación escrita radica en que, si se ha cometido un error en la traducción, no será posible luego solventarlo ni hacer un control, pues lo que se documenta es la interpretación y no la declaración original. En el capítulo 2.3, en el que se traza una panorámica sobre la situación real de la interpretación judicial en España, se detalla cómo se está incumpliendo este aspecto y el artículo de la Directiva.

Asimismo, la ley recoge el derecho a recurrir la decisión por la que se deniega el derecho a la interpretación o traducción, que ha de ser realizada por escrito, y la posibilidad de acta de protesta durante el juicio oral ${ }^{52}$.

Por lo que respecta al derecho a la traducción, el artículo 123.1d de la LECrim establece el «derecho a la traducción escrita de los documentos que resulten esenciales para garantizar el ejercicio del derecho a la defensa». Enumera de manera específica algunos documentos que deben ser traducidos ( $\ldots$... las resoluciones que acuerden la prisión del imputado, el escrito de acusación y la sentencia») y en el artículo 123.1.e se añade que los imputados acusados podrán presentar una solicitud motivada para que se considere esencial un documento. En el apartado 3 de este precepto, se especifica que podrá prescindirse de la traducción de los pasajes de los documentos esenciales que, a criterio del juez, tribunal o funcionario competente no resulten necesarios para que el imputado o acusado conozca los hechos que se le imputan. El problema es que no queda claro quién es el funcionario que debe tomarse estas atribuciones (Ortega Lorente, 2017; Guerrero Palomares, 2016, p. 15; Fernández Carrón, 2017, pp. 98-103). Por otra parte, considerar documentos esenciales solo tres y dejar que sea el tribunal quien tome la decisión de si otros documentos son esenciales o no plantea el problema de «desigualdades de trato entre justiciables [...] que van a depender del criterio que adopte cada tribunal en el caso concreto» (Fernández Carrón, 2017, p. 101).

Se añade, asimismo, que la traducción escrita podrá sustituirse excepcionalmente por un resumen oral (artículo 123.3), aunque no se especifica en qué casos, lo que puede conllevar abusos y problemas de aplicación (Fernández Carrón, p. 104). Se establece también que la traducción habrá de llevarse a cabo en un tiempo razonable, aunque tampoco se concreta qué se entiende por «tiempo razonable».

Respecto a la gratuidad de los derechos, el artículo 123.1 establece que los gastos serán sufragados por la Administración, sea cual sea el resultado del proceso.

En relación con la renuncia de los derechos a la traducción e interpretación, el artículo 126 de la LECrim establece dos disposiciones diferentes: la irrenunciabilidad del derecho a interpretación, y la posibilidad de renunciar al derecho de traducción.

\footnotetext{
52 Para una profundización mayor al respecto, se remite a Fernández Carrón (2017, p. 92-97).
} 
En cuanto a la designación del intérprete o traductor judicial, en el artículo 124.1 se habla de «listados elaborados por la Administración competente». Se deja la posibilidad (como excepción en casos urgentes) de habilitar como intérprete o traductor a una persona conocedora del idioma empleado y que se considere estar capacitado. En la disposición final primera de la LO 5/2015, se aplaza la creación del registro, por medio de un proyecto de ley, en un año. Dicho registro recogería las listas de los intérpretes y traductores cualificados y habilitados, y la inclusión en él sería un requisito necesario para poder actuar como traductor o intérprete judicial. Hoy día todavía no se ha creado este registro, a pesar de haberse superado con creces el plazo establecido, ni se ha elaborado ningún proyecto de ley que regule su creación, el acceso y el código deontológico. La preocupación de los profesionales se ha centrado también en el asunto de la posible inclusión en el registro de personas jurídicas planteada en distintos escenarios por el Ministerio de Justicia (Chacón García, 2015, p. 103; Blasco-Mayor, 2016), cuestión que entra a valorar Ortega-Herráez (2014): «Si incluimos a personas jurídicas en el registro no será más que un nuevo coladero de personal no cualificado a través de las empresas inscritas» ${ }^{53}$.

Por ende, existe una incongruencia entre lo que se recoge en dicho artículo y lo expuesto en el artículo 142.5, que señala que el tribunal puede habilitar como intérprete a cualquier persona conocedora de la lengua empleada, previo juramento, y en el artículo 441 de la LECrim, que no se ha modificado, relativo al uso de intérprete para los testigos: «El intérprete será elegido entre los que tengan el título de tales, si los hubiera en el pueblo. En su defecto será nombrado un maestro del correspondiente idioma, y si tampoco lo hubiere, cualquier persona que lo sepa», al igual que recoge el art 762.8, donde se reitera que no es necesario que el intérprete designado tenga el título oficial. Este artículo ha sido ya sobradamente criticado en la literatura (Ortega-Herráez, 2011, pp. 33-34; Fernández Carrón, 2017, p. 147).

Tal como aduce Chacón García, se permite que personas no capacitadas realicen la labor de intérprete, lo que no sucedería jamás con otras profesiones implicadas en el procedimiento penal:

Del mismo modo que la ley no permite que una persona que no cuente con la licenciatura en Derecho y no esté colegiada pueda ejercer de abogado ante cualquier tribunal, no deberíamos permitir que personas sin técnicas de traducción e interpretación y sin conocimiento de la terminología jurídica se hicieran cargo de la comunicación en este contexto (2015, p. 103).

\footnotetext{
${ }^{53}$ Disponible en la nota de prensa.
} 
Estos artículos darán pie a que la mayoría de los intérpretes que actúan hoy en día ante los tribunales españoles no tengan ni la titulación ni la formación necesaria para ejercer como tales, según se ha expuesto en el capítulo 2.3, en el que se presenta el panorama de la situación actual en España (Blasco-Mayor y Del Pozo Triviño, 2015; Ortega-Herráez, 2016; Alonso Araguás, Hernández Cebrián y Izquierdo Valverde, 2018; Bestué y Orozco Jurotán, 2017; Bestué, 2018) . $^{54}$.

El intérprete debe respetar la confidencialidad, tal y como recoge el artículo 124.2 de la LECrim, al igual que los demás intervinientes en la Administración de Justicia. Como señala Guerrero Palomares, este artículo se ubica en un lugar inadecuado dentro de la designación del traductor, cuando habría sido preferible elaborar un estatuto del intérprete y traductor que recogiera todos sus derechos y obligaciones (Guerrero Palomares, 2016, p. 17).

Por otra parte, en el texto español ha desaparecido prácticamente la mención a la calidad, en comparación con lo que dice la Directiva (Ortega-Herráez, 2016). Así, se opta por hablar de «garantías suficientes de exactitud, se podrá ordenar la realización de comprobaciones y designar un nuevo traductor o intérprete» (artículo 124.3). Solamente se alude a la calidad (más bien a su falta) en el $§ 2$ del artículo 125:

La decisión del juez o tribunal por la que se deniegue el derecho a la interpretación o a la traducción de algún documento o pasaje del mismo que la defensa considere esencial, o por la que se rechacen las quejas de la defensa con relación a la falta de calidad de la interpretación o de la traducción, será documentada por escrito (CPP, artículo 125).

Tampoco se especifican procedimientos de control de la calidad o de recusación de actuaciones por falta de calidad. Todo ello deriva en una interpretación jurisprudencial que mina la figura del intérprete y su credibilidad, a la vez que los derechos procesales del imputado (Gascón Nasarre, p. 2017; Fernández Carrón, 2017, pp. 130-132). El artículo 124.3 de la LECrim establece simplemente que, cuando se aprecie de oficio o a instancia de parte que la interpretación o traducción no ofrecen garantías suficientes de exactitud, se podrá ordenar la realización de comprobaciones y designar un nuevo traductor o intérprete, pero no se señala cómo ha de realizarse el control ni establece los plazos para impugnar la calidad deficiente (Gascón Nasarre, 2017, p. 152). Como indica Fernández Carrón, «parece claro que el legislador impone la carga al tribunal de controlar el valor de la interpretación, es decir, que no se trate de una interpretación con falta de garantías suficientes de exactitud, y por tanto deficiente,

\footnotetext{
${ }^{54}$ Para mayor información, se remite al sitio institucional de APTIJ (http://www.aptij.es/) y al de la Red Vértice (http://www.redvertice.org/p/comunicados.html).
} 
extremo sobre el que el tribunal deberá velar de oficio (2017, p. 129). La autora se plantea cómo puede el tribunal apreciar la inexactitud y cómo puede poner en duda un acusado o imputado la calidad si ni siquiera sabe a qué tiene derecho.

Por fin, en la disposición adicional segunda se establece que el Ministerio de Justicia, el Consejo General del Poder Judicial, la Fiscalía General del Estado y las comunidades autónomas asegurarán una formación de los jueces y del personal al servicio de la Administración de la Justicia que participen en procesos penales que presten atención a las particularidades de la comunicación con ayuda de intérprete, cosa que hasta ahora se ha hecho de manera muy restringida, con la organización de escasos seminarios de formación continua organizados por el Consejo General del Poder Judicial (CGPJ).

Cabe señalar, además, que la disposición adicional primera de la LO 5/2015 establece que «las medias incluidas en esta norma no podrán suponer incremento de dotaciones de personal, ni de retribuciones, ni de otros gastos de personal». Esto va a suponer en realidad la imposibilidad de que se lleven a cabo las previsiones de dicha ley (Blasco-Mayor y Martin, 2016), pues «la efectividad de los derechos que en ella se recogen no pueden pasar por su aplicación a «coste cero<» (Fernández Carrón, 2017, p. 114).

En conclusión, tal y como han lamentado las asociaciones profesionales del sector de la Red Vértice y la Conferencia de Centro y Departamentos Universitarios de Traducción e Interpretación (CCDUTI), la transposición de la Directiva ha desperdiciado la oportunidad de cambiar la situación, «al no incluir en la ley orgánica el requisito de obtener una acreditación profesional mediante examen oficial, que contenga pruebas diseñadas con criterios de objetividad, validez y fiabilidad, para acceder a formar parte del Registro Oficial de Traductores e Intérpretes» (Blasco-Mayor, 2014, p. 277; Blasco-Mayor y Del Pozo Triviño, 2015, pp. 16-24). Las autoras son partidarias también de establecer mecanismos que garanticen un control de la calidad y un seguimiento de la labor de los intérpretes. Martin, por su parte, califica la transposición como «patchy, unrealistic and incomplete» (2018).

\subsubsection{La transposición de la Directiva 2010/64/UE al ordenamiento italiano: una transposición formal y poco efectiva}

La figura del intérprete en el procedimiento penal estaba ya presente en la época decimonónica (Ballardini, 2002; 2005; 2014). Esta presencia se entendía, dependiendo de los casos, como un instrumento auxiliar de la autoridad (juez, ministerio público, policía judicial), cuyo propósito final es la ejecución de la justicia, o como un 
instrumento de ayuda para el imputado alófono o para la víctima (Ballardini, 2014, p. 60; Gialuz, 2018, pp. 275-279). La concepción de la figura del intérprete varía a lo largo de los años, de tal modo que no es la misma que se tiene en el Código Rocco, vigente de 1930 a 1988, que la que se establece en el Código Vasalli, que entró en vigor en 1989 (Sau, 2010, p. 44). En cambio, esta concepción del intérprete coincide en el tiempo con el paso de un sistema inquisitorial a un sistema acusatorio (Chiavario, 1990).

A diferencia de la Constitución española, la Constitución italiana contempla expresamente en su artículo 111 el derecho del acusado a ser asistido en el proceso por un intérprete: «La legge assicura che la persona accusata di un reato sia, nel più breve tempo possibile, informata riservatamente della natura e dei motivi dell'accusa elevata a suo carico, $[\ldots]$ sia assistita da un interprete se non comprende o non parla la lingua impiegata nel processo». La jurisprudencia reconoció también de forma temprana en varias sentencias la figura del intérprete como parte del derecho de defensa del acusado y no como un instrumento del juez después de haberse constatado que aquel no conocía la lengua italiana, incluso durante las investigaciones preliminares (Amato y Mack, 2015; Giangiacomo, 2015).

Con la entrada en vigor de la Directiva 2010/64/UE, podía advertirse la existencia de ciertas contradicciones, ya que, por un lado, propugnaba la aplicación de los preceptos del CEDH y reconocía el derecho a la asistencia lingüística, pero, por otro, desde un punto de vista práctico no se llegaba a los niveles mínimos que establecía la Directiva.

La Directiva 2010/64/UE se traspuso al ordenamiento italiano con el Decreto Legislativo n. ${ }^{\circ}$ 32, de 4 de marzo de 2014 (GU n. ${ }^{\circ}$ 64, de 18 de marzo de 2014). Lo cierto es que no comenzaron a adoptarse medidas para trasponerla hasta que en 2013 se aprobó la Ley Italiana n. ${ }^{\circ}$ 96, de 6 de agosto, de aplicación de las directivas. El decreto legislativo que adoptó el Consejo de Ministros el 3 de diciembre de 2013 fue revisado por las comisiones parlamentarias competentes. El Senado no formuló observación o enmienda alguna, mientras que la Cámara de los Diputados introdujo algunas propuestas de mejora del texto. Sin embargo, estas fueron absolutamente ignoradas por el Gobierno ${ }^{55}$.

El Decreto Legislativo n. ${ }^{\text { } 32, ~ d e ~} 4$ de marzo de 2014, añade el apartado 4-bis al artículo 104: «4-bis. L'imputato in stato di custodia cautelare, l'arrestato e il fermato, che non conoscono la lingua italiana, hanno diritto all'assistenza gratuita di un interprete per conferire con il difensore a norma dei commi precedenti. Per la nomina dell'interprete si applicano le disposizioni del titolo IV del libro II». Asimismo, en el

\footnotetext{
${ }^{55}$ Para los trámites parlamentarios, nos remitimos a Gialuz (2013, p.6; 2018, p.288-297).
} 
título IV del Codice di Procedura Penale (CPP), «Traduzioni degli atti», se introducen cinco artículos (artículos 143-147), además de las normas de desarrollo («Disposizioni di attuazione»).

Algunos autores han considerado positiva la transposición, admitiendo que se han aumentado las garantías procesales de los acusados e imputados (Giangiacomo, 2015, p. 22). Otros, sin embargo, estiman que se ha desaprovechado una ocasión para realizar una regulación más completa del derecho a la interpretación (Gialuz, 2014; 2018, p. 209) y que no se ofrecen garantías respecto de la calidad.

Por lo que se refiere al derecho de interpretación, el artículo 143.1 del CPP establece que el acusado que no conozca la lengua italiana tendrá derecho a ser asistido por un intérprete para comprender la acusación que le imputa, seguir el procedimiento y las vistas orales a las que participe. Esta asistencia será gratuita:

L'imputato che non conosce la lingua italiana ha diritto di farsi assistere gratuitamente, indipendentemente dall'esito del procedimento, da un inteprrte al fine di poter comprendere l'accusa contro di lui formulata e di seguire il compimento degli atti e lo svolgimento delle udienze a cui partecipa. Ha altresí diritto all'asistenza gratuita di un interprete per le comunicazioni con il diffensore prima di rendere un interrogatorio, ovvero al fine di presentare una richiesta o una memoria nel corso del procedimento (CPP, artículo 143.1).

Así, el artículo 143.1 del CPP reconoce el derecho a la interpretación a todas aquellas personas acusadas que no entiendan la lengua italiana. Ahora bien, el conocimiento de la lengua italiana se ha puesto en tela de juicio en varias ocasiones por ser un concepto vago (Amato y Mack, 2015, p. 47). El Tribunal Constitucional italiano, en la sentencia 254/2007, establece que la asistencia del intérprete no constituye un instrumento técnico de juez, sino un derecho individual de la persona acusada. Asimismo, extiende el concepto de conocer la lengua del procedimiento a la capacidad de comunicar y participar completamente en la vista. El derecho se tiene incluso si los jueces, abogados o fiscales conocen el dialecto del acusado. Además, el derecho puede ejercerse por el acusado en todas las fases del procedimiento.

El derecho a un intérprete se extiende en el artículo 143-bis1, 2 y 4 del CPP a los testigos y a las víctimas, de tal modo que pueden valerse de la asistencia gratuita de un intérprete para comprender las declaraciones y seguir los actos y el desarrollo de las vistas.

El conocimiento de la lengua italiana, según el artículo 143.4 del CPP, será evaluado por las autoridades judiciales. Dicho conocimiento se presume para todos los ciudadanos italianos, salvo prueba de lo contrario. En ese precepto no se especifica qué grado de conocimiento ha de tener la persona (Giangiacomo, 2015, pp. 23-24), de ahí 
que se deje a decisión de la autoridad judicial la asignación de un intérprete. Por lo que se refiere al derecho de interpretación, se amplía a las entrevistas con el abogado defensor (artículo 143.1 del CPP) o a las entrevistas en situación de prisión preventiva (artículo 104.4-bis del CPP). Sin embargo, no se alude a la irrenunciabilidad de este derecho.

Hay que resaltar que la legislación anterior obligaba al acusado a nombrar un intérprete independiente (Bargis, 2009; p. 2016). Tampoco se especifica la modalidad de interpretación que ha de utilizarse ni que deban interpretarse todas las actuaciones del juicio oral.

En relación con el derecho a la traducción, en el artículo 143.2 del CPP se establece la obligación de traducir una serie de documentos fundamentales, esto es, la «informazione di garanzia, l'informazione sul diritto di difesa e i provvedimenti che dispongono misure cautelari personali, l'avviso di conclusioni delle indagini preliminari, i decreti che dispongono l'udienza preliminare e la citazione a giudizio, le sentenze y i decreti penali di condanna ${ }^{56}$. En el apartado 4 del mismo artículo, se hace referencia a la posibilidad de recurrir a la traducción parcial de los documentos y a la posibilidad de realizar una traducción de la vista. Sin embargo, no se concreta el plazo de traducción, que se deja simplemente «entro un termine congruo tale da consentire l'esercizio dei diritti e la facoltà di difesa», que puede considerarse demasiado genérico (Giangiacomo, 2015, p. 22).

La renuncia a la traducción no se ha previsto de manera específica en el decreto legislativo, aunque está recogida explícitamente en el artículo 3 de la Directiva Europea 2010/64/UE (Giangiacomo, 2015, pp. 23-25). De ahí que sea utilizada normalmente en la praxis judicial, tal y como se explicará en el capítulo 5 .

Tampoco se concreta el idioma que ha de utilizarse en la interpretación o traducción, por lo que podrá usarse cualquier lengua que los acusados o imputados hablen o entiendan, a diferencia del considerando 22 de la Directiva, que aconseja el uso de la lengua nativa del acusado. La ambigüedad del artículo 143 del CPP da pie a un uso más amplio del que debiera hacerse, ya que la utilización de una lengua diferente a la nativa del acusado debería realizarse con cautela, cerciorándose del conocimiento suficiente de dicha lengua del acusado alófono (Falbo, 2013, p. 74; Gialuz, 2014, p. 92). De esta manera, se producen casos evidentes de uso de otros idiomas como lengua franca que, como se señala en el capítulo 7, no siempre son bien comprendidos por los acusados, afectando a sus derechos de defensa y de tutela judicial.

\footnotetext{
${ }^{56} \mathrm{~N}$. de la autora: el auto de apertura de la instrucción, la información sobre el derecho de defensa y las medidas que disponen prisión preventiva, el aviso de haber concluido las investigaciones preliminares, los decretos que disponen la vista preliminar, la citación judicial del acusado, las sentencias y los decretos penales de condena.
} 
En lo que se refiere a los gastos, el artículo 143 del CPP establece que serán siempre a cargo del Estado. Ahora bien, podemos estar ante un caso claro de voluntarismo político, pues la ley no ha sido acompañada de la correspondiente dotación presupuestaria ${ }^{57}$.

El nombramiento del intérprete ha de hacerse fundamentalmente entre los presentes en los listados de los juzgados, pero no se habla de ningún registro. Tampoco se hace mención acerca de cómo acceder a dichos listados, que en Italia depende de cada juzgado. Como señala Gialuz, el legislador se ha «olvidado» de establecer que el intérprete y el traductor han de elegirse entre los expertos inscritos en el registro según el art. 67 de las disposiciones de aplicación ${ }^{58}$ (2014, p. 90). Según este autor, se debería haber modificado el artículo 146 del CPP para que pudieran actuar como intérpretes solo los inscritos en el registro. Lamentablemente, no se modificó, por lo que se puede eludir sin problema el registro y seguir recurriendo a no expertos, casi profesionales: «Aggirare l'albo e continuare a rivolgersi a non esperti (quasi) professionisti» (Gialuz, p. 91 $)^{59}$. Esta cuestión se aborda de manera pormenorizada en el capítulo 5. En la ley no se hace la más mínima mención a los criterios de selección, la formación necesaria y las normas de calidad, ni de las cuestiones éticas que se requieren para formar parte de los registros de los tribunales (Amato y Mack, 2015, p. 52).

Cambia, pues, la visión respecto al papel de los traductores e intérpretes que, de esta manera, se equiparan a los demás expertos de las categorías que se indican en el artículo 67 de la disposición de aplicación al CPP. No obstante, el legislador se felicita en la norma de aplicación de los cambios introducidos sobre el papel que se atribuye al intérprete y traductor en el proceso penal, «affiancando all'inquadramento tradizionale pubblicistico che li qualifica esclusivamente come periti in ausilio dell'autorità giudiziaria, un approccio di tipo soggettivistico che li intende anche come tecnici della difesa a tutela dei diritti fondamentali de la persona accusata» ${ }^{60}$. El legislador se jacta también de implicar a las asociaciones nacionales de las profesiones no reguladas en el artículo 68.1 del Decreto Legislativo n. ${ }^{\circ}$ 271, de 28 de julio de 1989. El problema surge

\footnotetext{
57 El tema se debatió durante la conferencia Diritti Fondamentali dell'Indagato in Misura Cautelare e Reato di Tortura, organizada por la asociación AssITIG y celebrada en Siracusa el 17 de marzo de 2017, en la que se solicitó mayor implicación a la representante de la Cámara de los Diputados, Sofia Amoddio.

${ }^{58}$ Traducción de la investigadora: «Eludir el registro y seguir acudiendo a no expertos (casi) profesionales».

${ }^{59}$ Esto se ha expuesto de manera pormenorizada en el apartado 2.4 de este trabajo.

${ }^{60}$ Traducción de la investigadora: «Asignando a la clasificación tradicional publicista que lo califica exclusivamente como peritos que asisten a la autoridad judicial, un enfoque de tipo subjetivo que los considera también como técnicos defensores de le la protección de los derechos fundamentales de la persona acusada», en Decreto Legislativo n. ${ }^{\circ} 129$, de 23 de junio de 2016, disponible en: https://www.giustizia.it/giustizia/it/mg_1_2 1.wp;jsessionid=F26812073E089AC3936A46ABD645DEA7.ajpAL 02? facetNode_1 $=0 \_10 \&$ facetNode_3 $=0 \_10 \_16 \&$ facetNode_2=1_8(2014)\&previsiousPage $=$ mg_1_2\&contentId= SAN973135.
} 
al incluir a las asociaciones representativas de las profesiones no reguladas en las comisiones evaluadoras de los registros. Si el solicitante del registro del tribunal pertenece a una de las asociaciones, estas podrán establecer las competencias de sus socios por medio de la evaluación de los requisitos y la superación de un examen de admisión, además de un control de la formación continua (Caciagli, 2014). En este sentido, se plantea el problema de cómo evaluar y certificar las competencias de aquellas personas que no pertenecen a ninguna asociación. El legislador se ha limitado a atribuir un papel de evaluador a las mencionadas asociaciones, cuyo representante formará parte del comité responsable de la formación del registro de los peritos. Existe, pues, una incongruencia entre lo que defiende la ley respecto a las profesiones no reglamentadas y la voluntad de certificación que justificaría un nivel de calidad:

\begin{abstract}
Nell'ipotesi di una richiesta di iscrizione agli albi dei tribunali del soggetto NON appartenente ad alcuna associazione comporterebbe un obbligo di previa richiesta di iscrizione all'associazione di categoria, valutazione delle competenze e successivo superamento della prova di ammissione all'associazione, il che sarebbe, non soltanto una incongruenza ma in netto contrasto con la legge 4 del 2013 sulle professioni non regolamentate la quale si fonda sul libero esercizio della professione, libera appartenenza ad una associazione di categoria e la volontarietà del processo di certificazione che attesterebbe il livello di qualità ma che è rimesso alla libera volontà dell'individuo (Caciagli, 2014).
\end{abstract}

Por otra parte, la gestión centralizada podría garantizar una eficiencia mayor a la hora de hallar intérpretes para las lenguas de menor difusión, unificando las bases de datos de los registros (albi) de cada tribunal, tal y como prevé la Directiva (Gialuz, 2014b, p. 90).

Respecto a la calidad de la interpretación no se hace mención alguna en la ley italiana. Como aclaran Mack y Amato (2015, p. 51), cada vez que se menciona el tema de la calidad de la interpretación o traducción se considera que las leyes italianas son conformes a la Directiva, por lo que se estima que estas no requieren cambios. De hecho, en las razones por las que se puede recusar a un intérprete no aparecen ni la competencia de dicho intérprete ni la calidad de su labor. De esta manera, la calidad sigue dependiendo del instrumento de la «nullità di ordine generale» según el artículo 178.c del CPP (Gialuz, 2014) ${ }^{61}$.

Una cuestión de suma gravedad establecida en la ley italiana es que, según el artículo 143.6 del CPP, la prestación de oficio del intérprete y del traductor es

\footnotetext{
${ }^{61}$ La nulidad general hace referencia a las condiciones de capacidad del juez y al número de jueces necesarios para la pena juzgada, la iniciativa del ministerio público para el ejercicio de la acción penal y su participación al procedimiento y la intervención, la asistencia y la representación del acusado y de las demás partes particulares además de la citación al juicio de la parte perjudicada.
} 
obligatoria, por lo que una persona puede ser compelida a actuar como intérprete, incluso si no está o no se siente capacitada para ello. De hecho, puede ser sancionada con la imposición de una multa, tal y como dispone el artículo 146.2 del CPP: «L'interprete sostituito, dopo essere estato citato a comparire per discolparsi, può essere condannato dal giudice al pagamento a favore della cassa delle ammende di una somma da euro 51 a euro 516».

El Gobierno italiano ejerció su poder de adoptar disposiciones correctivas o de integración de la Directiva con el Decreto Legislativo n. ${ }^{\circ} 129$, de 23 de junio, cuyo propósito era establecer reglas que permitieran prevenir abusos e instrumentalizaciones en el ejercicio de la asistencia del intérprete, en relación con las entrevistas con el defensor. Se añadía un apartado más al artículo 146 del CPP que simplifica el procedimiento de asignación del encargo al intérprete y traductor. En el artículo 51-bis se proponía racionalizar el gasto a través de varias medidas: reglamentar el número de entrevistas con el abogado defensor asistidas por un intérprete a cargo del Estado, al tiempo que se disciplinaba la posibilidad de traducir oralmente la documentación durante la vista y, también, se admitía la utilización de herramientas de comunicación a distancia.

Por lo que se refiere a la calidad, la norma de desarrollo propuso la elaboración de un listado nacional de traductores e intérpretes en formato electrónico, que a fecha de hoy todavía no se ha realizado.

En 2016, una diputada del Movimento Cinque Stelle (M5E) formuló una pregunta en el Parlamento Europeo acerca de la falta de creación de un registro italiano de traductores e intérpretes judiciales ${ }^{62}$. El Parlamento respondió que se estaba haciendo un seguimiento. A falta de mayor información, se presentó una queja ante el defensor europeo, de la que se ha hablado ya en el apartado 3.4.4. Además, la asociación APTIJ presentó una queja ante el defensor del pueblo español, de la que ya se ha hablado en el capítulo 2.3.

Puede concluirse que la transposición italiana se ha atenido únicamente a la letra y no al espíritu de la Directiva 64/2010/EU (Amato y Mack, 2015, p. 52). Los legisladores son respetuosos con los derechos lingüísticos, pero no han hecho nada para asegurar la calidad de la interpretación, que es consustancial a ellos, ni se ha establecido un registro. Por el momento, siguen funcionando los registros de cada tribunal, cuyo acceso no está unificado en todo el país y depende de los criterios establecidos por cada tribunal, como se detallará en el capítulo 5. Asimismo, casi ningún tribunal utiliza los

62 Para más información, se remite a la página del Parlamento Europeo, disponible en: http://www.europarl.europa.eu/sides/getDoc.do?type=WQ\&reference=E-2016-004113\&language=EN. 
listados existentes. Como consecuencia de todo lo anterior, se puede decir que en la transposición italiana se observan muchos puntos débiles o problemáticos. Los representantes de las asociaciones profesionales consideran que la transposición se llevó a cabo para cumplir con la obligación y evitar la sanción, pero los legisladores no se han preocupado de realizar una transposición concienzuda y eficaz ${ }^{63}$.

\subsubsection{Una visión comparada de las trasposiciones de la Directiva 2010/64/UE a los ordenamientos italiano y español}

En ambos países, las trasposiciones llegaron con retraso en cuanto a la fecha establecida como límite en la Directiva. Tanto los juristas como las asociaciones de traductores e intérpretes judiciales de ambos países coinciden en que ambas trasposiciones se realizaron de forma aproximada, apresurada y superficial (Gialuz, 2013, 2014; Gialuz, 2018; Alonso Araguás et al., 2018).

A continuación, se exponen en un cuadro sinóptico algunos puntos fundamentales de ambas trasposiciones:

Tabla 2: Comparación entre las especificaciones de la Directiva y las transposiciones española e italiana

\begin{tabular}{|c|c|c|}
\hline $\begin{array}{l}\text { DIRECTIVA } \\
\text { EUROPEA }\end{array}$ & $\begin{array}{l}\text { LEY ESPAÑOLA DE } \\
\text { TRANSPOSICIÓN }\end{array}$ & $\begin{array}{l}\text { LEY ITALIANA DE } \\
\text { TRANSPOSICIÓN }\end{array}$ \\
\hline \multirow[t]{2}{*}{ Directiva Europea 2010/64/UE } & $\begin{array}{l}\text { Ley Orgánica 5/2015 (BOE, p. } \\
\text { 2015) }\end{array}$ & $\begin{array}{l}\text { Decreto Legislativo n. }{ }^{\circ} 32 \text {, de } 4 \\
\text { marzo } 2014 \text { (GU: 2014) }\end{array}$ \\
\hline & $\begin{array}{l}\text { LECrim, título V: Del derecho a } \\
\text { la defensa, a la asistencia } \\
\text { jurídica gratuita y a la traducción } \\
\text { e interpretación en los juicios } \\
\text { criminales. }\end{array}$ & $\begin{array}{l}\text { CPP Libro II. Atti. Titolo IV: } \\
\text { Traduzione degli atti (art. 143- } \\
\text { 147). }\end{array}$ \\
\hline \multirow[t]{2}{*}{ Art. 2. Derecho a interpretación } & Art. 123.1.a, b y c & Art. 143.1 \\
\hline & $\begin{array}{l}\text { Art. } 126 . \text { No pueden ser } \\
\text { renunciados los derechos que se } \\
\text { refieren a las letras a y c del art. } \\
123 \text {. }\end{array}$ & Art. 143-bis 1 y 2 \\
\hline 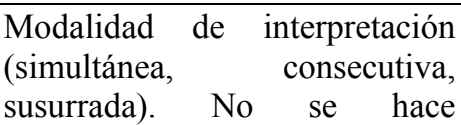 & $\begin{array}{lcc}\text { Art. } & 123.2 . \quad \text { Referencia a } \\
\text { interpretación simultánea, en las }\end{array}$ & No se hace referencia. \\
\hline
\end{tabular}

63 Conversación con Flavia Caciagli, presidenta de la Associazione Italiana Traduttori Interpreti Giudiziari (AssITIG). 


\begin{tabular}{|c|c|c|}
\hline referencia. & actuaciones del juicio oral. & \\
\hline \multirow{2}{*}{$\begin{array}{l}\text { Considerando } 17 . \text { Asistencia } \\
\text { lingüística gratuita }\end{array}$} & Art. 123.1e LECrim & Art. 143.1 \\
\hline & Art. 118.f & Art. 143-bis 1,2 y 3 \\
\hline $\begin{array}{l}\text { Art. 4. Costes de traducción e } \\
\text { interpretación. }\end{array}$ & $\begin{array}{l}\text { Art. } 127 \\
\text { Capítulo IV (Del ejercicio del } \\
\text { derecho de defensa), art. 520h. }\end{array}$ & $\begin{array}{l}\text { Art. 104.4-bis. "L'imputato in } \\
\text { stato di custodia cautelare, } \\
\text { l'arrestato e il fermato, che non } \\
\text { conoscono la lingua italiana, } \\
\text { hanno diritto all'assistenza } \\
\text { gratuita di un interprete per } \\
\text { conferire con il difensore». }\end{array}$ \\
\hline
\end{tabular}

Art. 2.3. Derecho de Capítulo IV, art. 520h interpretación en virtud de los apartados 1 y 2 incluye la asistencia a personas con limitaciones auditivas o de expresión oral.
LECrim, art. 442: si el testigo es sordo, se nombrará intérprete de lengua de signos.
Titolo I, libro II. Atti

Art. 119.1 del CPP. Participación del sordo, mudo o sordomudo en las actuaciones del procedimiento se hará por escrito.

119.2. Si el sordo no sabe leer o escribir, se nombrará un intérprete elegido preferiblemente entre las personas de su entorno.

Art. 3. Derecho a traducción

Titolo IV, libro II. Traduzione

\author{
Art. 123.1d. Derecho a la \\ traducción escrita de los \\ documentos que resulten \\ esenciales para garantizar el \\ ejercicio del derecho a la \\ defensa. Deberán ser traducidos, \\ en todo caso: \\ -las resoluciones que acuerden la \\ prisión del imputado, \\ -el escrito de acusación y \\ -la sentencia.
} degli atti

Art. 143.2. Se especifican los documentos esenciales:

- esercizio dei diritti e della facoltá di difesa;

provvedimenti che dispongono misure cautelari personale;

- l'avviso di conclusione delle indagini preliminari;

- decreti che dispongono l'udienza preliminare a la citazione in giudizio;

- le sentenze:

- decreti penali di condanna.

\begin{tabular}{llll}
\hline Art. 3.8. Traducción oral en & Art.123.3 & LECrim. \\
sustitución de la traducción & «Excepcionalmente $[\ldots]$ podrá \\
escrita. & & $\begin{array}{l}\text { ser sustituida por un resumen } \\
\text { oral». }\end{array}$
\end{tabular}

Art. 3.8. Renuncia a traducción. Art. 126. La renuncia a los No se especifica, pero praxis. derechos a que se refiere el art. 123 deberá ser expresa y libre, y solamente será válida si se produce después de que el 
imputado o acusado haya recibido asesoramiento jurídico suficiente y accesible que le permita tener conocimiento de las consecuencias de la renuncia.

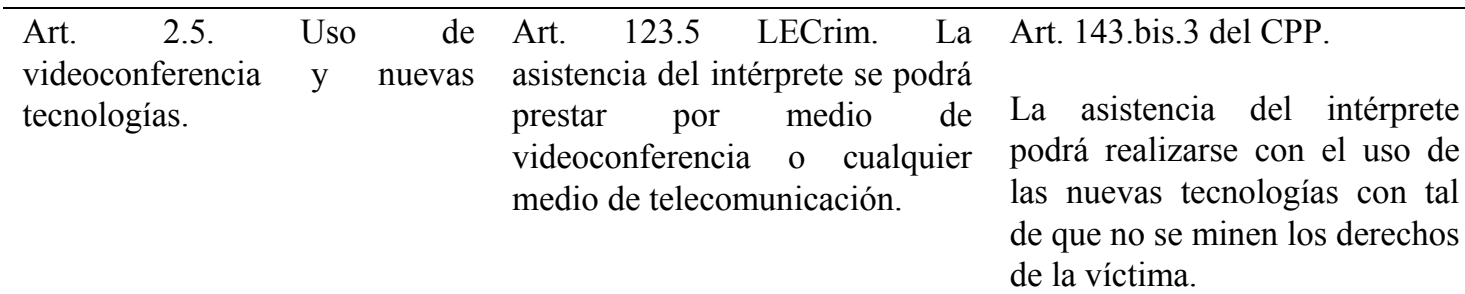

Art. 2.8 y 3.8. Calidad de la Art. 124.3. "Cuando el tribunal, No se hace referencia. interpretación y la traducción.

el juez o el ministerio fiscal, de oficio o a instancia de parte, aprecie que la traducción o interpretación no ofrecen garantías suficientes de exactitud, podrá ordenar la realización de las comprobaciones necesarias»».

Art. 5.2. Registro.

Los Estados miembros se esforzarán por establecer uno o varios registros de traductores e intérpretes independientes debidamente cualificados. Una vez establecidos dichos registros, se pondrán, cuando proceda, a disposición de los abogados y las autoridades pertinentes.
Art. 124.1. «El traductor o intérprete judicial será designado de entre aquellos que se hallen incluidos en los listados elaborados por la Administración competente. Excepcionalmente [...] se podrá habilitar como intérprete o traductor judicial eventual a otra persona conocedora del idioma empleado que se estime capacitado para el desempeño de dicha tarea».

Art. 441. «El intérprete será elegido entre los que tengan titulo de tales [...], si los hubiera en el pueblo».
El intérprete/traductor en Italia es considerado en sede judicial un perito, por lo que hay que remitirse al Libro III, Titolo II, Mezzi di Prova, capo VI Perizia, arts. 220-223, donde se establece el nombramiento y la función del perito.

Art. 221 del capo VI. Nombramiento del perito: «Il giudice nomina il perito scegliendolo tra gli iscritti negli appositi albi o tra le persone fornite di particolare competenza nella specifica disciplina».
Art. 124.2. «El intérprete o traductor designado deberá respetar el carácter confidencial del servicio prestado».
Art. 146.2 (Conferimento dell'incarico): «... viene ammonito sull'obbligo di adempiere bene e fedelmente l'incarico [...] e di mantenere il segreto di tutti gli atti che si faranno per suo mezzo o in sua presenza».
Art. 6. Formación de operadores judiciales.
Disposición adicional segunda Ley 5/1025. «El Ministerio de

Justicia, el Consejo General del
No se hace referencia. 


\begin{tabular}{|c|c|c|}
\hline & $\begin{array}{l}\text { Poder Judicial, la Fiscalía } \\
\text { General del Estado y las } \\
\text { comunidades autónomas, en el } \\
\text { ámbito de sus respectivas } \\
\text { competencias, asegurarán una } \\
\text { formación de los jueces, fiscales } \\
\text { y personal al servicio de la } \\
\text { Administración de Justicia que } \\
\text { participen en procesos penales } \\
\text { que presta atención a las } \\
\text { particularidades de } \\
\text { comunicación con ayuda de } \\
\text { intérprete». }\end{array}$ & \\
\hline 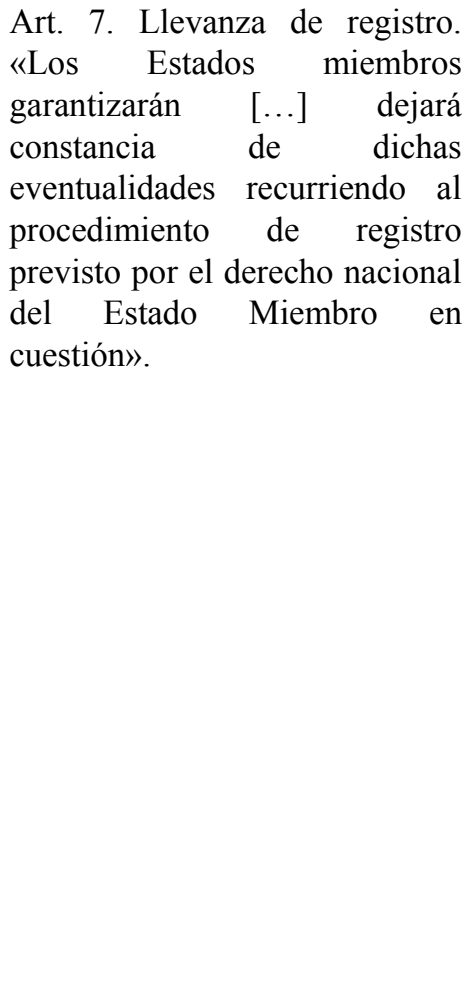 & $\begin{array}{l}\text { Preferiblemente grabada pero } \\
\text { opcional, no existe la } \\
\text { obligatoriedad. Puede sustituirse } \\
\text { por el acta escrita. } \\
\text { En sede judicial se remite al art. } \\
453,454.5 \text { y } 788.5 \text { de la } \\
\text { LECrim. }\end{array}$ & $\begin{array}{l}\text { Título III, libro II, } \\
\text { documentazione degli atti art. } \\
134.2 \text { (por estenotipia, } \\
\text { posibilidad de reproducción } \\
\text { fonográfica y audiovisual, solo } \\
\text { si absolutamente indispensable) } \\
\text { Art. 134.4. } \\
\text { Art. 141.bis. } \\
\text { «Ogni interrogatorio di persona } \\
\text { che si trovi, a qualsiasi titolo, in } \\
\text { stato di detenzione e che non } \\
\text { svolga in udienza, deve essere } \\
\text { documentato integralmente, a } \\
\text { pena di inutilizzabilità, con } \\
\text { mezzi di riproduzione } \\
\text { fonografica o audiovisiva. } \\
\text { Quando si verifica una } \\
\text { indisponibilità di istrumenti di } \\
\text { riproduzione o di personale } \\
\text { tecnico, si provvede con le } \\
\text { forme delle perizie, ovvero } \\
\text { della consulenza técnica». }\end{array}$ \\
\hline Lengua franca & $\begin{array}{l}\text { Art. 118.1. La información se } \\
\text { facilitará en una lengua } \\
\text { comprensible. }\end{array}$ & $\begin{array}{l}\text { Vago en los art. } 143 \text { y 143-bis } \\
\text { del CPP. }\end{array}$ \\
\hline $\begin{array}{l}\text { Considerando } 22 . \quad \text { «La } \\
\text { interpretación y traducción en } \\
\text { virtud de la presente Directiva } \\
\text { deben facilitarse en la lengua } \\
\text { materna del sospechoso o } \\
\text { acusado o en cualquier otra } \\
\text { lengua que entienda o hable con } \\
\text { objeto de permitir el pleno } \\
\text { ejercicio del derecho a la } \\
\text { defensa y con el objeto de } \\
\text { salvaguardar la equidad del } \\
\text { proceso». }\end{array}$ & $\begin{array}{l}\text { Art. 123.1. Derecho a ser } \\
\text { asistidos por un intérprete que } \\
\text { utilice una lengua que } \\
\text { comprenda. }\end{array}$ & \\
\hline
\end{tabular}


Puede concluirse de esta comparación que la transposición de la Directiva ha sido incompleta y parcial en ambos países. De ahí que se pueda cuestionar la transposición misma, pues no cumple con las exigencias jurisprudenciales de la Unión Europea (Gascón Nasarre, 2017, p. 27).

Las dos trasposiciones recogen de manera clara la gratuidad del derecho a traducción e interpretación del acusado. Ambas leyes reconocen el derecho a traducción de algunos escritos que resulten esenciales. La ley española es más vaga en cuanto a los documentos que han de traducirse, mientras que la italiana los especifica. Al mismo tiempo, la ley española recoge el carácter excepcional de la traducción o resumen oral que sustituye a la traducción escrita. Por su parte, la ley italiana no hace referencia a la renuncia a la traducción, aunque en la realidad es una praxis muy extendida.

Las dos recogen de manera clara el carácter confidencial de la interpretación judicial, teniendo en cuenta la importancia que esta reviste.

Llama la atención lo adelantado de la ley española, que requiere específicamente que la interpretación deba hacerse de modo simultáneo en las actuaciones del juicio oral. Lamentablemente, se abre la puerta a la excepción con la interpretación consecutiva, que en realidad se ha convertido en la norma.

Un aspecto curioso es el carácter retrógrado de la ley italiana en relación con las personas con limitaciones auditivas o de expresión oral, pues establece que las actuaciones se realicen por escrito, y, en caso de que la persona no sepa leer, se elegirá un intérprete entre las personas de su entorno, lo que va en contra de todos los principios expuestos en el capítulo 2 del intérprete judicial.

Ambas leyes permiten el uso de la videoconferencia y de las nuevas tecnologías.

En cuanto a la calidad, llama la atención precisamente que no se haga referencia a ella en la ley italiana, quedando reducida a una simple referencia en la ley española (Ortega-Herráez, 2016). En relación con los registros, ambas trasposiciones se han quedado cortas. Se hace referencia a los «listados», pero no existe la obligatoriedad de usar traductores e intérpretes del registro y tampoco queda claro el acceso a dichos registros.

Acerca de la formación de los operadores judiciales, que reviste gran importancia para el trabajo en común durante el procedimiento penal, la referencia es vaga ya en la Directiva, se recoge en la ley española y se ignora completamente en la ley italiana.

Por último, cabe señalar la libertad que se brinda a cada país a la hora de mantener una grabación de las actuaciones de los intérpretes, que queda reflejada también las dos trasposiciones y da lugar a que la grabación audiovisual en España y audio en Italia; además, pueden eludirse durante los interrogatorios o entrevistas, lo que da pie a que no exista constancia real de la actuación del intérprete. 


\subsubsection{El derecho a la interpretación y traducción en otras directivas europeas}

Además de la Directiva anteriormente analizada, se han aprobado otras normas europeas con posterioridad que incluyen el derecho a la traducción e interpretación, explicitado en mayor o menor medida en cada una de ellas. A continuación se presenta un análisis de cómo queda reflejado el derecho a interpretación y traducción.

\subsubsection{Directiva 2012/13/UE relativa al derecho a la información en los derechos penales}

La Directiva 2012/13/UE, en el considerando 25, establece que «los Estados miembros deben garantizar que, al facilitar información de conformidad con la presente Directiva, la persona sospechosa o acusada tenga acceso, cuando sea necesario, a la interpretación y a la traducción en una lengua que comprenda, de conformidad con las normas establecidas en la Directiva 2010/64/UE». También se recoge explícitamente el derecho en el apartado del artículo 3. Asimismo, se reconoce en la lectura de los derechos que se realiza al detenido, esto es:

\section{INTERPRETACIÓN Y TRADUCCIÓN}

Si no habla o no entiende la lengua de la policía o de otras autoridades competentes, tiene derecho a la asistencia de un intérprete gratuitamente. El intérprete puede ayudarle a hablar con su abogado y está obligado a mantener en secreto el contenido de esa comunicación. Tiene derecho a la traducción de, como mínimo, los pasajes pertinentes de los documentos esenciales, incluida toda orden de un juez que permita su detención o privación de libertad, toda acusación o auto de procesamiento y toda sentencia. En determinadas circunstancias, puede recibir una traducción o un resumen orales.

En la Directiva se adjunta un modelo indicativo de declaración de derechos, que de esta forma se encuentra ya traducido y a disposición en todos los idiomas de la Unión Europea. El artículo 4, § 5, establece que «la persona sospechosa o acusada reciba una declaración de derechos escrita en una lengua que comprenda». En el caso de que no esté a disposición, podrá sustituirse en el momento por una información oral, que deberá ser traducida sin demora excesiva. Además, se establece también que «la declaración de derechos se redactará en términos sencillos y accesibles». No se ha tenido en cuenta a personas que no sepan leer o todas las lenguas, por lo que da directiva carece de amplias miras. 
Esta Directiva se traspuso al ordenamiento jurídico español con la Ley Orgánica 2/2015, de 27 de abril, con la que se traspuso también la Directiva 201/64/UE, a la que se ha hecho ya referencia.

El Gobierno italiano traspuso la directiva con el Decreto Legislativo n. ${ }^{\circ} 101$, de 1 de julio de 2014, en el que se introdujo la posibilidad de proporcionar información de manera oral a la espera de facilitarle la versión escrita. El juez ha de cerciorarse durante la vista en la que se ratifica la detención (Gialuz, 2018, pp. 298-300).

\subsubsection{Directiva 2012/29/UE relativa a los derechos, apoyo y protección de las víctimas de delito}

La protección de las víctimas de delito se recoge ya en el artículo 82, apartado 2c, del TFUE, que prevé la posibilidad de introducir normas mínimas que protejan a las víctimas de actos criminales (Gialuz, 2018, p. 126) ${ }^{64}$. El derecho a traducción e interpretación se contempla en varios considerandos $(9,21,34,35$ y 36) y de forma específica en los artículos 5 y 7. Según el artículo 7, § 1, la interpretación a las víctimas deberá ser gratuita «al menos durante las entrevistas o las tomas de declaración en los procesos penales, ante las autoridades de instrucción y judiciales, incluso durante los interrogatorios policiales, e interpretación para su participación activa en las vistas orales del juicio y cualquier audiencia interlocutoria». Podrán usarse los nuevos medios de comunicación, y en el apartado 3 se garantiza también la traducción gratuita de «la información esencial para que ejerzan sus derechos en el proceso penal». Siguiendo las pautas de la Directiva 2010/64/UE, se podrá realizar una traducción oral o un resumen y podrá recurrirse la denegación del derecho. Por tanto, se establecen normas mínimas sobre los derechos y la protección de las víctimas de delito, prestándoles apoyo y asistencia en el caso de que desconozcan la lengua para presentar la denuncia. En el artículo 5.2 se establece que «las víctimas que deseen denunciar una infracción penal y no entiendan o no hablen la lengua de la autoridad competente puedan presentar la denuncia en una lengua que entiendan o recibiendo la asistencia lingüística necesaria», y el artículo 5.3 insiste en que reciban una traducción gratuita de la declaración por escrito de la denuncia, "previa solicitud en una lengua que entiendan». Llama la atención que en este caso no se haga ninguna referencia a la calidad. También se hace referencia a este derecho en los considerandos.

La Directiva 2012/29/UE ha permitido dar un gran paso adelante en relación con el derecho a la asistencia lingüística de la víctima (Gialuz, 2018, p. 255). Llama la

\footnotetext{
${ }^{64}$ Para todo el proceso, se remite a Gialuz, 2018, p.253-271.
} 
atención que no se haga ninguna referencia a la calidad de la interpretación o la traducción, por lo que se diferencia entre el derecho a la asistencia lingüística del acusado y de la víctima, o, como Gialuz expone:

Il mancato richiamo alla qualità dell'interpretazione e traduzioni (e ai suoi corollari) nella direttiva 2012/29/UE è una riprova definitiva di quanto l'Unione, nonostante gli sforzi, abbia corso il rischio di proclamare un diritto all'assistenza linguistica di serie A, che vale per i prevenuti, e uno di serie B, che viene in rilievo, invece, per le vittime di reato. Il messaggio che è passato, infatti, è che per quest'ultime ci si potrebbe accontentare di un livello qualitativo più basso, potendo ancora essere assistite da soggetti non qualificati, senza che ciò provochi alcuna conseguenza (Gialuz, 2018, p. 263).

En concreto, esta Directiva ha sido incorporada al ordenamiento italiano a través del Decreto Legislativo n. ${ }^{\circ} 212$, de 15 de diciembre de 2015 (GU n. ${ }^{\circ}$ 3, de 5 de enero de 2016), que traspuso dicha Directiva (Gialuz, 2018, pp. 463-484) y con la reforma del artículo 143.bis del CPP «Altri casi di nomina dell'interprete». En dicho artículo se establece el nombramiento del intérprete de manera gratuita. La declaración podrá realizarse en forma escrita y luego ser traducida $(\S 1)$, la asistencia del intérprete puede realizarse también en modo remoto $(\S 3)$ y la víctima que no conozca la lengua italiana tiene derecho a las traducciones de los documentos o parte de ellos que contengan la información útil para ejercer dichos derechos, aunque esta traducción puede llevarse a cabo también de forma oral ( $(4)$.

Por lo que respecta al ordenamiento español, la Directiva se traspuso a través de la Ley 4/2015, de 27 de abril, del Estatuto de la Víctima de Delito (LEVD), y en ella se recoge de manera específica el derecho a disponer de servicios de traducción e interpretación, tal y como expone Ariza Colmenarejo:

... al margen de que se produzca la denuncia, el art. $5 \mathrm{LEV}$ regula expresamente el derecho a la información desde el primer contacto con las autoridades competentes. Entre los derechos de los que se debe informar está el mismo derecho a denunciar, el procedimiento para llevarlo a cabo, la posibilidad de obtener asesoramiento y defensa jurídica, o disponer de servicios de traducción e interpretación (2018, p. 117).

A continuación, se promulgó el Estatuto de la Víctima del Delito, en el que se desarrollan los derechos de las víctimas en los artículos 5 y 6 , y de manera más detallada en el artículo 9, «Derecho a la traducción e interpretación». La LEVD crea un marco normativo más amplio si se compara con la LECrim, y se especifican actuaciones judiciales concretas, aunque no se señala en ninguna de los dos la posibilidad de la 
víctima de hacerse asistir de intérprete durante todo el juicio oral y el hecho de que no será preciso traducir todo el texto, sino que bastará con realizar un resumen. De esta manera, se da al intérprete una responsabilidad que escapa en realidad de sus funciones, pues no debería ser él quien eligiera qué es lo que se debe o no se debe interpretar o traducir:

\begin{abstract}
Una cuestión espinosa estriba en la limitación de la traducción, pues no se traducirá todo el texto sino un breve resumen. El problema reside precisamente en quién será el encargado de decidir qué se traduce y quién elabora el resumen, la decisión no debería ser en ningún caso responsabilidad del traductor/intérprete pues dicha decisión va más allá de sus funciones y de sus conocimientos. «De otro modo, deberían tener formación jurídica para identificar los aspectos de una resolución judicial relevantes para el ejercicio de los derechos de la víctima» (Ariza Colmenarejo, p. 133).
\end{abstract}

Dicha Directiva se traspuso al ordenamiento jurídico italiano con el Decreto Legislativo n. ${ }^{\circ}$ 212, de 15 de diciembre de 2015 (GU, 2016). Hace referencia al artículo 143-bis, para el nombramiento del intérprete, y se modifica el artículo 134-bis.3 del CPP, que permite el uso de tecnologías de comunicación a distancia para la asistencia del intérprete, en aquellos casos que sea posible, con tal de que no vaya en detrimento de los derechos de la víctima. La traducción de los documentos puede disponerse en forma de resumen oral si esto no perjudica los derechos de la persona ofendida.

\title{
3.4.8.3. Directiva $2013 / 48 /$ UE relativa al derecho a la asistencia de letrado en los procesos penales
}

La Directiva parte del artículo 47 de la Carta de Derechos Fundamentales de la Unión Europea, que recoge el derecho a la tutela judicial efectiva y a un juez imparcial, en vigor hasta 2009 (Álvarez de Neyra Kappler, 2018, p. 70), al artículo 6 del CEDH, al artículo 124 del PIDCP y al artículo 48.2 de la Carta.

En la Directiva se defiende que, para poder entenderse con el letrado, una persona que no habla la lengua del proceso deberá poder comunicarse con él mediante un intérprete, aunque solo se señala en los considerandos, por lo que ha sido tachada de poco innovadora (Gialuz, 2018, p. 115).

La transposición de esta Directiva al ordenamiento penal español ha conllevado la reforma de la regulación de la asistencia letrada con arreglo al artículo 118.2 de la LECrim, adaptándola de esta manera a las exigencias de la Unión Europea.

Dicha Directiva se traspuso al ordenamiento penal italiano con el Decreto Legislativo n. ${ }^{\circ}$ 184, de 15 de septiembre de 2016 (GU: 2016). Aunque en un primer momento fue visto como una ampliación de las competencias del intérprete de oficio, 
plantea dudas con relación al nombramiento de dicho intérprete y el número de veces que el acusado tiene derecho (Bubula, 2013).

\subsubsection{Directiva $2016 / 800 /$ UE relativa a las garantías procesales de los menores sospechosos o acusados}

Dicha Directiva remite directamente al Plan de Trabajo establecido en Estocolmo y, por tanto, a la Directiva 2010/64/UE. En esta Directiva se hace referencia explícita al derecho a intérprete, aunque sorprende que no remita en ningún apartado a la Directiva 2010/64/UE, teniendo en cuenta que sí que lo hace a las Directivas 2012/13, 2013/48 y 2016/343, y considerando las dificultades de comunicación y comprensión de los menores, aunque no deben quedar dudas de que las garantías que están previstas en la Directiva sobre la interpretación y la traducción deban aplicarse también a los menores (Gialuz, 2018, p. 111).

Esta directiva aún no ha sido traspuesta ni al ordenamiento penal español ni al italiano.

\subsection{Conclusiones}

A partir de mediados del siglo XX se han ido desarrollando, tanto en el ámbito internacional como en el plano europeo, normas y mecanismos que permiten garantizar el derecho a un justo proceso a través del derecho a la interpretación y traducción en los procesos penales de los acusados y sospechosos. Aparte de tratados internacionales en materia de derechos humanos, fueron los países con mayor variedad cultural y lingüística (como Estados Unidos) los que primero establecieron y desarrollaron dicho proceso debido a las necesidades a las que tuvieron que hacer frente en cuanto al acceso lingüístico de sus ciudadanos. Otros ejemplos de países pioneros son: Canadá, Austria, Suecia y Reino Unido. Por lo que se refiere a la Unión Europea, tras un primer reconocimiento en 1950 con la $\mathrm{CEDH}$, el aumento de la movilidad de sus ciudadanos, la globalización de las redes criminales y la llegada masiva de población extracomunitaria al territorio europeo provocaron una reflexión sobre la necesidad del derecho de traducción e interpretación a fin de poder garantizar un juicio equitativo, hasta llegar al establecimiento de una norma específica con la Directiva 2010/64/CE.

La Directiva ha marcado un punto de inflexión por lo que respecta a las garantías procesales. Por tanto, puede considerarse que hoy día existen los instrumentos normativos que permitirían que se produjera un juicio equitativo a nivel europeo, como sucede en otras partes del mundo. Lamentablemente, en algunos Estados miembros la 
transposición ha sido aproximada, superficial y borrosa (FRA, 2016; Blasco-Mayor y Del Pozo Triviño, 2015; Blasco-Mayor y Martin, 2016; Ortega-Herráez, 2016; Gialuz, 2014, 2018). Las trasposiciones italiana y española de la Directiva pueden considerarse insatisfactorias, pues permiten eludir ciertas obligaciones consagradas en ella, que minan los derechos efectivos de los sospechosos y acusados. Ambos países han cumplido teóricamente con la transposición, pero, como se ha señalado en los apartados 3.4.5 y 3.4.6, dichos derechos se incumplen en realidad por falta de capacitación de los intérpretes y mala praxis (Ortega-Herráez, 2016; APTIJ; 2016, 2017; Caciagli, 2017). La inexistencia actual de un registro en algunos países, como es el caso de Italia y España, hace difícil el cumplimiento de los postulados de la Directiva, al igual que la subcontratación de la provisión del servicio, como ha sucedido en Reino Unido (tal y como se indicaba en el capítulo 2), donde sí existe un registro pero ha dejado de utilizarse para este propósito.

Todo ello lleva a que lo establecido en la Directiva sea en cierto modo «papel mojado» (Blasco-Mayor, 2016), al no establecer ni los mecanismos ni los sistemas que permitan un cumplimiento efectivo de lo propugnado.

Para que la Directiva fuera verdaderamente eficaz, sería fundamental:

- evaluar la necesidad real del acusado o sospechoso de interpretación y traducción;

- concienciar a las autoridades judiciales de la importancia de la traducción de los documentos esenciales;

- asegurarse de que el acusado o sospechoso pueda comunicarse de manera eficaz y efectiva con su representante legal;

- salvaguardar la calidad de los servicios de traducción e interpretación, que se podría llevar a cabo mediante:

- la creación de un registro único europeo, que posea los mismos estándares, con un sistema de acreditación uniforme, que incluya un código deontológico. Este registro incluiría los distintos registros nacionales y permitiría, además, el intercambio de profesionales (Blasco-Mayor y Del Pozo Triviño, 2015);

- el establecimiento de un sistema unificado de acreditación (Giambruno, 2014);

- el seguimiento de la calidad de los intérpretes mediante sistemas de evaluación e instrumentos y herramientas de evaluación de la calidad.

El propósito de la segunda parte de este trabajo es, precisamente, diseñar una herramienta de evaluación del desempeño del intérprete en el ámbito judicial. 


\section{La calidad en interpretación: estado de la cuestión}

\subsection{Introducción}

La calidad se ha convertido en la actualidad en el punto clave de todas las actividades profesionales. Se instauran planes de calidad, programas de ayuda y fomento de la mejora de la calidad de las compañías y de las instituciones públicas. El empujón que llevó a un interés por la calidad procede de la crisis económica occidental de los años setenta y del modelo japonés que se había ido instaurando en las décadas precedentes.

Como señalan Camisón, Cruz y González:

La elaboración de las normas sobre el aseguramiento de la calidad y los modelos de excedencia, que han servido de base a los premios de calidad, han ayudado a consolidar los conceptos y los enfoques, estimulando la difusión del movimiento por la calidad en las empresas occidentales en los años ochenta, tres décadas después que en Japón (2006, p. XXI).

Hoy en día, la calidad es una condición necesaria para obtener el éxito de la empresa. Existe, por tanto, una relación positiva entre la gestión de la calidad y los resultados en la organización empresarial y del trabajo.

Para poder adentrarnos en el estudio y análisis de la calidad en la interpretación, se ha considerado necesario presentar un epígrafe dedicado al concepto de calidad en el sentido más amplio, donde se expondrá el significado del término dependiendo de los diferentes enfoques y la evolución que ha seguido hasta llegar a un planteamiento de gestión total de la calidad. A continuación, se pasará directamente a estudiar el concepto de calidad en interpretación, centrándonos en los estudios relativos a la interpretación en general y a la interpretación para los servicios públicos.

Considerando la importancia que posee para el presente trabajo el análisis de la calidad en interpretación judicial, se ha preferido dedicar un capítulo específico a ese tema. 


\subsection{La calidad como condición necesaria en todos los ámbitos}

\subsubsection{Introducción}

Desde el punto de vista etimológico, la palabra calidad deriva del latín qualitasatis, y el interés de este concepto se encuentra ya en las primeras civilizaciones (Miranda González, Chamorro Mera y Rubio Lacoba, 2007, pag. 2). Durante la Edad Media y Moderna estaba vinculada a los gremios, que establecían las especificaciones de los productos y los procesos y supervisaban la admisión de nuevos oficiales. A partir del siglo XVIII, con el arranque de la revolución industrial, el proceso de fabricación cambiará de manera radical y eso provocará un acercamiento diferente al producto.

A principios del siglo XX, se produce en Estados Unidos un movimiento en aras de la calidad orientada al producto con la producción en serie y la necesidad de intercambiabilidad y estandarización, que se desarrollará con las aportaciones de ingenieros como Shewhart, Deming, Juran y Feigenbaum, dedicados a la mejora de los sistemas de producción. Tras la segunda guerra mundial, el interés se traslada a Japón llevado por los mismos estadounidenses, donde se orienta hacia el coste con figuras como Ishikawa o Taguchi, quien creará el acercamiento japonés de la gestión de la calidad. A partir de los años setenta y ochenta se desarrollan, también en Occidente, corrientes de pensamiento que se centran en las personas y en la cultura organizativa. A partir de los años noventa, las aportaciones académicas ampliarán el campo.

Desde el punto de vista conceptual, se puede considerar que la calidad ha ido evolucionando desde un enfoque interno centrado en el control de la calidad del producto, pasando a preocuparse por un control estadístico de la calidad cuyo propósito era obtener procesos productivos eficientes, hasta llegar a un acercamiento más amplio, donde los factores externos adquieren una mayor importancia a favor de una calidad global, que tienen en cuenta la aptitud para el uso de un determinado producto, la satisfacción del cliente y los demás elementos que afectan a la empresa.

Aunque la calidad se introdujo en el mundo industrial como una preocupación empresarial, sobre todo tras la crisis económica de los años setenta, en la actualidad ha pasado a afectar a todos los aspectos de la sociedad. A partir de ahí, la preocupación por la calidad se ha ido extendiendo a todos los sectores, deslizándose desde una calidad del producto hacia una calidad del servicio. Tras el sector industrial en los años ochenta y noventa del siglo XX, la gestión de la calidad se fue extendiendo a otros sectores, entre los que cabe destacar los servicios públicos (Camisón et al., 2006, p. XXII). 
La gran complejidad de los conceptos de calidad y gestión de la calidad ha llevado a distintas interpretaciones, enfoques y modelos de implantación, con distintos principios y prácticas. En el siglo XXI, la calidad ya no se considera una prioridad competitiva, sino que se convierte en un requisito imprescindible que no garantiza el éxito, pero supone una condición previa (Miranda González et al., 2007, p. 6).

Uno de los enfoques que mayor fuerza ha obtenido ha sido el de la gestión de la calidad total (TQM en inglés y GCT en castellano), hasta tal punto que hoy afecta a todos los sectores de la sociedad, con la instauración de sistemas de premiación como reconocimiento a aquellas empresas que se han destacado en la gestión de la calidad (Camisón et al., 2006, pp. 24-45). La falta de unicidad del concepto de calidad crea incertidumbre, como señalan estos autores:

Existe una importante incertidumbre sobre el por qué, el para qué y el cómo puede implantarse el concepto [de Gestión de la Calidad]. Tras este desconcierto laten una serie de errores y mitos, que han lastrado tanto la práctica empresarial como la investigación académica sobre los enfoques de Gestión de la Calidad y su contribución a la mejora del desempeño organizativo (2006, p. XXII).

La introducción práctica de un enfoque que permita asegurar la calidad se basa en varios modelos normativos o normalizados, pues en ellos se establecen una serie de normas que regulan el proceso de diseño, implantación y certificación del sistema de calidad. El más conocido de ellos es el sistema ISO 9000, del que se hablará más adelante.

\subsubsection{El concepto de calidad}

No existe una definición única del concepto de calidad, y de ello da constancia la misma Real Academia Española (RAE) con la presencia de varias definiciones, lo que resalta el carácter polisémico de la palabra.

La RAE incorpora una nueva acepción al lema de calidad:

2. «Adecuación de un producto o servicio a las características especificadas», que lo convierte en más relativo y depende de una serie de factores.

El concepto de calidad posee, pues, una gran variedad de definiciones e interpretaciones, y puede considerarse «amplio y multidimensional» (Camisón et al., 2006, p. 201). A veces se ha definido desde perspectivas que podían ser complementarias o antagónicas (calidad estática contra calidad dinámica, calidad absoluta contra calidad relativa). La variedad de definiciones provoca, asimismo, en ciertas ocasiones, una división de los estudios e incluso una falta de rigor en las 
exposiciones. La confusión aumenta, pues los mismos tratadistas defienden posiciones muy lejanas entre sí.

Siguiendo a Moreno-Luzón, González Cruz y Peris Bonet (2001), existen variadas definiciones respecto al concepto de calidad, que pueden ser agrupadas en cuatro categorías principales: calidad entendida como conformidad de productos y servicios a unas especificaciones, calidad como satisfacción de las expectativas del cliente (en este caso, se puede aplicar tanto a productos como a servicios), calidad en relación con su valor y calidad como excelencia.

Camisón et al. (2006, pp. 145-176) agrupan las definiciones en seis conceptos, tal y como aparecen descritos en las publicaciones. Los cinco primeros podrían considerarse una aproximación parcial que se refieren al producto, a los procesos, al sistema y al servicio. El último, por su parte, se refiere al concepto de calidad como creación de valor, sintetizaría los conceptos parciales internos y externos, que se presentan a continuación en la tabla:

Tabla 3: Concepto de calidad según Camisón et al. (2006, p. 147)

\begin{tabular}{|c|c|c|c|}
\hline Autores & Enfoque & Acento diferencial & Desarrollo \\
\hline Platón & Excelencia & $\begin{array}{l}\text { Calidad absoluta } \\
\text { (producto) }\end{array}$ & $\begin{array}{l}\text { Excelencia, como superioridad absoluta, } \\
\text { «lo mejor». } \\
\text { Asimilación con el concepto de lujo. } \\
\text { Analogía con la calidad de diseño. }\end{array}$ \\
\hline $\begin{array}{l}\text { Shewhart } \\
\text { Crosby }\end{array}$ & $\begin{array}{c}\text { Técnico, } \\
\text { conformidad con } \\
\text { especificaciones }\end{array}$ & $\begin{array}{c}\text { Calidad } \\
\text { comprobada/controlada } \\
\text { (procesos) }\end{array}$ & $\begin{array}{l}\text { Establecer especificaciones. } \\
\text { Medir la calidad por la proximidad real a } \\
\text { las normas. } \\
\text { Énfasis en la calidad de conformidad. } \\
\text { Cero defectos. }\end{array}$ \\
\hline $\begin{array}{l}\text { Deming } \\
\text { Taguchi }\end{array}$ & $\begin{array}{l}\text { Estadístico: pérdidas } \\
\text { mínimas para la } \\
\text { sociedad, } \\
\text { reduciendo la } \\
\text { variabilidad y } \\
\text { mejorando } \\
\text { estándares }\end{array}$ & $\begin{array}{c}\text { Calidad generada } \\
\text { (producto y procesos) }\end{array}$ & $\begin{array}{l}\text { La calidad es inseparable de la eficacia } \\
\text { económica. } \\
\text { Un grado predecible de uniformidad y } \\
\text { fiabilidad a bajo coste. } \\
\text { La calidad exige disminuir la variabilidad } \\
\text { de las características del producto } \\
\text { alrededor de las normas y su mejora } \\
\text { permanente. } \\
\text { Optimizar la calidad de diseño para } \\
\text { mejorar la calidad de conformidad. }\end{array}$ \\
\hline $\begin{array}{l}\text { Feigenbaum } \\
\text { Juran } \\
\text { Ishkawa }\end{array}$ & Aptitud para el uso & $\begin{array}{l}\text { Calidad planificada } \\
\text { (sistema) }\end{array}$ & $\begin{array}{l}\text { Traducir las necesidades de los clientes } \\
\text { en las especificaciones. } \\
\text { La calidad se mide por lograr la aptitud } \\
\text { deseada por el cliente. } \\
\text { Énfasis tanto en la calidad de diseño } \\
\text { como de conformidad. }\end{array}$ \\
\hline
\end{tabular}




\begin{tabular}{cccl}
\hline $\begin{array}{c}\text { Parsuraman } \\
\text { Berry } \\
\text { Zeithaml }\end{array}$ & $\begin{array}{c}\text { Satisfacción de las } \\
\text { expectativas del } \\
\text { cliente }\end{array}$ & $\begin{array}{c}\text { Calidad satisfecha } \\
\text { (servicio) }\end{array}$ & $\begin{array}{l}\text { Alcanzar o superar las expectativas de los } \\
\text { clientes. } \\
\text { Énfasis en la calidad de servicio. }\end{array}$ \\
\hline Evans & Calidad total & $\begin{array}{c}\text { Calidad gestionada } \\
\text { (empresa y su sistema de } \\
\text { valor) }\end{array}$ & $\begin{array}{l}\text { Calidad significa crear valor para los } \\
\text { grupos de interés. } \\
\text { Eamble })\end{array}$ \\
& $\begin{array}{l}\text { Énfasis en la calidad en toda la cadena y } \\
\text { el sistema de valor. }\end{array}$ \\
\hline
\end{tabular}

Los autores hablan también de calidad como excelencia y de calidad total, pues en esta última definición se incluyen todas las demás conceptualizaciones parciales, a las que hay que añadir la calidad de servicio. Por tanto, se ocupan de la calidad desde el punto de vista del producto, del proceso, del servicio y del sistema de gestión.

En general, la doctrina en gestión de calidad propugna una diversidad conceptual de la calidad, pues el concepto es tan amplio que resultaría imposible que un modelo conceptual los abrazara todos (Reeves y Bednar, 1994, p. 400). Al contrario, en los últimos años se propugna por el concepto de calidad total que permite abordar la gestión de la calidad de manera holística, más eficaz y eficiente, de manera que coincidan la calidad esperada, la programada y la calidad realizada, lo que conlleva la satisfacción total del cliente (Camisón et al., 2006, pp. 193-197).

La estandarización normativa de la calidad se inicia en Estados Unidos de la mano de la American National Standards Institute (ANSI) para la normalización de la industria militar, y fueron desarrollándose varias normas teniendo en cuenta las necesidades de las industrias tecnológicas a fin de que sus productos respetaran ciertas especificaciones de calidad. El giro se produjo en 1984, cuando la British Standard Institute (BSI) propuso a la International Organization for Standardization (ISO), que había nacido en Ginebra en 1946 con el propósito de facilitar la coordinación y la unificación internacional de las normas industriales ${ }^{65}$, que desarrollara un estándar de SGC de uso universal basado en la norma que había creado en 1979, la BS 5759.

El conjunto de normas ISO surgió en 1987 con la voluntad de favorecer el comercio mundial. Se aplicaron el principio de Pareto y las mejoras en cuanto a aplicación estadística propuestas por Walter Stewart. Las normas más importantes para los SGC son la familia de normas 9000, cuyo reconocimiento es internacional. La adaptación nacional de dichas normas es competencia del organismo de normalización de cada país, que se encarga de la traducción al idioma local. La norma 9000 ha ido adaptándose y actualizándose varias veces a lo largo de los años, la última de las cuales fue realizada en 2015 .

\footnotetext{
${ }^{65}$ Para más información, se remite al sitio institucional de la ISO, disponible en: https://www.iso.org/about-us.html.
} 
La norma ISO 9001:2015 es una norma para el diseño, la gestión y la evaluación de sistemas de gestión, no para la certificación de calidad de los productos. La confianza que crea se extiende a la calidad de los productos. La norma ISO 9001 establece una serie de requisitos genéricos para el diseño y la implantación de un SGC, que se basan en distintos procesos: organización con su sistema de gestión, calidad y procesos (cláusula 4); liderazgo, política y responsabilidades (cláusula 5); procesos para la planificación y la consideración de riesgos y oportunidades (cláusula 6); procesos de soporte que incluyen los recursos, las personas y la información (cláusula 7); procesos operativos relacionados con los clientes, los productos y los servicios (cláusula 8); procesos para la evaluación del desempeño (cláusula 9) y procesos de mejora (cláusula $10)$.

Esta se complementa con la ISO 9000:2009, que establece unos fundamentos y un vocabulario con los principios fundamentales que inspiran la nueva versión. La ISO 9004:2015 establece las directrices para la mejora del desempeño, en las que se tiene en cuenta el aprendizaje y la evaluación. Se puede decir que las normas ISO 9001 y 9004 son complementarias, aunque la segunda no es certificable. A partir de 2000, se observa una aproximación de la ISO 9004 desde un modelo de aseguramiento a un modelo de la gestión de la calidad total (Camisón et al., 2006, p. 419).

A partir de la última década del siglo $\mathrm{XX}$, se ha producido una difusión de sistemas de gestión a otros ámbitos muy variados, como pueden ser la gestión de recursos humanos, la prevención de riesgos laborales o el turismo, hasta llegar a la exigencia de una responsabilidad social y de un comportamiento ético de la organización y de los miembros que la componen.

En la versión ISO 9000: 2005, la calidad recibe la definición de «el grado en el que un conjunto de características inherentes cumple con los requisitos» (ISO 9000:2005:3.1. Términos relativos a la calidad), donde características son entendidas como «rasgos diferenciadores» y requisitos como «necesidad o expectativa establecida, generalmente implícita u obligatoria». Las características pueden ser inherentes a un producto, a un proceso o a un sistema, y tienen relación con un requisito.

La versión ISO 9000:2015 recoge una definición ampliada y con matices nuevos de la calidad, que ya estaban presentes con todo en la nueva literatura que promueve la calidad total, donde la definición en castellano es la siguiente:

Una organización orientada a la calidad promueve una cultura que da como resultado comportamientos, actitudes, actividades y procesos para proporcionar valor mediante el cumplimiento de las necesidades y expectativas de los clientes y otras partes interesadas pertinentes. 
La calidad de los productos y servicios de una organización está determinada por la capacidad de satisfacer a los clientes, y por el impacto previsto y el no previsto sobre las partes interesadas pertinentes.

La calidad de los productos y servicios incluye no solo su función y desempeño previstos, sino también su valor percibido y el beneficio para el cliente (ISO 9000:2015, pp. 7-8).

Se puede observar, por tanto, un cambio de orientación en la definición, pues se incluye el valor que proporciona un producto o servicio en el concepto intrínseco de calidad. Por otra parte, la calidad de los productos o servicios no depende de la satisfacción que produce en los clientes, sino también del impacto previsto o imprevisto que puede provocar. Al mismo tiempo, añade también la percepción de la calidad y el beneficio.

\subsubsection{La gestión de la calidad}

Como ya se ha expuesto en los párrafos anteriores, el concepto de gestión de calidad varía dependiendo del enfoque que se siga. De hecho, dicho concepto se había abordado de manera parcial hasta la llegada de la gestión de la calidad total «que lo dota de un contenido multidimensional» (Camisón et al., 2006, p. 209) que abraza los distintos aspectos técnicos, organizativos, culturales y estratégicos.

Los diferentes enfoques reciben la influencia de los principios, las prácticas y las técnicas que los fundamentan. Se puede decir que los enfoques pasan de un control del producto a una gestión de la calidad.

Por consiguiente, la asunción de un enfoque específico llevará a admitir principios específicos, a implementar técnicas que permitan poner en práctica dichos principios y a desarrollar técnicas que hagan efectivas dichas prácticas (p. 211). Por otra parte, se crearán instrumentos de evaluación específicos para poder analizar los resultados, que adolecen del grado de diversidad a la hora de identificar los factores críticos, por lo que carecen a veces de una visión holística en la diversidad (Sila y Ebrahimpour, 2003).

Existen varios acercamientos a la gestión de la calidad, que se distinguen teniendo en cuenta los principios que determinan la acción corporativa y, con ellos, las prácticas y técnicas adoptadas para conseguirlos. Partiendo de un enfoque de la calidad cuyo propósito era corregir los errores, se ha pasado a otro orientado a prevenirlos. Al mismo tiempo, se han ido incorporando otros principios como son el de la economicidad, la mejora continua, el compromiso, el liderazgo, el aprendizaje, la satisfacción o la innovación, hasta llegar a responsabilidad social y corporativa y la creación de liderazgo, cooperación, aprendizaje, innovación, creación de valor y responsabilidad social. Estos principios que han ido enriqueciendo al concepto de gestión de la calidad 
han llevado a que la responsabilidad pasara de estar en manos de la producción a otros ámbitos de la empresa, como el marketing y los recursos humanos, a desembocar en la concepción de una obligación de la dirección general de la empresa, que implica a los miembros de la empresa y también a los proveedores.

\subsubsection{Modelos normativos de gestión de la calidad}

Los distintos enfoques de gestión de calidad conllevan que se pongan en práctica sistemas de gestión de la calidad (SGC) distintos, que implican su diseño, la implantación y su certificación. Según Camisón et al::

El sistema de gestión de una organización es el conjunto de elementos (estrategias, objetivos, políticas, estructuras, recursos y capacidades, métodos, tecnologías, procesos, procedimientos reglas e instrucciones de trabajo) mediante el cual la dirección planifica, ejecuta y controla todas sus actividades para el logro de los objetivos establecidos (2006, p. 346).

Si nos fijamos en la norma ISO 9000:2015, se define el sistema de gestión de la calidad de la siguiente manera:

Un SGC comprende actividades mediante las que la organización identifica sus objetivos y determina los procesos y recursos requeridos para lograr los resultados deseados.

El SGC gestiona los procesos que interactúan y los recursos que se requieren para proporcionar valor y lograr los resultados para las partes interesadas pertinentes. EL SGC posibilita a la alta dirección optimizar el uso de los recursos considerando las consecuencias de sus decisiones a largo y corto plazo.

Un SGC proporciona los medios para identificar las acciones para abordar las consecuencias previstas y no previstas en la provisión de productos y servicios ${ }^{66}$.

A lo largo de los años, han ido estableciéndose modelos normativos de gestión de la calidad, que pueden considerarse «marcos que brindan consejo y guía sobre cómo operativizar y poner en práctica los principios, las prácticas y los métodos de control, gestión y mejora de la calidad desde un enfoque determinado» (Camisón et al., 2006: p. 345) y permiten la mejora y el aseguramiento de la calidad. Estos modelos se basan en la normalización o estandarización de la calidad, ayudan a identificar cuáles son los elementos que debe incluir un SGC, los principios que han de inspirar su diseño y puesta en práctica y la manera de implantarlo y actualizarlo. Posteriormente, dichos modelos han de ser auditados para permitir así su acreditación a través de entidades específicas. Puede considerarse un trabajo colectivo en el que se unifican los distintos

\footnotetext{
${ }^{66}$ Disponible en https://www.iso.org/obp/ui/\#iso:std:iso:9001:ed-5:v1:es
} 
criterios de las partes interesadas. La certificación avala que una organización cumple con las directrices de la norma, conlleva la emisión de un documento y su vigencia. En general, dicha certificación comporta el derecho a usar una marca de calidad específica. Para poder otorgar dicha autentificación, las organizaciones han de poseer un certificado de acreditación que, según la Entidad Nacional de Acreditación Española (ENAC), es «la herramienta establecida a escala internacional para generar confianza sobre la correcta ejecución de un determinado tipo de actividades denominadas actividades de evaluación de la conformidad y que incluyen, entre otras, ensayo, calibración, inspección, certificación o verificación $»{ }^{67}$. Por ello, cualquier actividad cuyo propósito sea evaluar la conformidad de un producto, servicio o sistema puede estar sujeta a la acreditación. Los evaluadores de la conformidad han de demostrar una competencia técnica según unos requisitos establecidos en normas internacionales, que serán luego la base para el reconocimiento global: en España, es la Entidad Nacional de Acreditación (ENAC); en Italia, el Ente Nazionale Italiano di Normazione (UNI). Por tanto, puede decirse que los modelos normativos de SGC descansan sobre cuatro pilares: la norma de calidad, el sistema de certificación, la marca de calidad y el ente gestor.

\subsubsection{La calidad en el servicio}

Los servicios poseen una naturaleza y unas características específicas que distan de las de los productos, y por esta razón han de ser gestionados de distinta forma. En este caso, la calidad percibida por el cliente y por el usuario cobra una gran importancia. A continuación, se presentan distintos enfoques acerca de la gestión de calidad.

Camisón et al. establecen dos definiciones, ya que la calidad en el servicio puede ser tanto «las actividades económicas que integran el sector terciario de un sistema económico» o «servicio como prestación principal de una empresa» como cuando se refiere al sistema industrial como un «servicio como prestaciones accesorias o secundarias que acompañan a la prestación principal» (2006: pp. 893-894). Ferro (2012), Stanton, Etzel y Walter (2007, p. 301) la definen como «actividades identificables e intangibles que son el objeto principal de una transacción diseñada para brindar a los clientes satisfacción de deseos o necesidades» y excluyen los servicios complementarios. Kotler, Bloom y Hayes (2002/2004, p. 27) señalan asimismo que los servicios se distinguen de los productos por su carácter «intangible, inseparable, variable y perecedero» en los que el cliente participa en el proceso y difieren en el criterio de satisfacción. Son intangibles porque no se pueden palpar, e inseparables

\footnotetext{
${ }^{67}$ Para más información, se remite a: (https://www.enac.es/que-hacemos/-que-es-la-acreditacion-
} 
porque no se pueden separar del proveedor en cuanto al tipo de profesionalidad, apariencia y conducta. La calidad puede variar porque no se puede desligar de las personas, que no son infalibles. Como señalan los autores, «una de las características distintivas de los servicios es que el proveedor está vendiendo básicamente un desempeño» (2002/2004, p. 29).

De la misma forma, la medición de la calidad del servicio difiere de la del producto, pues es mucho más difícil de evaluar y ponderar, ya que hay que tener en cuenta tanto el proceso como el resultado del servicio. El carácter intangible de todos los servicios implica dificultades para estandarizar la calidad y establecer las especificaciones (Zeithaml, 1981, en Camisón et al., 2006, p. 895). En ella tiene gran importancia la percepción del servicio que poseen los clientes, es decir, la calidad percibida.

La percepción de la calidad es subjetiva y variable. Además de este concepto, cabría hablar también de la satisfacción del cliente que sería «la medida de la reacción emocional del consumidor en cada experiencia específica» (p. 898), y está profundamente interrelacionado con el anterior. Se podría decir, por tanto, que la calidad percibida es más estable que la satisfacción, que cambiaría cada vez.

El concepto de zona de tolerancia de las expectativas del cliente en relación con la calidad del servicio fue introducido por Parasuraman, Zeithaml y Berry (1991). Dicha zona está acotada por dos niveles extremos de servicio: por una parte, se encuentra el servicio deseado, que aquel al que aspira un cliente, es decir, el servicio ideal; por otra, el servicio adecuado, que es aquel que puede considerarse como aceptable. Dichos autores consideraron cinco dimensiones de la calidad del servicio: los elementos tangibles, la fiabilidad, la capacidad de respuesta, la seguridad y la empatía.

Por lo que atañe a la medición, esta es muy importante para poder mejorar la calidad del servicio. La dificultad mayor estriba precisamente en la falta de medidas objetivas. Según Davidow y Uttal (1990, en Camisón et al., 2006, p. 916), los mejores sistemas de medición tienen en cuenta el proceso de prestación del servicio, el producto o el resultado y la satisfacción del cliente. Han de tener en cuenta las expectativas, que pueden ser con todo variables.

A partir de los años noventa se han ido desarrollando sistemas de medición de la calidad del servicio teniendo en cuenta la satisfacción del cliente, medida como la diferencia entre sus expectativas y la percepción que recibe del modelo prestado. Los modelos más famosos son el modelo SERVQUAL (Service Quality), cuestionario desarrollado por Parasuraman, Zeithaml y Berry (1991), en el que se sugiere que la discrepancia entre las expectativas generales de los clientes y sus percepciones del servicio pueden constituir una medida de calidad. Ha sido muy utilizado para medir la 
calidad percibida del servicio y para la gestión de las expectativas, aunque ha recibido muchas críticas precisamente por ello. Otros ejemplos son el modelo SERVPERF, desarrollado por Cronin y Taylor (1992), que deriva de él, el modelo del Desempeño Evaluado (EP) de Teas (1993) y el modelo de la Calidad Normalizada (NQ), también de Teas (1993). A la vez, algunas empresas iban desarrollando sus propios cuestionarios y modelos de evaluación.

Al mismo tiempo que se establecen sistemas de evaluación, se han ido estableciendo sistemas de reclamación y corrección a fin de mejorar la calidad del producto o servicio y aumentar la satisfacción del cliente.

\subsection{La calidad en la interpretación}

\subsubsection{Introducción}

La calidad en la interpretación es uno de los conceptos clave en los estudios de interpretación y está presente en la mayoría de las áreas que se han ocupado del estudio de la interpretación, desde la cualificación individual, el desempeño de las tareas, la formación de las destrezas necesarias e incluso el entrenamiento. Todavía no existe un consenso universal sobre el significado de la calidad, los criterios que han de utilizarse para definirla y el modo de evaluar dichos criterios de manera objetiva (Collados Aís y Gile, 2002; Collados Aís y García Becerra, 2015a). Resulta difícil definir la calidad, pues hay que tener en cuenta una serie de aspectos que involucran a un número diferente de actores (intérpretes, clientes usuarios y ponentes), y cada uno de ellos tiene su propia percepción de la calidad (Garzone, 2002, p. 107).

Algunos autores apuntan que existe una desconfianza generalizada con relación a la figura del intérprete, pues los usuarios «contemplan con escepticismo al verse incapaces tanto de comprobar su corrección en el momento de su producción - de ser así no la necesitarían- como de someterla a una valoración posterior» (MartínezGómez, 2011, p. 87). Una interpretación equivocada puede pasar desapercibida y en algunas situaciones puede provocar hilaridad, debido también a su propio carácter efímero. Sin embargo, en ciertos contextos puede tener consecuencias nefastas para la salud de las personas con una diagnosis equivocada, minar la defensa y los derechos fundamentales de una persona, provocar graves crisis diplomáticas e incluso trastocar el orden mundial (Martínez-Gómez, 2011, p. 88). En cuanto a los servicios públicos, la ausencia de calidad puede tener repercusiones muy serias para la vida de las personas (Hale, 2007, p. 26; Corsellis, 2008; Corsellis y Fernández Leandro, 2001, entre otros). 
Como en otras actividades dirigidas a proporcionar un servicio, el interés por la calidad en los estudios de interpretación ha ido creciendo a lo largo de los años, a medida que se iba definiendo el concepto de calidad y también el acercamiento a una gestión de la calidad. Puede considerarse, por estas consideraciones, que la investigación sobre la calidad en interpretación es una de las áreas de investigación más cohesionadas y fructíferas, teniendo en cuenta la cantidad de estudios que se han llevado a cabo desde la década de los ochenta (Collados Aís y García Becerra, 2015b, p. 368), que ha dado como resultado una gran cantidad de trabajos empíricos.

En este apartado se intentará presentar el concepto y la definición de la calidad según la opinión de los autores que se han ocupado de ella. A continuación, se expondrán distintos enfoques en relación con el estudio de la calidad en interpretación. Más adelante, se hará referencia a los estudios de calidad hasta la fecha, refiriéndose a los puntos fundamentales.

\subsubsection{Hacia una definición del complejo concepto de calidad en interpretación}

Al igual que en los sectores de producción y de servicios, de los que forma parte la interpretación, no existe una definición clara, precisa, universal y compartida sobre lo que significa el término calidad, que podría aplicarse a todos los eventos de interpretación a través de los distintos contextos culturales y sociales. Algunos autores estiman el término como elusivo, como los miembros de la AIIC (1982), que se refieren a ella como «that elusive something which everyone recognises but no one can successfully define» o «escurridizo» (Shlesinger, 1997). Kahane, por su parte, afirma que «vivimos en un mundo obsesionado por la calidad» (2000), y otros autores suponen que el concepto aceptado para el marketing no puede aplicarse sin más a la interpretación de conferencias (Kurz, 2001). Como se ha constatado en páginas precedentes, tampoco en los estudios relativos a la gestión de la calidad existe una conceptualización unitaria del término.

Las definiciones serán, por tanto, múltiples y a veces contradictorias, pues subrayan algunos aspectos de la calidad que dependerán del objeto que se está estudiando, como pueden ser el entorno, la modalidad, la epistemología subyacente o su enfoque teórico (Grbić, 2015, p. 334).

Las reflexiones teóricas sobre la calidad de la interpretación constituyen un objetivo primordial tanto para las escuelas de intérpretes como para las asociaciones profesionales. Gile y Collados (2002) concluyen que la calidad se mide según el éxito del acto de comunicación, y que no existe una calidad absoluta, sino varios puntos de 
vista. A partir de los años ochenta, se realizaron algunos trabajos teóricos que marcaron las bases de los futuros trabajos empíricos, que siguen siendo actuales. Cartellieri (1983) apuntaba ya entonces que era preciso fijar una serie de características cuya cantidad podrá convertirse en criterios de calidad, y que había mucho por hacer.

La calidad puede evaluarse desde perspectivas muy variadas, que incluyen a los intérpretes, a los usuarios, a los intermediarios y a los formadores, dependiendo del propósito final de la comunicación (Moser-Mercer, 1995, p. 46). Ello dará como resultado que la calidad se evalúe dependiendo de estándares impuestos por los intérpretes o bien en opiniones, necesidades y expectativas de los usuarios. Influirán también una serie de condiciones situacionales (Moser-Mercer, 1996, p. 44). Gile (1995) señala que la calidad ha de ser vista como una suma ponderada y objetiva de una serie de elementos (1991a), en la que el valor de cada componente procede de los rasgos que definen el contexto y el punto de vista del evaluador. Sin embargo, el mismo autor defiende que el éxito o el fracaso de la interpretación no está relacionado de manera intrínseca con la calidad (Gile, 1991b), pues el éxito no garantiza que el intérprete haya desempeñado bien su trabajo ni que el fracaso suponga una calidad deficiente. El estudioso sostiene que, para poder comprender de manera concreta el concepto de calidad en interpretación, hay que referirse al papel del intérprete (1995, p. 40). En un trabajo posterior (2003), reitera el concepto de que la calidad de la interpretación varía según los usuarios y define la calidad de la interpretación como la suma de la fidelidad informativa, la propiedad de lenguaje, la calidad de la voz y la situación, proponiendo una fórmula matemática para describirla. Esta definición se basa en el resultado y no en el proceso, porque lo que cuenta al fin y al cabo es el producto final.

Garzone (2002) sostiene que el concepto de calidad en interpretación varía dependiendo de la percepción de los distintos actores y retoma la cuestión de la capacidad de los usuarios de juzgar la calidad de las interpretaciones planteada por Déjean Le Féal et al. (1997). Shlesinger (1997, p. 128) parte de la premisa de que las distintas definiciones de calidad han sido interiorizadas por los intérpretes y deberían ser analizadas a nivel intertextual, comparando el discurso original y el meta, a nivel intratextual como producto independiente, e instrumental como servicio. La calidad ha de considerarse, pues, como un concepto dinámico.

Pöchhacker $(1994 ; 2001 ; 2004,2014)$ afirma que la situación comunicativa es una «socio-psychological constellation of interacting parties» (Pöchhacker, 1994, p. 236), y que la teoría de la interpretación debe analizarse en el marco de la teoría del skopos, dentro de la teoría general de la translación, pues se configura un marco teórico amplio y se ocupa de la interpretación como producto. Los diferentes criterios dependen unos de otros (2001, p. 413), e incluye en este esquema el éxito de la comunicación: 


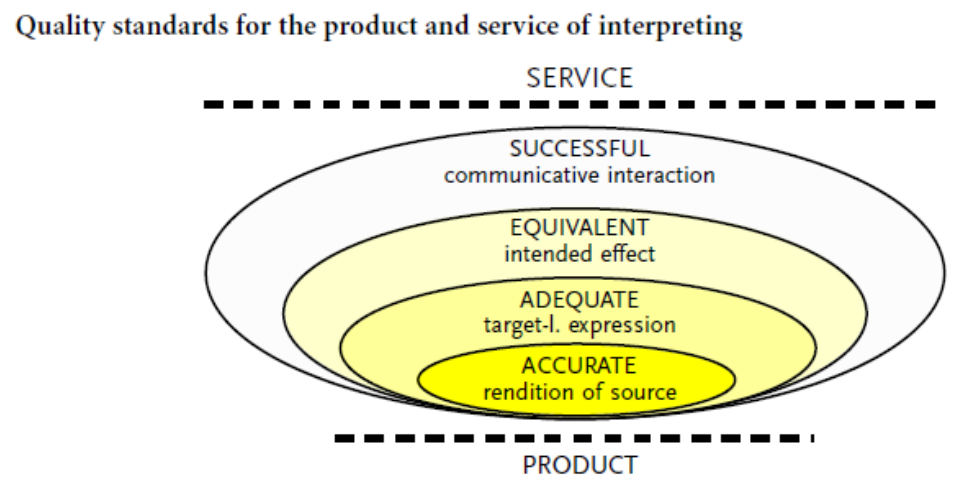

Figura 2: Modelo de calidad según Pöchhacker (2001, p. 413)

Expone, pues, que la calidad ha de considerarse como un concepto global donde todos los aspectos del producto y de la función del intérprete desempeñan un papel esencial «not as a self-contained topic but as a complex, overarching theme in which all aspect of the interpreters product and performance -textuality, source-target correspondence, communicative effect, and role performance- play an integral part (Pöchhacker, 2004, p 153). El estudioso se referirá a ella como una noción compleja y multidimensional (Pöchhacker, 2012).

En sus contribuciones, Viezzi (1996, 2003, 2007, 2011) parte de un enfoque funcionalista y elabora una serie de parámetros que permitan estudiar desde el punto de vista científico lo que difícilmente se puede medir partiendo del supuesto de que la interpretación es un servicio. Por ello, intenta dar un enfoque global a la calidad en interpretación, teniendo en cuenta estos criterios: equivalencia, en la que el discurso interpretado tendría el mismo efecto del discurso original, precisión y transmisión correcta del contenido semántico, adecuación a las convenciones estilístico-retóricas y a la cultura de los usuarios y la utilidad ${ }^{68}$, que hace que el texto sea comprendido.

La estudiosa Kalina $(2002 ; 2005 ; 2015)$ define la interpretación como un proceso de comunicación interactivo y considera que no puede ser juzgada únicamente por la producción del intérprete. Ha de establecer, por tanto, un proceso de interacción donde las condiciones de trabajo influyen en el resultado final. Fija una serie de parámetros que asegurarán la calidad del evento, y analiza las diferentes fases del proceso, teniendo en cuenta la situación comunicativa, las intenciones y los conocimientos de los distintos actores, entre los que se encuentra también el mismo intérprete.

En este nuevo paradigma de los estudios sobre la calidad de la interpretación, es importante señalar la introducción de un elemento que confiere un cambio de visión, ya

${ }^{68}$ Viezzi utiliza el término fruibilità en italiano (1996: 100-105; 2007: 149-151) y usability en los trabajos en inglés (2002; 2014, p. 134). 
que la calidad en interpretación se está dejando de ver como algo «volátil», ya que hoy en día es posible grabar las interpretaciones con distintos métodos digitales (Kalina, 2015, p. 16). El problema puede plantearse desde el punto de vista de la ejecución, pues existe un posible conflicto entre el acto comunicativo oral, volátil en sí mismo, efímero y con cierto grado de improvisación, en relación con la traducción escrita, y los nuevos sistemas de grabación y conservación de dicha comunicación oral.

Numerosos autores que se han ocupado de la calidad en la interpretación, principalmente en la interpretación de conferencias, concuerdan que es preciso aplicar una serie de parámetros para poder evaluar la calidad, aunque difieran sobre el peso que cada uno de ellos posee, pues dependerá también de la definición del papel del intérprete, de la metodología seguida, de los enfoques interdisciplinarios y los dominios de interpretación (Collados Aís y García Becerra, 2015b, p. 337). Bühler (1986) fijó una serie de parámetros en época temprana y, desde entonces, se han intentado definir e identificar los parámetros que influyen en una buena interpretación (Mack y Cattaruzza, 1995; Vuorikoski, 1998; Collados Aís, Pradas Macías, Stévaux y García Becerra, 2007; Collados Aís, Iglesias Fernández, Pradas Macías y Stévaux, 2011; Collados Aís y García Becerra, 2015a y b).

Según Martínez-Gómez, existirían dos concepciones de calidad en interpretación: la que «entiende la interpretación de un mensaje textual y la calidad, por tanto, como equivalencia, forma, contenido y presentación, que concibe la interpretación como un acto comunicativo interlingüístico en sí mismo, y la calidad como resultado de la capacidad de optimizar los actos de habla en el contexto de una situación comunicativa concreta» (2011, p. 168).

Si se considera que la interpretación es un servicio cuyo propósito es facilitar la comprensión entre las personas, sería lógico pensar que dicho servicio se rige por reglas (Collados Aís y García Becerra, 2015a, p. 370). Los primeros que abordaron dicho tema fueron Shlesinger y Harris. Shlesinger (1989, p. 112) planteó la importancia que desempeñan las normas en el producto y en el proceso de interpretación y la existencia de un nexo entre las reglas y el contexto comunicativo, de forma que las definiciones que existen sobre la calidad en interpretación reflejan las reglas que han hecho suyas los intérpretes, aún sin ponerse de acuerdo en la definición. Propone el concepto de normas que ya se estaba utilizado en traducción (Toury, 1980; Chesterman, 1999) como una herramienta para explicar la variabilidad de los criterios de calidad y las normas de los usuarios y los intérpretes. La calidad es, pues, un concepto normativo y se convierte en un compromiso entre la calidad ideal y las condiciones reales. Harris (1990) subrayó la variabilidad de normas, ya que dependía de la configuración misma de la interpretación. 
Las reglas y normas tienden a ser implícitas y rigen los códigos deontológicos y las normas profesionales que adoptan las distintas asociaciones de intérpretes, como pueden ser AIIC o la Dirección General de Interpretación de la Unión Europea (SCIC). Esto ha llevado a que algunos organismos de normalización hayan desarrollado normas de interpretación, como es el caso italiano de la UNI 10547:1996. No que hay que olvidar, sin embargo, que las normas pueden variar a medida que se produce una evolución de la profesión, en función del tipo de mercado, del tipo o de la modalidad de interpretación (Collados Aís y García Becerra, 2015a, p. 370). Esto se debe a que las normas de calidad deben adaptarse a la situación de una interpretación específica y a las limitaciones que dicha situación impone (Straniero Sergio, 2003, p. 171).

Grbić (2008) analiza la noción de calidad como relativa y dinámica, pues depende del evaluador y del contexto dado. La calidad en interpretación puede ser vista como el cumplimiento de las normas de calidad, el resultado de un proceso estratégico, una acción de soporte a las normas, un deber ético, la satisfacción de las expectativas de los clientes y el equilibrio entre el servicio real menos el servicio esperado. Presenta varios enfoques de la calidad en interpretación con el propósito de explorar algunos posibles baremos, señalando distintas dimensiones de la calidad en interpretación:

- calidad como excepción, reservada a una élite o de acuerdo con unos estándares muy rígidos, objetivos y estáticos, que es la visión de AIIC en la imposición de estándares extremadamente elevados, que se convierten en elitistas;

- calidad como ausencia de errores. Este enfoque no tiene en cuenta las distintas motivaciones que pueden alejar al discurso meta del discurso original. Otra perspectiva tiene que ver con el desarrollo de una cultura general de calidad, que es percibida como una misión colectiva. Un ejemplo de ello puede llegar de las asociaciones profesionales;

- calidad conforme a la finalidad, como actitud para un propósito dado. Puede identificarse con la satisfacción de las expectativas del cliente, que no siempre son realistas, pues el cliente desconoce las dificultades y las constricciones que provocan algunas situaciones; puede ser una calidad que tiene que ver con la remuneración, es decir, value for money (2008, p. 249);

- por último, puede ser vista como una misión, determinada directamente por el proveedor del servicio, que es quien fija las normas, como sucede en los sistemas de certificación de la calidad.

La autora apunta los posibles puntos de convergencia que se encuentran entre los distintos enfoques, considerando la calidad como un constructo social. 
Zwischenberger (2015) reitera la complejidad del concepto de calidad que ha ido evolucionando y que posee un carácter multidimensional, pero a la vez insiste en que la calidad es una característica que puede medirse, como refleja la misma norma ISO:

While the idea of quality as exceptionally high performance has largely been displaced by the assumption that quality is a common feature that can (and must) be measured, fitness for purpose is reflected, for instance, in the ISO definition, which stipulates that a product or service must meet specified needs or requirements, but also in functionalist theoretical approaches to translation and interpreting (2015, p. 334).

El concepto de calidad podrá aplicarse, pues, a varias dimensiones, a productos materiales que podrán basarse en la grabación y en la transcripción de una interpretación a procesos mentales, como cuando se analiza el resultado obtenido por un intérprete en relación con el uso de ciertas estrategias, o que depende de algunas acciones sociales, por ejemplo, el análisis de la interacción cara a cara mediada por intérprete u observar una conferencia como un hipertexto (Grbić, 2008).

\subsubsection{El paradigma de la calidad en la interpretación: evolución de los estudios}

En los albores de la interpretación como disciplina, las primeras aportaciones sobre la calidad fueron las realizadas por los llamados practitioners (Gile, 1995), quienes buscaban mejorar la práctica profesional, su reconocimiento y la acreditación. De esta manera, su interés por la calidad puede compararse en cierto modo a la de los gremios profesionales durante la Edad Moderna. Cabe citar el estudio realizado por Barik $(1971 ; 1975)$ y propuesto de nuevo en 1994, que se proponía describir la interpretación en función de un sistema de cómputo de errores respecto al texto fuente, que considera «desviaciones» y clasifica en omisiones, adiciones, sustituciones-errores de traducción y alteraciones, detectadas en una serie de interpretaciones simultáneas excluyendo explícitamente de sus propósitos la evaluación de la calidad. Pero, como señala Viezzi (1996), el sistema de clasificación que adopta es intrínsecamente un sistema de evaluación de la calidad, y como tal ha sido considerado. El estudio puede ser contemplado desde un punto de vista lingüístico y no pragmático, ya que la calidad es vista como un conjunto de normas rígidas de equivalencia. Aunque no existiera la noción de calidad, este planteamiento, al igual que el de Gerver sobre la inteligibilidad (1969/2002; 1975), estaba centrado en el estudio del proceso.

Más adelante, siguiendo la corriente de los estudios generales de calidad expuestos en este capítulo, que parten de la calidad del producto y evolucionan hacia el servicio, también en interpretación, comienza a desarrollarse un interés cada vez mayor 
por la calidad en interpretación. Durante las dos últimas décadas del siglo XX, se llevan a cabo los primeros estudios experimentales que tendrán una gran importancia para el establecimiento del paradigma de calidad en interpretación, como el trabajo pionero de Bühler (1986). Se realizan también estudios de caso, como el de Gile (1990) y la investigación de Collados Aís (1998) sobre la importancia de la comunicación no verbal, o el trabajo sobre la calidad en interpretación llevado a cabo por Peter Moser (1996), que le fue encomendado por el Comité de Investigación de la AIIC, sobre la evaluación cualitativa del servicio de interpretación simultánea (IS).

Desde entonces, la asociación ha seguido preocupándose por la cuestión de la calidad, fomentando cursos y seminarios en aras de mejorar la percepción de la calidad de sus asociados. En su sitio web institucional se recogen y actualizan las aportaciones de los estudios sobre calidad, como el publicado por Kahane (2000), la encuesta llevada a cabo en 2008 por Pöchhacker y Zwischenberger (2010) y contribuciones en blogs (Tiselius, 2011), así como la recopilación de la bibliografía actualizada. AIIC es probablemente la asociación más prestigiosa en el mundo de intérpretes de conferencias, pero otras asociaciones también están trabajando para obtener unos estándares unificados, como por ejemplo la American Translation and Interpreting Studies Association (ATISA), la European Legal Interpreters and Translator Association (EULITA) en Europa, la Associazione Italiana Interpreti Traduttori (AITI), la Associazione Italiana Traduttori e Interpreti Giudiziari (AssITIG) en Italia, o la Asociación Profesional de Traductores e Intérpretes Judiciales y Jurados (APTIJ) en España, entre otras.

A partir de la última década del siglo XX, empiezan a celebrarse conferencias y congresos que se centran precisamente en la calidad. Cabe destacar la Conference in Interpretation Research en Turku (1994), la Translation and Interpretation: Models in Quality Assesment en Saarbrücken (2000) o Interpreting in the 21st Century: Challenges and opportunities en Forlì (2000). Este interés académico culminará en el primer congreso internacional sobre evaluación de la calidad en interpretación de conferencia celebrado en Almuñécar (Granada) en 2001. A él acudieron los principales estudiosos del momento y obtuvo una gran notoriedad y participación. Contó con una gran participación y ello permitió compartir ideas, que habían proliferado desde el punto de vista cuantitativo y cualitativo. Algunos estudios se ocuparon de la incidencia relativa de los componentes de la calidad en las diferentes situaciones comunicativas y entre los distintos usuarios (Kurz, 2001), la interpretación de relé (Waliczek, 2003) la interpretación en psicoterapia (Bof, 2003), la respuesta de los usuarios a la prestación del intérprete y la comparación con sus expectativas (Garzone, 2003), en el que señala que los usuarios no son fiables a la hora de evaluar la exposición de los intérpretes. 
Algunos trabajos se centraron en ciertos parámetros de análisis de la calidad: las autocorrecciones (Petite, 2003), el acento (Cheung, 2003), la fluidez (Pradas Macías, 2003). Fueron también importantes las reflexiones que se consideraron en cuanto a los parámetros que se deben tener en cuenta (Harris, 2003; Viaggio, 2003; Collados Aís, 2003; Fernández Sánchez, 2003; Stévaux, 2003; Von Bernstorff, 2003, entre otros), a la formación, a ciertas figuras profesionales, como el intérprete en los servicios públicos (Valero Garcés, 2003), o los nuevos sistemas de interpretación, como la videoconferencia (Jiménez Serrano, 2003). Durante el congreso, se marcaron una serie de objetivos sobre el tema de la calidad en interpretación, a la vez que se señalaron las dificultades que plantea metodológicamente la investigación en este campo, y se llegó a una serie de conclusiones, pues se habían realizado un gran número de estudios empíricos, como se señala en la introducción:

La investigación sobre la calidad es quizás el campo de investigación en interpretación donde se ha llegado a un mayor índice de replicación, sobre todo en los estudios acerca de las expectativas, lo que ha llevado a la confirmación de algunos resultados y a la redefinición de otros (Collados Aís, Fernández Sánchez y Gile, 2003, p. X).

Desde entonces, el interés por la calidad en interpretación ha ido aumentando de manera exponencial (Gile, 2003), ampliando su disposición más allá de la interpretación de conferencias e incluyendo del campo de investigación a la formación, la certificación, la interpretación a distancia y los servicios públicos. En 2011 se celebró el II Congreso Internacional sobre Calidad en Interpretación en Almuñécar, y en 2017 el III Congreso sobre Calidad en Interpretación en Granada. Al mismo tiempo, los congresos de la asociación Critical Link se ocupan desde 1992 de la calidad en los servicios públicos, donde dicho aspecto se convierte en una de las mayores preocupaciones en el sentido más amplio (Grbić, 2015, p. 334), organiza conferencias, publica un boletín de noticias y promueve otras actividades. De hecho, la celebración del primer congreso que organizaron en Canadá en 1995, The Critical Link: Interpreters in the Community, marcó el nacimiento de los estudios de interpretación en los servicios públicos (Martin, 2003, p. 435). En dichos congresos se reunieron los principales estudiosos e intérpretes del sector para discutir y promover los aspectos más importantes de dicho perfil profesional, entre los que se encontraba la calidad. 


\subsubsection{Estudios empíricos sobre la calidad en la interpretación}

Por lo que respecta a los estudios empíricos, en este apartado se hablará de forma generalizada de los estudios de interpretación, que partieron fundamentalmente de la interpretación de conferencias, sobre todo en interpretación simultánea y en menor medida de interpretación consecutiva. Dichos estudios se pueden dividir en dos grupos fundamentales:

a) los que se centran en el producto, tanto por lo que respecta a las expectativas como los que se centran en la evaluación del producto final;

b) los que se ocupan principalmente del proceso, que tienen una importancia fundamental para la formación de los futuros intérpretes, o los que analizan la influencia de las condiciones de trabajo en la calidad o en la evaluación de la calidad desde un enfoque formativo.

La percepción de calidad de los usuarios puede ser una herramienta útil para investigar su nivel de satisfacción y el grado en que se cumplen sus necesidades en el desempeño de los intérpretes, pero se debe realizar otro tipo de estudio para abordar la calidad desde la perspectiva del proceso de interpretación.

Gile (1988, p. 15) ofrece una visión de la calidad como proceso cuando la define como el equilibrio óptimo entre los diferentes esfuerzos requeridos por el proceso de interpretación (escucha, memoria y producción). Sostiene que la calidad se deteriora cuando la capacidad se sobrecarga en una de estas áreas, como lo evidencia la pérdida de información o las deficiencias del lenguaje, o incluso la falta de claridad o coherencia en la interpretación (Collados Aís y García Becerra, 2015a, p. 371).

Martínez-Gómez (2011) recoge que existen varios momentos en los que un intérprete puede verse sometido a la evaluación de su desempeño, con una finalidad diferente en cada caso, y esto ha influido en los distintos tipos de estudios. Estos momentos son el acceso a la profesión, la formación, la acreditación y, por último, mientras lleva a cabo su actividad profesional; todos estarán presentes en los distintos estudios que tocan el tema de calidad.

Grbić indica que la complejidad de los estudios empíricos sobre calidad en interpretación está relacionada con la combinación de tres rasgos axiomáticos: la variabilidad del desempeño, la relatividad de los juicios dependiendo de las perspectivas de los evaluadores, y el proceso de evaluación con referencia a ciertos criterios $(2015$, p. $334)$. 
En España, la principal contribución llegó de la mano de Collados Aís (1998), quien investigó en su tesis doctoral sobre la influencia de la comunicación no verbal en la evaluación de la IS y, en concreto, de la evaluación de usuarios habituales de IS y de intérpretes de una interpretación monótona. En este caso, el intérprete no distorsiona el contenido y la presentación, porque la ponencia fue monótona. De esta forma, plantea el problema de la invisibilidad del intérprete, su implicación. Los resultados que obtuvo demostraron que existe una separación neta entre las expectativas de calidad, la percepción y el éxito de la IS y la evaluación. Retomó conceptos que ya habían sido señalados en trabajos precedentes (Gile, 1994), como que los receptores no son buenos evaluadores porque no pueden serlo. Se manifiesta una prioridad por el contenido sobre la forma, como ya habían demostrado los trabajos anteriores. Los receptores no percibieron los errores de contenido, por lo que la valoración fue nula. Por su parte, la entonación monótona fue indicada negativamente en la valoración de usuarios e intérpretes, y esto pone en tela de juicio las conclusiones de los trabajos anteriores (Kurz, 1993; Marrone, 1993, Vuorikosky, 1993; Kopczynki, 1994, Moser, 1995). El punto más importante es, quizá, que en la evaluación de la calidad de la interpretación no se puede dejar al margen ningún parámetro que incida en el concepto de calidad o éxito de esta, pues se trata una actividad comunicativa.

El trabajo de Collados fue experimental y no utiliza situaciones reales, sino manipuladas. Demostró que las expectativas genéricas respecto a componentes no verbales de calidad considerados menos importantes pueden no reflejar el impacto real en la evaluación de los usuarios finales de una interpretación simultánea.

Como señala Pöchhacker, la tesis de Collados Aís fue seminal:

... in both its thematic and its methodological orientation, that study proved seminal in several ways, not least as the foundation stone upon which more comprehensive research [...] came to be built. (2007, p. XVIII)

Se ha considerado que el estudio dio un salto cualitativo, pues tuvo en cuenta el producto en conjunto, no solo sus partes, incluyendo las circunstancias (Soler Caamaño, 2006). El trabajo de Collados Aís se convirtió en fuente de inspiración y punto de partida de estudios similares que versaban sobre otros aspectos de la calidad, como por ejemplo la tesis doctoral de Pradas Macías en 2003 (publicada en 2004). Collados Aís, Pradas Macías, Stévaux y García Becerra (2007) replican dicho diseño experimental y lo aplican a once parámetros textuales y no verbales por medio de manipulación de los parámetros. El estudio confirma las diferencias existentes entre expectativas y evaluación (Collados Aís et al. 2007, p. 220). El trabajo ha sido valioso por su carácter interdisciplinar, la vinculación entre los distintos parámetros y un enfoque que incluye 
estudios de cognición y análisis textuales, entre otros. Errico (2015) se cuestiona la validez ecológica porque la reacción de los participantes puede ser diferente a la que tendrán los usuarios de una simultánea en situación real, y están ausentes variables posicionales, que pueden interferir de manera considerable en el éxito de una interpretación (Moser-Mercer, 1996).

Los estudios que se llevaron a cabo en un primer momento en investigación sobre la calidad en interpretación poseían un carácter individual. Una de las características actuales, como apuntan Collados Aís y García Becerra (2015b, p. 376), es la creación de equipos de investigación, que aúnan esfuerzos para abarcar un campo más amplio, no solo a nivel nacional, sino colaborando entre grupos diferentes. El más significativo ha sido el grupo Evaluación de la Calidad en Interpretación Simultánea (ECIS), que ha aunado a estudiosos de varias universidades españolas que han llevado a cabo trabajos interdisciplinares, los proyectos Quality in Simultaneous Interpreting (QUASI) de la Universidad de Viena, o el proyecto European Parliament Interpreting Corpus (EPIC) de la Universidad de Bolonia.

La característica quizá más significativa de los estudios actuales es el carácter interdisciplinar, que integra aspectos lingüísticos, pragmáticos y de comunicación, teniendo en cuenta una visión de la calidad situada (Errico y Morelli, 2015).

Como ya se ha especificado, los estudios se centraron en un principio en la interpretación de conferencias, sobre todo hasta los años noventa del siglo $\mathrm{XX}, \mathrm{y}$ fundamentalmente en interpretación simultánea. A partir de ese momento, se irán desarrollando los estudios sobre calidad en interpretación dialógica, en la que están implicados dos personas o grupos de personas que podría presentar características diferentes dependiendo de los entornos en los que se presentan: interpretación de enlace (en la que los diferentes grupos o personas poseen en general el mismo estatus) o interpretación en los distintos contextos de los servicios públicos (en los que existe claramente un desequilibrio de poder entre los distintos participantes) (Errico, 2016, p. 165).

Se ha decidido no hacer un análisis pormenorizado de todos los estudios de interpretación. De ello se ha escrito ya profusamente en varios libros (Hale y Napier, 2013), capítulos de libros (Errico, 2015), enciclopedias de interpretación (Collados Aís y García Becerra, 2015a y b; Grbić, 2015), tesis doctorales (Ruiz Rosendo, 2005; Soler Caamaño, 2006; Martínez-Gómez, 2011) y trabajos fin de máster (Sancho Viamonte, 2013), entre otros. Se ha preferido, pues, exponer algunas de las clasificaciones que subyacen a estos estudios, no haciendo referencia a ellos. 


\subsubsection{Métodos desarrollados en los estudios de interpretación según Pöchhacker}

Pöchhacker (2001, p. 410) identifica algunos de los métodos seguidos en los estudios de interpretación para medir la calidad, que han sido:

- encuestas, realizadas tanto a los intérpretes (Bühler, 1986; Mesa, 1997, entre otras), los usuarios (Kurz, 2001; Kopczynki, 1994; Marrone, 1993; Vuorikoski, 1993) o los clientes (Kadric, 2000), que no siempre coinciden con los usuarios, y encuestas basadas en estudios de caso;

- diseños experimentales, que miden el rendimiento o analizan el cómputo de errores (Barik, 1971), o tratan la calidad como una entrada variable (Berk-Seligson, 1988; Shlesinger, 1994), reproduciendo situaciones de interpretación en laboratorio (Collados Aís, 1998). Todos estos estudios tratan el tema de la calidad en términos de un efecto pragmático o cognitivo de la interpretación en los oyentes;

- observación basada en corpus, que parten de una metodología observacional o centrada en el análisis de errores (Cokely, 1992; Pöchhacker, 1994; Kalina, 1998, en interpretación de conferencias; Roy, 1993; Mason, 1999, en interpretación para los servicios públicos);

- estudios de caso basados en encuestas (Gile, 1990; Marrone, 1993; Pöchhacker, 1994; Wadensjö, 1998).

Los diferentes estudios pueden integrar varios métodos, por lo que no es posible realizar una separación neta de ellos.

\subsubsection{Clasificación de los estudios sobre calidad según Collados Aís}

Collados Aís (2003) hace una propuesta de clasificación por objetivos de los estudios sobre calidad, evidenciando las siguientes líneas de investigación:

- estudios centrados en el establecimiento de tipologías de errores, como los de Barik (1971, 1975) o Altman (1994), que propuso un enfoque para establecer una jerarquía de errores y diferencia entre errors y mistakes, que se refieren a cuestiones de fondo o forma que serían estudios textuales; estudios que analizan las condiciones de trabajo, para observar la repercusión positiva o negativa en la calidad del producto, en los que se usa el método experimental;

- estudios de expectativas de calidad (por parte de usuarios e intérpretes), llevados a cabo por medio de encuestas (Bühler, 1986; Altman, 1990; Zwischenberguer, 2009; Pöchhacker y Zwischenberguer, 2010), como de los usuarios (Kurz, 1991, 1993, 
2001), que a su vez pueden variar dependiendo de que sean los ponentes, los oyentes $u$ otros intérpretes;

- estudios sobre la evaluación de la calidad por parte de los usuarios, como calidad real percibida, que han sido realizados utilizando métodos de encuesta, análisis de caso y la experimentación (Gile, 1990; Marrone, 1993; Meak, 1990; Ng, 1992; Marrone, 1993; Vuorikoski, 1993; Kopczynsky, 1994; Mack y Cattaruzza, 1995; Moser, 1996; Collados, 1998; Andres, 2000; Ruiz Rosendo, 2006). En estos estudios, los resultados obtenidos dependerán también del tipo de usuarios que participan en el evento, y también del tipo de evento;

- finalmente, añade los estudios verticales de parámetros de calidad concreta, donde se aíslan algunos intraparámetros para poder así estudiar el efecto sobre la evaluación de los usuarios. Dentro de este grupo, se integrarían los trabajos de Collados Aís (1998), Stévaux (2003), Pradas Macías (2005), Collados Aís y Gile (2002).

\subsubsection{Estudios de evaluación de la calidad según Martínez-Gómez}

Martínez-Gómez (2011) recoge que existen varios momentos en los que un intérprete puede verse sometido a la evaluación de su desempeño, con una finalidad diferente en cada caso, y esto ha influido en los distintos tipos de estudios. Estos momentos son el acceso a la profesión, la formación, la acreditación y, por último, su actividad profesional. A partir de esta premisa, clasificará los estudios de calidad en interpretación en varios grupos:

a) Evaluación por parte de expertos, que a su vez subdivide en:

- análisis de errores, que serán los primeros en aparecer en los estudios de interpretación (Napon, 1965/2002; Barik, 1971; Gerver, 1969/2002, 1974; Kopczynski, 1980; Gile, 1985; Altman, 1989; Faró y Fabbro, 1995; Schjoldager, 1996; Falbo, 1998, entre otros);

- análisis proposicional, como unidad de análisis que evalúa la fidelidad semántica como indicador de la calidad (Mackintosh, 1983; Lbert, 1989; Dillinger, 1994; Kurz, 2008);

- evaluación por puntuaciones, que cuantifica la calidad (Russo, 1989; Fäber, 2002; Kurz y Fárber, 2003; Bartlomiejczyk, 2010);

- valoración en forma de escalas, cuyo propósito es determinar la calidad global de las interpretaciones objeto de estudio (Gerver, 1974; Anderson, 1979; Tiselius, 2009; Clifford, 2005; Riccardi, 2002); 
- por fin, una valoración holística.

b) Evaluación por parte de participantes, que pueden tener en cuenta las expectativas (Bühler, 1998; Kurz 1993, 1996; Moser, 1995), las evaluaciones (Gile, 1990; Ng, 1992), ambas (Marrone, 1993; Vuorikoski, 1993, 1995; Mack y Cattaruza, 1995; Collados Aís, 1998, entre otros) o la comprensión.

\subsubsection{Métodos de investigación en calidad en interpretación según Hale y Napier}

Hale y Napier (2013) diferencian entre varios tipos de estudios que se ocupan de la investigación en interpretación. Muchos de ellos tocan de manera específica o de manera transversal el tema de la calidad en interpretación teniendo en cuenta el método seguido, y estos son:

a) estudios basados en encuestas;

b) estudios de corte etnográfico (Angelelli, 2004; Berk-Selingson, 1990), que pueden ser llevados a cabo a través de la observación directa, por medio de entrevistas o también de grupos de discusión, además de estudios de caso (Gile, 1990; Dickinson, 2002; Schlesinger, 2009);

c) estudios basados en el análisis del discurso (Berk-Selingson, 1990; Wandensjö, 2001; Russo, 2005; Del Fovo, 2013);

d) uso de métodos experimentales en la investigación en interpretación, entre los que cabe destacar, en el ámbito de la calidad, los estudios de Pöchhacker (2001), Shlesinger et al. (1997) y Kalina (2005), los llevados a cabo por el grupo ECIS de Granada (Collados Aís et al., 2007, 2013) o el grupo QUASI de Viena;

e) investigación sobre la formación y la evaluación de la interpretación, por medio de encuestas, métodos cualitativos y experimentales (Gile, 1998), role plays o investigación acción (Blasco-Mayor, 2005, 2009).

\subsubsection{Análisis de los estudios según Grbić}

Por su parte, Grbić (2015) indica que la complejidad de los estudios empíricos sobre calidad en interpretación está relacionada con la combinación de tres rasgos axiomáticos: la variabilidad del desempeño, la relatividad de los juicios dependiendo de las perspectivas de los evaluadores y el proceso de evaluación con referencia a ciertos criterios (2015, p. 334). Partiendo de esta proposición, distinguirá ciertos temas que han marcado los estudios relacionados con la calidad en interpretación: 
- estudios relacionados con el cómputo de errores, en términos de correspondencia texto fuente meta. Fueron los primeros estudios, analizando varios tipos de errores como la omisión (Barik, 1975), o estudios más recientes, relacionados con las elecciones estratégicas del intérprete (Napier, 2002) o las dificultades específicas de un par de idiomas (Gile, 2005);

- investigación experimental: utilizando la calidad del producto como variable dependiente y probando así el efecto de ciertas variables; también se ha llevado a cabo para probar el efecto de algunas variables de entrada como la velocidad de la elocución o el acento en el rendimiento de los intérpretes. Tiene en cuenta una desviación específica, en relación con ciertas restricciones, que tiene que ver también con las condiciones de trabajo (sonido, condiciones de la cabina, acceso visual) o desafíos tecnológicos que tienen que ver con las nuevas tecnologías en interpretación, como puede ser la interpretación remota;

- estudios de casos: la investigación sobre la calidad en la interpretación también se ha llevado a cabo en forma de estudios de casos, utilizando corpus auténticos. Pöchhacker (1994a) combinó un análisis basado en texto con una descripción exhaustiva de los factores situacionales y las condiciones contextuales en su estudio de la interpretación simultánea en el lenguaje hablado con respecto a toda una conferencia;

- formación y certificación: el interés por la medición y la evaluación de la calidad es central en los estudios de formación y certificación de intérpretes, ya sea en pruebas de admisión, de evaluación durante la formación, del desempeño de intérpretes expertos o durante los procedimientos de certificación. Por ello, considera que sigue siendo actual el desarrollo de criterios de evaluación y de instrumentos específicos;

- el paradigma centrado en experto-novato, que sirve de base para la formación y la evaluación de la calidad, las diferencias de desarrollo de la competencia en interpretación y las destrezas comparando el desempeño de los expertos con el de novatos o no intérpretes (Moser-Mercer et al., 2000; Liu, 2008);

- factores pragmáticos, situacionales y culturales, que tendrán una importancia especial en los estudios de ISP. Con esto en mente, Pöchhacker (2001) propone un modelo de «capas de cebolla» de estándares de calidad superpuestos, que van desde la «interpretación precisa de la fuente» y la «expresión adecuada del objetivo» hasta el «efecto intencional equivalente» e «interacción comunicativa exitosa»;

- evaluación dependiendo de una serie de parámetros: Collados Aís (1998, 1998/2002) se centró en el papel de la CNV en la interpretación simultánea y demostró hasta qué punto la entonación monótona puede tener un efecto negativo en la evaluación general de un producto de interpretación. Mientras que estos estudios que utilizan textos 
objetivos manipulados se centran en los juicios de las cualidades afectivas de una interpretación, otros han abordado el efecto cognitivo o comunicativo de la interpretación en la audiencia. En línea con el axioma de que una interpretación debe producir el mismo efecto y tener el mismo contenido cognitivo que el habla de origen (Déjean le Féal, 1990), estos estudios usan el grado de comprensión del oyente como un indicador de calidad y lo miden con un cuestionario de pruebas de comprensión basadas en eventos comunicativos simulados (Marschark et al., 2004; Reithofer, 2013);

- expectativas basadas en administración de encuestas: cuando la interpretación se trata como un servicio a un cliente, la calidad puede investigarse externamente en términos de expectativas del usuario o internamente en términos de la cultura de calidad de una organización o institución determinada. De esta manera, se establecen ciertas normas de expectativa (Chesterman, 1993), que implica que la calidad se entienda como el cumplimiento de dichas normas, la responsabilidad y un comportamiento deontológicamente correcto. Cuando la interpretación se conceptualiza como un proceso impulsado por normas, las cuestiones de responsabilidad y el comportamiento ético pasan a estar en primer plano (Grbić, 2015, p. 336);

- trabajos que se centran en la cultura de calidad, donde la calidad se considera como una misión colectiva (como puede ser un colectivo de empleadores, una asociación profesional o la Administración). Por esta razón, es posible controlarla, desarrollarla, asegurarla y mejorarla. La investigación aplicada en este campo se centra en medidas de política profesional destinadas a mejorar la calidad de la interpretación y la prestación de servicios, incluida la optimización de las condiciones de trabajo. Abarca la discusión y el desarrollo de estándares y modelos de buenas prácticas; procedimientos de pertenencia a asociaciones y certificación; estándares establecidos por agencias nacionales e internacionales (ISO, EN, DIN); esquemas de acreditación para garantizar las normas de calidad de los programas e instituciones de capacitación, y capacitación de proveedores y educación al cliente.

\subsubsection{Hacia una apertura del estudio de la calidad en la interpretación dialógica y en los servicios públicos}

Como se ha insinuado en el apartado anterior, el interés por la calidad en la interpretación en los servicios públicos puede considerarse más tardía, en parte debido a la falta de reconocimiento de la profesión, a diferencia de lo que ocurre con los intérpretes de conferencias, que disponen de organizaciones y estructuras más sólidas (Corsellis, 2008). Desde la última década del siglo XX, se irán desarrollando los estudios 
sobre calidad en interpretación dialógica, en la que están implicados dos personas o grupos de personas que podría presentar características diferentes dependiendo de los entornos en los que se presentan, que podían ser interpretación de enlace en entornos empresariales (en la que los diferentes grupos o personas poseen en general el mismo estatus) o interpretación en los distintos contextos de los servicios públicos (en los que existe claramente un desequilibro de poder entre los distintos participantes) (Errico, 2016, p. 165).

Será a partir del primer congreso de la red The Critical Link (The First International Conference on Interpreting in Legal, Heath and Social Service Setting), que se celebró en Toronto en 1995, cuando proliferaron los estudios y los grupos de investigación centrados en los servicios públicos, a nivel mundial y nacional. La conferencia Critical Link, que llegará en julio de 2018 a su novena edición, presenta en cada propuesta multitud de trabajos que se ocupan de la ISP ${ }^{69}$, y muchos de ellos específicamente dedicados a la calidad, en el ámbito judicial, médico, de refugio y asilo o escolar. Se han publicado monografías específicas dedicadas a la interpretación en los servicios públicos (Martin y Valero, 2008; De Pedro Ricoy, 2009; Pérez y Wilson, 2009; Rudvin y Spinzi, 2015) y se han publicado manuales (Hale, 2007; Corsellis, 2008; Bancroft García Bayaert, Allen, Carriero-Contreras, Socarras-Estrada, 2015; Tipton y Furmanek, 2016). Las universidades se están moviendo para activar cursos y máster especializados en la ISP, como el Máster TISP de Alcalá de Henares, entre otros, por hablar solo del caso español, que celebra también congresos que han llegado ya a su sexta edición en marzo de 2017. En las universidades de todo el mundo, y específicamente en las españolas e italianas, se están llevando a cabo trabajos de investigación que abordan el tema con la calidad en la ISP (tesis doctorales de MartínezGómez, 2011; Burdeos Domingo, 2015; García Bayaert, 2016; Tonioli, 2017, entre otras). Se han activado grupos de investigación como el grupo MIRAS en la Universidad de Barcelona, el grupo GRETI o la Red Comunica (Observatorio Permanente sobre Traducción e Interpretación en los Servicios Públicos) o el grupo FITISPOS (Grupo de Formación e Investigación en Traducción e Interpretación en los Servicios Públicos). Sería muy prolijo citar todos los estudios; por ello, baste citar el monográfico Panorama de la traducción y la interpretación en los servicios públicos españoles: una década de cambios, retos y oportunidades (Foulquié-Rubio, VargasUrpi y Fernández Pérez, 2018), que trata con detalle todos los trabajos publicados en España en estos diez últimos años.

\footnotetext{
${ }^{69}$ El último publicado es Interpreting in a Changing Landscape (Schäffner; Kredens, Fowler, p.2013).
} 
Por esta razón, los estudios sociológicos y etnográficos adquieren una gran relevancia considerable en este contexto, y han marcado un giro a la hora de estudiar la interpretación para los servicios públicos debido a que adolece de una falta de reconocimiento como profesión, pues no ha conseguido hasta tiempos muy recientes organizarse y abogar por su afirmación profesional.

En la investigación sobre interpretación en los servicios públicos existen distintos enfoques. Pöchhacker (2002) se centra en la calidad del producto, y Mason (2008) en el análisis del discurso. Martin (2003, pp. 433-446), por su parte, distingue tres grandes enfoques según la metodología aplicada y los objetivos de la investigación; los márgenes de dichos enfoques no están claramente delimitados, pues a menudo se solapan. En dicha clasificación se aborda el tema de la calidad. Se seguirá dicha clasificación para integrar los distintos estudios:

- en primer lugar, se encuentran los estudios descriptivos que reflexionan sobre la situación de la interpretación para los servicios en los distintos países, que incluyen también propuestas de clasificación y modelos. En este grupo se encuentran muchos de los trabajos pioneros y algunas publicaciones relacionadas con la serie Critical Link, sobre todo durante los primeros congresos. Al analizar el estado de la cuestión, hacen un análisis explícito sobre la calidad de estos servicios. Los objetivos de estos estudios son muy variados. En este grupo se podrían incluir los trabajos de Roberts (1997), Garber (2000), Ozolins (2000), Ortega-Herráez (2006), Ortega-Herráez (2011), Ortega-Herráez y Blasco-Mayor (2018) y Gavlovych (2017);

- la autora señala un segundo grupo de investigaciones, que recopila los datos sobre la situación y sobre la calidad en interpretación para los servicios públicos a través de encuestas y cuestionarios, indicando las expectativas de los distintos agentes implicados, las características que ha de tener un buen intérprete y en qué consiste una buena interpretación. Pöchhacker se refiere a dichos trabajos como estudios de calidad (2002). Cabe mencionar los trabajos realizados por Kadric (2000), Mesa (2000), Tomassini (2002), Pöchhacker (2002), Martin y Abril (2008), Martin y OrtegaHerráez (2009 y 2013);

- por último, se citan algunos estudios que se centran en la dimensión interpersonal y la interacción que se produce en situaciones dialógicas, que la diferencia del tipo de interpretación monológica. La comunicación mediada por intérprete posee una naturaleza oral, que no se puede alejar del contexto donde se produce y con un cariz participativo. En palabras de Hale y Napier: «... is oral in nature and is influenced by context and participants. Interpreting cannot be conducted or analyzed out of context, and dialogue interpreting is conducted in a participatory framework, where each turn 
affects the other» (Hale y Napier 2013, p. 128). Por esta razón, los estudios sociológicos y etnográficos adquieren una gran relevancia en este contexto, y han marcado un giro a la hora de estudiar la interpretación para los servicios públicos. Pöchhacker considera que se trata de un paradigma específico de los estudios de ISP, que denomina paradigma de interpretación dialógica (2004, p. 79). Este quizá sea el grupo más nutrido, con un acercamiento sociolingüístico al papel del intérprete y al análisis del discurso, en el que se demuestra que el intérprete que trabaja en contextos de IPS no es la figura aséptica e invisible que defienden los códigos deontológicos. Berk-Seligson $(1988 / 2002,1990)$ analiza la valoración de interpretaciones simuladas desde una perspectiva sociolingüística y demuestra que las elecciones del intérprete en relación con el registro, el estilo y la formalidad afecta a los receptores en cuanto a su opinión del emisor. Wandensjö (1992, 1998, 1999 y 2001) analiza la intervención activa del intérprete a través del análisis conversacional de entrevistas interpretadas en los servicios de inmigración y policiales. Roy (1996) realiza un estudio cualitativo. Angelleli (2004) demuestra la implicación del intérprete durante entrevistas médicas. Hale $(1997,2001)$ analiza los resultados en relación con la equivalencia pragmática. Kadric (1999) estudia la influencia de los intérpretes en la interacción.

La autora concuerda con Mason (2000, p. 219) y remarca la importancia de los trabajos de Berk-Seligson y Wadensjö en el avance de la investigación en interpretación para los servicios públicos, y apunta cuatro principios metodológicos ineludibles para abordar la investigación en ISP. En primer lugar, las expectativas de los usuarios no corresponden con la realidad de la interacción mediada por intérprete, ya que el intérprete no es una figura neutral, sino que influye en el desarrollo del evento. En segundo lugar, la pragmática adquiere un valor fundamental que ayuda a aclarar y comprender los motivos subyacentes de las conductas de todas las partes implicadas, incluidos los intérpretes. En tercer lugar, el marco de participación se convierte en un elemento fundamental, pues los cambios de posición o alineamiento durante un evento interpretado han de investigarse aún más. Por último, cabe destacar el enfoque descriptivo de los trabajos de investigación en los servicios públicos.

\subsection{Conclusiones}

A partir de mediados del siglo XX, el estudio de la calidad ha ido estrechamente vinculado a la producción industrial. De hecho, los primeros estudiosos fueron directivos y vinculados a la producción, y a partir de entonces se han ido desarrollando distintas conceptualizaciones y enfoques que a veces pueden ser contradictorios o 
complementarios. A la par, ha ido evolucionando una aproximación a la gestión de la calidad, con muy diferentes puntos de vista, y se han ido estableciendo normas de aseguramiento de la calidad y reconocimientos que premiaban la consecución de los objetivos. De una visión parcial se ha llegado a una gestión holística que tiene en cuenta los diferentes enfoques.

Con los años, se ha ido desarrollando un interés por la calidad del servicio, que difiere en algunos aspectos con respecto a la calidad de un producto, más difícil de evaluar y medir, no existiendo tampoco en este caso una unicidad conceptual. Existen, sin embargo, algunos puntos en común, como son su carácter intangible, inseparable, variable y perecedero.

En aras de la claridad conceptual y terminológica, entendemos la calidad, pues, como una característica intrínseca de excelencia inherente a algo, y una característica extrínseca de percepción que está determinada por condiciones y necesidades específicas que se pueden medir. Al mismo tiempo, habrá que considerar la gestión de la calidad como una estrategia y un proceso, visto desde un punto de vista holístico que tiene en cuenta muchos factores.

En el campo de la interpretación, existía hasta la fecha una dificultad para desarrollar un concepto uniforme de calidad, que hoy se considera dinámico, complejo y multidimensional.

Con el tiempo, se han ido identificando ciertos parámetros que permiten evaluar el desempeño de la interpretación, pues la falta de definición universal en interpretación hace que este sea uno de los mayores obstáculos para su medición (Collados Aís y García Becerra, 2015b). La naturaleza y el número de criterios de calidad propuestos hasta la fecha, así como sus definiciones y ponderaciones, varían según las diferentes metodologías de investigación, los enfoques interdisciplinarios y los dominios de interpretación.

En general, se puede decir que la calidad ha sido y sigue siendo un aspecto fundamental en los estudios de interpretación y se considera connatural a la reflexión misma sobre la materia, pues representa el hilo conductor que atraviesa todos los estudios especializados (Viezzi, 1996), del acceso a la profesión, la formación, la acreditación, el papel mismo del intérprete (Angelelli, 2004; Pöchhacker y Zwischenberger, 2015) y sus implicaciones éticas, sin olvidar los aspectos cognitivos.

Los primeros trabajos que se ocuparon de la calidad en interpretación se enfocaron principalmente hacia el producto, para luego abarcar aspectos que tenían que ver con el proceso. Al mismo tiempo, se pasó de un análisis de errores a un interés más amplio que cubría las expectativas, las condiciones de trabajo, la formación y la acreditación. El aspecto más interesante de la evolución de los estudios de calidad es 
que se pasó de un análisis centrado en un aspecto para evolucionar hacia un enfoque multidisciplinar y holístico, de acuerdo también con las tendencias generales del estudio de la calidad, que han llevado a un interés por la gestión de calidad total que abarca todos los aspectos y momentos.

La atención creciente que se brinda a la dimensión social de la evaluación de la calidad se refleja también en la importancia de las primeras impresiones (García Becerra, 2012, 2015a y b) o la activación de algunos estereotipos (Stéveaux, 2011; Cheung, 2013) que ayudan a comprender las relaciones complejas que existen entre las expectativas en relación con la interpretación y el juicio real. Subrayan asimismo que la calidad es un concepto dinámico que evoluciona dependiendo de unas variables ambientales y normas socialmente constituidas (Collados Aís y García Becerra, 2015b).

Los nuevos estudios sobre calidad la definen como algo medible de manera objetiva y tangible que está estrechamente vinculado con la situación, el contexto y las circunstancias generales en las que se realiza la evaluación (Grbić, 2015; Zwischenberger y Behr, 2015, pp. 7-8). Estos autores afirman que la calidad es parte integrante de una situación de comunicación interactiva, que se ve influenciada por los agentes sociales en el campo de la interpretación, sus funciones y la relación que existe entre ellos. Confirman que habría que añadir también un aspecto sociológico, retomando la definición de Pöchhacker de 2004 antes mencionada.

En este nuevo paradigma de los estudios sobre la calidad de la interpretación, es importante señalar la introducción de un elemento que les confiere un cambio de visión, pues la calidad en interpretación se está dejando de ver como algo «volátil», ya que hoy en día es posible grabar las interpretaciones con distintos métodos digitales (Kalina, 2015, p. 16). El problema puede plantearse desde el punto de vista de la ejecución, pues existe un posible conflicto entre el acto comunicativo oral, volátil en sí mismo, efímero y con cierto grado de improvisación, en relación con la traducción escrita y los nuevos sistemas de grabación y conservación de dicha comunicación oral. 


\section{La calidad en la interpretación judicial}

\subsection{Introducción}

La interpretación judicial presenta características muy específicas que influyen en el desempeño de la actividad y condicionan su ejecución ${ }^{70}$. En el contexto judicial, al igual que sucede en otros contextos de la esfera pública en los que confluyen la administración y los ciudadanos, se ha estimado que existe una disimetría de poder entre las distintas partes, esto es, las autoridades o los actores que desempeñan el cumplimiento del Estado de un país por una parte y la persona alófona que no es capaz de comunicarse directamente con dichos actores, por otra (Mason, 1999; Mason, 2014). Esta disimetría puede estar presente no solo entre los dos interlocutores, sino también entre uno de los interlocutores y el propio intérprete, pues en ocasiones al intérprete no se le reconoce como profesional (Corsellis, 2008, pp. 29-30).

Como se expone en el capítulo 3 con mayor profundidad, la actividad está regulada por ley en algunos países, además de estar contemplada en el Convenio Europeo de los Derechos Humanos (CEDH). No se trata pues únicamente de normas establecidas por comités de normalización de la calidad en aras de una ventaja económica, sino que se trata de un derecho fundamental e irrenunciable (OrtegaHerráez, 2011; Ortega Lorente, 2017), que está estrechamente vinculado al derecho de defensa.

A continuación se revisarán las especificidades de la interpretación judicial en su contexto, para después analizar todas aquellas fuentes en las que se explicitan aspectos relacionados directa o indirectamente con la calidad de la interpretación judicial, con el fin de reunirlos en un catálogo que sea de utilidad para el diseño de una herramienta de medición de la calidad de la interpretación en el ámbito judicial.

\footnotetext{
${ }^{70}$ En este apartado, se analizarán específicamente los casos de interpretación en los tribunales nacionales. En los tribunales internacionales, los intérpretes asumen y obtienen una consideración equiparable a la de los intérpretes de conferencias (Amodeo Perillo, 2017).
} 


\subsection{Características del contexto judicial y calidad de la interpretación}

Tal y como se ha expuesto en el capítulo 2, la actividad de la interpretación judicial se produce en un entorno que reúne una serie de características que pueden afectar directamente a su calidad. Quizá la más destacable de todas ellas sea la falta de reconocimiento profesional. Colin y Morris (1996, p. 15) ya resaltan a finales del siglo pasado que las personas que trabajan con intérpretes en este ámbito carecen de conocimientos sobre el tipo de trabajo que realiza el intérprete y su dificultad, además de ser recelosos y muy críticos. Esta falta de reconocimiento profesional es debida también al intrusismo del personal no capacitado ni formado y a la contraprestación exigua, tal y como se viene denunciando en España por distintas organizaciones, y se ha documentado en la literatura (Ortega-Herráez, 2013; De Luna Jiménez de Parga, 2010; Economía Digital, 15-05-2016).

Al igual que en otros entornos donde se requiere la asistencia de intérpretes, pero de manera muy evidente y a veces olvidada por el responsable último de la provisión del servicio (la administración), el «cliente» no coincide con el usuario. Los usuarios del servicio son varios (juez, acusado, policía), aunque el usuario último, tal como recoge el derecho de algunos países, es aquel que no comprende el idioma, acusado o víctima, cosa que a menudo también pasan por alto los demás actores de la comunicación.

La interpretación en el entorno judicial, además, se caracteriza especialmente por el cumplimiento de una serie de máximas traductológicas que tienen que ver con la equivalencia, la fidelidad y la minuciosidad, pues las variaciones pragmáticas pueden influir en las respuestas de los testigos y los acusados, y en las valoraciones de estas por parte del juez, de la policía, del abogado o del jurado (Berk Seligson, 1988, 1989, 1990, Mason 2008).

Por otro lado, no hay que olvidar que una interpretación de calidad puede no significar el éxito en la comunicación. Esto quiere decir que no necesariamente se obtendrá la comprensión efectiva de discurso jurídico a través de un intérprete, sino que se pondrá al usuario en las mismas condiciones de comprensión que tendría si fuera nativo (Mikkelson 2000, p. 69; González et al., 2012; Mikkelson, 2017). Se da el caso de que algunos participantes del acto comunicativo no terminan de comprender este fenómeno, pues consideran que el intérprete está allí para asistir al juez o a la policía.

En contraposición sobre todo con la corriente americana y australiana de máxima fidelidad y no intervención por parte del intérprete judicial se encuentra la tendencia surgida recientemente en Europa (Wadensjö, 1993, 1998; Mason, 2014) que indica que, 
además de reproducir con fidelidad las intervenciones de los participantes en el ámbito judicial y policial, el intérprete debe asegurarse de que sus intervenciones son comprendidas, adaptando o simplificando la información llegado el caso, e incluso interviniendo activamente en la comunicación (Gialuz, 2018, pp. 149-150). Hay que decir que ambas posturas no están enfrentadas por completo, pero tampoco buscan un consenso; además, esta diferencia añade mayor confusión al ya de por sí desconocido mundo de la interpretación en contextos judiciales. Todas estas características impregnan la actividad de una complejidad que debe tenerse en cuenta a la hora de plantear cualquier investigación en este campo.

\subsection{La calidad en la Directiva Europea 2010/64/UE sobre el derecho a interpretación y traducción en los procesos penales y en documentos europeos vinculados}

\subsubsection{La Directiva 2010/64/UE sobre el derecho a interpretación y traducción en los procesos penales}

La Directiva 2010/64/UE supone en cierta manera el punto de partida que permita establecer un marco sobre calidad en interpretación judicial, puesto que dicha ley es la que de alguna manera conforma el marco legal en el que hay que determinar lo que es la calidad, qué mecanismos se deben desarrollar para garantizarla, y cómo aplicarlos. Como ya se ha apuntado en páginas anteriores, dicha Directiva europea constituye un hito en cuanto al derecho a ser comprendidos de los acusados alófonos (Hertog, 2015b, p. 99). Se trata de la primera directiva europea cuyo propósito es observar las garantías procesales de los acusados dentro del territorio de la Unión Europea.

La Directiva subraya que la interpretación y la traducción han de ser de calidad suficiente de manera que pueda garantizarse la equidad del proceso. El derecho a una interpretación y traducción fidedignas debería ir de la mano de la calidad. Conviene recordar que este derecho tiene dos ramales: por un lado el derecho del acusado y de los testigos o víctimas a ser escuchados y a recibir información en su propio idioma, garantizando así la presencia efectiva; por otro lado, el derecho de los demás sujetos de la administración pública a recibir la comunicación fidedigna «que les permita cumplir sus funciones de conformidad con los niveles de calidad exigidos tanto por la ley como por sus propias normas profesionales (Vidal Fernández, 2007, pp. 215-216).

La Directiva propone varios mecanismos para tratar de alcanzar la calidad de la interpretación y la traducción. El primero posee un carácter preventivo (Arangüena 
Fanego, 2011), exhortando a los Estados miembros a que habiliten un registro o registro de traductores e intérpretes independientes debidamente cualificados, que será puesto a disposición de los abogados y las autoridades pertinentes. Desafortunadamente, y en comparación con las recomendaciones expuestas en el informe Aequitas. Acces to Justice across Language and Culture in EU (Grollmann, Martinsen, y Rasmussen, 2001), el artículo 5.2 se ha sintetizado sobremanera, desapareciendo por completo la referencia a la configuración del registro (tiempo limitado, formación profesional continua, adopción de un código deontológico y de directrices de buenas prácticas similares en todos los países miembros en aras de obtener una confianza mutua señalado previamente en el Libro Verde). El citado artículo especifica que «los Estados miembros se esforzarán» ${ }^{71}$, lo que ha dado pie a una gran laxitud en las distintas transposiciones y en su aplicación. Con la aprobación de la Directiva se buscaba una regulación uniforme para el acceso, las obligaciones y los derechos que rigen el ejercicio de la profesión de intérprete y traductor judicial en todos los Estados de la Unión Europea; sin embargo, de esta forma queda en manos de los Estados miembros el control de la cualificación exigible y la creación de registros, entre otros aspectos (art. $5.1)$.

La segunda herramienta de control de la calidad es la grabación de las actuaciones de los intérpretes (art. 7), aunque no se especifica cómo debe hacerse, dejando siempre a cada Estado miembro elegir el medio más oportuno. El hecho de que no exista una uniformidad en los métodos de grabación y que se pueda sustituir en ciertos casos con el acta escrita, mina la efectividad de este instrumento de control. Por otra parte, todos los remedios procesales y garantías contemplados en la Directiva pueden revelarse como promesas vacías, ya que no se ha previsto la garantía prejudicial de la grabación de los interrogatorios con la policía y las entrevistas con los abogados (Gialuz, 2018, p. 175).

La posibilidad de usar las nuevas tecnologías (art. 2.6), salvo en aquellos casos que requieran la presencia física del intérprete, facilita incluso el uso de intérpretes (cualificados) a nivel transnacional. En un mundo ideal, el uso de dichas tecnologías podría ser un instrumento para garantizar la calidad, pues permitiría la intervención de intérpretes cualificados a distancia, sin necesidad de desplazamiento, a lo largo y ancho de la Unión Europea; sin embargo, su implantación y funcionamiento aún está muy lejos de convertirse en una realidad desde el punto de vista logístico y tecnológico.

Por último, el art. 6 versa sobre la formación que deberían recibir jueces, fiscales y demás operadores judiciales que participen en los procesos penales, instándoles a conocer las particularidades de la comunicación mediada por intérprete, de manera que

\footnotetext{
${ }^{71}$ Cursiva mía.
} 
quede garantizada una comunicación efectiva y eficaz. La formación de los agentes judiciales es, por tanto, de una importancia capital si se desea conseguir la calidad de la interpretación que defiende la Directiva en sus articulados (Blasco-Mayor y Del Pozo Triviño, 2015, p. 33; Hale, 2013), teniendo en cuenta la asiduidad de personas extranjeras presentes en los procesos penales. Deberían formarse también los demás Cuerpos y Fuerzas de Seguridad de los Estados miembros, pues participan activamente en el proceso penal en fase de instrucción y precisan de la asistencia de un intérprete, al igual que los equipos forenses, que también deben trabajar con intérpretes. En tiempos recientes han salido a la luz publicaciones (Corsellis, Clement y Vanden Bosch, 2011, González, Vásquez y Mikkelson, 2012, pp. 533-658; Townsley, 2013; Blasco-Mayor, 2014, 2015) que se ocupan de manera específica de la formación de los operadores judiciales, explicando las características que ha de poseer un buen intérprete judicial profesional, y exponen las pautas que han de seguirse para trabajar de manera eficaz con la asistencia del intérprete durante el proceso penal. Si están bien preparados y maximizan el rendimiento de su trabajo, esto «redundará en beneficio de todos los implicados, del funcionamiento de la justicia [...] y de la salvaguardia de los derechos fundamentales» (Blasco-Mayor y Del Pozo Triviño, 2015, p. 35).

\subsubsection{Propuesta de Decisión Marco relativa al derecho a interpretación y a traducción en los procesos penales (2009)}

En el momento de la redacción de la Propuesta de Decisión Marco relativa al derecho a interpretación y a traducción en los procesos penales de 2009, documento precursor de la Directiva 2010/64/UE, se presentó también otro documento que se ocupaba de velar por la calidad de la traducción y la interpretación, a saber: la Proposal for a Resolution of the Council and of the Government of the Member States meeting within the Council fostering the implementation by Member States of the right to interpretation and to translation in criminal proceeding (Bruselas, 15 de julio de 2009), Consejo de la Unión Europea 12116/09, que debía acompañar la Propuesta de Decisión Marco ${ }^{72}$, que establecía una serie de estrategias muy precisas a fin de implementar la calidad de la interpretación y traducción judicial en los Estados miembros (Hertog, 2015b, pp. 9091). Entre dichas recomendaciones, para el objeto de este estudio, destaca la número 22 , que dispone que los Estados miembros deben asegurarse de que se establece un mecanismo de evaluación que asegure la calidad de la traducción y la interpretación

\footnotetext{
72 No se ha encontrado el documento en castellano. http://register.consilium.europa.eu/doc/srv?l=EN\&f=ST\%2012116\%202009\%20INIT
} 
«Members States should ensure that there is a mechanism for evaluation of the systems aiming to ensure the quality of interpretation and translation in criminal proceedings».

La Directiva debería haber sido el primer paso en la exigencia de una interpretación de calidad e insta a los Estados a crear registros de profesionales de traducción en interpretación (Arangüena Fanego, 2011). El descontento de algunos Estados miembros y su rechazo a delegar han conferido cierta vaguedad. Por otra parte, debería haber ido más lejos obligando a los Estados a establecer requisitos homogéneos de acceso a la profesión, cosa que no ha hecho. La vaguedad de algunos aspectos de la Directiva ha dado pie a usar la excepción como algo habitual, según se señalará más adelante, creando como mínimo serias dudas sobre la transposición en algunos países, y provocando en algunos casos, como ha sido en España, la presentación de una queja ante el defensor del pueblo sobre el servicio de traducción en interpretación en juzgados y comisarías.

Tabla 4: Análisis comparativo de las propuestas del PDM y de la Directiva 2010/64/UE en favor de la calidad

\begin{tabular}{|c|c|c|}
\hline Derechos y garantías & PDM & Directiva 2010/64/UE \\
\hline Derecho a interpretación & $\begin{array}{l}\text { Derecho a interpretación } \\
\text { gratuita (art. 6) }\end{array}$ & $\begin{array}{l}\text { Irrenunciable, aunque ha de } \\
\text { constatarse que el acusado, } \\
\text { testigo o víctima no entiende } \\
\text { el idioma }\end{array}$ \\
\hline Derecho a traducción & $\begin{array}{l}\text { Derecho a traducción gratuita } \\
\text { de los documentos pertinentes } \\
\text { (art. 7) }\end{array}$ & $\begin{array}{l}\text { Se deja la posibilidad de } \\
\text { renunciar, aunque supeditada } \\
\text { a asesoramiento jurídico (art. } \\
\text { 3.8) }\end{array}$ \\
\hline \multirow[t]{2}{*}{ Calidad de la interpretación } & $\begin{array}{l}\text { Exactitud de la traducción e } \\
\text { intrepretación (art. 8) }\end{array}$ & $\begin{array}{l}\text { Calidad de la traducción y la } \\
\text { interpretación (art. 5) }\end{array}$ \\
\hline & $\begin{array}{l}\text { Ha de ser una traducción } \\
\text { fidedigna }\end{array}$ & \\
\hline $\begin{array}{l}\text { Registro de traductores e } \\
\text { intérpretes }\end{array}$ & $\begin{array}{l}\text { Establecido a nivel EU con } \\
\text { igualdad de condiciones de } \\
\text { acceso } \\
\text { Obligatoria la formación } \\
\text { continua } \\
\text { Valor por cinco años } \\
\text { Código deontológico } \\
\text { Normas de actuación (Hertog }\end{array}$ & $\begin{array}{l}\text { Los Estados miembros se } \\
\text { esforzarán ... (art. 5.2) }\end{array}$ \\
\hline
\end{tabular}




\begin{tabular}{|c|c|c|}
\hline & y Vanden Bosch, 2001) & \\
\hline $\begin{array}{l}\text { Grabación de las actuaciones. } \\
\text { Características }\end{array}$ & $\begin{array}{l}\text { Grabación del proceso (art. 9) } \\
\text { Se efectuará una grabación de } \\
\text { audio o vídeo para garantizar } \\
\text { el control de calidad }\end{array}$ & $\begin{array}{l}\text { Varía dependiendo de los } \\
\text { países } \\
\text { Llevanza de registros (art. 7). }\end{array}$ \\
\hline $\begin{array}{l}\text { Formación de operadores } \\
\text { judiciales }\end{array}$ & $\begin{array}{l}\text { Los Estados miembros se han } \\
\text { de comprometer a ofrece } \\
\text { formacióna abogados y jueces } \\
\text { para que puedan comprender } \\
\text { mejor el papel de los } \\
\text { traductores e intérpretes y, por } \\
\text { lo tanto, trabajar con ellos } \\
\text { más eficientemente (Comisión } \\
\text { de las Comunidades } \\
\text { Europeas, 2003, p. 32) }\end{array}$ & Formación (art. 6) \\
\hline Formación de intérpretes & $\begin{array}{l}\text { Los Estados miembros } \\
\text { deberían instituir un sistema } \\
\text { de formación profesional } \\
\text { continua, de modo que los } \\
\text { traductores y los intérpretes } \\
\text { jurados pudieran actualizar } \\
\text { continuamente } \\
\text { cualificaciones Comisión de } \\
\text { las Comunidades Europeas, } \\
\text { 2003, p. 32) }\end{array}$ & No se considera \\
\hline Mecanismos de evaluación & $\begin{array}{l}\text { Establecimiento de varios } \\
\text { mecanismos de evaluación } \\
\text { (Comisión de las } \\
\text { Comunidades Europeas, 2003, } \\
\text { p. 32) }\end{array}$ & Considerando 24 \\
\hline
\end{tabular}

\subsubsection{Conclusiones del Foro de Reflexión sobre el Multilingüismo y la Formación del Intérprete (SCIC)}

Otro documento fundamental es el emanado de la Dirección General de Interpretación de la Comisión Europea (SCIC), Foro de Reflexión sobre el Multilingüismo y la Formación del Intérprete (2009), en el que un equipo de expertos en interpretación y traducción en los servicios públicos aboga por el reconocimiento de la figura profesional del intérprete judicial. En dicho documento se extienden una serie de recomendaciones específicas que tienen que ver con la profesionalización, la formación, 
certificación y acreditación del intérprete: necesidad de una formación continua, existencia de un código profesional de conducta y directrices de buenas prácticas que deberían ser comunes en toda la Unión Europea. Según sus autores, todo ello reforzaría la confianza en dicho perfil profesional, que sería reconocido por los demás profesionales, quienes a su vez deben recibir formación para trabajar con intérpretes. Además, preconiza la creación de registros nacionales similares en la Unión Europea que permitan el acceso mutuo.

\subsection{Avances en la investigación sobre la calidad de la interpretación judicial}

Tras revisar los aspectos legales establecidos a nivel europeo para garantizar la calidad en la interpretación judicial, y antes de avanzar en el análisis de los elementos componenciales de la calidad en interpretación judicial, cabe señalar el gran auge que ha adquirido la investigación en dicho ámbito, que ha dado lugar a manuales (González, Vásquez y Mikkelson 1998, 2012; Mikkelson 2000, 2017), monografías (Edwards, 1995; Colin y Morris, 1996; M. Shlesinger y Pöchhacker, 2010; Debra Russel y Hale, 2008; Mason, 2008; Ortega-Herráez 2011), artículos de revistas, actas de congresos, entre los que destacan los presentados en las distintas tesis doctorales (Ballardini, 2000; Giambruno, 1997; Ortega-Herráez, 2011; Wallace, 2012, Martínez-Gómez, 2011, entre otros) y trabajos fin de máster (Grandinetti, 2013; Perdichizzi, 2017) y de grado (Estañ Arellano, 2016). Los estudios se podrían clasificar temáticamente, de los que se darán algunos ejemplos. Es conveniente revisar la investigación que se ha llevado a cabo sobre esta, para lo cual se sigue y actualiza la clasificación propuesta por MartínezGómez (2011):

- estudios descriptivos donde se realiza una valoración de la calidad en ese momento (o de la falta de calidad, en la mayoría de los casos) (Ortega-Herráez, 2011, 2013; Martin y Ortega-Herráez, 2013; Blasco-Mayor y Del Pozo Triviño, 2015);

- estudios sobre el papel del intérprete (Roy, 2000; Wadensjö, 1991/2002, 1998; Lewellyn-Jones y Lee, 2014);

- valoración de cómputo de errores, generalmente basados en corpus, de análisis del discurso y de la pragmática (Berk-Seligson, 1990; Mason, 2008; Gallai 2012, 2015, Orozco Jurotán, 2017; Bestué, 2018);

- evaluación del desempeño y estudio de las expectativas (Martínez-Gómez, 2011); 
- estudios de formación (González et al., 1998, 2012; Mikkelson 2000, 2017; Hale 2007; Corsellis, 2010; Rudvin y Spinzi, 2015; Blasco-Mayor, 2014; Toledano Buendía y Del Pozo Triviño, 2015);

- estudios para la capacitación, la acreditación y la normativización (González et al., 1998 y 2012; Mikkelson, 2000 y 2017, Hertog, Blasco-Mayor et al., 2013; Giambruno, 2014; Wallace 2012, 2015a y b, 2017);

- a esta clasificación cabría añadir los trabajos publicados en relación con ciertos proyectos específicos para mejorar la calidad en la interpretación judicial (Hertog, 2001, (2003), entre otros, que se citarán en el subepígrafe 5.5.6.

Los trabajos arriba citados han servido en su mayoría de base sobre la cual se ha iniciado el proceso de selección que ha llevado al establecimiento de una serie de criterios de evaluación del desempeño del intérprete judicial, uno de los objetivos planificados en el presente trabajo. No obstante, para llegar a dicho proceso de selección, primero es preciso identificar los componentes de la calidad de la interpretación judicial tras una revisión de las publicaciones.

\subsection{Componentes de la calidad en interpretación judicial}

A continuación se analizan varios componentes que se ocupan de la calidad en interpretación judicial a partir de distintas fuentes que recogen los comportamientos, protocolos, y máximas traductológicas que tradicionalmente se han venido recogiendo y reconociendo dichas fuentes como parte esencial de un desempeño óptimo en la interpretación judicial tanto por profesionales y sus asociaciones, como por académicos del ámbito de la interpretación judicial.

\subsubsection{Los códigos deontológicos como aseguramiento de la calidad}

Según la definición de Hale (2007, p. 103) «un código ético profesional indica las pautas que los profesionales deben seguir para realizar su trabajo de forma ética por el bien de los clientes para los que trabajan, de la profesión a la que representan y para ellos mismos» ${ }^{73}$. Con él se establecen las normas de conducta y profesionales, y ayuda al intérprete a evitar tomar decisiones arbitrarias cuyas consecuencias podrían ser

\footnotetext{
${ }^{73}$ Traducción de Rosa Cobás Álvarez y Carmen Valero Garcés (2010, p. 107).
} 
desastrosas. Siguiendo a Gentile et al. (1996) y Roberts (1997), la existencia de un código deontológico unificado ayuda a dar visibilidad a la figura del intérprete y a su profesionalización, una de las razones por la que se extiende el interés por la calidad en interpretación (Zwischenberger y Behr, 2015, p. 7).

Como señala Hale (2010, p. 120), la conducta de un intérprete no solo le afectará a sí mismo, sino que tendrá repercusiones «para las partes implicadas en la interpretación y para la profesión en general porque marca el reconocimiento público que tan importante es». En relación con la conducta, los intérpretes han de comprender bien las normas para poder aplicarlas (Wandensjö, 1998, p. 286).

Sin embargo, la existencia de un código deontológico no es suficiente para garantizar la calidad. Se precisa también formación práctica (Hale 2010, p. 120) y unas normas de conducta. Como apunta Vidal Fernández: «La existencia de un código de buena conducta, y la consolidación de unas directrices o pautas de buenas prácticas derivadas del cumplimiento de dicho código es garantía de la integridad de los traductores e intérpretes, y en consecuencia de la calidad de la interpretación y de la traducción judiciales» (2007, p. 227).

Como ya se ha indicado en el capítulo 2, las deplorables condiciones de trabajo y la falta de apoyo por parte de los demás actores implicados pueden influir muy negativamente en la calidad de la interpretación judicial, pese a las normas de conducta y al cumplimiento del código deontológico (Vidal Hernández, 2007; Arangüena Fanego, 2011).

El papel del intérprete, por otro lado, está profundamente vinculado con el código deontológico $\mathrm{y}$, algunos estudiosos ponen en tela de juicio ciertos principios fundamentales que rigen los códigos éticos. Wandesjö (1998, p. 286) es crítica con el significado preciso del código deontológico y con lo que este implica. Se ha cuestionado la invisibilidad e incluso la imparcialidad del intérprete, pues no tiene en cuenta la realidad en la que se trabaja (Wadensjö, 1992; Angelelli, 2004; Roy, 2000; (Llewellyn-Jones y Lee, 2014). Algunos códigos deontológicos especifican que dicho intérprete debe poner en conocimiento de las personas implicadas su papel, para evitar confusiones. Lamentablemente, esto no siempre es posible, y puede provocar grandes dificultades a los profesionales.

Para la realización del presente estudio, además de consultar las referencias que se ocupan del tema en relación con la interpretación judicial y el análisis comparativo realizado por Hale respecto a los códigos éticos de nueve países (2010) se han consultado directamente seis códigos deontológicos y de conducta, esto es, el Code of ethics and Code of Conduct de AUSIT, el Codice deontologico de AssITIG, el Código deontológico para intérpretes y traductores judiciales y jurados de APTIJ, el Code of 
Professional Ethics de EULITA, el Códe of Ethics and Professional Responsabilities de NAJIT y el Code of Professional Conduct del National Register of Public Service Interpreters del NRPSI.

Siguiendo a Hale (2007), el contenido de los códigos puede subdividirse en tres áreas generales:

1. la responsabilidad del intérprete para con los autores de los enunciados, que incluye las nociones de fidelidad, imparcialidad y confidencialidad;

2. la responsabilidad del intérprete hacia la profesión que ejerce, que incluye cuestiones relacionadas con la conducta profesional: la vestimenta, la puntualidad y la solidaridad;

3. la responsabilidad del intérprete para consigo mismo, que incluye la necesidad de una formación profesional continua, la definición de su papel, condiciones laborales adecuadas y sus honorarios.

Si bien no todos los códigos deontológicos hablan específicamente de calidad (lo hace de manera explícita el de AUSIT, que apunta a la necesidad de promover las condiciones de trabajo, las relaciones y la comprensión del propio papel para un desempeño mejor y de calidad «promote woking conditions, relationships and an understanding of roles that facilitate collaboration and quality service delivery»; dicho código hará referencia a la calidad en cinco ocasiones. EULITA, por su parte, considera los obstáculos que minan la calidad y AssITIG la nombra en relación con la formación continua y especifica también que el código describe las normas profesionales que deben aceptar los socios para proteger la integridad de la profesión y garantizar un estándar profesional para todos aquellos que utilizan los servicios de traducción e interpretación.

A continuación se analizan dichos códigos en busca de los distintos conceptos que pueden servir como base para el diseño de los componentes de la calidad en interpretación judicial. En concreto, se señalan los conceptos de fidelidad, imparcialidad, confidencialidad, conflicto de intereses y formación continua. Para el objeto del presente trabajo, se incidirá con mayor detalle en los conceptos de fidelidad e imparcialidad por tratarse de aquellos que suelen presentar mayor dificultad en cuanto a una definición unívoca que se plasme en comportamientos concretos.

Respecto al concepto de fidelidad, este aparece recogido en los códigos deontológicos estudiados, especificando de manera clara qué es lo que se entiende en cada caso por fidelidad. 
Tabla 5: Concepto de fidelidad en los principales códigos deontológicos de interpretación judicial

\begin{tabular}{ll}
\hline \multicolumn{1}{c}{ Código } & \multicolumn{1}{c}{ Fidelidad } \\
\hline AUSIT & ACCURACY \\
& $\begin{array}{l}\text { Interpreters and translators use their best professional judgement in } \\
\text { remaining faithful at all times to the meaning of texts and messages. }\end{array}$ \\
& $\begin{array}{l}\text { Explanation: Accuracy for the purpose of this Code means optimal and } \\
\text { complete message transfer into the target language preserving the } \\
\text { content and intent of the source message or text without omission or } \\
\text { distortion. }\end{array}$
\end{tabular}

\begin{tabular}{ll}
\hline AssTIG & Articolo 1 Precisione \\
& La LP [lingua di partenza] deve essere resa fedelmente nella LA [lingua \\
di arrivo] mantenendo tutti gli elementi del messaggio originale e nel \\
contempo, regolando la sintassi e gli schemi semantici della LA. La resa \\
deve essere naturale, senza alterare il messaggio originale attraverso \\
aggiunte od omissioni, spiegazioni o parafrasi. Il registro linguistico lo \\
stile e il tono della LP deve'essere mantenuto. Mai tentare di ipotizzare \\
il significato di un termine o modo di dire. Qualora l'interprete non abbia \\
sentito o capito, ha l'obbligo di chiedere chiarimenti.
\end{tabular}

APTIJ El intérprete o traductor realizará una interpretación o traducción leal y completa, sin alterar, omitir o añadir nada a lo que se declare o escriba en la medida de lo posible.

Interpretarán y traducirán veraz y fidedignamente, de la mejor manera posible que permitan su capacidad y conocimiento, sin alterar el contenido o la intencionalidad del mensaje.

\section{EULITA Accuracy}

The source-language message shall be faithfully rendered in the target language by conserving all elements of the original message while accommodating the syntactic and semantic patterns of the target language. The register, style and tone of the source language shall be conserved.

Errors, hesitations and repetitions should be conveyed.

An interpreter shall request clarification when he or she did not understand a sign-language user or speaker, for example for reasons of acoustics, or ambiguity of a statement. He or she shall signal and correct any interpreting errors as soon as possible.

NAJIT Source-language speech should be faithfully rendered into the target
language by conserving all the elements of the original message while
accommodating the syntactic and semantic patterns of the target
language. The rendition should sound natural in the target language, and
there should be no distortion of the original message through addition or
omission, explanation or paraphrasing. All hedges, false starts and
repetitions should be conveyed; also, English words mixed into the other


language should be retained, as should culturally-bound terms which have no direct equivalent in English, or which may have more than one meaning. The register, style and tone of the source language should be conserved.

Estos artículos recogen, de hecho, el juramento que el intérprete ha de hacer cuando traduce en un tribunal. Excepto en el último caso, cuya definición es ligeramente más vaga, en todos los demás casos se da una explicación de lo que se entiende por fidelidad, por lo que deberían superarse los debates y las críticas relativas a una traducción literal (Mason y Stewart, 2001, p. 59; Jacobsen, 2002, p. 64). Esta visión ha sido corroborada por otros autores como Mikkelson (1998, 2000, 2017), BerkSeligson (1990/2002) y Hale (2004, 2010), quienes especifican que la fidelidad no significa literalidad, sino que ha de interpretarse el mensaje completo, incluyendo términos vulgares, vacilaciones, repeticiones, registro y estilo. Son interesantes las puntualizaciones que realiza AssITIG en este sentido: «Mai tentare di ipotizzare il significato di un termine o modo di dire. Qualora l'interprete non abbia sentito o capito, ha l'obbligo di chiedere chiarimenti.» [No intentar nunca suponer el significado de un término o manera de hablar. En el caso de que el intérprete no haya oído o entendido, tiene la obligación de pedir una aclaración] o, la especificación que realiza EULITA:

Obstacles to Performance Quality Legal interpreters and legal translators shall bring to a court's* attention any circumstance or condition that affects the quality of performance such as interpreter fatigue, inability to hear and/or see, inadequate knowledge of the specialized terminology, insufficient understanding of a dialect. They must decline assignments that would have to be delivered under conditions that make a qualified professional performance impossible.

En este sentido hay voces que defienden una intervención activa por parte del intérprete con el fin de nivelar la disimetría entre los participantes de la interacción, teniendo en cuenta diferencias culturales, expectativas, conocimiento de la materia y de la terminología (Errico, 2016, p. 166, siguiendo a Llewellyn-Jones y Lee, 2014, p. 47). La autora reconoce que se pierde el concepto de equivalencia defendido por Viezzi (1999, p. 146), pero se mantiene el éxito de la comunicación. Esta postura entra en conflicto con los comportamientos del intérprete judicial, tal y como se describe en los códigos consultados. 
En cuanto a la imparcialidad, este es otro de los conceptos cuya definición se ha debatido ampliamente entre los estudiosos de interpretación, y que en los códigos deontológicos consultados queda reflejado como sigue:

Tabla 6: Concepto de imparcialidad en los principales códigos deontológicos de interpretación judicial

\section{Código Imparcialidad}

AUSIT Interpreters and translators observe impartiality in all professional contacts. Interpreters remain unbiased throughout the communication exchanged between the participants in any interpreted encounter. Translators do not show bias towards either the author of the source text or the intended readers of their translation.

Explanation: Interpreters and translators play an important role in facilitating parties who do not share a common language to communicate effectively with each other. They aim to ensure that the full intent of the communication is conveyed. Interpreters and translators are not responsible for what the parties communicate, only for complete and accurate transfer of the message. They do not allow bias to influence their performance; likewise they do not soften, strengthen or alter the messages being conveyed.

AssTIG L'interprete giudiziario deve mostrarsi imparziale e neutrale durante il processo e in ogni situazione nella quale sia chiamato a svolgere il proprio compito. Egli deve astenersi dal fare commenti, o esprimere pareri inerenti ai soggetti per cui interpreta e/o su cui traduce, violando così il principio di imparzialità. L'interprete e/o il traduttore devono svolgere il proprio incarico con imparzialità, neutralità ed equità garantendo, attraverso una prestazione professionale altamente qualificata, l'equità dinanzi alla Giustizia e il rispetto dei diritti umani e delle libertà fondamentali dell'indagato.

\section{Conflitto di interessi}

L'interprete e/o il traduttore che si trovi dinnanzi a un qualsiasi conflitto d'interesse, reale o potenziale (conoscenza personale di una delle parti chiamate in giudizio e/o indagate), deve renderlo noto all'autorità giudiziaria che ha disposto la sua nomina.

APTIJ El intérprete o traductor permanecerá en todo momento imparcial y neutral y será independiente, preservando su independencia frente a toda clase de injerencias, exigencias o intereses ajenos qe pudieran menoscabaar su labor profesional y que provengan de los poderes públicos, económicos o fácticos, de los tribunales, de su cliente o de sus propios compañeros o colaboradores.

El hecho de que el pago de honorarios provenga de una de las partes procesales no influirá en el desempeño de su labor conforme a los 


criterios profesionales anteriormente expuestos. Cualquier
circunstancia que ponga en duda su objetividad e imparcialidad o
afecte a su integridad profesional constituirá un conflicto de intereses.
Si el intérprete o traductor judicial o jurado conoce a cualquier de las
partes, o no es percibido como una persona claramente independiente
de todas las partes, revelará a todas las partes cualquier conflicto de
intereses real o aparente. Un intérprete o traductor judicial o jurado
nunca aceptará regalos, gratificaciones o favores de ningún tipo por sus
servicios además de su salario u honorarios.
EULITA
Legal interpreters and legal translators shall remain neutral and also
maintain the appearance of impartiality, avoiding any undue contacts
with either witnesses, defendants and their families or members of the
legal professions.
Any potential conflict of interest shall be immediately disclosed to the
court*).
Court interpreters and translators are to remain impartial and neutral in
proceedings where they serve, and must maintain the appearance of
impartiality and neutrality, avoiding unnecessary contact with the
parties. Court interpreters and translators shall abstain from comment
on matters in which they serve. Any real or potential conflict of interest
shall be immediately disclosed to the Court and all parties as soon as
the interpreter or translator becomes aware of such conflict of interest.

El concepto de imparcialidad absoluta ha sido cuestionado por parte de algunos autores, pues consideran que es imposible de lograr, al igual que su invisibilidad y neutralidad (Rudvin, 2002, p. 223). Llewellyn-Jones y Lee (2014, pp. 21-22) consideran que el intérprete debería ser «bi-parcial» comprendiendo, evaluando abiertamente y siendo capaces de articular ambos puntos de vista por medio de una interpretación fiel. Sin embargo, Hale (2010, p. 126) defiende que aun teniendo su propio punto de vista como participantes en una interacción, los intérpretes judiciales han de ser capaces de evitar las interferencias (Hale, 2010, p. 126).

La imparcialidad resulta verdaderamente difícil en algunos contextos por los temas tratados o las personas implicadas, como puede ser en los casos de violencia de género, solicitud de asilo o asistencia a menores. En estos casos, la formación y la preparación de los intérpretes son fundamentales para poder hacer frente a presiones psicológicas y a una carga emocional considerable (Shlesinger, 2015, p. 434; Aguilera Ávila, 2015, pp. 272-292). Por otra parte, el desequilibro de poder que se produce en 
algunas situaciones lleva a que algunos estudiosos consideren positivo el papel mediador del intérprete (Barber, 2000, p. 19).

Unido a la imparcialidad se encuentra en cierto modo el conflicto de intereses, que puede ser real y potencial, debido al conocimiento de alguna de las partes. Aquí quizá habría que señalar dos cuestiones: por una parte, la situación de algunos intérpretes de lenguas minorizadas en comunidades pequeñas, donde puede suceder que haya que recurrir al uso de un intérprete que conozca a la persona acusada o testigo para poder comunicar con ella; en segundo lugar, la situación que se llega a crear entre algunos actores de la comunicación, que pueden llegar a ver al intérprete como un compañero más que trabaja en realidad en favor de la justicia y de la administración y, por tanto, a favor de él.

La confidencialidad es igualmente recogida en todos los códigos estudiados y se considera primordial en cualquier actuación del intérprete. Este principio del código deontológico $\mathrm{y}$, por tanto, de los profesionales contrasta con la desconfianza que albergan algunos actores implicados. Ello puede ser debido en parte a la falta de conocimiento del trabajo con intérpretes y también a la intrusión de intérpretes no profesionales, que no observan dichos principios.

Los códigos deontológicos hacen referencia también a la conducta y al comportamiento del intérprete, que ha de respetar los protocolos del entorno donde trabajará, además de respetar a los demás compañeros en aras de un trabajo común y colaborativo. Estos dos aspectos son bien conocidos en los intérpretes profesionales, mientras que en aquellos casos de intérpretes no profesionales se observan conductas que en ocasiones pueden ser delictivas, como en el caso de falso testimonio, descubrimiento y revelación de secretos o cohecho, entre otros (Blasco-Mayor, 2015; Ortega-Herráez, 2013; Ortega-Herráez, 2016; Alonso Araguás et al., 2018).

\subsubsection{Manuales}

Junto a los códigos deontológicos, han aparecido en los últimos años manuales que exponen la labor del intérprete que trabaja en los servicios públicos, explicando sus funciones y pautas de comportamiento. González, Vasquez y Mikkelson escribieron el manual Fundamentals of court interpretation en 1991 para la actuación en los tribunales americanos, que se ha convertido en una obra de referencia. La segunda edición de 2012 actualiza ampliamente la información sobre los avances que se han llevado a cabo en la profesión durante los veinte años que separan las dos ediciones. Mikkelson escribió, por su parte, Introduction to Court interpreting en 2000, y publicó una segunda edición en 2017, que actualiza información y bibliografía. Hale publicó a su vez Community 
interpreting en 2007, que se ocupa de la interpretación judicial integrándola en el marco más amplio de la interpretación para los servicios públicos, tomando ejemplos de su realidad en Australia. Corsellis, a su vez, publicó Public Service Interpreting: The first steps en 2008, además de trabajar activamente en programas europeos a los que se hará referencia más adelante. En Europa, se han publicado una serie de manuales vinculados a diferentes proyectos subvencionados por la Dirección General de Justicia de la Comisión Europea, de los que se hablará más adelante, con manuales, normas y vídeos de actuación para distintos entornos, como pueden ser el judicial y policial (proyectos Building Mutual Trust o IMpli) o sobre la violencia de género (proyecto Speak Out for Support - SOS-VICS, Toledano Buendia y Del Pozo Triviño, 2015; Borja Albi y Del Pozo Triviño, 2015). Algunos estudiosos han colaborado, por su parte, en manuales dirigidos a la formación de los futuros profesionales del derecho penal explicando el desarrollo del proceso penal en aquellos casos en los que está presente un intérprete (Blasco-Mayor, 2014, 2015, 2016).

Asimismo, existen pautas para la puesta en práctica de los principios sustentandos por los códigos deontológicos en situaciones específicas, que explican de manera detallada cómo actuar (Corsellis y Vanden Bosch, 2014, p. 73). Estas directrices mejorarán la actuación de los distintos actores implicados en cada contexto, incluidos los intérpretes, de manera que los demás participantes pueden entender la manera de trabajar del intérprete y este pueda cumplir con ciertos protocolos de actuación en aras de la seguridad, los principios deontológicos y las especificidades de cada contexto. Son buenos ejemplos los códigos ingleses y australianos, como el de la policía metropolitana de Londres (Metropolitan Police of London, 2010), el protocolo de la Association of Visual Language of Canada (AVLIC, 2011), las directrices de la NHANES (2006) o las recién publicadas recomendaciones nacionales para trabajar con intérpretes en los tribunales o juzgados australianos (Martin, 2018). Otro componente que aparece sistemáticamente en todos los códigos consultados es la formación continua, considerada esencial para garantizar la calidad como intérprete judicial profesional. Por último, aunque no secundario, deben poder tomarse acciones adecuadas en caso de incumplimiento o violación del código ético (Corsellis, 2004, p. 126).

\subsubsection{Formación}

En el ámbito universitario, existe una concienciación e involucración cada vez más grande en una gran cantidad de países sobre la necesidad de formación de los intérpretes para la justicia que se refleja en cursos específicos y formación especializada de posgrado en aras de una mayor profesionalización y formación de los intérpretes y 
traductores judiciales. En Estados Unidos han proliferado los cursos específicos para traductores e intérpretes en entornos judiciales, además de existir también sendos programas de formación a distancia (González et al., pp. 1145-1158). En Australia, la National Accreditation Authority for Translators and Interpreters (NAATI) enumera un gran número de universidades que imparten cursos de grado y posgrado en interpretación judicial ${ }^{74}$.

En Europa, un número cada vez mayor de universidades oferta cursos de formación en traducción e interpretación judicial y para los servicios públicos, a la vez que lidera o participa en programas europeos financiados por la Dirección General de Justicia de la Comisión Europea que se ocupan de la formación de intérpretes profesionales, y de operadores judiciales para trabajar con intérpretes, entre otros, de los que se hablará más adelante.

En España, la Conferencia de Centros y Departamentos de Traducción e Interpretación (CCDUTI), recientemente constituida como asociación con el nombre de AUnETI, vela para obtener un mayor reconocimiento de la profesión y mayores garantías a nivel judicial, como demuestra el informe presentado en 2013 sobre la transposición de la Directiva 2010/64/UE (Blasco-Mayor et al., 2013), además de mantener reuniones con representantes del Ministerio de Justicia y políticos con el fin de mejorar el estado actual de la interpretación judicial en España y promover la creación de un registro mediante ley, cuyo acceso debería establecerse a través de un examen de acreditación (comunicación personal de Blasco-Mayor, 2018).

Dentro de los programas europeos, se han publicado normas de actuación y, se han realizado vídeos con role-plays que explican el modo de actuar en ciertos contextos específicos como pueden ser el policial (proyecto IMpli) o la violencia de género (proyecto SOS-VICS). Por su parte, algunos estudiosos han colaborado en la formación de los futuros profesionales del derecho explicando el desarrollo del proceso penal en aquellos casos en los que está presente un intérprete (Blasco-Mayor, 2015).

Blasco-Mayor organiza y dirige en 2017 un curso de capacitación específico en la Universidad Jaume I de Castellón, según la propuesta de acreditación realizada junto con Del Pozo Triviño (2015), de la que se hablará más adelante; su propósito fue desarrollar dichos conocimientos y capacitar mediante un examen a intérpretes y traductores cuyo entorno fuera el legal ${ }^{75}$.

\footnotetext{
74 Para una exposición detallada de los cursos, se remite a

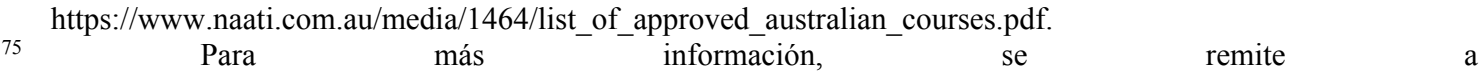
http:/www.uji.es/serveis/cepfc/base/cursos/2016_2017/cursos/?urlRedirect=http:/www.uji.es/serveis/cepfc/base/ cursos/2016_2017/cursos/\&url=/serveis/cepfc/base/cursos/2016_2017/cursos/\&pId=21640.
} 
Rudvin, por su parte, organiza en Bolonia desde 2014 el Corso di formazione permanente Assitenza lingüistica per l'ambito giudiziario, de duración semestral, dirigido a aquellas personas que desempeñan o han desempeñado actividades de interpretación en el ámbito institucional y en los servicios públicos ${ }^{76}$.

\subsubsection{Normas ISO relativas a la interpretación relacionadas con los entornos judiciales}

El interés creciente por la calidad en los servicios de interpretación en distintos ámbitos ha llevado a la International Organization for Standardization (ISO) a establecer una serie de normas para dichos servicios, bajo la dirección de un comité técnico específico, en este caso el TC37/SC 5, que se ocupa específicamente de traducción, interpretación y tecnologías afines.

Como apunta la misma ISO, en dicha organización se elaboran normas que se definen como «documents that provide requirements, specifications, guidelines or characteristics that can be used consistently to ensure that materials, products, processes and services are fit for their purpose ${ }^{77}$. Esto significa que no existe una obligación legal de cumplir dichas normas pues su aplicación no es vinculante. Representan, con todo, la opinión compartida de personas que trabajan en un campo específico y el nivel de calidad deseable para una profesión o un campo específico y que ha sido establecido por los especialistas profesionales en un ampo específico como punto de referencia (Katschinka 2015, p. 18).

\subsubsection{La ISO/DIS 29228 en favor de una interpretación legal de calidad}

El intérprete profesional ha de poseer una serie de cualidades y destrezas, tal y como determinan los códigos deontológicos (Ortega-Herráez, 2011, p. 44). Más allá de dichos códigos, ya revisados al principio del presente capítulo, se encuentran las normas de calidad desarrolladas para empresas o instituciones que desean ser certificadas por entidades auditoras, como es el caso de las normas internacionales ISO.

Partiendo de esta premisa, parece imprescindible crear unas normas específicas para la interpretación en entornos legales. De hecho, se acaba de aprobar la norma ISO/DIS 20228 relativa a los requisitos de la interpretación legal, y se encuentra en fase de proyecto la ISO/CD 20771, que se ocupa de los requisitos de los servicios de traducción legal. 
La primera propuesta para la realización de la normalización de los servicios de interpretación en entornos judiciales fue presentada por primera vez por EULITA en junio de $2014^{78}$. Con harto retraso con respecto a las expectativas, la ISO/DIS 20228.2 ha terminado su fase de revisión del segundo borrador por falta de coincidencia entre los miembros del comité, pues algunos deseaban incluir también un capítulo relativo a las condiciones de trabajo. El borrado final se votó en primavera y será eficaz a finales de año.

La necesidad de establecer estándares en la interpretación legal resulta acuciante a la vista de la falta de uniformidad en los distintos países por lo que atañe a la formación y acreditación de los intérpretes judiciales, a la par que de la provisión del servicio. La profesionalización creciente por una parte y el intrusismo debido a las subcontratas por otra hacen cada vez más acuciantes la fijación de normas bien definidas (Katschinka 2015, pp. 14-15). La norma podrá convertirse en una guía para los usuarios de los servicios de interpretación. Además, la necesidad de establecer registros nacionales será un punto de referencia para los actores implicados, que pretenden normas comparables con las de otros países para así promover la confianza mutua. Además, podrá utilizarse como herramienta para armonizar los servicios de interpretación legal y promover de esta manera la calidad de dicho servicio. Como señala la autora «standards can support countries in adapting their own legal interprting and translation regimen to the generally established state of the art» (Katschinka 2016, p. 19).

Recientemente se ha publicado información sobre el diseño de la norma ISO/DIS 29228 que establece los requisitos y las competencias que han de poseer los intérpretes que trabajan en entornos jurídicos y judiciales:

- tienen que tener competencias basadas en la experiencia del dominio, la práctica y la cualificación profesionales;

- tienen que obligarse a una formación personal permanente;

- deben poseer un conocimiento exhaustivo de los sistemas legales y de la administración de la justica en los países donde se hablan sus idiomas de trabajo;

- deben comprender los campos legales pertinentes (sustantivos, procesales, criminales, civiles, administrativos, etc.);

- deben comprender las funciones de los distintos operadores judiciales: abogados, jueces, funcionarios judiciales, fiscales e intérpretes;

- deben dominar su papel como intérpretes judiciales (introducción, posicionamiento, gestión de turnos, cuándo y cómo pedir aclaraciones, según corresponda;

\footnotetext{
${ }^{78}$ Nota: para una narración pormenorizada de la trayectoria de norma, se remite a Katschinka, 2015, pp. 20-21.
} 
- han de poder trabajar en distintos entornos legales, situaciones o condiciones;

- deben ser conscientes y estar familiarizados con las diferencias culturales y presentarlas en su idioma, gestos y tonos lingüísticos. Cuando sea necesario, tenderán puentes en relación con las brechas culturales y conceptuales que separan a los participantes;

- deben poseer destrezas sólidamente fundadas de comunicación e interpretación porque, a menudo, deben lidiar con la gran diversidad cultural y lingüística de las personas, con frecuencia en circunstancias estresantes y en entornos difíciles. Deberán ser, por tanto, capaces de establecer una buena relación y mostrar autocontrol e imparcialidad en todos los entornos legales;

- deben demostrar la capacidad de utilizar los equipos de interpretación (como el micrófono o la tecnología audio y vídeo para trabajar por videoconferencia) que puedan ser necesarios para interpretar en un entorno legal determinado (v. gr. el volumen, el uso del micrófono);

- deben mantener un registro y ser capaces de reproducir la certificación que atestigüe su preparación y capacitación según cada país. En estas se incluirán los documentos que certifiquen su acreditación, autorización, licencia o registro nacional que confirme el derecho a trabajar como intérprete en el ámbito de la justicia, otorgados por un Gobierno, organismo intergubernamental o internacional, organización, asociación u organización sin fines de lucro;

- cuando se requiera para trabajos especiales, el intérprete deberá conservar, proporcionar evidencia y cumplir con todas las reglamentaciones nacionales o profesionales pertinentes en relación con los antecedentes penales (Katschinka, 2016, pp. 13-21).

Aunque no se señala entre los requisitos de manera específica, se hacen constar las modalidades de interpretación más utilizadas, así como el uso de tecnologías que permiten la interpretación a distancia:

- en su trabajo, generalmente trabajan en modo mixto alternando la modalidad consecutiva y la simultánea, con equipo cuando trabajan con grupos grandes o sin equipo (susurrada);

- a veces trabajan cara a cara y en algunos casos a distancia utilizando tecnologías vídeo o teleconferencia. Los intérpretes en ámbito judicial deben adaptar su manera de trabajar a la situación específica (Katschinka 2016, pp. 13-21); 
La estructura de la norma se manifiesta aproximadamente de la siguiente manera (Katschinka, 2017):

- propósito, que pretende identificar normas y reglas compartidas universalmente para la provisión del servicio;

- en el segundo capítulo se recogen las definiciones de los términos utilizados, relacionados con la interpretación legal, las modalidades de interpretación, las personas implicadas, el lenguaje y los requisitos;

- se presenta la naturaleza de la interpretación legal, realizando una definición en la que la interpretación facilita el acceso equitativo a la justicia de todas las partes implicadas «legal interpreting facilitates equal access to the law for all parties»;

- se definen los criterios aplicables a los proveedores de servicios de interpretación en varios países;

- se especifica una lista de entornos en los que se utiliza la interpretación, que aparece en el anexo B. Se define asimismo que puede implicar la transposición de señales, verbales en ambas direcciones;

- se especifica, por tanto, que se trata de una comunicación fundamentalmente triádica, bidireccional y en la que los intérpretes han de dominar al menos dos lenguas (orales o de señas) y han de ser capaces de facilitar la comunicación. También enuncian las modalidades de trabajo, que incluyen la interpretación consecutiva y simultánea, con equipamiento o susurrada;

- se apunta que puede tratarse de trabajo presencial o utilizando las nuevas tecnologías. Por ello, los intérpretes en ámbito legal han de adaptar el modo de trabajo a situaciones específicas, que se adjuntan en el apartado B;

- se enumeran las competencias y requisitos que ha de poseer un intérprete legal, que como se ha señalado previamente, se basan en la experiencia, la práctica profesional y la cualificación profesional. No puede olvidarse tampoco la formación continua y el conocimiento de los sistemas legales y de la administración de la justicia de las lenguas que interpreta, que incluye también el conocimiento y las formas ritualizadas de todas las partes implicadas en la administración de la justicia. Por tanto, las competencias han de integrar conocimientos lingüísticos, de interpretación, legales e interculturales, además de saber emplear los equipos necesarios para desempeñar su trabajo. Se expresa de manera explícita que deben poder demostrar que están acreditados para realizar dicho trabajo y tener limpio el certificado de penales. 
Se puede decir, por tanto, que la norma citada especifica de manera precisa todas las destrezas y los requisitos que debe reunir un intérprete que trabaja en el ámbito judicial, y entre estas se encuentra poseer la acreditación oportuna. Como apunta Ortega-Herráez (2011, p. 46), el requisito de conocimiento de la cultura de los sistemas jurídicos y legales de las lenguas en las que se trabaja puede ser casi imposible cuando se utiliza una lengua franca, pues parece difícil (si no imposible) conocer todos los aspectos culturales y legales si se utilizan lenguas habladas en muchos países con distintas tradiciones culturales y sistemas legales, como inglés, francés, árabe y castellano, entre otros. No obstante, en su labor cotidiana el intérprete debe estar familiarizado con los sistemas y la cultura más habituales.

\subsubsection{Otras normas ISO en relación con los servicios de interpretación}

El comité técnico TC37/SC 5 comenzó su andadura en 2012, y a él pertenecen institutos de normalización nacionales como la Austrian Standards Institute (ASI), asociaciones como EULITA y otros actores implicados; en él trabajan varios subcomités que se ocupan de aspectos específicos, y existen varios grupos de trabajo. A partir de ese momento, el comité ha trabajado intensamente para establecer una serie de normas en relación con los servicios de traducción e interpretación, algunas de ellas relacionadas con directrices generales de servicios de traducción como la ISO/TS 11669/2012, (relativa a las directrices generales para los proyectos de traducción), la ISO 17100:2015 (sobre las exigencias generales en los servicios de traducción) y la ISO 18587: 2017 (sobre las exigencias de postedición de textos traducidos automáticamente).

Respecto a los servicios de interpretación, se han establecido exigencias de tipo técnico para las cabinas permanentes (ISO 2603:2016) o móviles (ISO 4043: 2016), exigencias de equipamiento de interpretación simultánea (ISO 20109: 2016) y exigencias de calidad y transmisión de las señales audio y vídeo (ISO 20208: 2017). Por último, se han establecido las exigencias y las recomendaciones generales de los servicios de interpretación (ISO 18841: 2018).

Merece la pena detenerse en la norma ISO 13611: 2014 que se ocupa de las directrices para la interpretación en los servicios públicos. Esta propone criterios y recomendaciones para la comunicación oral y signada que permita a las personas que no saben un determinado idioma o discapacitadas poder acceder a los servicios públicos. Marca la diferencia entre la interpretación y la traducción y especifica claramente que se trata de una profesión y no de una práctica informal, como puede ser la interpretación realizada por amigos, miembros de la familia u otras personas que no posean ni la 
cualificación ni las competencias necesarias, ni tampoco un código deontológico. Se trata pues de un documento guía que establece principios básicos de buenas prácticas que permitan proveer un servicio de calidad. Proporciona directrices que son comunes a todos los ámbitos de la interpretación para los servicios públicos, cuyos contextos pueden variar, como ya se ha especificado anteriormente, y que pueden incluir: instituciones, servicios sociales y humanitarios, instituciones sanitarias y de seguridad social, sociedades de seguros e inmobiliarios, confesiones religiosas, situaciones de emergencia como pueden ser catástrofes naturales o epidemias. La norma apunta las competencias y la capacitación que habrían de tener los intérpretes para los servicios públicos y recomendaciones también para los usuarios y los clientes, estableciendo las responsabilidades de los proveedores del servicio y de los intérpretes.

La ISO 13611 hace una mención especial a la interpretación en entornos legales, que en cierto modo incluye, apuntando con todo que en algunos países dicho tipo de interpretación no es considerado como «community interpreting» y está supeditada a las normas legales y leyes específicas. A continuación se presenta el diagrama que ilustra la complejidad de la comunicación mediada por intérpretes en entornos jurídicos, que en ciertos casos se solapa con la interpretación en los servicios públicos:

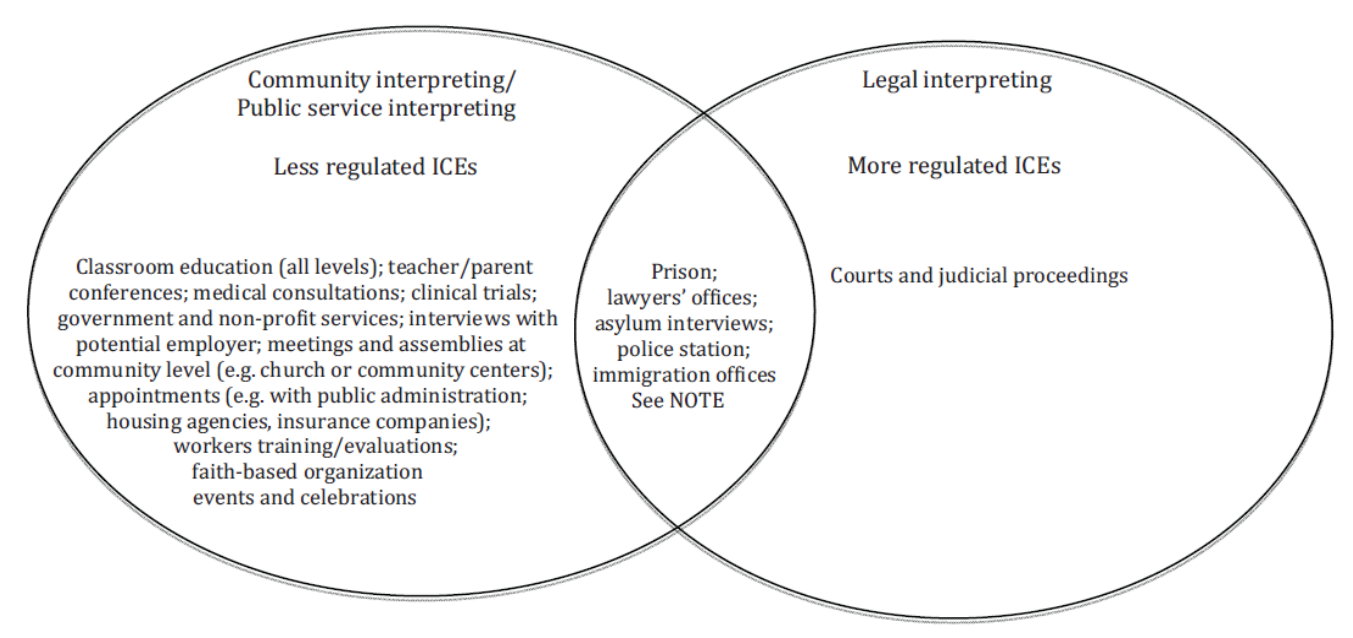

Figura 3: Distinciones y solapamiento relacionado con los eventos mediados con intérpretes para los servicios públicos según la ISO 13611

\subsubsection{Sistemas de acreditación y registros profesionales}

Siguiendo la definición de la Real Academia Española, que define acreditar como 'la condición de una persona y su facultad para desempeñar una actividad o cargo', BlascoMayor y Del Pozo Triviño entienden como acreditación en interpretación judicial: 
... un procedimiento previamente establecido, en el cual los candidatos deben demostrar una destreza suficiente, es decir, que ofrezca garantías de calidad, al realizar una serie de pruebas diseñadas con métodos fiables y basadas en la realidad profesional. Dicho procedimiento o sistema, para ofrecer garantías de calidad, debe ser diseñado y evaluado por expertos externos (2015, pp. 27-28).

Esta exposición no pretende ser exhaustiva, pues en los últimos cuarenta años se han establecido algunos sistemas de acreditación cuya andadura y fiabilidad está ya bien demostrada, y que están sometidos a un seguimiento y evaluación, aunque no estén libres de puntos críticos y posibilidades de mejora (Wallace, 2015a). De su análisis se han ocupado ya otros autores (González et al., 1991, 2012, Mikkelson, 2000, 2017; Corsellis, 2010; Hale, 2007; Ortega-Herráez 2011; Wallace, 2012, 2015a y b). Además, las principales entidades encargadas de procesos de acreditación de intérpretes judiciales ofrecen en sus webs información pública de manera más o menos detallada sobre el tipo de examen y sus requisitos, v.gr. el Manual for Candidates de la NAATI. Además, algunas universidades ofertan cursos para la preparación de los exámenes de acreditación (González et al,, 2012, pp. 1145-1149). Al mismo tiempo, se han presentado propuestas estructuradas de sistemas de acreditación, tanto para las lenguas que se enseñan habitualmente en universidades y centros de lenguas como para aquellas de menor difusión, que presentan mayores dificultades a la hora de diseñar pruebas de acreditación.

En términos generales y como punto de partida para que un sistema de acreditación sea fiable se deberían tener en cuenta los cuatro criterios de Hewitt (1991, p. 91 apud Ortega-Herráez, pp. 54-55) para que un examen de acreditación en interpretación judicial tenga validez:

1. los candidatos han de demostrar la aptitud en los tres modos de interpretación: simultánea, consecutiva y traducción a la vista;

2. las pruebas están refrendadas por leyes que se aplican en todo el estado;

3. las pruebas han sido sometidas al escrutinio de investigadores y profesionales;

4. La agencia encargada de su administración actualiza los datos relativos a su validez y fiabilidad.

Las pruebas de acreditación deben aplicarse siguiendo principios psicométricos que permitan evaluar de manera objetiva y fiable los resultados. Idealmente, deberían constar de dos fases: una eliminatoria, que sirve de cribado de los candidatos, y una 
final, donde se evalúan las destrezas de los candidatos en las distintas modalidades de interpretación.

A continuación se presentan, de manera somera, los sistemas de acreditación de Estados Unidos, Canadá, Australia y Reino Unido.

\subsubsection{Estados Unidos}

Como ya se ha apuntado en el capítulo 2, Estados Unidos es uno de los países donde la figura del intérprete judicial está más reconocida, gracias a la labor de políticos, instituciones académicas y profesionales. También ha contribuido el hecho de que los derechos lingüísticos estén reconocidos en la Constitución y que se tuviese que contar con la presencia e intervención de intérpretes en el ámbito judicial desde los principios fundacionales del país (Zaragoza de León, 2014).

El Federal Court Interpreters Certification Examination (FCICE) es el examen de certificación federal, que llegó de la mano de la Court Interpreters Act de 1978, cuyo propósito es capacitar a los intérpretes que trabajan en los tribunales de jurisdicción federal (González et al. 2012, p. 156). En dicho documento, el Gobierno de Carter reconoce la labor del intérprete y exige que, en los tribunales federales, la interpretación hacia otra lengua o hacia la lengua de signos sea realizada por intérpretes certificados. La ley incorporaba también los emolumentos que debía recibir el intérprete y se reconocía como prioritaria la calidad de la interpretación. En 1988 se promulgó la Court Interpreters Ammendements Act, que se ocupa de la necesidad de certificación de otras lenguas y los criterios sobre los que debía basarse. El Congreso de los Estados Unidos delegó la tarea de desarrollar, testar e implantar dicho examen a la Administrative Office of the United States Courts (AOUSC). El primer modelo de examen teórico fue realizado y testado en 1979 (Navarro-Hall, 2017). El primer examen fue muy sencillo, por lo que fue superado por muchos intérpretes. Después se dieron cuenta de que la gente que lo había superado no estaba preparada para trabajar en el entorno judicial y se llevaron a cabo varias pruebas hasta llegar al formato actual ${ }^{79}$. Al mismo tiempo, el Registry of Interpreters for the Deaf (RID) desarrolló un certificado de aptitudes jurídicas que complementaba el examen de certificación general ya impartido desde 1972 (Mikkelson, 2017, p. 7).

La responsabilidad del examen pasaría luego a la Universidad de Arizona y más adelante al National Center for State Courts (NCSC), que se ocupó de desarrollar y

\footnotetext{
${ }^{79}$ Para un detalle pormenorizado de los exámenes federal y estatal, véanse los cap. 46 y 47 de González et al. 2012, pp. 1159-1207.
} 
administrar las pruebas desde el año 2000. En 2016 se pasó a la empresa Prometric, y en 2017 a la empresa Paradigm ${ }^{80}$. En un primer momento se implantó para los intérpretes de inglés-español.

El examen consta de dos partes. La primera es escrita y tiene un carácter eliminatorio; con ella se pretende comprobar el conocimiento de los registros formales en los dos idiomas por parte del candidato, además del lenguaje legal. El material utilizado para el examen refleja el auténtico en una sala de vistas. Dura dos horas y media $\mathrm{y}$ ha de obtenerse una puntuación mínima del 75\%. Es corregida automáticamente y se ha establecido un umbral mínimo pues, por debajo de él, se considera inaceptable para garantizar la equidad del proceso ${ }^{81}$.

La prueba oral, por su parte pretende testar las destrezas relacionadas con la profesión, en un examen que dura alrededor de cuarenta y cinco minutos y en el que el candidato deberá demostrar sus competencias en traducción a la vista, interpretación simultánea e interpretación consecutiva, en la que existen porciones de interpretación dialógica. La parte oral es grabada y es corregida por evaluadores formados para tal propósito.

El examen federal servirá luego de modelo para la implantación de otros sistemas de acreditación a nivel estatal y es considerado uno de los modelos más exigentes en todo el mundo (Ortega-Herráez 2011, p. 55). El nivel de éxito del examen es más bien bajo, pues a lo largo de los años ha oscilado entre el 1 y el $10 \%$, que refleja las normas rigurosas establecidas para el examen, tal como reza Mikkelson «the rigorous standards set by the exam, the difficulty of court interpreting and the lack of training programs to help candidates prepare for it» (2017, p. 20). Por ello ha recibido amplias críticas, siendo considerado además muy costoso. A pesar de ser cuestionado, se considera que es una prueba válida y viable para evaluar las destrezas necesarias para trabajar como intérpretes en tribunales.

A nivel de tribunales estatales, cada Estado tuvo que establecer sus estándares y elaborar sus propios exámenes de certificación. Con todo, existía el problema del uso de intérpretes certificados en los distintos Estados, pues no había reciprocidad. Por ello se promovió un examen de certificación que pudiera ser válido para todos los Estados del país. En 1997 se creó el Consortium for Language Access in the Courts Interpreters Certification, cuyo propósito era desarrollar pruebas de certificación de acuerdo con los estándares de los distintos Estados, de manera que los intérpretes que poseyeran dichos

\footnotetext{
${ }^{80}$ Hubo un gran escándalo porque una tercera parte de los exámenes orales no se pudieron corregir por ineptitud de la empresa (Wallace, comunicación oral).

${ }^{81}$ para una descripción exhaustiva, véase http://www.uscourts.gov/services-forms/federal-court-interpreters/federalcourt-interpreter-certification-examination.
} 
certificados pudieran trabajar en todos ellos, existiendo reciprocidad. En 2012, se obligó a todos los Estados y a todos los territorios estadounidenses a participar en el consorcio. A partir de ese año, todos los Estados tienen acceso a los exámenes (Wallace, comunicación personal).

La National Association of Judiciary Interpreters and Translators (NAJIT) tuvo hasta 2015 su propia certificación en español, que incluía también ejercicios de traducción. Además de la asociación nacional, existen varias asociaciones estatales. La importancia del asociacionismo en Estados Unidos es fundamental. En ellas se establecen códigos deontológicos, reglas de conducta, además de una obligación de formación continua.

\subsubsection{Canadá}

Durante los años ochenta hubo un mayor interés por la calidad de las interpretaciones ante los tribunales, que adolecían en cierto modo de calidad. Por ello, se estableció un grupo de trabajo, el Task Group on Court Interpreting in British Columbia, en 1985, que aboga para que se realice un examen de acreditación de los intérpretes judiciales, al igual que son los estenógrafos (González et al., 2012, p. 317). Gracias a su labor, ahora existe un examen de acreditación de intérpretes judiciales, que al principio fue desarrollado y establecido en Colombia Británica y Ontario, y luego fue adoptado por todo el país en 1993, por la Canadian Translators, Terminologists and Interpreters Council (CTTIC). El examen consta de un juicio simulado para probar las destrezas del candidato para interpretar y un examen escrito para evaluar el nivel de inglés y del otro idioma del candidato, además de los conocimientos legales y terminológicos. La acreditación puede obtenerse también por medio de historial académico o de mentores ${ }^{82}$.

\subsubsection{Australia}

El modelo de acreditación de que dispone Australia no es exclusivo de la interpretación judicial, sino que incluye la interpretación en un sentido más amplio. La interpretación para los servicios públicos cobra una gran importancia en dicho país. La práctica profesional está vinculada a la obtención de la acreditación. La obtención de dicha acreditación se puede obtener de varias formas, estando incluida la formación universitaria homologada por la National Accreditation Authority for Translators and Interpreters (NAATI). Algunas titulaciones extranjeras también dan el acceso a la

\footnotetext{
${ }^{82}$ Para más detalles, véase http://www.cttic.org/certification.asp?lang=E.
} 
profesión y a la acreditación. Existen cuatro niveles de acreditación: 1) paraprofessional interpreters, 2) intepreter, 3) conference interpreter y conference interpreter (senior).

Como apunta Mikkelson este enfoque permite que todos los intérpretes anspiren a obtener el nivel más alto de certificación y equipara a los intérpretes judiciales con los de conferencias: "This generalist approach is unique in that it allows all interpreters to strive for the highest level of certification, regardless of what setting they work in. In other words, court interpreters are not automatically regarded as inferior to conference interpreters» $(2017$, p. 21).

Los candidatos que han de emprender el examen de intérprete deben realizar pruebas en el que demuestran componentes socioculturales, de código deontológico, interpretación consecutiva dialógica y una monológica.

La prueba se realiza hoy en día en más de cincuenta idiomas ${ }^{83}$, aunque no necesariamente todos los años se realiza en todos ellos ${ }^{84}$. A partir de 2018, está previsto que la certificación sea ratificada cada tres años, demostrando el trabajo en el sector y la formación continua.

\subsubsection{Reino Unido}

El sistema de acreditación de intérpretes en los servicios públicos (Diploma in Public Service Interpreting, DPSI) del Reino Unido fue puesto en marcha en 1989 por el Chartered Institute of Linguists (Corsellis, 2010, pp. 14-23). Se trata de una acreditación que habilita para trabajar en distintos contextos de los servicios públicos: derecho inglés, derecho, escocés, sanidad y servicios municipales, a elegir por el candidato. Las personas acreditadas en la rama jurídica pueden trabajar en los tribunales y en los demás entornos jurídicos, salvo en la London Metropolitan Police, que requiere un examen propio también administrado por la misma institución.

El examen tipo incluye la interpretación de dos simulaciones y la traducción en ambas direcciones (Giambruno, 2014). Según Ortega-Herráez, las pruebas han sido diseñadas con una atención especial que asegura la comparabilidad (2011, p. 51), a la vez que evalúa las destrezas que se han identificado previamente. Las personas encargadas de la confección, administración y corrección de las pruebas han sido rigurosamente seleccionadas y formadas para ello ${ }^{85}$. En 1994 el Chartered Institute of Linguists creó el National Register of Public Service Interpreters (NRPSI) para servir

83 Para más información, se remite al sitio https://www.naati.com.au/.

84 Para un examen exhaustivo, véase la página http://www.uscourts.gov/services-forms/federal-courtinterpreters/federal-court-interpreter-certification-examination.

${ }^{85}$ Para más información, véase para más información consulte el http://www.ciol.org.uk/dpsi. 
como entidad reguladora de la profesión a la vez que gestora del servicio. En 2011 el NRPSI pasó a convertirse en entidad independiente del Chartered Institute of Linguists.

Tras ser una referencia para los estudiosos dedicados al diseño de sistemas de acreditación en distintos países, el modelo británico de profesionalización de la interpretación judicial ha sufrido un descalabro tras la externalización del servicio, de modo que las personas acreditadas están dejando de trabajar para los servicios públicos a causa de las bajas contraprestaciones, y su lugar está siendo ocupado principalmente por intérpretes ad hoc sin formación ni acreditación.

\subsubsection{Otros países europeos}

Otros exámenes destacables son los realizados en Suecia, pues se trata de uno de los sistemas más antiguos y mejor desarrollados para garantizar la calidad de la interpretación judicial (Mikkelson 2017, p. 20). La agencia encargada de los servicios administrativos, financieros y legales lleva a cabo pruebas de certificación de intérpretes judiciales, con pruebas de conocimiento legales y exámenes orales (Mikkelson 2017, p. 20). Noruega posee también un examen de acreditación para los intérpretes en los servicios públicos, que incluye la interpretación judicial (Skaaden, 2013; Giambruno, 2014). Holanda posee una larga tradición en cuanto a sistemas en favor de la calidad en interpretación en los servicios públicos; en 2007 se promulgó una ley que refuerza los estándares de la interpretación judicial, con intérpretes certificados, que deben ser los que deben utilizar las autoridades de inmigración y los agentes judiciales (De Boe, 2015) $)^{86}$.

Un aspecto muy importante que contribuye a garantizar la calidad de la interpretación judicial son las normas de actuación publicadas por la Policía Metropolitana de Londres (Metropolitan Police of London, 2010) o las directrices publicadas por AUSIT para jueces y abogados para trabajar con intérpretes (Hale, 2011), las recomendaciones para trabajar con intérpretes (Judicial Council on Cultural Diversity, 2017) que explican a los demás actores implicados el modo de proceder cuando se trabaja con intérpretes.

La creación de registros puede contribuir a mitigar aspectos negativos del desorden del mercado, registros cuyo uso deberá ser obligatorio para la provisión del servicio (Wallace, 2015b, p. 127). Esto ayudaría a profesionalizar la labor del intérprete y contribuiría a fomentar una mayor transparencia y confianza en el servicio.

\footnotetext{
${ }^{86}$ Para información más detallada de todos los sistemas de acreditación, se remite a Giambruno (2014).
} 


\subsubsection{Nuevos modelos y propuestas de acreditación}

El proyecto Qualitas, del que se hablará también a continuación, unió a una serie de expertos de siete países europeos con el propósito de diseñar un sistema de acreditación a nivel europeo de intérpretes judiciales, basándose precisamente en los sistemas apenas analizados, por medio de una serie de criterios y de técnicas de psicometría para el desarrollo de pruebas de evaluación, todo ello en aras de un examen de acreditación uniforme en todo el territorio de la Unión Europea que condujera a la creación de un registro de traductores e intérpretes en estos países. Este examen debía basarse en una evaluación basada en el desempeño, que implicaba la demostración de las destrezas considerdas relevantes para el ejercicio laboral en el mundo real (Van Deemter, Maxwell-Hyslop, y Townsley, 2014, p. 27). Se tuvieron en cuenta las diferentes destrezas que habían de ser evaluadas y los exámenes: consecutiva a través de una situación dialógica, interpretación simultánea y traducción a la vista, donde ser evaluarían las técnicas de interpretación, la destreza lingüística y terminológica. Por otra parte, era también preciso tener en cuenta el código de conducta y de buenas prácticas, cuyo conocimiento debería ser evaluado.

En cuanto a las lenguas de menor difusión de las que resulta más difícil proveerse de intérpretes cualificados y certificados, el proyecto proporciona una serie de pautas para identificar, formar, tutorizar y evaluar a posibles intérpretes hasta llegar a una eventual acreditación, donde las demás partes implicadas han de tener un papel fundamental por medio de reglas bien precisas y manuales específicos para los intérpretes (Giambruno, 2014).

Blasco-Mayor y Del Pozo Triviño presentan una propuesta de acreditación para España (2015, pp. 31-33) que se basa en el informe de la CCDUTI realizado para el Ministerio de Justicia (María Jesús Blasco-Mayor et al., 2013) y en los resultados del proyecto Qualitas recién citado, donde se establecieron una serie de requisitos previos, como son el dominio de las lenguas de trabajo, los conocimientos del sistema legal y de los códigos deontológicos y buenas prácticas. A partir de ellos, se pretende elaborar un instrumento de evaluación de la interpretación que lleve a un cierto tipo de acreditación y que tenga también en cuenta la organización administrativa del examen de traducción e interpretación judicial.

Asimismo, existe un dilema en relación con el alto número de fracasos de algunos exámenes de certificación, como sucede en Estados Unidos, pues los candidatos no cumplen con los requisitos mínimos en los exámenes de certificación (Wallace, 2015a, p. 221) o de acceso a los cursos especializados, o surge también la necesidad de 
intérpretes cualificados en lenguas de menor difusión, que no están contempladas en los cursos de formación.

Los programas de acreditación han de considerarse pues fundamentales para poder reconocer a los intérpretes formados, acreditados y certificados. Dichos exámenes de acreditación incluyen normalmente ejercicios de consecutiva, simultánea en la versión susurrada o clásica, traducción a la vista e interpretación dialógica. Además de tener en cuenta las destrezas lingüísticas y comunicativas en los dos idiomas de trabajo, son fundamentales los conocimientos legales del país donde trabaja el intérprete y del ordenamiento legal de la otra lengua. También resulta fundamental una formación y evaluación de la deontología y de las buenas prácticas del intérprete. Deben estar bien organizados e incluir en el diseño a una serie de especialistas específicos que incluyan a los distintos actores implicados, además de psicometristas capaces de establecer los modos de evaluación. Al mismo tiempo, se ha de proveer a los candidatos del material necesario para poderse preparar, saber cómo se realizarán las pruebas y cómo serán evaluados.

\subsubsection{Propuestas sobre registros de intérpretes cualificados}

Uno de los mecanismos de control de la calidad establecido por la Directiva 2010/64/UE es la creación y el uso de registros que controlen el acceso a la profesión de intérprete judicial que resulta esencial por dos razones decisivas: la profesionalización de los traductores e intérpretes judiciales por una parte y el fomento de la confianza pública en el sistema judicial y en la labor de los intérpretes (Wallace, 2015b, p. 19). La creación y el uso de registros deben ir acompañados del establecimiento de un sistema de acreditación profesional, «fundamental de cara a garantizar un mínimo de calidad y competencia en el desempeño de la interpretación en entornos judiciales» (OrtegaHerráez, 2011, pp. 46-63). Al mismo tiempo, certificar las competencias de los intérpretes utilizando un enfoque que tenga en cuenta las destrezas, un sistema de evaluación y un código de conducta a través de un esquema de evaluación válido, pondrá a los intérpretes en una situación paritaria con los demás profesionales en el contexto legal (Giambruno, 2014, p. 13).

Corsellis, Cambridge, Glegg, y Robson (2007) consideran que la implantación de un registro tiene ventajas obvias para establecer normas, haciendo que las destrezas acreditadas de los intérpretes en ISP sean de acceso más fácil y poniendo a disposición una gama muy amplia de combinaciones de idiomas (2007, p. 139), además de favorecer la difusión de un código deontológico y de ciertos estándares, y la posibilidad de incurrir en procedimientos disciplinarios en el caso de que no los cumplieran. El 
modelo establecido por el Nationa Register for Public Service Interpreters (NRPSI) británico ha sido un ejemplo, del que ya se ha hablado en el capítulo 2.

Corsellis (2011) reitera la importancia de los registros para someter a un control la profesión, y para un mayor conocimiento de los profesionales efectivamente cualificados que se encuentran a disposición y en qué combinaciones lingüísticas, lo que beneficiará a los organismos involucrados. Blasco-Mayor et al. (2003, p. 13) defienden que «desarrollar un proceso de evaluación y acreditación es la mejor manera de identificar y seleccionar a los profesionales que hayan alcanzado el nivel necesario de conocimientos y destrezas para ejercer como traductores-intérpretes judiciales»y, al mismo tiempo, diferenciarlos de quienes precisan de mayor formación, evitando así el uso de traductores e intérpretes ad hoc. Esto fomentará la confianza mutua y la seguridad jurídica, además de mejorar la provisión del servicio. Al mismo tiempo, la existencia de un registro nacional podría ser un buen modo para socavar la invisibilidad tradicional con la que trabajan los intérpretes judiciales, pues al aumentar su visibilidad se fomenta la profesionalización y el reclutamiento (Wallace, 2015b, p. 132).

En Italia, Rudvin (2014) especifica la importancia del proyecto LEGAII (Legal Interpreting in Italy: Training, Accreditation and the Implementation of a National Register) de la Universidad de Bolonia para promover la colaboración con las instituciones italianas en aras de la creación de un registro en Italia.

Dentro de los proyectos de la Unión Europea, se han llevado a cabo varias iniciativas para promover la creación de registros, de los que se hablará en el siguiente subepígrafe.

\subsubsection{Proyectos de la Dirección General de Justicia (CE) y otras acciones en aras de la calidad en interpretación judicial}

En los últimos años del siglo XX y en un panorama que favorecía la protección del derecho de las personas alófonas, tras una serie de sentencias jurisprudenciales dentro del TEDH, entre las que cabe destacar Luedicke contra Germany (1978), Cuscani contra Reino Unido (2002), Conka contra Bélgica (2002), Van der Leer contra Países Bajos (1990) y Kamasiski contra Austria (1989) (Ortega-Herráez 2016, p. 10), Broziecek contra Italia (1989) (Arangüena Fanego, 2011), se produjeron en Europa una serie de acontecimientos, a saber:

- la celebración del Consejo de Europa de Tampere en 1999, donde los Estados miembros se comprometieron a crear un espacio de libertad, seguridad y justicia en la 
Unión Europea y a intensificar la cooperación en materia de prevención y de lucha contra la delincuencia organizada;

- la convocatoria por parte de la Dirección General de Justicia de la Comisión Europea de una serie de proyectos e iniciativas con el fin de desarrollar y promover el derecho a interpretación y traducción en los procesos penales;

- la publicación en 2003 del Libro Verde sobre garantías procesales para sospechosos e inculpados en procesos penales en la Unión Europea;

- la propuesta de Decisión Marco sobre garantías procesales en los procedimientos penales celebrados en la Unión Europea, ya mencionada en el capítulo 3;

- el plan de trabajo para reforzar los derechos procesales en 2009 con la presentación de la Propuesta de Decisión Marco sobre el derecho a interpretación y traducción en los procesos penales, que también se citó en el capítulo anterior;

- la fundación en 2009 de EULITA, la asociación internacional sin ánimo de lucro de intérpretes y traductores jurídicos europeos, que participará como asociación en buena parte de dichos proyectos.

Se han realizado numerosos esfuerzos con la creación de grupos de trabajo y projectos financiados con fondos de la Comisión Europea para abordar la capacitación y profesionalización de los intérpretes judiciales a fin de mejorar la interpretación en el ámbito de la justicia, promover la mutua confianza e impulsar un modelo de sociedad multicultural y multilingüe (Wallace, 2015, p. 119). A continuación se analizan cronológicamente los citados proyectos, todos ellos enfocados a garantizar una interpretación y traducción de calidad en el ámbito judicial en el marco de la Unión Europea, que comparten algunas características:

- están financiados por la Dirección General de Justicia de la Unión Europea;

- su objetivo es fomentar el establecimiento de estándares similares de interpretación y traducción judicial en todos los Estados miembros. De esta manera se promovería también la cooperación judicial entre ellos, favoreciendo la confianza mutua (Corsellis 2011, p. 144);

- se trata de trabajos que implican a varios socios europeos entre los que se encuentran universidades, Administraciones públicas e instituciones de varios países. Se realiza, por tanto, un trabajo científico y en muchos casos multidisciplinar, donde se comparten conocimientos y experiencias;

- generalmente, se realiza un trabajo previo que ilustra la situación en ese momento como punto de partida del proyecto, por medio de encuestas u otros medios de obtención de datos suministrados en los distintos países de la Unión Europea. Estos 
permitirían identificar puntos críticos, diferencias en los distintos países y posibles vías por recorrer;

- se redactaron una serie de recomendaciones en aras de la calidad en los entornos de la interpretación judicial, tanto lingüística como de signos;

- se desarrolló material de formación para los distintos entornos, mediante folletos informativos, vídeos y simulaciones, plantillas de autoevaluación y manuales de actuación tanto para intérpretes como para los demás actores implicados en la comunicación mediada por intérpretes;

- se llevaron a cabo seminarios y talleres durante las fases intermedias para poder desarrollar el material de apoyo y se celebraron congresos y jornadas en los que se difundían los resultados obtenidos;

- en general, se habilitaron webs institucionales que permiten el acceso al material. Dichos sitios proporcionan una visión general del proyecto y en la mayoría de los casos facilitan un acceso libre a todo el material, que incluye recomendaciones, vídeos, manuales de formación e informe final del proyecto;

- se produjo una difusión de los resultados mediante la participación en congresos, conferencias y la promoción de las páginas web, entre otros.

Los primeros proyectos, que sirvieron de punto de arranque para la posterior elaboración y aprobación de la Directiva 2010/64/UE, comienzan en 1998 con los proyectos Grotius. En ese momento ya se estaban realizando trabajos para fraguar el establecimiento de unos estándares unificados en vista de la creación de un espacio único europeo de justicia, libertad y seguridad como tercer pilar de la Unión Europea. Por esta razón, los proyectos pueden subdividirse también en dos grupos:

- los primeros proyectos pueden ser considerados dentro de este marco previo, en los que se razona sobre el papel del intérprete judicial, y que culminaron con la publicación del Libro Verde;

- a partir del plan de trabajo de Estocolmo (2009) y la emanación de la Directivas 2010/64, 2012, 2013, los demás pueden ser considerados como instrumentos para implementar las condiciones que se habían normalizado mediante dichas directivas. A partir de ese momento, cada proyecto se centra en uno de los aspectos del plan de trabajo. 


\subsubsection{Los proyectos Grotius}

Los proyectos Grotius I y II pretendían instaurar un marco definitivo para la profesionalización de los intérpretes judiciales en la Unión Europea. Fueron financiados por la Comisión Europea (Dirección General de Justicia e Interior) con el propósito de sentar las bases para una armonización de la traducción e interpretación jurídicas en Europa.

Grotius I (98/GR/131) se centró en el establecimiento de estándares entre los miembros de la Unión Europea, por lo que respectaba a la selección, formación y acreditación de los traductores e intérpretes judiciales (LIT - legal interpreters and translators, por sus siglas en inglés), el código deontológico y la guía de buenas prácticas, además de establecer disposiciones de trabajo interdisciplinarias entre los traductores e intérpretes y los sistemas legales. En ese momento se hablaba ya de los modelos existentes y deseables de registros nacionales. En él participaron representantes de cinco instituciones de Bélgica, Dinamarca, España y Reino Unido. Los resultados se plasmaron como recomendaciones y se publicaron en el informe Aequitas - Acces to Justice across Language and Culture in the EU, cuyo propósito era establecer unos niveles de formación exigibles y equivalentes en cuanto a selección, formación, evaluación y reglamentación de la profesión por medio de la acreditación y la implantación de un código deontológico a escala comunitaria, buenas prácticas y mecanismos de cooperación interdisciplinar entre los profesionales de interpretación y los profesionales de la justicia (Hertog y Vanden Bosch, 2001). Se ofrece asimismo un modelo de código de conducta y de buenas prácticas y, al mismo tiempo, se recogen una serie de recomendaciones para la inscripción en un registro y los posibles procedimientos disciplinarios.

El proyecto constó de tres fases que se llevaron a cabo entre 1988-2000 y los resultados se publicaron en 2001. Durante la primera fase se establecieron comités nacionales de los cuatro países participantes, interdisciplinarios, que reunían a miembros del poder judicial y profesionales traductores e intérpretes legales. Debían reunir información que se convertiría en la base del debate. La segunda fase se desarrolló por medio de varias reuniones y seminarios en los que se debatió sobre los temas citados. La última fase se ocupó de la difusión del proyecto con la publicación de las recomendaciones y de otro material que permitiera instaurar una relación con las instituciones, con los medios de comunicación y la organización de conferencias y eventos (Hertog 2000, p. 10). El propósito era salvaguardar las libertades de los individuos y estados, tal como se había establecido en la cumbre de Tampere (1999) en donde las lenguas y culturas tenían un papel fundamental para establecer una 
cooperación judicial real entre los Estados miembros y la aplicación del CEDH (ya abordado en el capítulo 3).

A partir del primer proyecto recién finalizado se puso en marcha el Grotius II (2001/GPR/015), en el que participaron cinco países: Bélgica, Dinamarca, Países Bajos, Reino Unido y República Checa, y profesionales de la Administración de la justicia de Alemania, España, Francia, Italia y Suecia. Los objetivos eran obtener información sobre los desarrollos que se habían realizado para establecer normas equivalentes en traducción e interpretación legal, difundir las recomendaciones que se habían establecido durante el proyecto Grotius I a todos los Estados miembros y a los países candidatos a adhesión, proponiendo instrumentos prácticos, métodos de formación, directrices y competencias que posibilitaran su aplicación en aras de conseguir los estándares y modelos, a la vez que implementaran la trayectoria integral de calidad en interpretación y traducción jurídica en todos los Estados miembros (Hertog, 2003). El proyecto culminó con la celebración de un congreso en Amberes en noviembre de 2002, al que asistieron quince delegaciones de los Estados miembros, entre las cuales había una de la Comisión Europea. Las conclusiones se publicaron en Aequalitas. Equal Access to Justice across Language and Culture in the EU Grotius project 2001/GPR/015 (2003) que, junto a la publicación precedente, se tuvieron en cuenta para la elaboración por parte de la comisión del Libro Verde sobre garantías procesales para sospechosos e inculpados en procesos penales en la Unión Europea (Ortega-Herráez 2006, p. 64). Dichas recomendaciones se ocuparon de los estándares en cuanto a la selección, la formación, la evaluación, la acreditación y los códigos éticos, que incluían procedimientos disciplinarios; directrices de buenas prácticas, la formación continua de los profesionales, y estándares de los demás actores implicados para trabajar con intérpretes.

Los resultados fueron los que se preveían, pues hubo un acuerdo general entre todos los participantes de la conferencia en cuanto a que las recomendaciones necesitaban implementarse, aun mostrándose los gobiernos reacios a hacerlo, a pesar de los requisitos legales, por razones que se consideraron poco convincentes, como eran la falta de recursos (Corsellis, 2011, p. 148).

\subsubsection{EI Libro Verde}

Al mismo tiempo que la Dirección General de Justicia financiaba y promovía varios proyectos, llevó a cabo una serie de iniciativas cuyo propósito era armonizar en cierto modo los derechos fundamentales y las garantías procesales en los distintos Estados miembros. Dichas iniciativas llevaron a la publicación del Libro Verde sobre garantías 
procesales para sospechosos e inculpados en procesos penales en la Unión Europea (2003), a fin de obtener la confianza en los sistemas judiciales de los restantes Estados miembros. En el estudio participaron las distintas partes interesadas, entre las que se encontraban abogados, expertos en la materia, intérpretes y representantes de los gobiernos. Se llegaron a identificar algunos campos prioritarios, entre los que se encontraban el derecho a la defensa y a la asistencia letrada y el derecho a la traducción e interpretación. El problema surgía en el momento de intervenir y a qué nivel hacerlo, pues el «inculpado debe estar en condiciones de comprender todo lo que se dice [...]. El Tribunal Europeo de Derechos Humanos ha declarado que la «asistencia en interpretación ha de ser de tal naturaleza que permita al inculpado tener conocimiento del cargo que se le impute y defenderse, en particular, mediante la capacidad de exponer ante el tribunal su versión de los acontecimientos» (Comisión de las Comunidades Europeas, 2003, p. 32).

Al mismo tiempo, los Estados miembros deberán garantizar la formación, la acreditación y el registro a los traductores e intérpretes jurados, cuyo propósito último es proporcionar una traducción e interpretación de calidad. Las propuestas se fundamentan en las elaboradas en el proyecto Aequitas, cuyos requisitos mínimos son:

1) los Estados miembros han de tener un sistema de formación de intérpretes y traductores especializados, con formación en el ordenamiento jurídico, visitas a tribunales, comisarías de policía y prisiones, que conduzca a una calificación reconocida;

2) los Estados miembros deben tener un sistema de acreditación/homologación de estos traductores e intérpretes;

3) los Estados miembros deberían poner en marcha un sistema de registro que no fuera ilimitado en el tiempo (válido por 5 años, por ejemplo) para que los profesionales se vieran impulsados a actualizar sus capacidades lingüísticas y conocimientos procesales antes de renovar su inscripción en el registro;

4) los Estados miembros deberían instituir un sistema de formación profesional continua, de modo de los traductores y los intérpretes jurados pudieran actualizar continuamente sus cualificaciones;

5) los Estados miembros han de adoptar un código ético y unas directrices de buenas prácticas, que deben ser idénticas o muy similares en la Unión Europea.

6) los Estados miembros se han de comprometer a ofrecer formación a abogados y jueces para que puedan comprender mejor el papel de los traductores e intérpretes y, por lo tanto, trabajar con ellos más eficientemente;

7) los Estados miembros deben adoptar un enfoque interdisciplinar de los requisitos anteriormente mencionados, en el que estén implicados tanto el Ministerio de Justicia como el de Interior en la selección, formación y acreditación de traductores e intérpretes jurídicos. (Comisión de las Comunidades Europeas 2003, p. 32).

Una característica importante del Libro Verde es que se propugna por una diferenciación de ambas profesiones, las de intérpretes y traductores, teniendo en cuenta 
el diferente papel durante los procesos penales y las cualificaciones necesarias para desempeñarlo.

El Libro Verde fue sometido a debate público y tras la adopción por parte de la Comisión, fue remitido al Parlamento Europeo para que fuera estudiado por la Comisión de Libertades y Derechos de los Ciudadanos, Justicia y Asuntos de Interior (LIBE) y la Comisión de Asuntos Jurídicos y Mercado Interior (JURI). De este modo, se aprobó la resolución que permitía adoptar una decisión marco sobre las garantías procesales mínimas, que desgraciadamente se malogró y nunca se llevó a cabo ${ }^{87}$.

\title{
5.5.6.3. Los proyectos AGIS
}

Al finalizar el Grotius II, se inició un nuevo programa marco denominado AGIS que compartía propósitos e intereses con los anteriores, respecto a la cooperación policial y judicial en materia penal. El objetivo, de hecho, era:

\begin{abstract}
Establecer un programa marco único para la cofinanciación de proyectos presentados por promotores de los Estados miembros y los países candidatos en los ámbitos de Justicia y Asuntos de Interior, que permita un enfoque coordinado y multidisciplinario de las distintas actividades relacionadas con la creación del espacio de libertad, seguridad y justicia así como la prevención y la lucha contra la delincuencia organizada en la Unión Europea (Comisión de las Comunidades Europeas, 2005) $)^{88}$.
\end{abstract}

El nuevo programa marco debía cubrir un periodo de cinco años, de enero de 2003 a diciembre de 2007.

Dentro de los proyectos que se desarrollaron bajo AGIS, cabe señalar Instruments for Lifting Language Barriers in Intercultural Legal Proceedings (JAI/2003/AGIS/048) Fue un proyecto de dos años de duración (2003-2004) llevado a cabo por el ITV Hogeschool voor Tolken en Verlaten de Utrech en cooperación con el Stichting Instituut van Gerechtstolken en Vertalers de Ámsterdam. El proyecto estaba coordinado por Heleen Keijzer-Lambooy y Willen Jan Gasille, y del comité directivo formaban parte representantes de Bélgica, Dinamarca, Grecia, Polonia, Reino Unido, República Checa y Holanda. Se trataba de un programa marco cuyo propósito era desarrollar un proyecto que ayudara a la policía, al estamento judicial y a los profesionales de los Estados miembros de la Unión Europea en asuntos de cooperación criminal sobre la

\footnotetext{
${ }^{87}$ Para una información más exhaustiva, se remite al trabajo de Ortega-Herráez (2011, p. 26), Jimeno Bulnes (2008, p. 172) y Vidal Fernández (2008, p. 219).

${ }^{88}$ Disponible en https://eur-lex.europa.eu/legal-content/ES/TXT/?uri=LEGISSUM\%3A133177.
} 
base de lo expuesto en el Libro Verde. Involucró a miembros del estamento judicial, que trabajaron con intérpretes y traductores, cuyos resultados llevaron a la propuesta de Decisión Marco de la Comisión Europea relativa a las garantías procesales en la Unión Europea, publicada en 2004. Se celebraron varias conferencias intermedias en Alicante y Varsovia y los resultados finales fueron presentados en un congreso en La Haya en 2004, en el que participaron jueces, miembros de la policía, ministros, universidades y traductores e intérpretes profesionales. La publicación de Aequilibrium. Instruments for lifting Language Barriers in Intercultural Legal Proceedings (Keijzer-Lambooy y Gasille, 2004) dio como resultado la extensión del Libro Verde y la Propuesta de Decisión Marco (Ortega-Herráez, 2011; Corsellis, 2011). En este programa se profundizaron los temas ya tratados en los proyectos Grotius I y II. El primero es el derecho a un intérprete y/o traductor competente y cualificado, por lo que se ahonda en el rol del intérprete. En segundo lugar, el proyecto estudia la integridad del intérprete legal y por fin, desarrolla la protección de categorías vulnerables como son los ciudadanos con problemas de oído o de lenguaje. Cabe señalar que entre las preocupaciones del proyecto se incluyó también la lengua de signos.

Durante la conferencia de La Haya, se subrayaron dos temas que era necesario desarrollar: la creación de una concienciación sobre la figura del intérprete y traductor por parte de los usuarios de los servicios, y la expansión de la profesionalización de los proveedores de servicios de traducción e interpretación (Kiijzer-Lambooy y Jan Gasille 2004, p. 17).

La conclusión del proyecto fue que los intérpretes y traductores profesionales precisan de estructuras profesionales sólidas, entre las que cabe destacar, tal como apunta Corsellis (2011, p. 150), demostrar su papel a las demás profesionales y a los clientes, confirmar que desempeñan su trabajo de la manera adecuada y que, si no lo hacen, si no se le ponen impedimentos, sus propias asociaciones u organismos profesionales tomarán las medidas pertinentes. En segundo lugar, dichas estructuras proporcionan asistencia en aquellos casos en el que los estándares fijados y sus códigos se vean amenazados.

Al proyecto anterior siguió Questionnaire on the Provision of Legal Interpreting and Translation in the EU (JLS/2006/AGIS/052), siempre dentro de los proyectos AGIS. En él participaron cinco instituciones de Bélgica, España y Holanda y cooperaron la European Criminal Bar Association (ECBA) y el The Council of Bars an Law Societies of Europe (CCBE). El proyecto se proponía obtener información más detallada y objetiva sobre las disposiciones existentes en relación con la interpretación y la traducción judicial en la Unión Europea. La labor se llevó a cabo mediante un cuestionario, que se suministró a traductores e intérpretes de los distintos Estados 
miembros, así como a los distintos operadores judiciales y departamentos gubernamentales para obtener los datos sobre el uso de profesionales calificados, las combinaciones de idiomas necesarios, las buenas prácticas y las distintas políticas, con el propósito de fomentar una comunidad de buenas prácticas a nivel comunitario, con una implementación del derecho al acceso a la justicia a través de las lenguas y las culturas. Uno de los propósitos de la encuesta era identificar los puntos fuertes y débiles de la situación en cada Estado miembro a fin de poder fomentar la ayuda mutua. Los resultados se publicaron en Status questionis (Hertog y Van Gucht, 2006), donde se recogen los datos obtenidos por países, especificando la reglamentación, la calidad y la provisión del servicio, teniendo también en cuenta los indicadores apuntados en el Libro Verde. Como conclusióxn, se apunta que aún no se han cumplido los propósitos en cuanto a calidad y protección del derecho a traducción e interpretación en todos los países de la Unión Europea; además, se estaba llevando a cabo un proceso de mejora, aunque seguía siendo variable, por lo que apuntaba a la coherencia, calidad y cantidad (Corsellis, 2011, p 189). El trabajo se completó con una serie de recomendaciones en aras de mejorar la calidad del servicio de traducción e interpretación en los procesos legales y de fomentar así la confianza mutua en los distintos sistemas judiciales.

\subsubsection{EULITA}

En este contexto de la justicia criminal, la Dirección General de Justicia de la Comisión Europea fomentó la creación de una asociación europea sin fines de lucro de intérpretes y traductores en entornos legales, la European Legal Interpreters and Translators Association (EULITA), en el marco del Programa de Justicia Penal (JLS/2007/JPEN/249), en cuya formación participaron también asociaciones europeas, entre otros. Para su presentación, fue organizada una conferencia de tres días en Amberes del 26 al 28 de noviembre de 2009, y tras la jornada de fundación del primer día, se debatieron amplios aspectos relativos a la traducción e interpretación en ámbito jurídico y judicial.

La misión de EULITA es promover la calidad de la justicia, asegurando el acceso a ella a través de las lenguas y las culturas y, en última instancia, garantizar los principios fundamentales de los derechos humanos consagrados por la CEDH. Su objetivo era reunir a los miembros de pleno derecho de todas las asociaciones profesionales de intérpretes y traductores en el ámbito de la justicia en los Estados miembros de la Unión Europea, además de las otras asociaciones que incluyen también a esta categoría de intérpretes y traductores. Daba la bienvenida a todas las 
organizaciones, instituciones y personas que estuvieran interesadas y comprometidas en mejorar la calidad de la interpretación y traducción en el ámbito legal.

Otro de sus objetivos era fortalecer y representar los intereses y las preocupaciones de las asociaciones y sus miembros frente a las organizaciones e instituciones nacionales, europeas e internacionales para promover el establecimiento de asociaciones de intérpretes y traductores en el ámbito legal en los Estados miembros donde aún no existen, así como promover una colaboración estrecha con las instituciones académicas en el ámbito de la formación y la investigación y fomentar el establecimiento de registros nacionales e internacionales de intérpretes y traductores jurídicos y judiciales cualificados, respetando siempre la diversidad de los sistemas judiciales y culturales.

EULITA se comprometía además, a promover la calidad en la interpretación y traducción en ámbito legal a través del reconocimiento del estatus profesional de los traductores e intérpretes, con el intercambio de información y mejores prácticas en capacitación y desarrollo profesional continuo, organizando congresos y conferencias que tuvieran que ver con la capacitación, la investigación o la profesionalización y promoviendo la cooperación judicial y la confianza de los Estados miembros en los sistemas de traducción e interpretación en ámbito legal en cada uno de ellos.

Por último, se planteaba también el objetivo de fomentar la cooperación y las buenas prácticas en los acuerdos de trabajo con los servicios legales y los profesionales del derecho. (EULITA, 2013).

De ella forman parte un gran número de asociaciones de traductores e intérpretes jurídicos y judiciales de los países miembros, instituciones y miembros individuales ${ }^{89}$. El proyecto preveía dotar a la asociación de un código deontológico, que ya se ha mencionado, de una web institucional y de material para la promoción y la investigación en traducción e interpretación judicial. A partir de ese momento, la asociación mantiene una agenda muy apretada de iniciativas para promover y difundir la profesionalización de los intérpretes judiciales en Europa, participando en los proyectos europeos y de la normalización de la profesión, entre otros mediante la participación en el comité de elaboración de la norma ISO específica sobre interpretación judicial de la que se ha hablado en el subepígrafe 5.5.4.1.

\footnotetext{
${ }^{89}$ Se remite al sitio institucional de EULITA http://eulita.eu/members-admitted-executive-committee-eulita
} 


\subsubsection{Building Mutual Trust}

El proyecto Building Mutual Trust (JLS/2007/219) fue financiado por la Dirección General de Justicia, Libertad y Seguridad de la Unión Europea, que constó de dos etapas, implicando la primera (de 2007 a 2010) a catorce instituciones de Bélgica, Italia, España, Rumanía e Italia.

El proyecto pretendía contribuir al establecimiento de normas comunes en interpretación y traducción jurídica y judicial facilitando el establecimiento de la formación en interpretación y traducción judicial en los Estados miembros de la Unión Europea. Lo hizo proporcionando descripciones de las competencias mínimas, facilitando pautas para el diseño de cursos de capacitación y materiales de muestra para la capacitación, información sobre el uso de tecnologías y sugerencias de cómo capacitar a los futuros formadores.

El proyecto se ocupó ampliamente de la formación de los operadores judiciales, pues se había observado que no conocíann suficientemente los deberes y la profesión del intérprete y traductor judicial. Por ello, el proyecto se proponía orientar y capacitar a los operadores judiciales en el trabajo con intérpretes cuando están desempeñando su trabajo (BTM, 2008).

Los participantes en el proyecto, bajo la dirección de Brooke Townsley (de la Universidad de Middlesex de Londres), establecieron los criterios de referencia para la normalización de la interpretación y traducción judicial en los Estados miembros de la Unión Europea, basándose en los proyectos anteriores. Para ello, elaboraron plantillas de evaluación y formación de intérpretes y traductores y crearon un banco de datos de acceso abierto de materiales de formación que puede ser utilizado por profesores de traducción e interpretación o por personal que tiene que ver con los entornos donde se utilizan (policías, etc.), teniendo en cuenta que muchas veces dicho personal carece de la formación necesaria para comprender el tipo de trabajo que ejecuta un traductor o intérprete judicial y las necesidades específicas que ello conlleva.

Al finalizar la primera fase se inició Building Mutual Trust II (JUST/2010/JPEN/AG/1566), programa de dos años (2011 a 2013) en el que participaron ocho socios de Bélgica, España y Reino Unido. En él se desarrollaron una serie de vídeos relacionados con puntos de aprendizaje, que estaban dedicados fundamentalmente al personal que trabaja en los entornos de la justicia. El material está disponible en red (www.buildingmutualtrust.com), donde se recogen las mejores prácticas para trabajar con sospechosos, acusados y testigos por medio de intérpretes. 


\subsubsection{Video-Mediated Interpreting (AVIDICUS)}

Este proyecto europeo constaba también de tres fases, y fue liderado por la Universidad de Surrey (Reino Unido). El objetivo general del proyecto AVIDICUS 1 (JLS/2008/JPEN/037) era explorar la calidad de la interpretación por videoconferencia y la interpretación remota y evaluar si puede considerarse adecuada para los procesos penales, puesto que esto implicaría dar un paso significativo para mejorar la cooperación judicial en la Unión Europea.

Más específicamente, los objetivos eran los siguientes:

- identificar situaciones en el ámbito de la justicial penal donde la interpretación por videoconferencia fuera más útil y especificar un conjunto de situaciones relevantes;

- evaluar la fiabilidad de la interpretación por videoconferencia en estas situaciones desde una perspectiva de la interpretación por medio de una serie de estudios de casos comparativos, y formular así una serie de recomendaciones para los servicios de la justicial penal de la Unión Europea sobre el uso de la interpretación por videoconferencia;

- diseñar y poner a prueba tres módulos de capacitación sobre interpretación por videoconferencia que se basaran en los resultados del punto 2: el primer módulo para los operadores judiciales, incluida la policía, el segundo para los intérpretes judiciales, y el tercero para los estudiantes de interpretación (Braun y Taylor, 2012).

Al mismo tiempo, pretendía abordar la formación de intérpretes y profesionales del derecho en la interpretación remota y por videoconferencia. Esta primera fase se llevó a cabo de 2008 a 2011. En un primer momento, se realizó una revisión del uso que se hacía en ese momento de la videoconferencia y de la interpretación a través de una encuesta para así poder diseñar prácticas y material de formación para intérpretes y para los operadores. Se completó con una reunión donde se expusieron las conclusiones, donde se sugiere que es preciso seguir investigando sobre cómo afecta la interpretación remota y por videoconferencia a los objetivos de comunicación legal y se elaboran estrategias para mitigar los efectos negativos.

La segunda parte, AVIDICUS 2 (JUST/2010/JPEN/AG/1558), se propuso difundir los conocimientos existentes y que estaban naciendo sobre las aplicaciones de la videoconferencia en los procedimientos penales ante las autoridades nacionales, los profesionales de la justicia, los intérpretes y los ciudadanos europeos; mejorar la información actual sobre estas formas de interpretación e identificar las mejores prácticas a través de la investigación sobre los aspectos conductuales y comunicativos de la interpretación por videoconferencia y la interpretación remota en los procesos 
penales; mejorar las oportunidades de formación para los profesionales de la justicia y los intérpretes en el uso de videoconferencia e intepretación remota.

Los objetivos principales fueron:

- difundir los conocimientos que existían en ese momento y emergentes sobre el uso de la interpretación por videoconferencia en procesos penales a las autoridades nacionales, a los operadores judiciales, a los intérpretes y a los ciudadanos europeos;

- mejorar los conocimientos sobre dicha forma de interpretación e identificar las buenas prácticas a través de la investigación de los aspectos conductuales y comunicativos de la interpretación por videoconferencia en procesos penales;

- mejorar las oportunidades de formación de los operadores judiciales y de los intérpretes en el uso de la videoconferencia.

El proyecto llevó a cabo una serie de talleres de formación inicial en interpretación por videoconferencia a unos trescientos profesionales de la justicia e intérpretes, se llevaron a cabo trabajos empíricos sobre la interpretación por videoconferencia, se establecieron una serie de recomendaciones y directrices en relación con el uso, los beneficios y los retos que implicaban la interpretación por videoconferencia en los procesos penales, dirigidas sobre todo a las autoridades nacionales, un módulos de formación para intérpretes y operadores de la justicia y tres miniguías: una para los profesionales de la justicia, otra para intérpretes y otra para los ciudadanos europeos que debían integrarse en el portal europeo e-Justice ${ }^{90}$.

Por último, AVIDICUS 3: Assessment of Video Mediated Interpreting in Criminal and Civil Justice - Assessing the implementation (JUST/2013/JPEN/AG/4553) se desarrolló de 2013 a 2015 y se centró en el uso de la videoconferencia en los procesos legales bilingües en los que participa un intérprete, debido también al crecimiento de la migración y el multilingüismo en el espacio europeo. El objetivo principal fue llevar a cabo una evaluación exhaustiva de las soluciones utilizadas en las distintas instituciones jurídicas europeas para poder determinar si eran apropiadas para una comunicación bilingüe. Se proponía también desarrollar soluciones de formación más accesibles a las ya propuestas en AVIDICUS 1 y 2, por medio precisamente de la videoconferencia. Como resultado se publicó un informe que documentaba las conclusiones de las entrevistas, las observaciones y análisis cualitativos sobre la videoconferencia bilingüe en los procedimientos penales, un amplio manual dirigido a los responsables de

\footnotetext{
${ }^{90}$ El material está disponible en el sitio web del proyecto http://wp.videoconference-interpreting.net/). Por último, se celebró un simposio para poder difundir los resultados del proyecto.
} 
implantar y gestionar las instalaciones y, por último, un servicio de capacitación que utiliza una plataforma por videoconferencia (Braun et al., 2016).

\subsubsection{Trafut: Training for the Future}

El proyecto Trafut (JUST/2010/JPEN/AG/1549) se proponía como objetivo ayudar y contribuir a la aplicación de la Directiva 64/2010/UER mediante cuatro seminarios regionales que se celebraron durante los años 2011 y 2012 en Ljubjiana, Madrid, Helsinki y Amberes. En ellos, los expertos trataron con los participantes (jueces, fiscales, abogados, personal judicial y autoridades judiciales, además de representantes de los Ministerios de Justicia y asociaciones nacionales de traductores e intérpretes judiciales y jurídicos) los aspectos que tratan los artículos 2, 3, 5 y 6 de la Directiva, esto es: el establecimiento de sistemas de control de la calidad en la provisión del servicio de traducción e interpretación judicial y las consecuencias de una calidad insuficiente, la calidad en el servicio también en relación con la orden de arresto europea, la creación de registros nacionales de intérpretes y traductores jurídicos (procedimientos de admisión, gestión de los registros e integración en el banco de datos único europeo), la formación y el perfeccionamiento de los intérpretes y traductores legales y las mejores prácticas para una comunicación efectiva entre los actores implicados en el procedimiento penal y los traductores e intérpretes.

De los distintos talleres se publicó un informe final que incluía también el código deontológico ${ }^{91}$.

\subsubsection{ImPLI: Improving Police and Legal Interpreting}

ImPLI (JUST/2010/JPEN/AG/1562) fue un proyecto que se desarrolló en 2011 y 2012, tras un convenio con la Dirección de Justicia de la Comisión Europea, la red UNITI (University Network of Interpreter Training Institutes) y el ISIT de París, cuyo propósito era contribuir a la aplicación de la Directiva 2010/64/UE recién establecida, en particular los artículos 2 y 6 , relativos a la interpretación judicial.

Los dos objetivos fundamentales eran, pues, proporcionar a las instituciones de formación de intérpretes una mejor comprensión de las técnicas de interrogatorios desarrolladas por la policía, las aduanas, los jueces y fiscales, y mejorar sus métodos de formación. Al mismo tiempo, el segundo objetivo era informar a la policía y a la fiscalía sobre las técnicas de intepretación y cómo dichas técnicas pueden ayudarlos en su labor

\footnotetext{
91 El material está disponible en el sitio de EULITA http://www.eulita.eu/sites/default/files/TRAFUT\%20$\% 20$ final\%20report.pdf.
} 
cuando se han implementado de la manera adecuada (Comisión de la Comunidades Europeas, 2010).

Para conseguirlos, se llevó a cabo un estudio sobre la situación de la interpretación en entornos policiales en los distintos países de la red UNITI, analizando las estrategias de entrevistas y las técnicas de interpretación. Se organizaron seis mesas redondas a las que participaron las fiscalías, las academias de policía e intérpretes para aportar sus percepciones y visión. De esta manera, se fomentó el diálogo entre los distintos profesionales y se establecieron buenas prácticas. Al mismo tiempo, se prepararon seis vídeos con fines pedagógicos. Los resultados se presentaron en París en septiembre de 2012. Se dieron asimismo una serie de recomendaciones técnicas y de trabajo, en las que se señala la necesidad de formación específica para intérpretes, para los profesionales responsables de la realización de entrevistas y conjuntos de intérpretes con policías.

\subsubsection{Qualitas: Assessing LI Quality through Testing and Certification}

El proyecto Qualitas (JUST/2011/JPEN/AG/2889) es un proyecto de tres años que partió de los ya realizados y que fue liderado por la Universidad de Alicante, con la participación de universidades de siete países europeos (España, Reino Unido, Suecia, Holanda, Italia, Bélgica y Noruega), cuyo propósito principal era mejorar la prestación efectiva de servicios de interpretación de la lengua hablada en los procedimientos penales y asuntos policiales en los Estados miembros de la Unión Europea para garantizar que se respeten las garantías procesales de todos los sospechosos, acusados y las víctimas de delitos. El proyecto pretendía contribuir al desarrollo de un espacio único de justicia, libertad y seguridad a lo largo de la Unión Europea a través del reconocimiento y la confianza mutua ${ }^{92}$.

Para ello, el proyecto desarrolló una serie de instrumentos de certificación válidos $\mathrm{y}$ fiables que permitieran identificar a las personas que reunían las competencias necesarias para garantizar una interpretación de calidad en el entorno judicial. Incluía también recomendaciones para la realización eficiente de los exámenes de certificación, proporcionó plantillas de examen y prototipos que era posible adaptar a las distintas realidades de los Estados miembros y también una consulta directa.

El proyecto desarrolló una web donde se publicaron los resultados finales (Giambruno, 2014), en el que se pormenorizaban las competencias que debían ser evaluadas, cómo debía ser llevado a cabo el examen, el formato y se analizaban varios códigos deontológicos. Al mismo tiempo, se planteaba el problema de las lenguas

\footnotetext{
${ }^{92}$ Para los objetivos completos se remite al sitio electrónico del proyectohttp://www.qualitas-project.eu/.
} 
minorizadas para las que resulta difícil poder implementar dichos procesos. Como colofón, se analizaba la situación real en los países miembros en cuanto a la realidad lingüística en el momento da publicación del informe, la realidad de los servicios de interpretación, la existencia o no de registros de intérpretes profesionales para la justicia, la certificación y los procedimientos de acreditación. En dicho informe se enumeraban una serie de conclusiones en las que se remarcaba la falta de actuación de la Directiva en algunos Estados miembros, que los procedimientos de certificación, formación y registro de los intérpretes no eran uniformes, siendo muy diferentes en los distintos Estados miembros.

\subsubsection{SOS-VICS: Speak out for Support}

El proyecto Speak out for Support (JUST/2011/JPEN/2912) fue un proyecto piloto cofinanciado por el Programa de Justicia Penal de la Unión Europea y las universidades socias que participaron en él, además de una serie de personas implicadas y entidades que colaboraron para poder llevar a cabo el proyecto. Su objetivo era mejorar la formación de intérpretes en el ámbito de la violencia de género. Al. mismo tiempo, pretendía contribuir a sensibilizar sobre la necesidad de contratar intérpretes profesionales durante la mediación lingüística.

El proyecto, que duró dos años, se articuló en varias fases: durante la primera, se compilaron y analizaron las necesidades de comunicación de las personas implicadas en los casos de violencia de género, tanto víctimas como agentes. En la segunda fase se creó material para todos los actores implicados, esto es: víctimas, agentes e intérpretes. Los materiales incluían un sitio web de difusión ${ }^{93}$ y uno de formación ${ }^{94}$, información multilingüe para las víctimas, un manual de buenas prácticas para los agentes, además de material y recursos especializados para los intérpretes y docentes. Durante la tercera fase se difundieron los resultados y la metodología, de manera que fuera posible traspasar la información y los métodos más allá de las fronteras españolas. En septiembre de 2014 se celebró el congreso Construir puentes de comunicación en el ámbito de la violencia de género.

El sitio de formación incluía también un código deontológico y los entornos en los que se puede producir la violencia de género, que no se limita al ámbito judicial y policial, pues la comunicación mediada se produce también en ámbito médico y psicosocial. Toca también el tema de la interpretación remota en algunos casos y tiene en cuenta las dificultades también emotivas y psicológicas que este tipo de

\footnotetext{
${ }^{93}$ Disponible en http://sosvicsweb.webs.uvigo.es/blogs/ver.php?id=14.

${ }^{94}$ Disponible en http://sosvics.eintegra.es/.
} 
interpretación puede conllevar, por lo que presenta algunas técnicas que permitan al intérprete gestionar las dificultades que debe afrontar.

\subsubsection{Co-Minor INQUEST}

El proyecto Co-Minor INQUEST (JUST/2011/JPEN/AG/2961) se concentra en los interrogatorios de policía con intérpretes que implican a víctimas, sospechosos y testigos menores de 18 años y «vulnerables» (debido a la edad y a su lengua), con el propósito de identificar las herramientas y los métodos más apropiados para proporcionarles información, apoyo y protección.

Implicó a varias universidades y organizaciones de seis países europeos Bélgica, Holanda, Francia, Reino Unido, Italia y Hungría, bajo la dirección de Katalig Balogh y Heide Salaets. Tuvo en cuenta las referencias con la Convención de las Naciones Unidas sobre los derechos del niño y las Directivas 2010/64/UE y 2012/29/UE. El proyecto se desarrolló en varias fases:

- en la primera se investigó sobre la situación de la interpretación de menores en la fase previa del juicio en casos y criminales. Fue realizado por un equipo interdisciplinario que incluía estudiosos de la conducta, psicólogos, psiquiatras, jueces, abogados y oficiales de policía e intérpretes que se plantearon cómo trabajar para respetar los derechos de los menores;

- durante la segunda etapa, se analizaron las necesidades existentes en los distintos países mediante una encuesta internacional en línea que implicaba a profesionales de las tres disciplinas interesadas (justicia, psicología e interpretación) que proporcione información sobre los problemas y desafíos específicos en relación con la existencia ya existente y colmar las lagunas. De esta manera pudieron presentar una serie de recomendaciones y se prestó atención a los menores más vulnerables ${ }^{95}$;

- por fin, los resultados se presentaron en una conferencia en Amberes, en noviembre de 2014 y llevó a cabo una publicación que presentaban las recomendaciones. Así se podían difundir los resultados a fin de mejorar el intercambio interdisciplinario de conocimiento, experiencia y mejores prácticas en este sector (Balogh y Salaets, 2015).

\footnotetext{
${ }^{95}$ El material del proyecto está disponible en https://www.arts.kuleuven.be/english/rg_interpreting_studies/researchprojects/co_minor_in_quest.
} 


\subsubsection{Understanding Justice}

El proyecto Undestanding Justice (JUST/2013/JCIV/AG/4000004684) fue un proyecto de dos años financiado por la Dirección General de Justicia de la Comisión Europea, centrado en el estudio de la interpretación del lenguaje oral en la mediación y la justicia civil. En él que participaron varios socios, que reunía a un grupo multidisciplinar de seis Estados miembros (Bélgica, Holanda, Italia, Rumanía, España y Reino Unido), bajo la dirección de Brooke Townsley.

Sus objetivos fueron los siguientes:

- adaptar el corpus de conocimientos y recomendaciones existentes para la interpretación y traducción jurídica en la justicia penal a la justicia civil;

- investigar sobre la provisión de metodologías de autoevaluación para intérpretes jurídicos que desearan ejercer en entornos de justicia civil;

- examinar la función de los intérpretes en las actividades de mediación cuando una o ambas partes no comparten el mismo idioma (Townsley, 2016).

Para ello se llevaron a cabo varias acciones:

- se emprendió una evaluación del acervo de la Unión Europea y de las demás leyes que posean un impacto directo o indirecto sobre la provisión de servicios de interpretación y traducción en los procedimientos de justicia civil;

- se investigó sobre cómo se puede adaptar el corpus de trabajo en sucesivos proyectos financiado por la Unión Europea para la interpretación y traducción en justicia penal para la justicia civil;

- se desarrollaron metodologías y materiales en línea para que los intérpretes y traductores en entornos judiciales pudieran autoevaluar sus competencias frente a los requisitos de la interpretación de la justicia civil;

- se investigó la práctica y el impacto de la interpretación en la mediación civil y la resolución alternativa de conflictos, incluido el uso de mediadores bilingües.

El proyecto llevó a cabo una serie de iniciativas que culminaron en la publicación de un sitio en el que se explicaba el proyecto ${ }^{96}$, que recogía asimismo la publicación del informe final. Había una serie de vídeos sobre interpretación en entornos de la justicia

\footnotetext{
${ }^{96}$ Disponible en http://www.understandingjusticeproject.com.
} 
civil y la mediación, con explicaciones de la labor de los intérpretes y evaluación por parte de los mediadores. Proporcionaba también pautas de autoevaluación.

El proyecto culminó con la celebración de un simposio el 10 de marzo de 2016 en el Chartered Institute of Arbitrators de Londres, que se centró en el papel de la interpretación en las mediaciones donde existe además el obstáculo de la diferencia de idioma.

\subsubsection{TraiLLD: Training in Languages of Lesser Diffusion}

El objetivo del proyecto TraiLLD (JUST/2013/JPEN/AG/4594), financiado por la Unión Europea, era centrarse en los diferentes aspectos y métodos de capacitación para intérpretes en idiomas de menor difusión. El proyecto fue liderado por la universidad de KU Leuven de Amberes y en él participaron cinco países de la Unión Europea (Bélgica, Holanda, Italia, Eslovenia y Alemania). Su propósito era:

- realizar una cartografía de la situación en relación con los distintos marcos metodológicos de formación;

- desarrollar una metodología y estrategia de capacitación que permita a hablantes de lenguas de menor difusión convertirse en intérpretes tras un periodo de formación corto pero intenso que permita eliminar las diferencias de calidad con respecto a los intérpretes de los idiomas principales.

Por último, a fin de obtener los propósitos establecidos, se realizó un sitio que proporcionaba el acceso al proyecto ${ }^{97}$ y se llevaron a cabo varios talleres. Se publicó el informe final (Balog y Salaets, 2016), donde se recogen los resultados obtenidos. También se difundieron los resultados en varios congresos internacionales en Holanda, Tampere y Edimburgo (2016).

\subsubsection{JUSTISIGNS}

Este proyecto (538899-LLP-1-2013-1-IE-LEONARDO-LMP) se integra en el programa de aprendizaje permanente de la Unión Europea. Fue un programa de tres años (2013 a 2016) que se centraba en la identificación de competencias para la interpretación de la lengua de signos en contextos legales y la capacitación de intérpretes de lengua de signos en dicho entorno, que incluye las vistas orales, la interacción con abogados y con los servicios de policía.

97 Disponible en https://www.arts.kuleuven.be/home/english/rg_interpreting_studies/research-projects/trailld. 
El material de capacitación incluía capacitación general y de formación continua. Los grupos a los que iba dirigido el material eran los intérpretes de lenguas de signos y las personas con discapacidad auditiva. Dicho material sería puesto a disposición de todos los socios implicados en el proyecto. En él participaron seis instituciones europeas, y el coordinador del proyecto fue el Interresource Group del Trinity College de Dublín, que se encargó de difundir los talleres de formación. En la Universidad Heriot Watt se llevó a cabo un curso específico de formación con el Servicio de Policía escocés. El material también sería puesto a disposición de los abogados y los demás actores implicados, en aras de una mejor comprensión de la comunidad sorda y de desarrollar sus competencias en el trato con personas sordas e intérpretes de la lengua de signos $^{98}$.

\subsubsection{Lit Search}

El proyecto Lit Search (JUST/2013/JPEN/AG/4556, liderado por EULITA, se proponía crear una base de datos de intérpretes y traductores judiciales en el portal e-Justice, que fue un proyecto piloto para explorar las modalidades y las características prácticas de dicha base de datos ${ }^{99}$.

En la conferencia de mayo de 2014 en Amberes, los cobeneficiarios y los socios discutieron sobre el propósito general y las actividades del proyecto, definiendo las tareas específicas y distribuyéndolas entre los socios.

La asociación implementó los aspectos técnicos de proyecto piloto, desarrollando los requisitos técnicos para interconectar los distintos registros y desarrollar una base de datos modelo. Durante un periodo de quince meses, se organizaron cinco reuniones, para compilar información con respecto a los registros nacionales de los países participantes.

La base de datos piloto de intérpretes y traductores legales fue presentada en la conferencia final de Amberes, en noviembre de 2015.

\footnotetext{
${ }^{98}$ Material disponible en http://justisigns.com/JUSTISIGNS_Project/About.html.

99 Material disponible en http://eulita.eu/lit-search-\%E2\%80\%93-pilot-project-eu-database-legal-interpreters-andtranslators.
} 


\subsection{Conclusiones}

La interpretación judicial ha ido adquiriendo mayor importancia en el mundo debido a los cambios sociales que se están produciendo globalmente. Cabe señalar que en distintos países existen disposiciones legales que establecen la calidad en este ámbito como un requisito básico e imprescindible. Por otro lado, la interpretación judicial tiene lugar en un entorno muy específico y ritualizado, que requiere de conocimientos jurídicos y de conducta profesional. Por esta razón, la calidad de la interpretación judicial está profundamente vinculada tanto a las leyes que la regulan como a normas de actuación, códigos deontológicos y de conducta, pruebas de acreditación y certificación.

El interés académico y profesional en el sector ha ido creciendo en los últimos años, pero la característica principal de dicho interés es que este es de carácter práctico, pues se han publicado manuales y se ofertan cursos de formación para la acreditación de intérpretes judiciales. En esta línea, se han producido movimientos relacionados con la promoción de la mejora de la interpretación en los servicios públicos, como los promovidos por la asociación mundial Critical Link, o proyectos específicos, como los subvencionados por la Dirección General de Justicia de la Comisión Europea, cuyo propósito es precisamente mejorar la calidad de la interpretación en los procesos penales.

En el seno de la Unión Europea, se han promulgado una serie de directivas y leyes que propugnan el derecho a interpretación y traducción en los procesos penales, que ha de tener como característica imprescindible la calidad, tal y como recoge la Directiva 2010/64/UE. Por otra parte, el organismo internacional de normalización ISO acaba de ultimar, junto con expertos del sector, la redacción de una norma específica para la interpretación judicial, que deberá ser trasladada a normas nacionales por los organismos encargados de normalización en cada país.

Es preciso evidenciar la importancia del establecimiento de exámenes de acreditación y la creación de registros nacionales e internacionales que promuevan y defiendan una capacitación y profesionalización de los intérpretes judiciales, evitando así el intrusismo profesional (Blasco-Mayor et al., 2013; Rudvin, 1014; Wallace, 2015a y b). A su vez, dichas medidas contribuirán a un mayor reconocimiento de los intérpretes profesionales, que podrán así defender sus derechos y consolidarse como colectivo profesional.

Es necesario señalar que se precisa una mayor colaboración entre los intérpretes y los operadores judiciales que permita un mejor reconocimiento de la figura del intérprete por parte de estos y contribuya a la mejora de las condiciones de trabajo de todos los intervinientes en el proceso judicial. Esto conllevaría la confianza mutua entre 
los intérpretes y los operadores judiciales, lo que repercutiría positivamente en el principio fundamental de la interpretación judicial, que es proporcionar un juicio equitativo para las personas alófonas.

Si bien se han realizado iniciativas muy loables en aras de fomentar la calidad, no existe aún un mecanismo de control que tenga en cuenta la dificultad intrínseca de evaluación y utilice un sistema diferente a la comprobación de la concordancia entre el texto fuente y el texto meta. Este mecanismo debería basarse en métodos objetivos y científicos, punto de partida del diseño y validación de una herramienta de evaluación de la calidad en la interpretación en entornos judiciales que se presenta en los próximos capítulos. 


\section{Método}

\subsection{Introducción}

En esta parte de la tesis doctoral se describe el procedimiento que se ha seguido para la construcción y validación de un cuestionario destinado a medir la actuación de un intérprete judicial.

La creación de un cuestionario es un proceso largo y minucioso que incluye los siguientes pasos (Meyer, 2014, p. 61):

1. Definición del objetivo.

2. Descripción de lo que se intenta medir.

3. Redacción del borrador inicial.

4. Estudio piloto, a partir del cual se redacta la versión experimental.

5. Estudio empírico, que incluye análisis de los ítems, fiabilidad y validez. Este estudio pretende, en última instancia, demostrar que el cuestionario es una herramienta de medida adecuada. Esto implica, en primer lugar, que tiene fiabilidad (precisión, consistencia, ausencia de errores de medida) y, en segundo lugar, validez y utilidad, es decir, demostrar que mide lo que se quiere medir y sirve para el propósito aplicado para el que se ha construido.

Para la elaboración del cuestionario se han seguido los principios y métodos propios de la construcción de test. El término test se utiliza en sentido amplio, por lo que se pueden aplicar a muchos procedimientos de evaluación se denominen o no test $^{100}$. Según las Directrices Internacionales para el uso de los test ${ }^{101}$, las características que ha de reunir un procedimiento para ser considerado como tal son las siguientes:

- se utilizan en evaluación psicológica, educativa y ocupacional (siendo este último el caso del presente trabajo);

- evalúan conductas tanto normales como anormales o disfuncionales. En este trabajo se trata de conductas normales (tanto adecuadas como inadecuadas) dentro de una actuación y contexto profesionales;

\footnotetext{
100 En este trabajo se ha evitado el uso de expresiones como «test» o «cuestionario» en el nombre definitivo del instrumento.

${ }^{101}$ Se remite al sitio (www.cop.es).
} 
- se aplican bajo condiciones controladas o estandarizadas, y conllevan la utilización de protocolos de puntuación rigurosos (en este caso se han utilizado preguntas cerradas, con respuesta dicotómica y una codificación de cada pregunta que contribuye a una puntuación total del cuestionario);

- proporcionan medidas de muestras de conducta y conllevan la obtención de inferencias a partir de estas (mediante las puntuaciones de este cuestionario se pretende valorar la competencia de un intérprete en un contexto judicial);

- incluyen también procedimientos que proporcionan clasificaciones cualitativas $\mathrm{u}$ ordenamientos de las personas (a partir de los resultados en el cuestionario se puede clasificar la actuación del intérprete como excelente, buena, regular o inaceptable).

Según las directrices, cualquier procedimiento que tenga las características que se acaban de describir puede considerarse como un test, independientemente de su forma de aplicación, el profesional que lo haya construido, o si requiere contestar a preguntas o realizar tareas $\mathrm{u}$ operaciones. Por otra parte, un test para ser considerado adecuado, debe estar apoyado por datos empíricos sobre su fiabilidad y validez para medir los objetivos que se propone (Anastasi y Urbina, 1998).

La fiabilidad significa precisión o estabilidad de las medidas. Esta estabilidad se refiere a las puntuaciones obtenidas por las mismas personas cuando se vuelven a evaluar con el mismo test en diferentes ocasiones, o con diferentes combinaciones de ítems equivalentes, o bajo otras condiciones de evaluación diferentes.

Teniendo en cuenta las diferentes fuentes de error que afectan a los resultados de un test, puede haber distintos tipos de fiabilidad. Sin embargo, los tipos de fiabilidad que se calculan en la práctica son relativamente pocos. Todas las categorías de fiabilidad pueden expresarse en forma de un coeficiente de correlación. Los coeficientes de correlación tienen valores entre 0 (fiabilidad nula) y 1 (fiabilidad perfecta). Los tipos de fiabilidad que se calculan en la práctica son la fiabilidad test-retest, que indica estabilidad temporal de las puntuaciones, fiabilidad de las dos mitades, coeficientes alfa y Kuder-Richardson y de formas paralelas, que señalan la consistencia interna de un test y la representatividad de dos subconjuntos de ítems y, por último, la fiabilidad entre evaluadores, que es una medida de objetividad. Para esta investigación interesan los coeficientes de consistencia interna y de objetividad.

La validez de un test se refiere a qué mide un test y hasta qué punto lo mide. Es la pregunta más importante sobre un instrumento que pretenda evaluar el comportamiento humano. Nos dice qué se puede inferir a partir de las puntuaciones. Otra forma más precisa de expresarlo sería definir la validez como la medida en que se sabe lo que mide un test y en qué grado cumple su función. A diferencia de la fiabilidad, la validez no se 
estudia solo con coeficientes de correlación, sino mediante diseños de investigación más amplios, que incluyen intervenciones experimentales, análisis de la literatura o juicio de expertos, entre otros. No existen diferentes tipos de validez, sino diferentes aspectos de la misma que se estudian con métodos específicos. No todos los procedimientos y técnicas de evaluación son igual de precisos ni proporcionan las mismas garantías, por eso el considerar las fuentes de validez o invalidez de interpretación de los datos es un elemento clave del proceso de evaluación (Alonso Tapia, 2004). Desde los años cincuenta, la American Psychological Association (APA) (2014) ha clasificado la validez en tres tipos diferentes, conocidos como validez de contenido, de criterio y de constructo.

Determinar la validez de contenido de un test supone, fundamentalmente, el examen sistemático de su contenido a fin de comprobar si las instrucciones, materiales o preguntas, alternativas de respuesta que lo componen son una muestra relevante y representativa de lo que intenta medir. En definitiva, la adecuada validez de contenido de un test se consigue construyéndolo con los elementos adecuados (véase el punto 6.3 más adelante en el que se describe el procedimiento seguido para la redacción del borrador inicial), y siguiendo una serie de pasos que se describen a continuación:

1) El enfoque habitual en la especificación del ámbito conductual consiste en una serie de procedimientos como análisis de puestos, de tareas, de programas docentes, de libros de texto, la revisión de la literatura, entre otros.

2) A continuación, se elaboran las especificaciones del test. Las especificaciones se formulan en términos del conjunto de información que teóricamente se espera que explique aquello que pretende medir el test, y debe abarcar lo siguiente (Cronbach, 1998): a) el rango adecuado de tareas, estímulos o situaciones; b) el tipo de respuesta que ha de reflejarse en la puntuación o registrar el observador y c) las instrucciones que indiquen a la persona que contesta lo que ha de hacer. A partir de aquí se decide cuántos ítems de cada tipo se redactan.

3) Otro procedimiento muy frecuente es recurrir a expertos en la materia. Es un componente importante en la estimación de la relevancia del contenido y el formato de un test. También es necesario para estimar la calidad técnica de los ítems, el nivel de legibilidad, la ausencia de ambigüedad e irrelevancia, la adecuación de los distractores, la relevancia de los formatos y la claridad de las instrucciones. Sin embargo, los niveles de dificultad y la potencia de discriminación de los ítems se han de estimar mediante evidencia empírica. La dificultad y discriminación son dos propiedades cuantitativas de los ítems que se explican más adelante, en el punto 5.1.4. 
4) También se pueden utilizar coeficientes de correlación (Messick, 1995), concretamente entre cada ítem y la puntuación total. Esto nos permitirá conocer si el grado de homogeneidad del test es el adecuado según predice la teoría sobre el constructo o variable (ver punto 5.1.4.).

\subsection{Definición del propósito del cuestionario}

Como se expone en la Introducción, la presente tesis doctoral pretende contribuir al diseño de un sistema objetivo de evaluación de la calidad de la actuación de los intérpretes judiciales, la necesidad del cual se señala en la Directiva 2010/64/UE (considerando 24), y recomiendan diferentes proyectos llevados a cabo bajo el patrocinio de la DG de Justicia de la Unión Europea (Aequitas, Aequilibrium, BMT, SOS-VICS, Qualitas, entre los más importantes), y las asociaciones nacionales e internacionales de traductores e intérpretes judiciales (NAJIT, NAATI, EULITA, APTIJ, AssITIG, entre otras). En el caso específico de España, podemos citar a BlascoMayor y Del Pozo Triviño (2015, p. 32) que señalan que el establecimiento de mecanismos de control permitirá que se cumplan las garantías procesales del acusado o testigo y además favorecerá la confianza de los operadores judiciales sobre la labor de los intérpretes. Todo ello debería conllevar una mayor consideración del trabajo del intérprete judicial y el reconocimiento de la profesión (Corsellis, 2010, 2013).

El propósito del cuestionario es valorar de manera objetiva el desempeño de un intérprete judicial en los distintos contextos en los que puede trabajar. No se pretende, por lo tanto, que este instrumento se utilice como medida única de la calidad de la interpretación, sino que mida únicamente el desempeño observable del intérprete en el contexto y circunstancias que se describen con más detalle a continuación. Tal y como se ha visto en el capítulo 4, autores como Grbić $(2008,2015)$ y otros han señalado que la calidad en la ejecución de los intérpretes puede y debe medirse, ya que se pueden definir y concretar aspectos objetivos de su actividad, de la interacción y del contexto.

El cuestionario va dirigido a aquellos agentes judiciales que trabajan con el intérprete en las diferentes situaciones y contextos: policías, fiscales, abogados, letrados de la administración de justicia, jueces y médicos forenses. 


\subsection{Descripción de lo que se intenta medir}

El contexto al que va dirigido el instrumento de evaluación es el entorno judicial y cuasi-judicial durante todas las fases del proceso penal, que engloba distintas etapas que van desde las fases previas de instrucción e investigación hasta el momento de dictar sentencia. Aunque dichas etapas comparten un mismo sistema jurídico subyacente y los mismos conceptos jurídicos, cada una de ellas posee características específicas en cuanto a la interacción de los interlocutores, la finalidad de la interacción, la formalidad del evento, la función del lenguaje y el papel de los participantes, entre otros (Hale, 2010, p. 66).

Por lo tanto, el cuestionario se centra fundamentalmente en la labor del intérprete judicial, tal y como se define en el capítulo 2, y se limita al desempeño del intérprete en tribunales nacionales. El intérprete que trabaja para tribunales internacionales realiza sus tareas de manera similar a la de los intérpretes de conferencias y, por tanto, es muy diferente de los tribunales nacionales: trabaja en cabina, en pareja, se le proporciona el material para poder preparar su ejecución y generalmente trabaja solo hacia su lengua nativa (véase el cap. 2, pág. 15).

El cuestionario evalúa, pues, el desempeño del intérprete judicial que lleva a cabo su labor en tribunales nacionales, que generalmente trabaja sin el soporte de medios técnicos, normalmente en situaciones de interpretación dialógica, bidireccional y habitualmente sin la posibilidad de prepararse de manera detenida para una situación específica. Evalúa comportamientos directamente observables.

\subsection{Redacción del borrador inicial}

Dando por supuestos los requisitos mínimos que se exigen o que debería tener un intérprete judicial, y que se han visto en el capítulo 2, se procedió a una revisión de la literatura y al análisis y la clasificación de las competencias y los comportamientos del intérprete, con el objetivo de diseñar el contenido de las preguntas del cuestionario. Una primera clasificación constó de los siguientes componentes: a) comportamiento y comunicación no verbal, b) competencia lingüística en L1, c) conocimiento del proceso, del modo de actuación y de los términos jurídicos, d) emoción y conducta interpersonal, y e) competencias de interpretación. Además se clasificaron las situaciones del proceso judicial en las siguientes: 1) interrogatorio policial, 2) juicio, 3) vista intermedia y 4) entrevista con abogado. 
En la elaboración del cuestionario se han consultado las siguientes fuentes:

- principales códigos deontológicos de las distintas asociaciones europeas e internacionales, citdos en el capítulo 4.3.2;

- bibliografía fundamental relativa a la interpretación en los servicios públicos (Hale, 2007, Corsellis, 2010) y judicial (Blasco-Mayor y Del Pozo Triviño, 2015; Rudvin y Spinzi, 2015);

- manuales sobre interpretación judicial (González et al., 1998 y 2012, Mikkelson, 2000);

- normas australianas y británicas de actuación con intérpretes en entornos judiciales;

- capítulos de libro dedicados a la actuación judicial (Blasco-Mayor, 2014);

- sistemas de acreditación de intérpretes judiciales internacionales (capítulo 4.3.3);

- resultados de los proyectos europeos sobre interpretación judicial (expuestos en el capítulo 4.3.5);

- documentos de posición de las principales asociaciones profesionales;

- la Norma ISO 13611:2014 Community interpreting;

- trabajos de fin de grado (Viejo, 2014) y trabajos de fin de máster (Gascón Nasarre, 2015; Estañ Arellano, 2016) etc) y tesi di laurea magistrale e triennale (Olivier, 2015).

Durante la realización de este trabajo han aparecido publicaciones relevantes que no se pudieron consultar para la redacción inicial. Sin embargo, sí se han consultado para el análisis de los resultados (v. gr. Mikkelson, 2017, Orozco Jurotán, 2017, Ariza Colmenarejo, 2018).

Tras la revisión de las distintas publicaciones, se redactaron preguntas referidas a las acciones del intérprete en las diferentes situaciones. La redacción se realizó de forma conjunta entre las dos directoras y la autora de la tesis. En la Tabla 7 aparecen identificadas las preguntas referidas a los comportamientos según las distintas situaciones y contextos: 
Tabla 7: Situaciones y contextos de interpretación

SITUACIONES Y CONTEXTOS DE INTERPRETACIÓN

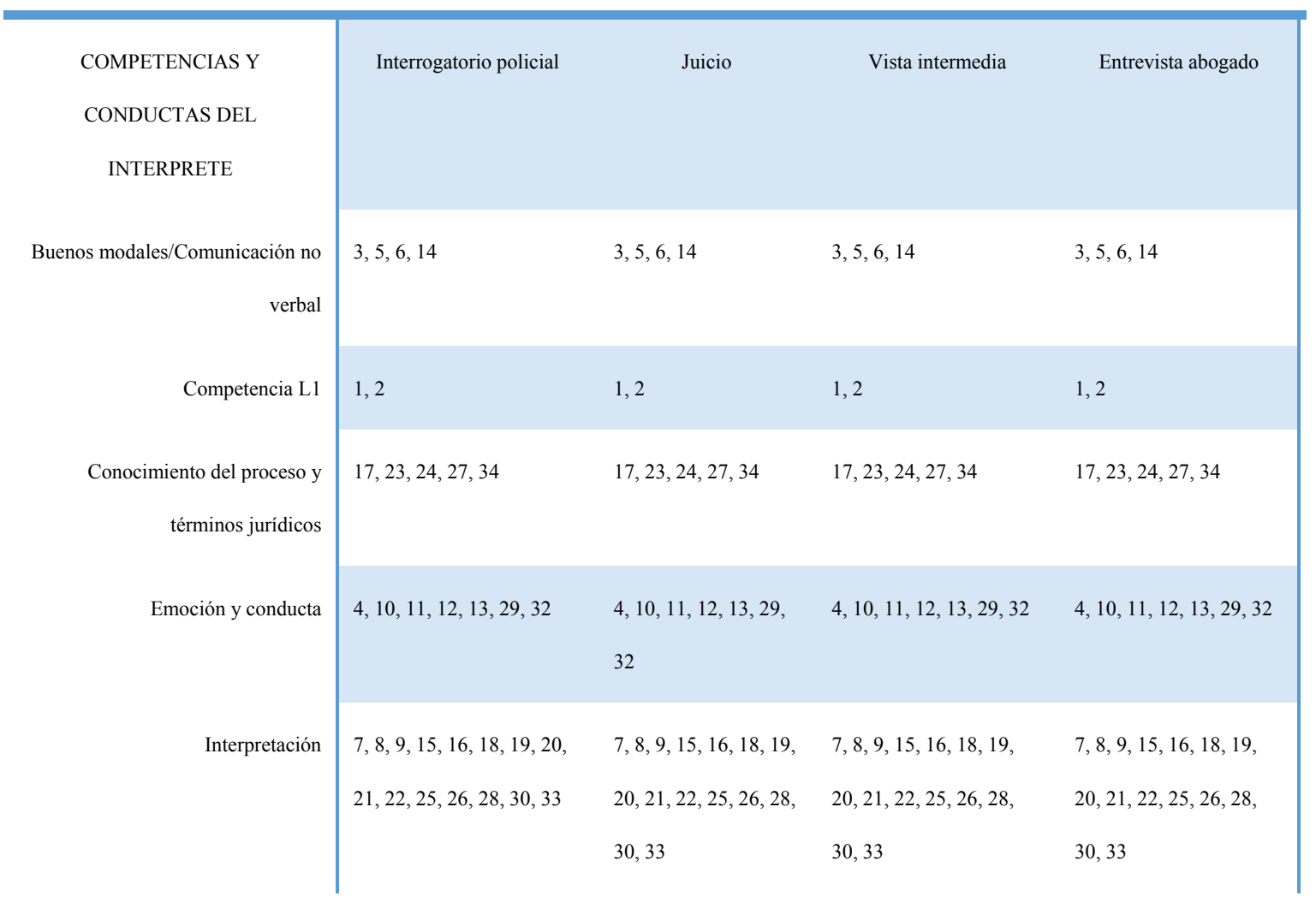

Para la elaboración del cuestionario se eligió un formato de respuesta dicotómica (verdadero/falso). Las razones fueron la conveniencia de la mayor brevedad posible de la cumplimentación del cuestionario y la mayor discriminación posible de las respuestas. La redacción de las preguntas, por lo tanto, tenía en cuenta el formato de respuesta, de forma que la actividad sobre la que se preguntaba debía darse por lo menos una vez durante la situación observada (p.ej.: bostezar) o ser permanente (p. ej. llevar libreta para tomar notas). Si la frecuencia podía cambiar el sentido de la pregunta, se especificaba con un adverbio (p. ej.: interrumpir esporádicamente a la persona interpretada para pedir aclaración).

Los enunciados se redactaron en modo afirmativo, indicándose en las instrucciones que se señalara si en la situación que se acababa de observar el intérprete había realizado o no lo que se describía a continuación. En caso de no recordar alguna conducta en concreto o que no se hubiera producido, se debía señalar la alternativa de respuesta marcada como «no procede» $(\mathrm{np})$.

La versión inicial del cuestionario consta de 34 preguntas, que aparecen en la Tabla x. Las preguntas que aparecen con asterisco son las que requieren invertir el sentido de la puntuación $(\mathrm{SÍ}=0 ; \mathrm{NO}=1)$ : 
Tabla 8: INTER-Q Versión inicial

INTER-Q (versión inicial)

1.Le ha entendido bien cuando hablaba en [L1]

2.La pronunciación en [L1] del intérprete era comprensible en general

3.El volumen del intérprete era adecuado a la sala y situación

4. *Ha hablado con el [acusado/detenido] en ausencia del [operador judicial/policía/abogado]

5. Iba vestido de manera apropiada

6.La presencia física del intérprete (aseo, peinado, comiendo chicle...), era adecuada a la situación

7.Ha tomado notas

8.Llevaba libreta u otro dispositivo para tomar notas

9.Informaba susurrando al [sujeto] del procedimiento en curso, en caso de que se lo permitieran

10. *Ha mostrado expresiones como risas o bostezos

11. *En sus gestos o expresiones ha mostrado sorpresa, rechazo o asco

12. *Ha mostrado gestos o expresiones de compasión, comprensión, apoyo o empatía

13. Ha mantenido el espacio interpersonal apropiado

14. *Titubea, carraspea

15. *Se ha producido sistemáticamente una clara desproporción entre lo que dice el [sujeto] y la intervención del intérprete

16. En caso de que ya haya trabajado con el mismo intérprete, el mensaje traducido es muy similar al emitido en otras ocasiones con otros sujetos

17. Se dirige de manera correcta a los operadores judiciales

18. Cuando el [operador judicial/abogado/policía] se dirige al [sujeto] por su nombre, el intérprete también lo hace.

19. Cuando quiere pedir una aclaración, utiliza la fórmula: "El intérprete tiene que pedir una aclaración"

20. *Ha interrumpido con frecuencia a la persona a la que está interpretando

21. Mientras está interpretando se refiere a si mismo en tercera persona

22. Utiliza la primera persona cuando está interpretando el discurso del [sujeto]

23. *Lee los derechos, acusación u otros documentos, en lugar del [policía/abogado]

24. *Habla con el [sujeto] sin que antes haya hablado el [operador judicial/abogado/judicial]

25. Cuando se le insta, explica al [sujeto] algún aspecto del proceso

26. *Por iniciativa propia explica al [sujeto] algún aspecto del proceso

27. Utiliza correctamente los términos judiciales/policiales en [español/italiano]

28. Puntualmente pide repetición o aclaración a la persona a la que está interpretando

29. En caso de tener que traducir un documento escrito de forma oral, lo hace con fluidez, sin demoras excesivas

30. *Muestra gestos de amenaza, abuso o prepotencia hacia el [sujeto]

31. Durante toda o la mayor parte de su actuación ha mantenido una expresión facial neutra

32. *Manifiesta explícitamente o mediante gestos temor o sumisión hacia la persona interpretada o la situación de interpretación

33. Cuando el intérprete necesita intervenir lo indica haciendo una señal con la mano

34. El operador judicial/policial o el intérprete explica la función del intérprete antes de comenzar a trabajar

\subsubsection{Estudio piloto}

Para la realización del estudio piloto se contactó con un grupo de expertos, formado por ocho magistrados, ocho abogados y ocho intérpretes, todos ellos con más de siete años de experiencia en procesos judiciales con intérpretes. Se solicitó que contestaran dos veces al cuestionario, en un caso describiendo una situación que recordaran como una «buena» actuación y en otro, describiendo lo que recordaran como «mala» actuación. Un segundo cuestionario, llamado «Cuestionario de valoración», preguntaba sobre 
algunos aspectos de validez de contenido y validez aparente del test. En el anexo 1 se puede consultar la carta de presentación y las instrucciones.

En total respondieron tres abogados, cuatro intérpretes y cinco jueces/magistrados. Se obtuvieron un total de 24 respuestas a cuestionario INTER-Q y 12 al «Cuestionario de valoración».

\section{Resultados del «Cuestionario de valoración»}

Las valoraciones de los expertos (media aritmética) se resumen en la gráfica de la figura 4. El rango de respuesta oscilaba entre 0 (muy negativa) a 5 (muy positiva):

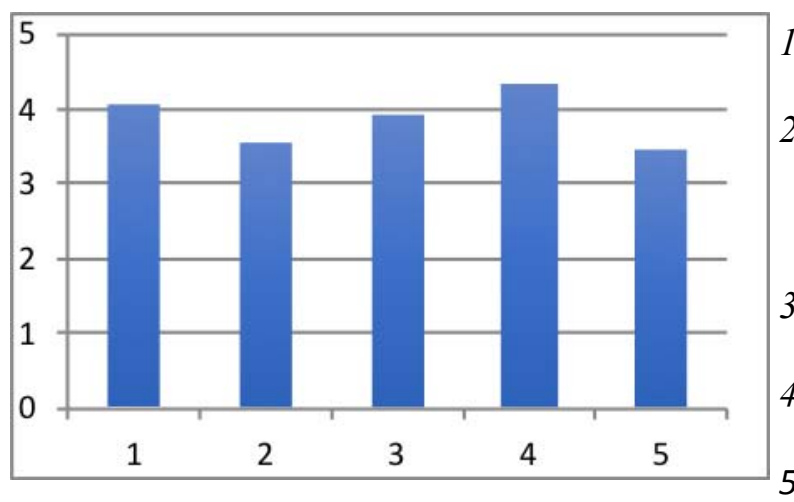

1. Claridad de las instrucciones

2. Se han cubierto todas las situaciones de interpretación judicial, según su experiencia

3. Redacción de las preguntas

4. Comodidad para contestar

5. Utilidad para su trabajo

Figura 4: Resultados de valoración por parte de expertos

Los encuestados realizaron comentarios sobre cada una de las preguntas y sobre el cuestionario total. Un comentario general fue la sugerencia de que el cuestionario se pudiera aplicar en las distintas fases del procedimiento, incluyendo los interrogatorios policiales, las entrevistas con el médico forense o con el abogado. Algunos participantes señalaron que no podían responder a ciertas preguntas como, por ejemplo, si mantienen conversaciones en privado, pues no controlan directamente la custodia o la intervención fuera de la sala de vistas.

Es interesante señalar que algunos expertos mostraron su sorpresa ante la pregunta de la toma de notas (pregunta 7), y manifestaron que no lo habían visto hacer nunca. Otra práctica correcta (pregunta 34, que el operador judicial explique la función del intérprete) fue seguida del siguiente comentario: «se da por hecho que la parte entiende la función del intérprete».

Sobre la pregunta 9, es llamativo el comentario de algunos participantes que afirman que «no ha de ser el intérprete quien decida sobre la pertinencia o no de la susurrada, sino el juez, el fiscal o el abogado». Otro de los participantes, señaló que sí 
se había realizado, «sin permitírselo», lo que le ocasionó un apercibimiento ${ }^{102}$. Hay que indicar que un participante consideró que sí que forma parte de la labor de un intérprete «pues si no al interrogado le es imposible contextualizar la situación».

La pregunta 15 resultó ambigua para algunos participantes, por lo que se especificó que la desproporción del mensaje se refería a la duración de la intervención con respecto a la duración de la interpretación.

\section{Resultados cuantitativos de INTER-Q}

Se llevó a cabo un análisis cuantitativo de las respuestas a las preguntas, calculando dos índices: el índice de dificultad o $p$, el índice de discriminación o $\mathrm{D}$ y la correlación entre la respuesta a cada pregunta y la puntuación total del cuestionario.

El índice de dificultad se define como la proporción de participantes que responden ese ítem en el sentido correcto (buena actuación profesional) ${ }^{103}$. Al haber solicitado a los expertos que evaluaran un desempeño correcto y otro incorrecto, se obtuvieron dos subgrupos. Así, se calcularon las $p$ del grupo total, las del grupo de «buenas» interpretaciones y las del grupo de «malas» interpretaciones (ver Tabla 8).

Según los expertos, se deberían conservar aquellas preguntas que obtienen una $p$ total entre 0,4 y 0,6 (Johnson y Morgan, 2016), sin embargo, queda a decisión de los investigadores incluir ítems más fáciles (con $p$ superiores a 0,6 ) y más difíciles (con $p$ inferiores a 0,4$)$, por lo que se ha ampliado el margen entre 0,3 y 0,7 en el grupo total. Además, se ha tenido en cuenta que en el grupo de «buenas» interpretaciones la $p$ sea superior a 0,7, mientras que en el de «malas» interpretaciones sea igual o inferior a 0,3 .

Además, se ha calculado el índice $\mathrm{D}$, que es la diferencia entre los valores de $p$ del grupo de alta puntuación y el de baja puntuación. Se han considerado niveles aceptables a partir de 0,7 .

A continuación, se calculó la correlación ítem-total, que indica la capacidad del ítem para distinguir entre los evaluados con alta capacidad (en este caso, buena competencia como intérprete) y los de baja capacidad. La forma de interpretar esta correlación es la siguiente: cuánto más cerca esté el valor de 1, mayor relación hay entre haber realizado correctamente la actividad descrita en la pregunta y haber obtenido una puntuación alta en el total del cuestionario.

\footnotetext{
102 En conversaciones informales con la investigadora, algunos jueces han manifestado su desacuerdo y malestar cuando se realiza esta práctica.

${ }^{103}$ En la mayoría de las preguntas una actuación correcta conlleva una respuesta afirmativa, pero en otras, es negativa, como en las preguntas $4,10,11$ y 12 .
} 
Por último, se calculó el porcentaje de respuestas no contestadas, que se consideró como una indicación de la utilidad de la pregunta en cuestión. Se decidió rechazar los ítems con un porcentaje de respuestas no contestadas superior al $20 \%$.

En la tabla siguiente se muestran estos coeficientes para cada una de las preguntas del borrador inicial del cuestionario. Se han señalado en color rojo aquellas medidas que cumplían los criterios de descarte:

Tabla 9: Análisis de las propiedades métricas de los ítems del borrador inicial

\begin{tabular}{|c|c|c|c|c|c|c|}
\hline ÍTEM & & & & & & \\
\hline & $p$ (total) & p ("buenas" int.) & $p$ ("malas" int.) & Índice D & Corr. ítem $\mathrm{x}$ total & $\%$ np \\
\hline 1. & 0,7 & 1,0 & 0,3 & 0,7 & $.655^{*}$ & 4 \\
\hline 2. & 0,8 & 1,0 & 0,5 & 0,5 & $.622 *$ & 8 \\
\hline 3. & 0,7 & 1,0 & 0,5 & 0,5 & $.611^{*}$ & 4 \\
\hline 4. & 0,6 & 0,8 & 0,3 & 0,4 & .442 & 13 \\
\hline 5. & 0,7 & 0,9 & 0,3 & 0,6 & $.674 *$ & 4 \\
\hline 6. & 0,7 & 0,9 & 0,3 & 0,6 & $.636^{*}$ & 13 \\
\hline 7. & 0,3 & 0,5 & 0,0 & 0,5 & $.610^{*}$ & 4 \\
\hline 8. & 0,3 & 0,7 & 0,0 & 0,7 & $.611^{*}$ & 4 \\
\hline 9. & 0,7 & 0,7 & 0,3 & 0,4 & .416 & 13 \\
\hline 10. & 0,7 & 1,0 & 0,4 & 0,6 & $.557^{*}$ & 8 \\
\hline 11. & 0,6 & 1,0 & 0,1 & 0,9 & $.692 *$ & 13 \\
\hline 12. & 0,6 & 0,9 & 0,2 & 0,7 & .428 & 8 \\
\hline 13. & 0,8 & 1,0 & 0,4 & 0,6 & $.549^{*}$ & 17 \\
\hline 14. & 0,5 & 1,0 & 0,0 & 1,0 & $.709^{*}$ & 13 \\
\hline 15. & 0,6 & 1,0 & 0,1 & 0,9 & $.738^{*}$ & 13 \\
\hline 16. & 0,4 & 0,5 & 0,2 & 0,3 & .500 & 46 \\
\hline 17. & 0,8 & 1,0 & 0,5 & 0,5 & $.586^{*}$ & 8 \\
\hline 18. & 0,6 & 0,8 & 0,3 & 0,5 & .652 & 21 \\
\hline 19. & 0,7 & 0,5 & 0,0 & 0,5 & $.593^{*}$ & 13 \\
\hline 20. & 0,5 & 0,9 & 0,0 & 0,9 & $.706^{*}$ & 17 \\
\hline 21. & 0,3 & 0,6 & 0,0 & 0,6 & $.637^{*}$ & 29 \\
\hline 22. & 0,3 & 0,6 & 0,0 & 0,6 & $.581^{*}$ & 8 \\
\hline 23. & 0,4 & 0,7 & 0,2 & 0,5 & $.556^{*}$ & 17 \\
\hline
\end{tabular}




\begin{tabular}{ccccccc}
\hline 24. & 0,8 & 1,0 & 0,1 & 0,9 & $.729^{*}$ & 21 \\
25. & 0,7 & 0,5 & 0,9 & $-0,4$ & -.382 & 17 \\
26. & 0,6 & 0,9 & 0,3 & 0,6 & $.647^{*}$ & 13 \\
27. & 0,6 & 0,8 & 0,1 & 0,7 & $.700^{*}$ & 13 \\
28. & 0,7 & 0,8 & 0,6 & 0,2 & .410 & 8 \\
29. & 0,6 & 1,0 & 0,1 & 0,9 & $.735^{*}$ & 17 \\
30. & 0,8 & 1,0 & 0,5 & 0,5 & .517 & 4 \\
31. & 0,7 & 1,0 & 0,1 & 0,9 & $.707^{*}$ & 4 \\
32. & 0,9 & 1,0 & 0,5 & 0,5 & .536 & 21 \\
33. & 0,8 & 1,0 & 0,4 & 0,6 & $.651^{*}$ & 4 \\
\hline 34. & 0,5 & 0,7 & 0,4 & 0,3 & .291 & 8 \\
\hline
\end{tabular}

* las correlaciones se consideran significativas con $p<0,001$

A partir de estos resultados se realizan los siguientes cambios (ver figura 5):

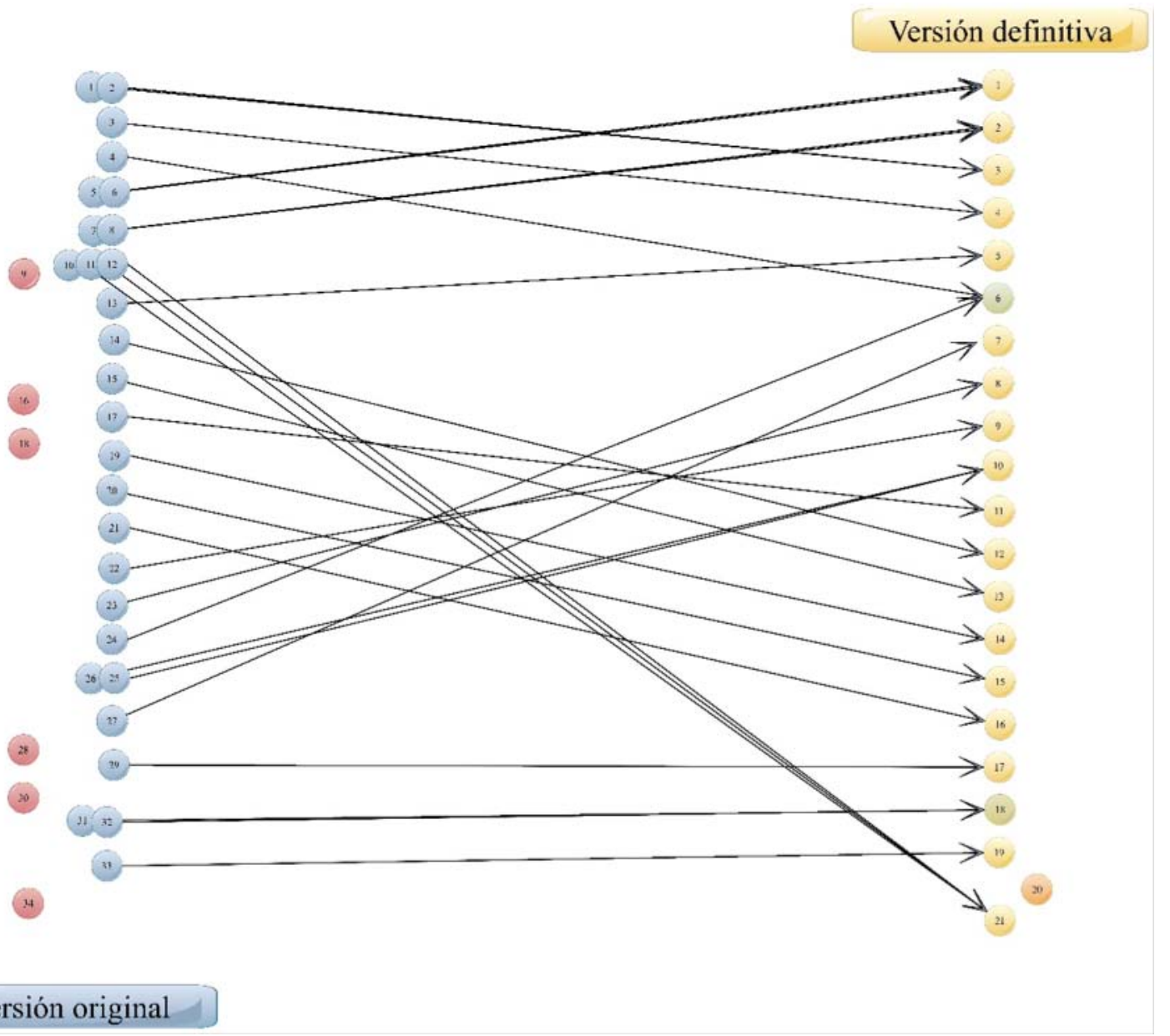

Figura 5: Transformación de los ítems del borrador inicial y composición del cuestionario definitivo. 
A continuación se explican los criterios utilizados para realizar los cambios:

- por sus bajas propiedades métricas se eliminan las preguntas: $2,9,16,18,28,30$ y 34 ;

- la pregunta 1 tiene una buena calidad, sin embargo, se cambia su redacción, añadiendo pronunciación y especificando gramática y léxico como elementos necesarios para la comprensión. En el nuevo cuestionario se sitúa en la posición 3;

- la pregunta 3 no cumple uno de los dos criterios de discriminación, pero se decide conservar, ya que sí cumple los otros. Se sitúa en cuarta posición;

- la pregunta 4 tenía bajos índices de discriminación y, según los expertos, parecía presentar dificultades de comprensión o de acceso a la información. Se cambia la redacción para reflejar mejor el sentido de la acción que se pretende evaluar y se transforma en la pregunta 6 del nuevo cuestionario;

- las preguntas 5 y 6 superaron todos los criterios, pero presentaban una correlación muy alta entre sí, por lo que se decide fundirla en una, la número 1 del nuevo cuestionario. Se decide situar esta pregunta en primera posición ya que es la primera en observarse y la más fácil de recordar, si se contesta el cuestionario inmediatamente después de observar la actuación del intérprete;

- se combinan las preguntas 7 y 8 , ya que el contenido relevante es el llevar cuaderno u otro dispositivo para tomar notas, y el tomarlas o no dependerá de la situación. En el nuevo cuestionario esta pregunta es la número 2;

- las preguntas 10, 11 y 12 se combinan dando lugar a la nueva pregunta 21;

- la pregunta 13 se convierte en la 5 del nuevo cuestionario;

- la pregunta 14 es una de las que tiene mejores propiedades de medida. Se sitúa en la posición 12 en el nuevo cuestionario;

- la 15 se conserva, ya que tiene buenas propiedades de medida, pero se modifica ligeramente la redacción, ante el comentario de uno de los expertos. En el nuevo cuestionario es la 13;

- la 17 se convierte en la 11 ;

- la 19 se convierte en la 14 del nuevo cuestionario;

- la 20 tiene muy buenas propiedades métricas y se sitúa en posición 15 ;

- la 21 se mantiene y se convierte en la 16;

- la 22 se convierte en la 9;

- la 23 se convierte en la 8 ;

- la 24 se convierte en la 6, con una ligera modificación en la redacción, para facilitar la observación;

- las preguntas 25 y 26 se combinan para formar la 10 en el nuevo cuestionario; 
- la pregunta 27 tiene buenas propiedades métricas y se convierte en la pregunta 7 del nuevo cuestionario;

- la pregunta 29 tiene unas buenas propiedades métricas, situada en posición 17 en el nuevo cuestionario;

- la pregunta 31 tiene unas buenas propiedades métricas y se transforma en la 18 , que modifica ligeramente su redacción para incluir el contenido de la 30;

- la pregunta 32 se recoge en la 18 ;

- la pregunta 33 se transforma en la 19;

- se añade un ítem completamente nuevo a partir de las observaciones de los expertos (ítem 20).

El cambio de las secuencias de ítems se realizó para evitar que se situaran de forma contigua ítems pertenecientes a la misma categoría y que no aparecieran juntas dos preguntas con corrección en sentido inverso. Por último, se realizó una revisión general de estilo, dando lugar a la versión definitiva, que aparece a continuación: 
Tabla 10: Cuestionario definitivo

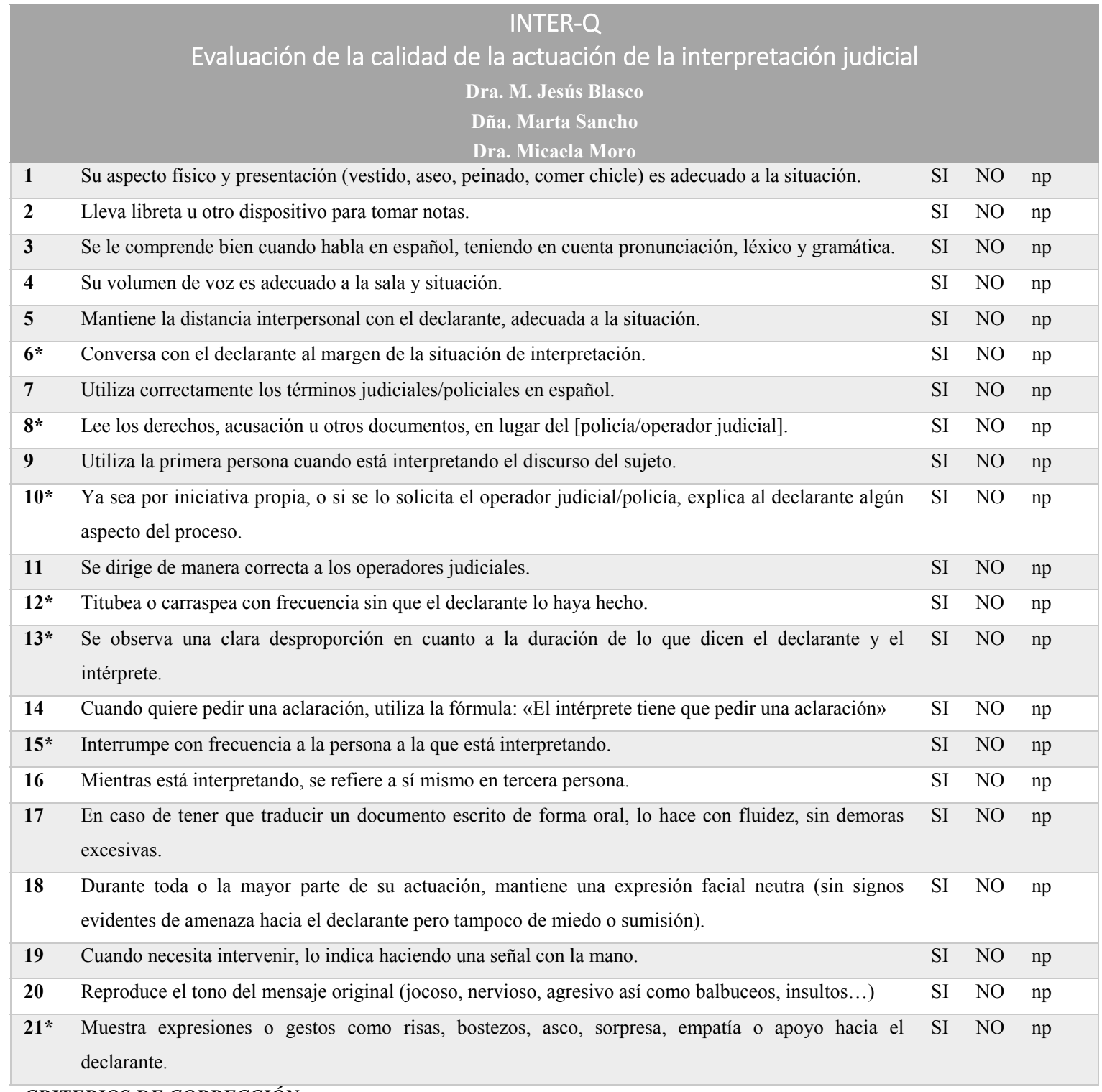

\section{CRITERIOS DE CORRECCIÓN}

SÍ $=1 ;$ NO= 0

* En las preguntas marcadas con asterisco: $\mathbf{S I ́}=0$; $N O=1$

Puntuación máxima $=21$

Niveles de calidad de la interpretación

$\begin{array}{ll}\text { EXCELENTE: } & 19-21 \\ \text { BUENA: } & 15-18 \\ \text { REGULAR: } & 12-14\end{array}$

INACEPTABLE: 110 menos 


\subsection{Estudio empírico}

Una vez redactado el borrador definitivo, se llevó a cabo un estudio de campo para calcular sus propiedades métricas. El trabajo se llevó a cabo en Italia y España.

El cuestionario se tradujo al italiano y posteriormente fue revisado por una traductora profesional nativa y por varios intérpretes expertos que aportaron sus sugerencias para mejorar su comprensión.

Se realizó la versión electrónica del cuestionario mediante la aplicación Google Formularios, tanto en italiano como en castellano, y una versión en papel en una sola hoja impresa por las dos caras.

Para poder distribuir el cuestionario en las distintas sedes judiciales, policiales y forenses se solicitaron los permisos pertinentes mediante correo electrónico y fax.

\subsubsection{Estudio en Italia}

En Italia se envió la solicitud de permiso para asistir a las distintas actuaciones de los intérpretes y administrar los cuestionarios a los distintos operadores a los presidentes de los tribunales de Varese, Novara, Busto Arsizio, Pavía y Milán; a la Dirección General de Polizia di Stato de Génova y Milán; al Director de la DIGOS (Divisione Investigazioni Generali e Operazioni Speciali) de Milán y Génova; a la Dirección General de los Carabinieri di Roma; al Colegio de abogados de Milán y a la Scuola di Magistrati di Milán.

Respondieron de forma afirmativa los tribunales de Milán y Génova. La Presidente de la Corte di Assise de Milán solicitó información adicional sobre el proyecto y ofreció su colaboración, obteniendo autorización oral del Presidente del Tribunal de Milán (no fue posible recibir la autorización escrita).

Para conseguir la autorización del Tribunal de Génova fue necesario contactar por teléfono. El presidente del Tribunal de Génova brindó su apoyo y firmó la autorización escrita.

La Dirección General de los Carabinieri respondió negativamente tras una conversación telefónica en la que se les proporcionó información adicional. Se comunicó la decisión negativa, mediante correo electrónico que aparece en el Anexo 7.

Por último, no se recibió respuesta de resto de los Tribunales, la Dirección General de Polizia di Stato de Génova y Milán, el Colegio de Abogados de Milán ni la Scuola di Magistrati, por lo que no se pudo acceder a estas instituciones como se había previsto inicialmente. En definitiva, la administración de los cuestionarios en el estudio italiano se circunscribió a los tribunales de Milán y Génova. 
No fue posible obtener un calendario general de las vistas en las que se precisaba la asistencia de intérpretes. En general, cada Sezione penale (Sala de lo Penal) organizaba directamente la programación de las vistas. En algunas ocasiones se intentó solicitar la información el día anterior a los Cancellieri (equivalentes a la figura española de Letrados de la Administración de Justicia) de cada sala, pero no fue posible obtener sistemáticamente la información. Todos respondían a la investigadora que se dirigiera a las direttissime donde se requería habitualmente servicio de interpretación. Gracias a la colaboración de las juezas Ichino y Canevini se pudo programar las vistas en algunos casos. También se obtuvo la colaboración de algún Pubblico Ministero (Fiscal) que facilitó con antelación las fechas de actuaciones previstas con intérprete.

Por lo demás, se asistió en general a los juicios de direttissima, pues según la opinión de los operadores judiciales es los juicios en direttissima en los que hay una mayor presencia de extranjeros y, por tanto, de necesidad de asistencia del intérprete. Dichos juicios se celebran todos los días, dependiendo de la ciudad, salvo los domingos. Los jueces de lo penal de cada tribunal están obligados a realizar un cierto número de estos juicios al mes por turnos. Antes de empezar la jornada, y puesto que no se tenía a disposición una autorización escrita, se solicitaba una pequeña entrevista con magistrados, fiscales y abogados para tener acceso a las vistas y poder distribuir el cuestionario, pero en algunas ocasiones no fue posible obtenerla. En algunos casos solicitaron la autorización escrita del Presidente y no al no tenerla, instaron a la investigadora a abandonar la sala. Algunos jueces y fiscales declararon asimismo que «no tenían tiempo que perder en nimiedades, que ellos estaban ahi para cosas importantes».

No fue posible, en ningún caso, obtener respuesta en formato electrónico. Todos los encuestados cumplimentaron el formato en papel. Durante los primeros meses se enviaron cuestionarios por correo electrónico el mismo día de la vista con la esperanza de que los cumplimentaran durante la vista de ese día o de las siguientes, pero no se obtuvo ninguna respuesta. Por otro lado, se fecharon los cuestionarios para tener un registro de cada situación e identificar al intérprete.

Finalmente, la investigadora estuvo presente en el $90 \%$ de los juicios en los que se cumplimentaron cuestionarios. Aunque el planteamiento inicial era distribuir los cuestionarios previamente y recogerlos después, este cambio facilitó un mayor control de la situación, supervisando la cumplimentación de los mismos. De esta forma se obtuvieron varias evaluaciones de la misma interpretación, cumplimentadas por los distintos operadores de justicia además de por la investigadora.

Los datos cuantitativos se complementaron con los cualitativos recogidos mediante un cuaderno de campo, en el que se registraba información como: fecha, tipo 
de vista, participantes y comentarios sobre las distintas actuaciones y sobre la situación en general.

A continuación, se presentan las características de los participantes en el estudio empírico realizado en Italia:

- Cuestionarios cumplimentados: 183.

- Los evaluadores eran 32,6\% hombres y $67,4 \%$ mujeres, con una mediana de edad entre 40 y 50 años. En el 34,7\% de los casos tenían un año de experiencia profesional con intérpretes, en el $11,8 \%$ dos años de experiencia y en el $53 \%$, tres años. Las profesiones de los evaluadores aparecen en la Figura 6:

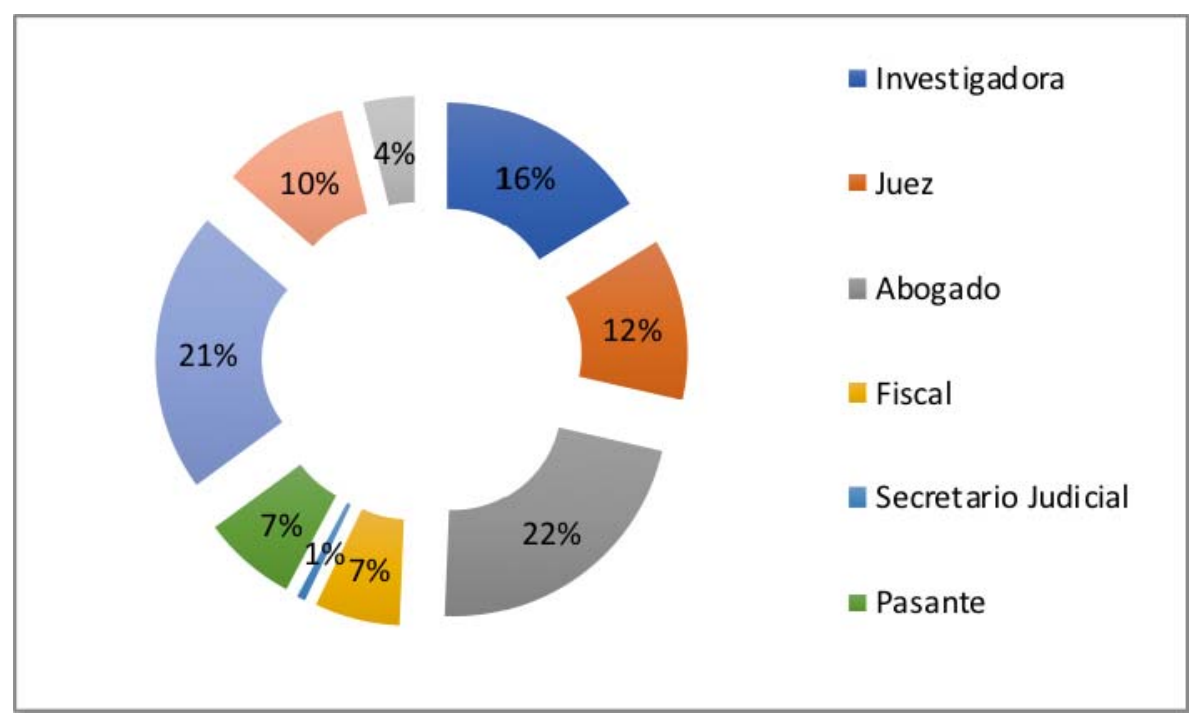

Figura 6: Participantes en el cuestionario italiano por profesión

- Las situaciones procesales en las que se llevó a cabo la interpretación fueron las siguientes: Direttisisima/Convalida di arresto/1 grad: $55 \%$; Udienza collegiale: $21 \%$ y Corte di Assise: $24 \%$.

- Los intérpretes evaluados fueron 22 , de los cuales 18 eran mujeres y 4 eran hombres. El $18 \%$ tenía entre 20 y 25 años, el 36,36 \% entre 40 y 50, el $22,72 \%$ entre 50 y 65 años y $13 \%$ eran mayores de 65 años. Las lenguas interpretadas aparecen en la Figura 7: 


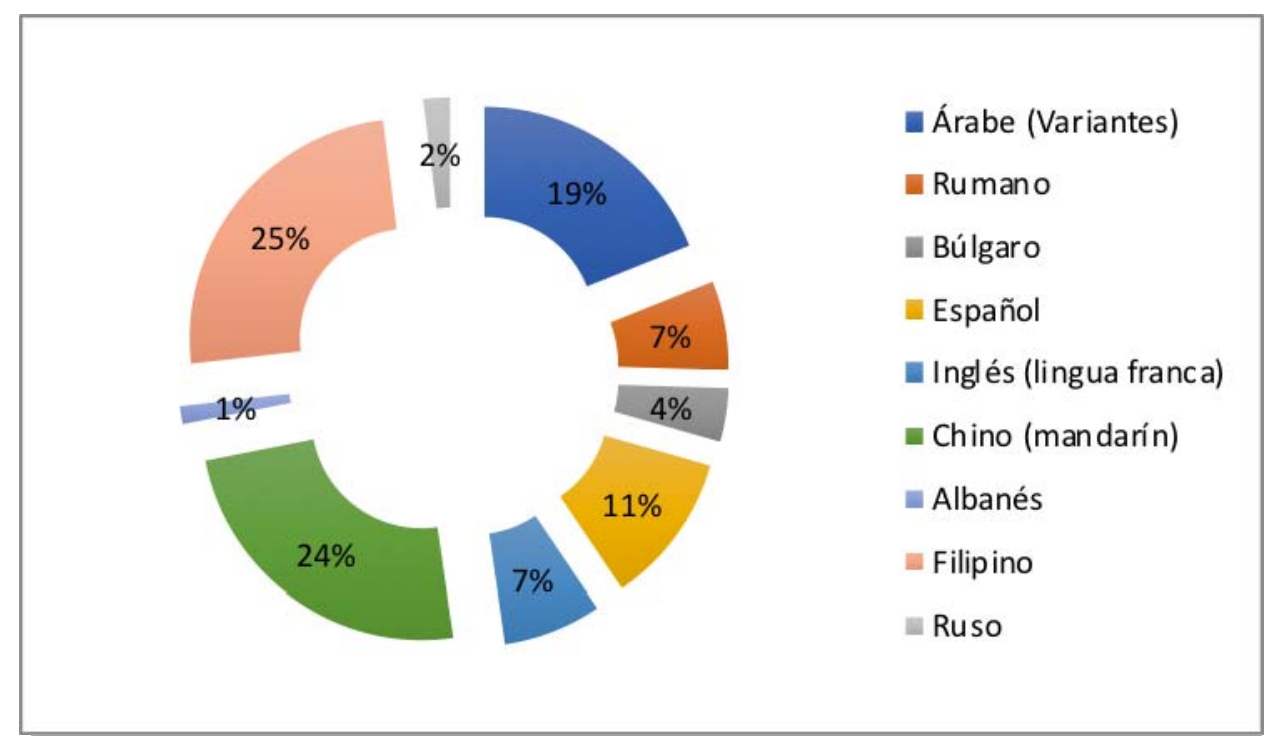

Figura 7: Lenguas de los intérpretes evaluados en el cuestionario en Italia

\subsubsection{Estudio en España}

En España, los permisos se solicitaron a las siguientes instituciones: Dirección General de Policía de Valencia y de Burgos; Dirección General de la Guardia Civil; Decanato del Ilustre Colegio de Abogados de Valencia; Decanato de la Ciudad de la Justicia de Valencia; Instituto de Medicina Legal y Ciencias Forenses de Valencia.

Para la distribución del cuestionario en España se realizó una estancia en la Ciudad de la Justicia de Valencia del 9 de enero al 10 de febrero de 2017. Esta elección se tomó por varias razones: la población en Valencia es de cerca de 800.000 habitantes y la Universidad Jaume I tiene un convenio de colaboración con la Ciudad de la Justicia, una institución que ha sido puntera por lo que atañe al diseño del espacio y a la organización de los servicios del juzgado.

El Decanato de Jueces de la Ciudad de la Justicia de Valencia brindó su apoyo y transmitió a los distintos juzgados la solicitud de ayuda para cumplimentar un cuestionario tras la celebración de juicios y audiencias por parte de jueces. Su ayuda fue fundamental para conseguir la colaboración de los distintos jueces.

El Instituto de Medicina Legal y Ciencias Forenses autorizó la distribución del cuestionario, sin embargo, los especialistas forenses no colaboraron.

El Decanato del Ilustre Colegio de Abogados no respondió, pero sí que lo hicieron a título personal un grupo de letrados, aunque las evaluaciones que realizaron tuvieron que descartarse porque se basaron en sus recuerdos y no en observaciones de situaciones de interpretación. Con dichos letrados se mantuvieron contactos y se obtuvo su opinión sobre la situación actual de la interpretación en entornos judiciales. 
La Jefatura Superior de Policía de Valencia respondió en varias ocasiones, pero finalmente no se pudo obtener su colaboración. La Guardia Civil respondió negativamente.

Durante la estancia en la Ciudad de la Justicia de Valencia, la investigadora asistió a todos los juicios, audiencias e interrogatorios con intérprete a los que fue autorizada a asistir, tanto en los juzgados ordinarios como en los juzgados de guardia. En algunos le fue denegada la asistencia por tratarse de delitos de violencia de género.

En general, los abogados y los fiscales, al igual que otros funcionarios de la justicia, respondieron a los cuestionarios siguiendo el ejemplo de los jueces.

La información sobre los juicios que precisaban de intérprete era facilitada diariamente por la encargada de la subcontrata del servicio de interpretación y traducción judicial en la ciudad de Valencia.

La investigadora también se puso en contacto con los distintos intérpretes que trabajaron durante ese periodo en la Ciudad de la Justicia de Valencia, obteniendo información sobre sus condiciones de trabajo, honorarios y demás cuestiones relativas a su desempeño laboral. Su ayuda fue fundamental porque en algunos casos avisaban directamente ellos del trabajo que tenían que realizar, lo que permitió ir a citas que no habían sido proporcionadas por la empresa adjudicataria. De la misma forma, el permiso de los intérpretes, de los abogados y de los acusados permitió asistir a algunos interrogatorios con abogado durante las guardias.

En las vistas e interrogatorios a los que asistió la investigadora, se solicitó a los distintos operadores que respondieran al cuestionario. Se obtuvo de esta forma la evaluación de diferentes actores implicados de un mismo desempeño, incluyendo la investigadora.

A continuación, se presentan las características de los participantes del estudio empírico realizado en España:

- Cuestionarios cumplimentados: 111.

- Los evaluadores eran $36 \%$ hombres y $70 \%$ mujeres, con una mediana de edad entre 40 y 50 años. En el $5 \%$ de los casos tenían un año de experiencia profesional con intérpretes, y en el $95 \%$ tres años de experiencia. Las profesiones de los evaluadores aparecen en la Figura 8: 


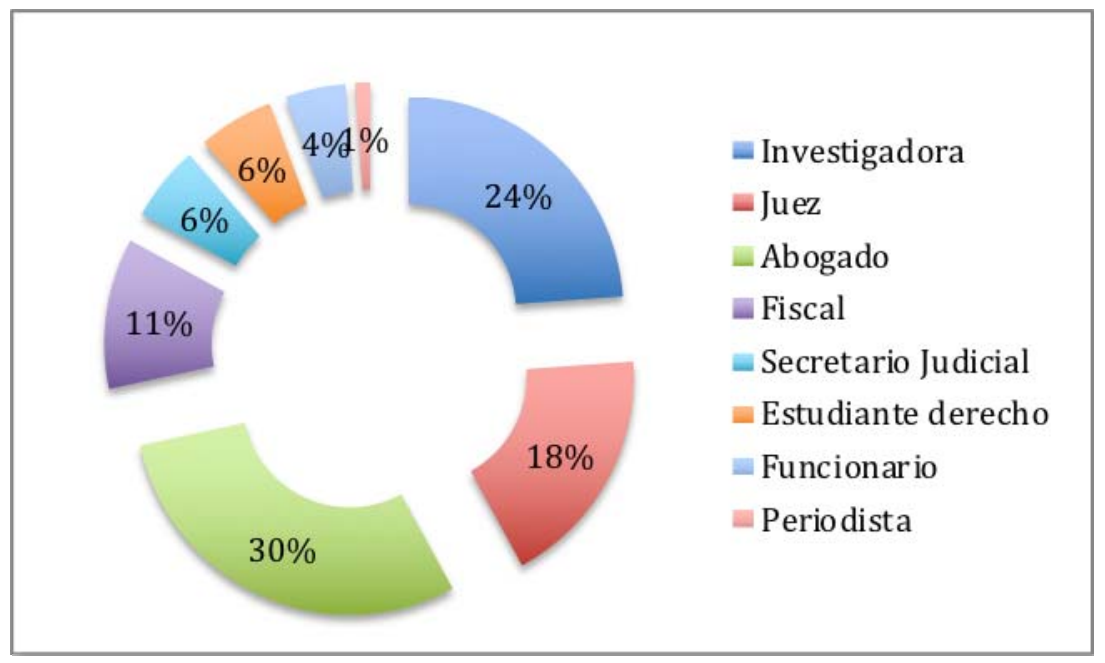

Figura 8: Participantes en el cuestionario español por profesión

- Las situaciones procesales en las que actuaron los intérpretes evaluados fueron las siguientes: $1^{\text {a }}$ Instancia. Conformidad/Juicio rápido: $32 \%$; Diligencias previas. Instrucción/Detención (JG): 27 \%; Entrevista con abogado/Diligencias previas (JGI): $9 \%$; Juicio. Vista oral (acusado o testigo): $21 \%$ y Juicio popular: $11 \%$.

- En cuanto a los intérpretes, fueron un total de 16 , de los cuales 10 eran mujeres y 6 eran hombres. El $26 \%$ tenía entre 20 y 25 años, el $54,5 \%$ entre 25 y 40 y el $19 \%$ entre 40 y 50 años. Las lenguas interpretadas fueron las siguientes (ver Figura 9):

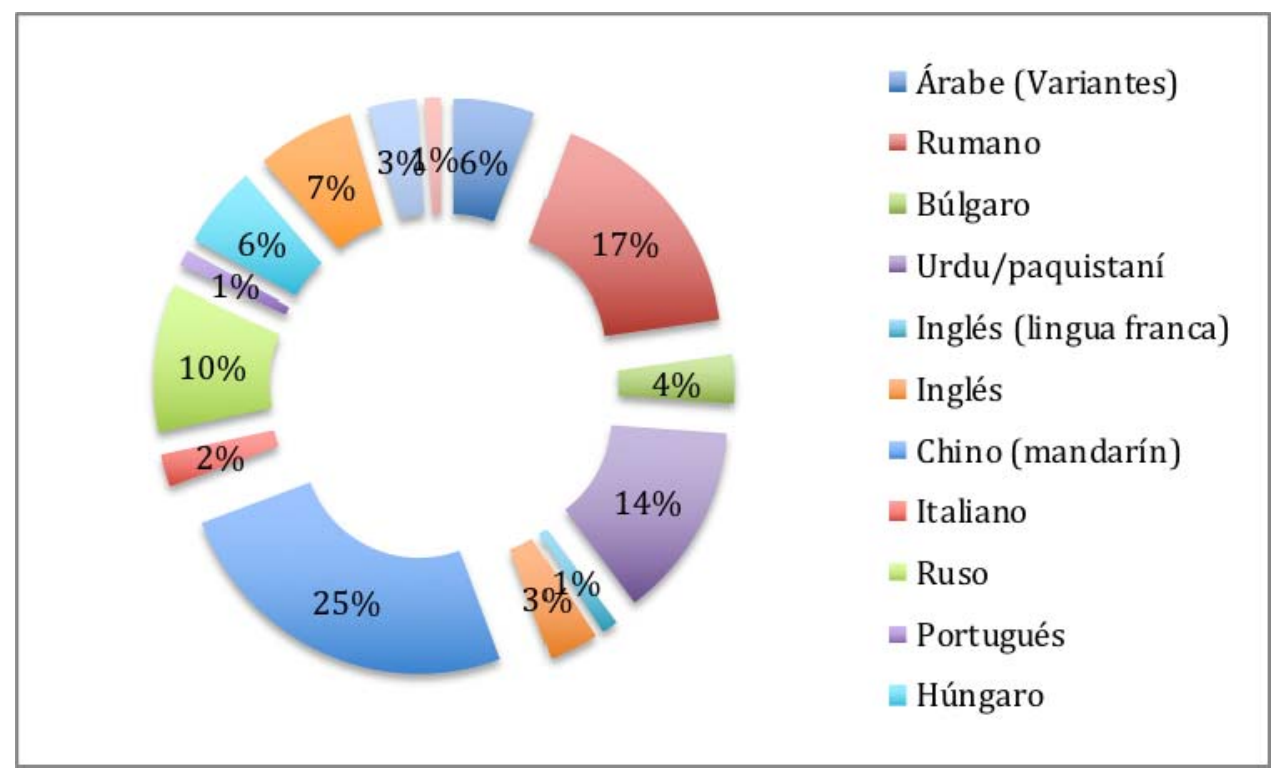

Figura 9: Participantes en el cuestionario italiano por profesión 


\subsection{Método del estudio cualitativo}

Durante la investigación se llevaron a cabo una serie de actividades complementarias a la realización y validación del cuestionario. Dichas actividades poseen un cariz etnográfico y cualitativo, llevadas a cabo siguiendo las recomendaciones de Hale y Napier (2013) y permitieron, por una parte, programar el trabajo de campo, y por otra obtener la máxima información posible durante el estudio. Esta parte cualitativa del estudio permitió, además, centrar los ítems del cuestionario durante la fase intermedia del diseño, analizarlos y sacar conclusiones en la fase de validación, y obtener datos que se comentarán en el capítulo dedicado a la discusión.

El estudio cualitativo se llevó a cabo en Italia y España con dos métodos distintos de recogida de datos:

1) entrevistas a jueces, letrados y fiscales sobre la percepción de la calidad de los intérpretes en entorno judicial;

2) observación mediante trabajo de campo de la praxis de la interpretación judicial.

La opción de entrevistar a jueces en lugar de a otros profesionales jurídicos se justifica por las siguientes razones: poseen una identidad profesional y social muy marcada; tienen el poder en el proceso judicial ya que son los encargados de administrar la justicia; forman el tercer poder; se trata de una profesión muy regulada, de gran prestigio y reconocimiento y no solo obedecen a reglas normativas sino que establecen una praxis institucionalizada (Hernández García, 2017).

Además, en la literatura se pueden consultar trabajos previos en los que recoge la opinión de los jueces por medio de cuestionarios, tanto en Italia (Sandrelli, 2011; Falbo, 2013; Falbo y Viezzi, 2014; Mometti, 2014; Olivier, 2015; Perdichizzi, 2016) como en España (Zañon Monzó, 2014, Viejo Jovani, 2014; Estañ Arellano, 2016). Estos trabajos son de gran interés, puesto que ya apuntan en parte hacia las expectativas de los jueces y las deficiencias del sistema, además de exponer posibles soluciones y puntos de encuentro (Blasco-Mayor, 2016). 
Los métodos utilizados para recabar los datos del colectivo de los jueces fueron los siguientes:

- un grupo de discusión formado por tres jueces y dos investigadoras;

- tres entrevistas semiestructuradas con otros jueces y magistrados;

- comentarios de los jueces y otros operadores recogidos en el transcurso de la administración del cuestionario INTER-Q.

Dichas entrevistas se llevaron a cabo en el plazo de un año en España. Las entrevistas son anónimas a fin de permitir una mayor libertad de expresión de los jueces. Una de las entrevistas se realizó telefónicamente, mientras que las demás tuvieron lugar en persona. Fueron grabadas para su posterior transcripción y análisis. En general, la experiencia del trabajo con intérpretes superaba los diez años, y había tenido lugar en diferentes órganos judiciales (instrucción, audiencia y primera instancia). Las entrevistas se realizaron en diferentes regiones españolas, aunque algunos de los jueces habían tenido una movilidad considerable por lo que su experiencia profesional abarcaba diferentes comunidades autónomas y regiones.

En cuanto a Italia, los datos se recabaron mediante apuntes de la investigadora y proceden de entrevistas más informales y comentarios de jueces durante o después de las vistas. Los jueces italianos son menos proclives a conceder entrevistas y no deseaban ser grabados, por ello se decidió no insistir. Por esta razón también, y para completar la imagen lo más posible, se consultaron fuentes adicionales que se han ocupado de la percepción de los jueces (Falbo, 2013 y 2014, Sandrelli, 2014, Rudvin y Spinzi, 2014 y 2015, Favière Català, 2015; Estañ Arellano, 2016; Perdizzichi, 2017, Tagliaferro, 2015; Falbo, 2014).

Por último, se añadieron comentarios de los jueces durante el trabajo de campo realizado durante la administración del cuestionario INTER-Q.

Los temas abordados en las entrevistas versaron sobre los siguientes aspectos:

- calidad del servicio;

- cualificación de los intérpretes;

- opinión sobre el tipo de provisión;

- posibles actuaciones en caso de situación inaceptable. 
Durante las entrevistas surgieron varios subtemas relacionados, como los siguientes:

- las expectativas respecto a la labor del intérprete;

- cuándo se usa un intérprete;

- la provisión del servicio. Cómo consideran que debiera realizarse dicha provisión;

- el papel del intérprete;

- la preparación que debe tener el intérprete;

- la importancia de la comunicación no verbal;

- el uso del inglés como lingua franca.

Los resultados de la investigación, tanto cuantitativos como cualitativos, se presentan en el capítulo 7 . 


\section{Resultados}

\subsection{Estadística descriptiva}

Las respuestas a los cuestionarios se tabularon en hojas de cálculo Excel. Se codificaron como 1 las respuestas «SÍ», excepto los ítems inversos, que aparecen señalados en la tabla anterior (ver Cuestionario Inter-Q definitivo). Los datos se exportaron a dos programas de análisis estadístico, IBM SPSS versión 24 y JMetrik (Meyer, 2014).

Las puntuaciones se calcularon sumando 1 punto por cada respuesta en el sentido de una actuación adecuada. En el estudio total, la puntuación mínima fue de 7,96 ${ }^{104}$ y la máxima de 15,43, con una media de 12,48. La distribución de las puntuaciones aparece en la siguiente figura.

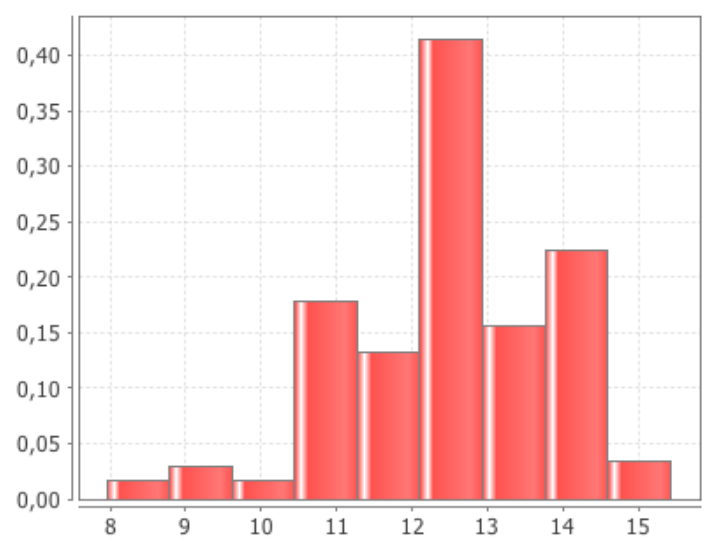

Figura 10: Distribución de las puntuaciones

A continuación, se presentan por separado los datos de las puntuaciones del INTER-Q en las muestras italiana y española, desglosando los datos según la profesión del evaluador (se excluyen aquellas con pocas evaluaciones, como secretario judicial).

En la Tabla 11 aparecen las estadísticas descriptivas de la muestra italiana y por profesiones.

\footnotetext{
${ }^{104}$ En el cálculo de las puntuaciones totales se ha utilizado el método de Kelley (Meyer, 2014) que tienen en cuenta el error de medida (intervalo en el cual estaría la puntuación verdadera teniendo en cuenta la fiabilidad). Esto explica que las puntuaciones tengan decimales.
} 
Tabla 11: Estadísticas de la muestra italiana por profesiones

\begin{tabular}{|l|l|l|l|l|l|}
\hline & Abogado & Fiscal & Juez & Investigadora & TOTAL \\
\hline $\mathrm{N}$ & 54 & 13 & 28 & 24 & 123 \\
\hline Mínimo & 7,96 & 11,16 & 10,63 & 9,56 & 7,96 \\
\hline Máximo & 14,90 & 13,83 & 14,90 & 14,36 & 14,90 \\
\hline Media & 12,66 & 12,18 & 13,10 & 12,18 & 12,59 \\
\hline Desviación típica & 1,46 & 0,85 & 1,18 & 1,20 & 1,33 \\
\hline
\end{tabular}

En la Tabla 12 aparecen las descriptivas de la muestra española y desglosada por profesiones:

Tabla 12: Estadísticas de la muestra española por profesiones

\begin{tabular}{|l|l|l|l|l|l|}
\hline & Abogado & Fiscal & Juez & Investigadora & TOTAL \\
\hline $\mathrm{N}$ & 16 & 11 & 26 & 20 & 86 \\
\hline Mínimo & 9,03 & 11,69 & 10,09 & 8,49 & 8,49 \\
\hline Máximo & 13,83 & 15,43 & 15,43 & 14,36 & 15,43 \\
\hline Media & 12,09 & 13,09 & 12,61 & 11,79 & 12,33 \\
\hline Desviación típica & 1,26 & 1,12 & 1,12 & 1,40 & 1,23 \\
\hline
\end{tabular}

Se han calculado los puntos de corte para delimitar los cuatro niveles de ejecución que se proponían al diseñar el cuestionario (excelente, buena, regular y deficiente). El primer cuartil corresponde a la puntuación 11,69 , la mediana a 12,76 y el tercer cuartil a 13,29, con una distancia intercuartil de 1,6. Así, la clasificación de la ejecución de los intérpretes quedaría de la siguiente manera:

- EXCELENTE

13,3 a 21

- BUENA 12,8 a 13,2

- REGUlar 11,7 a 12,7

- DEFICIENTE 0 a 11,6 


\section{2. $\quad$ Fiabilidad}

El cálculo de los coeficientes de fiabilidad se realizó con los cuestionarios cumplimentados por la investigadora, tanto en Milán como en Valencia, para garantizar que cada uno de los formularios correspondía a una sola situación de evaluación y no había valores artificialmente altos (lo que hubiera ocurrido, por ejemplo, si se hubieran analizado conjuntamente cuestionarios cumplimentados por fiscales, abogados o jueces, además de por la investigadora, observando la misma actuación).

El número de cuestionarios fue de 44 y se obtuvo un coeficiente Alfa de 0,59, con un intervalo de confianza de 0,40 a 0,75 , y un error típico de medida de 1,56. También se ha calculado la fiabilidad ítems utilizando la Teoría de Respuesta al Item (TRI), obteniéndose un coeficiente de la escala de 0,99.

Para calcular la objetividad o fiabilidad interjueces es necesario disponer de cuestionarios referidos al mismo intérprete y en la misma situación, cumplimentados por dos evaluadores. Solo se disponía de cuatro casos que habían sido observados tanto por la investigadora como por una jueza, en el tribunal de Milán. Se ha calculado el coeficiente Kappa, que indica el grado de acuerdo entre dos evaluadores. El valor del coeficiente ha sido de 0,57 (siendo 1 el máximo), y resulta significativo al 0,000. Es decir, se puede concluir que existe una adecuada fiabilidad entre evaluadores.

\subsection{Validez}

Como se señaló en el capítulo 6, el estudio de la validez incluye diferentes tipos de análisis tanto cuantitativos como cualitativos, que proporcionan evidencias y justificaciones racionales a favor de la interpretación y el uso de las puntuaciones.

En este caso, el estudio de la validez supondría obtener datos independientes sobre la calidad del desempeño y la competencia de los intérpretes y demostrar su acuerdo con las puntuaciones del test. Dadas las condiciones del estudio y la dificultad para obtener datos externos sobre los intérpretes (por ejemplo, su cualificación, años de experiencia o acreditaciones oficiales), se utilizaron los cuadernos de campo para identificar varios ejemplos de situaciones que la investigadora consideró representativos y se compararon con las puntuaciones otorgadas por los evaluadores. 


\section{Caso 1}

Se trata de una mujer de alrededor de 50 años. La primera impresión que causa es de una intérprete profesional. Sabe actuar y se comporta de forma adecuada al contexto judicial. No lleva cuaderno ni otro dispositivo para tomar notas. Hay dos personas interrogadas, una habla italiano y la otra no.

La mujer interpreta el interrogatorio. Se mantiene alejada físicamente del acusado, por lo que no puede interpretar en simultánea susurrada. Antes de la vista, el letrado y la intérprete se dirigen a una habitación situada junto a la sala de vistas para realizar la entrevista. El policía lee el escrito de acusación sin pausas, la intérprete resume lo que el policía ha leído.

La jueza habla de forma que se facilite la comprensión. Cuando se dirige a los interrogados, lo hace indirectamente.

La jueza lee los derechos y después la intérprete los resume. En un momento determinado, el acusado protesta y habla directamente con la intérprete. La jueza decide prescindir de la intérprete y señala que se renuncia a la traducción.

Resultados del INTER-Q: Contestaron al cuestionario la jueza, el fiscal y la investigadora. Para el fiscal y la investigadora, la actuación de la intérprete se valoró como REGULAR, obteniendo ambos la misma puntuación $(12,7)$. Para la jueza, sin embargo, la actuación era BUENA $(13,2)$, a pesar de los incidentes y evidentes irregularidades que ella misma señaló.

\section{Caso 2}

En este caso es una intérprete profesional, con un comportamiento correcto en la situación judicial. Lleva un cuaderno para tomar notas.

Por el tipo de actuación el acusado está situado detrás de unas rejas. Para poder escucharle con claridad, la intérprete tiene que acercarse cada vez que interviene.

La situación resulta compleja para la interpretación ya que hay varias intervenciones simultáneas. Se leen varios documentos y tanto el juez como el fiscal realizan preguntas a una velocidad muy alta.

El juez no utiliza la primera persona. En varios momentos apremia a la intérprete, pero esta no se inmuta y continúa trabajando correctamente.

La intérprete habla en primera persona. Al principio no toma apuntes, pero cuando la cantidad de información y la velocidad de los interrogatorios lo exigen, empieza a tomar notas. A pesar de la tensión, ella mantiene la calma. 
Cuando el acusado vuelve a estar situado tras la zona enrejada, la intérprete realiza un resumen de lo que se está diciendo en la sala.

Resultados del INTER-Q: Contestaron al cuestionario el juez, el abogado y la investigadora. El juez y la investigadora consideraron EXCELENTE la actuación de la intérprete $(13,8)$. Para el abogado, la puntuación fue algo menor, concretamente de 12,8 (BUENA).

\section{Caso 3}

La intérprete es una mujer de más de 60 años. Su aspecto físico y presentación destaca por su corrección, pero llama la atención que mastica chicle. Durante la vista precedente conversa con frecuencia con el letrado, gesticulando de forma muy evidente.

Cuando tiene que intervenir, se acerca a la reja tras la que están situados los acusados para traducir en susurrada, pero lo hace resumiendo. Tras unos minutos, cuando empieza a hablar el fiscal, se aleja. Vuelve cerca de la reja y hace una susurrada pero no le hacen caso, pues el otro acusado le está traduciendo a georgiano.

Se trata de dos acusados georgianos, de los cuales uno habla italiano y el otro no. A este último se le pregunta si prefiere que le hablen en italiano o en ruso, y contesta que prefiere en georgiano.

Se hace constar que el otro acusado habla italiano aunque incorrectamente. La jueza parece molesta y le reitera que puede elegir entre italiano o ruso, pero no georgiano.

El acusado habla de vez en cuando en italiano. La intérprete se confunde los idiomas al hacer la interpretación bilateral. El acusado empieza a hablar en un italiano defectuoso. La intérprete se queda, indicando que es imprescindible para poder cobrar sus emolumentos. Los operadores tienen muchas dificultades para comprender a la intérprete, por lo que se plantea interrumpir el juicio y solicitar un intérprete de georgiano. El abogado habla con los dos acusados y les convence para que elijan el ruso.

Resultados del INTER-Q: En este caso hubo unanimidad entre el juez, el fiscal y la investigadora en cuanto a la valoración como DEFICIENTE de la actuación de esta intérprete. El juez y el fiscal obtuvieron la misma puntuación en el cuestionario $(11,6)$ y la investigadora algo menor $(11,1)$. 


\section{Caso 4}

La intérprete es una mujer mayor. En la sala de vistas los abogados, policías, intérpretes y otros operadores hablan entre sí, por lo que el ambiente es muy ruidoso. Hay dos intérpretes más que hablan entre sí y con los acusados sin que estén presentes los abogados. La jueza está tomando decisiones sobre la vista por lo que está trabajando con su secretario. La intérprete recibe una llamada de teléfono y responde. Permanece en la sala de vistas durante toda la conversación telefónica.

En un momento determinado, empieza a hablar con la acusada, ante lo cual la jueza le pregunta qué es lo que está haciendo. Se acerca y se aleja de la acusada aleatoriamente. Muestra durante toda la actuación una actitud muy poco profesional.

Utiliza tercera persona. Cuando el fiscal lee la petición de detención, no la traduce. Resume la sentencia, en lugar de interpretar. Tiene un buen conocimiento de italiano, pero mezcla los dos idiomas.

Resultados del INTER-Q: Según las evaluaciones de la jueza y la investigadora, la actuación de esta intérprete es $\operatorname{REGULAR~}(12,7)$, mientras que para el abogado fue DEFICIENTE $(10,6)$.

\section{Caso 5}

La intérprete llega con retraso (probablemente porque estaba en el juzgado de guardia). Se trata de un caso de violencia de género. La declarante habla algo de español. Cuenta que en casos anteriores tuvo problemas con la intérprete, dice que estaba muy descontenta y se sintió muy desprotegida (su pareja es español). Tanto la declarante como la letrada se muestran recelosos respecto a la intérprete.

Cuando esta llega y empieza a hablar, es evidente que su competencia en español es deficiente. Tampoco el ruso es su idioma natal. Se muestra claramente nerviosa, se rasca el cuello y se ruboriza.

Durante el interrogatorio, la letrada apunta que ella entiende el ruso y que hay cosas que la intérprete no ha traducido como, por ejemplo «la víctima tiene miedo».

La letrada de la otra parte protesta por las frecuentes interrupciones de la víctima y le impele a que impugne la interpretación. El juez y la Letrada de la Administración de la Justicia (LAJ) hacen caso omiso de la discusión entre ambas letradas y continúan.

La intérprete traduce en tercera persona. Resume y comete continuamente errores gramaticales cuando habla en español. Se aprieta las manos y continúa mostrando evidentes señales de ansiedad. 
Aunque la declarante se dirige directamente al juez y habla con él mirándole a la cara, los demás operadores usan la tercera persona.

Resultados del INTER-Q: La abogada y la investigadora consideran la actuación DEFICIENTE (11,6 Y 11,1, respectivamente), mientras que para el juez es REGULAR $(12,7)$.

\section{Caso 6}

Intérprete joven y de aspecto poco profesional. Parece como despistado, fuera de lugar en la sala de vistas Lleva una mochila que no se retira ni cuando está interpretando. Habla un español muy coloquial, con un registro inapropiado.

Usa la tercera persona. Resume mucho, a veces con monosílabos o frases muy cortas. No interpreta en simultánea susurrada.

Tras la declaración se produce un período de silencio y el intérprete empieza a moverse de forma peculiar hacia adelante y hacia atrás. También da pequeños saltos.

Resultados del INTER-Q: La actuación se considera claramente DEFICIENTE tanto para la Investigadora como para el Juez $(11,1$ y 11,6). En esta ocasión también cumplimentó el cuestionario un funcionario, que puntuó más alto $(12,7)$, que corresponde a un nivel de REGULAR.

\section{Caso 7}

La intérprete es una estudiante de Derecho con un buen nivel de español. Se comporta de forma adecuada y mantiene la distancia correcta con los declarantes. Muestra una buena capacidad de memoria y es capaz de interpretar frases largas sin tener que interrumpir. Sin embargo, no realiza la interpretación simultánea susurrada al declarante cuando debiera. No toma notas. Usa la tercera persona.

Los abogados conocen ya a la intérprete y a menudo le dan tareas que no son competencia de ella.

Resultados del INTER-Q: En esta ocasión solo contamos con dos evaluaciones, del juez y de la investigadora. Ambos consideraron su actuación REGULAR (12,2 y 12,7 , respectivamente). 


\section{Caso 8}

El declarante es una persona con buen nivel sociocultural y nivel de comprensión de español alto, pero prefiere tener un intérprete para mayor seguridad.

El intérprete habla con el declarante antes de la entrevista con el juez, delante del abogado y de la investigadora. Se cuentan su vida, hablan de otros casos. El declarante informa al intérprete de cómo se ha preparado con el abogado. El intérprete afirma «Yo, lo que digáis, hago»».

La jueza pide al intérprete que informe al declarante de sus derechos. El intérprete habla claramente durante más tiempo del necesario para el mensaje.

El declarante empieza hablando en español, pero después se pasa al inglés. Dado que el declarante entiende el español, el intérprete deja intervenciones sin interpretar. No toma notas.

Tanto el intérprete como la jueza hablan en tercera persona.

Mientras la jueza dicta al LAJ, el intérprete conversa con el declarante pidiéndole explicaciones de los hechos y luego traduce. El declarante y el intérprete siguen hablando mientras la jueza dicta. Mantienen conversaciones paralelas, incluso le explica quién es la investigadora.

El intérprete sorbe por la nariz. No va vestido de una manera apropiada al protocolo.

Se expresa en inglés con fluidez (explica que nació en Reino Unido y después vino a España).

El intérprete muestra claramente simpatía por el declarante. Mantienen conversación paralela en un tono amistoso.

También habla con la investigadora y le explica que cuando interpreta a personas de bajo nivel cultural, adapta el registro, simplifica el léxico «porque muchas veces la gente no sabe». Cuenta que no ha recibido formación, lo que ha aprendido lo ha hecho de manera autodidacta. Considera que sabe comportarse ante el juez. Dice, por ejemplo, que «hasta que no se sienta el juez, yo no lo hago».

Resultados del INTER-Q: La actuación de este intérprete se considera DEFICIENTE para la investigadora $(11,6)$ y para el abogado $(11,1)$. Sin embargo, para el juez, tan solo es REGULAR $(12,7)$. 


\section{Caso 9}

La intérprete es una estudiante de turismo sin formación como intérprete. Su competencia en español es bastante deficiente.

Interpreta al declarante en tercera persona. Da la impresión de que le cuesta entender las cuestiones jurídicas. Resume lo que se está hablando y no interpreta en susurrada. En alguna ocasión hace preguntas al declarante antes de interpretar.

Resultados del INTER-Q: En este caso solo tenemos dos evaluaciones. Para la investigadora, la actuación de la intérprete es DEFICIENTE $(11,6)$, mientras que para el juez es solo REGULAR $(12,2)$.

\subsection{Comportamiento de los ítems}

A continuación, se presentan las propiedades métricas de cada uno de los ítems del cuestionario. Se presentan en gráficas (Figuras 11, 13, 15, 17, 19, 21, 23, 25, 27, 29, 31, $33,35,37,39,41,43,45,47,49$ y 51) el porcentaje de aciertos, errores y respuestas en blanco. El porcentaje de aciertos, como se ha explicado en el capítulo anterior, se denomina «dificultad» (que en el caso del INTER-Q será la aquiescencia o probabilidad de se haya realizado la buena práctica descrita por la pregunta).

Además, se presenta un valor que se denomina «capacidad de discriminación», es decir, el grado en que un acierto en esa pregunta se relaciona con una puntuación alta en el cuestionario. Dicho de otra manera, si los buenos intérpretes suelen realizar correctamente la acción descrita por la pregunta. Los valores adecuados de discriminación deberían encontrarse entre 0,3 y 0,7 (Meyer, 2014).

Por último, se presenta la curva característica del ítem, que presenta la relación entre diferentes grados de excelencia en la interpretación y la probabilidad de tener una respuesta correcta (figuras 12, 14, 16, 18, 20, 22, 24, 26, 28, 30, 32 34, 36, 38, 40, 42, 44, 46, 48, 50 y 52). En el eje de las $\mathrm{X}$ aparece la distribución de la habilidad (competencia de interpretación). En el eje de la $\mathrm{Y}$ aparece la probabilidad de realizar correctamente el ítem en cuestión. Observando esta gráfica se puede conocer el grado de dificultad del ítem: los ítems fáciles son aquellos en los que intérpretes con habilidades menores a la media (menores a 0 ) tienen una probabilidad de realizar correctamente la pregunta mayor de 0,5 .

Esta curva también nos indica la capacidad de discriminación del ítem. Por ejemplo, en la pregunta número 1, intérpretes con habilidades muy bajas (entre -1,5 y 3,5 ) tienen una probabilidad mayor del $50 \%$ de hacer bien lo que describe la pregunta. 
1.- Su aspecto físico y presentación (vestido, aseo, peinado, comer chicle) son adecuadas a la situación $($ Discr $=0,1599)$.

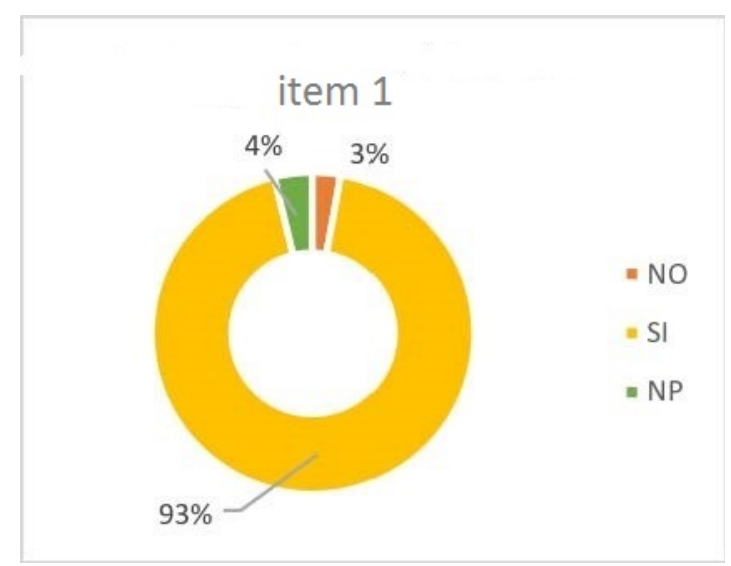

Figura 11: Porcentaje de aciertos, fallos y respuestas en blanco del ítem 1

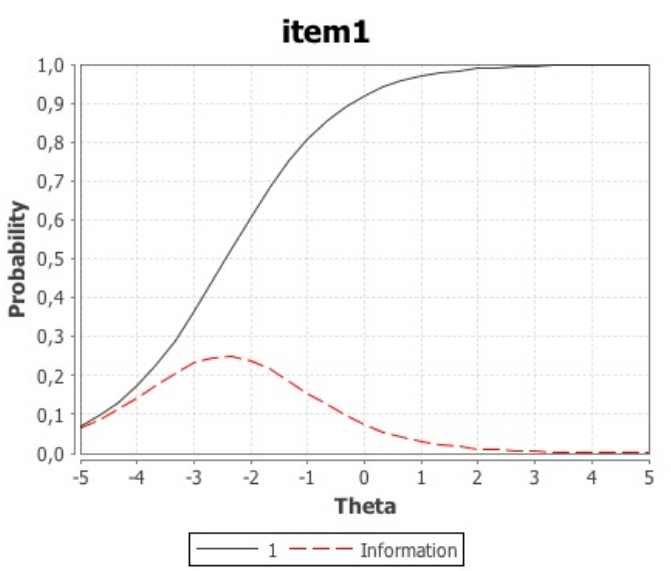

Figura 12: Dificultad del ítem 1

2. Lleva libreta $u$ otro dispositivo para tomar notas $($ Discr $=0,0304)$.

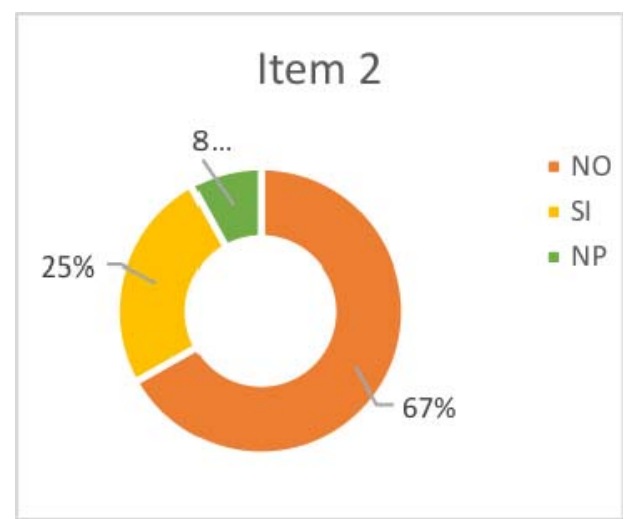

Figura 13: Porcentaje de aciertos, fallos y respuestas en blanco del ítem 2

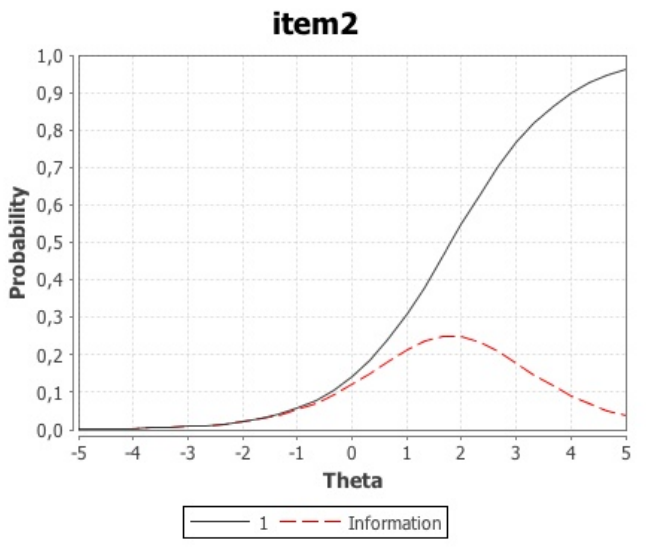

Figura 14: Dificultad del ítem 2 
3. Se le comprende bien cuando habla en [español/italiano], teniendo en cuenta pronunciación, léxico y gramática (Discr. $=0,1228)$.

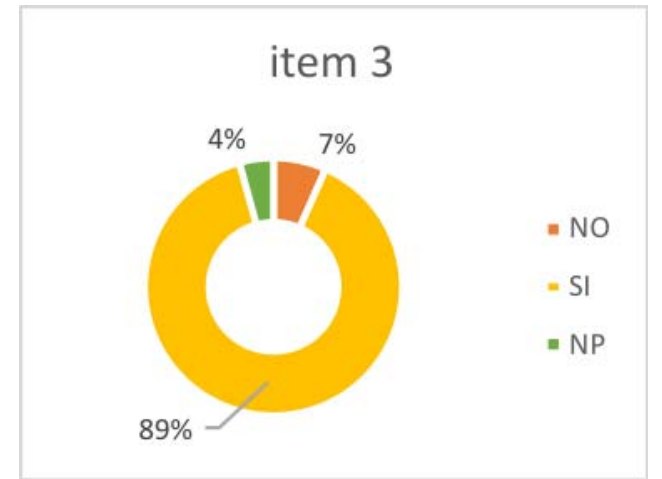

Figura 15: Porcentaje de aciertos, fallos y respuestas en blanco del ítem 3

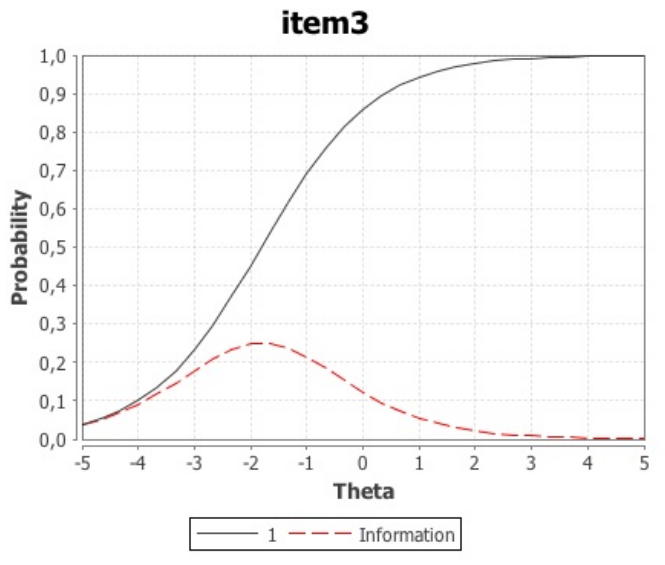

Figura 16: Dificultad del ítem 3

4. Su volumen de voz es adecuado a la sala y situación $($ Discr $=0,1517)$.

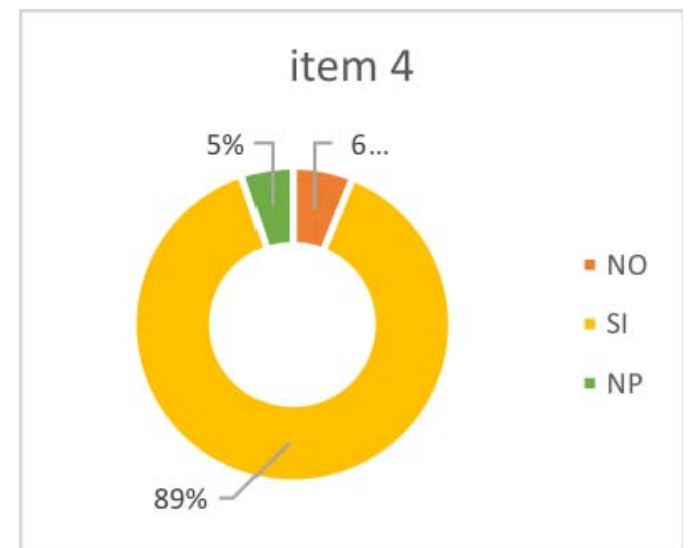

Figura 17: Porcentaje de aciertos, fallos y respuestas en blanco del ítem 4

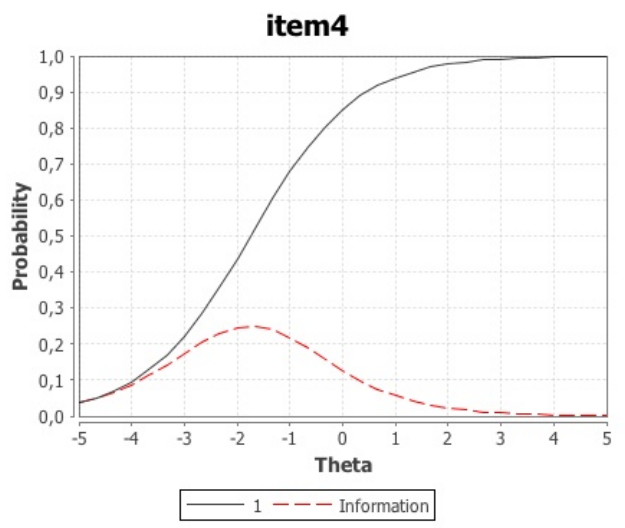

Figura 18: Dificultad del ítem 4 
5. Mantiene la distancia interpersonal con el declarante, adecuada a la situación (Discr $=0,2793)$.

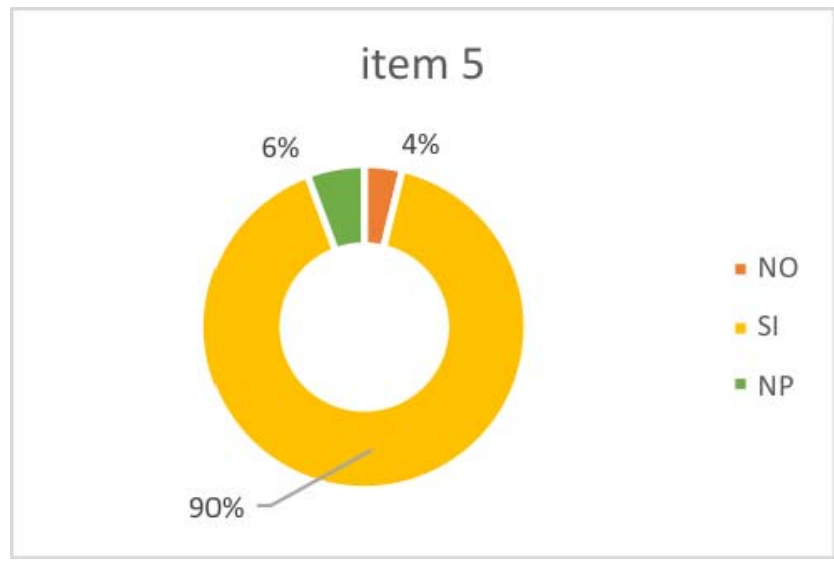

Figura 19: Porcentaje de aciertos, fallos y respuestas en blanco del ítem 5

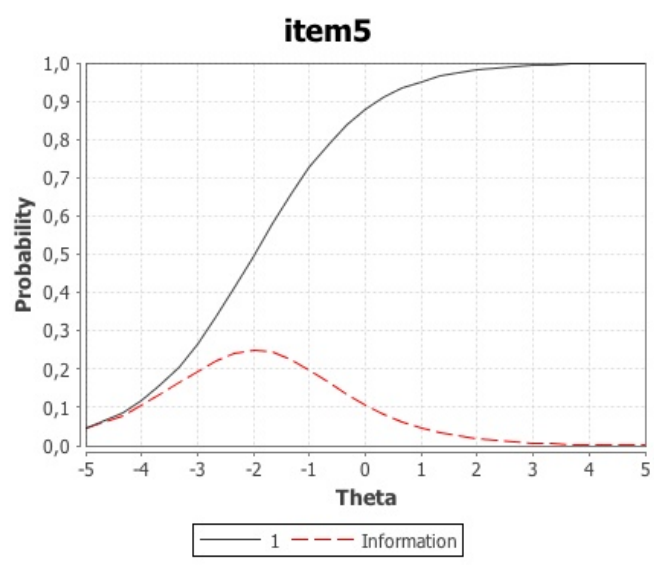

Figura 20: Dificultad del ítem 5

6*. Conversa con el declarante al margen de la situación de interpretación (Discr = $0,2381)$.

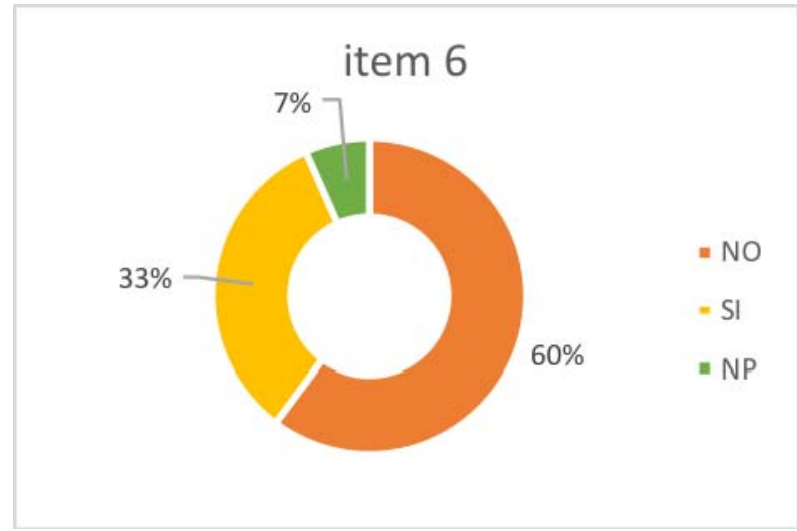

Figura 21: Porcentaje de aciertos, fallos y respuestas en blanco del ítem 6

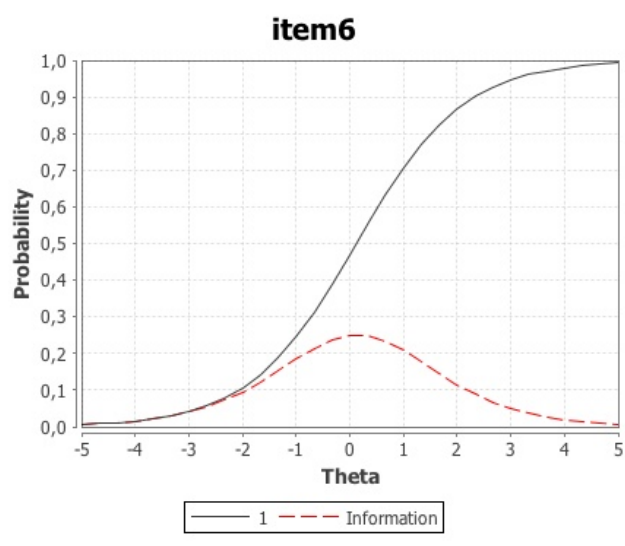

Figura 22: Dificultad del ítem 6 
7. Utiliza correctamente los términos judiciales/policiales en [español/italiano] (Discr $=0,2942)$.

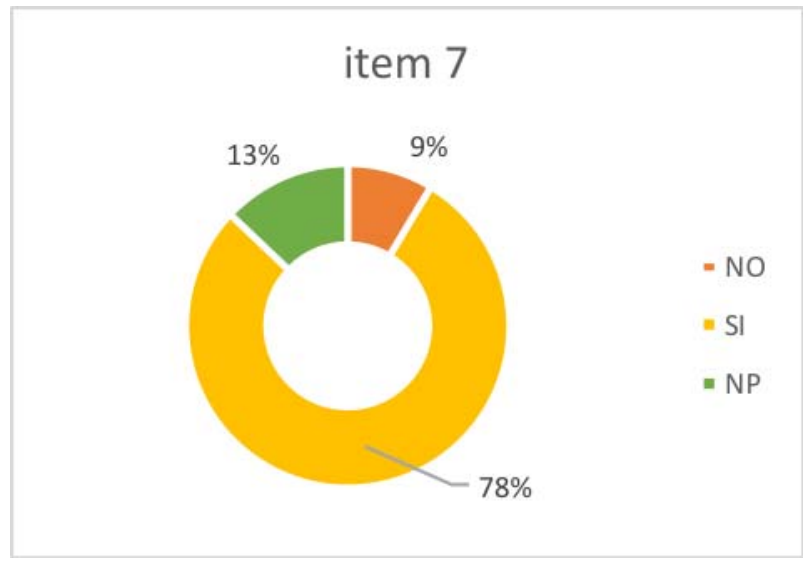

Figura 23: Porcentaje de aciertos, fallos y respuestas en blanco del ítem 7

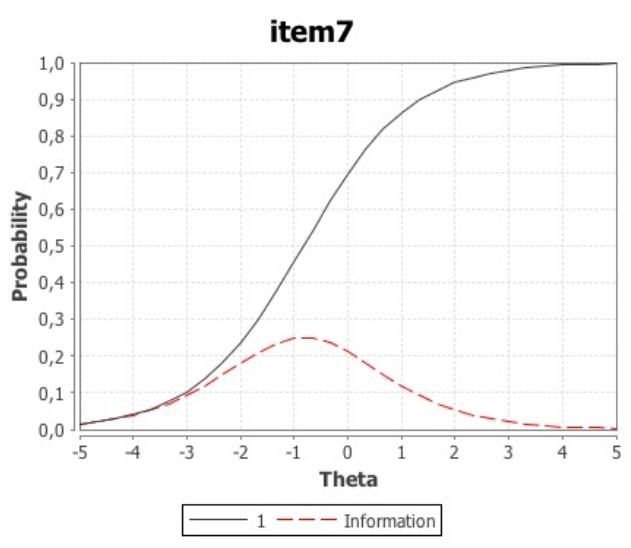

Figura 24: Dificultad del ítem 7

8. Lee los derechos, acusación u otros documentos, en lugar del [policía/operador judicial] (Discr $=0,0263)$.

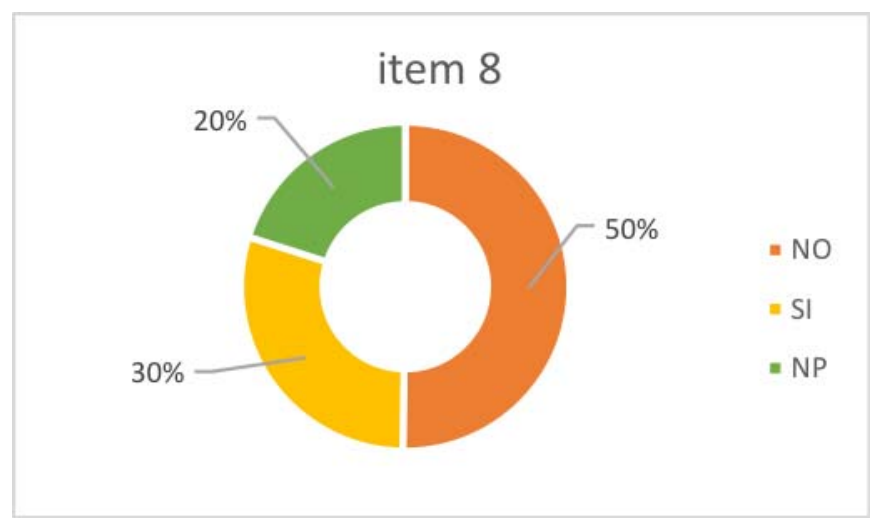

Figura 25: Porcentaje de aciertos, fallos y respuestas en blanco del ítem 8

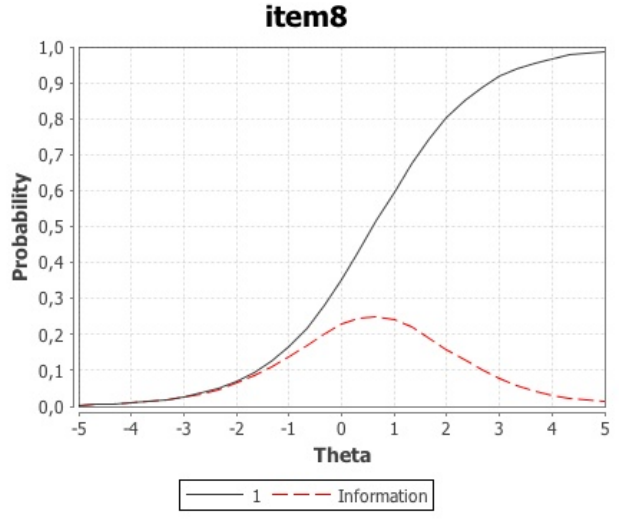

Figura 26: Dificultad del ítem 8 
9. Utiliza la primera persona cuando está interpretando el discurso del sujeto (Discr = $0,0435)$.

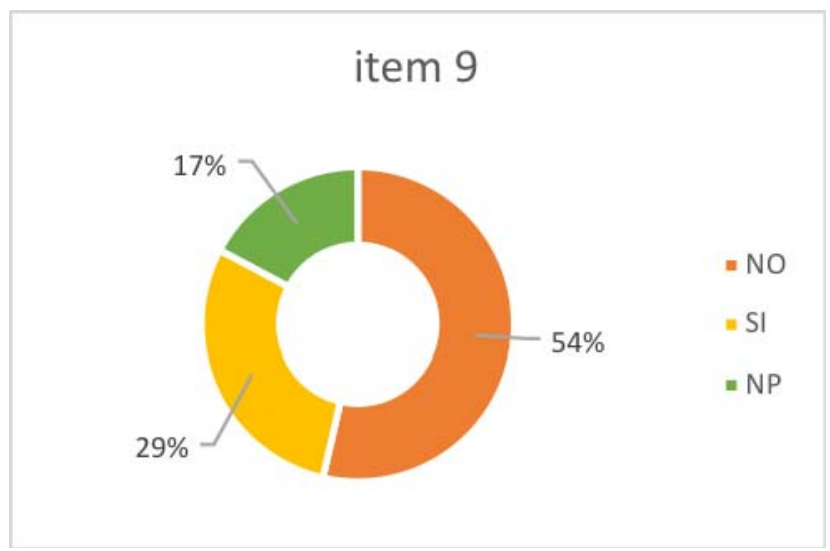

Figura 27: Porcentaje de aciertos, fallos y respuestas en blanco del ítem 9

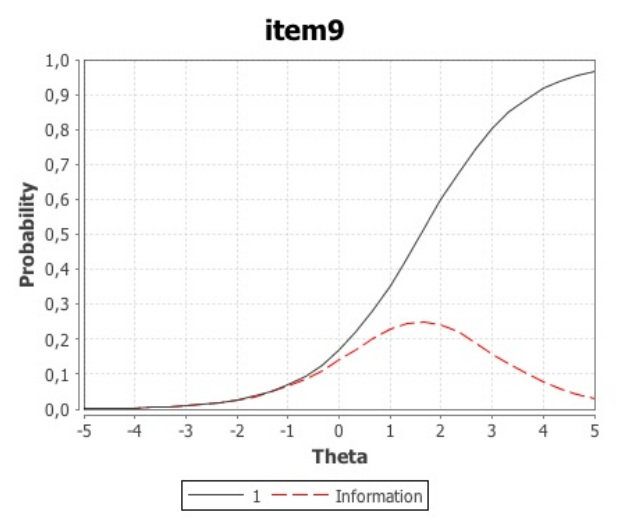

Figura 28: Dificultad del ítem 9

10*. Ya sea por iniciativa propia, o si se lo solicita el operador judicial/policía, explica al declarante algún aspecto del proceso $($ Discr $=0,002)$.

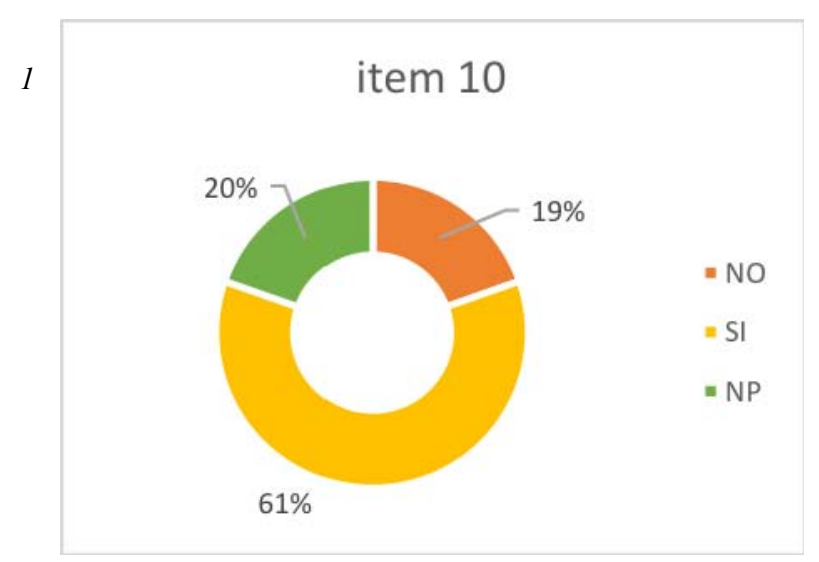

Figura 29: Porcentaje de aciertos, fallos y respuestas en blanco del ítem 10

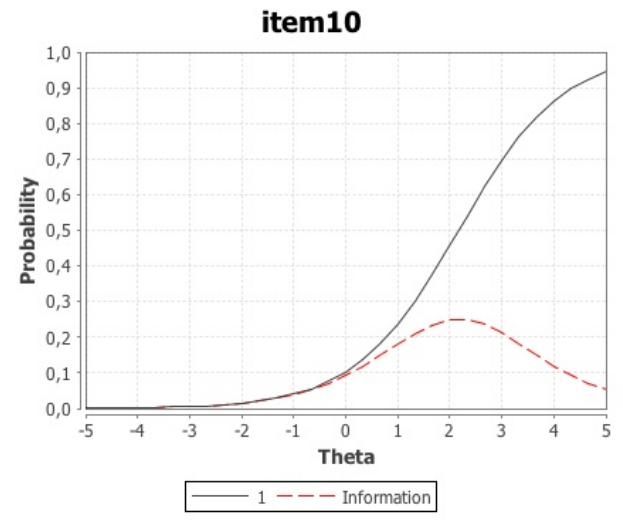

Figura 30: Dificultad del ítem 10 
1. Se dirige de manera correcta a los operadores judiciales $($ Discr $=0,3020)$.

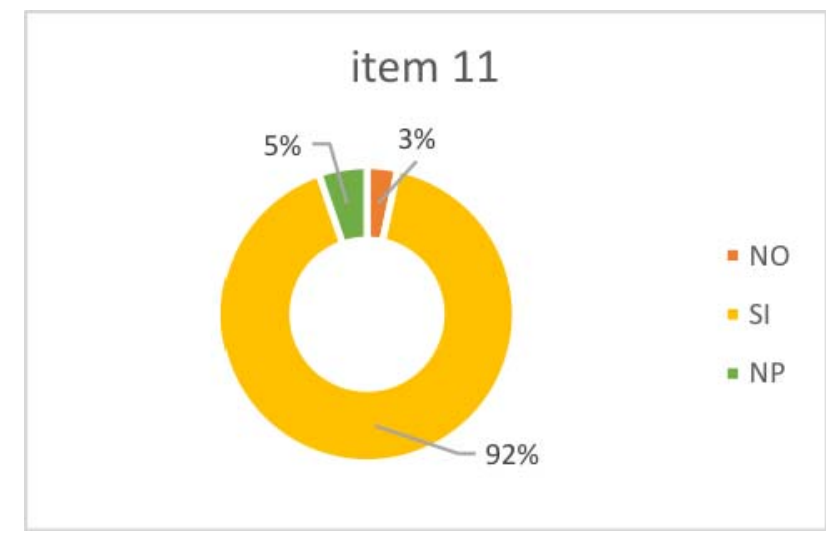

Figura 31: Porcentaje de aciertos, fallos y respuestas en blanco del ítem 11

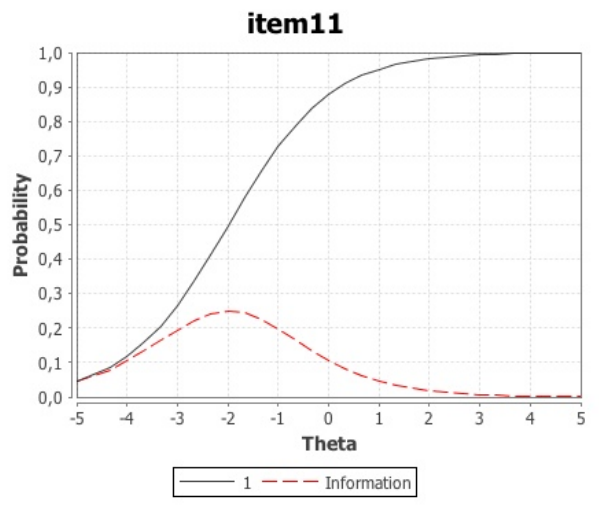

Figura 32: Dificultad del ítem 11

12*. Titubea o carraspea con frecuencia sin que el declarante lo haya hecho (Discr $=$ $0,2810)$.

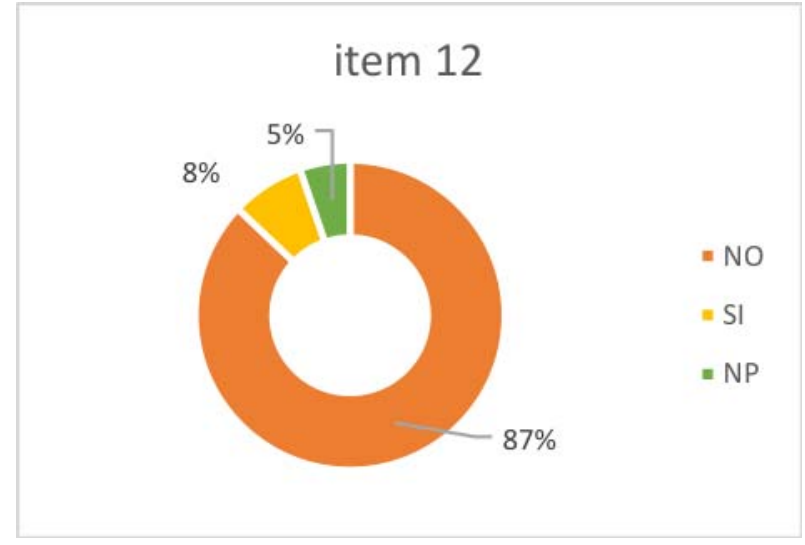

Figura 33: Porcentaje de aciertos, fallos y respuestas en blanco del ítem 12

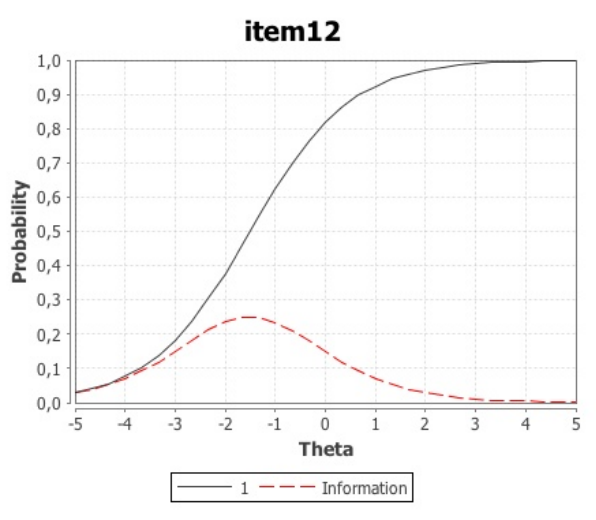

Figura 34: Dificultad del ítem 12 
13*. Se observa una clara desproporción en cuanto a la duración de lo que dicen el declarante y el intérprete $($ Discr $=0,4069)$.

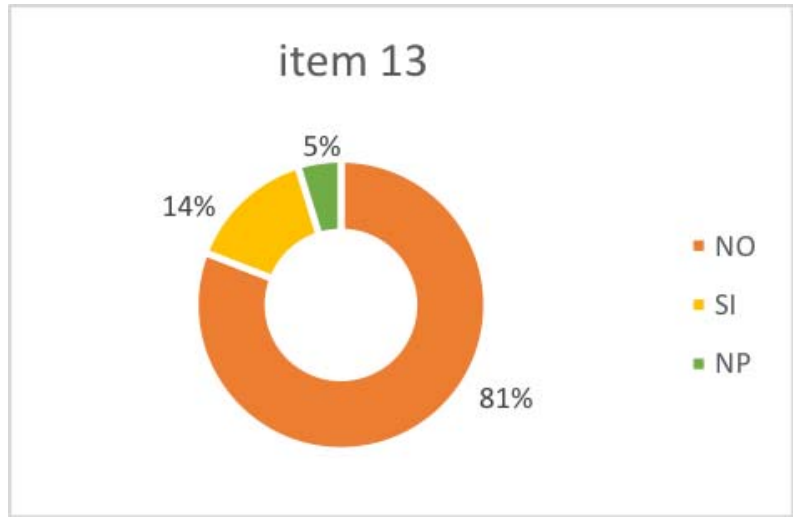

Figura 35: Porcentaje de aciertos, fallos y respuestas en blanco del ítem 13

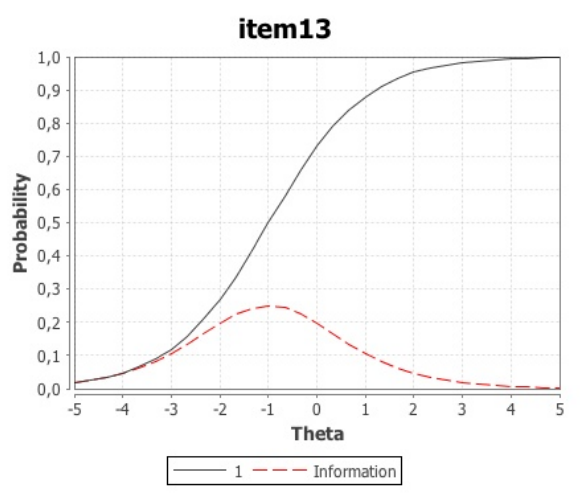

Figura 36: Dificultad del ítem 13

14. Cuando quiere pedir una aclaración, utiliza la fórmula: «El intérprete tiene que pedir una aclaración» $($ Discr $=0,1836)$.

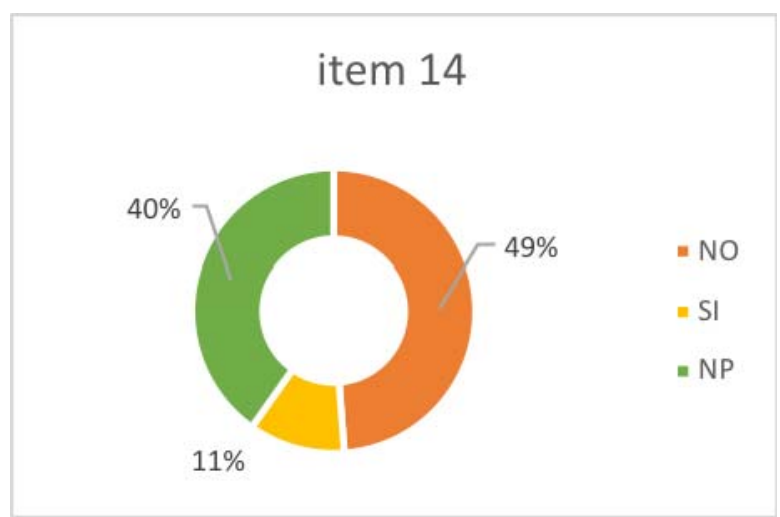

Figura 37: Porcentaje de aciertos, fallos y respuestas en blanco del ítem 14

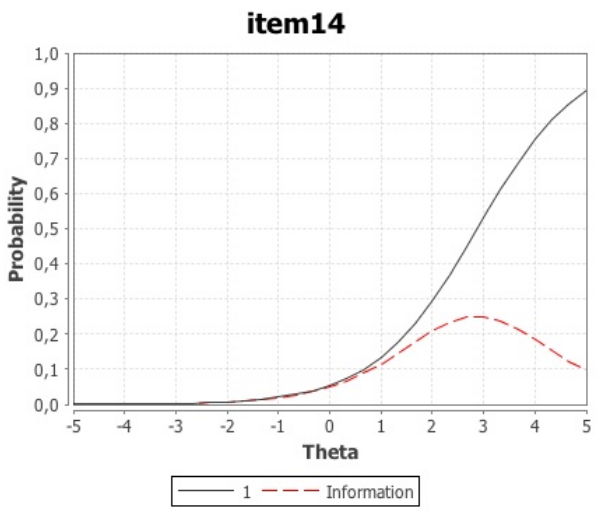

Figura 38: Dificultad del ítem 14 
15*. Interrumpe con frecuencia a la persona a la que está interpretando (Discr = $0,221)$.

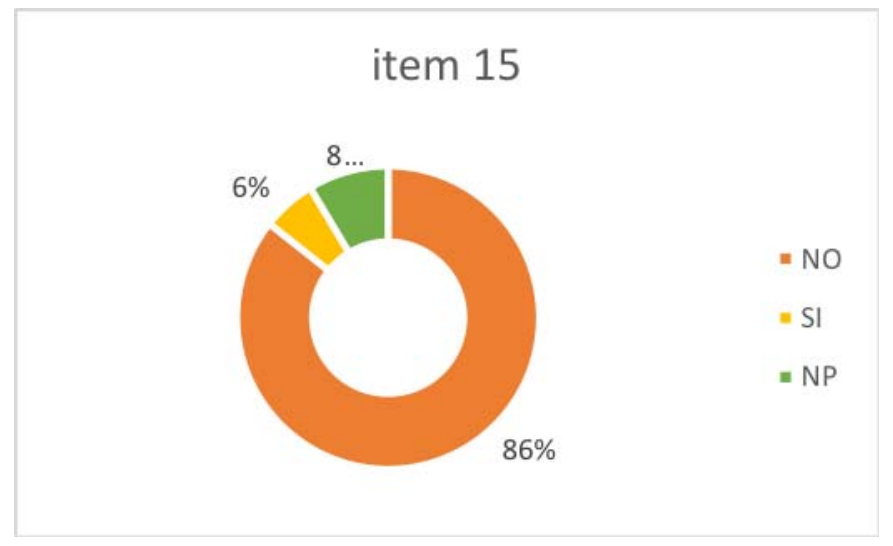

Figura 39: Porcentaje de aciertos, fallos y respuestas en blanco del ítem 15

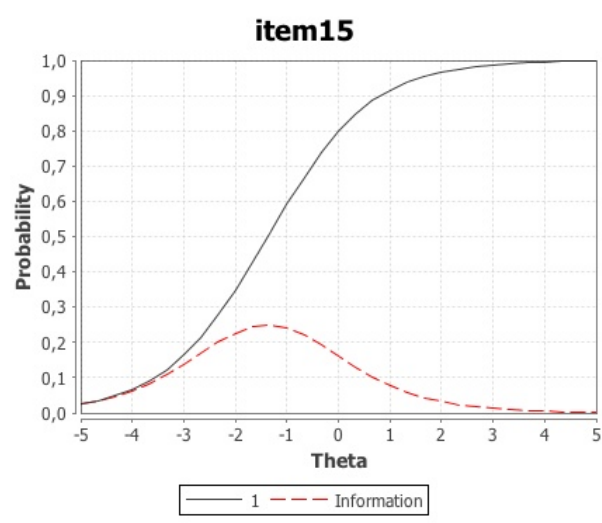

Figura 40: Dificultad del ítem 15

16. Mientras está interpretando, se refiere a si mismo en tercera persona (Discr = $0,0480)$.

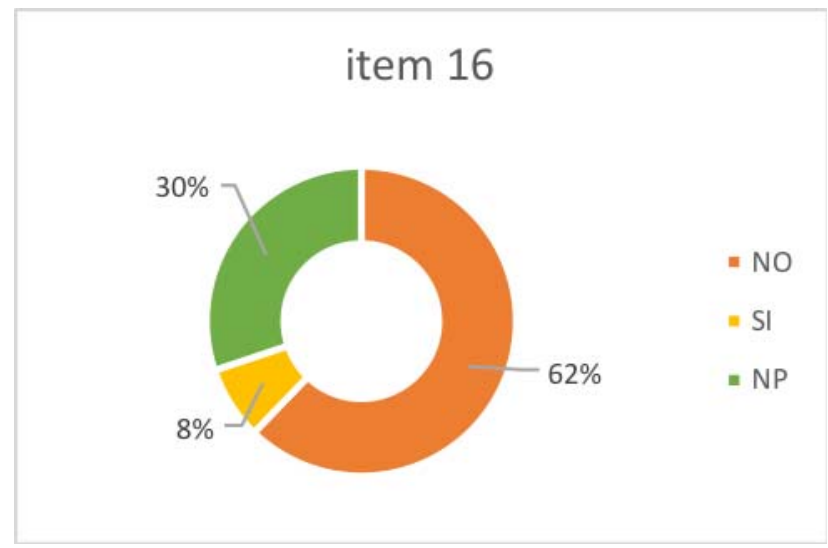

Figura 41: Porcentaje de aciertos, fallos y respuestas en blanco del ítem 16

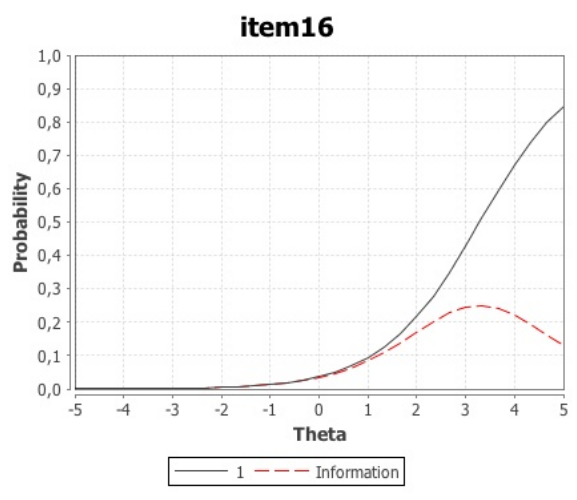

Figura 42: Dificultad del ítem 16 
17. En caso de tener que traducir un documento escrito de forma oral, lo hace con fluidez, sin demoras excesivas (Discr $=0,2699)$.

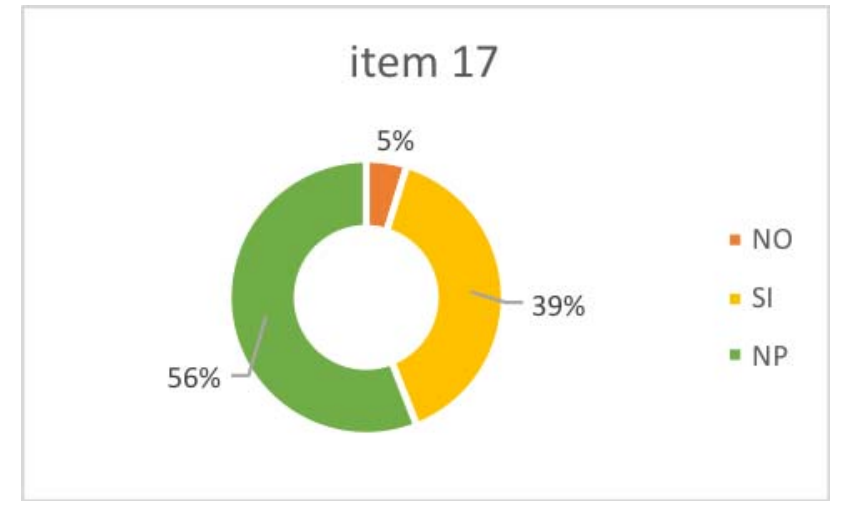

Figura 43: Porcentaje de aciertos, fallos y respuestas en blanco del ítem 17

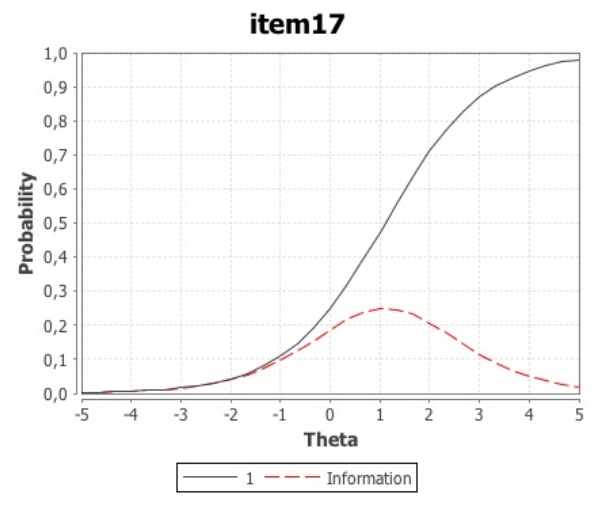

Figura 44: Dificultad del ítem 17

18. Durante toda o la mayor parte de su actuación, mantiene una expresión facial neutra (sin signos evidentes de amenaza hacia el declarante, pero tampoco de miedo o sumisión) (Discr. $=0,1787)$.

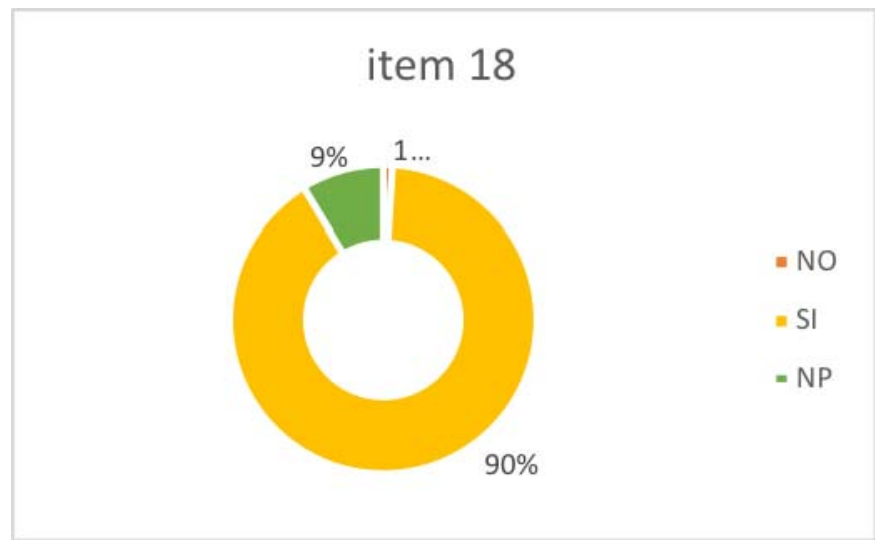

Figura 45: Porcentaje de aciertos, fallos y respuestas en blanco del ítem 18

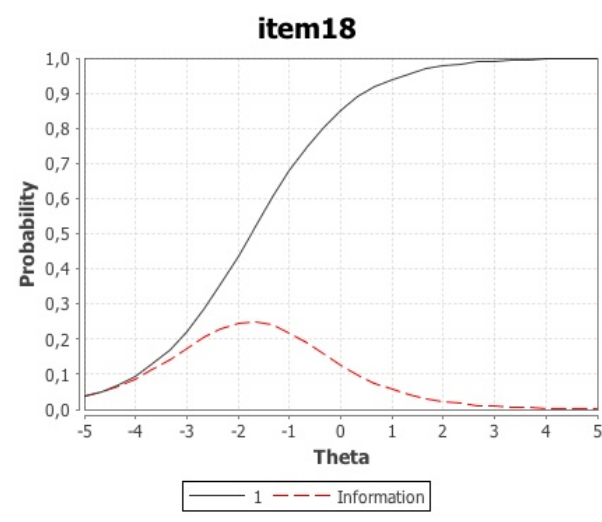

Figura 46: Dificultad del ítem 18 
19. Cuando necesita intervenir, lo indica haciendo una señal con la mano (Discr = 0,2057).

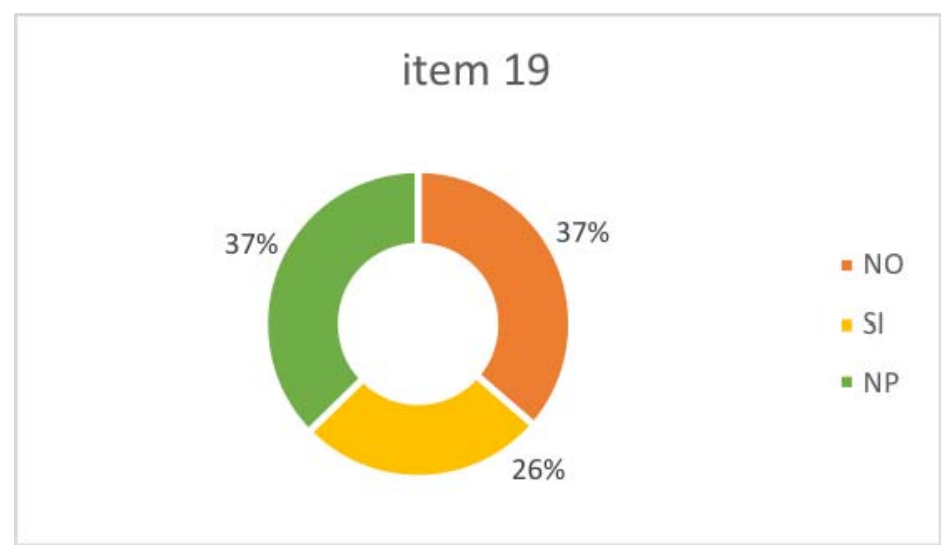

Figura 47: Porcentaje de aciertos, fallos y respuestas en blanco del ítem 19

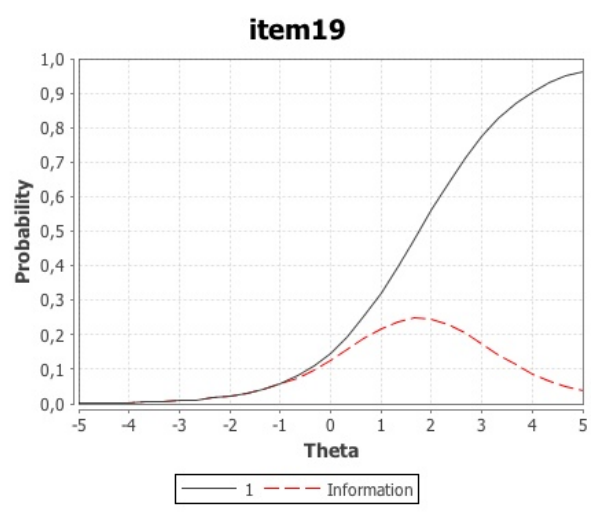

Figura 48: Dificultad del ítem 19

20. Reproduce el tono del mensaje original (jocoso, nervioso, agresivo, así como balbuceos, insultos ...) (Discr. $=0,0831$ ).

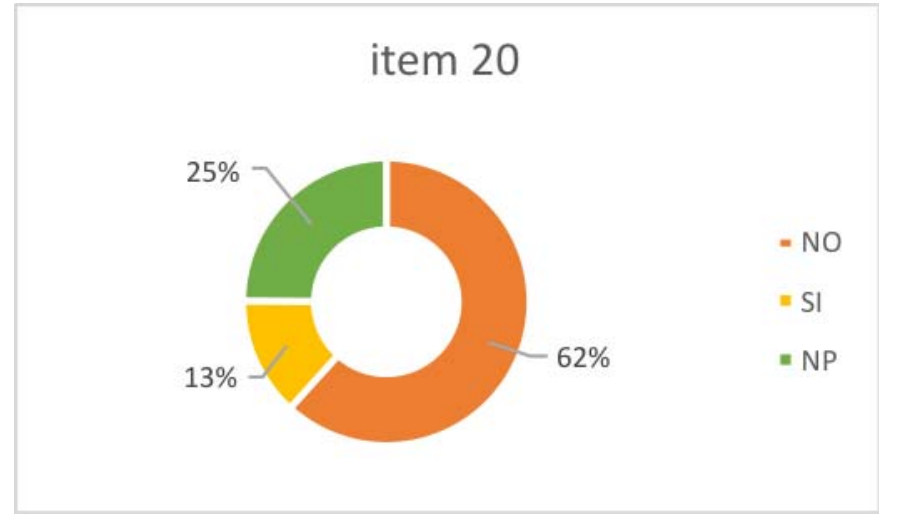

Figura 49: Porcentaje de aciertos, fallos y respuestas en blanco del ítem 20

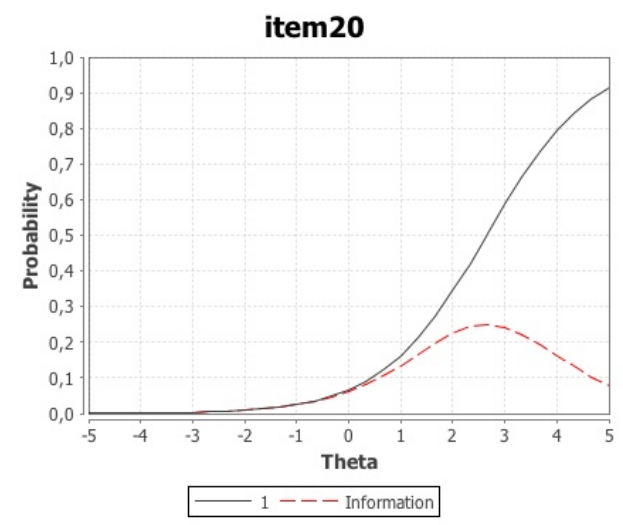

Figura 50: Dificultad del ítem 20 
$21 *$. Muestra expresiones o gestos como risas, bostezos, asco, sorpresa, empatía o apoyo hacia el declarante (Discr. = 0,2086).

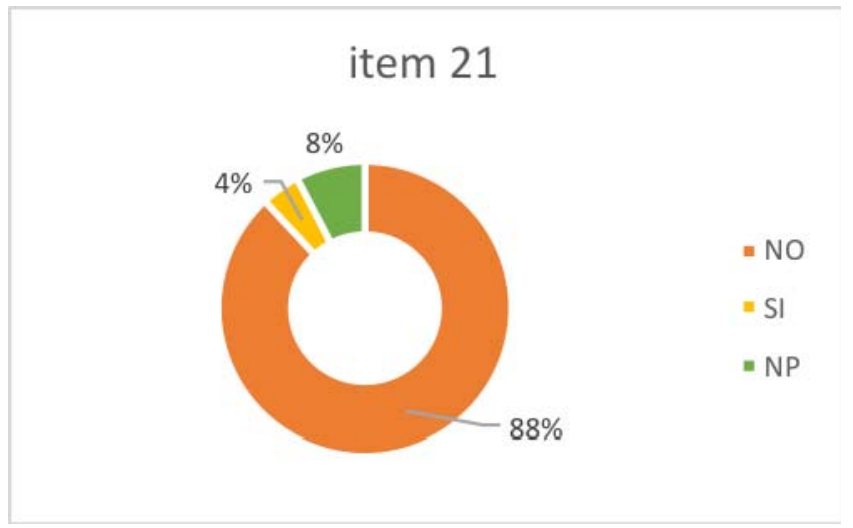

Figura 51: Porcentaje de aciertos, fallos y respuestas en blanco del ítem 21

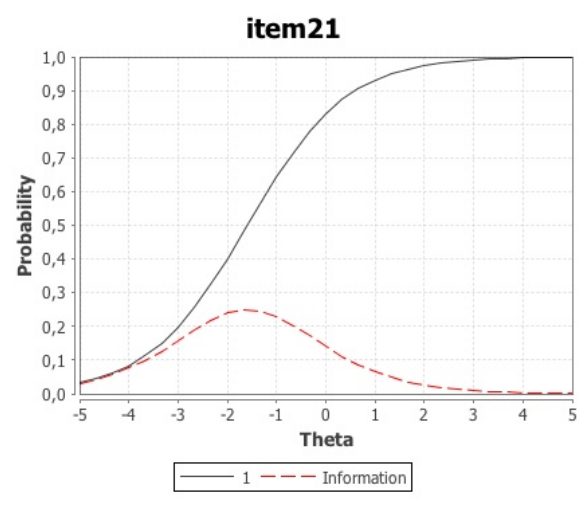

Figura 52: Dificultad del ítem 21

\subsection{Resultados de los datos cualitativos}

\subsubsection{Expectativas respecto a la labor del intérprete}

Los jueces y magistrados consideran muy necesaria la figura del intérprete para poder cumplir con las garantías procesales del acusado. Sin embargo, aunque son conscientes de la importancia del servicio de interpretación en cuanto a las garantías del proceso, afirman que «trabajar con intérpretes suele ser un escenario de problemas», «Trabajar con intérpretes es muy cansado, resulta premioso, agotador y provoca además la prolongación de los tiempos».

La consideración de los entrevistados respecto a sus expectativas hacia el intérprete son las siguientes:

- los jueces quieren que el proceso se celebre respetando los principios de equidad;

- según un interpelado, el intérprete debe traducir fielmente. Reconoce como características de buen intérprete «el que es fiel, mantiene la distancia, posee una competencia avanzada de la lengua castellana, tiene iniciativa para pedir explicaciones cuando no entiende algo». Para otro. «Traducir conforme a las necesidades de esta 
persona exige también mucho rigor y no ponerse ni dejarse influenciar por un aspecto positivo o negativo, sino simplemente traducir lo que uno está escuchando»;

- el intérprete no debe adaptar el registro, es el juez que adapta su lenguaje al nivel sociocultural de la víctima do del acusado. «el intérprete va a tener que intentar acompasar lo que se ha dicho al idioma al que tiene que traducir». El intérprete puede advertir al juez «Su señoría, el término que utiliza usted no he encontrado cómo traducirlo y puede dar lugar a ambigüedades» o «cuando el intérprete no comprende, me parece prudente que pida aclaraciones». El problema es cuando me doy cuenta yo y no el intérprete»;

- en Italia, los jueces son conscientes de las deficientes condiciones laborales de los intérpretes pues firman ellos mismos la minuta y autorizan su pago. Por ello, se reconoce que las personas que trabajan en sede judicial no son intérpretes profesionales y los operadores judiciales se han de conformar y aceptan lo que tienen a su disposición. Estos mismos jueces tienen también el poder de reducir o duplicar los honorarios y esto crea una relación poco clara: se aprecia un cierto temor y sumisión por parte de los intérpretes hacia los jueces. En España por su parte, los jueces son conscientes en algunos casos de que los honorarios son bajos, pero no tienen seguridad de ello. Se trata de rumores que han oído o leído. Consideran que es un tema que depende y tiene que controlar la Administración de la justicia.

\subsubsection{Cuándo se usa un intérprete}

Como se acaba de señalar, los jueces son conscientes de la importancia del servicio de interpretación para las garantías del proceso. Además, saben de lo difícil que es para un sospechoso o acusado no entender el idioma del país y muestran empatía por ellos (por ejemplo, casi todos los encuestados dieron el ejemplo de situaciones tan desagradables que son frecuentes en Tailandia o China). Sin embargo, si no es absolutamente imprescindible recurrir al intérprete, no lo hacen. A continuación, reproducimos un fragmento de una entrevista dónde se recoge este equilibrio que se pretende mantener. Se solicita intérprete si:

... es una persona... por ejemplo el acusado, nos viene y nos dice que necesita un traductor [sic]. Evidentemente, ya parte de hacer las cosas con sentido común, el acusado tiene derecho con base en el enjuiciamiento criminal a tener un traductor que le asista, entonces, de cara a evitar cualquier tipo de indefensión y evitar 
cualquier problema, en ese caso lo que hacemos es suspender el juicio, señalar otro día y citar a un traductor para que venga a asistirle ${ }^{105}$

Pero por otra, se aportan razones para continuar el procedimiento sin interpretación:

...por razones funcionales, económicas, económicas del proceso no de economía, que también, provoque que se plantee la situación de la necesidad de intérprete o de conveniencia, pero se continúa. «Bueno, usted más o menos entiende» Nadie se opone. Las defensas no se oponen. No suelen ser particularmente reivindicativas en reclamar que el juicio se celebre en dichas condiciones. Si es un supuesto de necesidad absoluta, evidentemente sí. Si el acusado lo solicita, evidentemente sí. Pero si nadie dice nada, incluso a veces el propio acusado no es consciente de transcendencia que puede tener para él. Si hay una cierta coerción, o no se le asiste, o no se le ha informado correctamente de sus derechos, el juicio se celebra en unas condiciones de baja calidad del de proceso, de comunicación y de comprensión con el acusado. Más aún, esto sucede más aún en juzgado fuera de [nombre de una ciudad española], ¿Por qué? Porque realmente podemos hablar de dos circuitos en materia de medios y calidad de la prestación, ...tiene servicio público en la administración de la justicia y a los pueblos tarda más en llegar, es más complicada la localización, suelen ser juzgados... por personal menos experto y a veces con una carga aún mayor de trabajo, con lo cual, la eficiencia en términos cuantitativos se antepone a la eficiencia en términos cualitativos, por ejemplo.

De alguna manera, la necesidad de intérprete es una más de las carencias y problemas del sistema judicial y en el trabajo de cada día se intentan responder los que parecen más graves o urgentes. Uno de los entrevistados se refería a esto como «intento de sobrevivir»:

Yo creo que el problema fundamental es este, que seguramente los operadores no somos conscientes de lo que hay en juego, de los valores. Y, o se ignoran, o se desproblematizan, pues es una manera de sobrevivir en el fondo. Ante una situación muy precaria, pues al final el riesgo, los problemas no se tienen si no se ven, sabes, es una buena manera de superarlos. Y así estamos. Esa es desgraciadamente la realidad más generalizada en nuestro país, por lo menos. Surgen grupos de operadores concienciados pero sin medios, se identifican los problemas pero las soluciones no son sencillas". En la mayoría de los países, en todos los periodos de crisis, de sobresaturación del sistema. Hay muchos marcadores que también son de tipo logístico, estructural, que hace muy difícil la situación. Además de económico, es un problema que no merece la pena políticamente. Porque la solución pasa primero por dinero. A veces no lo hay. O lo

${ }^{105}$ Se ha utilizado el formato citación pues se trata de las entrevistas de los jueces. No se hacen referencias por ser anónimas. En los anexos 9 y 10 se han transcrito el grupo de discusión y las entrevistas completas. 
hay, pero no se invierte aquí, o no merece la pena políticamente, o no hay presión para que se haga.

\subsubsection{Provisión del servicio}

Con respecto a la provisión del servicio, algunos jueces consideran que no pueden entrar en ello, pero que se está corriendo un riesgo si no existe un control de la calidad, que debería ser mayor. Dos jueces alegaron que debiera estar más controlado por la Administración y la contratación debiera ser directa, aún tratándose de profesionales autónomos y no debería hacerse a través de una empresa o una agencia privada. El problema de la provisión directa está también en la contraprestación y el control de la calidad, que en Italia es muy baja en los dos aspectos. Varios jueces consideran que es un servicio que no debiera externalizarse, sino estar totalmente bajo el control de la administración. «no se trata de simple dotación de material, sino que considera las fuertes implicaciones judiciales que tiene». Algunos jueces llegan a poner en tela de juicio la constitucionalidad de la externalización del servicio de contratación pues «se trata de una garantía procesal vinculada de manera indeclinable al derecho de defensa, por lo que el acudir a las normas de contratación administrativa podría suponer una vulneración del derecho a un proceso con todas las garantías». Uno de los jueces cita un trabajo de investigación que defiende la inconstitucionalidad de la externalización de ciertos servicios (Favières Català, 2013, p. 61).

Algunos jueces abogan por auditorías fuertes: «No existen controles para el acceso de los profesionales a la interpretación, se presta el servicio, se privatiza el servicio. La privatización no implica necesariamente falta de profesionalidad de los intérpretes, pero puede ser un riesgo». Uno de los entrevistado señalaba: «Se contrata, yo no sé cuáles son las condiciones, me gustaría saber cuáles son las condiciones de la contratación». Añade también que «la concepción del intérprete no puede ser vista como una simple dotación de medios materiales cuando influye directamente en el derecho de defensa». Para alguno de los entrevistados debería haber un cuerpo oficial de intérpretes del Servicio de Administración de la Justicia.

En general, los jueces tienden a pasar por alto el problema para sobrevivir en un entorno laboral difícil. Algunos se preguntan si la Administración es la que debería controlar el acceso y los casos de incumplimiento, si tiene la capacidad financiera para hacerlo, o si existe voluntad política. Algunos llegan incluso a decir que «no salen plazas para intérpretes jurados». 
Existen propuestas para la creación de un servicio dentro de la administración encargado de identificar las necesidades y coordinar de alguna manera los niveles requeridos

para tener varios niveles de capacitación o competencia y en función de eso, ir asignando o contratando. Igual, para un juicio concreto, de una determinada dificultad, contratas a unos profesionales, no tienen que estar en nómina los cincuenta y, las cincuenta y seis semanas del año.

Un juez aduce que debiera haber un observatorio en materia de derechos $y$ garantías. Algunos han oído rumores de malas prácticas por parte de las agencias:

Aquí hace años, eso era un rumor, yo no sé si finalmente es cierto o no, supongo que lo es pero...oí hablar hace muchos años. Igual hace diez, doce años, de que la empresa que entonces llevaba la historia, estaba contratando a ciudadanos extranjeros en situación irregular, quizás no de una manera consciente, pero claro...desde luego personas que iban a estar dispuestas a cobrar $13 €$ la hora, como si limpiaran una casa o desgraciadamente, porque también trece euros si estás limpiando una casa es una miseria.

\subsubsection{Papel del intérprete}

En relación con el papel del intérprete, los jueces consideran que muy a menudo el intérprete asume un rol que no le corresponde: de abogado, consejero o incluso juez. Afirman que «no saben estar en su lugar».

Una vez el intérprete le estaba diciendo «di la verdad, pero di la verdad» y yo le dije «limítese a contestar lo que está diciendo» El intérprete respondió «Es que está diciendo algo que es mejor que no diga», por ello, asumen una función que no les corresponde. A veces parece que quieren ganarse la simpatía del juez o del fiscal y que ello conllevara un mayor beneficio a los ojos del tribunal. Algunos le recriminan al acusado «iHay que ver lo que has hecho!», por lo que he tenido que advertirles «Oiga, No tiene usted que recriminar a nadie». Otros asumen el papel de abogado defensor y se indican al procesado a que no actúe de esa u otra manera.

Afirman claramente que esperan que el intérprete se limite a decir lo que el acusado o testigo quiera manifestar. 


\subsubsection{Preparación que debe tener un intérprete}

Los entrevistados han señalado que muchos intérpretes adolecen de una falta de conocimientos jurídicos y terminológicos. Además, el hecho de que a menudo no sean imparciales demuestra que carecen o no siguen un código ético y de buenas prácticas. A veces el juez tiene que amonestar al intérprete, como en aquellas situaciones donde la interpretación es demasiado corta o demasiado larga con respecto al original «Discúlpeme, señor intérprete, realmente no conozco su idioma, pero me parece de alguna manera sorprende que traduzca oraciones largas cuando la respuesta es corta o viceversa».

Algunos jueces ignoraban qué preparación debe tener un intérprete, cuando se les formuló concretamente esta pregunta. Existe una confusión generalizada en la administración de la justica sobre los traductores e intérpretes jurados, ya que muchos profesionales del derecho están convencidos de que los intérpretes son jurados y por esta razón calificados, porque firman un documento en el que prometen cumplir fielmente con su tarea. Según las palabras de uno de los entrevistados:

Yo creo que no somos tan conscientes de cuál es la cualificación necesaria y el grado de preparación, y por tanto de años de formación necesarios para desarrollar perfectamente el trabajo de intérprete, de intérprete judicial. Parece que en los otros espacios nadie cuestiona, intérprete en organismos internacionales, son personas cualificadísimas, con una formación extensísima [...]En cambio llega aquí, sobre todo en la justicia penal. La justicia penal es la justicia de la marginalidad, de la pobreza. Eso tampoco lo podemos olvidar cuando las instituciones responden en función de a qué sector de la sociedad está dirigido. O porque son sectores que no ejercen sus derechos, porque no los conocen. Nadie se plantearía que en un procedimiento mercantil de decenas de millones de euros, hubiera problemas por temas vinculados con cuestiones idiomáticas.

Otros consideran que es suficiente el título de Escuela de Idiomas:

...más allá de la titulación que pueda tener, que desconozco cuál pueda ser, entiendo que debe hablar correctamente tanto el idioma español como el idioma de la persona que debe traducir. Ya digo, sin entrar en la titulación. Al final a mí lo que me interesa es que traduzca fielmente lo que el declarante me dice

y añade

Yo no sé si hay ya a nivel de la Escuela Oficial de Idiomas. Es que tampoco. Pero desde luego, conocimientos suficientes para poder con fluidez poder traducir y poder dar respuesta a lo que al final desde la administración de la justicia se les pide. 
Otros jueces están más concienciados con los problemas involucrados. Admiten que solo recusan a un intérprete en situaciones extremas y que no controlan el tipo de preparación que tiene, se presentan con el carnet de la empresa. Pedir explicaciones de preparación les resulta violento o fuera de lugar. No hay interrelación entre intérprete y juez antes de la vista. Algunas veces, los intérpretes le piden al juez que hable despacio, pero las expectativas de los jueces son que «si llegan a trabajar como intérpretes, deberían estar calificados para ellos. Como regla general, la tarea del intérprete no es explicada a los usuarios. Las dudas surgen cuando un intérprete tiene escaso dominio del castellano, entonces el juez considera «si no domina muy bien la lengua a la hora de traducir, tengo dudas si la domina a la hora de interpretar».

En el caso de Italia, la tendencia es cumplir con la ley, con respecto al derecho a la interpretación y a la traducción, y justifican el empleo de personas no muy preparadas a causa de la falta de recursos económicos y de los bajos salarios. Aceptan la situación como un mal menor; de hecho, tienden a quejarse cuando el intérprete susurra. Sin embargo, algunos argumentan que la falta de capacitación de los intérpretes no solo se refleja en el componente de lenguaje de la interpretación, sino más específicamente en la función real del intérprete como intérprete judicial.

También se trató la cuestión de la preparación de los jueces para el trabajo con intérpretes. En este sentido, ninguno de los jueces que ha participado en este estudio ha recibido formación específica sobre el trabajo con intérpretes.

Ha habido en un momento determinado, al final de la anterior legislatura, que hubo muchísimas modificaciones en materia de procedimiento criminal, fue como una especie de pronto de avalancha de modernizaciones, sin que se diese aquí la formación. Yo estuve una vez en un curso en Italia con fiscales italianos. Aquí en España la formación es voluntaria. Si hay modificaciones legales no hay una formación obligatoria, que sería conveniente. Casi sería necesario. En horario laboral, pero es que es necesario. Nadie puede continuar trabajando después de una reforma legal sin conocerla claramente. «Usted se la lee». Es verdad, es que leer es tu obligación. Por supuesto, pero hay más cosas.

Alguno de los jueces conocía las recomendaciones de Vieira Morante (2012) y la labor de De Luna Jiménez de Parga (2009, 2010). En Italia, algunos jueces se han involucrado personalmente organizando o participando en seminarios, congresos y cursos de formación, interpelan directamente a las universidades y existe una preocupación por el tema, como se puede observar con la Universidad de Forlì, La Statale di Milán o la de Trieste. Llama la atención que están convencidos de que saben trabajar con intérpretes. 


\title{
7.5.6. La importancia de la comunicación no verbal (CNV)
}

Los jueces y magistrados usan con frecuencia la comunicación no verbal como parte de sus interrogatorios y para determinar si el sospechoso acusado está diciendo la verdad. Por esta razón considera este canal de comunicación muy importante y puede evidenciar una falta de calidad.

\begin{abstract}
A veces los acusados solicitan intérprete para dilatar el procedimiento, pues saben que es muy difícil que se lo nieguen. Si conocen el idioma y no están de acuerdo con lo que está traduciendo el intérprete, la CNV los delata. entonces de repente, empieza a traducirles el intérprete y se empiezan a poner nerviosísimos, porque alguno incluso que se nota que el intérprete lo ha pedido para dilatar el procedimiento, y de repente dice «Que yo no estoy diciendo eso!» en español perfecto.
\end{abstract}

También el público reacciona ante lo que sucede en la sala a través de la CNV, cuando cree que alguien no está diciendo la verdad o la interpretación es equivocada. De la misma manera, la CNV de los intérpretes proyecta una falta de seguridad, especialmente cuando no entiende y se empieza a poner nerviosos, lo que crea desconfianza respecto a su labor.

\subsubsection{Uso de lingua franca}

Por último, respecto al uso de una lingua franca, ya sea esta inglés, francés o árabe, algunos jueces no están seguros de la medida en que el usuario la entiende y, de hecho, surgen problemas de comprensión en tales situaciones, incluso cuando la lingua franca es el segundo o tercer idioma del intérprete. Es el caso, por ejemplo, de los ciudadanos subsaharianos que «Se expresan en un francés muy pobre. Creo que esto dificulta la plenitud de su defensa ya que el francés es una lengua aprendida, pero no propia». 
7. Resultados 


\section{Discusión y conclusiones}

\subsection{Discusión}

Tras el diseño, el pilotaje y la validación en varios entornos, cabe preguntarse si INTER-Q es un buen instrumento de evaluación del desempeño de un intérprete que actúa en el contexto judicial.

Existen diferentes procedimientos para conocer las propiedades de un instrumento de medida de comportamiento o actividad humana (Meyer, 2014). Estos procedimientos se clasifican en dos tipos, los que se refieren a la precisión o ausencia de error (fiabilidad) y los que indican el significado de las medidas y su utilidad para conseguir objetivos aplicados (validez).

En este trabajo se han obtenido dos tipos de medidas de fiabilidad. En primer lugar, se ha calculado la consistencia interna, que informa del grado de error debido a la selección de las preguntas. Se han calculado dos métodos para obtener la consistencia interna. El primero es el más habitual, pero tiene el inconveniente de que depende de las características de la muestra. En este estudio el valor es modesto (cercano a 0,50). Con el segundo procedimiento se ha obtenido un valor significativamente más alto $(0,90)$, lo que indica que la selección de los ítems y la longitud del cuestionario son adecuados.

La segunda medida de fiabilidad que se ha calculado ha sido la objetividad, o grado de congruencia entre diferentes evaluadores. Se ha calculado de dos formas: con el cálculo de un coeficiente de concordancia a partir de cuatro casos en los que han coincidido la investigadora y la misma jueza y, en segundo lugar, se ha comprobado un alto grado de coincidencia en los casos descritos mediante el cuaderno de campo.

Un aspecto importante que hay que destacar en la objetividad del INTER-Q es que estamos comparando las evaluaciones realizadas por una profesional de la interpretación (la investigadora) y operadores judiciales con mayor o menor experiencia en el trabajo con intérpretes y que no necesariamente conocen en qué consiste el trabajo del intérprete. Tanto el valor del coeficiente como el análisis de los casos mediante los cuadernos de campo indican una gran congruencia entre los evaluadores. Así pues, se puede afirmar razonablemente que el cuestionario INTER-Q es una herramienta de evaluación objetiva, que puede utilizarse por personas $\sin$ conocimientos de interpretación (aunque sí debería tenerlos de términos y procedimientos jurídicos, ya que varias preguntas se refieren a estos aspectos). 
Esto no significa en modo alguno que no sea imprescindible la formación de los operadores judiciales para trabajar con intérpretes, sino que el cuestionario proporciona datos fiables y válidos, con independencia de si se conoce o no la función del intérprete.

El idioma del cuestionario y las diferencias en las situaciones judiciales italiana y española no influyen de forma significativa en las puntuaciones. Cabe suponer que la traducción y adaptación a otros idiomas dentro del contexto europeo produzca resultados equivalentes.

En definitiva, los resultados de este estudio sugieren que INTER-Q es un instrumento de evaluación bastante objetivo, que solo precisa de un entrenamiento mínimo.

La segunda pregunta sobre las propiedades de medida de un cuestionario es, quizá, la más importante, ya que se refiere a su validez. Nuestros resultados sugieren que INTER-Q sí discrimina bien entre los buenos y malos intérpretes, incluso cuando los evaluadores son operadores judiciales.

Los análisis de los ítems nos indican que existen diferentes niveles de preguntas. En primer lugar, tenemos un grupo de ocho preguntas muy fáciles, con poca capacidad de discriminación entre los «buenos» $\mathrm{y}$ «malos» intérpretes. Las preguntas de este grupo son:

1.- Su aspecto fisico y presentación (vestido, aseo, come chicle) es adecuado a la situación.

3. Se le comprende bien cuando habla en [español/italiano], teniendo en cuenta pronunciación, léxico y gramática.

4. Su volumen de voz es adecuado a la sala y situación.

5. Mantiene la distancia interpersonal con el declarante, adecuada a la situación.

11. Se dirige de manera correcta a los operadores judiciales.

12*. Titubea o carraspea con frecuencia sin que el declarante lo haya hecho.

18. Durante toda o la mayor parte de su actuación, mantiene una expresión facial neutra (sin signos evidentes de amenaza hacia el declarante, pero tampoco de miedo o sumisión).

$21 *$. Muestra expresiones o gestos como risas, bostezos, asco, sorpresa, empatía o apoyo hacia el declarante.

Se trata de comportamientos y habilidades básicos que se esperan de un profesional en un entorno de trabajo en el que hay unos protocolos determinados y se toman decisiones fundamentales que afectan a personas. Tenemos tres preguntas relacionadas con buenos modales (1, 5 y 11), capacidad de expresión verbal y 
paraverbal (3, 4 y 12) y, por último, neutralidad respecto al procesado (18 y 21). La mayoría de los interpretes puntúan correctamente en estas preguntas, pero pueden funcionar como criba o identificador de personas que deberían rechazarse para trabajar como intérpretes. Es decir, en posteriores usos del cuestionario INTER-Q, una puntuación baja en estas preguntas indicaría que, muy probablemente, estamos ante una persona que no tiene formación ni cualificación como intérprete judicial.

A pesar de que en la mayoría de los cuestionarios las respuestas a estas preguntas han sido afirmativas (o negativas en el caso de las preguntas 12 y 21), en los cuadernos de campo se recogen casos de intérpretes que mastican chicle, visten de forma inadecuada al contexto o muestran otros comportamientos inadecuados como los que describen las preguntas de esta parte del cuestionario.

Un segundo grupo de seis preguntas tienen una dificultad y capacidad de discriminación media. Son las siguientes:

6*. Conversa con el declarante al margen de la situación de interpretación.

7. Utiliza correctamente los términos judiciales/policiales en [español/italiano].

8. Lee los derechos, acusación u otros documentos, en lugar del [policía/operador judicial].

13*. Se observa una clara desproporción en cuanto a la duración de lo que dicen el declarante y el intérprete.

15*. Interrumpe con frecuencia a la persona a la que está interpretando.

17. En caso de tener que traducir un documento escrito de forma oral, lo hace con fluidez, sin demoras excesivas.

Hay que señalar que alguna de estas actividades no dependen solo de los conocimientos, habilidades o actitudes del intérprete, sino del juez y otros operadores (como la lectura de derechos u otros documentos). También hay otras que se han dado con poca frecuencia (como la 17), sin embargo, se ha decido conservarlas en el cuestionario por necesidades prácticas.

La pregunta número 13 es especialmente importante, ya que indica probablemente una interpretación incompleta. En los códigos deontológicos se recoge específicamente que es crucial traducir fielmente el enunciado para permitir la comunicación entre las personas implicadas en el procedimiento judicial, es decir, operadores judiciales, acusados, víctimas y testigos. Solo así se colocará a la persona alófona o con dificultades de audición en igualdad de condiciones con respecto a una persona que habla la lengua del proceso, que es lo que se ha denominado en esta tesis como presencia efectiva y que se denomina en Estados Unidos linguistic presence. 
Por último, nos encontramos siete actividades y habilidades que distinguen al buen intérprete. Pocos participantes las han realizado correctamente y son las que tienen mayor correlación con la puntuación total. Es interesante señalar que son aquellas características técnicas propias de la interpretación (incluso aunque los operadores judiciales que han contestado no sabían que esa actividad era correcta o aún más, pensaban lo contrario (como se ha descrito en el capítulo 8). Estas preguntas son las siguientes:

\section{Lleva libreta u otro dispositivo para tomar notas.}

9. Utiliza la primera persona cuando está interpretando el discurso del sujeto.

10*. Ya sea por iniciativa propia, o si se lo solicita el [operador judicial/policía], explica al declarante algún aspecto del proceso.

14. Cuando quiere pedir una aclaración, utiliza la fórmula: «El intérprete tiene que pedir una aclaración»

16. Mientras está interpretando, se refiere a si mismo en tercera persona.

19. Cuando necesita intervenir, lo indica haciendo una señal con la mano.

20. Reproduce el tono del mensaje original (jocoso, nervioso, agresivo, así como balbuceos, insultos...).

Como se ha señalado antes, algunas malas prácticas están asociadas al poco conocimiento de los operadores judiciales sobre las características y el trabajo del intérprete judicial, como lo indicado en la pregunta número 10.

La pregunta número 20 se añadió a la primera versión, como se ha explicado en el capítulo 6, por indicación de alguno de los jueces entrevistados en el estudio cualitativo. Es interesante que los análisis cuantitativos hayan incluido esta pregunta entre las que mejor identifica a un buen intérprete. Para llevar a cabo una traducción fiel, han de mantenerse el registro y los elementos del mensaje original, sin alterar el tono y el estilo, las omisiones o repeticiones.

Los análisis empíricos de las respuestas a las preguntas, como los índices de dificultad y discriminación, tienen sentido desde un punto de vista teórico y profesional y sugieren posibilidades de uso aplicado del cuestionario INTER-Q en la acreditación de intérpretes y en su formación. Sin embargo, hay que señalar que, si se pretende utilizar el cuestionario INTER-Q para calificar o acreditar calidad, sería necesario realizar varias evaluaciones al mismo intérprete y en diferentes situaciones. Para ello habría que realizar nuevos estudios empíricos. 
La importancia de este trabajo radica en que es una aportación al desarrollo de los mecanismos establecidos por la ley para controlar la calidad de la actuación de los intérpretes en sede judicial. La calidad de la interpretación es imprescindible para garantizar los derechos de los procesados, tal y como reconocen la Declaración de Derechos Humanos de la Organización de Naciones Unidas tras la publicación precursora en Estados Unidos de la Court Interpreters Act de 1978. En el contexto europeo, la Directiva 2010/64/UE ha marcado un hito (Hertog, 2015a y b; OrtegaHerráez, 2016), por el establecimiento del derecho a la asistencia lingüística. Se trata de un derecho fundamental e irrenunciable.

Las entrevistas a los jueces que se han realizado en el estudio cualitativo de esta tesis reflejan que, por su parte, se asume y comprende la necesidad de la interpretación de calidad para garantizar la tutela judicial efectiva:

El acusado tiene derecho con base en el enjuiciamiento criminal a tener un traductor que le asista de cara a evitar cualquier tipo de indefensión y evitar cualquier problema.

Pero el derecho estará garantizado solo cuando el servicio de interpretación sea de calidad. Las disposiciones legales establecidas en la Directiva son claras: no solo debe existir el derecho a la interpretación, sino que esta ha de ser de calidad (art. 5). Sin la calidad en la interpretación y en la traducción, en realidad dichos derechos no existen. Por ello, la Directiva adopta una serie de mecanismos, que parten de los ya expuestos en el proyecto AEQUITAS (Hertog y Vanden Bosch, 2001), en el PDM (Comisión Europea, 2003) y en el Libro Verde (Comisión Europea, 2003), tal como se expone en el capítulo 3.4.2 $2^{106}$. Las medidas son las siguientes:

1. los Estados miembros han de velar para que el acusado pueda recurrir si la interpretación y la traducción sean de calidad (art. 2.5 y 3.5);

2. los Estados miembros han de garantizar que se lleve a cabo un control de la calidad de la interpretación y de la traducción (considerando 24);

3. se debe establecer un registro de traductores e intérpretes independientes debidamente cualificados (art. 5.2.);

4. se debe formar a los operadores judiciales (art. 6);

5. se debe grabar las interpretaciones (art. 7).

\footnotetext{
${ }^{106}$ En cualquier caso, las disposiciones de la Directiva suponen una reducción del grado de exigencia en cuanto a lo dispuesto previamente (Ortega-Herráez, 2016).
} 
Sin pretender ser representativo de la situación en la Unión Europea, este estudio indica que aún se está lejos de responder a estas prescripciones. Aunque no se ha tratado específicamente en la investigación los procedimientos de recursos, sí que se ha observado durante el trabajo de campo la irregular situación respecto a la grabación de las actuaciones, tanto en Italia como España, donde lo que se graba principalmente son las vistas orales. En España no se graban los interrogatorios en la policía ni las entrevistas en los despachos de instrucción o con el abogado. En Italia, se realiza solo la grabación de audio de los interrogatorios de policía y las vistas orales, pero no se graban las de las direttissime. En estos casos quedan las actas redactadas, que no recogen la versión original ni la traducción. Las consecuencias de estas carencias son importantes: si no existe una grabación en formato de audio o de vídeo, no es posible comprobar si la calidad del desempeño del intérprete ha sido suficiente.

En cuanto al control de la calidad de la interpretación judicial, la situación no es mucho más halagüeña en los países en los que se ha llevado a cabo el estudio. Sin embargo, esta tesis es una aportación sustancial para este objetivo. De hecho, las preguntas del cuestionario definitivo abarcan la mayor parte de las competencias descritas en la literatura (Blasco-Mayor, 2015, p. 277-278; Mikkelson 2017, p. 52-53), a saber:

- competencias lingüísticas: con una capacitación en las lenguas de trabajo: preguntas 3 y 4 ;

- competencia en las técnicas de interpretación, imprescindibles para la ejecución de la tarea: consecutiva, toma de notas, simultánea susurrada: preguntas 2, 9, 12, 13, 14, 16, 17,19 y 20 ;

- el conocimiento del contexto y la terminología judicial, además de los ordenamientos jurídicos de las lenguas de trabajo, de las estructuras, los procesos, los protocolos de actuación y las instituciones: preguntas 7, 8, 10 y 11;

- competencias profesionales en el aspecto deontológico y de buenas prácticas: preguntas $1,5,6,15,18$ y 21 .

Es interesante señalar que los jueces entrevistados en el estudio cualitativo de esta investigación mostraron desconocimiento sobre la cualificación necesaria para un intérprete (pensaban, por ejemplo, que era suficiente un conocimiento de ambas lenguas), sin embargo, sí que eran conscientes de la necesidad de competencias en términos jurídicos, formación deontológica y buenas prácticas y, sobre todo, neutralidad en su actuación. En algunos casos, este desconocimiento de las técnicas propias de la 
interpretación lleva a situaciones como recriminar o impedir que se realice interpretación simultánea en susurrada.

El punto 3 se refiere al registro de los traductores e intérpretes cualificados, un aspecto de gran complejidad. En general, y dependiendo de los países que se analicen, existe una gran disparidad entre la normativa, lo publicado en los manuales y guías profesionales (es decir, los postulados teóricos) y la realidad. Incluso en algunos países con una larga tradición en la interpretación judicial y con estándares asentados como en Estados Unidos, se producen grandes diferencias entre el nivel federal, que cuenta con intérpretes muy preparados y formados, y los niveles estatales o comarcales (NavarroHall, 2017; Blasco-Mayor, conversación personal). En el caso de los países donde se ha llevado a cabo el trabajo empírico, esto es, Italia y España, esta brecha es aún mayor, con personal capacitado que en muchos casos no trabaja en el entorno judicial pues se prefiere contratar a personal con menor formación, pero más barato.

Tras la revisión de la literatura y documentación oficial realizada durante esta investigación, se puede afirmar que, en la actualidad, no existe un registro único europeo de intérpretes y traductores judiciales capacitados y acreditados para trabajar ante la justicia en toda la Unión Europea. No existen ni siquiera registros y exámenes de acreditación en todos los países de la Unión. El haber dejado a cada Estado miembro la posibilidad de elegir la forma de establecimiento de dichos registros ha llevado a grandes disparidades e incongruencias (Giambruno, 2014; FRA, 2016), lo que provoca que no exista un reconocimiento mutuo ya que algunos países carecen de un registro único y reconocido, como sucede en Italia. El hecho mismo de que la Comisión no haya publicado ni presentado aún al Parlamento Europeo y al Consejo el informe relativo a las medidas adoptadas por cada Estado miembro para el cumplimiento de la Directiva dice mucho sobre la falta de interés por este tema por su parte, al igual que la respuesta del Defensor del pueblo europeo, ya expuesto en el capítulo 3.4.4.

En este sentido, es interesante comentar las declaraciones de los jueces durante las entrevistas, en las que se habla del registro de intérpretes con acreditación como «propuestas», pero son poco optimistas de que se realice en un plazo breve, debido a limitaciones presupuestarias.

No existen controles para el acceso de los profesionales a la interpretación, se presta el servicio, se privatiza el servicio. La privatización no implica necesariamente falta de profesionalidad de los intérpretes, pero puede ser un riesgo

Alguno de los entrevistados señaló incluso que debería haber un cuerpo oficial de intérpretes de la Administración. En cualquier caso, pese a ser evidente que la situación está lejos de ser ideal, al menos hemos encontrado en los jueces entrevistados 
conciencia y sensibilidad hacia el problema. Como afirmó uno de los participantes: «la concepción del intérprete no puede ser vista como una simple dotación de medios materiales cuando influye directamente en el derecho de defensa».

El cuarto punto se refiere a la formación de los operadores judiciales para el trabajo con intérpretes (art. 6). Tanto la revisión de la literatura como los datos cualitativos y cuantitativos de esta tesis apuntan a la conclusión de que muchos profesionales de la justicia no saben trabajar con intérpretes. Aunque en algunos países, como Estados Unidos son una excepción, (González et al., 2012; Mikkelson 2017), muchos de los Estados miembros de la Unión Europea todavía están relativamente en sus inicios en la normalización de la interpretación judicial, por lo que requieren de una mayor concienciación y formación para poder trabajar de manera eficiente con intérpretes. Tenemos ejemplos de normas de actuación y recomendaciones claras y precisas que indican cómo proceder en determinados contextos (como los Recommended National Standars for Working with Interpreters in Courts and Tribunal de Judicial Council on Cultural Diversity australiano, las Working with interpreters y Translators - Standard Operating Procedures de la Policía Metropolitana de Londres o el Position Paper - Interpreters of Legal Discours \& Working in Legal Settings de la Association of Visual Language Interpreters of Canada (AVLIC) o las Prevenciones para mejorar la traducción e Interpretación en procedimientos legales (Vieira Morante, 2012) y manuales (González et al., 2012, Blasco-Mayor, 2014, 2015, Mikkelson, 2017). Como apunta Navarro-Hall (2017), es posible recoger la experiencia y la labor ya realizada en muchos países y aplicarla al resto del mundo.

De la consulta de la literatura, de conversaciones y entrevistas con jueces y otros operadores implicados y de la observación directa de la investigadora, se puede deducir que, al menos en los países donde se ha llevado a cabo este estudio, se está lejos de saber trabajar con intérpretes. No existen normas de actuación, no se traducen todas las actuaciones, sino que se resume y además la velocidad del habla es muy alta (esto concuerda con lo observado por otros estudiosos (Orozco Jurotán, 2017; Bestué Salinas, 2018, Arumí Ribas, 2018) o lo denunciado por las asociaciones (Caciagli, 2017; APTIJ, 2018, Vieira Morante, 2017). En las respuestas al cuestionario INTER-Q, por ejemplo, la pregunta número 8 (Lee los derechos, acusación u otros documentos en lugar del policía/operador judicial), se contestó afirmativamente en el $30 \%$ de las situaciones observadas y la número 10 (Ya sea por iniciativa propia, o si se lo solicita el operador judicial/policía, explica al declarante algún aspecto del proceso) fue observada en el $61 \%$ de las ocasiones. Otras prácticas incorrectas, cómo dirigirse directamente al intérprete y referirse al procesado en tercera persona, se han observado y registrado con frecuencia en los cuadernos de campo. 
Se podría concluir que tanto en Italia como en España una gran parte de los profesionales de la administración de justicia no han recibido formación. Algunos jueces intuyen cuales deberían ser las características que posee un intérprete, pero desconocen la manera de trabajar con ellos, su posición y su papel. En las entrevistas realizadas, por ejemplo, había unanimidad en cuando a la necesidad de neutralidad del intérprete. Recordemos aquí alguna de las respuestas de las entrevistas:

Algunos le recriminan al acusado «iHay que ver lo que has hecho!», por lo que he tenido que advertirles «Oiga, No tiene usted que recriminar a nadie». Otros asumen el papel de abogado defensor y le indican al procesado que no actúe de esa u otra manera

Algunos jueces son conscientes de muchos matices que son parte de la interacción mediada por intérpretes, incluso sin conocer el idioma extranjero. Es interesante señalar que, en las respuestas al cuestionario INTER-Q, cuando se observaba la misma actuación de un intérprete por parte de fiscal, abogado, juez y la investigadora, la calificación de los jueces mostraba una tendencia a ser la más alta. Estos resultados apuntan hacia un sesgo por parte de los jueces a favor de los intérpretes, que debería ser estudiado con más detalle, pero de la que se puede avanzar una explicación.

Esta mayor tolerancia a errores y malas prácticas podría explicarse por el hecho de que en la mayoría de las ocasiones, en los tribunales observados tanto en Italia como en España, los operadores judiciales trabajan con intérpretes no profesionales, que desconocen sus funciones, no están sometidos a un código deontológico ni están regulados por reglamentos de buenas prácticas. Los bajos salarios y las precarias condiciones laborales pueden despertar simpatía por parte de los jueces y una cierta tolerancia a una actuación poco correcta desde el punto de vista profesional. Como señalaba uno de los entrevistados:

Yo creo que no somos tan conscientes de cuál es la cualificación necesaria y el grado de preparación, y por tanto los años de formación necesarios para desarrollar perfectamente el trabajo de intérprete judicial. Parece que en los otros espacios nadie se lo cuestiona. Por ejemplo, los intérpretes en organismos internacionales son personas cualificadísimas, con una formación extensísima [...] El cambio llega aquí, sobre todo en la justicia penal. La justicia penal es la justicia de la marginalidad, de la pobreza. Eso tampoco lo podemos olvidar cuando las instituciones responden en función de a qué sector de la sociedad está dirigido. $\mathrm{O}$ porque son sectores que no ejercen sus derechos porque no los conocen. Nadie se plantearía que en un procedimiento mercantil de decenas de millones de euros hubiera problemas por temas vinculados con cuestiones idiomáticas. 
Para terminar esta discusión, y como colofón de la creación y validación del cuestionario INTER-Q se realiza una propuesta para su uso en el contexto judicial:

1. Quién debe administrarlo y valorarlo: aunque hemos encontrado niveles de concordancia altos entre la investigadora y algunos operadores judiciales, el mejor evaluador de INTER-Q sería un intérprete judicial cualificado y experimentado, preferiblemente un coordinador del servicio de interpretación judicial vinculado a la administración o auditor externo.

2. Frecuencia de administración: sería deseable contar con varias evaluaciones del mismo intérprete en distintas situaciones. La puntuación total sería una combinación de los resultados de los cuestionarios. En lenguas con escasa demanda, obviamente, tendrían un requisito menor.

3. Conocimiento de los evaluados: los intérpretes deberían ser notificados de que su actuación puede ser evaluada en algún momento, pero no sería deseable que se avisara el día y situación concretos en los que se va a proceder a la cumplimentación del INTER-Q.

4. Cuántos evaluadores por situación: si se cuenta con un evaluador que cumple los requisitos descritos en el punto 1 , no sería necesario más de un evaluador para el mismo intérprete y situación.

5. Otro tipo de controles de calidad complementarios: en cumplimiento de lo establecido por la legislación revisada, las actuaciones deberían grabarse en audio o vídeo. Además de la garantía de los derechos que esto supondría, permitiría entrenar a los evaluadores y mejorar el conocimiento de las propiedades métricas de INTER-Q, concretamente su fiabilidad interevaluadores. 


\subsection{Conclusiones en castellano}

- La fiabilidad del cuestionario INTER-Q es satisfactoria en cuanto a la consistencia de los ítems. Sin embargo, para confirmar este resultado es necesario obtener más datos con una muestra que incluya un mayor número de intérpretes y más situaciones por cada intérprete.

- Se ha utilizado un carácter interdisciplinar que aúna estudios de derecho, marketing, psicometría y evaluación de la calidad en interpretación.

- El cuestionario ha demostrado ser objetivo, obteniéndose puntuaciones similares cuando la misma situación es evaluada por un intérprete con experiencia y por un operador judicial.

- Esto no significa en modo alguno que no sea imprescindible la formación de los operadores judiciales para trabajar con intérpretes, sino que el cuestionario proporciona datos fiables, con independencia de si se conoce o no la función del intérprete.

- Las evidencias sobre validez de las puntuaciones del INTER-Q son adecuadas, permitiendo discriminar entre actuaciones de intérpretes de diferente grado de calidad. Se ha encontrado congruencia entre la puntuación del cuestionario y descripciones cualitativas e impresiones en observaciones de campo.

- Líneas futuras: a partir de los tres niveles de dificultad y discriminación de las preguntas del cuestionario se puede crear un modelo de puntuación, de forma que no todas las preguntas se calificarían con 1 punto, sino que se ponderarían.

- Otro plan futuro es traducir INTER-Q a otras lenguas.

- Otra de las líneas de trabajo futuras es la redacción de un modelo de informe que describa e interprete los resultados numéricos mediante el uso de una aplicación informática.

- Este cuestionario no pretende ser una forma única de evaluación de la calidad, pero sí un elemento más que cuenta con una construcción siguiendo métodos científicos y que ha sido validado en este estudio.

- Para lograr un control de la calidad efectivo que se acerque al concepto de calidad total, es preciso poner en marcha otras medidas como la formación de los operadores, la acreditación de los intérpretes, la creación de un registro profesional y procesos de evaluación protocolizados.

- Para terminar, reproducimos de nuevo la reflexión de uno de los jueces entrevistados: "Yo creo que el problema fundamental es que seguramente los operadores no somos conscientes de lo que hay en juego, de los valores». 


\subsection{Conclusioni in italiano}

- L'affidabilità del questionario INTER-Q può essere ritenuta soddisfacente rispetto alla consistenza degli item. Per poterlo confermare occorrerebbero però più dati con un campione che comprenda un maggior numero di interpreti in situazioni diverse per ciascuno di essi.

È stato utilizzato un metodo interdisciplinare tenendo conto di nozioni di diritto, marketing, psicometría e valutazione della qualità in interpretazione.

- Il questionario si è rivelato obiettivo, con punteggi simili quando la stessa situazione è stata valutata da un interprete esperto e da un operatore della giustizia.

- Ciò non significa in alcun modo modo che la formazione degli operatori della giustizia non risulti indispensabile per lavorare con gli interpreti, bensì che il questionario fornisce dati affidabili, a prescindere dal fatto che il ruolo dell'interprete sia più o meno noto.

- Le prove della validità delle valutazioni dell'INTER-Q sono corrette, in quanto consentono di distinguere fra le prestazioni di interpreti con diversi livelli qualitativi. È stata riscontrata una certa rispondenza tra $\mathrm{i}$ punteggi del questionario e le descrizioni qualitative e le impressioni sulle osservazioni sul campo.

- Linee future: a partire dai tre livelli di difficoltà e dalla risposta e carattere significativo delle domande del questionario è possibile stabilire un modello di punteggio, in modo che non a tutte le domande venga assegnato 1 punto, ma che possano essere ponderate.

- Un ulteriore progetto è quello di tradurre INTER-Q ad altre lingue.

- Un'altra linea guida per il lavoro futuro consiste nella stesura di un modello di rapporto in grado di descrivere e interpretare $\mathrm{i}$ risultati numerici tramite l'utilizzo di un'applicazione informatica.

- Il presente questionario non intende porsi come l'unico metodo di valutazione della qualità, bensì come un elemento in più di una progettazione che preveda metodi scientifici, e che è stata convalidata in questo studio.

- Per riuscire a ottenere un effettivo controllo della qualità che si avvicini al concetto di qualità totale, occorre sviluppare altre misure come la formazione degli operatori, l'attestazione degli interpreti, la creazione di un albo professionale, nonché delle procedure di valutazione standardizzate.

- In conclusione, ci piace riportare nuovamente la riflessione di uno dei magistrati intervistati: «Penso che il problema fondamenale consista nel fatto che noi operatori non ci rendiamo conto di ciò che vi sia in gioco e dei relativi valori». 


\section{Referencias}

AA.VV. (2008). Report of Steering Group meeting. Lodon, 22-23 de mayo de 2008. $\begin{array}{llllll}\text { Recuperado el } & 31 & \text { marzo } & 2018 & \text { en }\end{array}$ http://www.buildingmutualtrust.com/assets/steering-group-report.pdf.

Abril Martí, M. I. (2006). La interpretación en los Servicios Públicos: Caracterización como género, contextualización y modelos de formación. Hacia unas bases para el diseño curricular. Universidad de Granada. Facultad de Traducción e Interpretación. Recuperado el 20 abril de 2016 en https://hera.ugr.es/tesisugr/16235320.pdf.

Abril Martí, M. I., Toledano Buendía, C., Ugarte Ballester, X., y Fernández Pérez, M. M. (2015). Introducción a la interpretación en contextos de violencia de género: conceptos básicos de interpretación, contextos, competencias y deontología. En C. Toledano Buendía y M. Del Pozo Triviño (Eds.), Interpretación en contextos de violencia de género (p. 48). Valencia: Tirant Humanidades.

Aguilera Ávila, L. (2015). Estrategias de prevención y autoayuda para intérpretes que trabajan en contextos de violencia de género. En C. Toledano Buendía y M. del Pozo Triviño (Eds.), Interpretación en contextos de violencia de género (pp. 272293). Valencia: Tirant Humanidades.

Alonso Araguás, I., Hernández Cebrián, N., y Izquierdo Valverde, L. (2018). Responsabilidad penal y código deontológico de los traductores e intérpretes judiciales. En M. J. Ariza Colmenarejo (Ed.), Traducción, interpretación e información para la tutela judicial efectiva en el proceso penal, 2018, ISBN 97884-9169-233-1, págs. 11-42 (pp. 11-42). Valencia: Tirant lo Blanc.

Alonso Tapia, J. (2004). Evaluación psicológica. Coordenadas, procesos y garantías. Madrid: Universidad Autónoma de Madrid.

Altman, J (1994). Error analysis in the teaching of simultaneous interpreting, en S. Lambert. y B. Moser Mercer (Eds). Bridging the gap. Empirical research in simultaneous Interpretation. (pp. 25-38). Amsterdam: John Benjamins.

Alvarez de Neyra Kappler, S. (2018). El derecho a la traducción y a la interpetación en la detención. En M. J. Ariza Colmenarejo (Ed.), Traducción, interpretación e información para la tutela judicial efectiva en el proceso penal (pp. 63-89). Valencia: Tirant lo Blanc.

Amato, A., y Mack, G. (2015a). The ImPLI project, pre-trial interpreting in Italy and the transposition of directive 2010/64/EU. TRANS, 19.1, 43-56. Recuperado el 20 mayo de 2018 en: http://www.trans.uma.es/Trans_19-1/Trans19-1_043-056.pdf.

Amodeo Perillo, D. (1989). La "Mediazione giuridica" dell'interprete alla Corte di Giustizia delle Comunitá Europee. PARALLELES, 11, 63-66.

Amodelo Perillo, D. (2017). Quality through preparation. En Third International Conference on Interpreting Quality, Granada 5-7 de octubre de 2017.

Anastasi, A., y Urbina, S. (1998). Tests Psicológicos (7th ed.). Mexico: Prentice Hall.

Anderson, S. R. (2010). How many languages Are There in the World? Linguistic Society of America. Washingtong. Recuperado el 31 de marzo de 2017 en https://www.linguisticsociety.org/sites/default/files/how-many-languages.pdf. 
Angelelli, C. V. (2004). Revisiting the Interpreter's Role: A Study of Conference, Court, and Medical Interpreters in Canada, Mexico, and the United States. Amsterdam: John Benjamins.

Arangüena Fanego, C. (2011). El derecho a la interpretación y a la traducción en los procesos penales. Comentario a la Directiva 2010/64/UE del Parlamento Europeo y del Consejo, de 20 de octubre de 2010). Revista General de Derecho Europeo, 24. Recuperado el 24 agosto de 2017 en https://www.iustel.com/v2/revistas/detalle_revista.asp?id_noticia $=410537 \& d=1$

Ariza Colmenarejo, M. J. (2018). Traducción, interpretación e información para la tutela judicial efectiva en el proceso penal. Valencia: Tirant lo Blanc.

Arumí Ribas, M. (2017). Análisis de un corpus oral de intepretaciones en los juzgados de lo penal de Barcelona. Creación de instrumentos de mejora de la calidad de la interpretación en los procesos penales. En Third International Conference on Interpreting Qualiti, Granada 5-7 de octubre de 2017.

Arumí Ribas, M. (2018). Interpretar para la justicia en España hoy. En M. J. Ariza Colmenarejo (Ed.), Traducción, interpretación e información para la tutela judicial efectiva en el proceso penal (pp. 43-62). Valencia: Tirant lo Blanc.

AVLIC. (2011). Interpreting legal discourse \& working in legal settings: an AVLIC position paper.

Baigorri Jalón, J. (2004). De Paris à Nuremberg: Naissance de l'interprétation de conférence, traduit de l'espagnol sous la direction de Clara Foz. Otawa: Les Presses de l'Universitè d'Ottawa.

Ballardini, E. (2002). The interpreter/translator in Italian criminal proceedings: quality of linguistics assistance for non Italian speaking foreigners. En G. Garzone, P. Mead, y M. Viezzi (Eds.), Perspectives on Interpreting (pp. 205-215). Bologna: CLUEB.

Ballardini, E. (2005). L'interprete nel processo penale italiano: profilo professionale e ipotesi di formazione. En M. Russo y G. Mack (Eds.), Interpretazione di trattativa. La mediazione linguistico-culturale nel contesto formativo $e$ professionale (pp. 167-182). Milano: Hoepli.

Ballardini, E. (2014). L'interprete traduttore nel procedimento penale italiano: quale formazione alla luce delle recenti direttive europee? En C. Falbo y M. Viezzi. Traduzione e Interpretazione per La Società e Le Istituzioni, (pp. 59-72).

Balogh, K., y Salaets, H. (2015). Chidren and Justice: overcoming language barriers. Cooperation in interpreter-mediated questioning of minors. (K. Balogh y $\mathrm{H}$. Salaets, Eds.). Cambridge - Antwerp - Portland: Intersetia. Recuperado el 30 marzo de 2018 en en https://www.arts.kuleuven.be/tolkwetenschap/projecten/co_minor_in_quest/childr en-and-justice.

Balogh, K., y Salaets, H. (2016). TraiLLD Training in Languages of Lesser Diffusion EU Criminal Justice Programme, JUST/2013/JPEN7AG74594. (K. Balogh y H. Salaets, Eds.). Leuven: Lannoo Campus. Recuperado el 30 marzo de 2018 en https://www.arts.kuleuven.be/tolkwetenschap/projecten/trailld/training-inlanguages-of-lesser-fiffusion.

Bancroft, M., Bendana, L., Bruggeman, J. y Feuerle, L. (2013). Interpreting in the Gray Zone: Where community and Legal Interpreting Intersect. En Translation \& 
Interperting .org. Recuperdo el 20 junio 2027 en http://www.transint.org/index.php/transint/article/view/238.

Bancroft, M. A., Bendana, L., Bruggeman, J., y Feuerle, L. (2013). Interpreting in the gray zone: Where community and legal interpreting intersect. Translation and Interpreting. Recuperado el 15 de marzo de 2017 en http://doi.org/10.12807/ti.105201.2013.a05.

Baraldi, C. (2014). An interactional perspective on interpreting as mediation. The interpreter and translator trainer, 8(3), 336-353.

Bargis, M. (2009). Inammissibile l'impugnazione redatta in lingua straniera: punti fermi e lacune di sistema dopo le pronuncie delle Sezioni unite. Cassazione Penale, 2016-2034.

Barik, H. C. (1971). A description of various tipes of omissions, additions and errors of translation encountered in Simultaneous Interpretation. Meta: Journal Des Traducteurs, 16(4), 199-210.

Barik, H. C. (1975). Simultaneous interpretation. Qualitative and linguistic data. Language and Speech, 18(3), 272-297.

Barrena, G. (2012). El Pacto internacional de Derechos Civiles y Políticos (Fascículo 3). México: Comisión Nacional de los Derechos Humanos. Recuperado el 30 marzo de 2018 en http://www.corteidh.or.cr/tablas/r29904.pdf.

Berk-Seligson, S. (1990). The Bilingual Courtroom: Court Interpreters in the Judicial Process. Chicago: Chicago University Press.

Berk-Seligson, S. (1999). The impact of court interpreting on the coerciveness of leading questions. Speech, Language and the Law, 6(1), 30-56.

Berk-Seligson, S. (2002). The Bilingual courtroom: court interpreters in the judicial process with a new chapter. Chicago : University of Chicago Press.

Bestué, C. (2018). Aproximación empírica a la labor del intérprete en los Tribunales de Justicia. En M. J. Ariza Colmenarejo (Ed.), Traducción, interpretación e información para la tutela judicial efectiva en el proceso penal (pp. 139-158). Valencia: Tirant lo Blanc.

Bestué Salinas, C., y Orozco Jurotán, M. (2017). Resultados del proyecto TIPp (Traducción e interpretación en los procesos penales) a cargo de los investigadores del proyecto TIPp. Barcelona. Recuperado el 15 de noviembre de 2017 en http://grupsderecerca.uab.cat/miras/es/node/245.

Blasco-Mayor, M. J. (2013). Quality of interpreting in criminal proceeding in Spain under Europea Directive 2010/64/EU. Cuadernos de ALDEEU, 25, 165-190. Recuperado el 30 de marzo de 2017 en http://repositori.uji.es/xmlui/bitstream/handle/10234/89189/58951.pdf.

Blasco-Mayor, M. J. (2015). La asistencia de intérprete en el procedimiento penal. Especial referencia a su papel en la vista oral. En M. L. Cuerda Arnau (Ed.), Vistas penales. Casos resueltos y guías e actuación en sala (pp. 267-286). Valencia: Tirant lo Blanc.

Blasco-Mayor, M.J. (2016). Con la venia, Señorías. El papel de jueces y abogados en la profesionalización de la figura del intérprete judicial. En De la Traducción Jurídica a la Jurilingüística, Universidad Pablo de Olavide. Sevilla, 27-28 octubre. 
Blasco-Mayor, M. J., y Del Pozo Triviño, M. (2015). Legal interpreting in Spain at a turning point. (M.J. Blasco Mayor y $\mathrm{M}$ del Pozo Triviño (Eds.), Legal interpreting at e turning point. MonTI 7. Special Issue.

Blasco-Mayor, M. J., del Pozo Triviño, M., Giambruno, C., Martin, A., Ortega Arjonilla, E., Rodriguez Ortega, N., y Valero Garcés, C. (2013). Informe sobre la transposición de la Directiva 2010/64/UE del Parlamento europeo y del Consejo relativa al derecho a interpretación y traducción en los procesos penales. $\begin{array}{llllll}\text { Recuperado el } & 30 & \text { marzo } & \end{array}$ file:///C:/Users/admin/Downloads/Informe_sobre_la_transposicion_de_la_Dir (2).pdf.

Blasco-Mayor, M. J. y y Martin, A. (2016). Legal Interpreting in the Future. A Blueprint for the Transposition of Directive 2010/64/EU in Spain. En Critical Link 8. Edimburgo, 28-30 de junio de 2016.

Bancroft, M., García Bayaert, S, Allen, KI, Carriero-Contreras, G y Socarras-Estrada. (2015) The Community Interpreter: An International Texbook. Culture y Language Press.

Borja Albi, A. (2012). La traducción jurídica: didáctica y aspectos textuales. Anabel Borja Albi. Aproximaciones a La Traducción. Recuperado el 15 de marzo de 2018 en https://cvc.cervantes.es/lengua/aproximaciones/borja.htm.

Borja Albi, A., y Del Pozo Triviño, M. (Ed.) (2015). La formación del personal de justicia para trabajar con intérpretes en el ámbito judicial en contextos de violencia de género. Valencia: Tirant lo Blanc.

Braun, S., Davitti, E., Dicerto, S., Balogh, K., Hertog, E., Vanden Bosch, Y. Corsellis Avidicus, A. (2016). AVIDICUS 3 PROJECT Assessment of Video-Mediated Interpreting in the Criminal Justice System - Assessing the Implementation Handbook of bilingual videoconferencing The use of Videoconferencing in Proceedings Conducted with the Assistance of an Interpreter. Guildord: University of Surrey. Recuperado el 30 abril de 2018 en http://www.videoconference-interpreting.net.

Braun, S., y Taylor, J. L. (2012). Video-mediated interpreting: an overview of current practice and research. En S. Braun y J. L. Taylor (Eds.), Videoconference and Remote Interpreting in Criminal Proceedings (pp. 27-58). Antwerp/Cambridge: Intersetia. Recuperado el 14 de abril de 2018 en http://wp.videoconferenceinterpreting.net/?page_id $=27$.

Bühler, H. (1986). Linguistic (semantic) and Extra-Linguistic (pragmatic) criteria for evaluation of conference interpretation and interpreters. Multilingua - Journal of Cross-Cultural and Interlanguage Communication, 5(4), 231-235.

Caciagli, F. (2014). Italia recepisce la direttiva 2010/64/UE, pro e contro. Recuperado el 15 de marzo de 2018 en http://www.interpretigiudiziari.org/italia-recepisce-ladirettiva-201064ue-pro-e-contro/.

Caciagli, F., Balleto, C., y Rivezzi, G. (2009). POSITION PAPER L'Interprete giudiziario e il traduttore giuridico. Recuperado el 20 de marzo de 2017 en http://www.aiti.org/system/files/utenti/position_paper_interprete_giudiziario_trad uttore_giuridico.pdf.

Camisón, C., Cruz, S., y González, T. (2006). Gestión de la calidad: conceptos, enfoques, modelos y sistemas. Madrid • México • Santafé de Bogotá • Buenos 
Aires • Caracas • Lima Montevideo • San Juan • San José • Santiago • São Paulo • White Plains: Pearson/Prentice Hall. Recuperado el 30 de marzo de 2018 en https://books.google.es/books/about/Gestión_de_la_calidad.html?id=95A3GQAA CAAJ\&redir_esc $=\mathrm{y}$.

Candi, M. (2014). Valutazione dei magistrati sugli interpreti e traduttori giudiziari. Indagine conoscitiva presso i tribunali e le procure dell'Emilia-Romagna. Tesi di laurea. Università degli Studi di Bologna.

Cartellieri, C. (1983). The Inescapable Dilemma: Quality and/or Quantity. Babel, 29(4), 209-213.

CEPEJ. (2017). Scheme for evaluating judicial system 2016-2018 cycle. Recuperado el 28 de marzo de 2018 en https://rm.coe.int $/ 16807477 \mathrm{f} \% \% 22$ /1\%22_Toc468089760.

Cheung, A. (2003). Does accent matter? The impact of accent in simultaneous Interpretation into Mandarian and Cantonese on perceived performance quality and listener satisfaction level en A. Collados Aís, M. Fernández Sanchez y D.Gile (Eds.) La evaluación de la calidad en interpretación. Investigación. (pp. 85-96). Granada: Comares.

Chesterman, Andrew (1993) From "is"to "ought": Laws, norms and strategies in translation studies. Target 5 (1), 1-20.

Chiavario, M. (1990). La riforma del processo penale: appunti sul nuovo codice. Torino: UTET.

Cokely, Dennis (1992b) The effects of lag time on interpreter errors. In D. Cokely (ed.) Sign Language Interpreters and Interpreting. Burtonsville, MD: Linstok Press, 39-69.

Colin, J., y Morris, R. (1996). Interpreters and the legal process. (W. Press, Ed.). Winchester.

Collados Aís, Á. (1998). La evaluación de la calidad en interpretación simultánea. La importancia de la comunicación no verbal. Granada: Comares.

Collados Aís, Á, Padras Macías, E. M., Stéveaux, E. y García Becerra (Eds) (2007). La evaluación de la calidad en interpretación simultánea: parámetros de incidencia. Granada: Comares.

Collados Aís, Á, Iglesias Fernández, E, Padras Macías, E.M. y Stéveaux, E (Eds.) (2011) Qualitätsparameter beim Simultandolmetschen, Interdisziplinäre Perspektiven. Tübingen Gunter Narr.

Collados Aís, Á., y García Becerra, O. (2015a). Quality. En H. Mikkelson y R. Jourdenais (Eds.), The Routledge Handbook of Inerpreting (pp. 368-383). Abindon y New York: Routledge.

Collados Aís, Á., y García Becerra, O. (2015b). Quality criteria. En Routledge Encyclopedia of Interpreting studies (pp. 337-338). London/New York: Routledge.

Collados Aís, Á., y Gile, D. (2002). La qualité de l'interprertation de conférence: une synthèse des travaux empiriques. Recent Research into Interpreting: New Methods, Concepts and Trends (in Chinese), 312-326. Recuperado el 23 de marzo de 
http://www.academia.edu/11689042/La_qualit\%C3\%A9_de_linterpr\%C3\%A9ta tion_de_conf $\% \mathrm{C} 3 \% \mathrm{~A} 9 \mathrm{rence}$ une_synth $\% \mathrm{C} 3 \% \mathrm{~A} 8 \mathrm{se}$ _des_travaux_empiriques.

Comisión de las Comunidades Europeas. (2003). Libro Verde de la Comisión. Garantías procesales para sospechosos e inculpados en procesos penales en la Unión Europea. Bruselas. 19 de febrero de 2013. Recuperado el 30 de junio de 2017 en https:/eur-lex.europa.eu/legalcontent/ES/TXT/PDF/?uri=CELEX:52003DC0075\&from=ES.

Comisión de las Comunidades Europeas. (2004). Propuesta de Decisión Marco del Consejo relativa a determinados derechos procesales en los procesos penales celebrados en la Unión Europea. Bruselas. Bruselas 28.4.2004. Recuperado el 30 de marzo de 2018 en https:/eur-lex.europa.eu/legalcontent/ES/TXT/PDF/?uri=CELEX:52004PC0328\&from=ES.

Comisión de las Comunidades Europeas. (2007). Tratado de la Unión Europea. Lisboa. Recuperado el 30 de marzo de 2018 en https://eur-lex.europa.eu/legalcontent/ES/TXT/?uri=LEGISSUM\%3Aai0033.

Comisión de las Comunidades Europeas. (2009). Propuesta de Decisión Marco del Consejo relativa al derecho a interpretación y traducción en los procesos penales. Bruselas, 8.7.2009. Recuperado el 30 de marzo de 2018 en https://eurlex.europa.eu/legal-content/ES/ALL/?uri=CELEX\%3A52009PC0338.

Comisión de las Comunidades Europeas. (2010) Directiva 2010/64/UE del Parlamento Europeo y del Consejo, de 20 de octubre de 2010, relativa al derecho a interpretación y a traducción en los procesos penales. DOUE de 28.10.2009. Recuperado el 30 de marzo de 2018 en https://eurlex.europa.eu/LexUriServ/LexUriServ.do?uri=OJ:L:2010:280:0001:0007:es:PDF.

Comisión de las Comunidades Europeas. (2012) Directiva 2012/13/UE del Parlamento Europea y del Consejo, de 22 de mayo de 2012, relativa al derecho a la información en los procesos penales. DOUE. 1.6.2012. Recuperado el 30 de marzo de 2018 en $\quad$ https://eurlex.europa.eu/LexUriServ/LexUriServ.do?uri=OJ:L:2012:142:0001:0010:es:PDF.

Comisión de las Comunidades Europeas. (2013) Directiva 2013/48/UE del Parlamento Europeo y del Consejo, de 22 de octubre de 2013, sobre el derecho a asistencia de letrado en los procesos penales y en los procedimientos relativos a la orden de detención europea, y sobre el derecho a que se informe a un tercero en el momento de la privación de libertad y a comunicarse con terceros y con autoridades consulares durante la privación de libertad. recuperado el 30 de marzo de 2018 en https:/eur-lex.europa.eu/legalcontent/ES/TXT/?uri=LEGISSUM\%3A2303_2.

Comisión de las Comunidades Europeas. (2016) Directiva 2016/343 del Parlamento Europeo y del Consejo, de 9 de marzo de 2016, por la que se refuerzan en el proceso penal determinados aspectos de la presunción de inocencia y el derecho a estar presente en el juicio. DOUE. 11.3.2016. Recuperado el 30 de marzo de 2018 en content/EN/TXT/?uri=CELEX\%3A32016L0343.

https://eur-lex.europa.eu/legal-

Comisión de las Comunidades Europeas (2016). Directiva 2016/800/UE del Parlamento Europeo y del Consejo, de 11 de mayo de 2016, relativa a las garantías procesales de los menores sospechosos o acusados en los procesos penales y a las personas 
buscadas en virtud de un procedimiento de orden europea de detención. DOUE. 21.5.2016. Recuperado el 30 de marzo de 2018 en https://eur-lex.europa.eu/legalcontent/ES/TXT/?uri=uriserv:OJ.L_.2016.132.01.0001.01.SPA.

Comisión de las Comunidades Europeas. (2016) Directiva 2016/1919/UE del Parlamento Europeo y del Consejo, de 26 de octubre de 2016, relativa a la asistencia jurídica gratuita a los sospechosos en los procesos penales y a las personas buscadas en virtud de un procedimiento de orden europea de detención: DOUE. 4.11.2016. Recuperado el 30 de marzo de 2018 en https://www.boe.es/doue/2016/297/L00001-00008.pdf.

Corsellis, A. (2008). Public Service Interpreting. The First Steps. Houndmills, UK: Palgrave Macmillan.

Corsellis, A. (2011). Seven EU projects. A journey toward a regulated language profession. En M. J. Blasco-Mayor y A. Jiménez Ivars (Eds.), Interpreting naturally. A Tribute to Brian Harris. Frankfurt am Main: Peter Lang.

Corsellis, A. (2015). Strategies for progress: Looking for firm ground. En M.J. Blasco Mayor y M. Del Pozo Tribiño (Eds). Legal Inaterpreting at a Tourning Point. Monti 7, 101-114.

Corsellis, A., Cambridge, J., Glegg, N., y Robson, S. (2007). Establishment, maintenance and development of a national register. En C. Wadensjö, B. Englund Dimitrova, y A.-L. Nilsson (Eds.), The Critical Link: Professionalisation of Interpreting in the Community (pp. 139-150). Amsterdam/Philadelphia.

Corsellis, A., y Fernández Leandro, F. (2001). Code of Ethics and Conduct and Guidelines to Good Practice. En E. Hertog (Ed.), Aequitas. Access to Justice across Language and Culture in the EU (p. 222). Departement Vertaler-Tolk, Lessius Hogeschool (2001). Recuperado el 30 de marzo de 2018 en http://eulita.eu/wp/wp-content/uploads/files/Aequitas_Acces to Justice across Language and Culture in the EU.pdf.

Cronbach, L. (1998). Fundamentos de los tests psicológicos. Aplicaciones a las organizaciones, la educación y la clínica. Madrid: Biblioteca Nueva.

Cronin, J. J., y Taylor, S. A. (1992). Measuring Service Quality: A Reexamination and Extension. Journal of Marketing, 56(3), 55-68.

De Boe, E. (2015). The influence of governmental policy on public service: Interpreting in the Netherlands. Translation and Interpreting, 7(3), 166-184.

De Luna Jiménez de Parga, P. (2009). El derecho a interpretación y a traducción en los procesos penales Noticias Jurídicas. Recuperado el 15 de marzo de 2018 en http://noticias.juridicas.com/conocimiento/articulos-doctrinales/10127-el-derechoa-interpretacion-y-a-traduccion-en-los-procesos-penales/.

De Luna Jiménez de Parga, P. (2010). Informe a la Directora General de Relaciones con la Administración de Justicia. Diario La Ley. No 7368, Sección Dictamen, 24 de Marzo de 2010, Año XXXI,. Recuperado el 30 de marzo de 2018 en http://guiasjuridicas.wolterskluwer.es/Content/Documento.aspx?params=H4sIAA AAAAAEAMtMSbF1jTAAASNzE1NztbLUouLM_DxbIwNDoJCRGUggM63SJ T85pLIg1TYtMac $4{ }^{\circ} \mathrm{FQB} 15 \mathrm{MMJNQAAAA}==\mathrm{WKE}$.

De Pedro Ricoy, R., Perez, I y Wilson, C. (Eds) (2009) Interpreting and translating in public service settings. Manchester: St. Jerome. 
Del Pozo Triviño, M. (2008). La interpretación en las notarías españolas. En L. Pegenaute, J. Decesaris, M. Tricás y E. Bernal (Eds). Actas del III Congreso Internacional de la Asociación Ibérica de Estudios de Traducción e Interpretación. La traducción del futuro: mediación lingüistca y cultural en el siglo XXI. Barcelona 22-24 de marzo de 2007. (pp. 491-504). Barcelona: PPU. Vol. n. ${ }^{\circ}$ 2,. Recuperado el 30 de marzo de 2018 en http://www.aieti.eu/wpcontent/uploads/AIETI_3_MPT_Interpretacion.pdf.

Del Pozo Triviño, M. (2009). La traducción de documentos marítimos. Clasificación de los principales géneros y marco de análisis. Sendebar, 20, 179-214. Recuperado $\begin{array}{llllll}\text { el } & 20 & \text { de } & \text { noviembre } & \text { de } & 2017\end{array}$ http://revistaseug.ugr.es/index.php/sendebar/article/viewFile/396/428.

Del Pozo Triviño, M., y Baigorri Jalón, J. (2015). El trabajo con intérpretes: aspectos comunes. En A. Borja Albi y M. Del Pozo Triviño (Eds.), La comunicación mediada por intérpretes en contextos de violencia de género (guía de buenas prácticas para trabajar con intérpretes) (pp. 17-49). Valencia: Tirant Humanidades.

Déjean le Féal, Karla (1990) Some thoughts on the evaluation of simultaneous interpretation. In D. Bowen y M. Bowen (eds) Interpreting: Yesterday, Today, and Tomorrow. Binghamton, NY: SUNY, 154-160.

Dirección General de Interpretación. Comisión Europea. (2006). Special Interest Group on Translation and Interpreting for Public Services. Final Report. Recuperado el 15 de marzo de 2018 en http://eulita.eu/wp/wp-content/uploads/files/SIGTIPS Final Report.pdf.

Di Donato (2004). L'interprete forense in Italia: un'indagine sull'esperienza professionale. Tesi di laurea. Università di Bologna.

Diriker, E. (2015). Conference Interpreting. En H. Mikkelson y R. Jourdenais (Eds.) (pp. 171-185). London/New York: Routledge.

Driesen, C. (1985). L'Interprétation dans les Cours Pénales. Université Sorbonne Nouvelle - Paris 3.

Edwards, A. B. (1995). The Practice of Court Interpreting. Amsterdam: John Benjamins Publishing Company.

Errico, E. (2016). Qualità in interpretazione, modalità interpretative e ruolo dell'interprete: alcune osservazioni. Estudios de Traducción, 6, 163-178. Recuperado el 30 de marzo de 2018 en http://dx.doi.org/10.5209/ESTR.53010.

Errico, E., y Morelli, M. (2015). Le sfide della qualità in interpretazione: ricerca, didattica e pratica professionale. Milán: F. Angeli.

Estañ Arellano, E. (2016). Estudio sobre la calidad de la interpretación en la Ciudad de la Justicia de Valencia. Trabajo de Fin de Grado. Universidad Jaume I Castellón.

EULITA. Code of Professional Ethics (2013). Recuperado el 30 de marzo de 2018 en https://eulita.eu/wp/wp-content/uploads/files/EULITA-code-London-e.pdf.

European Court of Human Rights (2018). Rules of Court. Strasbourg. Recuperado el 30 de marzo de 2018 en https://www.echr.coe.int/Documents/Rules_Court_ENG.pdf

Falbo, C. (2013). La comunicazione interlinguistica in ambito giuridico. Temi, problemi e prospettive di ricerca. Trieste: EUT Edizioni Università di Trieste. 
Falbo, C. (2014). I risultati emersi dal Progetto FRA 2011. Bisogni e bisogni formativi nella comunicazione interlinguistica con i servizi di polizia e nei procedimenti penali. in C. Falbo y M. Viezzi (Eds.) Traduzione e Interpretazione per la società e le istituzioni (pp. 19-40). Trieste. EUT.

Feria García, M. C. (1999). El traductor-intérprete en la Administración de Justicia. En M. C. Feria García (Ed.), Traducir para la Justicia (pp. 87-108). Granada: Comares.

Fernández Carrón, C. (2017). El Derecho a Interpretación y a Traducción en los Procesos Penales. Valencia: Tirant lo Blanc.

Ferro, M. A. (2012). Asseverazioni in Italia. La prassi dei Tribunali a confronto in un'indagine pilota. Pisa: Filodiritto editore. Recuperado el 30 de marzo de 2018 en

http://www.filodirittoeditore.com/index.php?route=product/product\&product_id= 70

Foulquié Rubio, A. I. (2002). La interpretación en la policía ¿un derecho o un privilegio? Traducción Como Mediación Entre Lenguas y ÇCulturas. Translation As a Mediation or How To Bridge Linguistic And Cultural Gaps, 93-98.

Foulquié-Rubio, A.-I., Vargas-Urpi, M., y Fernández Pérez, M. (2018). Panorama de la traducción y la interpretación en los servicios públicos españoles : una década de cambios, retos y oportunidades. Granada: Comares.

Fowler, Y. (2013). Business as usual? Prison video link in the multilingual courtroom. En C. Schäffner, K. Kredens, y Y. Fowler (Eds.), Interpreting in a Changing Lansdcape: Selected Papers from Critical Link 6 (pp. 225-248). Amsterdam: John Benjamins.

FRA - EUROPEAN UNION AGENCY FOR FUNDAMENTAL RIGHTS. (2016). Rigts of suspected and accused person accross the EU: translation, interpretation and information. Luxemburgo: Publications Office of the European Union.

Gaiba, F. (1999). Interpretation at the Nuremberg Trial. Interpreting, 4(1), 9-22.

Gallai, F. (2012). Legalising EU legal interpreters: a case for the NRPSI. The Interpreters' Newletter, 17, 139-156.

García Roca, F. J. (2007). La propuesta de Decisión Marco sobre derechos procesales en los procesos penales a la luz del Convenio Europeo de Derechos Humanos, el Tratado Constitucional para Europa y las tradiciones constitucionales comunes. En C. Arangüena Fanego y S. Allegrezza (Eds.), Garantías procesales en los procesos penales en la Unión Europea = Procedural safeguards in criminal proceedings throughout the European Union, 2007, ISBN 978-84-8406-765-8, págs. 47-66 (pp. 47-66). Valladolid: Lex Nova.

Garwood, C (2012). Court Interpreting in Italy. The daily violation fo a fundamental human right. The Interpreters'Newsletter 17, 173-189.

Garzone, G. (2002). Quality and norms in interpretation. En G. Garzone y M. Viezzi (Eds.), Interpreting in the 21st Century. Challenges and opportunities (pp. 107120).

Garzone, G. (2003). Reliability of quality criteria evaluation in survey research. En Á. Collados Aís, M. M. Fernández Pérez, y D. Gile (Eds.), La Evaluación de la Calidad en Interpretación: Investigación. (pp. 23-30). Granada: Comares. 
Gascón Nasarre, F. (2015). La percepción de los abogados de oficio de las actuaciones de intérpretes judiciales en el partido judicial de Zaragoza: análisis cualitativo de un grupo focal. Trabajo Fin de Master. Universidad Jaume I. Recuperado en http://hdl.handle.net/10234/152668.

Gascón Nasarre, F. (2017). La Directiva 2010/64/UE: antecedentes de hecho, fundamentos de Derecho y claroscuros de su transposición en España. Punto y Coma, marzo/abril(152), 19-31.

Gavioli, L. (2009). La mediazione linguistico-culturale come interazione. Introduzione al volume. En L. Gavioli (Ed.) (pp. 11-40). Perugia: Guerra Edizioni.

Gavioli, L., y Baraldi, C. (2012). Introduction: Understanding coordination in interpreter-mediated interaction. En C. Baraldi y L. Gavioli (Eds.), Coordinating Participation in Dialogue Interpreting (pp. 1-22). Amsterdam: John Benjamins. http://doi.org/10.1075/intp.13.2.03gav

Gavlovych, N. (2017). La calidad de los servicios de traducción e interpretación médico-sanitaria en el contexto de turismo de salud en el área de la Comunidad Valenciana. Universitat Jaume I. Trabajo Fin de Máster.

Gentile, A. (2015). Australia. En Routledge Encyclopedia of Interpreting studies (pp. 26-29). London/New York: Routledge.

Gerver, D. (1971). The effects of source language presentation rate on the performance of simultaneous interpreters. En F. Pöchhacker y M. Shlesinger (Eds.), The Interpreting Studies Reader (pp. 53-66). London/New York: Routledge.

Gerver, D. (1975). A psychological approach to simultaneous interpreting. Meta, 20(2), 119-128.

Gialuz, M. (2013). È scaduta la Direttiva sull'assitenza linguistica. Spunti per una trasposizione ritardata, ma (almeno) meditata. Diritto Penale Contemporaneo, 19. Recuperado el 30 de marzo de 2018 en en https://www.penalecontemporaneo.it/upload/1383234742GIALUZ 2013 a.pdf.

Gialuz, M. (2014). L'assistenza linguistica nella prassi giudiziaria e la difficile attuazionee della Direttiva 2010/64/UE en C. Falbo y M. Viezzi (Eds). Traduzione e Interpretazione per La Società e Le Istituzioni, (pp. 83-96).

Gialuz, M. (2018). L'assitenza linguistica nel processo penale. Un meta-diritto fondamentale tra paradigma europeo e prassi italiana. Milán: Wolters Kluwer.

Giambruno, C. (2014). Assessing Legal Interperter Quality Through Testing and Certification: The Qualitas Project. Alicante: Publicaciones de la Universidad de Alicante. Recuperado el 23 de marzo de 2018 en http://www.qualitasproject.eu/sites/qualitas-project.eu/files/the_qualitas_project_web.pdf.

Giangiacomo, B. (2015). La voce del magistrato. En M. Rudvin y C. Spinzi (Eds.), L'interprerte giuridico. Profilo professionale e metodologie di lavoro (pp. 21-28). Milano: Carocci Faber.

Gibbons, J. (2003). Forensic Linguistics: an Introduction to Language in the Language System. Melbourne: Black-well Publishing.

Gile, D. (1988). Le partage de l'attention et le 'modele d'effort' en interpretation simultanee. En The Interpreters' Newsletter 1/1988. 4-22.

Gile, D. (1990). Scientific research vs. personal theories in the investigation of interpretation. En L. Gran y C. Taylor (Eds.), Aspects of Applied and 
Experimental Research on Conference Interpretation (pp. 28-41). Udine: Campanotto.

Gile, D. (1991a). A communication-oriented analysis of quality in nonliterary translation and interpretation. En M. L. Larson (Ed.), Translation: Theory and Practice. Tension and Interdependence (pp. 188-200). Binghamton, NY: SUNY.

Gile, D. (1991b). Prise de notes et attention en début d'apprentissage de l'interprétation consécutive - une expérience - démonstration de sensibilisation. Meta, 36(2-3), 431-439.

Gile, Daniel (1994) Opening up in interpretation studies. In M. Snell-Hornby, F. Pöchhacker y K. Kaindl (eds) Translation Studies: An Interdiscipline. Selected Papers from the Translation Studies Congress, Vienna, 9-12 Sept. 1992. Amsterdam: John Benjamins, 149-158.

Gile, D. (1995). Basic Concepts and Models for Interpreter and Translator Training. Amsterdam: John Benjamins.

Gile, D. (2003). Quality assessment in conference interpreting: Methodological issues. En Á. Collados Aís, M. M. Fernández Sanchez, y D. Gile (Eds.), La evaluación de la calidad en interpretación. Investigación (pp. 109-123). Granada: Comares.

Goldsmith, J. (2016). TRAINAC Assessment, good practices and recommendations on the right to interpretation and translation, the right to information and the right of access to a lawyer in criminal proceedings. Council of Bars and Law Societies of Europe, European Lawyers Foundation. Recuperado el 23 de marzo de 2018 en http://europeanlawyersfoundation.eu/wp-content/uploads/2015/04/TRAINACstudy.pdf.

González, R. D., Vásquez, V. F., y Mikkelson, H. (1991). Fundamentals of court interpretation Theory, policy and practice. Durham, NC: Carolina Academic Press.

González, R. D., Vásquez, V. F., y Mikkelson, H. (2012). Fundamentals of court interpretation Theory, policy and practice Second edition. Durham, NC: Carolina Academic Press.

Grandinetti, G. (2013). Il ruolo e la protezione degli interpreti nei Tribunali Internazionali. Tesi di Laurea Magistrale. Università IULM de Milán.

Grbić, N. (2008). Constructing interpreting quality. Interpreting, 10(2), 232-257.

Grbić, N. (2015). Quality. En F. Pöchhacker (Ed.), Routledge Encyclopedia of Interpreting studies (pp. 333-336). London/New York: Routledge.

Grollmann, D., Martinsen, B., y Rasmussen, K. W. (2001). Professional Working Arrangements. En E. Hertog (Ed.), Aequitas. Access to Justice across Language and Culture in the EU (pp. 88-93). Antwerpen: Lessius Hoges-chool. Recuperado el 30 de marzo de 2018 en https://eulita.eu/wp/wpcontent/uploads/files/Aequitas_Acces to Justice across Language and Culture in the EU.pdf.

Guerrero Palomares, S. (2016). El derecho a la traducción e interpretación en el proceso penal. Análisis de los nuevos artículos 123 a 127 de la LECRIM, tras la reforma operada por la Ley Orgánica 5/2015, de 27 de abril. Revista de Derecho y Proceso Penal, 23-58. 
Hale, S. (2004). The Discourse of Court Interpreting: Discourse Practices of the Law, the Witness and the Interpreter. Amsterdam: John Benjamins.

Hale, S. B. (2007). Community Interpreting. New York: Palgrave and Macmillan.

Hale, S. (2008). Controversies over the role of the court interpreter. En C. Valero Garcés y A. Martin, (Eds.). Crossing borders in Community Interpreting. Defintions and dilemmas (pp. 99-122) Amsterdam: John Benjamins.

Hale, S. (2010). La interpretación comunitaria Traducción de Rosa Cobas Álvarez y Carmen Valero Garcés. Granada: Comares.

Hale, S. (2011). The positive side of community interpreting: An Australian case study. Interpreting, 13(2), 234-248.

Hale, S. (2013). Interpreting culture. Dealing with cross-cultural issues in court interpreting. Perspectives, 22(3), 321-331.

Hale, S. (2015). Approaching the Bench: Teaching Magistrates and Judges how to Work Effectively with Interpreters. en M:J. Blasco-Mayor y M. Del Pozo Triviño (Eds.) La interpretación judicial en España en un momento de cambio. MonTI. Monografias de Traducción e Interpretación. 2015, (7) 163-180.

Hale, S. (2017). The impact of court interpreting on evaluation of credibility. En VII Jornada de traducción e interpretación en los servicios públicos en Cataluña. Barcelona, julio de 2017.

Hale, S., y Napier, J. (2013). Research Methods in Interpreting. A Practical Resource. London/New Delhi/New York/Sydney: Bloomsbury.

Harris, B. (1990). Norms in interpetation. Target 2(1), 115-119.

Harris, B. (2003). The need for several Standards of Conference Interpretation. En Á. Collados Aís, M. Pradas Macías, C. Sánchez, y S. E (Eds.), La evaluación de la calidad en interpretación: docencia y profesión. Granada: Comares.

Hernández García, J. (2017). Conferencia en Jornada de Traducción e Interpretación en los Servicios Públicos en Cataluña. Barcelona, 7 de Julio de 2017.

Hertog, E. (Ed.). (2003). Aequalitas Equal Access to Justice across Language and Culture in the EU Grotius project 2001/GRP/015. Recuperado el 30 de marzo de $2018 \mathrm{en} \mathrm{http://www.eulita.eu/sites/default/files/Aequalitas.pdf.}$

Hertog, E. (2012). TRAFUT - Training for the Future Final report. Recuperado el 30 de marzo de 2018 en http://eulita.eu/wp/wp-content/uploads/files/TRAFUT - final report.pdf.

Hertog, E. (2015a). Directive 2010/64/EU of the European Parliament and of the Council on the Right to Interpretation and Translation in Criminal Proceedings: Transposition Strategies with regard to Interpretation and Translation. En M. J. Blasco-Mayor y M. Del Pozo Triviño (Eds.), MonTI. Monografías de Traduccióne Interpretación. (7). 73-100.

Hertog, E. (2015b). Legal Interpreting. En F. Pöchhacker (Ed.), The Routledge Enciclopedia of Interpreting (pp. 230-235). London/New York: Routledge.

Hertog, E., y Van Gucht, J. (2006). STATUS QUAESTIONIS Questionnaire on the Provisión of Legal Interpreting and Translation in the EU AGIS project $J L S / 2006 / A G I S / 052$. (E. Hertog y J. van Gucht, Eds.). Antwerp - Oxford Portland: Intersetia. 
Hertog, E., y Vanden Bosch, Y. (2001). Aequitas Access to Justice across Language and Culture in the EU. (E. Hertog, Ed.). Department Vertaler-Tolk. Lessius Hogeschool. Recuperado el 30 de marzo de 2018 en https://eulita.eu/wp/wpcontent/uploads/files/Aequitas_Acces to Justice across Language and Culture in the EU.pdf.

Ibrahim, N. (2007). Interpreting in Malaysia. Puentes, 7, 89-96.

Iglesias Buhígues, J. L. (2009). Derechos Fundamentales y Derecho Comunitario. En J. L. Calderón Cuadrado, M.P; Igliesias Buhígues (Ed.), El espacio europeo de libertad, seguridad y justicia: avances y derechos fundamentales en materia procesal (pp. 23-38). Navarra: Thomson Reuters.

Jiménez Ivars, A. (2004). La interpretación como prestación de servicios. Trans, 4, 135-143. Recuperado el 30 de marzo de 2018 en http://www.trans.uma.es/Trans_6/t6_1135-143_AJimenez.pdf.

Jimeno Bulnes, M. (2007a). Acceso a la interpretación y traducción gratuitas. En C. Arangüena Fanego y S. Allegrezza (Eds.), Garantías procesales en los procesos penales en la Unión Europea = Procedural safeguards in criminal proceedings throughout the European Union (pp. 155-183). Valladolid: Lex Nova.

Jimeno Bulnes, M. (2007b). El derecho a la interpretación y traducción gratuitas. La Ley. Revista Jurídica Española de Doctrina, Jurisprudencia y Bibliografía (Año XXVIII, número 6671), 1607-1623.

Jones, R. (1998). Conference Interpreting Explained. Manchester: St. Jerome.

Judicial Council on Cultural Diversity. (2017). Recommended National Standards for working with Interpreters in Courts and Tribunals. Recuperado el 30 de marzo de 2018 en https://www.naati.com.au/media/1680/mca04694-national-standardsweb-171025pdf.pdf.

Déjean Le Féal, K, Kurz, I, Mack, G, Cattaruzza, L, Nilson, A, NIska, H, Viezzi, M. (1997). Quality in Simultaneous Interpreting. Round table report. En Y. Gambier, D. Gile, y C. Taylor (Eds.), Conference Interpreting: Current Trends in Research (pp. 123-131). Amsterdam: John Benjamins.

Kadric, M. (2000). Interpreting in the Austrian Courtroom. En R. Roberts, S. E. Carr, D. Abraham, y A. Dufour (Eds.), The Critical Link 2. Interpreters in the Community (pp. 153-164). Amsterdam/Philadelphia: John Benjamins.

Kahane, E. (2001). Algunas consideraciones sobre calidad en interpretacion. Recuperado el 30 de marzo de 2018 en https://aiic.net/page/198/.

Kalina, S. (2002). Quality in interpreting and its prerequisites - a framework for a comprehensive view. En G. Garzone y M. Viezzi (Eds.), Interpreting in the 21st Century: Challenges and Opportunities. (pp. 121-130). Amsterdam: John Bejamins.

Kalina, S. (2005). Quality assurance for interpreting processes. Meta, 50(2), 769-784.

Kalina, S. (2015). Measure for Measure - Comparing Speeches with Their Interpreted Versions. En C. Zwischenberger y M. Behr (Eds.), Interpreting Quality: A Look Around and Ahead. Berlin: Frank y Timme GmbH.

Katschinka, L. (2016). An ISO Standard for Interpreting Services in Judicial Settings. En M. Bajčić y K. Dobrić Basaneže (Eds.), Towards the Professionalization of 
Legal Translators and Court Interpreters in the Eu (pp. 14-22). Cambridge, UK: Cambridge Scholar Publishing.

Katschinka, L. (2017). DIS 20228 - An ISO Standard on Legal Interprerting. EULITA Conference. Viena, 31 de marzo de 2017.

Keijzer-Lambooy, H., y Gasille, W. J. (2004). Aequilibrium Instruments for Lifting Language Barriers in Intercultural Legal Proceedings EU project $J A I / 2003 / A G I S / 048$. Recuperado el 30 de marzo de 2018 en http://www.eulita.eu/sites/default/files/Aequilibrium_Instruments for Lifting Language Barriers in Intercultural Legal Proceedings_0.pdf.

Kelly, D. (2000). La traducción y la interpretación en España hoy: perspectivas profesionales. Granada: Comares.

Kolb, W., y Pöchhacker, F. (2008). Interprereting in asylum appeal hearings: Roles and norms revisited. En D. Russel y S. Hale (Eds.), Interpreting in Legal Settings. Washington DC: Gallaudet University Press.

Kopczynski, A. (1994). Quality in Conference Interpreting: Some Pragmatic Problems. En S. Lambert y B. Moser-Mercer (Eds.), Bridging the Gap. Empirical Research in Simultaneous Interpretation (pp. 87-99). Amsterdam: John Bejamins.

Kotler, P., y Amstrong, G. (2004). Principles of Marketing. New Jersey: Pearson/Prentice Hall.

Kurtz, I. (1993). Conference interpretation: Expectations of different user groups. The Interpreters'Newsletter, 5, 13-21.

Kurz, I. (2001). Conference Interpreting: Quality in the Ears of the User. Meta, 46(2, juin), 394-409.

Kurz, I. (2003). Quality from User Perspective, en Collados Aís, Á, Padras Macías, y D. Gile (Eds). La evaluación de la calidad en interpretación simultánea: investigación (pp. 3-22). Granada ComaresM. Stéveaux y García Becerra (Eds) (2007). La evaluación de la calidad en interpretación simultánea: parámetros de incidencia. Granada: Comares.

Lee, J. (2009). Conflicting views on court interpreting examined through surveys of legal professional and court interpreters. Interpreting 11(1), 35-56.

Lee, J. (2015). Court Interpreting. En H. Mikkelson e Y. Jourdenais (Ed.s), The Routledge Handbook of Inerpreting (pp. 186-201). Abingdon, New York: Routledge.

Llewellyn-Jones, P., y Lee, R. G. (2014). Redefining the Role of the Community Interpreter: The concept of role-space. Lincoln, UK: SLI Press.

Mack, G., y Cattaruzza, L. (1995). User surveys in SI: A means of learning about quality and/or raising some reasonable doubt. En Topics in Interpreting Research (pp. 37-49). Turku: Centre for Translation and Interpreting.

Maffei, F. G. (2013). La mediazione linguistico-culturale in ambito giudiziario. En M. Rudvin y C. Spinzi (Eds.), Mediazione linguistica e interpretariato. Regolamentazione, problematiche presenti e prostettive future in ambito giuridico. Bologna: CLUEB.

Marrone, S. (1993). Quality: A Shared Objective. The Interpreters' Newletter, 5, 35-41. 
Martin, A. (2003). Investigación en interpretación social: Estado de la cuestión. En Panorama actual de la investigación en traducción e interpretación. Vol. I (pp. 431-446). Granada: Atrio.

Martin, A.; Ortega-Herráez, J.M. (2009). Court Interpreters'Self-Perfection: A Spanish case study. In De Pedro, R. et al. (eds.). Interpreting and Translating in Public Service Settings: Policy, Practice, Pedagogy. St Jerome.

Martin, A., y Ortega-Herráez, J. M. (2013). From invisble machines to visible experts: Views on interpreter role and performance during the Madrid train bomb trial. En C. Schäffner, K. Kredens, y Y. Fowler (Eds.), Interpreting in a Changing Landscape: Selected Papers from Critical Link 6 (pp. 101-114). Amsterdam: John Benjamins.

Martin, W. (2018). National Standards for Working with Interpreters in Australia's Courts and Tribunal Address by The Honourable Wayne Martin AC Chief Justice of Western Australia. 17 mayo 2018. David Malcolm Justice Center, Perth. Recuperado el 10 de marzo de 2018 en http://www.supremecourt.wa.gov.au/ files/Speeches/2018/National Standards for Working with Interpreters in Australias Courts and Tribunals by Martin CJ 17 May 2018.pdf.

Martínez-Gómez, A. (2011). La interpretación en instituciones penitenciaria. La relevancia del componente interpersonal en la calidad de la actuación de intérpretes naturales. Tesis doctoral. Universidad de Alicante.

Martínez-Gómez, A. (2015). Prison settings. En F. Pöchhacker (Ed.), Routledge Encyclopedia of Interpreting studies (p. 320). London/New York: Roudledge.

Marc Marschark, Greg Leigh, Patricia Sapere, Denis Burnham, Carol Convertino, Michael Stinson, Harry Knoors, Mathijs P. J. Vervloed, William Noble; Benefits of Sign Language Interpreting and Text Alternatives for Deaf Students' Classroom Learning, The Journal of Deaf Studies and Deaf Education, Volume 11, Issue 4, 1 October 2006, Pages 421-437, https://doi.org/10.1093/deafed/enl013.

Martin, A y Valero C. (Eds) (2008). Crossing Borders in Community Interpreting. Definitions an dilemmas. Amsterdam: John Benjamins.

Maryns, K. (2015). Asylum settins. En F. Pöchhacker (Ed.), The Routledge Enciclopedia of Interpreting (pp. 23-26). London/New York: Routledge.

Mason, I. (1999). Dialogue Interpreting. Special Issue The Translator Studies in Intercultural Communication.

Mason, I. (2001). Triadic Exchanges: Studies in Dialogue Interpreting. Manchester: St. Jerome.

Mason, I. (2009). Role, positioning and discourse in face-to-face interpreting. En R. de Pedro Ricoy, I. Perez, y C. Wilson (Eds.), Interpreting and Translating in Public Service Settings: Poliicy, Practice, Pedagogy (pp. 52-73).

Mason, I. (2014). Interpreting justice. Ethics, politics and language. The Translator, 20(3), 252-254.

Mason, I., y Steward, M. (2001). Interactional pragmatics, face and the dialogue interpreter. En Triadic Exchages: Studies in Dialogue Interpreting (pp. 51-70). Manchester: St. Jerome. 
Mason, M. (2008). Courtroom Interpreting. London Boulder New York Toronto, Plymourth, Uk: University Press of America.

Mayoral, R. (2000). Consideraciones sobre la profesión de traductor jurado. En D. A. Kelly (Ed.) (pp. 117-144). Granada: Comares.

Mayoral, R. (2003). Los cambios en la profesión dle traductor o intérprete jurado en España. En C. Valero Garcés (Ed.) (pp. 127-132). Granada: Comares.

Meak, L. (1990) Interprétation simultanée et congrès medical: Attentes et commentaires, The Interpreter's Newsletter 3: 8-13.

Messick, S. (1995). Validity of Psychological Assessment, 741-749.

Metropolitan Police of London. (2010). Working with Interpreters y Translators Standard Operating Procedure. London.

Meyer, J. P. (2014). Applied measurement with jMetrik. New York: Routledge.

Mikkelson, H. (1999). Relay interpreting: A viable solution for languages of limited diffusion? The Translator, 5(2), 361-380.

Mikkelson, H. (2000). Introduction to Court interpreting. St Jerome. UK y Northampton MA: St. Jerome.

Mikkelson, H. (2008). Evolving views of the court interpreter's role Between Scylla and Charybdis. En C. Valero Garcés y A. Martin (Eds.), Crossing Borders in Community Interpreting Definitions and dilemmas (pp. 81-99). Amsterdam/Philadelphia: John Benjamins.

Mikkelson, H. (2009). Interpreting is interpreting - or is it? En Presentation at the 1999 Annual conference of the National Association of Judiciary Interpreters abd Translators (NAJIT). Recuperado el 23 de marzo de 2018 en https://acebo.myshopify.com/pages/interpreting-is-interpreting-or-is-it

Mikkelson, H. (2017). Introduction to Court Interpreting. London/New York: Routledge.

Miranda González, F. J., Chamorro Mera, A., y Rubio Lacoba, S. (2007). Introdución a la gestión de la calidad. Madrid: Delta Publicaciones.

Mometti, F. (2013). Il diritto all'assistenza lingüística nel procedimento penale italiano. Indagine conoscitiva presso il Tribunale di Trieste. Tesi di laurea. Università degli Studi di Trieste.

Mometti, F. (2014). Il diritto all'assistenza lingüística dell'imputato straniero nel procedimento penale. Indagine conoscitiva presso il tribunale di Trieste. En C. Falbo y M. Viezzi (Eds.). Traduzione e interpretazione per la società e le instituzioni (pp. 41-58). Trieste: EUT.

Moreno-Luzón, M. D., González Cruz, T., y Peris Bonet, F. J. (2001). Gestión de la calidad y diseño de organizaciones: teoría y estudio de casos. Pearson Educación.

Morris, R. (1999). The gum syndrome: Predicaments in court interpreting. Forensic Linguistics, 6(1), 6-29.

Morris, R. (2007). Dies, Attard or Lockerbie? Enlightened and unerlightened judicial views of interpreters in English-speaking legal systems. En F. Pöchhacker, A.L. Jackobsen y I.M. Mess (Eds). Interpreting Studies and Beyond. A tribute to Miriam Shlesinger. (pp. 103-119). Copenhagen: Samfundsliteratur Press. 
Morris, R. (2015). Courtroom interpreting. En F. Pöchhacker (Ed.), Routhledge Encyclopedia of Interpreting Studies (pp. 91-93). London/New York: Routledge.

Moser-Mercer, B. (1996). Quality in interpreting: Some methodological issues. The Interpreters' Newletter, 7, 43-55.

Moser-Mercer, Barbara (2000) Simultaneous interpreting: Cognitive potential and limitations. Interpreting 5 (1), 83-94.

Moser, P. (1996). Expectations of users of conference interpretation. Interpreting, 1(2), $145-178$.

NAJIT. (1988). Code of ethic. Atlanta. Recuperado el 30 de marzo de 2018 en https://najit.org/wp-content/uploads/2016/09/NAJITCodeofEthicsFINAL.pdf.

Nartowska, K. (2017). The role of court interpreters in criminal proceedins in the context of the right to a fair trial. Case studies from a Polish and an Austrian court. En Legal Translation and Court Intepreting: Ethical Values, Quality, Competence Training (pp. 95-124). Berlin: Frank \& Timme GmbH.

Navarro-Hall, E. M. (2017). La interpretación judicial en Estados Unidos y su evolución hasta el momento actual. Conferencia plenaria de la Jornada sobre traducción e interpretación judicial, jurada y policial, viernes, 3 de noviembre, 2017. Madrid.

Ng, E. (2015). Teaching and Research on Legal Interpreting: A Hong Kong Perspective. MonTi: Monografías de Traducción e Interpretación, 2015(7), 243-270.

NHAES. (2006). Interpretation Guidelines. Recuperado el 20 marzo 2017 en https://www.cdc.gov/nchs/data/nhanes/nhanes_07_08/Interpretation_Guidelines.p df.

Niska, H. (2007). From helpers to professionals: Training of community interpreters in Sweden. En C. Wadensjö, B. Englund Dimitrova, y A.-L. Nilsson (Eds.), Professionalisation of interpreting in the community (pp. 297-310). Amsterdam: John Benjamins.

Olalla Fernandez, P. (2006). El intérprete en la investigación policial. Revista Española de LInguïstica Aplicada (RESLA). Monográfico Retros Del s. XXI Para La Lingüística Aplicada: Nuevo Mapa Lingüístico-Cultura de La Península Ibérica, 1, 239-248.

Orozco-Jurotán, M. (2017). Anotación textual de un gran corpus multilingüe de interpretación judicial a partir de grabaciones de procesos penales. Revista de Llengua $i$ Dret, Journal of Language and Law, 68, 33-56. http://doi.org/10.7202/1040470ar.

Ortega-Herráez, J. M. (2006). Análisis de la práctica de la interpretación judicial en España: el intérprete frente a su papel profesional. Universidad de Granada. http://hdl.handle.net/10481/977.

Ortega-Herráez, J. M. (2011). Interpretar para la justicia. (Comares, Ed.) (Comares). Granada.

Ortega-Herráez, J. M. (2013). "la intérprete no solo tradujo lo que le vino en gana, sino que respondió ella a las preguntas que los abogados le realizaban al testigo": requisitos de calidad en la subcontratación de servicios de interpretación judicial y policial en España. Sendebar, Vol 24, 24, 9-42. y http://revistaseug.ugr.es/public/sendebar/sendebar24_completo.pdf. 
Ortega-Herráez, J. M. (2016). En busca de la calidad: el nuevo marco normativo de la interpretación jurídica en la Unión Europea y España. De la Traducción Jurídica a la Jurilingüistica, Universidad Pablo de Olavide. Sevilla, 27-28 octubre.

Ortega-Herráez, J. M., y Blasco-Mayor, M. J. (2018). Radiografía (2006-2016) de la provisión de servicios lingüísticos en los servicios públicos de la Comunitat valenciana. En A. I. Foulquié Rubio, M. Fernández Pérez, y M. Vargas-Urpi (Eds.), Panorama de la traducción y la interpretación en los servicios públicos españoles: una década de cambios, retos y oportunidades. Granada: Comares.

Ortega-Herráez, J. M., y Foulquié Rubio, A. I. (2008). Interpreting in police settings in Spain: Service providers' and interpreters' perspectives. En C. Valero-Garcés y A. Martin (Eds.), Crossin borders in Community Interpreting. Definition and dilemmas (pp. 123-146). Amsterdam/Philadelphia: John Benjamins.

Ortega-Herráez, J. M., Plaza Vázquez, S., Fiol Wolfrum, C., y Hernández Cebrián, N. (2007). Los intérpretes judiciales ante la propuesta de Decisión Marco del Consejo sobre garantías procesales en los procesos penales de la Unión Europea. En Coral Arangüena Fanego (Ed.), Garantías procesales en los procesos penales en la Unión Europea = Procedural safeguards in criminal proceedings throughout the European Union, 2007, ISBN 978-84-8406-765-8, págs. 251-269 (pp. 251-269). Valladolid: Lex Nova.

Ortega-Herráez, J.M. y Martin, A. (2013) From invisible machines to visible experts: Views on interpreter role and performance during the Madrid train bomb trial. En C. Schaffner, K. Kredens y Y. Fowler (Eds). Interpreting in a Changing Landscape: The Selected Papers from Critical Link 6 (pp. 101-114). Amsterdam: John Benjamins.

Ortega Lorente, J.M. (2017). Derecho Procesal Europeo: Directivas de la UE y sus efectos en los procesos penales nacionales. Las Directivas 2010/64 y 2012/13 y su trasposición. Nuevos contenidos y garantías de los derechos de defensa. En especial a conocer la acusación, a entender y a ser entendido. Ponencia Valencia 16 de febrero de 2017.

Ortiz Soriano, A. (2015). La imparcialidad en la interpretación policial. MONTI: Monografias de Traducción e Interpretación, 207-241.

Osoro Pérez-Puchal, O. (2002). Funcionalismo e Interciones jurídicas. Método de traducción jurídica. En Puentes. Recuperado el 20 de marzo de 2018 en http://wpd.ugr.es/ greti/revista-puentes/pub2/07-articulo.pdf

Ozolins, U. (1998). Interpreting and Translating in Australia: Current Issues and International Comparisons. Melbourne: Language Australia.

Palomo del Arco, A. (2007). Derecho a la asistencia de intérprete y derecho a la traducción de documentos en el proceso penal: Primera aproximación a su contenido en el ordenamiento español. En C. Arangüena Fanego (Ed.), Garantías procesales en los procesos penales en la Unión Europea = Procedural safeguards in criminal proceedings throughout the European Union (pp. 185-211). Valladolid: Lex Nova.

Parasuraman, A., Berry, L. L., y Zeithaml, V. A. (1991). Refinement and Reassessment of the SERVQUAL Scale. Journal of Retailing, 67(4), 420-450.

Perdichizzi, F. (2017). Interpretazione giudiziaria: osservazione e analisi del Tribunale di Palermo. Tesi di Laurea Magistrale. Università degli Studi di Genova. 
Perez, I. (2015). Police settings. En F. Pöcchacker (Ed.), Routledge Encyclopedia of Interpreting studies (pp. 310-312). London/New York: Routledge.

Perez, Isabelle A. y Wilson, Christine W. L. (2007) Interpreter-mediated police interviews: Working as a professional team. In C. Wadensjö, B. Englund Dimitrova y A.-L. Nilsson (eds) The Critical Link 4: Professionalisation of Interpreting in the Community. Amsterdam: John Benjamins, 79-93.

Phelan, M. (2001). The interpreter's Resource. Clevedan Buffalo Toronto Sydney: Multilingual Matters LTD.

Pöchhacker, F. (1994). Quality assurance in simultaneous interpreting. En C. Dollerup y A. Lindegaard (Eds.), Teaching Translation and Interpreting: Aims, Insights, Visions. (pp. 233-242). Amsterdam: John Benjamins.

Pöchhacker, F. (2001). Quality assessment in conference and community interpreting. Meta, 46(2), 410-425.

Pöchhacker, F. (2002). Researching Interpreting quality: Models and methods. En G. Garzone y M. Viezzi. Interpreting in the $21^{\text {st }}$ Century. (pp. 96.196). Amsterdam: John Benjamins.

Pöchhacker, F. (2004). Introducing Interpreting Studies. London and New York: Routledge.

Pöchhacker, F. (2008). 2. Interpreting as mediation. En C. Valero Garcés y A. Martin (Eds.), Crossing borders in Community interpreting. Definitions and dilemmas (pp. 9-26). London/New York: John Benjamins.

Pöchhacker, F. (2012). Interpreting quality:Global professional standards? En V. Ren (Ed.), Interpreting in the Age of Globalization: Proceedings of the 8th National Conference and International Forum on Interpreting (pp. 305-318). Beijing: Foreign Language Teaching and Research Press.

Pöchhacker, F. (2016). Introducting Interpreting studies. Second edition. New York: Routledge.

Pöchhacker, F., y Zwischenberger, C. (2010). Survey on quality and role: conference interpreters' expectations and self-perceptions. Aiic.Net. Recuperado el 30 de marzo de 2018 en https://aiic.net/page/3405/survey-on-quality-and-roleconference-interpreters-expectations-and-self-perceptions/lang/1.

Pöchhacker, F., y Zwischenberger, C. (2015). Quality an Role in Conference Interpreting. Views from the East and South of Europe. En C Zwischenberger y M. Behr. Interpreting Quality: A Look Around and Ahead. (pp. 269-296). Berlin: Frank \& Timme.

Pöllabauer, S. (2007). Interpreting in asylum hearings. En C. Wandesjö (Ed.), The Critical Link 4: Professionalisation of interpreting in the community. Selected papers from the 4th International Conference on Interpreting in Legal, Health and Social Service Settings, Stockholm, Sweden, 20-23 May 2004 (pp. 39-52). Amsterdam/New York.

Pradas Macías, E. M. (2003). Repercusión del intraparámetro pausas silenciosas en la fluidez. Influencia en las expectativas y en la evaluación de la calidad en interpretación simultánea. Tesis doctoral. Universidad de Granada.

Pradas Macías, E. M. (2004). La Fluidez y sus pausas. Enfoque desde la interpretación de Conferencias. Granada: Comares. 
RITAP (2011). Libro Blanco de la traducción y la interpretación institucional. Madrid: Ministerio de Asuntos Exteriores y Cooperación. Recuperado el 30 de marzo de 2018 en http://www.ritap.es/wpcontent/uploads/2012/11/libro_blanco_traduccion_vfinal_es.pdf.

Reeves, C. A., y Bednar, D. A. (1994). Defining Quality: Alternatives and Implications. Academy of Management Review, 19(3), 419-445.

Roberts-Smith, L. (2009). 2. Forensic interpreting. En U. O. and L. andra Hale (Ed.), The Critical Link 5: Quality in interpreting - a shared responsibility (pp. 13-35). London/New York: John Bejamins.

Roberts, R. P. (1997). Community interpreting today and tomorrow. En S. E. Carr, R. P. Roberts, A. Dufour, y D. Steyn (Eds.), The Critical Link: Interpreters in the Community: Papers from the 1st international conference on interpreting in legal, health and social service settings, Geneva Park, Canada, 1-4 June 1995. Amsterdam.

Roy, C. (1993). The problem with definitions, descriptions and the role metaphors of interpreters. Journal of Inerpretation, 3, 127-154.

Roy, C. B. (2000). Interpreting as a discourse process. New York/Oxford: Oxford Univesity Press.

Rudvin, M. (2015). La deontologia professionale. En M. Rudvin y C. Spinzi (Eds.), L'interprete giuridico. Profilo professionale e metodologie di lavoro (pp. 153170). Torino: Carocci Faber.

Rudvin, M., y Tomassini, E. (2011). Interpreting in the Community and Workplace. A practical Teaching guide. Palgrave Macmillan.

Ruiz Rosendo, L. (2005). La evaluación de la calidad en interpretación desde la perspectiva del usuiario los congresos de medicina. Sendebar, 16, 219-250.

Ruiz Rosendo, L (2006). La interpretación de conferencias y la comunicación especializada en el ámbito de la medicina: estudio de la situación en España. Tesis doctoral. Universidad de Granada.

Russel, D., y Hale, S. (2008). Interpreting in Legal settings. (D. Russel y S. Hale, Eds.). Washington, D.C.: Gallaudet University Press.

Sammons, S. (1993). Challenges in Minority Langage programming in Canada's Eastern Artic: The Training of Aboriginal Language Interpretor-Translators. Meta: Journal Des Traducteurs, 38(1), 45.

Sandrelli, A. (2011). Gli interpreti presso il tribunale penale di Roma Un'indagine empirica. Recuperado el 11 de marzo de 2018, dehttp://www.intralinea.org/archive/article/Gli_interpreti_presso_il_tribunale_pen ale_di_Roma.

Sau, S. (2010). Le garanzie linguistiche nel processo penale. Padova: CEDAM.

Schweda Nicholson, N. (2010). Interpreting at the International Criminal Tribunal for the Former Yugoslavia (ICTY). Linguistics and Cultural Challenges. En H. Tonkin y M. Esposito Frank (Eds.), The Translator as Mediator of Cultures (pp. 37-52). London: John Benjamins.

Seleskovitch, D. (1978). Interpreting for International Conferences: Problems of Language and Communication. Washington: Pen \& Booth. 
Shlesinger, M. (1989). Extending the theory of translation to interpretation: Norms as a case in point. Target, 1(1), 111-115.

Shlesinger, M. (1997). Quality in simultaneous interpreting. En Y. Gambier, D. Gile, y C. Taylos (Eds.), Conference Interpreting: Current Trends in Research. Proceedings of the International Conference on Interpreting: What Do We Know and How? (pp. 123-131). Amsterdam: John Benjamins.

Shlesinger, M., y Pöchhacker, F. (2010). Doing justice to court interpreting. John Benjamins.

Shlesinger, Y. (2015). Vicarious trauma. En F. Pöchhacker (Ed.), Routledge Encyclopedia of Interpreting studies (p. 434). London/New York: Routledge.

Soler Caamaño, E. (2006) La calida den formación especializada en interpretación: Análisis de los criterios de evalaución de un jurado en un posgrado de interpretación de conferencia médica. Tesis doctoral. Barcelona: Universitat Pompeu Fabra.

Spinzi, C. (2013). La mediazione linguistico-culturale nelle istituzioni giuridiche italiane: il contesto demografico, etnico e detentivo. En M. Rudvin y C. Spinzi (Eds.), Mediazione linguistica e inerpertariato. Regolamentazione, problematiche presenti e prospettive future in ambito giuridico (pp. 17-40). Bologna: CLUEB.

Spinzi, C. (2015). La comunicazione interculturale e l'impatto dei fattori culturali sull'interprete giuridico. En M. Rudvin y C. Spinzi (Eds.), L'interprete giuridico. Profilo professionale e metodologie di lavoro (pp. 135-152). Torino: Carocci Faber.

Straniero Sergio, F. (2003). Norms and quality in media interpreting: The case of Formula One press-conferenc. The Interpreters' Newletter, 12, 135-174.

Summers, C. (2005). Interpreter shortage pose threat. BBC News. Recuperado en http://news.bbc.co.uk/2/hi/uk_news/4416984.stm

Takeda, K. (2010). Interpreting at the Tokyo War Crimes Tribunal. En M. Shlesinger y F. Pöchhacker (Eds.), Doing Justice to Court Interpreting. Amsterdam: John Benjamins.

Teas, R. K. (1993). Expectations, Performance, Evaluation and Consumer's Perceptions of Quality. Journal of Marketing, 57(4), 18-34.

Tipton, R., y Furmanek, O. (2016). Dialogue interpreting: a guide to interpreting in public services and the community. London: Routledge.

Tiselius, E. y Jenset. G. B. (2011).Process and Product in simultaneous interpreting: What the tell us about experience and expertice. En C. Alvstad, A. Hild y E. Tiselius (Eds). Methods and strategies of process research: Integrative appropaches in translation studies (pp. 269-280). Amsterdam: Jonh Benjamins.

Tomassini, E. (2012) Health-care Interpreting in Italy: Current needs and proposals to promote collaboration between universities and health care services. En The Interpreters' Newsletter n. 17/2012.

Tonioli, V. (2016) La mediazione interlinguistica ed interculturale in Italia: stato dell'arte, formazione professionale e implicazioni glottodidattiche. Tesis doctoral. Universidad Autónoma de Barcelona.

Townsley, B. (Ed). (2016). Understanding Justice an enquire into interpreting in civil justice and mediation. (B. Townsley, Ed.). London: Middlesex University, 
London. Recuperado el 30 de marzo de 2018 en http://www.understandingjusticeproject.com/assets/uj_report.pdf.

Turner, G. H. (2007). Professionalisation of interpreting with the community. Refining the model. En C. Wadensjo, B. D. Englund, y A.-L. Nilsson (Eds.), The Critical Link 4: Professionalisation of interpreting in the community. Selected papers from the 4th International Conference on Interpreting in Legal, Health and Social Service Settings, Stockholm, Sweden, 20-23 May 2004 (Vol. 70, pp. 181-192). Jonh Benjamins.

Valbuena González, F. (2008). Adaptación de la propuesta de deción marco sobre garantías procesales al ordenamiento jurídico español. En M. De Hoyos Sancho (Ed.), El proceso penal en la Unión Europea: Garantías esenciales = Criminal proceedings in the European Union: essential safeguards, 2008, ISBN 978-848406-881-5, págs. 170-179 (pp. 170-179). Valladolid: Lex Nova.

Valbuena González, F. (2011). Justicia versus seguridad en el espacio judicial europeo. En Orden de detención europea y garantías procesales (pp. 201-229).

Valero Garcés, C. (2003). Traducción e interpretación en los servicios públicos. Contextualización, actualidad y futuro. Granada: Comares.

Van Deemter, R., Maxwell-Hyslop, H., y Townsley, B. (2014). Principles of testing. En C. (Ed) Giambruno (Ed.), Assessing legal interpreters quality through testing and certification: the Qualitas project (pp. 27-39). Alicante: Publicaciones de la Universidad de Alicante.

Vanden Bosch, Y. (2003). Adequate legislation to 'Equal access to justice across language and culture. En E. Hertog (Ed.), Aequitas: equal access to justice across language and culture in the EU. Grotius project, 2001/GRP/015. Amberes: Lessius Hogeschool.

Vidal Fernandez, B. (2007). Derecho a una interpretación y traducción fidedigna y de calidad. Artículos 8 y 9 de la Propuesta de Decisión Marco sobre las garantías procesales de los inculpados en procesos penales en la Unión Europea. En C. Arangüena Fanego (Ed.), Garantías procesales en los procesos penales en la Unión Europea $=$ Procedural safeguards in criminal proceedings throughout the European Union (pp. 214-233). Valladolid: Lex Nova.

Vecchione, F. (2014). Tradurre per le istituzioni. Panoramica dei traduttori che operano nelle principali istituzioni governative italiane e della loro attivitá, en mediAzione 16. Recuperado el 13 de abril de 2017 en http://www.mediazioni.sitlec.unibo.it/images/stories/PDF_folder/documentpdf/2014/dossierTradSpec/08_vecchione.pdf.

Viezzi, M. (1996). Aspetti della qualità in interpretazione. Trieste: SERT 2, Università degli studi di Trieste.

Viezzi, M. (2003). Interpretation quality: a model. En Á. Collados Aís, M. Pradas Macías, C. Sánchez, y E. Stévaux (Eds.), La evaluación de la calidad en interpretación: docencia y profesión. Granada: Comares.

Viezzi, M. (2007). Aspetti della qualità nell'interpretazione. En C. Falbo, M. Russo e F. Straniero (Eds), Interpretazione simultanea e consecutiva. Problemi teorici e metodologie didattiche (pp. 140-157). Milan: Hoepli. 
Vigier Moreno, F. J. (2007). El nombramiento de traductores-intérpretes jurados de inglés mediante acreditación académica: descripción de la formación específica y del grado de satisfacción de los egresados.

Vuorikoski, A.-R. (1998). User responses to simultaneous interpreting. En Unity in Diversity? Current Trends in Translation Studies (pp. 184-197). Manchester: St. Jerome.

Wadensjö, C. (1992). Interpreting as Interaction. On Dialogue Interpreting in Immigration Hearings and Medical Encounters. Linköping: Linlöping University, Department of Communication Studies.

Wadensjö, C. (1993). Dialogue interpreting and shared knowledge. En Y. Gambier y J. Tommola (Eds.), Translation and Knowledge (pp. 101-113). Turku: Centre for Translation and Interpreting, University of Turku.

Wadensjö, C. (1995). Dialogue Interpreting and the Distribution of Responsability. Hernes. Journal of Linguistics, 14, 111-131. Recuperado el 31 marzo 2018 en https://pdfs.semanticscholar.org/b90a/e584afcd5b7a057a14c73f3aef0c18029c55.p df

Wadensjö, C. (1998). Interpreting as Interaction. London/New York: Longman.

Waliczek, B. (2003). Quality Interpreting in Poland: Facing Local Challenges. En Á. Collados Aís, M. M. Fernández Pérez, y D. Gile (Eds.), La evaluación de la calidad en interpretación: investigación. Granada: Comares.

Wallace, M. (2012). Predictors of successful performance on US. Consortium Court interpreter certification exams. Universidad de Alicante.

Wallace, M. (2015a). Current_Dilemmas_in_Court_Interpreting.pdf. En I. Gheorghiu y J. M. Ortega-Herráez (Eds.), Insight in interpreting. Status and Developments. Reflexiones sobre la interpretación. Presente y futuro. MonTI. Monografias de Traducción e Interpretación 5 (pp. 2017-236). Universidad de Alicante. Universidad Jaume I. Universidadd de Valencia.

Wallace, M. (2015b). Resisting Market Disorder and Ensuring Public Trust: Reimagining National Registers for Legal Interpreters in the United States and the European Union. MonTi: Monografías de Traducción e Interpretación, 7, 115140. Recuperado el 20 de marzo de 2018 en http://doi.org/10.6035/MonTI.2015.7.6.

Watanabe, T. (2009). Interpretation at the Tokio War Crimes Tribunal: An overview of Tojo's cross-examination. TTR: Traduction, Terminologie, Rédaction, 22(1), 5791.

Zwischenberger, C., y Behr, M. (2015). Interpreting Quality: A Look Around and Ahead. Frank \& Timme GmbH. 
REFERENCIAS 
MARTA SANCho Viamonte

Anexos 



\section{Anexo 1: Carta de acompañamiento a fase de pilotaje}

Estimado/a XXXX:

Mi nombre es Marta Sancho y estoy realizando la tesis doctoral bajo la supervisión de las Dras. María Jesús Blasco y Micaela Moro de la Universitat Jaume I.

Solicito unos minutos de su valioso tiempo para que rellene dos veces el mismo cuestionario: una vez pensando en una interpretación judicial que haya presenciado que considere óptima, y la otra pensando en una interpretación judicial que haya presenciado que considere pésima. Adjunto dos enlaces diferentes y un tercero para evaluar el cuestionario.

He añadido un espacio en blanco después de cada pregunta para que pueda escribir su opinión al respecto, si lo considera pertinente u oportuno. Si considera que falta algún aspecto o situación, por favor, indíquelo. Su opinión experta es muy importante para llevar a cabo la investigación, por lo que no tenga reparos en añadir lo que considere necesario.

Enlaces:

- Buena interpretación:

https://docs.google.com/forms/d/1zrBjcgy9mA6232GPlFzyNqqdMThHi3Ke33AYi_LC kR0/viewform

- Mala interpretación: https://docs.google.com/forms/d/1g2mavkMLqaPuDdnPqzEV9bUJFwZuOUMVrWIX kw5hms4/viewform

- Evaluación del cuestionario: https://docs.google.com/forms/d/1Y-u1V4kr8NbGYUsb1NOP8JPlveMnyIqFX2jgsYwOJo/viewform

En mi nombre y en el de las directoras de la investigación, le agradezco su amabilidad y le deseo un feliz periodo estival.

Atentamente,

Marta Sancho

Marta Sancho Viamonte

Traduttore interprete di conferenza, CTU Milano

Via Giovanni XXIII, 6

20018 Sedriano (MI)

Tel: +39.02 .90111238 cell: +348.8045122

Móvil: +34630931491

Email: marta@msancho.com; skype: msanchov 


\section{Anexo 2: INTER-Q en castellano}

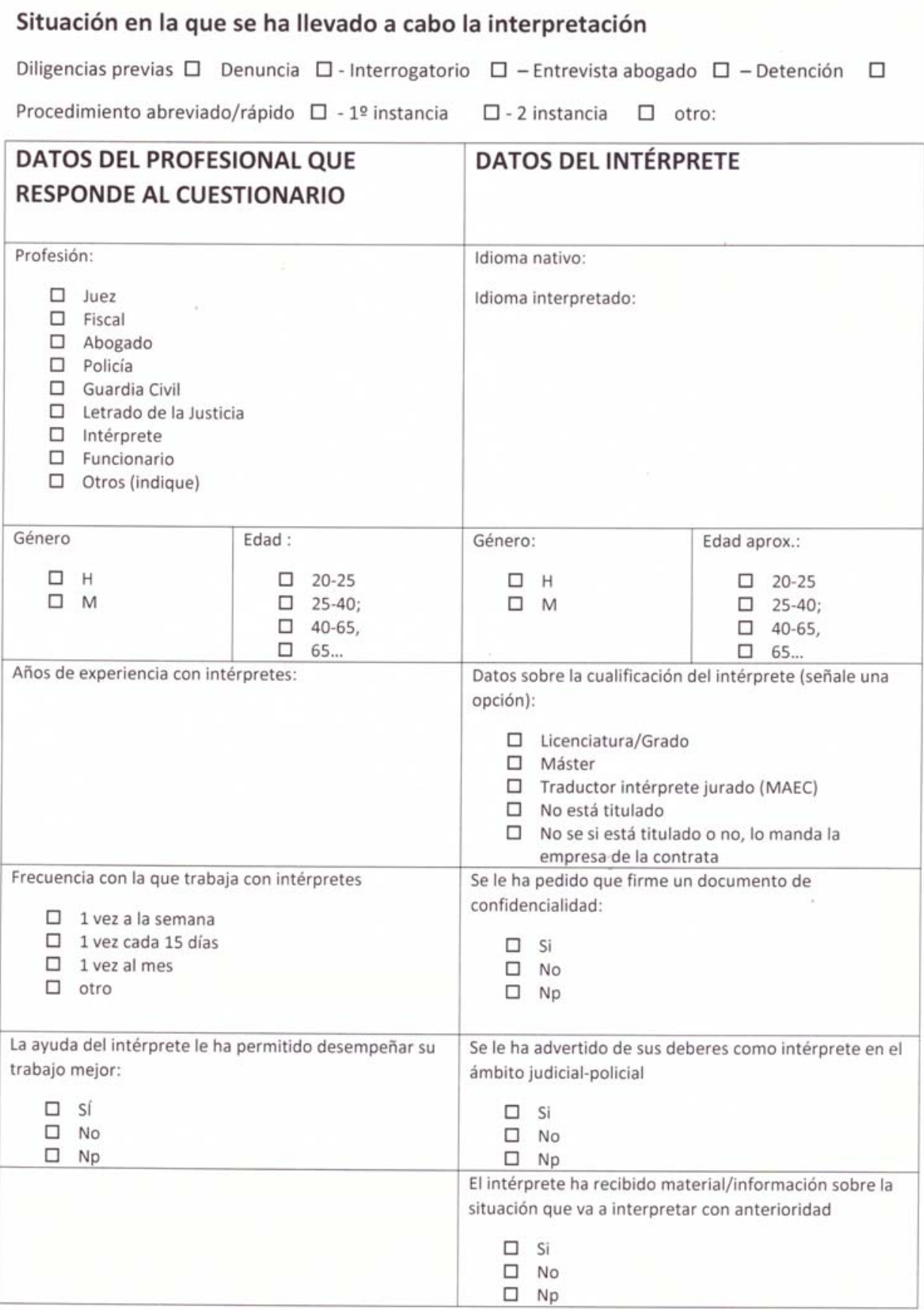


A continuación encontrará una serie de frases/preguntas sobre el rendimiento de la interpretación judicial a la que acaba de asistir.

Por favor, responda a todas las preguntas. En el caso de que tuviera duas sobre las dos alternativas, elija la que más se acerque a su sensación/opinión. Si no posee la información sobre la pregunta planteada, elija la

\begin{tabular}{|c|c|c|c|c|}
\hline & $\begin{array}{c}\text { INTER-Q } \\
\text { Evaluación de la calidad del rendimiento del intérprete jud }\end{array}$ & cial & & \\
\hline 1 & $\begin{array}{l}\text { Su aspecto fisico y presentación (vestido, aseo, peinado, comer } \\
\text { chicle...) es adecuado a la situación. }\end{array}$ & $\mathrm{SI}$ & NO & $\mathrm{np}$ \\
\hline 2 & Lleva libreta u otro dispositivo para tomar apuntes. & $\mathrm{SI}$ & NO & $\mathrm{np}$ \\
\hline 3 & $\begin{array}{l}\text { Se le comprende bien cuando habla en español, teniendo en cuenta } \\
\text { pronunciación, léxico y gramática. }\end{array}$ & SI & NO & $\mathrm{np}$ \\
\hline 4 & Su volumen de voz es adecuado a la sala y situación. & $\mathrm{SI}$ & NO & $\mathrm{np}$ \\
\hline 5 & $\begin{array}{l}\text { Mantiene la distancia interpersonal con el declarante, adecuada a la } \\
\text { situación. }\end{array}$ & SI & NO & $n p$ \\
\hline 6 & Conversa con el declarante al margen de la situación de interpretación. & SI & NO & $\mathrm{np}$ \\
\hline 7 & Utiliza correctamente los términos judiciales/policiales en español. & $\mathrm{SI}$ & NO & $\mathrm{np}$ \\
\hline 8 & $\begin{array}{l}\text { Lee los derechos, acusación u otros documentos, en lugar del } \\
\text { policia/operador judicial. }\end{array}$ & SI & NO & np \\
\hline 9 & $\begin{array}{l}\text { Utiliza la primera persona cuando está interpretando el discurso del } \\
\text { sujeto. }\end{array}$ & SI & NO & $\mathrm{np}$ \\
\hline 10 & $\begin{array}{l}\text { Ya sea por iniciativa propia, o si se lo solicita el operador } \\
\text { judicial/policia, explica al declarante algún aspecto del proceso. }\end{array}$ & SI & NO & $n p$ \\
\hline 11 & Se dirige de manera correcta a los operadores judiciales. & $\mathrm{SI}$ & NO & $\mathrm{np}$ \\
\hline 12 & Titubea o carraspea con frecuencia sin que el declarante lo haya hecho. & SI & NO & $\mathrm{np}$ \\
\hline 13 & $\begin{array}{l}\text { Se observa una clara desproporción en cuanto a la duración de lo que } \\
\text { dicen el declarante y el intérprete. }\end{array}$ & SI & NO & $\mathrm{np}$ \\
\hline 14 & $\begin{array}{l}\text { Cuando quiere pedir una aclaración, utiliza la fórmula «El intérprete } \\
\text { tiene que pedir una aclaración». }\end{array}$ & SI & NO & $\mathrm{np}$ \\
\hline 15 & Interrumpe con frecuencia a la persona a la que está interpretando. & $\mathrm{SI}$ & No & $\mathrm{np}$ \\
\hline 16 & Mientras está interpretando, se refiere a sí mismo en tercera persona. & $\mathrm{SI}$ & NO & $\mathrm{np}$ \\
\hline 17 & $\begin{array}{l}\text { En caso de tener que traducir un documento escrito de forma oral, lo } \\
\text { hace con fluidez, sin demoras excesivas. }\end{array}$ & $\mathrm{SI}$ & NO & $\mathrm{np}$ \\
\hline 18 & $\begin{array}{l}\text { Durante toda o la mayor parte de su actuación, mantiene una expresión } \\
\text { facial neutra (sin signos evidentes de amenaza hacia el declarante pero } \\
\text { tampoco de miedo o sumisión). }\end{array}$ & SI & NO & $\mathrm{np}$ \\
\hline 19 & Cuando necesita intervenir, lo indica haciendo una señal con la mano. & $\mathrm{SI}$ & NO & $\mathrm{np}$ \\
\hline 20 & $\begin{array}{l}\text { Reproduce el tono del mensaje original (jocoso, nervioso, agresivo así } \\
\text { como balbuceos, insultos...). }\end{array}$ & $\mathrm{SI}$ & NO & $\mathrm{np}$ \\
\hline 21 & $\begin{array}{l}\text { Muestra expresiones o gestos como risas, bostezos, asco, sorpresa, } \\
\text { empatia o apoyo hacia el declarante. }\end{array}$ & SI & NO & $\mathrm{np}$ \\
\hline
\end{tabular}

opción no pertinente (np). Muchas gracias. 



\section{Anexo 3: INTER-Q en italiano}

\section{Situazione in cui si è svolto l'interpretariato}

Denuncia

$\square$ - Interrogatorio

$\square$-Intervista avvocato

Data:

Riti semplificati -

$\square \quad 1^{\mathrm{a}}$ grado -

$\square \quad 2$ arado

$\square$-Convalida di arresto

\begin{tabular}{|c|c|c|c|}
\hline \multicolumn{2}{|c|}{$\begin{array}{l}\text { SCHEDA OPERATORE } \\
\text { RISPONDENTE ALLA } \\
\text { VALUTAZIONE }\end{array}$} & \multicolumn{2}{|c|}{ SCHEDA INTERPRETE } \\
\hline \multicolumn{2}{|c|}{$\begin{array}{l}\text { Professione: } \\
\quad \square \text { Giudice } \\
\square \text { Pubblico ministero } \\
\square \text { Avvocato } \\
\square \text { Polizia } \\
\square \text { Carabiniere } \\
\square \text { Cancelliere } \\
\square \text { Interprete } \\
\square \text { Altro (indicare) }\end{array}$} & \multicolumn{2}{|c|}{$\begin{array}{l}\text { Lingua madre: } \\
\text { Lingua interpretata: }\end{array}$} \\
\hline $\begin{array}{l}\square \text { Genere } \\
\square \mathrm{M} \\
\square \mathrm{F}\end{array}$ & 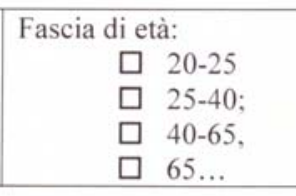 & $\begin{array}{l}\text { Genere: } \\
\qquad \begin{aligned} \square & \mathrm{M} \\
& \square \mathrm{F}\end{aligned}\end{array}$ & 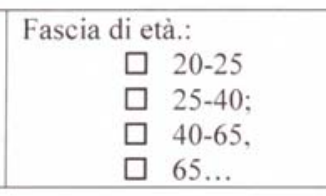 \\
\hline \multicolumn{2}{|c|}{$\begin{array}{l}\text { Anni di esperienza con interpreti: } \\
\begin{aligned} \square & 1-5 \\
\square & 5-10 \\
\square & 10-\ldots\end{aligned}\end{array}$} & \multicolumn{2}{|c|}{$\begin{array}{l}\text { Qualifica dell'interprete (indicare un'opzione): } \\
\square \text { Laurea Breve } \\
\square \text { Laurea Magistrale } \\
\square \text { CTU/perito Tribunale } \\
\square \text { Senza un titolo } \\
\square \text { Non lo so, è stato inviato da un'agenzia }\end{array}$} \\
\hline \multicolumn{2}{|c|}{$\begin{array}{l}\text { Frequenza di lavoro con interpreti } \\
\qquad \begin{array}{l}1 \text { volta a settimana } \\
\square \text { 1 volta ogni } 15 \text { giorni } \\
\square \text { 1 volta al mese } \\
\square \text { altro }\end{array}\end{array}$} & \multicolumn{2}{|c|}{ 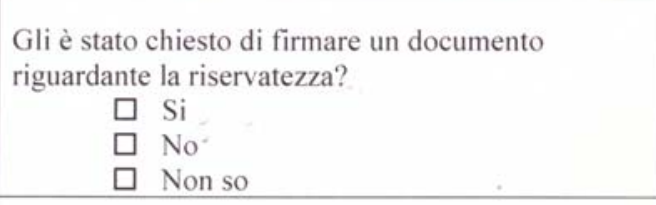 } \\
\hline \multicolumn{2}{|c|}{$\begin{array}{l}\text { L'intervento dell'interprete è stato positivo per lo } \\
\text { svolgimento del Suo lavoro }\end{array}$} & \multicolumn{2}{|c|}{$\begin{array}{l}\text { L'interprete è stato ammonito dei propri doveri } \\
\text { nell'ambito giudiziario/della polizia } \\
\quad \square \text { Si } \\
\square \text { No } \\
\square \text { Non so }\end{array}$} \\
\hline & & $\begin{array}{l}\text { È stato fornito } \\
\text { materiale/inforı } \\
\text { procedura } \\
\square \mathrm{Si} \\
\square \mathrm{No} \\
\square \mathrm{No}\end{array}$ & $\begin{array}{l}\text { te del } \\
\text { l'interprete riguardante la }\end{array}$ \\
\hline
\end{tabular}


Di seguito troverà una serie di frasi/domande sulla performance dell'interpretariato giudiziario/poliziale a cui ha appena assistito.

Per favore, risponda a tutte le domande. Qualora avesse dei dubbi sulle due alternative, scelga quella che più si avvicina alla sua sensazione/opinione. Se non dispone delle informazioni sulla domanda formulata, scelga l'opzione non pertinente (np).

\begin{tabular}{|c|c|c|c|c|}
\hline \multicolumn{5}{|c|}{$\begin{array}{c}\text { INTER-Q } \\
\text { Valutazione della qualità della performance dell'interprete giudiziario }\end{array}$} \\
\hline 1 & $\begin{array}{l}\text { L'aspetto fisico e la presentazione dell'interprete (abbigliamento, } \\
\text { pettinatura, aspetto generale, eventuale gomma da masticare) erano } \\
\text { adatte alle circostanze. }\end{array}$ & $\mathrm{SI}$ & NO & $\mathrm{np}$ \\
\hline 2 & Porta un quaderno o altro dispositivo per la presa di appunti. & $\mathrm{SI}$ & NO & $\mathrm{np}$ \\
\hline 3 & $\begin{array}{l}\text { Parla un italiano corretto e comprensibile, con riferimento a pronuncia, } \\
\text { lessico e grammatica. }\end{array}$ & SI & NO & np \\
\hline 4 & Il volume della voce è consono alla sala o circostanza. & $\mathrm{SI}$ & NO & $\mathrm{np}$ \\
\hline 5 & $\begin{array}{l}\text { Mantiene la giusta distanza interpersonale con il deponente in base alle } \\
\text { circostanze. }\end{array}$ & $\mathrm{SI}$ & NO & $\mathrm{np}$ \\
\hline 6 & Conversa con il deponente al di fuori della situazione interpretata. & $\mathrm{SI}$ & NO & $\mathrm{np}$ \\
\hline 7 & Utilizza correttamente la terminologia giuridico-giudiziaria in italiano. & $\mathrm{SI}$ & NO & $\mathrm{np}$ \\
\hline 8 & $\begin{array}{l}\text { Legge gli articoli di legge, i documenti sostituendosi al } \\
\text { personale/autorità giudiziaria. }\end{array}$ & $\mathrm{SI}$ & NO & $\mathrm{np}$ \\
\hline 9 & Ricorre alla prima persona mentre interpreta l'enunciato del deponente. & $\mathrm{SI}$ & NO & $\mathrm{np}$ \\
\hline 10 & $\begin{array}{l}\text { Sia di propria iniziativa, o perché gli viene richiesto dalla polizia o dal } \\
\text { personale/autorità giudiziaria, spiega al deponente alcuni aspetti del } \\
\text { procedimento. }\end{array}$ & SI & NO & $\mathrm{np}$ \\
\hline 11 & Si rivolge in modo corretto al personale e alle autorità giudiziaria. & $\mathrm{SI}$ & NO & $\mathrm{np}$ \\
\hline 12 & $\begin{array}{l}\text { Esita, si dimostra titubante o si schiarisce la voce frequentemente senza } \\
\text { che il deponente lo faccia. }\end{array}$ & $\mathrm{SI}$ & NO & $\mathrm{np}$ \\
\hline 13 & $\begin{array}{l}\text { Vi è una sproporzione manifesta riguardo la durata di quanto detto dal } \\
\text { deponente e l'interprete? }\end{array}$ & $\mathrm{SI}$ & NO & $\mathrm{np}$ \\
\hline 14 & $\begin{array}{l}\text { Quando vuole chiedere un chiarimento, ricorre alla formula } \\
\text { "l'interprete deve chiedere un chiarimento" }\end{array}$ & SI & NO & np \\
\hline 15 & Interrompe frequentemente la persona che sta interpretando. & $\mathrm{SI}$ & NO & $\mathrm{np}$ \\
\hline 16 & Mentre sta interpretando, si riferisce a sé stesso in terza persona. & SI & NO & $\mathrm{np}$ \\
\hline 17 & $\begin{array}{l}\text { Qualora debba tradurre oralmente un documento scritto, lo fa in } \\
\text { maniera fluida, senza troppe esitazioni. }\end{array}$ & $\mathrm{SI}$ & NO & np \\
\hline 18 & $\begin{array}{l}\text { Durante tutta o la maggior parte della prestazione, mantiene una } \\
\text { mimica facciale neutra (senza segni evidenti di minaccia o } \\
\text { intimidazioni nei confronti del deponente ma neanche di paura o } \\
\text { sottomissione. }\end{array}$ & SI & NO & $\mathrm{np}$ \\
\hline 19 & $\begin{array}{l}\text { Quando deve intervenire, attira l'attenzione con un cenno della mano } \\
\text { per chiedere la parola. }\end{array}$ & $\mathrm{SI}$ & NO & $\mathrm{np}$ \\
\hline 20 & $\begin{array}{l}\text { Riproduce il tono del messaggio originale (scherzoso, nervoso, } \\
\text { aggressivo e anche i balbettamenti, insulti...). }\end{array}$ & SI & NO & np \\
\hline 21 & $\begin{array}{l}\text { Lascia trasparire con gesti o segni (risate, sbadigli, ecc.) ripugnanza, } \\
\text { sorpresa, empatia o sostegno verso il deponente. }\end{array}$ & SI & NO & $\mathrm{np}$ \\
\hline
\end{tabular}




\section{Anexo 4: Carta al Presidente del Tribunal de Génova con firma de autorización}

La sottoscritta, Marta Sancito Viamonte. nata Burgos (Spagna) il 12.11.1965, traduttrice ed interprete, iscritta all'Albo dei Consulenti Tecnici del Giudice di Milano presso il tribunale di Milano (numero 9554 e. per il settore penale, numero 966). nonché insegnante/libera professionista di traduzione e interpretazione presso la Scuola interpreti SSML Carlo Bo di Milano e alla facoltà di lingue e culture straniere presso l'Università degli Studi di Genova, attualmente

Svolge il dottorato di ricerca presso l'Università Jaume I di Castellón (Spagna), all'interno del Programma di Dottorato in Lingue applicale, Letteratura e Traduzione sotto la direzione delle Dolt.sse Maria Jesus Blasco Mayor e Micaela Moro Ipola.

Alla scrivente è stato assegnato il compilo di svolgere una tesi sul tema: la valutazione della performance degli interpreti in ambiente giudiziario alla luce della Direttiva 2010/64/UE relativa al diritto dell'Imputato all'interpretazione e alla traduzione nei procedimenti penali e la relativa attuazione tramite il Decreto legislativo, $04 / 03 / 2014 n^{*} 32$.

L'opera della studiosa consiste, quindi, nel dover confrontare la performance degli interpreti in alcuni paesi dell'Unione Europea tramite la redazione di questionari da somministrare ai diversi operatori nell'ambito del procedimento giudiziario e, segnatamente, giudici, cancellieri, procuratori, agenti di polizia ed interpreti.

I paesi prescelti per l'indagine sono: Italia. Spagna e Regno Unito.

Per quanto innanzi, la scrivente, rispettosamente, si pregia di inoltrare richiesta affinché Ella, nella Sua qualità, Voglia autorizzarla a contattare Cancellieri, Giudici. Procuratori ed Awocati che operano presso il Tribunale di Genova al fine di condurre lo studio come meglio sopra descritto.

Preciso sin da ora che l'attività della scrivente verrebbe ad essere espletata, per quanto attiene alla fase di raccolta dati, presenziando alle udienze e solo nella fase finale della ricerca, somministrando un questionario a tutte le parli implicate in un procedimento successivamente allo svolgimento di una interpretazione reale.

L'attività di elaborazione dei dati raccolti e di sintesi verrà poi espletata dalla scrivente in una fase successiva che non coinvolgerà le unità statistiche interpellate.

Lo scopo ultimo dell'indagine è la ricerca scientifica in interpretazione.

Resto in attesa di cortese riscontro, instando sin da ora, laddove la presente richiesta venisse considerata favorevolmente, affinchè venga designato un Ufficio $\mathrm{e} / \mathrm{o}$ un nominativo al quale presentare nel dettaglio it progetto e concordare gli interventi in udienza.

Allego alla presente lettera di presentazione rilasciala dalle mie direttrici di lesi, le dottoresse Maria Jesus Blasco e Micaela Moro e della Dottoressa Mara Morelli dell'Università di Genova, oltre al curriculum vinte della scriverne.

Con osservanza.

Marta Sancito Viamonte

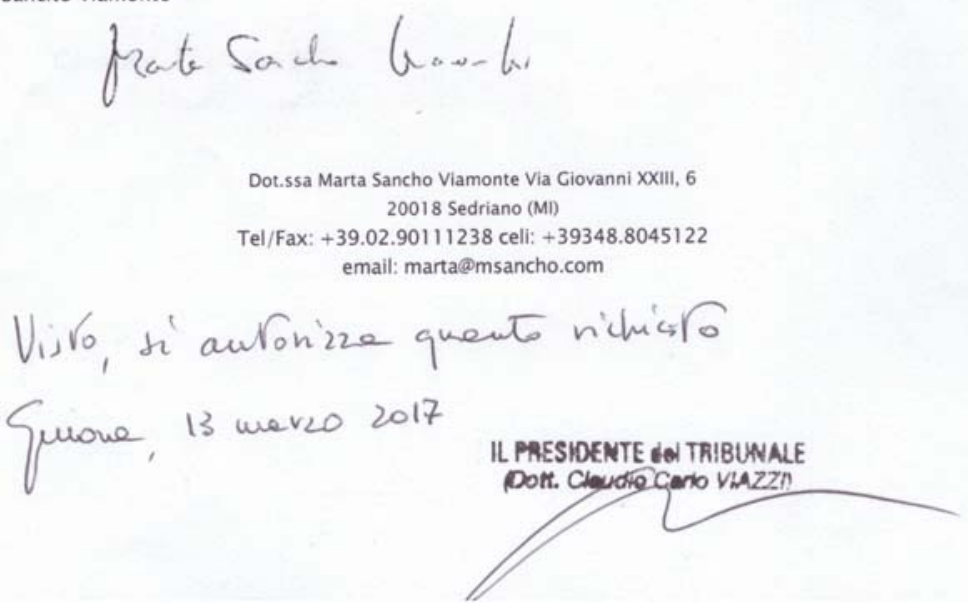




\section{Anexo 5: Carta al Juez Decano de la Ciudad de la Justicia de Valencia.}
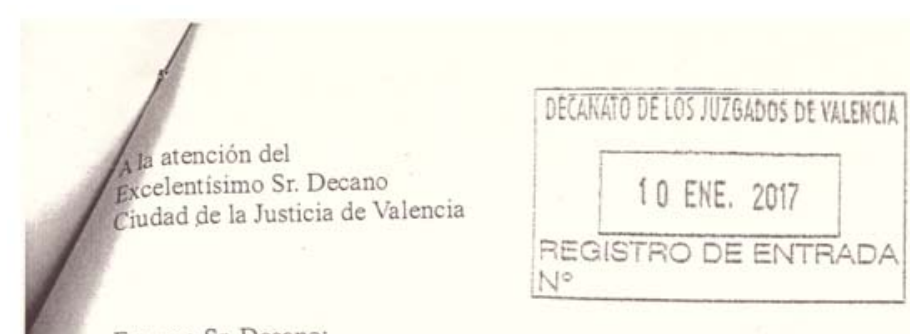

Valencia, a 10 de enero de 2017

Exc.mo Sr. Decano:

La solicitante, Marta Sancho Viamonte, es traductora e intérprete jurada en Italia en el Tribunal de Milán, además de enseñar traducción e interpretación en la Scuola Interpreti SSML Carlo Bo/Università IULM de Milán.

Paralelamente lleva a cabo los estudios de Doctorado en la Universidad Jaume I de Castellón, con una tesis sobre la evaluación del desempeño de los intérpretes en el entorno judicial y policial en relación con la directiva 2010/64/UE relativa al derecho a interpretación y a traducción en los procesos penales y su transposición a las leyes de los distintos paises.

El objetivo del estudio es comparar el desempeño de los intérpretes en algunos paises de la Unión Europea mediante cuestionarios a operadores judiciales y policias. Los países que se tomarán en consideración durante la investigación serán en primer lugar Italia y España y eventualmente también Reino Un la Universidad Jaume I de Castellón, en el programa de Doctorado en Lenguas Aplicadas, Literatura y Traducción (RD 99/2011), bajo la dirección de las Dras. Maria Jesús Blasco Mayor y Micaela Moro Ipola.

A tal propósito, desearia solicitar el permiso y Su ayuda para poder distribuir el cuestionario, en formato electrónico o en papel, entre los operadores judiciales (jueces, fiscales y abogados) tras una interpretación real en un juicio o vista. El cuestionario es totalmente anónimo.

El fin último del estudio es la investigación cientifica para la realización de la tesis doctoral.

Adjunto a la presente curriculum vitae.

Quedo a la espera de recibir su amable respuesta y aprovecho la ocasión para saludarle muy atentamente,

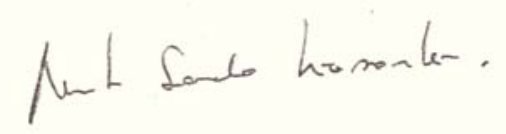

Marta Sancho Viamonte

Traductora intérprete de conferencia, perito del tribunal de Milán

Via Giovanni XXIII, 6

20018 Sedriano (MI)

Tel: +39.02 .90111238 móvil +39348.8045122

Móvil España: +34630931491

email: marta(a) msancho.com skype: msanchov 


\section{Anexo 6: Autorización a realizar las prácticas en la ciudad de la Justicia de Valencia}

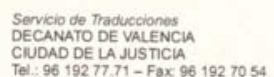

A quien corresponda,

Habiéndosele concedido las prácticas formativas en el departamento de traducción de la Ciudad de la Justicia con la que a partir del dia de hoy será su supervisora, Ma Rosa Sena Blanco, Traductora-Intérprete del Servicio de Traducciones,

Solicito se autorice la entrada a esta entidad a Dña. MARTA SANCHO VIAMONTE con DNI 13130354E

Por lo expuesto solicito le sea concedido el acceso solicitado.

Atentamente

En Valencia, a 9 de enero de 2017

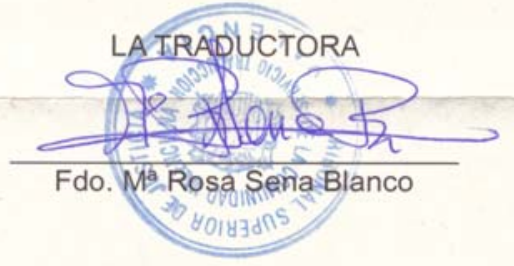




\section{Anexo 7: Nota del Juez Decano de la CJV}

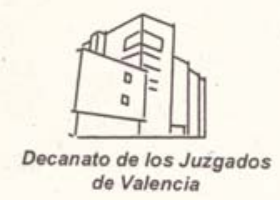

Secretaria Decano

Telf. 961.92 .70 .30

\section{NOTA DE SERVICIO}

ILMO/A. SR/A. MAGISTRADOJUEZ DEL JUZGADO DE INSTRUCCIÓN NN VEINTE.-

Adjunto a la presente, copia del escrito presentado en esta Secretaria por Dña. Marta Sancho Viamonte, y conforme a lo Acordado en el expediente gubernativo 22/2017, en la medida de lo posible presten su colaboración, en la encuesta que la misma les hará entrega personalmente, para realizar su tesis doctoral.

Valencia, a 11 de Enero de 2017.

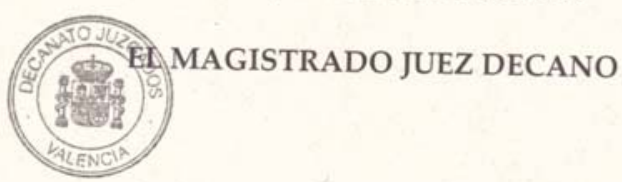




\section{Anexo 8: Permisos denegados}

\section{CARABINIERI}

Comando Generale dell'Arma dei Carabinieri

S.M. - Vfficio Cerimoniale

II Capo Vfficio

Roma, 9 dicembre 2016

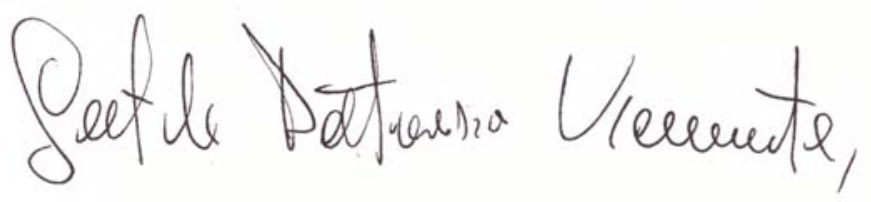

Le comunico che, nonostante ogni più favorevole predisposizione, non è stato possibile valutare favorevolmente la Sua richiesta di collaborazione dell'Arma al fine di acquisire i dati utili al completamento della Sua tesi di dottorato.

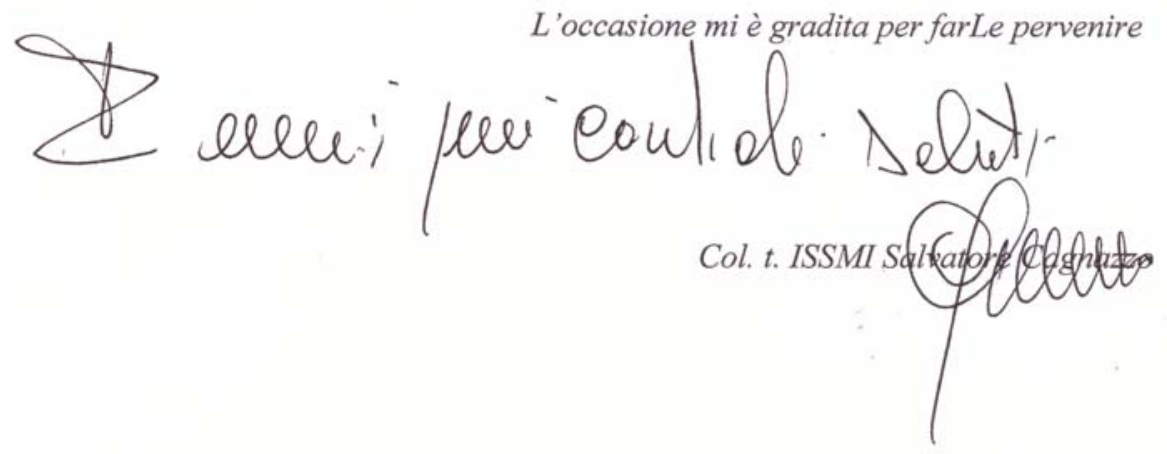

Dott.ssa

Marta SANCHO VIAMONTE

e-mail: marta@pec.msancho.com 


\section{GUARCIA CIVIL}

\section{Marta Sancho}

\section{Da:}

Inviato:

A:

Oggetto:
ORIS < dg-oris-plm@guardiacivil.org>

viernes, 17 de febrero de 2017 10:21

Marta Sancho

Solicitud colaboración en investigación para tesis doctoral sobre calidad de la interpretación policial y judicial

Estimada Sra. Sancho,

En relación con su correo electrónico inserto más abajo, sentimos comunicarle que debido al alto nivel de ocupación de las Unidades de investigación y los recursos humanos en ellas destinados, nos es imposible detraer de las mismas efectivos para este tipo de cometidos y colaboraciones.

Asi mismo le comunicamos que las colaboraciones que se vienen llevando a cabo actualmente en el ámbito académico, lo son en el marco de Acuerdos o Convenios de colaboración ratificados oficialmente entre las diversas Universidades o centros educativos y la Guardia Civil, no siendo posible con las solicitadas a título particular.

Sin otro particular, reciba un cordial saludo

Lourdes Rodriguez Galán.-

Directora de la Oficina de Relaciones Informativas y Sociales (O.R.I.S.)

Dirección General de la Guardia Civil

12 Planta del Edificio I del Director General

C/ Guzmán el Bueno, 110

28003.-MADRID.-

Tef: 91.514 .25 .59

Fax 91.514.60.14

Email: dg-oris-plm@guardiacivil.org

From: Marta Sancho

Sent: Sunday, January 29, 2017 11:27 PM

To: ingreso@guardiacivil.org ; sugerencias@guardiacivil.org

Subject: Solicitud colaboración en investigación para tesis doctoral sobre calidad de la interpretación policial y judicial

Estimados Sres:

Me pongo en contacto con ustedes para que consideren la solicitud de colaboración, pues actualmente realizo mi tesis doctoral bajo la supervisión de la Dra. Maria Jesús Blasco Mayor y la de la Dra. Micaela Moro Ipola, también de la Universitat Jaume I. Mi tesis consiste en el diseño y validación de una herramienta (cuestionario) de control de calidad de la interpretación en el ámbito judicial y policial, para lo cual es necesario que los usuarios de este servicio en este ámbito rellenen dicho cuestionario, actualmente en fase de pilotaje. 
Adjunto solicitud de la doctoranda, asi como un breve CV y el cuestionario que deseariamos pilotar con guardias civiles que trabajan habitualmente con intérpretes. Estariamos muy agradecidas si usted pudiera hacer llegar dicho cuestionario a guardias civiles con el ruego de que lo rellenen y envien nada más terminar un servicio asistido por intérprete, o bien que nos permitan distribuirlo personalmente durante mi estancia en Valencia o en Burgos. Lo más cómodo es que accedan al formulario electrónico y lo envien:

https://goo.gl/forms/VynvEUJ378UtSrpq1

La doctoranda ha recogido datos proporcionados por jueces, fiscales y abogados en los juzgados de Milán (Italia) y actualmente está haciendo lo mismo en la Ciudad de la Justicia de Valencia. La colaboración de su colectivo profesional sería muy beneficioso para el objetivo de la investigación.

Quedo a su disposición para cualquier aclaración sobre el particular. Mi móvil español es +34 630931491

Marta Sancho Viamonte

Traduttore interprete di conferenza, CTU Milano

Via Giovanni XXIII, 6

20018 Sedriano (MI)

Tel: +39.02 .90111238 cell: +348.8045122

Email:marta@msancho.com; skype: msanchov 


\section{Anexo 9: Transcripción grupo de discusión}

$(\ldots)$

J1 - Es que es un problema que se ve bastante, porque la mayoría de las personas que necesitan un intérprete, salvo a lo mejor los chinos con lenguas cerradas. Pero por ejemplo, tanto las personas del este de Europa como los magrebís, generalmente, algo de la lengua conocen.

$\mathrm{J} 2$ - Si

I1 - ¿De español?

J1 - De español. Y entonces de repente, empieza a traducirles el intérprete y se empiezan a poner nerviosísimos, porque alguno incluso que se nota que el intérprete lo ha pedido para dilatar el procedimiento, y de repente dice « QQué yo no estoy diciendo eso!» en español perfecto.

J2 - Y el te pilla hablar.

J1 - Entonces dice, ya prefiero hablar yo porque...

J2 - Si, prefiero hablar yo.

J1 - La verdad es que la experiencia que yo tengo con los intérpretes tengo que ponerla un poco, no negativa, pero ...si que siempre he tenido el recelo de pensar si realmente estaba siendo, porque viendo las, las reacciones de las personas y viendo muchas veces la falta de correlación entre la longitud de la pregunta y la traducción, que entiendo que en determinados idiomas puede haber una cierta diferencia, pero vamos, pasar de una pregunta de un minuto a traducirla en tres palabras.

$\mathrm{J} 1$ - (...) El interprete ...y el chino se pegaba una parrafada ahí, que y el otro decía «que no, que no lo ha hecho».

J2 - Eso, es que era muy famoso, el del dicho. A ver, cada vez que me llegaba a XXXX, llegaba con una bolsita. Un señor ya con mucha solera, muy pasota, (risa, no se entiende) Ejercía ya casi de abogado.

J1 - Incluso un día pregunté al intérprete si había venido en sala.

J2 - Porque hacia falta de rumano y la rumana ...discutiendo.

$\mathrm{J} 1$ - Si, eso, mucho.

I1 - Y el rumano siempre se entiende algo. La misma raíz latina.

$\mathrm{J} 2$ - $\mathrm{Si}$.

J1 - Escuchas que estaba diciendo el intérprete: «Di la verdad, pero di la verdad». Este estaba diciéndole al intérprete.

J1 - «Limítese a contestar lo que esta diciendo», «Es que está diciendo algo que es mejor que no diga, y no sé». Es que muchas veces asumen la función.

$(\ldots)$

J2 - Yo cuando...Cuando le comentaba a I1 ...que la falta de formación de los intérpretes para dedicarse profesionalmente al mundo judicial se evidencia sobre todo no ya en que tengan mayor facilidad o aptitudes para traducir, que bueno, eso es una cosa que es de idiomas, sino en la falta de aptitud para saber su función como intérprete judicial. Es decir, usted no es ni el abogado defensor, ni un familiar, ni 
un amigo ni un enemigo. Y entonces, o bien adoptan una postura claramente a favor de la persona interrogada o bien una postura en contra.

J1 - El evidentemente en contra como queriendo ganarse la simpatía del juez o del fiscal porque parece que le va a suponer luego un mayor beneficio a los ojos del tribunal. Y hay cosas como recriminándole « ¡Hay que ver lo que has hecho!» «iOiga! No tiene usted que recriminar a nadie». O asumiendo el papel de abogado defensor que ... como decía J2 - «Di que lo has hecho que vas a tardar menos». Oiga que usted no tiene que aconsejar judicialmente a este señor. Simplemente, limitarse a decir lo que este señor quiera manifestar».

J2 - Entonces, es cierto que en muy muy contadas excepciones, yo. Bueno, yo sí que tengo un muy buen recuerdo de un traductor de árabe, que además es el único que iba con su libretita y apuntando las preguntas para hacer lo que, para ir traduciendo. En el resto de los casos, he visto un poco de dejadez, o sea, se está jugando un procedimiento judicial, y apuntar una pregunta judicialmente no es fácil. Traducir conforme a las necesidades de esta persona exige también mucho rigor y no ponerse ni dejarse influenciar por un aspecto positivo o negativo, sino simplemente traducir lo que uno está escuchando. Entonces, ahí se ven muchos problemas, en ese sentido.

J1 - Yo creo que está, de la necesidad surge el problema...hay mucha necesidad de traducción y entonces se tira de lo que se pueda. Y entonces no hay un, no hay digamos un nivel de exigencia fuerte a la hora de...más que nada que sepa el idioma.

J2 - Porque como además, tampoco la ley motiva para que se haga de otra forma, porque la ley además ...un traductor oficial permite que cualquier persona que conozca el idioma previo prestación de juramento pueda ejercer la profesión/las funciones de traductor, entonces parece que le está quitando ya importancia a la interpretación, diciendo que...a mí con que me traduzca el idioma, me vale. Cuando luego puede afectar mucho.

J1 - Yo me ponía siempre en la situación. Yo me veo en China, y veo que el traductor me empieza, empieza a poner malas caras con lo que yo le voy diciendo, este juez ya se va a poner en mi contra. Porque claro, va a pensar que estoy diciendo algo «No le digas al juez». Yo ya me voy a hacer maquinaciones, este señor le está diciendo al juez algo que yo no estoy diciendo. O sea, que

I1 - Oye y cuando has comentado, tu compañero y tú habéis comentado que ha habido ocasiones. Claro, yo pensaba. Tú me tienes que...pensaba o le decías, apercibías al intérprete «oiga, usted...haga su función».

J1 - Si, claro.

J2 - Si. Cuando ya notabas que era una cosa un poco...primero con educación «Señor intérprete, mire, perdone, yo realmente no conozco su idioma, pero me resulta un tanto chocante que a respuesta muy cortas, usted haga unas traducciones muy largas o a respuestas muy largas haga traducciones muy cortas».

J1 - Inicialmente, nos decía «No, no, no. Yo le estoy preguntando, yo le estoy preguntando lo que le diga». Ahí ya empezaba un poco a cambiar el chip y ya empezaba a haber un poco más de correlación. Y bueno, pero claro, es que nunca tienes capacidad total de saber si aquello que se está expresando efectivamente es así, o el filtro de control de los intérpretes tendría que ser muy alto.

I1 - Y tú conoces algún filtro de control establecido por la Administración.

J1 - ¡No! ¡Al revés! Nosotros, están en el caso nuestro, está externalizado el servicio detrás de una empresa.

I1 - Si, pero igualmente, se podría hacer un control ¿no?

J1 - Si antes, se tendría que auditar la empresa que entiendo yo que tenga que hacer ciertos controles para la administración, pero vamos, creo que, como decía antes, la necesidad de contar con intérpretes 
hace que pues se vaya. Hombre yo creo también que entiendo que es difícil tener formados quizás a veinte personas a disposición con formación de intérpretes de personas chinas, no. A lo mejor sí que hay bastante población china... pero quizás de otros países que haya menor afluencia de gente. Y yo personalmente, yo creo que es un servicio que no se debería externalizar, es decir, yo entiendo que eso debería ser una competencia exclusiva del Estado, de igual que en determinadas cuestiones pues no se acude, por su dotación de material, sí, a lo mejor se acude, pero esto ya no es una simple dotación de material sino que tiene unas implicaciones ya judiciales que a lo mejor exigiría o bien que lo asumiera la correspondiente, o bien que esas empresas externalizadas estuvieran sometidas a unas auditorías importantes, que desconozco realmente si es así.

I2 - Ya.

J1 - Me da a mí que por la experiencia que yo tengo que no debe ser. Hace poco en Madrid hubo un caso muy famoso de intérpretes low cost. La empresa...

I1 - Si...Me lo mandó también.

J2 - Entiendes, hubo una gran polémica porque se descubrió que los intérpretes que asistían a los juzgados eran gente que no hablaba, no que tuviera... que conociera el idioma y pudiera traducir. ¡Simplemente no conocía del todo ese idioma! Y se han llegado a situaciones en las que por conocer, yo puedo, el juez puede conocer el idioma, pero así no puedo hacer de intérprete. No puede dirigirse directamente a la persona en su idioma.

Por ejemplo, yo hablo inglés y francés, y el inglés y francés difícil que alguien no sepa. Pero notas en un juicio en el que hay varias personas de una misma nacionalidad, que hablan bien español y que están escuchando al intérprete en su idioma y están diciendo «este señor no está diciendo...».

I2 - ¿Tienes mucho en cuenta la CNV entre toda la gente de la sala, claramente?

J2 - Claro, claro. Es donde la reacciones lo que te permiten ver. Por ejemplo, en el caso de que una persona conozca un poco el idioma y ya de repente, cuando a empieza a escuchar a su intérprete y ve que no van los tiros por donde...se empieza a poner nervioso y...«Oiga, no, no, no» y, claro, encima muchas veces se coartan porque como han empezado el interrogatorio diciendo que no entienden el idioma para que les pongas un intérprete y ahora tengo que echar para atrás y decir que sí que lo estoy entendiendo.

I1 - Ya. En esos casos en los que tú percibes que hay conflictos en la sala en cuanto al desempeño del intérprete, ya has tanteado decir, mire,... «usted no puede actuar en esta sala porque usted no está ofreciendo garantías suficientes y, por tanto, puede tener consecuencias negativas para el proceso», y pedir otro intérprete o exigir a lo mejor que venga con una titulación, por ejemplo. No sé si lo has hecho o lo has visto o lo has pensado.

J1 - Es el planteamiento correcto en el caso. Yo no me he llegado a pasar, porque se ha podido solucionar la situación con un cierto apercibimiento al intérprete que tenía que ajustar mucho más su actuación a la hora de interpretar y no hacer aspavientos ni afirmaciones ni negaciones.

I1 - Fuera de...

J2 -Y entonces. Me consta, sí me consta, que por el juzgado de al lado, que alguna ocasión en la que ha habido un problema serio de traducción, sí que se ha suspendido la declaración, porque efectivamente eso no estaba siendo una declaración válida. Se ha suspendido la declaración y se ha requerido en este caso a XXX. A la empresa a que se enviara a otro intérprete y además se da cuenta de esta circunstancia a la Junta de XXXX (la Comunidad Autónoma de competencia) que es la competente para que tenga conocimiento de esa circunstancia.

I2 - Pero al ministerio de Justicia, por ejemplo, ¿esa queja, esa incidencia, no llegaría?

F-El problema es que en España, la competencia para la dotación de ... 
I2 - El servicio es de la Administración local, ya, autonómica.

J2 - No, no, no. En algunos casos es de la comunidad autónoma. En otras, es del Ministerio de Justicia.

I2 - Sí, pero muy pocas ¿no?

$\mathrm{J} 2$ - Si, me parece que son...Eso, en el territorio de...Castilla la Mancha.

I2 -- Castilla y León, está Ofilingua.

J2 - No recuerdo cuáles son. En esos casos sería él quien recibe cuentas, claro. Y en los otros casos es el interlocutor de los juzgados a los efectos de esta concesión, siempre es la comunidad autónoma. Que, efectivamente, debía ser una cuestión...

I2 - Claro, porque si pensamos que realmente, que el garante del Derecho es el Estado, del derecho a la interpretación en un proceso penal y de la tutela judicial efectiva es el Estado, ¿no? O sea, que está por encima de las Comunidades autónomas, ahí hay como un vacío quizá. No. Un desentendimiento.

J1 - Pues....

J3 - Desentendimiento del asunto.

F Es quizás lo que hablábamos antes de la concepción del intérprete como una simple dotación de medios materiales cuando influye directamente en el Derecho de defensa. Efectivamente, desde ese punto y ahora, sería exigible que fuera una cuestión, que hubiera un cuerpo, un cuerpo oficial de intérpretes del Servicio de Administración de la Justicia.

I2 - Vosotros, cómo, bueno, ya nos has dicho más o menos los idiomas que más concurren, el rumano, el chino me imagino.

J1 - Rumano, chino y árabe son los que más, son los tres que más ...

I2 - Y que además son los más difíciles para una persona.

J1 - Ya lo son. Son idiomas que no te.... El rumano sí lo captas, un poquito ciertas, pero el chino ya no. El chino generalmente tiene el chino mandarín, el chino cantonés. O sea que tiene varios. Pero claro, son idiomas en los que estás absolutamente entregado a lo que te pueda decir el intérprete.

I2 - $\mathrm{Si}$, en este caso. Cuando vosotros, cuando os llega el intérprete a la sala. ¿Cómo lo habéis llamado? ¿Directamente? ¿por la provisión de servicios subcontratada?

J1 - Sí. Nosotros cuando una persona es detenida, en lo penal, cuando una persona es detenida, inmediatamente se le informa ya antes incluso de la modificación de este año de la ley, se informa del derecho que tiene de ser asistido por un intérprete. Entonces, desde ese mismo momento, claro, incluso la propia policía, ya tiene la localización de la empresa que se dedica. Y entonces directamente hace la gestión. Generalmente, ya el intérprete que ha asistido a esa persona en la policía, posteriormente sea la que continúe con ella en el juzgado.

I2- ¿Ah si?

J2 - Pero puede suceder que una persona venga al juzgado no porque esté detenida sino porque ha sido citada. En este caso, se le advierte en la comunicación si va a querer hacer uso de intérprete, lo comunicamos al juzgado para que ese día, se haya podido oficiar a la empresa externalizada y que ese día haya preparado un intérprete.

I2 - Entonces, vosotros cuándo llega ese intérprete, se presenta con el carnet o con algo de la empresa, me imagino. 
$\mathrm{J} 1$ - Si.

I2 - Y no tenéis medios de constatar si es licenciado...

J3 - Nada, nada, nada.

I2 - No lo preguntáis nunca ¿no?

J1 - No, la verdad es que no es una ...

I2 - No sabéis.

$\mathrm{J} 1$-.es una previsión hay que tomarles juramento o promesa que va a desempeñar fielmente su cargo y no hay que, no, la verdad es que no. No, no se le pregunta. Claro, no estaría de más, pero no debe el juez tampoco preguntarle eso porque ya, si se le ha presentado antes, por parte de la administración a un intérprete, pues ya tiene que asumir que ya concurren las circunstancias necesarias para llevar a cabo la traducción. Porque luego, el juez, lo que no puede hacer, es preguntarle a una persona «Usted, ¿qué formación tiene?» Y que por la formación que tenga no le parezca adecuada, rechazar a ese intérprete.

I2 - ¿No lo podéis rechazar?

J1 - Yo entiendo que solo cuando está viendo, puedes estar viendo que puede verse afectado el Derecho de defensa porque lo estás apreciando, ahí sí, pero con una manifestación que ha hecho el intérprete.

I1 - Ese interprete ¿Qué tipo de formación recibe? ¿Tiene una pequeña entrevista con vosotros, jueces, antes de empezar?

I2 - La vista.

J1 - No. No la tienen. La única interrelación que se produce entre el juez y el intérprete de forma un poco directa entre ellos dos, quizás se produzca al inicio de la vista o del interrogatorio que, por ejemplo, el intérprete se dirige al juez diciéndole «Si no le importa, vaya parando cada poco tiempo para que le pueda ir traduciendo» o el propio juez le dice, «oiga, a usted, si yo le digo todos los derechos, ¿va a ser capaz de traducirlos?» Y para más o menos ordenar cómo va a desarrollarse el interrogatorio.

I1 - ¿Se explica la función del intérprete?

J1 - ¿Se explica la función del intérprete? No, yo creo que es una cuestión que da por hecha.

I2 - Bien, ¿conocéis a algún intérprete que por algún caso, previamente ha habido un intérprete con la policía? ¿Tenéis alguna forma de saber si el intérprete ya ha trabajo en el mismo caso anteriormente para la policía?

J1 - Extraoficialmente. Es decir, yo puedo, yo puedo por datos objetivos que puedo saber. Si yo por ejemplo veo o el propio intérprete me lo dice, «ya he estado con él en la policía», o veo que la firma del intérprete es la misma que...en el juzgado.

MJ: ¿Aparece ahí en el expediente? ¿Está la firma?

J1 - Sí, sí. Tienen que firmar la declaración los intérpretes.

I2 - Si. No me refiero. La actuación anterior también queda registrada en tu expediente.

J1 - Sí, sí, si. Todo lo que se practica en sede policial, se abre un atestado, y tiene que ir al juzgado. Hombre, no las cuestiones meramente de logística, por ejemplo. Si se le ha dado un bocadillo, eso no.

I2 - Ya no, no. 
J1 - Las actuaciones.

I2 - Las que luego vayan a tener efectos en...

I1 - Y del caso, a quién le informa el intérprete. ¿El secretario judicial? ¿Le pasa, le pasa, no sé, alguna información sobre el nombre del acusado?

I2 - ¿Puede tener acceso al expediente?

J1 - ¿Quién? ¿El intérprete?

I2 - El intérprete.

J1 - Sí, sí. Claro. El intérprete, desde el punto que...el acusado, desde el momento que tiene acceso a toda la información, salvo que se haya detectado, se han detectado situaciones en que ...pero el derecho que tiene al acceso a la comunicación implica que le pueda decir también al intérprete. Aquí pone, que deja de poner. Es verdad que muchas veces los abogados asumen la función de decírselo al intérprete, solo, de ir indicando al intérprete lo que quieren pero ... si el acusado quiere. Y eso si que le tiene que informar, porque actualmente, antes, antes no, antes no tenía el derecho reconocido de la traducción de la documentación. Ahora sí, y yo no sé cómo se va a hacer, de hecho, porque me parece imposible. Creo que es una premisa.

I2 - Bueno, pero la ley dice...los documentos más básicos, más importantes, y además incluso dice que se puede resumir, en fin, fragmentos más importantes, no todo. Ahí intenta un poco.

I1 - Vosotros sabéis si por ejemplo, si la persona se ve con el abogado directamente también con el intérprete o se supera también un poco todo esto.

J1 - Yo, puede que sean también las circunstancias. Puede que el intérprete hable solo con el cliente, con la persona interrogada o puede ser que lo haga en presencia del abogado. Yo ahí...

M ¿No lo sabes?

J1 - Muchas veces no lo sé. Tampoco creo que se pongan muchas cortapisas a partir de que el hombre, el intérprete haya prestado juramento que va a desempeñar fielmente sus funciones. Ya está. No puedes controlar absolutamente todo.

I1 - No. A ver, vosotros en España grabáis todas las actuaciones en sala ¿no?

J1 - Um, en sala sí. En sala hay que grabar todo. Lo que pasa es que las declaraciones de los investigados no se practican en sala. En instrucción, las declaraciones se practican en el despacho del juez, entonces, generalmente no son grabadas. Se suelen grabar en ocasiones en los que, por la transcendencia del caso o por la duración del interrogatorio se considere que es más apropiado, o lo pidan algunas partes expresamente. Pero ahí, no. Igual que se dice que los juicios civiles y los juicios penales se dice que legalmente tienen que estar grabados, las diligencias de instrucción no tienen que estar grabadas. Entonces, el interrogatorio, se va dejando constancia en un acta escrita, de lo que se vaya produciendo y luego, de esa acta, para que se le dé a las partes para a ver si están de acuerdo con la misma, se firme. Ya queda ahí como recogida. Pero no se graba.

I1 - No, más que nada, porque en ese caso, ¿Cómo se puede?

J1 - La única forma de acreditar, de que el juez pueda acreditar que se está produciendo alguna circunstancia anómala en la declaración, ya no solo del intérprete, aunque por ejemplo, un abogado cuando esté haciendo un uso ....de defensa, es a través de él, la figura del letrado de la administración de la justicia, que es quien da fe de lo que está ocurriendo.

I2 - El antiguo secretario, verdad. Es que le han cambiado el nombre y ahora se llama. 
I1 - El secretario judicial se llama letrado.

J1 - Letrado de la administración de la justicia. El secretario judicial es quien da fe. Y entonces, pues, por ejemplo, el secretario judicial puede hacer constar una manifestación de que en este acto, el juez, en este momento el juez advierte al intérprete que, por favor se atenga al tenor de las preguntas que está haciendo. Toda vez que el intérprete, perdón, toda vez que el juez advierte que el intérprete no ha compasado su actuación a aquello que se había exigido, el juez acuerda la d...del acto. Entonces queda documentado...,es la forma de acreditar. Efectiavamente, en caso de que haya grabación no hay problema, se ve todo lo que está pasando, y ya está.

I1 - Quería saber también más que nada qué criterios son los más importantes Voy a decir una serie de criterios: la comunicación fluida. Es importante para ti, ¿cuánto es importante? Mucho, poco...

J1 - Muy importante. Muy importante porque me da la sensación de que no está. si veo uan comunciación de que está traduciendo, sino, ya se ve que está seleccionando. De que está seleccionando lo que quiere transmitir.

I1 - ¿El conocimiento del lenguaje jurídico?

J1 - Es muy importante, pero también al mismo tiempo, cuando una persona se ve obligada a declarar con un traductor, generalmente, por parte del juez se hace un esfuerzo, al igual que el abogado, de utilizar una terminología lo más coloquial posible de tal forma que, efectivamente, no haya, se ...en la mayoría de las diligencias un término jurídico que quizás no exista en la lengua, o que quiera decir una cosa totalmente distinta.

I1 - Si porque ahí va también una pregunta. Generalmente, los extranjeros que os llegan, ¿qué tipos de extranjeros son aquí?

J1 - Bueno, la mayoría de, el $90 \%$ de los intérpretes trabajan en el orden judicial penal, y claro, generalmente desde el punto de vista de personas investigada, contra la cual ...El $90 \%$ de las personas que necesitan intérpretes son contra las cuales se dirige un proceso penal. ¿Por qué? Porque en los procesos civiles entre extranjeros no son tan comunes, por la propia naturaleza de la jurisdicción española, que está muy limitada a los casos españoles; en segundo lugar, quien tiene pleitos civiles, generalmente es ya una persona que tiene una cierta raigambre en España y entonces tiene cierto conocimiento del idioma y porque, bueno, por las circunstancias que es fundamentalemente tema penal, efectivamente son personas a las que se les imputa haber cometido un delito. Entonces, pues son....

I1 - ¿Emigrantes? ¿o de todo?

J1 - Hombre, en el sentido de persona. Hombre, emigrantes en todo caso, porque las persoans que ....actuaciones, son personas que...

I2 - Pueden ser también residentes extranjeros en la zona, ¿no? No sé si aquí hay colonias de extranjeros

$\mathrm{J} 1$ - Si, si, claro, a esos les llamo yo también emigrantes.

I2 - Si, bueno, a lo mejor, no sé. Son jubilados.

I1 - Turistas también.

$\mathrm{J} 1$ - Ah, bien.

I2 - Quieren comprarse una casa, pero...

J1 - Pero, esos son el $10 \%$ de los casos. Cuando he dicho el $90 \%$ de los casos. Ese es el $10 \%$, efectivamente se llevan en el ámbito civil con extranjeros. Pues efectivamente, personas que a lo mejor por turismo, ya sea por jubilación ya estén asentados, que han llevado a cabo una compraventa de una 
vivienda y tengan algún problema.

I1 - Yo estaba pensando por ejemplo en los hinchas de fútbol, los hinchas que a veces vienen y arman bulla y pueden acabar en...

J1 - Si, ese es el caso. Ese ocurrió el otro día. Hubo partido de fútbol, hubo detenidos y eran polacos, efectivamente son penal. Eso es, pasaron a disposición de la ordenación judicial. Los intérpretes. Fueron condenados a través de un juicio rápido y sin problema.

$\mathrm{M}_{\text {¿La fiabilidad? Imagino }}$

J1 - Bueno, la fiabilidad,

M ¿Y la discreción? ¿Cuánto es importante que respeten un código?

J1 - Bueno, la discreción hacia fuera yo no la puedo controlar. No sé hasta qué punto el intérprete que ha escuchado una conversación luego va a publicitarla en el exterior. No sé si te refieres más a en el momento del acto que mantenga una ...

I1 - No, no.

J1 - Una actuación discreta, que no se le vea.

I2 - De la misma forma que un abogado tiene la confidencialidad, de la misma forma que un abogado, que un letrado, tu mismo tenéis un código deontológico, donde tenéis que ser...

J1 - Hombre, él tiene la misma obligación de guardar reserva de aquello que haya escuchado.

I1 - ¿Os has pasado alguna vez? Saber que...

J1 - A través de...yo no tengo conocimiento de que alguna noticia se haya podido filtrar, de un intérprete. Pero desgraciadamente, cuando he tenido un caso, dificultad, no puedo determinar si ha sido un abogado u otra parte. El acusado, un funcionario, un policía. Tanta gente la que filtra una noticia.

I2 Ya. ¿Habéis tenido alguna vez alguna constancia de que haya habido algún problema con los intérpretes, de que les hayan chantajeado o que hayan tenido algún problema por parte de alguno de los $\cdots$

J1 - Yo mira. El único problema que, yo no he tenido ningún problema. Sí que he escuchado un problema de una persona que acabó siendo intérprete y que había sido prostituta, en el pueblo. Entonces, pues recibió algún tipo de recriminación, en el sentido, antes de empezar la declaración, como diciendo, bueno, encima esta que ha sido prostituta es la que me interpreta. No lo he vivido yo, eh. Es un caso que me han contado. Bueno, si eso se puede considerar chantaje, o por lo menos minusvalorarla, o coaccionarla, en cierta forma antes de empezar. El único caso así por referencia que tengo noticia.

I2...que sea el propio intérprete el que intente sacar algún partido, chantajearle al detenido, al acusado.

J1 - Desde el punto de vista, más que chantaje, si que he notado intentar ganarse la simpatía del órgano judicial a lo mejor poniéndose en actitud policial contra él.

I2 - Asumiendo un rol que no es.

J1 - Así es, casi un acusador. Además, no teniendo empatía con el él, poniéndose en situación y de estar preguntando en un país extranjero, ya es suficientemente duro eso como para que encima, la persona que está para auxiliarle le esté también pinchando.

Era, cuando he dicho, ah si. Efectivamente es un operador jurídico que está absolutamente expuesto efectivamente a importantísimas presiones. Mira, nada más que decir «mira ahora este, bueno cuando te 
digan, tu di esto esto y esto y se acabo». Es que eso no hay forma de controlarlo.

I2 - Ha habido casos.

J1 - Ha habido casos ¿no? Claro, claro, es que no me extraña. La forma, posiblemente, si yo me pongo en la mente del malvado, la forma presumiblemente más fácil de manipular un juicio, sea que haya un sujeto extranjero y llego a tocar al intérprete. Porque tocar al juez es muy difícil, tocar al fiscal es muy difícil, el abogado de la otra parte, ciertamente tiende a sus intereses, ya tiene cubiertos sus intereses. Donde yo puedo ir, y a la policía también es complicado. Donde yo puedo ir y además sin riesgo de ser descubierto, con muy poco riesgo de ser descubierto es al intérprete. Porque efectivamente, quién acredita, solo a través de una grabación y que haya surgido duda de que aquello podía ser...

I2 - Exacto.

I1 - ¿Qué partes del proceso se interpretan? ¿Todas las partes? Solo las partes más...cuando...cuando estás hablando con el abogado, o cuando estás interrogando, o cuando estás hablando con el fiscal. Se interroga $<$ sic $>$ o se interroga solo una parte.

I2 - Se interpreta, quieres decir.

I1 - Se interpreta, perdón.

J1 - Si. Son muchas veces. Efectivamente es un error que se comete, en el que el intérprete solo actúa cuando se dirige directamente, es muy buena pregunta, cuando se dirige directamente contra la persona que tiene que interpretar. Cuando eso no vale para nada, porque si la persona que se está interrogando no adquiere constancia del contexto en el que se está preguntando y todo lo que está pasando. Entonces, un buen intérprete tiene que, de forma reservada, aunque sea al oído, le va explicando todo lo que va pasando. Pues entonces, el juez está preguntando, tal y tal.

I1 - O sea, tú instas a que se haga esto.

$\mathrm{J} 1$ - Si, así debe ser.

I2 - Es que lo que dices, ese es el derecho.

J1 - Claro, es que si, no, por mucho que tú hayas hecho las preguntas, digo, si tú no sabes por qué te están preguntando, no estás contextualizando la situación. También uno es suficientemente listo para que según cómo se vean las cosas puedas tomar una postura u otra. Eso es el derecho de defensa.

I1 - Entonces, ¿Dónde se sienta normalmente el juez? El intérprete, perdón.

J1 - El intérprete se sienta siempre al lado del acusado. Nunca hay separación física. No la hay, desde un punto de vista práctico, porque efectivamente es la forma de facilitar pues eso, si el resto de la sala está hablando, como se puede dirigir al oído sin molestar y sin interrumpir, es precisamente por la proximidad física. $\mathrm{Y}$ además esa proximidad física yo creo que también es una forma de que la persona interpretada tenga una cierta sensación de seguridad, por lo menos de verse auxiliado. Que la sensación de auxilio sí que es real. Seguramente si el intérprete estuviera en una mesa al lado del juez, y el acusado estuviera abajo, la escenografía misma no facilitaría la interpretación.

I2 - Ya.

J1 - Tiene que haber cierta empatía, no. Que exista una cierta empatía entre ellos es muy importante, manteniendo ciertamente el rigor, pero sabiendo que es la boca de esta persona en ese momento.

I1 ¿Generalmente cómo se dirige el intérprete?

J1 - Bueno. Son muy correctos. Y además conocen los formalismos. Tratan al juez de señoría, que al señor letrado. Es cierto que algunas personas, se nota quienes tienen una formación académica en el 
idioma, que se nota que han estudiado el idioma, manejan con más facilidad el usted, y a lo mejor aquellos que se nota que por haber vivido aquí e ir soltándose en el idioma y luego haber ya accedido a la interpretación han adquirido un lenguaje mucho más coloquial, entonces el uso del usted no es tan común. Por ejemplo, aquí, la gente coge mucho el deje de como se habla, utilizan también las derivaciones de ...

I1 - Ya, claro, claro. ¿Te ha pasado tener que usar la videoconferencia en alguna intepretación?

J1 - Si, yo he hecho videoconferencias. A ver, ¿qué caso fue?

I2 - ¿Transfronterizo?

J1 - No. No, estando en España, porque estaba en prisión. Porque estaba una persona en prisión.

I2 - Para que no desplazarlo.

J1 - Efectivamente. Ahora cada vez más, sobre todo en temas de prisión, se intentan llevar a cabo las actuaciones judiciales utilizando la videoconferencia para organizar un traslado de presos nunca es fácil, para la seguridad no es lo más adecuado. Entonces se intenta hacer por videoconferencia y en este caso se trataba de una persona que ya estaba cumpliendo condena por una cuestión, no sé qué cuestión, pero era indiferente para mí, y estaba. Yo tenía que practicar un interrogatorio, el caso que llevaba yo. Lo hicimos a través por videoconferencia, y entonces, la pregunta también es buena porque plantea la duda si el intérprete tiene que estar allí con él o tiene que estar aquí conmigo para que me vaya traduciendo. Yo entiendo que tiene que estar con él, allí, para que se cumpla efectivamente la posibilidad de que le vaya informando de todo. E incluso, que las preguntas que de forma reservada le quiere hacer la persona interrogada.

I2 - Perdona. Has dicho que esa persona que está en la cárcel, ya estaba cumpliendo condena.

$\mathrm{J} 1-\mathrm{Si}$

I2 - Y entonces ¿por qué está declarando otra vez?

J1 - Porque vino otro procedimiento.

I2 - ¿Tiene otro delito?

$\mathrm{J} 1$ - Eso es.

I2 - O sea, se le acusa de otro delito. Vale perdona, es que no me había...

J1 - Pues ahora que lo pienso. Estoy pensando dos cosas. He tenido dos casos de videoconferencia, y uno lo hice con el intérprete allí que creo que es lo suyo, y en el otro caso lo mandaron aquí, a mi juzgado, donde estaba yo.

I2 - O sea, ¿que el intérprete fue a la cárcel?

J1 - Si, el intérprete fue a la cárcel, en uno de ellos.

I1 - Hay casos en Inglaterra, y en Sicilia, esto lo sé en Italia, donde el intérprete está en un sitio totalmente alejado del juez y del acusado. A lo mejor el acusado están juntos y hay un espacio separado para los intérpretes donde reciben todo por video conferencia. La señal de un sitio y del otro.

J1 - Claro, entonces puede dirigirse. Claro, en el caso en que el intérprete vino a mi juzgado, me acuerdo que yo salí de la sala y le dije que si quería hablar con su abogado y con su intérprete reservadamente porque es la forma, claro, es la única forma. Porque a lo mejor dice, este desgraciado, ¿este desgraciado quién es? Este desgraciado es el juez. Pues delante del juez no querrá preguntarle que este desgraciado quién es. 
I ${ }^{\circ}$ Cual de las. Más que nada, hay varias técnicas de interpretación. La simultánea, que es al mismo tiempo, como decías al oído, la consecutiva que es después. Cual es la forma que para tú...

J1 - La consecutiva después, ¿de qué?

I2 - Uno habla y después se tiene el intérprete. Habla el juez e interviene el intérprete. Contesta el interrogado e interviene el intérprete.

J1 - Así es como se hace normalmente. El juez intenta hacer preguntas, por ejemplo, los derechos. La lectura de los derechos. Tiene usted derecho a guardar silencio, esperas a que se le diga que tiene derecho a guardar silencio y continuas. También puede pasar que el intérprete, hay pues, ya conocen y le puedes decir, usted conoce cuáles son los derechos, ¿no? Pues, dígaselos. Si ya sabe, que es una persona que está acostumbrada.

I2 - Y se los sabe de memoria.

J1 - Y se los sabe de memoria. Pero en realidad, el debería ir diciendo derecho a derecho, y que los vaya traduciendo. Eso es como hay que hacerlo.

I1 - Una pregunta. Aquí hay una serie de declaraciones, una serie de ideas de lo que tendría que ser verdaderamente el intérprete. ¿Cuál es la que te parece que es la más correcta?

El intérprete asiste a la víctima o al testigo. ¿Estás de acuerdo, en desacuerdo? ¿Te parece bien? mal?

I2 - ¿Asiste?

J1 - El intérprete auxilia, asiste al imputado, pero en ningún momento puede apoyarlo.

I1 - Ya.

J1 - En ningún momento puede apoyarlo.

I1 - El intérprete sostiene al juez.

I2 - Asiste. Perdona pero la palabra es asiste. Que no sé de donde ha salido sostiene

J1 - Bueno, sostiene. Si sostiene vamos a cambiarla. Sí es verdad que en algunos sitios ...Si, el intérprete asiste al juez también.

I1 - ¿El intérprete debiera explicar las referencias socioculturales al sujeto? ¿Al entrevistador y a la persona a la que está traduciendo?

J1 - Sí, eh, si resulta pertinente para el objeto de la declaración. Por ejemplo, si estamos enjuiciando un caso de violencia de género, el que yo sepa, cómo, independientemente, me da igual cómo sea su cultura, yo tengo que aplicar la ley que está en España, si eso me permite contextualizar la situación para yo entender si ha habido efectivamente una situación de violencia, pura y dura, o se puede contextualizar a lo mejor dentro de una riña o en un caso de consumo de drogas, pues entonces quizás, sí que me interesa saber, si es una persona que viene de Sudamérica, donde se consume la coca masticada que me explique esa circunstancia porque me está queriendo. Bueno, ella no me lo va a decir, en español no hay problema. Por poner un ejemplo, vale. En Brasil. Porque a lo mejor él está interesado en explicarme que pues que su relación con la droga desde niño es común. Entonces, a lo mejor, si me dice eso una persona de España, pues le diría no me cuadra, y en cambio si me dice el intérprete le está diciendo porque en su país. Pero claro, eso siempre que lo diga él, ¿no?

I2 - Claro.

J1 - No es que el intérprete asuma la función del operador turístico y me dé.

I2 - Exactamente. Y luego. Hay, por ejemplo, se te ocurre, cuando es un extranjero, que la cultura de esa 
persona puede ser muy lejana de lo que a lo mejor tú.

J1 - Si claro, absolutamente. Eso pasa mucho. He puesto el caso de violencia de género, porque es el que más se da.

I2: Ya.

J1 - En violencia de género, muchos están de repente con determinadas nacionalidades que están absolutamente sorprendidos, no saben qué hacen ahí, porque han tenido una discusión con su mujer y le han insultado. Entonces, claro, en España, pues eso no nos cabe duda de que es una situación delictiva, en otros países eso no es una situación delictiva. En países árabes, que a lo mejor la desigualdad está incluso legalmente reconocida, pues obviamente no es admisible para ellos pensar que puedan estar siendo interrogados por un juez por haber llevado a cabo una actuación que consideran de los más normal del mundo.

I1 - El intérprete debería adaptar su lenguaje al lenguaje de la víctima o debiera reproducir la...

J1 - ¿Del interrogado?

I1 - No, del juez o del abogado al nivel sociocultural de la víctima o debiera mantenerlo.

I2 - O sea, lo que el propio abogado.

J1 - El propio juez lo hace. Por ejemplo, yo si interrogo, si yo interrogo, pero eso a un español también, si yo interrogo a un licenciado doctor en química, le puedo, sé al nivel al que le puedo preguntar. Bueno, a lo mejor empiezo, y veo que no, lo bajo. Y si sí, lo subo. Con esta persona igual. Es decir, ahí me cuesta más saber si la persona se está enterando, pero lo que sí intento utilizar, es no utilizar términos jurídicos. Es decir, intento no decir, no términos jurídicos, términos que a lo mejor me sean más fáciles desde el punto de vista de la ley. Por ejemplo, consumo de droga, yo no le digo « ¿Ha consumido droga? ¿Has tomado droga?», que va a ser más fácil a lo mejor, porque el consumo es algo que, me viene ...o por ejemplo decir..«fuiste asistido por el abogado en la policía?» A lo mejor te dice, «estuviste con un abogado en la policía», oh.

I1 - Simplificas un poco...

J1 - Claro.

I2 - Simplificas el registro.

J1 - Claro claro. Si porque además es lo que te decía, ahí corres el riesgo de que haya terminología jurídica que no sea traducible o que incluso la traducción sea distinta. Decir, hay figuras jurídicas que en España quieren decir una cosa y en el extranjero quieren decir otra cosa. Entonces, hay que hilar muy fino. Por ejemplo, lo que aquí llamamos robo, en otros países no es robo. Entonces, efectivamente, no puedes utilizar la palabra robo. Tienes que dar el hecho. «¿Usted cogió tal después de haberle puesto una navaja en el cuello?» Entonces tienes que ir utilizando...

I1 - Entonces, claramente. Eres tú el que tienes que explicar los términos jurídicos, ¿no es el intérprete? O el intérprete se puede permitir explicar los términos jurídicos.

J1 - Hombre, si el juez quiere hacer un interrogatorio así, y el interprete jurídico. Claramente el intérprete va a tener que intentar acompasar eso al idioma que se lo tiene que traducir. Es cierto que el propio intérprete puede advertírselo al juez. «Su señoría, ese término que utiliza usted no he encontrado cómo traducirlo o puede dar lugar a ambigüedades».

I2 - ¿Ecuentras bien que algún intérprete pide una aclaración cuando has hecho alguna pregunta?

J1 - Sí. Sin problemas. Y además se agradece porque tú no sabes si estás utilizando un término ...tienes 
que ir midiendo.

I2 - ¿El nivel?

J1 - Si. Incluso me parece una actuación prudente.

I2 - Correcta.

J1 - Si una persona no ha entendido bien lo que le está contando el juez, entonces. Bueno me tiro a la piscina $\mathrm{y} .$.

I2 - Ya se apañará.

I1 - Esta era una de las siguientes preguntas. Si has experimentado alguna vez que el profesional, el intérprte no haya entendido de lo que estabas hablando.

J2 - Sí. Si que me ha resultado. Me ha resultado desde el punto de vista positivo de que me haya preguntado, me haya dich, «mire, que no le he entendido lo que quiere decir» y yo se lo digo otra vez y, y estupendo, y otras veces en las que me doy cuenta de por no querer decir, a lo mejor, está dando la sensación de qué no se hasta que punto se está...

I1 - enterando

J1 - Yo generalmente, cuando tengo esa sensación, lo que suelo hacer es vuelvo a repetir la pregunta con otras palabras para ver si, y si le veo que reitero otra vez, entonces, debe ser que sí, que más o menos le ha preguntado.

I1 - Ya, no sé si. Otra pregunta. Muchas veces los interrogados pueden hacer gestos que no son palabras, ¿Cómo transponen los intérpretes eso? ¿Cómo lo ...?

$\mathrm{J} 1$ - Bueno, eso es también muy interesante porque, eso ya no es una cuestión de interpretación, ...

(entra otro juez)

J1 - J2 - XXX es magistrado. [Presenta a las investigadoras]. Sientate

J2 - Tuve un inglés que no entendía ni papa. Eran del Rangers, que violaron a una chica, y el problema que tuve yo es que el interprete no se enteraba de nada. Era con un acento muy cerrado, muy mal escocés, no se enteraba denada. Porque yo creo que. Y al final consiguió que le hablaran muy despacio,

I1 - ¿ahí cómo? Es muy interesante ver cómo actuaste, ¿qué se pudo hacer?

J2 - Bueno, hablando despacito, .... Y del chino si que...

J1 - Bueno, es que el chino es famoso aquí en la provincia, ¿verdad? Porque es una persona española.

I2 - ¿Hay muchos chinos entonces?

$\mathrm{J} 1$ - Si, yo creo que hay bastante población,

J3 - Sí, el problema es que el chino nunca le entiendes.

J1 - Es lo que hablábamos.

I2 - Oye, os ha llamado alguna vez la atención que os hayan mandado intérpretes que digáis «iPero si no sabe hablar español!»

J1 - ¿Que no sepa hablar español? 
I2 - Que lo habla como muy rudimental. Como Tarzán. Yo Jane, tú Tarzán.

J3 - No.

J1 - No. Yo generalmente el español bien también. Es verdad que los asiáticos, los más...

I1 - Los que peor.

J1 - Digo los que peor porque claro.

J3 - Había uno de árabe. Hay muchísimo marroquí.

$\mathrm{J} 1$ - Los de árabe,

$\mathrm{J} 2 \ldots$

J1 - Yo con los de árabe tengo muy buena experiencia porque, además de que son bastante educados, el traductor de árabe que yo he tenido, domina el idioma fenomenal.

J3 - Es muy desinteresado también.

J1 - Es verdad. Son árabes que se les nota que se han criado aquí.

J2 - Una vez que tuve una declaración con un tío ...él mismo te explicaba cómo le hablaba las respuestas porque era un caso no sé lo que era. Bueno, que quería romper el marido...Porque pobre, ya ...la señora. Y si es cierto que en principio si que tuvo problemas de acento? Unos traductores que no querían, si tenían

Que eso era significativo, ....No tenía ni idea de español. No que no eran traductores, y eso si querías

F Yo mi ...si me quieren hablar español

J2 -Lo que pasa es que el marido decía que no se iba del despacho., porque la mujer no podía estar con otro hombre. Entonces ya te das cuenta de que cómo va a pasar el examen. Como va a saber español. Yo creo que. Que está demostrando una forma maravillosa, está demostrando

I1 - Qué fuerte. Pues la primera lista de la reacción. Por ejemplo también, si una persona, cuando la están interrogando, a mí me pasó en un juicio que esta persona empezó a decir frases desconectadas y a hacer muchos gestos. ¿Cómo debiera actuar en ese caso el intérprete? ¿Qué debiera hacer? ¿Repetir las mismas frases tal cual las está diciendo? No se va a poner hacer el mono.

J1 - No, lo que decía, los gestos no son ya interpretación. Es una valoración que hace el juez. Eso ya lo juzgas tú. La expresión corporal la valora el juez para decir si te están engañando. Yo, por ejemplo, cuando declara una persona, siempre le digo que saque las manos de los bolsillos, para que yo le vea cómo mueve las manos, cómo gesticula. Generalmente, el que es espontáneo mueve las manos, el que trae un discurso muy férreo está muy quieto, son cosas que normalmente. Si una persona se está poniendo nervioso escuchando a su intérprete, es que efectivamente el intérprete no está...¿¿Así?

J2 - Se pueden aplicar diferentes técnicas de interrogatorio. Una persona que ...Como lo vas a hacer tú, Las preguntas... es muy complicado, y hay veces que te das cuenta que el otro...

I2 - Perdona, ¿qué es lo que has dicho? Dices que es muy complicado el qué, no te he entendido.

$\mathrm{J} 2$ - Hacer técnicas de interrogatorio con una persona que tenga un traductor.

J1 - Parece imposible.

J2 - Muy complicado. 
I2 - ¿Por qué? ¿Sí?

J2 - Porque tú cuando le vas a hacer una serie de preguntas, ...si le haces una pregunta que tenga que ver verdaderamente con el caso, es para intentar cogerle en el ese aspecto. Es para intentar sacarle información. Con un traductor es todo mucho más complicado, porque pierdes dinamismo.

I2 - Pierdes dinamismo, pero quizás, el intérprete, debería conocer estas técnicas, ¿no?

J2 - Es más complicado. ¿Cómo lo hacemos?

I2 - ¿Si? ¿Cómo lo hacemos? ¡Con formación específica! En América se está haciendo.

J1 - Yo creo que deberían tener un poco de

I2 - En América.[solapado de voces] técnicas de interrogatorio

I1 - interesante. Entonces, el intérprete en una técnica de interpretación (sic) debiera traducir fielmente o adaptar para poder respetar estas técnicas de itnerrogatorio

J3 - Es que es muy complicado. Insisto. Si estás con un asesinato y están intentando de un modo determinado, ... sin intentar que haya una cierta contradicción.

I1 - Por ejemplo, vamos a poner un ejemplo.

I2 - Bueno, tú un mal intérprete te puede

I1 - Tu le puedes decir. Hola Pepe, cóm o está. Vamos a poner el caso. Y el otro puede decir, hola Sr, como está. Es lo que quiero decir, cómo

J2 - Intentando darle confianza. Lo que pasa que no es

I1 - Es un ejemplo

J2 - Jamás me permitiría. Eso no. Confianza no. No. Porque yo creo que hay más dudas a la hora hay que marcar las distancias. Porque la autoridad eres tú en ese caso y para que se reforme un poco. Si es un golfo, no se fa ....en la vida

I1 - Pues al revés, bien. Perfecto. Esta me ha dado la vuelta a la tortilla perfectamente. Tú le estás tratando de usted. Estás marcando una distancia, el intérprete le está tratando de tú.

J2 - Eso nunc ha pasado. Jamás.

J1 -Pero tú no lo sabes si lo está tratando de tu o de usted.

J2 - Yo no lo sé, yo no tengo ni idea del idioma

J1 - Tú no lo sabes si lo está tratando de tú o de usted

J2 - E incluso los matices de la respuesta que da que le esté dando la otra persona, yo tampoco los voy a coger porque está hablando otro idioma. porque está. Yo no sé qué matiz, me da un matiz ana una respuesta que si no mela traduce, ahí es muy complicado, hay expresiones en inglés, chino o rumano que no se pueden producir en español, ni viceversa. No sé, es mu incongruente lo que me estás contando.

M Se pierden los matices

J2 - Se pierden muchísimo. Por eso digo que hay veces que el idioma lo saben perfectamente, que a veces no entiende una pregunta y entonces se la repite. ¿Qué no me está entendiendo?

I1 - De todas formas. A veces hay una cuestión, y es que a veces sí que entiende, porque están aquí. Pero 
a lo mejor para contestar no tienen la misma capacidad. Otros lo utilizan porque tienen el derecho y el derecho es irrenunciable, es decir, el intérprete tiene que estar en la sala y ya dicen, me viene mejor porque así, no sé, o incluso...

J1 - Bueno, el derecho de, si desconocen verdaderamente el idioma. Si lo conocen no hay ese derecho.

I2 - Sí, si que lo hay

J1 - si, pero si estás viendo que

I2 - A menos que la administración se dedique a hacer pruebas de nivel lingüístico de español, para cada acusado, eso no es factible.

J2 - es que yo creo que hay también el personaje que está siendo investigado, el imputado....Una vez que saben por donde van los tiros, o el que por primera vez se enfrenta con el juzgado, el que ya lleva mucho tiempo. Yo cuando tenía a los que llevaban ya muchísimo tiempo, casi no no hacía falta. La pregunta se la llevaban. Llevaban mucho de porque llevaban de cometer un hecho delictivo. Tu me estás diciendo que no quieres ir para adentro, y se enteraban perfectamente, lo de que tú quieres ir para adentro. Perfectamente. Y sabían ¿A qué me estás entendiendo? Dondee stá fulanito y tal, ni intérprete ni leche, no sabía hablar español. Que esos son más que cómo hay que tratar con esa persona. El traductor te puede transmitir, no se lo puedes decir,

$\cdots$

Porque al final estamos hablando de intérpretes metiéndose en unos roles

J1 - eso me ha preguntado.

I2 - El intérprete está de la mafia

J2 - que te suelta algo, y luego tú cambias de..chupao, porque te cortan el cuello. Como se lo hicieron al...ese

I2 - En V hubo un caso, estaban investigando a la Mafia china, entonces empezó a ver juicios e iban unos intérpretes. Y de repente, lo contaba el director de la CdJ que ahí se veía que $\mathrm{Y}$ de pronto se empezaron a dar cuenta de que los intérpretes que habían ido yendo ya no iban, iban otros. Uy, esto, empezaron a investigar y estaban en la Mafia

I1 - En Milán....

I2 - Tuvieron que ir intérpretes de Madrid, meterlos en pisos francos, porque estos habían entrado y habían dicho fuera de aquí...porque os cortamos el pescuezo. Nosotros vamos a entrar a interpretar. Tremendo. Entonces, cómo, cómo se puede controlar esto, pues con formación, con controles de acceso a la profesión y luego con control de la calidad, por supuesto. Pero si no hay nada de esto, y la ley lo que dice es...bueno, que entre el uno y si no que entre el otro y si no otro que pase por aquí.

J1 - ¿Qué es lo que dicen?

I2 - ¿Qué es lo que dicen?

J1 - Que cojas al primero.

I1 - Al de restaurant de chino que sabe algo de español.

J2 - Yo el caso es que el caso más usual que he tenido de estos, se lo conté a .... y se lo conté a I2 es que cómo si no sabía si me estaban vacilando, fui a buscar a mi compañera para que estuviera presente porque yo no me lo creía. Era una madre y su hija, que a su hija la tenía en una situación de la jungla, un pueblo cerrado, que no iba al colegio ni nada, se había criado solo con ella en la típica pedanía, habían 
ideado entre ellas, habían creado un idioma. Cuando me lo dijeron pensé estas me están vacilando. Bueno, pues la hija solo sabía hablar con su madre, no entendía el castellano.

I2 - ¿Era española?

J1....Era una salvaje. Y yo decía oye...creo que me están vacilando cómo no va a saber hablar español, y cómo va a poder solo hablar con la madre...

I1 - investigadora 1

I2 - Investigadora 2

J1 - Juez 1

$\mathrm{J} 2-\mathrm{Juez} 2$

$\mathrm{J} 3-\mathrm{Juez} 3$ 


\section{Anexo 10: Transcripción entrevistas}

\section{ENTREVISTA 1}

I - Como me estabas diciendo, ¿desde hace cuántos años trabajas, te ha pasado tener que trabajar con intérpretes?

J - Bueno, lógicamente, yo he trabajado con intérpretes desde que he empezado a trabajar como juez. Yo llevo desde el año 2003. De hecho, he tenido, ahora estoy en XX, pero he tenido destinos en otras zonas de España, en concreto en Canarias, allí he trabajado mucho más con intérpretes porque hay mucha más población extranjera, son zonas de costa y bueno, muchos turistas también. En fin, ha habido mucha actuación más con intérpretes. Aquí la hay, pero no es tan habitual.

J- Yo, a ver, en cuanto a mis actuaciones, desde luego, tampoco conozco los detalles de contratación de los intérpretes. Esa es una cuestión ya más administrativa, de las administraciones competentes, vamos a decirlo, contratar a los traductores. Mi actuación fundamentalmente se ciñe a en los actos procesales correspondientes, ya sea en el acto del juicio oral o si ha habido de realizar pruebas preconstituidas. Una prueba preconstituida no sé si lo conoces, es como realizar el acto de juicio oral antes del juicio oral porque por la razón que sea, no se puede realizar la declaración de un señor, por ejemplo, el día del juicio, que no va a estar en la sede judicial o por otra razón, entonces digamos que se anticipa esa prueba de la práctica de la prueba en el juicio oral a un momento anterior. Se me está ocurriendo por ejemplo un caso que te comento, porque puede ser interesante, un señor, cuando estaba yo en Canarias destinado, un señor bielorruso al que le roban, este es un turista que al día siguiente se va a ir a su país, entonces claro, este señor no va a estar el día del juicio en España para celebrar el juicio, y hay que hacer previamente, aparte de su declaración de la fase de instrucción, su declaración en el acto del juicio oral, como prueba preconstituida. Ahí, por ejemplo, es un caso en el que vino un traductor. Lo que te quería decir es que mi actuación se ciñe a la participación o intervención del traductor en el acto del juicio. Yo los trámites anteriores tampoco entro.

I - ¿Hablas algún idioma a parte del castellano?

J - No. Vamos, a ver, puedo entender algo de inglés, pero tampoco lo hablo de forma fluida, y desde luego en las actuaciones procesales, que creo que es lo que interesa, en español, que a parte,

I - No, no, eso lo sé, pero...

$\mathrm{J}$ - A parte es la lengua oficial en la que tenemos que trabajar.

I. -No. Y sé que no son los idiomas más habituales en las salas, el inglés o el francés. Pero claramente, ahí si el juez se encuentra con un intérprete.

J - Sí, que va diciendo una cosa que tal vez no se corresponde...

I - Uno se da cuenta.

J - Sí, puede ser, a mí no se me ha dado el caso. En inglés, por ejemplo, sí que puedo entender más o menos lo que el testigo o el acusado o la persona que esté utilizando el traductor, digamos, está diciendo. Yo eso lo puedo estar entendiendo. De entrada, yo me tengo que fiar de lo que dice el intérprete, ya no te digo nada, en aquellos casos en lenguas que no entiendo. Imagínate un traductor de chino o lenguas que para mí absolutamente desconocidas, no. En ese caso, evidentemente, me tengo que ceñir a lo que me dicen y creérmelo.

I - Cuándo ha llegado alguna persona que no entendía el idioma, ¿cómo lo habéis gestionado? siempre 
mediante...los funcionarios.

$\mathbf{J}$ - Evidentemente, si es una persona...por ejemplo el acusado, nos viene y nos dice que necesita un traductor. Evidentemente, ya parte de hacer las cosas con sentido común, el acusado tiene derecho con base en el enjuiciamiento criminal a tener un traductor que le asista, entonces, de cara a evitar cualquier tipo de indefensión y evitar cualquier problema, en ese caso lo que hacemos es suspender el juicio, señalar otro día y citar a un traductor para que venga a asistirle.

I - Me parece que aquí está licitados ¿Eso lo sabes tú?

J - A ver, a íi me parece que aquí hay un servicio, me parece que es Ofilingua, que creo que es de la Administración de justicia. En CyL, las competencias relativas a la justicia no están trasferidas, no están trasferidas a la comunidad autónoma. Se llevan por el ministerio de Justicia, entonces creo que a través de una entidad que se llama Ofilingua, es como se gestiona la cuestión de los traductores. Pero sinceramente, yo tampoco conozco muchos detalles, no por nada, sino porque yo al final, mi actuación se ciñe al acto del juicio y a esa intervención de los traductores.

I - ¿Los controles de los intérpretes los hace el letrado de la administración de la justicia?

$\mathrm{J}$ - Bueno, en principio, yo creo que el letrado de la administración de la justicia yo creo que no lleva a cabo un control propiamente dicho, sino que simplemente el traductor que nos llega de Ofilingua es el que actúa en el acto del juicio.

I - ¿Jura siempre? ¿Jura o promete?

J - Se le suele preguntar, sí.

I - Por lo cual ¿no sabes tú el tipo de formación que ha recibido esta persona?

J - No. Yo en eso no entro. Yo parto de la base de que si Ofilingua a mí me facilita un traductor, tiene conocimientos en la lengua correspondiente. Yo tampoco puedo llegar hasta ese punto de indagación, la verdad.

I - ¿Te ha pasado a veces de trabajar con intérpretes que ves que desconocían la terminología Jurídica en español o que hablaban mal el español?

J. No recuerdo. Yo creo que cualquier intérprete que ha venido ha dado contestación o ha ido traduciendo lo que ha contestado el acusado o el testigo. Sí que hay una cosa que alguna vez me ha llamado la atención y, pero es una curiosidad, lo he tenido puntualmente, no es generalizado, ni muchísimos menos. Lo habré visto dos o tres veces, que en alguna ocasión yo le hago una pregunta, yo o el abogado o el ministerio fiscal se le hace una pregunta al acusado o al testigo, y el traductor contesta directamente. Cosa que evidentemente es improcedente, claro, porque la función del traductor no es contestar a las preguntas porque él pueda conocer la versión de los hechos que vaya a responder el acusado o el testigo. Pero es que su función no es esa. Su función es traducir lo que conteste el acusado o el testigo.

I - ¿Qué haces en ese caso?

$\mathrm{J}$ - Evidentemente indicarle que no es su función. Dar constancia a lo que se pregunta a una de las partes, sino que su función es traducir lo que conteste el declarante. Parece lógico, pero es una situación curiosa, que en estos años que llevo trabajando, desde el año 2003, se me puede haber planteado dos o tres veces, pero no deja de ser una anécdota, porque es totalmente aislado.

I - Una de las preguntas, precisamente, es esta, se interrumpía a los interlocutores el intérprete de vez en cuando, hay un tamaño entre lo que lo que el declarante habla y lo que se traduce. Una desproporción. ¿Generalmente corresponde?

J - Normalmente corresponde. Sí que es cierto que a veces también llama la atención, puntualmente 
también, a lo mejor que el declarante, voy a decir declarante para no estar distinguiendo entre acusado y testigo, la persona que declarada y que está asistida por el traductor, le da una contestación que tú ves que es muy larga, te está hablando a lo mejor uno o dos minutos, y luego el traductor te da una contestación muy corta. Yo ahí ya lo que no sé si es él hace un resumen, que entiendo que debe ser así, de lo que el acusado ha dicho, o no sé por qué responde así. Pero, insisto, esto es una cosa puntual también.

I - ¿No toman notas?

$\mathrm{J}-$ ¿El traductor?

I - Sí.

J. No, no. Normalmente su actuación es totalmente oral. Entonces, pero ya te digo que es puntual. Lo habitual es que ante una contestación del acusado se de una contestación proporcionada del traductor. Hay que entender que lo que hace es traducir lo que dice el declarante.

I - Y en esos casos, ¿qué es lo que has hecho? Cuando has visto que la...

$\mathrm{J}$ - Bueno, pues se le ha dicho, se le puede indicar que, no recuerdo tampoco ahora exactamente, porque ya te digo que ha sido algo que es muy puntual la situación. Sí se le puede indicar al traductor «Oiga, el declarante ha dado una contestación con contenido, vamos a decir, y usted da una respuesta muy escueta, ¿puede aclarar eso?». Más que aclarar, que nos diga lo que ha dicho el declarante y ya luego nosotros valoraremos la contestación.

I - Otra cosa también importante, interesante: la comunicación no verbal. ¿Has visto alguna vez que la persona, el declarante, ponga caras raras, o el público ponga caras raras, cuando está hablando el intérprete?

J - Pues yo no lo he detectado. También hay que darse cuenta de que, hay veces que los declarantes, aunque haya un traductor, pueden entender en parte la lengua española. Ahí, en ese caso, yo no recuerdo haberlo tenido, pero en ese caso pudiera entenderse que pueda poner una cara rara ante una contestación del traductor. Pero claro, si estamos hablando de una persona que no conoce ahora nada la lengua española, cuando el traductor dé una contestación, difícilmente van a poder sorprenderse de lo que digan, porque no entiende lo que dicen en español.

I - O público. En una vista oral.

J - Yo no recuerdo que haya tenido eso. Normalmente tampoco tenemos mucho público en los juicios orales. A veces un testigo que esté en la sala o lo que sea, pero vamos, yo no recuerdo.

I - ¿Qué idiomas son los que más te ocurre?

$\mathrm{J}$ - La verdad es que no hay un idioma que prevalezca, tenemos de vez en cuando de árabe, de portugués, a ver...es que no hay un idioma que predomine, la verdad.

I - Ya, porque en otras zonas.

$\mathrm{J}$ - De ruso, en algunas ocasiones. Pero no hay un idioma que predomine.

I - En otras zonas que dependía. En la costa, había mucho árabe, pero también había mucho rumano y un montón de chinos. Entonces, depende de la zona.

J - Aquí tenemos alguno de chino, de rumano, no hay un idioma desde luego que predomine. Y los idiomas que puedas decir más habituales, inglés, francés, pues tampoco tenemos muchos casos.

I - ¿Qué tipo de cualificación debería tener para ti un intérprete judicial? ¿Qué tipo de formación? 
J - A mí lo que me interesa como juez, en este caso, es que me traduzca fielmente lo que me dice el declarante. Entonces, lo que entiendo es, que más allá de la titulación que pueda tener, que desconozco cuál pueda ser, entiendo que debe hablar correctamente tanto el idioma español como el idioma de la persona que debe traducir. Ya digo, sin entrar en la titulación. Al final a mí lo que me interesa es que traduzca fielmente lo que el declarante me dice.

I - Claro, lo que pasa es que para aprender a traducir y traducir un lenguaje también técnico.

$\mathrm{J}$ - Sí, por supuesto.

I - Y con tantas implicaciones.

J - Yo no sé si hay ya a nivel de la Escuela Oficial de Idiomas. Es que tampoco. Pero desde luego, conocimientos suficientes para poder con fluidez poder traducir y poder dar respuesta a lo que al final desde la administración de la justicia se les pide.

I - ¿Qué tipo de contratación garantiza una mayor calidad? ¿Estás a favor de que sea subcontratado el servicio?

J - Yo ahí poco tengo que decir, porque yo creo que me planteas una cuestión administrativa, al final. Yo vuelvo a lo mismo, yo me limito a mi actuación en la sala de vistas. Yo quiero una persona que me traduzca. El tipo de contratación cómo se realice, es que tampoco puedo llegar yo a eso. Yo entiendo que esos son al final medios que las administraciones nos tienen que suministrar a nosotros a la hora de hacer nuestro trabajo. Pero ya digo, yo ahí lo que creo es que hay que disociar nuestra propia actuación de la actuación administrativa de suministrarnos esos medios. Entonces, por eso ahí, tampoco entro. Tomo el partido de la base de que los medios que se suministran son los correctos para que podamos hacer bien nuestra labor.

I - Lo que pasa es que ha habido muchos escándalos, en España, de gente contratada por agencias, por algunas de estas compañías, que no tenían ni titulación, que no sabían ni siquiera el idioma, que no sabía el español.

$\mathrm{J}$ - Evidentemente, esas son situaciones que hay que erradicar, y por eso te digo que sin entrar en detalles administrativos concretos de cómo deba hacerse, lo que se debe requerir es que personas, con la titulación oficial o del modo que sea correspondiente, hagan correctamente su trabajo. Pero ya te digo, yo creo que esa es una cuestión administrativa que a mí en principio se me escapa un poco. Creo que tampoco le doy vuelta en ella.

I - ¿Sabes si se hace algún tipo de control de calidad de la actuación de los intérpretes?

J - Lo desconozco. Vuelvo a decirte lo mismo. Yo me limito a la actuación en sala, yo no sé si luego los que intervienen como traductores han de dar algún tipo de cuenta a Ofilingua o a una administración, al Ministerio de Justicia, lo desconozco.

I - A ti no te ha pasado nunca recusar un intérprete o lamentarte de un intérprete.

J - No. Mi actuación con los traductores. más allá de los hechos puntuales que te he comentado anteriormente, no recuerdo tampoco ninguna irregularidad ni ninguna circunstancia que me haya llamado la atención.

I - ¿Has trabajado alguna vez con videoconferencia?

$\mathrm{J}$ - Muy habitualmente.

I - ¿Y qué tal?

J - De todas maneras, ¿me estás preguntando con traductor? No creo que el hecho de actuar en 
videoconferencia afecte a la actuación del traductor.

I - Puede ser más difícil.

J- Puede ser más difícil por el hecho físico de no estar todos en la misma sala. Pero no porque el traductor haya actuado de una manera distinta, es decir, si tenemos una persona por videoconferencia, la tenemos en otra ciudad, lo que sí solemos hacer es en algún caso en el que el declarante declara por videoconferencia, el traductor está con él. Es decir, no tenemos el traductor en XXX y el declarante en $\mathrm{XXX}$, por ejemplo, eso sí que lo tenemos en cuenta. Creemos que es más correcto hacerlo de esa manera. Que la persona, el traductor en este caso, acompañe a la persona que está fuera de XXX declarando. Ya digo, más allá de los inconvenientes técnicos que pueda haber con la videoconferencia, que es al margen de la actuación de los traductores, cuando hemos tenido esos supuestos, que también han sido excepcionales, en pocas ocasiones yo recuerdo haber tenido traductores a través de videoconferencia, pues yo no recuerdo tampoco que haya habido nada raro.

I - El otro día me comentaron de un caso, de una videoconferencia entre Milán, Siracusa y Valladolid, que debió ser la locura. Eso es muy complicado.

$\mathrm{J}$ - Suena complicado, y sobre todo cuando actúas con varias videoconferencias al tiempo es más complicado todavía.

I - En cuestión de técnicas de interrogación, donde declarantes, vamos a llamarlos así también, ¿cómo consideras que se tiene que comportar un intérprete? ¿Tiene que reproducir fielmente o tiene que adaptar para que comprenda la otra persona?

$\mathrm{J}$ - O sea, lo que me preguntas es, cuando yo hago una pregunta, si el traductor le tiene que decir al acusado lo que yo le he dicho o adaptárselo. Hombre, yo no sé si es necesario ese tipo de adaptación a la que me haces referencia, porque si yo por ejemplo al acusado le digo «Usted como acusado tiene el derecho a no declarar, el derecho a no declararse culpable», entiendo que eso se puede traducir fielmente, pero claro, yo tampoco entiendo lo que le dice el traductor al declarante, con lo que igual, parto de la base de que el traductor le está diciendo a la persona que tiene que declarar lo que le están preguntando. Tampoco puedo llegar más allá porque no conozco la lengua extranjera.

I - No, pero claramente me imagino que, otros jueces me han dicho que son ellos los que adaptan el registro. Que ellos son los que si ven que la otra persona no entiende, porque tiene un nivel cultural.

J - Pero bueno, yo a mí eso me parece razonable, incluso ya no con una persona que necesite traductor, sino a lo mejor, tú le estás preguntando una persona, o un abogado está preguntando a una persona una cuestión que no entiende pues por términos jurídicos, o términos de cualquier tipo y evidentemente ha de adaptar la pregunta en unos términos en los que la persona pueda entender. Yo entiendo que si el traductor, cuando tiene que traducir una pregunta que se ha hecho, o bien él mismo no es capaz de decírselo con esas palabras, o bien advierte que al acusado hay que preguntárselo de una manera que lo pueda entender, pues se lo adapta. Pero bueno, yo creo que ya es una cosa de sentido común.

I - Pero se lo tenéis que advertir vosotros, que se lo adapte o tiene que hacerlo él por propia iniciativa.

J - Yo tampoco se me ha dado nunca el caso. En principio creo que se traduce fielmente o se debe traducir fielmente lo que se pregunta. Si se diera el caso, yo creo que sí haríamos una indicación de que si él no entiende, porque el traductor una vez que le ha hecho o le ha traducido al declarante la pregunta y dice «es que no entiendo lo que significa», pues tal vez puede reconducir o hacer la pregunta de otra manera.

I - ¿Ha habido algún caso en el que el intérprete haya explicado alguna cuestión cultural del declarante?

$\mathrm{J}-$ Yo no lo recuerdo.

I - Porque podía complicar. 
$\mathrm{J}$ - No lo recuerdo.

I - ¿Y qué opinas? ¿Piensas que el intérprete debería explicar las diferencias socioculturales?

$\mathrm{J}$ - ¿Qué comentar el traductor?

I - Puede haber en algunos casos.

J - Yo creo que propiamente en el acto del juicio no. Es decir, volvemos a lo mismo. El traductor lo que ha de hacer es traducir lo que ha de preguntarse al declarante. Que antes del juicio nos pueda indicar alguna circunstancia referente al declarante, pero como nos lo puede indicar cualquier otra persona, porque no oye bien, o cualquier otra circunstancia, por poner un ejemplo. El funcionario que tenemos en la sala haciendo de auxilio judicial nos lo puede indicar. Yo no recuerdo que se haya dado el caso, pero bueno.

I - ¿Tenéis alguna pequeña entrevista antes con el interprete antes de la vista?

J - No. Yo por mi parte no. Yo no sé mis compañeros lo que hacen.

I -¿Recibe información? Tampoco lo sabes.

$\mathrm{J}$ - No que yo sepa. Sabe que tiene que venir al juicio porque se le cita.

I - Si, pero recibir información para prepararse para el juicio. Material. O venir antes para consultar.

J - No, y además. Que yo sepa no, pero además no le veo cuál pueda ser esa función, porque al fin y al cabo, yo creo que el traductor, tampoco creo yo, tampoco creo que tenga que buscarle en el expediente.

I - Es muy difícil traducir si no sabes de qué va un juicio. Puedes tener que traducir de todo, desde un informe médico o forense, hasta un peritaje.

$\mathrm{J}$ - Yo te hablo de mi experiencia o lo que he tenido hasta ahora, yo no he tenido traductores que en principio hayan venido a traducirnos documentos. Por ahí voy, por el hecho de que a lo mejor no veo la relevancia de, es decir, el traductor viene a traducir lo que dice algún declarante, en lo que yo he visto.

I - Pero hay cosas muy técnicas.

$\mathrm{J}$ - Otra cosa es que, a lo mejor, tengamos algún documento en legua extranjera que haya que traducir. Ese documento entonces sí se traduce pero no en el acto del juicio. Tenemos una traducción por escrito y en principio ahí queda. Yo no recuerdo tampoco que hayamos traído al juicio, porque tampoco lo ha pedido nadie, a traductores de documentos por escrito. ¿Me explico? Yo los traductores que recuerdo para traducir.

I - Y los documentos traducidos por escrito, ¿qué tal están?

J - Bien. No tengo queja. Pero vamos, vuelvo un poco a lo mismo. Documentos en francés se puede entender algo.

I - No, pero a veces... una traducción si está mal hecha se nota. A veces...

J - Yo no lo he detectado. También es verdad. Igual que los traductores con los declarantes, sin ser habituales de todos los días, no son excepcionales, las traducciones por escrito sí que son excepcionales, tenemos muy pocas.

I - Quería preguntarte algo más. A ver si me acuerdo, ya me lo has dicho lo de la traducción escrita, la última pregunta y ya te dejo. Durante el juicio, ¿se le traduce todo al acusado o solo las partes? Cuando vosotros estáis hablando, cuando está hablando el abogado? ¿se le traduce al oído o no lo permites?

J- No, yo no lo prohíbo en ningún caso, por supuesto, pero la práctica habitual en lo que yo veo es que el 
acusado o mejor dicho el traductor interviene fundamentalmente en la declaración del declarante. Hay que distinguir dos supuestos, cuando declara el testigo, no hay problema, porque el testigo declara, se le traduce lo que dice y se va o se queda en la sala, pero no tiene más intervención. Y tampoco tiene a lo mejor más interés. En cuanto al acusado que sí que permanece en el juicio todo el rato, lo que yo veo habitualmente es que el traductor en los casos en los que lo hemos sostenido, traduce cuando él declara y luego en algunas ocasiones sí que le hace algún comentario, pero yo tampoco veo que cuando tenemos traductor con el acusado continuamente le esté diciendo todo lo que se dice.

I - ¿Y no te parece que ahí se está minando un poco su derecho a la información?, porque en el fondo...

$\mathrm{J}$ - Sería tal vez lo deseable, quiero decir para que el acusado conociera todo lo que se está diciendo, que el traductor.

I - El acusado no se puede defender ahí si no entiende.

$\mathrm{J}$ - Sería deseable que el traductor de continuo le estuviera diciendo, más que nada para que él supiera lo que se está diciendo. Efectivamente.

I - Y las sentencias, generalmente vosotros las dictáis después, es diferente que en Italia. En Italia se dictan en el momento, in voce, entonces claro, nunca se hacen en forma oral en la vista, ¿no? Las conformidades.

J - Bueno aquí, las conformidades sí. Las conformidades se dictan todas. Hay que distinguir entre lo que son conformidades y lo que son no conformidades. Aquellos asuntos en los cuales, tras la práctica de la prueba, se declaran asuntos listos para sentencia, terminado el juicio y luego la sentencia se dicta ya cuando corresponde. En las conformidades, sí que se dicta sentencia in voce, y luego esa sentencia se redacta por escrito. Las partes conocen en el acto del juicio cuál es su contenido.

I - ¿Y eso se le traduce?

J - Evidentemente sí. De hecho. Yo de todas maneras, ahora mismo, no recuerdo si he tenido algún caso en el que haya habido una sentencia de conformidad con intervención de traductor, vamos a decir. Pero en este caso, evidentemente, si lo hubiera, el acusado necesariamente conoce todo, eh. Conoce todo, porque por la propia dinámica de los juicios con conformidad, el acusado antes de prestar su conformidad, él presta su conformidad a las penas que se piden y con carácter previo conoce cuáles son esas penas. Ya digo, yo no recuerdo de haber tenido supuestos de conformidad con intervención de traductor para el acusado, pero desde luego, si lo hubiera, el acusado tiene que, mejor dicho, el traductor tiene que decirle cuáles son las penas que se piden, los hechos por los que se le acusa, porque él tiene que prestar su conformidad. Y evidentemente, si él no conoce todas esas circunstancias, no puede prestar la conformidad válidamente. Entonces, yo no recuerdo acusados, pero si he tenido alguno, luego eso se garantiza absolutamente que si él no conoce cuáles son los hechos y la pena que se le pide, él no pude prestar la conformidad válidamente, por lo tanto, eso lo aseguraríamos del todo.

I - Yo he visto algún caso en qu,e con los abogados, es lo mismo, conformidad porque es mucho más cómodo para ellos, pero otros abogados se lamentaban de ello, que no se les está explicando bien los abogados en lo que se están metiendo.

J- Ya, pero esa ya es una cuestión creo yo de que el abogado haga fielmente su trabajo, de información de defensa, de conocer las consecuencias de prestar una conformidad, de que se le va a imponer una condena, de las consecuencias que ello tiene, que no puede cometer unos delitos, hay que ir al caso concreto, eso ya es una cosa que queda fuera del traductor, sino que es una función del abogado claro. En aquellos casos en que el acusado requiere de traductor, pues ahí el abogado tendrá que hablar con el traductor, el traductor se lo tendrá que explicar al acusado, pero el acusado en todo ese círculo al final tiene que acabar sabiendo lo que está sucediendo.

i - ¿Habéis recibido alguna vez formación de trabajo con intérpretes? 
J - No. Vamos, yo en mi caso no. Otros compañeros no lo sé.

I - Habiendo estado en varios sitios te podía haber pasado, en cualquiera de los ..., en las mismas islas Canarias.

$\mathrm{J}$ - En principio, no recuerdo, no hemos recibido.

I - Ni unas normas. Porque sí que han salido del Tribunal Superior de Justicia hay unas recomendaciones para trabajar con intérpretes, pero no se han hecho una gran publicidad de ello.

J - Yo desde luego desconozco esas normas o esas instrucciones o protocolos. Ya te digo, yo no recuerdo de haber recibido ningún tipo de formación.

I - Pues nada más, creo que ya he acabado. Muchas gracias.

Luego me habla de su experiencia en Canarias cuando llegaban las pateras. Había varios intérpretes de diferentes idiomas. El juez hablaba y los traductores iban traduciendo a los distintos grupos directamente al mismo tiempo todos.

I - Investigadora

J - Juez 
ENTREVISTA 2

I - Pues muchísimas gracias que no todo el mundo lo acepta de buena gana.

$\mathrm{J}-$ No bueno, es que yo creo que para hacer un trabajo cualitativo, es necesario tener la mayor fidelidad entre la información que se utiliza y el soporte del que uno parte.

I- Quería saber tu opinión, en primer lugar del trabajo con intérpretes, sobre la calidad de los intérpretes, y cuál es un poco tu experiencia.

$\mathrm{J}$ - Vamos a ver, el trabajo con intérpretes suele ser un escenario de problemas. Suele ser un escenario de problemas, primero, porque los órganos jurisdiccionales no siempre sabemos identificar la necesidad. La necesidad de intérprete. En nuestro caso no llega un enjuiciamiento por parte de los acusados y también por parte de testigos. ¿Esto qué provoca? En ocasiones, por razones funcionales, económicas, económicas del proceso no de economía, que también, provoque que se plantee la situación de la necesidad de intérprete o de conveniencia, pero se continúa. «Bueno, usted más o menos entiende». Nadie se opone. Las defensas, no se oponen. No suelen ser particularmente reivindicativas en reclamar que el juicio se celebre en las condiciones que el juicio se.... Si es un supuesto de necesidad absoluta, evidentemente si. Si el acusado lo solicita, evidentemente sí. Pero si nadie dice así nada, incluso a veces el propio acusado no es consciente de transcendencia que puede tener para él. Esta, hay una cierta coerción, o no le asiste, no se le ha informado correctamente de sus derechos, el juicio se celebra en unas condiciones de baja calidad del de proceso, de comunicación y de comprensión con el acusado. Más aún, esto sucede más aún en juzgado fuera de XXX, ¿Por qué? Porque realmente podemos hablar de dos circuitos en materia de medios y calidad de la prestación, ...tiene servicio público en la administración de la justicia y a los pueblos tarda más en llegar, es más complicada la localización, suelen ser juzgados... por personal menos experto y a veces con una carga aún mayor de trabajo, con lo cual, la eficiencia en términos cuantitativos se antepone a la eficiencia en términos cualitativos, por ejemplo. El otro día veía una grabación de un juicio por delitos leves en el que el denunciante y un testigo eran árabes. Bueno, al denunciante se le entendía difícilmente, afortunadamente, el testigo, aunque no era español, hablaba un castellano correcto, entendía correctamente. La prueba de cargo para la condena del denunciado de una cuestión leve era la declaración del denunciante y el testigo. El testigo bien, el denunciante...porque ¿Además esto qué provoca? Que se interrogue de forma sugestiva, para suplir las necesidades de comprensión. «Bueno, entonces, ¿usted quiere decir esto?» Usted ya dijo y posiblemente el testigo, el denunciante y a veces el propio acusado están en un espacio donde se sienten cohibidos pueden tender a decir lo que no en condiciones donde el proceso comunicativo se desarrollara con plena comprensión de lo que se dice. Esto es por un lado.

El problema de la calidad de los intérpretes. Te pongo un ejemplo de la semana pasada. Es un ejemplo que «ejemplifica». Tenemos un juicio con videoconferencia con Noruega para tomar declaración a unos testigos. Viene una intérprete de la empresa que presta el servicio de interpretación de forma concertada, empresa privada, viene una intérprete de noruego. El noruego evidentemente lo manejaba bien porque ella era noruega, pero el castellano no. Yo incluso le ofrecí la posibilidad de leerse es escrito de acusación previamente porque se familiarizada, eran cuestiones económicas. Yo creo que nos entendía con dificultad al formular las preguntas, incluso en alguna ocasión tuve que intervenir en la que se formulaban preguntas en la que la intérprete tenía que trasladar, traducir para que fueran contestadas por los testigos que estaban en Noruega intervinimos para masticar un poco el contenido de la pregunta porque, esta es otra, los que intervienen en el proceso muchas veces no son conscientes de la dificultad y no son claros en el interrogatorio. Deberían serlo siempre, pero hay gente, hay profesionales que tienen más capacidad de comunicación oral y de exposición oral, y hay otros que son más desordenados. Cuando son desordenados suelen trasladar las preguntas de forma desordenada y con eso se suman, o igual el tipo, los términos que se utilizan, es que cuando uno ve que hay problema con la interpretación, debe acudir a la paráfrasis, en lugar de utilizar una terminología especialmente técnica. Problemas de calidad con los intérpretes hay. ¿Por qué? Pues porque en este país no hay, está previsto porque lo prevé la Directiva, lo prevé la ley. Ya ha pasado más de un año y aquí no se ha creado el registro de intérpretes, ni sabemos nada de ese registro de intérpretes. Normalmente cuando una ley en España pone un plazo 
para que se dicte otra en desarrollo de, podemos esperarnos sentados, no.

Entonces, no hay controles para el acceso de los profesionales a la interpretación, se presta el servicio, se privatiza el servicio, eso no implica necesariamente, pero desde luego en el caso español si. No es un caso parecido al inglés. Aquí no se controla la calidad. Se contrata, yo no sé cuáles son las condiciones, me gustaría saber cuáles son las condiciones de la contratación.

I - Muy malas. Las condiciones de los intérpretes por lo que estoy averiguando yo son pésimas, les pagan verdaderamente una miseria.

$\mathrm{J}$ - Que les pagan poco, seguro.

I - y no es gente profesional. No es gente, están tomando estudiantes de turismo, estudiantes de derecho, Cuando son estudiantes de derecho, va bien, Hay gente que no está capacitada.

J - Aquí luego hay otros problemas que son también serios. Por ejemplo, el otro día, en un juicio, venían dos intérpretes de una lengua africana, que habían participado como intérpretes auxiliando a la policía, traduciendo unas conversaciones telefónicas que se habían intervenido con la autorización judicial. ...en el idioma de los interlocutores, y ellos habían intervenido en la ...Cuando llegan, tienen que ir a juicio para confirmar que lo que constaba transcrito se correspondía con lo que ellos decían, que unos y otros decían. Era esencial, pues al final hubo que suspenderlo por otras razones. Estaban asustados y nos pidieron que al intervenir en juicio, por favor, no se les pudiera ver a los acusados. Esta es una situación en principio legalmente no prevista, aunque entiendo que al intérprete se le puede dar un trato análogo al de perito. Por tanto, sí que hay una ley que escasa en sus previsiones la protección para proteger a testigos y peritos. Ya veremos cuando se nos vuelva a plantear. ¿Qué sucede? Pues lo que en otros países está contemplado aquí no está contemplado, y es que el intérprete que interviene en fase de investigación, ¿debe intervenir en fase de juicio? Aquí ni se contempla.

I - En Italia no se puede. Yo soy perito en Italia y en Italia no se puede.

$\mathrm{J}$ - Claro, pero es que hay que analizar cómo, lo cual no quiere decir que un intérprete pueda, en determinadas ocasiones, ser el intérprete de la investigación, ser en determinadas ocasiones intérprete en juicio oral. O habría que ver, no, debería de haber un cuerpo de intérpretes que intervinieran en una fase, y otro cuerpo de intérpretes que intervinieran en otra. ¿Si intervienes en una fase es conveniente que intervengas en la otra? Bueno, el problema de contaminación o problemas de pretensiones espúreas de como has intervenido ahí, ahora que vas a intervenir, me cuentas o intervienes en la manera que yo te pueda decir, pero problemas de presiones va a haber, hay veces que conforme interprete, conforme traduzca el intérprete, puede interesar o puede recibir presiones porque lo que diga, puede afectar a una cosa o la otra.

En España, escasa calidad porque se invierte muy poco, por el modelo que ya conoces. Poca sensibilidad, por parte de los operadores jurídicos. Yo, a veces lo he planteado, con compañeros de otros territorios, de otras comunidades, además en XXX, la entrada en vigor de la Le.Crim 5 del 2015 no ha supuesto un cambio verdaderamente. Claro, yo no estoy en la fase de investigación, yo no sé si los abogados están solicitando poderse entrevistar asistidos por intérpretes.

I - A mí lo que me dijeron algunos abogados, sí. Ahora parece ser que algo les dejan hacer. Pero hay algunos abogados que me han dicho que están muy satisfechos, otros que me han dicho que están muy insatisfechos, ideas para todo, la verdad. Que llama la atención.

J- Aquí, aquí deberíamos. Escritos de acusación, los escritos de acusación se tienen que traducir cuando el idioma de la persona, salvo que haya habido una renuncia. Bueno, tu puedes renunciar a la traducción, a la interpretación en un juicio de apelación no puedes, es irrenunciable, aunque de facto se renuncia por la vía de no identificar la necesidad, o sea, es una vía espúrea de renuncia. No se traducen los escritos de acusación, no se traducen los autos de prisión y no se traducen las sentencias. No se está haciendo, por la...bueno. Mira, hace años, una compañera, éramos jueces de lo penal, lo penal son jueces unipersonales que enjuician delitos hasta penas de cinco años. Lo planteamos en una junta al decano, y 
era la necesidad de traducir las sentencias ¡antes de la Directiva incluso! Y antes de la entrada en vigor de reforma legal que la transpone. Planteamos la necesidad de que las sentencias fueran traducidas al menos a los acusados extranjeros que no manejaban el castellano y que estaban ingresados en un centro penitenciario, por las dificultades especiales que puede tener alguien que está privado de libertad. El decano dijo, bueno, voy a hacer una consulta a ver si esto es un problema ...ipues lo detectamos nosotros! Nadie nos dijo nada. La respuesta fue «Bueno... en la cárcel dicen que eso nunca ha planteado problemas porque siempre hay algún interno que habla el idioma y se lo traduce». Bien, pero eso no era la cuestión.

En fin, no sé, probablemente mi análisis es muy poco esperanzador, pero creo que la cuestión es que para empezar, uno, no hay medios, pero otra, tampoco hay la cultura de la aceptación, de la trascendencia de los procesos comunicativos. Perdona, hago un salto, nuestro modelo de enjuiciamiento, a veces, parece que el que se está defendiendo es el abogado del acusado. Entonces, el acusado a veces parece un convidado de piedra, de manera que hay muchos abogados para los cuales lo trascendente es que es él, es importantísimo que él se sienta en condiciones de ejercer adecuadamente, de asistir adecuadamente a su cliente, pero el cómo el cliente viva el proceso, eso es algo secundario. Ya está él. Evidentemente, él, con las herramientas que tenga, pues si tiene algún conocimiento de idiomas o no, pues podrá ir trasladándole la información. Pero yo creo que hay, digamos que somos poco empáticos, ¡somos poco empáticos! Entonces el acusado es a veces casi como un personaje molesto en el proceso, que tiene derechos, que los derechos a veces se observan como inconvenientes para el avance del proceso, en lugar de tenerlos integrados como....lo que tenemos que garantizar y no podemos permitir que el proceso termine si no es resetando las reglas de tratamiento y las reglas de obtención de la información y las reglas de la valoración de la información. Esta es un poco mi visión.

I - Y vosotros como jueces, ya me lo has dicho en parte, que habéis notado la falta de preparación de intérpretes, ¿qué es lo que hacéis en estos casos? ¿A veces les habéis preguntado que tipo de formación tienen? o ¿habéis recusado algún intérprete?

J - A mi, a nosotros nos ocurrió en una ocasión, era un juicio muy complejo, con treinta y tantos, cuarenta y tantos acusados de nacionalidad búlgara, a parte de algunos españoles, y parte de los acusados de nacionalidad búlgara llevaban tiempo en España y manejaban el castellano. Algunos perfectamente. Pero había otros que no. Comenzamos el juicio con una sola intérprete. Y una intérprete de muy baja calidad, escasísima cualificación. El primer día, ya observamos, había como malestar y hubo un momento que casi, cuando la intérprete estaba traduciendo, bueno, estaba interpretando, estaba haciendo la acción de interpretación en el juicio, le costaba mucho porque, claro, esta es otra, aquí no se hace la interpretación simultánea, se hace consecutiva. Esto en procesos largos, con mucha prueba, es muy fatigoso para el intérprete, pero muy fatigoso.

I - Y para vosotros también.

J. Y para nosotros también. Desde luego. Provoca que el juicio sea premioso, sea cansado, sea agotador, y provoca además prolongación de los tiempos. Bien, pues hubo algunos de los acusados que hablaban, eran búlgaros, hablaban el castellano «¿Pero esta qué está diciendo?». Y ella misma reconoció que no se sentía capaz. Era un asunto de una estafa, había, pues había documenteos que tenían una denominación particular, documentos que son habituales en la recogida de la naranja en el mundo de la recogida agrícola. Tampoco era gran cosa pero ella, un albarán, una lista de campo, había conceptos, había palabras que ni siquiera sabía lo que significaban. Bueno, pues paramos el juicio, lo suspendimos, hablamos con ella, ella misma dijo que ella renunciaba, pero ella no podía renunciar, ella no sea sentía capacitada. Bueno, al final vimos que la solución era, ella no se sentía capacitada, ella estaba tensa, estaba siendo cuestionada de modo permanente por los acusados, y hablamos con la empresa que presta el servicio. Al día siguiente teníamos a dos intérpretes jurados, de búlgaro, y además a dos.

I - ¿Y buenos?

J - Y buenos. Con lo cual. Además, nos plantearon un juicio de estas características, tiene que haber dos. Aquí, no tenemos un protocolo de cómo trabajar con los intérpretes sin la preparación de un juicio. 
Bueno, está el Libro Blanco de la Interpretación.

I- Están las prevenciones...

$\mathrm{J}$ - No tenemos formación de qué es lo que necesita un intérprete para poder desarrollar su trabajo. De hecho, intérpretes de los que participan tampoco lo saben, o no lo reclaman.

I - No, no lo reclaman. Ahora la UJI está organizando un curso de capacitación. Me he apuntado, yo soy ya perito en Italia.

$\mathrm{J}$ - Lo vi, lo vi si.

I - La verdad es que está muy bien porque es muy intensivo. Y dejan las cosas claras. Si después esta gente no es contratada...ese es el problema.

$\mathrm{J}$ - Difícil que esas personas admitan ser contratadas en las condiciones laborales en las que se contratan. Cito, acción de necesidad, uno puede admitir lo que sea, pero con el esfuerzo, la preparación. Yo creo que no somos tan conscientes de cuál es la cualificación necesaria y el grado de preparación, y por tanto de años de formación necesarios para desarrollar perfectamente el trabajo de intérprete, de intérprete judicial. Parece que en los otros espacios nadie cuestiona, intérprete en organismos internacionales, son personas cualificadísimas, con una formación extensísima. Filólogos, no sé cuántos, a todo el mundo le parece normal. En cambio, llega aquí, sobre todo en la justicia penal. La justicia penal es la justicia de la marginalidad, de la pobreza. Eso tampoco lo podemos olvidar cuando las instituciones responden en función de a qué sector de la sociedad está dirigido. O porque son sectores que no ejercen sus derechos, porque no los conocen. Nadie se plantearía que en un procedimiento mercantil de decenas de millones de euros, hubiera problemas por temas vinculados con cuestiones idiomáticas. ¡Vamos! ¡De lejos! El asunto de cuatro senegaleses o veinticinco o veintisiete, treinta y siete búlgaros que se dedican a recoger naranjas, algunos de ellos por cierto con formación universitaria, pero en un espacio de vulnerabilidad. Pues no. Fueron ellos, no sus abogados, fueron ellos quienes dijeron ehhhh, oiga, este intérprete, y tenían toda la razón. Y hubo una respuesta. Y en ese caso, sí. La respuesta fue la correcta. Bueno, funcionó el juicio.

¿Hacemos nosotros lo que la ley prevé de detectar? Pues no lo estamos haciendo. Detectar la competencia. Claro, en ocasiones es muy complicado detectar la competencia. Aunque hay a veces que es el lenguaje gestual te lo permite identificar.

I - La comunicación no verbal, me lo decía también otro juez, que muchas veces os permite percataros directamente de lo que está pasando.

$\mathrm{J}$ - Cuando ves que el intérprete temeroso, o incluso la respuesta del acusado, del interrogado que no entiende muy bien, no sé muy bien de qué están hablando, pero ves que ahí hay un problema de comunicación. Buenos, pues si es de inglés o de francés, algún compañero que sepa algo de alemán, ahí te..., pero normalmente son esos idiomas en los que menos problemas hay en la calidad. El intérprete que presta servicios de inglés, que también interpreta de alemán, cuando comenzó no era muy bueno, pero después de unos años, pues sabe hacer su trabajo. Y es que además no hay, e incluso muchas veces miembros del tribunal o abogados muchas veces tiene cierta competencia en el idioma como si hay algo para poderlo identificar. Pero claro, no estamos hablando de eso, estamos hablando de idioma árabe, idiomas de países africanos, los idiomas difíciles. ...precisamente esto, en el trabajo el informe de la FRA, de la agencia europea, decía que en Estonia, solo había un intérprete de farsi. Ponte.

I - Es que hay algunos idiomas que son dificilísimos de encontrar. Son muy difíciles.

J - Claro. A veces acudir a la vía de las sustituciones. Del uso de otro idioma con el que se maneje. Aunque hay muchas veces que hay acusados, sobre todo de países africanos, que el inglés o francés como segunda lengua, que la manejan sin que les cree ningún problema. Creo que somos poco sensibles. Ves, hay veces que lo he puesto como ejemplo. Dando clase. Si a mí me detuvieran en Tailandia y me imputaran llevar una bola de heroína, porque alguien me la hubiera metido, estaría horrorizado si no 
pudiera tener a alguien, a quien me agarraría como una lapa para que dijera lo que yo estoy diciendo, para que me dijera lo que están contando. Y eso es algo esencial. Yo creo que somos poco, hay poca sensibilidad, quizás también por falta de formación, o bien porque la manera en la que funcionamos, que es con muchas prisas, con pocos medios, al final proyectas la frustración de carecer de medios sobre quien te está reclamando que los tengas, en vez de no te dirijas contra quien no te los da. Mire usted, no me toque las narices, esto tiene que avanzar y si la calidad no es mucha, yo no tengo la culpa. Ya, pero es que yo tengo la obligación de garantizarla.

I - Claro claro. El mismo hecho que muchas veces los intérpretes debieran tener acceso a la documentación para poder preparar.

J - Claro, y para poder manejar, para poder prever y reaccionar ante el tipo de preguntas. Yo ahí veo un conflicto que no está bien resuelto, y es el riesgo que puede generar en el intérprete el que el desconocimiento de la causa, pueda provocarle, a la hora de interpretarla, el sentido de lo que se dice.

I - Pero bueno, es como un abogado también. Uno, su deontología. ¿Cuál es el problema? Que hay intérpretes no preparados. Si hubiera verdaderamente el registro, y al registro accedieran solo los intérpretes.

$\mathrm{J}$ - Con un intérprete verdaderamente preparado, el acceso a la causa no tendría problema alguno. Él no lo hace para suplir al declarante, sino para contextualizar e incluso saber qué terminología se va a utilizar, y previamente prepararse. Oye, yo no recuerdo muy bien, ¿Aquí se va a hablar de terminología médica? Por ejemplo. Puede darse perfectamente que tengamos una querella médica con testigos extranjeros, y estamos hablando. Bueno, quizás ese sea una terminología menos compleja porque está casi universalizada, o del latín o del inglés.

I - Sí, pero...

J - Pero puede ser complejísimo. Si tuviéramos algún médico que hablara, iyo qué sé!

I - El otro día me llegó un estudio forense para traducirlo a la vista ...

$\mathrm{J}-i$ De medicina?

I - Si, claro. Es dificilísimo. Si uno no se ha preparado...

$\mathrm{J}$ - Claro, y de eso no somos conscientes. Pensamos que el intérprete sabe todo lo que necesitamos. Como todos, tendría que prepararse. Eso no lo estamos haciendo. Tampoco los intérpretes nos lo están pidiendo.

Hay una compañera que desgraciadamente se jubiló por problemas de salud. Una compañera, que fue Pilar Luna.

I - Pilar Luna. Si, no la conozco directamente, he oído hablar mucho de ella.

J - De hecho le dieron un premio en la Asociación de intérpretes de Madrid, y es una mujer que ha peleado por estas cosas...porque se lo creyó y porque tuvo formación y porque tuvo contacto con personas del mundo de la interpretación que le permitieron abrir los ojos. Esta mujer le hacía un verdadero test a cada intérprete y excluía a intérpretes cuando consideraba que no estaban en condiciones de desarrollar el trabajo. Lo que pasa es que era tan exigente, que eso generaba a veces problemas, pues a la empresa que obtuvo la contrata en Madrid, provocó que eso generara una respuesta de la Sala de Gobierno del Tribunal Superior y al final cambió, pero claro, era un ejercicio de voluntarismo, de una persona concreta.

I - Por lo que consideras, que os falta también a vosotros, en cierto modo, formación.

$\mathrm{J}$ - Sin duda. Sin duda. 
I - ¿Y cómo se podría solventar esto?

$\mathrm{J}$ - Bueno, la directiva dice que «los países desarrollarán programas para formar a jueces, fiscales y más». Yo he participado en algún curso de formación, pero al final, por supuesto que es formación, pero es la incorporación a la práctica cotidiana. Y tenemos una ley. Ha habido en un momento determinado, al final de la anterior legislatura, que hubo muchísimas modificaciones en materia de procedimiento criminal, fue como una especie de pronto de avalancha de modernizaciones, sin que se diese aquí la formación. Yo estuve una vez en un curso en Italia con fiscales italianos. Aquí en España la formación es voluntaria. Si hay modificaciones legales no hay una formación obligatoria, que sería conveniente. Casi sería necesario. En horario laboral, pero es que es necesario. Nadie puede continuar trabajando después de una reforma legal sin conocerla claramente. «Usted se la lee». Es verdad, es que leer es tu obligación. Por supuesto, pero hay más cosas.

Y yo creo, a mí me parece, que hay algunas de las refor«mas legales introducidas en el año 2015 que en la práctica no son muy aplicadas. Está ahí, está la ley. Bueno claro, como todas aquellas leyes que se dictaron en aquella época, y también está la cláusula final, «no implicará un incremento de gasto ni de personal», esto lo dice expresamente.

I - Lo vimos el otro día.

$\mathrm{J}-$ ¿Cómo puedes pensar que vas a prestar un servicio de interpretación y traducción en las condiciones de la nueva ley sin un incremento de gasto ni de personal? ¡Es imposible! Si más horas de interpretación seguro, a partir del momento que los abogados empiezan a reclamar, loa acusados empiecen a reclamar el derecho a tener la entrevista previa de preparación del juicio, la entrevista para valorar si recurres o no, la entrevista en el centro penitenciario para ver si recurren el auto de prisión o no, todo con el abogado y el intérprete. La única manera de resolverlo es que lo piden, porque es costoso, porque van a tener problemas, es poniendo problemas en la rueda, gente, disuades. Lo que llaman los ingleses el deterrent effect, ¿no? El efecto disuasorio. Pues no le dices que no tiene derecho porque la ley se lo dice, pero miras para otro lado. Miras para otro lado, la gente se inhibe, no quieren tener problemas con el juez, y las cosas no funcionan.

Igual mi visión es muy catastrofista, pero no...

I - No, nosotros, yo ahora desde mi punto de vista de doctoranda, pero también pertenezco a la asociación italiana de traductores e intérpretes judiciales, pertenecemos a la red EULITA, estamos haciendo todo lo posible para que esto cambie. Va a ser difícil por cuestiones económicas, porque no hay interés. Por cuestión de dinero, pero haremos todo lo que esté en nuestras manos. Y colaborar con los operadores es la cosa fundamental, y el encontrar gente comprometida con ello nos anima. Claro, muchísimas gracias también por ello.

Otra cosa que quería decir, ¿qué opinas de la subcontrata?

$\mathrm{J}$ - No quiero ser demagógico, en teoría creo que hay determinados servicios que creo que no pueden, es decir, tiene que responsabilizarse la administración que lo presta, como manera de controlar el acceso y de controlar los incumplimientos. Desde luego, aquí está claro que funciona mal. ¿Tiene la administración capacidad económica actualmente? Bueno, es una decisión política. De hecho, uno de los problemas que tenemos en la justicia penal es la falta de colaboradores cualificados necesarios, peritos o expertos en materia económica, expertos en materia fiscal, expertos en materias que habitualmente pasan por los tribunales. Los únicos que tenemos son los médicos, del instituto de medicina legal, que efectivamente son colaboradores que forman parte de la administración y forman parte de una institución, funcionarios públicos, la administración de justicia están incorporados ahí, pero no tenemos otros. Bueno, los peritos policiales y luego acudimos a funcionarios públicos para determinados informes. Informes de naturaleza, en materia de impuestos. En materia, hay intérpretes jurados. Salen ocho plazas al año. Pero claro, para el Ministerio de Asuntos Exteriores, yo creo que sería imprescindible tener. Es más, con una buena red, no todos tuvieran que ser, pero que igual hubiera coordinadores, responsables que fueran funcionarios públicos con la preparación, que evidentemente tiene que ser un nivel alto, gente muy experta y competente, que fueran los responsables. ¿Que ahí pudiéramos hablar de 
otro tipo de contratación? Bueno, ya vemos. Eso es ya otra cuestión, igual no es necesario que sean funcionarios con la inamovilidad del funcionario, pero que hubiera, yo creo que eso es de hecho una de las propuestas que se hace en el informe de la FRA, o el modelo de algún país, ya no recuerdo, pero la responsabilidad del servicio no puede estar externalizada.

I - Yo creo que era el viejo sistema inglés, que desgraciadamente se lo han cargado en la época de Cameron. Ahora, de hecho, a ver qué pasa ahí.

J - Pero lo que yo creo es que tenía que haber una oficina que se encargara de identificar las necesidades cuando acudiera a los tribunales, que podía identificar, aquí tenemos un nivel de exigencia y tener distintos niveles de capacitación o competencia y en función de eso pedir, ir asignando, ir contratando. Igual, para un juicio concreto, de una determinada dificultad, contratas a unos profesionales, igual no tienen que estar en nómina los cincuenta y, las cincuenta y seis semanas del año. No sé, por ejemplo.

I - No, no. Si.

J - un modelo que jugara con la flexibilidad, que puede exigir las características del servicio. Hay idiomas que posiblemente los tienes que ener en nómina: inglés, francés, los idiomas de la Unión Europea, el italiano, en fin. No hay estudios que yo sepa cuantitativos de cuál es la, igual las empresas de interpretación la hacen, no sé. Cuántos intérpretes de cuantos idiomas, cuántas horas de interpretación según que idiomas se utilizan...

I - Lo hizo Juan Miguel Ortega. No sé si has leído la tesis. Hizo la tesis sobre el intérprete para la justicia. Él era intérprete en Madrid, judicial, hizo un trabajo. Si quieres, la tesis, yo la tengo porque está en línea. El libro lo tengo el mío, ha hecho trabajos muy interesantes. Hay alguna cosa que si te interesa te la mando.

I - No te preocupes. En esto, el Consejo General del Poder Judicial y sería muy interesante que hubiera una especie de observatorio en materia de derechos y garantías. ¿Cómo se...cuáles son las necesidades en materia de juicio justo dentro de los tribunales, ¿no? Esas necesidades para luego pedir, el Consejo no tiene competencia. Pero si puede promover, le interesan esas cosas, como no tenemos más que ver desgraciadamente Bueno, pues eso sería un escenario. En el gabinete de estudios e informes, a ver dictar, cada vez que hay una modificación legal, que impacto ha producido, y si se ha plantaeado un objetivo, ver si se está complimiendo o no. ¿Hay un evidente objetivo? Aquí el único objetivo era transponer la directiva, punto. Parece que no había otro objetivo, es decir, que no nos puedan decir, que no nos puedan sancionar en un procedimiento de responsabilidad por no transposición de la Directiva ante el Tribunal de justicia. Nada más, pero ¿se han implementado los procesos, se han mejorad, los objetivos perseguidos se están consiguiendo? ¿Qué situación era la anterior? ¿Cuál es la posterior? ¿Eso se estudia? ¡No lo estudia nadie! Y sin eso, no puede saberse qué está sucediendo y no puedes adoptar medidas. Aquí nunca se hace eso. Aquí, las modificaciones legales son sin haber hecho un estudio de campo previo. Aquí la sociología de la justicia apenas existe y existió para determinadas cosas, un excelente profesional como es Tuaria ¿?, un sociólogo que ha hecho estudios sobre la Justicia, el estado de la Justicia y demás, en otros tiempos, ahora ya nada. Al final no sabemos ni se pretende saber cómo estamos, ni pretendemos saber qué pretendemos, ni se analiza el impacto de la medida normativa sobre la situación previa. Por tanto, no se adoptan medidas para conseguir que las normas se cumplan. Es así. No es así. Es mi visión. Quizás me equivoco.

I - Yo espero terminar la...yo lo que estoy haciendo, no te lo había dicho, es preparar un constructo de evaluación de la calidad. Lo estoy haciendo aquí y en Italia para comparar las dos situaciones pero la idea es crear una forma estándar para poder...claramente no puede tener en cuenta las cuestiones lingüísticas, porque uno se encuentra que sí, inglés, francés, lo que hemos dicho. Lo sabe. Pero hay tantas formas de ver si una persona verdaderamente está cumpliendo bien con su trabajo. Eso es lo que estamos intentando hacer. A ver qué tal, y ver la situación. Curiosamente en Italia, que la contratación es directa, es un desastre como aquí. Si que están, hay que estar en el registro peritos y expertos de los tribunales, pero claro, si se les paga $13 €$ la hora al máximo, y el máximo en el día me parece que es $50 €$. ¿Quién va a trabajar? 
J - Pues personas que están en situación de necesidad. Aquí hace años, eso era un rumor, yo no sé si finalmente es cierto o no, supongo que lo es pero...oó hablar hace muchos años. Igual hace diez, doce años, de que la empresa que entonces llevaba la historia, estaba contratando a ciudadanos extranjeros en situación irregular, quizás no de una manera consciente, pero claro...desde luego personas que iban a estar dispuestas a cobrar $13 €$ la hora, como si limpiaran una casa o desgraciadamente, porque también trece euros si estás limpiando una casa es una miseria.

I - Aquí ganan ahora menos. Están ganando menos. Y el problema es que, claro, en estos casos ¿A quién contratan? No hay un control de la contratación. Vale, está subcontratado, pero debieran poner gente de un cierto tipo.

$\mathrm{J}$ - Por eso. Hay un artículo, que no llegó a ser publicado, de un trabajo en un master de una, no es compañera es técnico de la administración, que analizaba la constitucionalidad de la externalización del servicio de contratación. Es un trabajo de hará tres años, yo lo tengo, si le pido permiso, si me autoriza te lo mando.

I - Encantadísima.

$\mathrm{J}$ - Es de Laura Favière. Ella. Está bien porque ella es fundamentalmente administrativista, ella se mueve, se conoce, ella es técnica de la administración, ha sido juez suplente en lo contencioso administrativo, entonces manejaba. Hacía un análisis original, en el sentido que entraba analizar en parámetros normativos si podía plantearse la constitucionalidad de la externalización de servicios.

I - Es superinteresante.

$\mathrm{J}$ - Le mandaré un correo, estoy convencido de que va a estar encantada. Es un trabajo no publicado. Hubo un momento que lo queríamos publicar en una revista, bueno, yo estoy en una asociación judicial, en Jueces para la Democracia, que tenemos una revista, una revista en la que siempre hay muchos autores italianos, porque la dirige un magistrado que tiene muchísima conexión con gente de la sección de la magistratura italiana.

I - Yo, la lueza que más me ha ayudado en Milán, ha habido dos personas que han estado muy disponibles, que son Giovanna Ichino, ella es la presidente de la Corte di Assise de Milán, y Elisabetta Cannevini, que se ocupa mucho de violencia contra la mujer. Y la verdad es que las dos están concienciadas y me han dado una mano. Por otras partes me han echado de la sala. Ha sido bastante difícil. En Génova me dieron la autorización escrita para entrar allí con los juicios en directísima, como está considerado que es el momento que deciden, o tienes el permiso o no entras. Después, en Milán, el Presidente del tribunal me dio la autorización verbal pero nunca escrita. Entonces si un juez o alguien cuestionaba mi presencia, fuera. En Valencia, sin embargo, el decanato se ha comportado francamente bien, me han ayudado muchísimo.

J - Los juicios son públicos.

[Saludos y agradecimientos]

J- Magistrado

I - Investigadora 
ENTREVISTA 3

[Entrevista telefónica]

I - Si, fueron Anabel Borja y Maria Jesús Blasco. Yo estoy haciendo la tesis con Maria Jesús Blasco para validar una herramienta de evaluación de los intérpretes prácticamente en ámbito judicial.

J- Qué bien, qué bien. Es fundamental. Es una herramienta fundamental. Y yo lo tengo muy claro que la clave está ahí. ¿Sabes?

I - La pena no haberte conocido también antes, porque al principio lo que hicimos fue, el instrumento, lo pasamos primero a expertos para que vieran las preguntas que podían ir bien y mal, y luego lo he testado en la ciudad de la Justicia de Valencia y en Milán.

J - ¿En Milán?

I- Yo es que vivo en Milán.

$\mathrm{J}$ - ¿Estás con los resultados todavía?

I - Estoy prácticamente, ahora lo que estoy haciendo es analizar datos y ponerme a escribir. Pero claro, también nos interesaba tener un poco de información de tipo cualitativo de vuestra experiencia como jueces y saber qué es lo que se puede hacer. O cual es vuestra opinión. Ahora te haré una serie de preguntas si te parece bien. Me parece que la conferencia se va a publicar en Youtube ¿verdad? La del otro día.

J - Me parece que sí. Me parece que sí. Pero tampoco lo sé muy bien. Creo que sí. No sé si en un canal propio de youtube del departamento. No lo sé sinceramente, pero algo me comentó Carmen Bestué, que fue la coordinadora.

I - Más que nada porque MJ me ha pasado los apuntes, de lo que dijiste, y la verdad es que hay cosas superinteresantes. Escucharla aunque sea después será muy bueno.

$\mathrm{J}$ - A ver, se trataba de una reflexión desde el juicio oral, de las condiciones que determinan de alguna manera todos los elementos comunicativos del juicio. Una reflexión más principialística. A veces, es justificar, yo creo que los foros multidisciplinares yo creo que lo que hay que intentar abordar la cuestión desde una perspectiva, desde un análisis que pueda ser compartido porque si te metes en el intríngulis técnico jurídico de los problemas de los procedimientos del nombramiento y de toda la...entonces puede ser aburrido y poco. Entonces fue la reflexión más...Yo creo que el problema fundamental es este, que seguramente los operadores no somos conscientes de lo que hay en juego, de los valores. Y o se ignoran, o se desproblematizan, como si, bueno, pues es una manera de sobrevivir en el fondo. Ante una situación muy precaria, pues al final el riesgo, los problemas no se tienen si no se ven, sabes, es una buena manera de superarlos. Y así estamos. Esa es desgraciadamente la realidad más generalizada en nuestro país, por lo menos.

I - Sí, es que la verdad que hablando del argumento con varios jueces he visto gente muy implicada, gente que se leve que se le están abriendo los ojos hablando con ellos y gente que más, dejan hacer las cosas como están. Pero bueno, hay de todo. Entonces, no nos vamos a quejar, mientras haya gente con ganas de hacer como vosotros, ya es positivo.

$\mathrm{J}$ - No si lo que creo es que hay colegas que vamos, que hay un grupo de jueces que estamos tomando conciencia. Pero el problema es que, Marta, tomada la conciencia, los medios que tienes para asegurar los fines de la interpretación son muy escasos.

I - Si si si. 
$\mathrm{J}$ - El problema no es solo la toma de conciencia, Una vez que ya has identificado los problemas, pues yo, la solución es muy complicada. Muy complicada.

I - Si, eso me lo han dicho también aquí. En Milán.

$\mathrm{J}-$ Me imagino.

I - Porque la situación es prima hermana.

J - Yo creo que es un problema generalizado, sabes. En la mayoría de los países, en todos los periodos de crisis, de sobresaturación del sistema. Hay muchos marcadores que también son de tipo logístico, estructural, que hace muy difícil la situación. Porque la solución pasa primero por dinero. A veces no lo hay. O lo hay pero no se invierte aquí, o no merece la pena políticamente, o no hay presión para que se haga. No lo sé, pero eso es muy, hay un problema metodológico evidente, de capacidad evidente, pero claro si tú al final las empresas monopolísticas en el fondo, se quedan con los concursos públicos y al final son...pagan lo que pagan, pues el efecto llamadas sobre los intérpretes. Pero ¡sobre los mejores no!

I - Aquí en Italia, por ejemplo, que es directa la contrata, pero pagan también tan poco, pagan más o menos como en España, por eso la gente buena no va.

J - Claro, ese es el problema. La gente buena no va. Oye mira, Con que me den la traducción de un documento jurídico voy a ganar tres veces más de lo que gano pasando diez horas en una guardia, pues no.

I - Hay de todo, claro, porque hay gente muy comprometida y entonces esta gente está luchando o está trabajando a pesar de las condiciones y entonces también es muy loable. Y nada te iba a hacer una serie de preguntas.

J- Vale. A ver si te las puedo responder.

I - Tú, a parte. Claramente, experiencia con intérpretes, llevas mucho tiempo, ¿verdad?

J. Si, si. Por lo menos. A ver. También es cierto y ese es otro elemento, que hay que valorar, y es que nuestro contacto con el llamado elemento extranjero en el proceso, que suena muy feo, pero que es un tecnicismo., es relativamente novedoso. O sea, por lo menos en los términos cuantitativos en los que se están produciendo ahora, pues llevamos veinte años. Entonces eso es verdad que es un modelo de administración ...por ejemplo los de extranjería eran muy escasos. Claro, de pronto hay una irrupción de la extranjería en el proceso muy potente y creciente. Partimos de una situación casi de, bueno, de un fenómeno desapercibido, que no causa problemas y yo recuerdo, fijate, cuando yo empecé, casi hace treinta años, teníamos un intérprete, un señor marroquí, encantador, que era un primer emigrante, que había venido al partido judicial y que el hombre, pues tenía su negocio, y prestaba su asistencia pues casi como una fórmula de en beneficio de la comunidad. Era como, él lo decía, «es que yo me veo obligado de asistir al juzgado porque son ustedes buena gente y yo además ayudo a la gente de mi país». ¡Ese era el modelo! Era algo anecdótico. En los últimos veinte años, quince años tal vez, pues hemos pasado a no ser no una anécdota, tampoco tengo los datos muy afinados, Marta, pero en la posición penal que yo trabajo en la audiencia provincial en los juicios que se celebran que ya sabes que son delitos de particular gravedad, a lo mejor estamos hablando de un $35 \%$ de procesos donde alguna persona es de nacionalidad extranjera. O sea, que no tiene dominio de la lengua española o del catalán en su caso. Eso es mucho, ¿no? Es un porcentaje muy importante.

I -Tú, claramente, bilingüe serás, porque entre catalán y castellano, ya parte de estos dos idiomas, ¿sabes hablar más?

J - A ver, un cierto nivel medio de francés y un cierto nivel medio de italiano. Son mis dos...tengo algún certificado al respecto, pero bueno. Me gustaría hablarlo mejor.

I - No, no es por eso, es que claramente te ha podido pasar que si tú has tenido algún juicio en el que se 
hablaba alguno de estos dos idiomas te hayas podido dar cuenta.

J - Sí, en francés detectamos, además un tema muy importante, ya hace bastante tiempo, eh. Quizás fue el año 98 o 99, detectamos una horrenda interpretación, absolutamente insuficiente. Era un problema, yo creo que era un problema de comprensión del castellano, sabes, del intérprete, al volcarlo al francés. Era un problema, el cortocircuito se producía en el entendimiento de la lengua, porque después él tenía muchas dificultades a la hora de expresarse en la interpretación. Ahí yo, claro. Después alguna cosa, sobre todo con personas subsaharianas que es otro gran problema, que es la presunción de que las lenguas oficiales africanas, subsaharianas, son bien habladas por todos los ciudadanos de esos países. Y no es verdad, eso nos plantea, senegaleses, cameruneses, se presume, en francés. ¡Pero no es verdad! Yo creo que muchos de ellos tienen un francés muy pobre. Yo creo que les dificulta la plenitud de su defensa. Tú te expresas mucho mejor en tu lengua propia, obviamente, y la lengua propia no es el francés. El francés es una lengua aprendida, pero no es lengua propia. Ahí también, ahí si que he tenido la posibilidad de intervenir puntualmente sobre el alcance de alguna pregunta, o el giro que se le ha dado. O no entender yo, la propia traducción que le hacía el intérprete. Eso sí que ayuda, claro. Pero es una islita.

I - No, claro, pero es una forma para darse ya cuenta. Porque está claro que con un idioma como el chino, o con ciertos idiomas no nos enteramos, pero cuando ya lo vemos reflejado en un idioma que más o menos conocemos, nos planteamos la pregunta ¿Qué estará pasando con los demás?

$\mathrm{J}$ - Claro, evidente, si.

I - Entonces, por ejemplo, la comunicación no verbal. No sé, dos casos quería comentar. Uno, en el caso de que tantas veces piden el intérprete, pero en realidad algo lo conocen el idioma, ¿has notado alguna vez en el acusado o en algún testigo o en algún asistente al juicio, una comunicación no verbal en la que se demuestra una discordancia con lo que está diciendo el intérprete? ¿Te ha llamado la atención? ¿Lo has pensado alguna vez esto?

$\mathrm{J}$ - ¿En qué sentido? ¿Cuál sería el...?

I - Nos comentaban...

$\mathrm{J}-$ ¿Notar que el acusado no entienda la información transmitida?

I -O que no entienda, o que piense, «yo no he dicho eso». Las dos cosas, que no entiendan lo que se les está diciendo.

J - Sí, que no entienda alguna vez. Eso nos ha ayudado. Es más, fijate, en alguna ocasión hemos tenido la ayuda de algún coacusado. Que si que tenía una competencia mayor en castellano, y que ha percibido que lo contestado por su connacional no se ajustaba, sabes, la traducción del intérprete no se ajustaba al contenido de la pregunta. Eso hemos tenido en alguna ocasión. Por ejemplo, en rumano, hemos tenido un caso muy curioso, porque los declarantes eran moldavos y entonces el coacusado. Pero entonces «perdone, pero es que la intérprete utiliza un rumano, es verdad que el moldavo es la proximidad, pero no es esto, nosotros tenemos variables lingüísticas y esta señora no lo está traduciendo bien. No está traduciendo bien lo que le están preguntando a mi compañero». Y fue muy interesante. Esa fue una experiencia muy interesante.

I - Si, claro. Entonces, generalmente, bueno, ahora ya generalmente se contrata a un intérprete. ¿Cómo evaluáis la necesidad de intérprete generalmente? ¿Antes del juicio?

J - Nosotros, a ver. En nuestra praxis, de alguna manera partimos de la presunción de necesidad, es decir, nosotros, cuando la persona tiene nacionalidad extranjera y de idioma no castellano, nosotros siempre llamamos al intérprete. No comprobamos la competencia lingüística previa de la persona sino que siempre está. ¿Por qué? Porque a mí, en ocasiones, lo que mi experiencia me ha permitido confirmar, es que muchas veces, es muy curioso como muchas personas extranjeras hacen un gran esfuerzo para hablar en castellano, parece que quieren hablar en castellano, como una suerte de 
demostración, no sé. Algún día, lo que pasa es que es muy delicado nuestra posición para pedirles explicación profunda de porqué lo hace. Yo creo que hay como un mecanismo, yo quiero como sugerir o demostrar un nivel cierto de cooperación, sabes, o de ayuda, al desarrollo del juicio, y voy a demostrar mi integración en el país. Yo no sé qué variables son, que explican esto, pero son muy frecuentes. A ver, personas que tienen un nivel de competencia notable, pero desde luego, a mi entender, no suficiente. Eso se nota mucho en los tiempos verbales. Entonces, yo cuando informo del derecho a la asistencia de intérprete con estas personas, con estas que tienen un nivel de competencia en castellano notable, yo siempre insisto. «mire, es fundamental que nos entienda y es fundamental que le entendamos, pero sobre todo es fundamental que usted se sienta absolutamente cómodo en el ejercicio de su derecho a defenderse., y por tanto a contestar a las preguntas que usted quiera contestar, que no tenga ninguna barrera idiomática para contestarlas bien». «No, no se preocupe, yo creo, que yo hablaré bien. Yo entiendo todo, creo que lo hablo bien». ¿Qué ocurre? Bueno, a veces sí, a veces tienen un dominio efectivamente magnífico. Pero es también muy frecuente que haya problemas de tiempos verbales. Sabes, la utilización imprecisa, descontextualizada, sobre todo el pasado, a veces el subjuntivo también el modo, se mezcla. Entonces yo, cuando hay un problema de tiempo y de modo, y me genera dudas en el relato, entonces ahí siempre paro, digo no. Yo siempre digo lo mismo, «me encantaría hablar su lengua como usted habla el castellano, quiero felicitarle, pero es difícil dominar, no. Los verbos. Su relato me resulta algo confuso, entonces yo prefiero que habla usted en su lengua». En mi tribunal, yo te diría que prácticamente, las personas extranjeras que no tienen un dominio nativo, o con un nivel muy alto, terminan utilizando el intérprete. Nos curamos en salud y siempre siempre.

I - En estos casos es por los que, por ejemplo, si un intérprete es bueno, pues no hay problemas, pero si el intérprete es mediocre.

$\mathrm{J}$ - Claro, puede ser peor el remedio que la enfermedad. Lo que pasa es que...

I - ¿Cómo es, en general, el nivel de vuestros intérpretes?

J - Yo estoy enormemente satisfecho con los intérpretes de árabe. Los que tenemos son excelentes. En concreto tenemos una intérprete absolutamente alucinante, ejemplar, porque además tiene un, todos los ...cumple, fidelidad en la interpretación, distancia, riqueza el conocimiento de la lengua castellana, iniciativa para pedir explicaciones cuando no entiende algo. Muy bien, a mi me parece absolutamente ejemplar. A partir de aquí, pues yo por ejemplo te diría que el rumano, depende quien venga, hay una intérprete también, creo, tengo la sensación de que tiene un nivel altísimo, y tengo otra que con frecuencia viene y ahí ya tengo muchas más dudas. Sobre todo porque lo que percibo es que su dominio de la lengua castellana no es tan alto. Entonces, si no domina muy bien la lengua a la hora de traducir, tengo dudas si la domina a la hora de interpretar. Tengo dudas. Por ejemplo, el tema el francés, a veces sí, los niveles son correctos tanto de entendimiento de la lengua castellana como de traducción y de interpretación de la lengua francesa, pero me encuentro con el problema sobre todo con los franceses no nativos, o sea, con las personas que hablan francés pero no como primera lengua. Entonces, ahí. Luego, de pronto, surgen idiomas muy singulares, el problema es que no solemos tener grandes bolsas que nos permitan comparar. Yo tengo una interpretación de un búlgaro, no tengo, es que no lo sé. No puedo comparar porque es una vez al año o dos.

I - Generalmente, está claro que en XXX también funciona Seprotec, ¿no?

$\mathrm{J}-\mathrm{Si}$, Seprotec.

I - Por lo cual a vosotros os llegan directamente de la agencia. ¿Tenéis alguna forma de controlar el tipo de titulación o el tipo de formación que tienen estas personas o ninguna?

J - No. Ninguna. He de reconocerte también que yo no lo pido. Sabes, en el momento del juicio, parece una situación un poco violenta, debería poder pedirse. Yo, por ejemplo, sí que lo he hecho en alguna ocasión pero muy contada o cuando el intérprete no tenía ninguna referencia y el idioma era particularmente minoritario. Entonces sí, yo ahí sí que he pedido del conocimiento de la lengua, del tiempo que llevaba en España, a veces nos preocupamos mucho del dominio de la otra lengua, que el intérprete domine la lengua a traducir, a interpretar, hay que preocuparse también del nivel de 
entendimiento de la lengua castellana, sabes.

I - Y la terminología también que usáis, que no es particularmente fácil.

$\mathrm{J}$ - Claro, claro. Yo, por ejemplo, esa es una de las cosas que quiero introducir algún cambio en nuestra praxis en el tribunal, intentar introducir algún test ligero, no una prueba muy exigente, pero algún test de datos, de capacidad de competencia técnica del intérprete. El tiempo que lleva en España, estudios realizados, conocimiento de la lengua por la que es llamado a interpretar, porque claro, nosotros no es infrecuente que de inglés no nos vengan ingleses, no nos vengan personas de inglés como lengua nativa. Eso es bastante frecuente, gente me imagino con una alta capacidad lingüística en inglés, pero que son, su lengua no es el inglés.

I - ¿Qué son? ¿Españoles?

J - No, no, suelen ser también extranjeros y del este. Por ejemplo, Tenemos una intérprete rusa hace en ocasiones interpretación en inglés también.

I - Aquí también pasa lo mismo, que dominan varios idiomas y lo hacen si. Claro, en esos casos, la terminología pues por una parte, y después una pregunta. A veces sucede que los intérpretes no trasponen fielmente si no que intentan simplificar, ¿qué es lo que opinas tú de estos?

J - Si, claro, pero ahí ya me faltan los instrumentos de control. Sabes.

I - ¿Pero te parece bien o te parece mal?

J - No, me parece horrible. Horrible. Pero sobre todo, lo que me parece es la transformación, digamos, de la respuesta. Es decir, la evitación de la palabra utilizada, porque sea grosera o porque sea incorrecta, sea de argot. Esa traducción de la traducción a mí me parece que no se puede hacer. Y en ocasiones es una intuición, yo no tengo. A ver, hay idiomas que me impiden absolutamente cualquier tipo de control más allá de algo intuitivo. Eso nos pasa con los chinos, con frecuencia. Bueno, la pregunta puede ser larga, la respuesta puede ser larga, y sin embargo la interpretación que nos hace el intérprete es brevísima. En esa comparación, hay una parte de significantes que no se han traducido, creo yo, porque si este señor ha utilizado doscientas palabras en su respuesta y nos traducen cien, pues ¿dónde están las otras cien? Es verdad que hay lenguajes que tienen una estructura. Bueno jeso pasa con italiano y el castellano! Tú lo sabes. Un libro en italiano de quinientas páginas traducido a castellano pueden ser trescientas cincuenta. Es verdad que existen fórmulas sincopadas, y palabras que a lo mejor ¡no lo sé! Sé que hay una parte de lo dicho que cuantitativamente no se traduce. Entonces, eso me causa mucha inquietud. Pero no sé controlarlo. Alguna vez lo he hecho, como diciendo, oiga, ¿pero no ha sido muy larga la respuesta para que usted nos dé una respuesta tan concisa?

I - En estos casos usted, tú, ¿sí que se lo dices directamente lo que me estás diciendo?

J - Sí, sí. Cuando lo percibo alguna vez sí.

I - ¿Qué pasa en tu sala, se le traduce, me imagino que sí por lo que he leído, tú si que instas a que el intérprete traduzca todo, ¿verdad?

J - Sí, si. Lo que pasa es que hay intérpretes que lo tienen muy claro y que lo hacen y no se lo tienes que recordar, y hay otros que se lo tienes que ir recordando. Y el problema, ¿cuál es? Un juicio absorbe muchísima energía, muchísima atención, entonces no puedes estar a todo. Nosotros tenemos una escenografía judicial relativamente singular, siempre sentamos a la persona acusada al lado de su abogado, y utilizamos los estrados para ellos. Nosotros no tenemos banquillo nunca. El intérprete se sienta en un lado. Entonces, eso ¿qué ocurre? Por estar a un lado, a veces no me fijo. Entre los tres colegas del tribunal intentamos repartir la función, cuando vemos que no lo está haciendo me da un codazo mi compañero, «oye, XXX, que el intérprete no ...está callado», «Por favor, le he pedido que haga usted una actualización continua de lo que está pasando, de los términos, que vaya informando de lo que esté pasando». «Perdón, sí, sí». Hay gente que lo hace muy bien y otra gente que no lo hace, o que 
se lo tienes que recordar, eso es muy frecuente.

I - ¿Te ha pasado alguna vez verdaderamente que has recusado al intérprete por alguna razón?

J -Mira, me pasó una vez por obviedad, era ese tema que te dije de la intérprete francesa, sobre todo por desconocimiento de la lengua castellana. Y eso nos pasó una cosa alucinante. A veces cuando yo, yo por mí pocas veces, o por algún factor, pues bueno, distinto, porque percibimos incompetencia, evidentemente para mí es un tema que reclama una solución quirúrgica, es clarísimo, sobre eso no tengo nunca ninguna duda. El problema es cuándo. No es fácil. Tuvimos un caso precioso, de japonés, en que cambiamos tres veces, ¿por qué? Primer intérprete, japonés con escaso conocimiento o insuficiente conocimiento de castellano. Español con conocimiento deficiente de japonés. Y esta fue la propia muchacha quien nos lo...Ella ponía caras extrañas, y eso es «¿qué pasa?», «No le entiendo bien». Y después tuvimos, ya fue muy costoso encontrar ese tercer intérprete que dominaba esos dos registros. Yo creo que de manera suficiente, porque ya no, de nacionalidad japonesa. Tuvimos que acudir a otro japonés. Pero que ya no estaba en el circuito de Seprotec, se tuvo que buscar fuera. Era además un tema muy delicado, un tema de violencia habitual, en un contexto familiar enormemente complejo, lleno de oscuridad y tinieblas. Un personaje atroz el acusado, una cosa muy compleja. Como muy además dentro de las claves japonesas, uf, un asunto muy interesante. Sobre esto te podría facilitar la grabación, porque es un caso interesantísimo. Un caso muy interesante.

I-Sí, sin duda alguna me interesa. Sí, gracias.

J - Yo creo que esto fue en el año 2010 o 2011. Pero es uno de esos casos que no se olvidan. Fue un caso muy interesante.

I - Pues sin duda alguna me interesa. Gracias, X.

J - Además es que los japoneses son muy reservados, por lo cual había también una cierta barrera comunicativa por la propia víctima, sabes. Había mucha resistencia a hablar, fue enormemente complejo. Este juicio.

I - Otra cuestión importante. La deontología en el intérprete. Tú has visto, claro en las vistas muchas veces no os dais cuenta de lo que pasa antes, porque estáis en la sala. Has visto una cierta conversación entre intérpretes y acusados o testigos, una conducta que te parece impropia. ¿Lo has observado o has hecho comentarios?

J - No. Obvia no, porque si fuera muy obvia yo intervendría. No tengo muestra. Para poder darte una opinión, una respuesta como muy informativa.

$\mathrm{I}-i \mathrm{Y}$ no te ha pasado nunca?

J - Lo que sí nos ha pasado es que en mi audiencia, en la otra sección de lo penal, hace tres años se juzgó a una intérprete de rumano y a un intérprete de urdu o paquistaní por el secuestro de un niño en Paquistán, cuyo rescate fue exigido a su familia residente en Londres. Un asunto alucinante, y él interpretaba a la policía. Eso es otro problema fundamental, que es la falta de control, digamos, de las condiciones socio-personales de los intérpretes. Es un tema enormemente delicado. Mucho más delicado de lo que parece. Ojo, en contextos por ejemplo, y se ha detectado. De hecho, ha habido quejas formuladas por asociaciones, sobre todo mujeres y me consta en Andalucía, asociaciones de mujeres contra la violencia, que se han quejado de que algunos intérpretes en algunas comunidades pequeñas actuaban como elementos de transmisión, de consignas o de amenazas veladas a las mujeres que denunciaban.

I - Esto me ha llegado también a mí la noticia.

$\mathrm{J}$ - Después, piensa $\mathrm{M}$, que cuanto más pequeña sea la comunidad de origen, más vínculos hay entre las personas que declaran y la persona que hace de traductora. Claro, en algunas microcomunidades, esto tiene también costes de seguridad. Y esto tiene de pérdida de libertad del intérprete, porque el intérprete 
se la está jugando. Por ejemplo, las mafias nigerianas son muy peligrosas y los intérpretes en ocasiones pretenden anonimato. Sobre todo, los intérpretes durante la investigación.

I - Además has contemplado este caso.

$\mathrm{J}$ - No porque habría que darle casi un estatus de ...Bien, cabría la ley de protección de testigos en el tratamiento que se le da al intérprete en el tratamiento que se le da a nivel procesa, ese es un perito, y cabría una protección que supusiera la anonimización de sus datos y una protección de su identidad ya muy potente. Pero nuestra ley tiene un agujero, que yo creo que hay que repararlo, que la parte puede pretender conocer la identidad siempre y en todo caso en el juicio oral. Y no se le puede negar. Entonces algunos intérpretes sufren, no es por un incumplimiento, no es por falta de ética, sino porque están asustados. Y pueden estar amenazados. Eso no es nada... eso es un tema al que tampoco se le presta excesiva atención. El nivel de relación entre el intérprete y el interpretado en contextos de comunidades pequeñas, pues es un tema delicado. Muy delicado.

I - Si. ¿Qué opinas tú de la licitación externa, de la externalización del servicio?

$\mathrm{J}$ - Bueno, yo, al final es un poco lo de siempre, si el servicio público se precariza. La licitación como tal, pues no es, bueno, yo no puedo afirmar como una especie de dogmática, no. Es ontológicamente inaceptable. No sería necesariamente así. Si las reglas de los concursos fueran muy exigentes en cuanto a los estándares de calidad. El problema no está en la fórmula, el problema es que la fórmula, que puede ser buena o mala, funciona, depende de los resultados que dé. Es claro, que si al final, las fórmulas de concurso generan duopolio o generan al final monopolio, pues claro al final monopolio es un mecanismo que permite, la empresa termina comiéndose las condiciones de los estándares de calidad, los termina devorando, porque el Estado, la Administración se hace dependiente de la empresa monopolística. Entonces claro, pues muy bien, «tiene usted que asegurar un nivel alto de competencia». Pero, ¿quién me controla? ¿Qué alternativa hay si no lo cumplo?

I - Alguna vez os habéis quejado directamente con la empresa, o...

J - Sí, nosotros vehiculamos, en Cataluña tenemos una especie de canal que estatuimos en la sala de gobierno para que las quejas nos vengan por sala de gobierno. Entonces, cuando hay colegas que se quejan. Pero fijate, la mayoría de las quejas, no están tanto en problemas de calidad o de competencia, sino de cumplimiento del horario. De disponibilidad. Es cuando nos llegan más quejas. Cuando no se presenta, cuando llega tarde.

I - Hay algún tipo, me decías que es muy difícil tener un control de calidad.

$\mathrm{J}$ - Muy complicado, ya te digo. Yo solamente lo puedo tener. Puedo intuir dificultades cuando percibo la falta de competencia en castellano, porque ahí sí. Si se expresa mal, si traduce mal, a lo mejor entiende mal.

I - Pues nada, quería hacerte unas preguntas sobre cómo debería ser la figura del intérprete. Qué tipo de interpretación prefieres, la corta no, primero, qué tipo de interpretación prefieres, consecutiva, simultánea no tenéis la posibilidad.

J - No, simultánea. Pero fijate, en este asunto que te he comentado de la intérprete que han sido condenados por sentencia firme por secuestro, en este caso sí que tuvimos simultánea. Era la otra sección, pero se tramitó una solicitud y medios porque fijate, tenían que venir, garantizar la interpretación en rumano y en urdu. Después, vinieron policías franceses, vinieron policías británicos y vinieron policías paquistanís. Al final se pusieron dos cabinas y el resultado fue espléndido. Absolutamente espléndido. Pero ese modelo es un modelo absolutamente anecdótico. Nada, eso fue porque era un caso de algo que se necesitaba generar una infraestructura de interpretación distinta porque era imposible hacerlo de otra manera, pero no, la mayoría de las veces la consecutiva, y tampoco tenemos los agentes, los actores del juicio tampoco tenemos un método que tome en cuenta para poder, pues eso, lo de las 180 palabras, las secuencias, los descansos, de eso no tenemos nada. No tenemos ningún criterio de formación, ninguna formación que nos permita adaptarnos, que el desarrollo dl juicio. 
ANEXos

$\cdots$

[La grabación se interrumpe aquí. Estuvo hablando de la falta de formación de los operadores para trabajar con intérpretes].

J- Magistrado

I - Investigadora 